UNIVERSIDADE DE SÃO PAULO

FACULDADE DE ECONOMIA, ADMINISTRAÇÃO E CONTABILIDADE DE RIBEIRÃO PRETO

DEPARTAMENTO DE ADMINISTRAÇÃO

PROGRAMA DE PÓS-GRADUAÇÃO EM ADMINISTRAÇÃO DE ORGANIZAÇÕES

RAFAEL POVEDANO

Práticas administrativas e pedagógicas para a melhoria de leitura e escrita: um estudo em escolas municipais de ensino fundamental II

ORIENTADOR: PROF. DR. ALEXANDRE PEREIRA SALGADO JUNIOR

RIBEIRÃO PRETO 
Prof. Dr. Vahan Agopyan

Reitor da Universidade de São Paulo

Prof. Dr. André Lucirton Costa

Diretor da Faculdade de Economia, Administração e Contabilidade de Ribeirão Preto

Prof. Dr. Jorge Henrique Caldeira de Oliveira

Chefe do Departamento de Administração

Prof. Dr. João Luiz Passador

Coordenador do Programa de Pós-Graduação em Administração de Organizações 


\section{RAFAEL POVEDANO}

Práticas administrativas e pedagógicas para a melhoria de leitura e escrita: um estudo em escolas municipais de ensino fundamental II

Dissertação apresentada ao Programa de PósGraduação em Administração de Organizações da Faculdade de Economia, Administração e Contabilidade de Ribeirão Preto da Universidade de São Paulo, para obtenção do título de Mestre em Ciências. Versão Corrigida. A original encontra-se disponível no Serviço de Pós-Graduação da FEARP/USP.

Orientador: Prof. Dr. Alexandre Pereira Salgado Junior

\section{RIBEIRÃO PRETO}


Autorizo a reprodução e divulgação total ou parcial deste trabalho, por qualquer meio convencional ou eletrônico, para fins de estudo e pesquisa, desde que citada a fonte.

\section{FICHA CATALOGRÁFICA}

\section{Povedano, Rafael}

Práticas administrativas e pedagógicas para a melhoria de leitura e escrita: um estudo em escolas municipais de ensino fundamental II. Ribeirão Preto, 2019.

308 p. : il. ; $30 \mathrm{~cm}$

Dissertação de Mestrado, apresentada à Faculdade de Economia, Administração e Contabilidade de Ribeirão Preto/USP. Área de concentração: Geração de Valor.

Orientador: Salgado Junior, Alexandre Pereira.

1. Boas práticas educacionais; 2. Gestão escolar; 3. Desempenho em leitura; 4. DEA; 5. 
POVEDANO, Rafael. Práticas administrativas e pedagógicas para a melhoria de leitura e escrita: um estudo em escolas municipais de ensino fundamental II. 2019. 308 p. Dissertação (Mestrado em Administração de Organizações) - Faculdade de Economia, Administração e Contabilidade de Ribeirão Preto, Universidade de São Paulo, Ribeirão Preto, 2019.

Aprovado em:

Banca Examinadora

Prof. Dr.

Instituição:

Julgamento: Assinatura:

Prof. Dr.

Instituição:

Julgamento: Assinatura:

Prof. Dr.

Instituição:

Julgamento:

Assinatura: 
Dedico este trabalho aos meus filhos, à minha esposa, meus pais, irmãos e amigos. 


\section{AGRADECIMENTOS}

Agradeço inicialmente ao meu orientador, Prof. Dr. Alexandre Pereira Salgado Junior pela oportunidade. Seu voto de confiança e os ensinamentos transmitidos ao longo deste processo serão para sempre lembrados.

Agradeço ao meu amigo e chefe, Francisco Elíseo Fernandes Sanches que, desde o início, foi um apoiador e incentivador incondicional desta jornada. Foi o responsável por me proporcionar as condições para que esta jornada fosse possível.

Agradeço aos amigos do GREFIC, Felipe Furlan Soriano, Letícia Fuggi, Alexandre Melo, Marco Antonio Alves de Souza Junior, Yago Marinzeck, Maurílio Benite, Ornella Pacífico, Ricardo Donegá e à profa Perla Calil Pongeluppe Wadhy Rebehy que me acolheram, apoiaram e auxiliaram com o compartilhamento de suas experiências.

Aos professores Perla Calil Pongeluppe Wadhy Rebehy e Amaury Gremaud pelas valiosas contribuições durante a etapa de qualificação.

Registro o necessário agradecimento às Secretarias Municipais de Educação, às diretoras escolares e professores que me receberam de coração aberto e que, com suas valiosas contribuições, permitiram a consecução deste trabalho.

À minha mãe, Aparecida, pelo amor, dedicação e direcionamento de vida e ao meu pai, Antônio, que me incentivou para o ingresso no mundo universitário.

Aos meus irmãos, Eduardo e Lilian, pela presença em minha vida e pelas constantes palavras de incentivo.

Agradeço especialmente à minha esposa Josiane, pela compreensão e paciência neste período de constantes ausências, e aos meus filhos Pedro Rafael e Sabrina, que, apesar de tão pequenos, foram maduros para compreender a importância do meu projeto e souberam abdicar de alguns momentos de convívio e lazer para que este trabalho pudesse ser concluído.

Agradeço, ainda, aos professores com quem convivi e com os quais muito aprendi, e à Faculdade de Administração, Economia e Contabilidade de Ribeirão Preto, que, desde 2015 tem sido uma extensão de minha casa. Registro aqui um agradecimento especial à equipe da Casa de Hóspedes da FEARP, sempre tão cuidadosos, carinhosos e dedicados conosco nos períodos de hospedagem. 
"É impossivel para um homem aprender aquilo que ele acha que já sabe".

Epicteto 


\section{RESUMO}

POVEDANO, Rafael. Práticas administrativas e pedagógicas para a melhoria de leitura e escrita: um estudo em escolas municipais de ensino fundamental II. 2019. 308 p. Dissertação (Mestrado em Administração de Organizações) - Faculdade de Economia, Administração e Contabilidade de Ribeirão Preto, Universidade de São Paulo, Ribeirão Preto, 2019.

Diversos pesquisadores têm associado à melhoria dos índices de desenvolvimento social e econômico dos indivíduos e dos países a melhoria da qualidade da educação. O Brasil tem ampliado o gasto público no setor sem, no entanto, incrementar os índices de qualidade, o que se verifica nas avaliações padronizadas de leitura e escrita, realizadas em âmbito nacional (Prova Brasil) e internacional (PISA). Em geral, os estudos na área buscam identificar os fatores intra e extraescolares que influenciam nos resultados educacionais, sem, no entanto, fornecer um ferramental que auxilie os agentes educacionais na implantação de ações para a melhoria do serviço educacional. Assim, este estudo tem como objetivo propor boas práticas administrativas e pedagógicas que possam ser adotadas nos sistemas municipais de ensino fundamental II. Estas práticas foram identificadas a partir da análise dos dados de 3.330 escolas municipais brasileiras do ensino fundamental, coletados a partir do Censo Escolar e dos Questionários Contextuais da Prova Brasil. Para isso utilizou-se a metodologia qualiquantitativa proposta por Salgado Junior e Novi (2014). Inicialmente as escolas foram agrupadas pelo nível socioeconômico, visando à redução dos efeitos deste fator nos resultados. A seguir foi aplicada a técnica DEA dois estágios, para a identificação das escolas de alto e baixo desempenho em agregar resultados aos seus alunos em leitura escrita na Prova Brasil. Finalmente foram realizados múltiplos estudos de caso em escolas de alto e baixo desempenho, para compreender in loco como as práticas se diferenciam entre os grupos. Verificou-se que, mesmo depois de controlados os fatores socioeconômicos, as escolas ainda apresentam significativas diferenças de desempenho e que o aumento do investimento anual médio por aluno não tem correlação com melhoria nos resultados educacionais. Os resultados enfatizam a importância da participação da família e da comunidade no processo educacional, bem como do diretor escolar como agente de integração escola-família e como suporte ao corpo docente na oferta das condições básicas ao desempenho de suas funções. Foram encontradas 55 práticas que podem ser aplicadas pelas Secretarias Municipais de Educação, professores e diretores escolares, bem como pelos alunos e seus familiares para a promoção da melhoria do desempenho dos estudantes do ensino fundamental II em leitura e escrita.

Palavras-chave: boas práticas educacionais; gestão escolar; desempenho em leitura; análise envoltória de dados; IDEB. 


\begin{abstract}
POVEDANO, Rafael. Administrative and pedagogical practices for the improvement of reading and writing: a study in municipal primary schools. 2019. 308 f. Dissertação (Mestrado em Administração de Organizações) - Faculdade de Economia, Administração e Contabilidade de Ribeirão Preto, Universidade de São Paulo, Ribeirão Preto, 2019.
\end{abstract}

Several researchers have associated the improvement of the social and economic development indexes of individuals and countries with the improvement on the quality of education. Brazil has expanded public spending in the sector without, however, increasing quality indexes, which can be verified in the standardized reading and writing assessments carried out at the national level (Prova Brasil) and international (PISA). In general, the studies in the area seek to identify in-school and out-of-school factors that influence educational outcomes, without, however, providing a tool to assist educational agents in implementing actions to improve educational services. Thus, this study aims to propose good administrative and pedagogical practices that can be adopted in municipal systems of elementary education II. These practices were identified from the analysis of the data of 3,330 Brazilian municipal schools of primary education, collected from the School Census and the Contextual Questionnaires of the Brazil Test. For that, the qualitative-quantitative methodology proposed by Salgado Junior e Novi (2014) was used. Initially, the schools were grouped by the socioeconomic level, aiming to reduce the effects of this factor on the results. The two-stage DEA technique was applied to identify high and low-performance schools in aggregating results to their students in written reading in "Prova Brasil". Finally, multiple case studies were conducted in high and low performing schools to understand in situ how practices differ among groups. It was found that even after the socioeconomic factors were controlled, schools still show significant performance differences and that the increase in the average annual investment per student has no correlation with the improvement in educational outcomes. The results emphasize the importance of family and community participation in the educational process as well as the school director as an agent for school-family integration and as a support to the teaching staff in offering the basic conditions to the performance of their duties. We found 55 practices that can be applied by the Municipal Secretariats of Education, teachers and school principals, as well as by students and their families to promote the improvement of the performance of students of elementary education II in reading and writing..

Keywords: good educational practices; school management; performance in reading; data envelope analysis; IDEB. 


\section{LISTA DE FIGURAS}

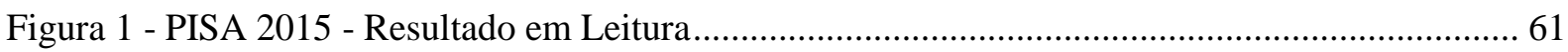

Figura 2 - Sistema de Avaliação da Educação Básica Brasileira ........................................................ 63

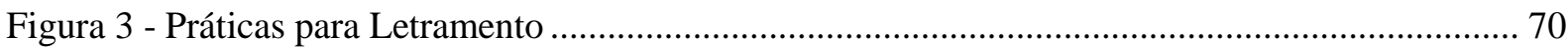

Figura 4 - BNCC - Língua Portuguesa - Eixos Organizadores ................................................................ 70

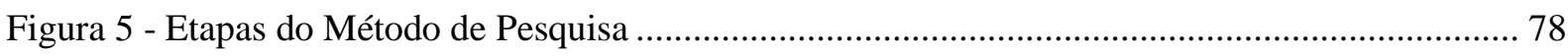

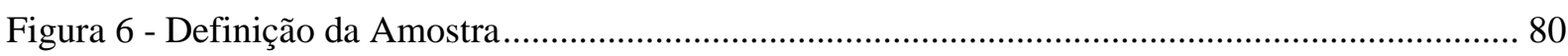

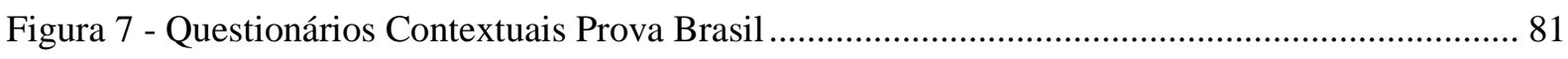

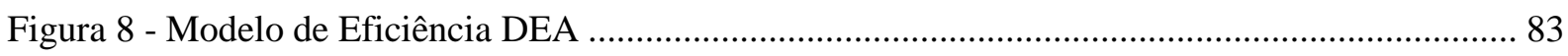

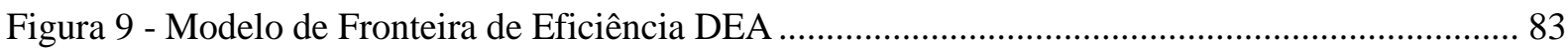

Figura 10 - Ciclo de Avaliação Prova Brasil - Modelo de Eficiência ...................................................... 86

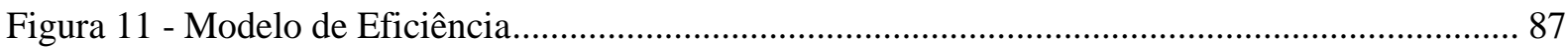

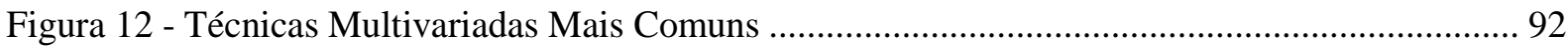

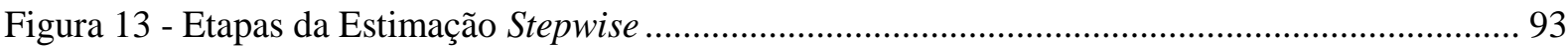

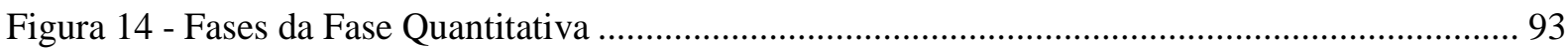

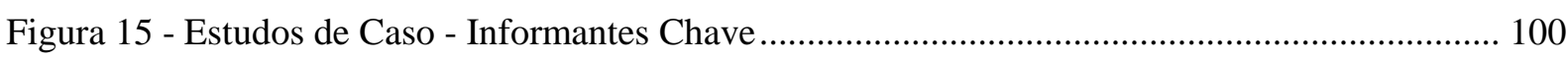

Figura 16 - Processo de Elaboração dos Roteiros de Entrevista ....................................................... 102

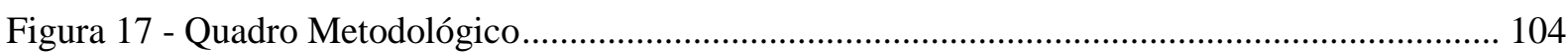

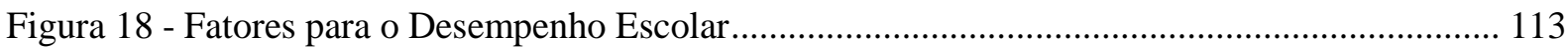

Figura 19 - Mapa de Localização - Município A …………................................................................. 119

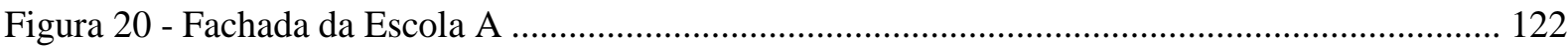

Figura 21 - Mapa de Localização da Escola A .................................................................................. 122

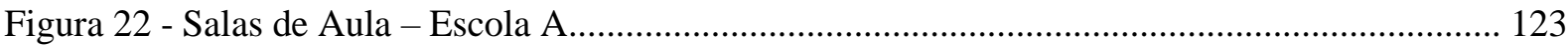

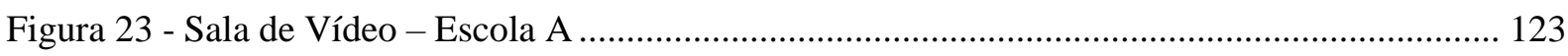

Figura 24 - Laboratório de Informática - Equipamentos Doados por Empresa - Escola A ............... 124

Figura 25 - Rampas de Acesso Interno - Escola A ............................................................................ 125

Figura 26 - Mesas de Jogos e Quadra Poliesportiva- Escola A ...................................................... 125

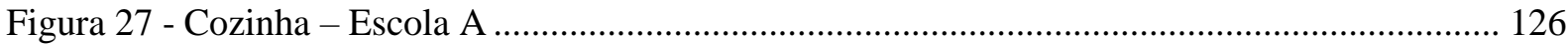

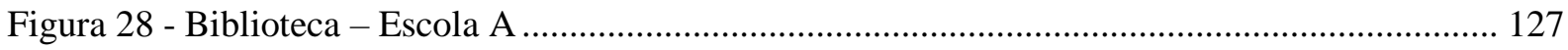

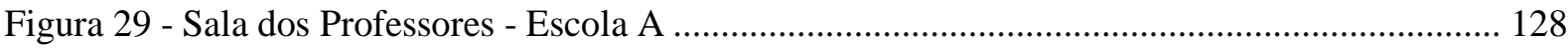

Figura 30 - Obra de Reforma da Brinquedoteca - Escola A................................................................. 132

Figura 31 - Prédio do Núcleo de Apoio Pedagógico - NAPE - Escola A ........................................... 133

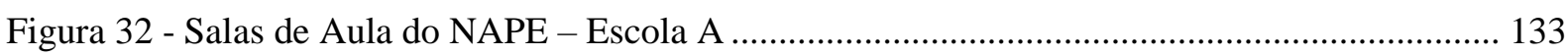

Figura 33 - Jogos Pedagógicos e Materiais de Apoio - NAPE - Escola A ........................................ 134

Figura 34 - Cartaz Atividade "Teatro de Leitores" - NAPE - Escola A ............................................. 134 
Figura 35 - Refeitório do NAPE - Escola A

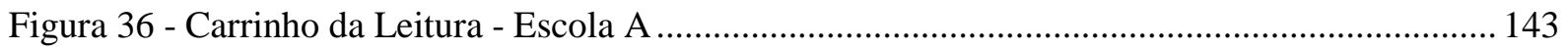

Figura 37 - Mapa de Localização - Município B ............................................................................... 146

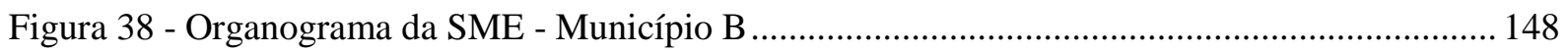

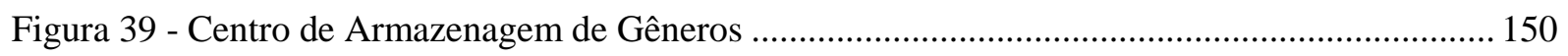

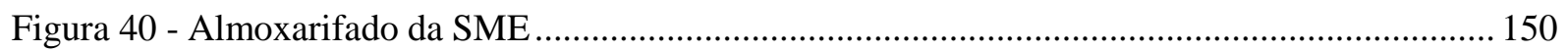

Figura 41 - Placas de Reconhecimento do Programa de Formação Continuada de Alfabetizadores Município B

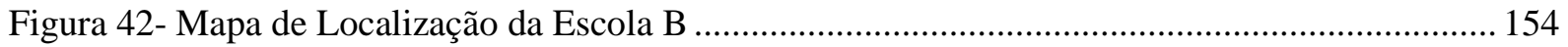

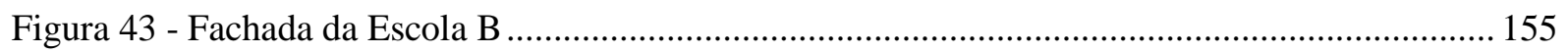

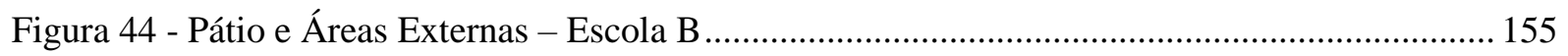

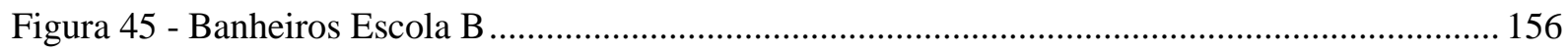

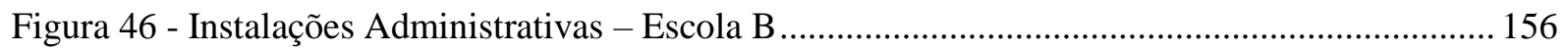

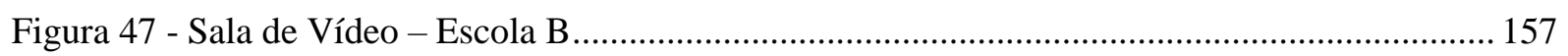

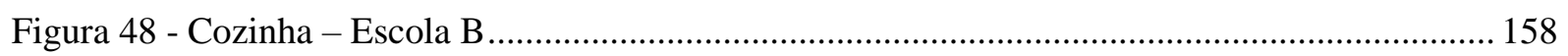

Figura 49 - Cardápio Semanal da Merenda - Escola B ................................................................. 159

Figura 50 - Fichas de Avaliação da Merenda - Projeto Amigos da Merenda - Escola B .................... 160

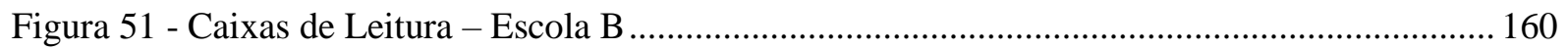

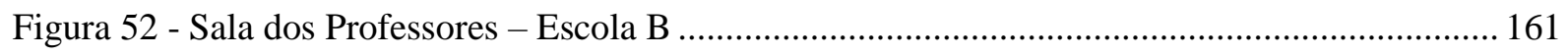

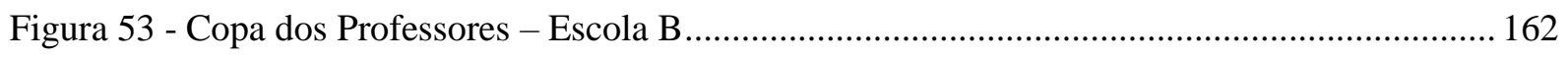

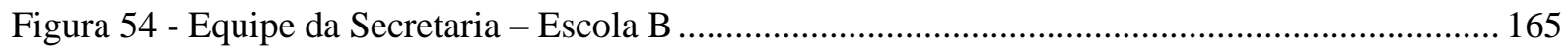

Figura 55 - Envelope para Contribuição com a APM - Escola B ..................................................... 166

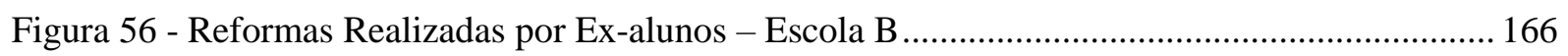

Figura 57 - Quadro de Risco - Alunos com Baixo Rendimento - Escola B ......................................... 168

Figura 58 - Relatório de Avaliação de Alunos com Defasagem (Frente e Verso) - Escola B ............. 168

Figura 59- Plano de Estratégias Individual para Recuperação de Alunos em Risco - Escola B......... 169

Figura 60 - Placa com Resultado do IDEB - Escola B .................................................................. 170

Figura 61 - Tabela de Resultados da Avaliação de Aprendizagem e Processo (AAP) - Escola B ..... 170

Figura 62 - Cartaz do Projeto Sementeira - SME - Município B ........................................................ 171

Figura 63 - Projeto Patrono - Lista de Professores Responsáveis - Escola B ..................................... 172

Figura 64 - Mapa de Distribuição Geográfica de Matrículas - Escola B .............................................. 173

Figura 65 - Quadro de Horários de Trabalho dos Funcionários - Escola B ......................................... 174

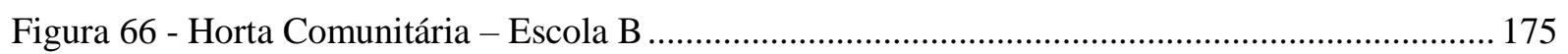

Figura 67 - Cronograma de Reuniões - Conselho de Classe e Conselho Escolar .................................. 176

Figura 68 - Lista de Comparecimento - Reunião de Pais - Escola B .................................................. 176

Figura 69 - Modelo de Plano de Ensino - Escola B ........................................................................ 178

Figura 70 - Relação de Alunos que Não Realizaram o Dever de Casa - Escola B .............................. 180 
Figura 71 - Mapa de Localização - Município C............................................................................... 182

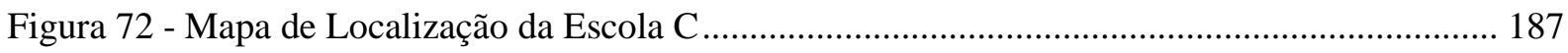

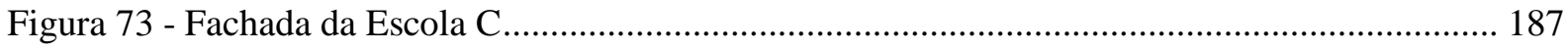

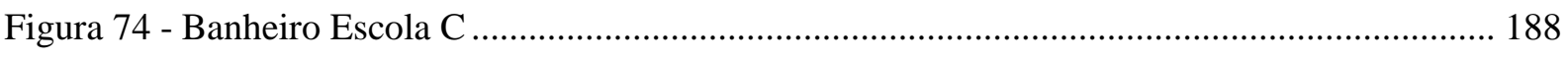

Figura 75 - Áreas Externas - Escola C …............................................................................... 188

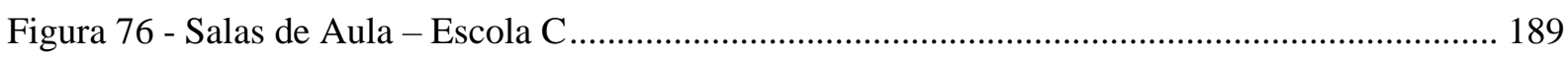

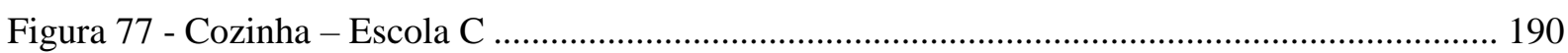

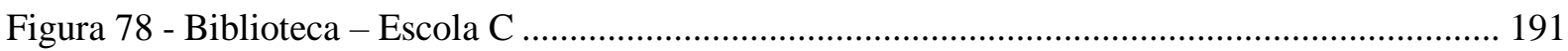

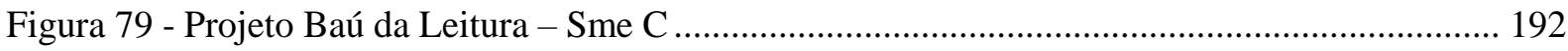

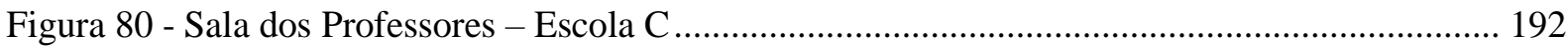

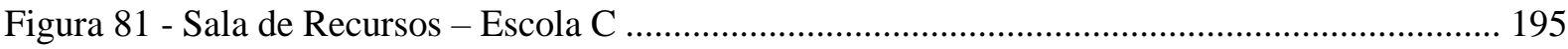

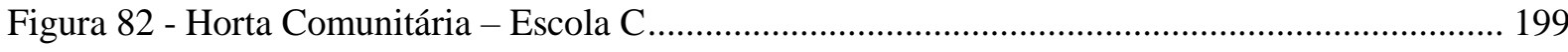

Figura 83 - Mapa de Localização - Município D ........................................................................... 204

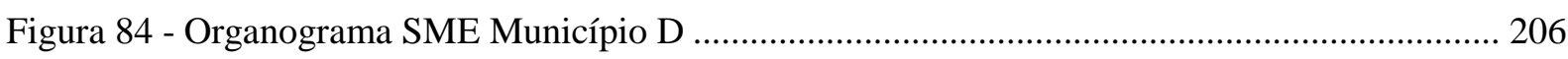

Figura 85 - Mapa de Localização da Escola D................................................................................. 208

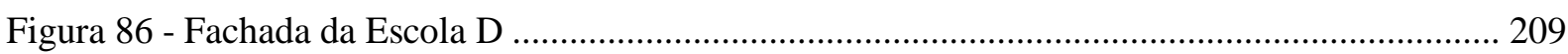

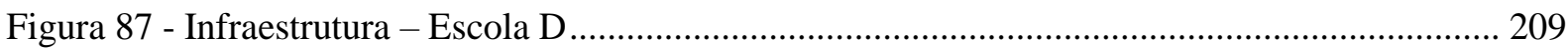

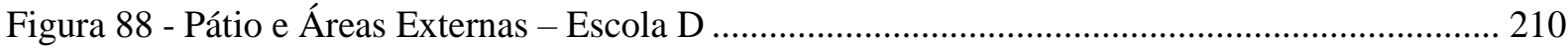

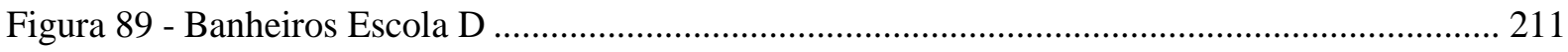

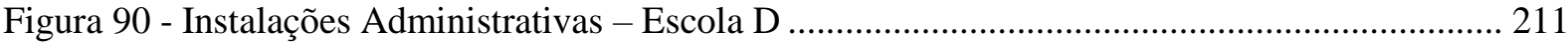

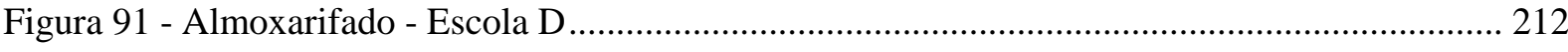

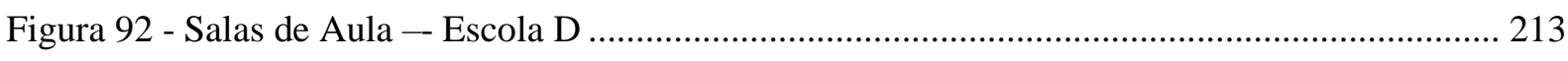

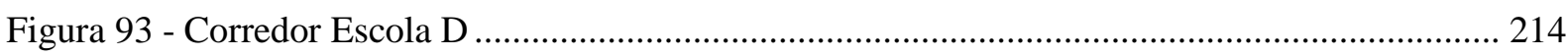

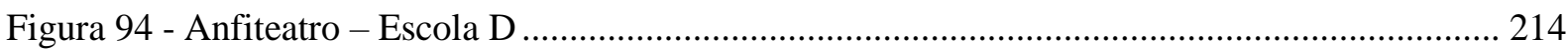

Figura 95 - Rampa para Cadeirantes e Banheiro Acessível - Escola D.............................................. 215

Figura 96 - Elevador para Cadeirantes Desativado - Escola D......................................................... 215

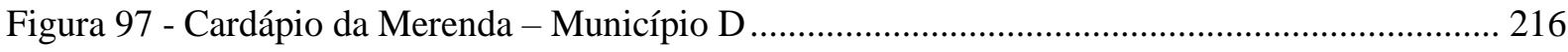

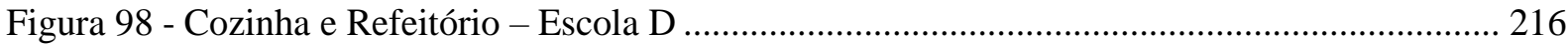

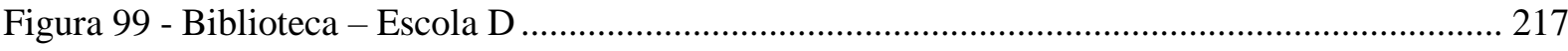

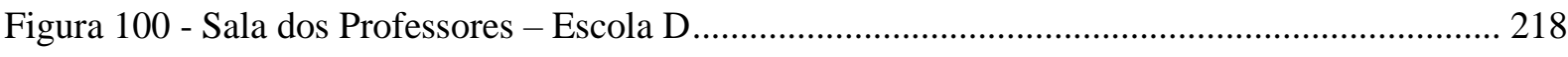

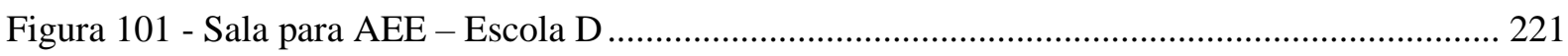

Figura 102 - Quadro de Horários de Trabalho dos Funcionários - Escola D .................................... 225

Figura 103 - Cronograma de Reuniões - Conselho Escolar ........................................................... 225

Figura 104 - Lista de Comparecimento - Reunião de Pais - Escola D................................................ 226

Figura 105 - Práticas para a Melhoria do Desempenho Escolar Associadas ao Professor.................. 235

Figura 106 - Práticas para Melhoria do Desempenho Escolar Associados ao Diretor ......................... 241

Figura 107 - Fatores para a Melhoria do Desempenho Escolar Associado à Escola ........................... 247 


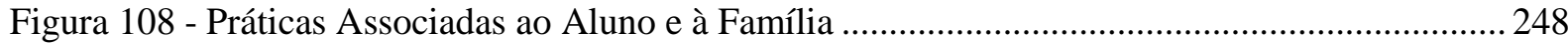

Figura 109 - Práticas Associadas à Secretaria Municipal de Educação 


\section{LISTA DE QUADROS}

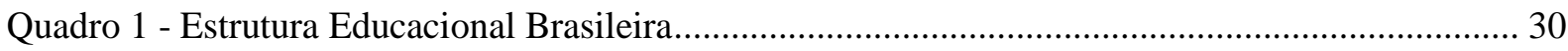

Quadro 2 - Trabalhos Internacionais - Eficiência em Educação - Nível Escola.................................... 41

Quadro 3 - Trabalhos sobre Eficiência em Educação no Brasil ............................................................. 42

Quadro 4 - Trabalhos sobre Eficiência em Educação no Brasil - Bases de Dados, Inputs e Outputs ... 44

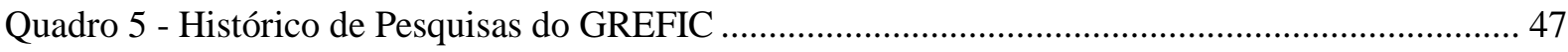

Quadro 6 - Revisão de Inputs: Variáveis Relacionadas à Família ......................................................... 49

Quadro 7 - Escala de Nível Sócioeconômico de Alves e Soares .............................................................. 50

Quadro 8 - Descrição dos Níveis de Complexidade de Gestão.............................................................. 57

Quadro 9 - Trabalhos com Uso da Técnica DEA em Educação ........................................................... 84

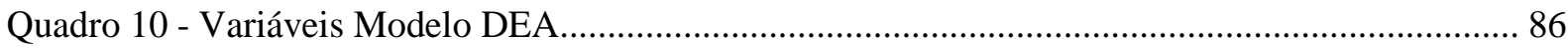

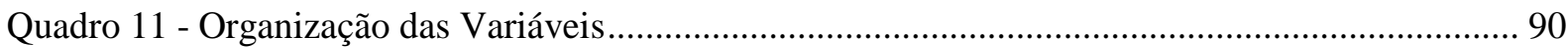

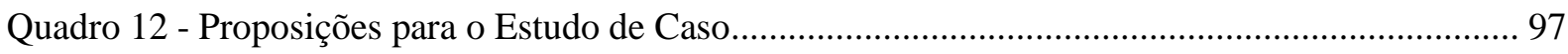

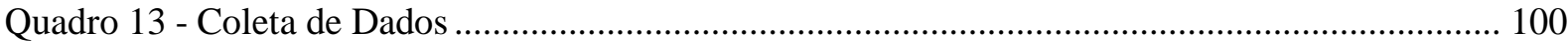

Quadro 14 - Resumo do Protocolo de Estudo de Caso ..................................................................... 103

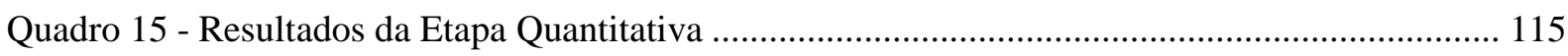

Quadro 16 - Práticas Identificadas na Etapa Quantitativa.................................................................... 232 


\section{LISTA DE GRÁFICOS}

Gráfico 1 - Percentual de Matrículas do Ensino Fundamental por UF e Dependência Administrativa 32

Gráfico 2 - Percentual de Escolas Básicas por Categoria Administrativa - Brasil 2016 ...................... 33

Gráfico 3 - Distribuição de Docentes Educação Básica por Nível de Escolaridade - Brasil 2016 ........ 34

Gráfico 4 - Indicador de Adequação da Formação Docente dos Anos Iniciais do Ensino Fundamental

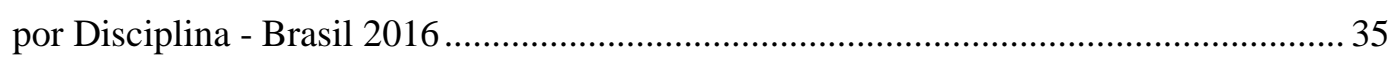

Gráfico 5 - Indicador de Adequação da Formação Docente dos Anos Finais do Ensino Fundamental

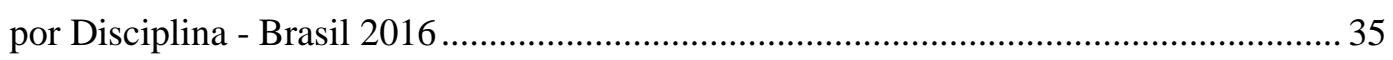

Gráfico 6 - Evolução das Taxas de Distorção Idade-Série por Etapa de Ensino - Brasil 2008-2016 .... 36

Gráfico 7 - Taxa de Não Aprovação por Séries do Ensino Fundamental e Médio Segundo Rede de Ensino (Pública/Privada) - Brasil 2015 ........................................................................ 37

Gráfico 8 - Índice de Gasto Público em Educação em Relação ao PIB (Variação 2008 - 2014) .......... 38

Gráfico 9 - Investimento Anual por Aluno 2014 - Educação Primária - US\$/Ano................................ 38

Gráfico 10 - Investimento Acumulado por Aluno (6 A 15 Anos) Versus Desempenho em Leitura -

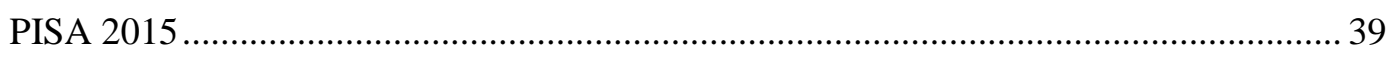

Gráfico 11 - Histograma do Escore de Complexidade da Gestão da Escola .......................................... 57

Gráfico 12 - PISA - Desempenho em Leitura - Brasil Versus Média OCDE - Evolução 2000 - 201562

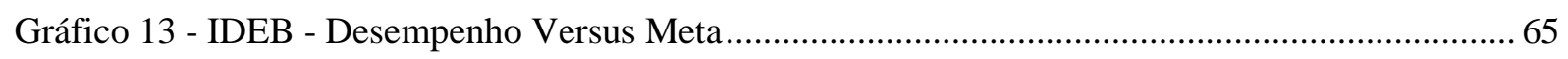

Gráfico 14 - Evolução dos Resultados em Língua Portuguesa no SAEB (1995 a 2015) ....................... 67

Gráfico 15 - Distribuição Percentual das Disciplinas Obrigatórias - Letras........................................... 69

Gráfico 16 - Distribuição de Escolas NSE 5 e 6 por UF .................................................................... 95

Gráfico 17 - Histograma DEA BCC - Escolas de NSE 5 e 6 - Brasil ................................................. 106

Gráfico 18 - Investimento Anual Médio por Aluno (2012 A 2014) X Desempenho no IDEB 2015 . 108

Gráfico 19 - Investimento Anual Médio por Aluno (2012 A 2014) X Escore DEA ............................ 108

Gráfico 20 - Histograma dos Resíduos da Regressão................................................................... 111

Gráfico 21 - Distribuição do Investimento em Educação - Município A .............................................. 120

Gráfico 22 - Distribuição dos Investimentos em Educação - Município B .......................................... 147

Gráfico 23 - Distribuição dos Investimentos em Educação - Município C ........................................... 183

Gráfico 24 - Distribuição dos Investimentos em Educação - Município D......................................... 205 


\section{LISTA DE TABELAS}

Tabela 1 - Matrículas Brasil - Censo da Educação Brasileira 2016 ..................................................... 32

Tabela 2 - Matrículas por Dependência Adminsitrativa - 2016 .............................................................. 33

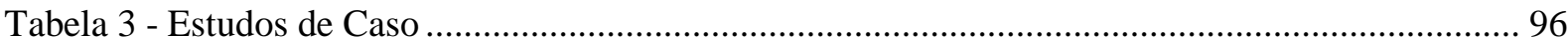

Tabela 4 - Teste de Normalidade - Ranking DEA BCC - NSE 5 e 6 - Brasil ...................................... 106

Tabela 5 - Estatística Descritiva para o Escore DEA.......................................................................... 106

Tabela 6 - Estatística Descritiva - Análise dos Escores DEA por Estado (UF).................................. 107

Tabela 7 - Resumo do Modelo de Regressão Linear Múltipla .............................................................. 110

Tabela 8 - Teste de Normalidade Kolmogorov-Smirnov dos Resíduos da Regressão ......................... 111

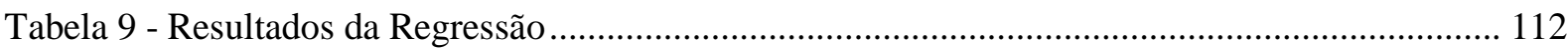

Tabela 10 - Dados Demográficos - Município A ……………………............................................... 119

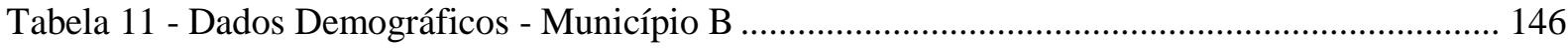

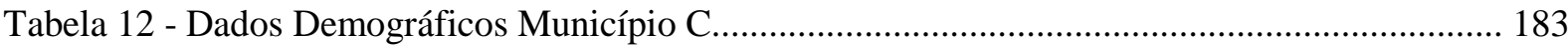

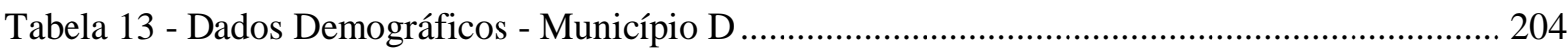

Tabela 14 - Concursos para Docentes de Língua Portuguesa - Conteúdos Avaliados ......................... 237 


\section{LISTA DE ABREVIATURAS E SIGLAS}

\begin{tabular}{|c|c|}
\hline ANA & Avaliação Nacional da Alfabetização \\
\hline ANEB & Avaliação Nacional da Educação Básica \\
\hline ANRESC & Avaliação Nacional do Rendimento Escolar \\
\hline $\mathrm{BCC}$ & Banker, Charnes e Cooper \\
\hline BNCC & Base Nacional Comum Curricular \\
\hline CCR & Charnes, Cooper e Rodhes \\
\hline CRS & Constant Returns to Scale \\
\hline DEA & Data Envelopment Analysis \\
\hline DFA & Distribution-Free Approach \\
\hline DMU & Decision Making Unit \\
\hline ENADE & Exame Nacional de Desempenho de Estudantes \\
\hline ERIC & Educational Resources Information Center \\
\hline FINBRA & Finanças do Brasil \\
\hline FUNDEB & $\begin{array}{l}\text { Fundo de Manutenção e Desenvolvimento da Educação Básica Fundamental e } \\
\text { da Valorização dos Profissionais da Educação }\end{array}$ \\
\hline FUNDEF & Fundo de Manutenção e Desenvolvimento da Educação Fundamental \\
\hline GREFIC & Grupo de Estudos em Eficiência \\
\hline IDEB & Índice de Desenvolvimento da Educação Básica \\
\hline INEP & Instituto Nacional de Estudos e Pesquisas Educacionais Anísio Teixeira \\
\hline LDB & Lei de Diretrizes e Bases da Educação Nacional \\
\hline MEC & Ministério da Educação \\
\hline MMF & Modelo de Misturas Finitas \\
\hline NSE & Nível Socioeconômico \\
\hline OCDE & Organização para a Cooperação e Desenvolvimento Económico \\
\hline PIB & Produto Interno Bruto \\
\hline PISA & Programme for International Student Assessment \\
\hline SAEB & Sistema de Avaliação da Educação Básica \\
\hline SBM & Slacks-Based Measure \\
\hline SFA & Stochastic Frontier Approach \\
\hline TDI & Taxa de Distorção Série-Idade \\
\hline TFA & Thick Frontier Approach \\
\hline TRI & Teoria da Resposta ao Item \\
\hline VRS & Variable Returns to Scale \\
\hline WOS & Web of Science \\
\hline
\end{tabular}




\section{SUMÁRIO}

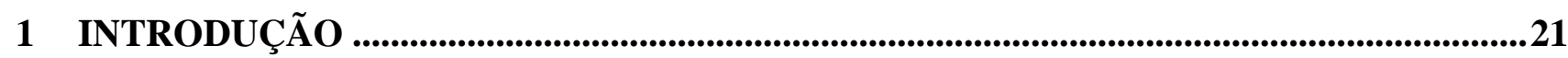

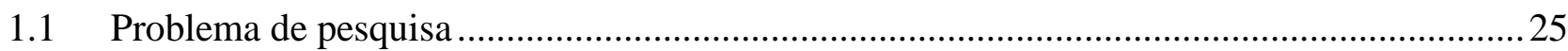

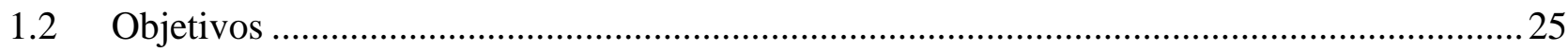

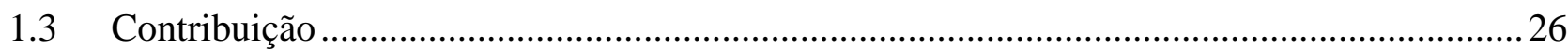

2 REFERENCIAL TEÓRICO ...........................................................................................27

2.1 A educação e o desenvolvimento social e econômico .....................................................2

2.2 A educação no Brasil............................................................................................ 29

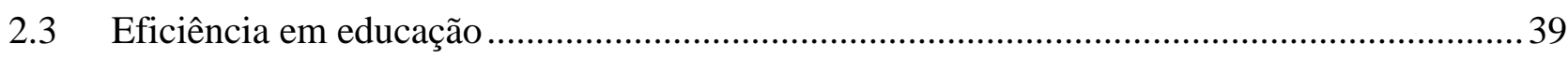

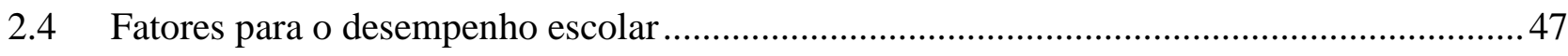

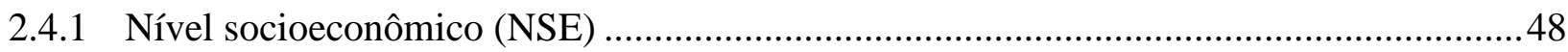

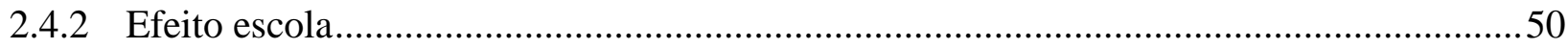

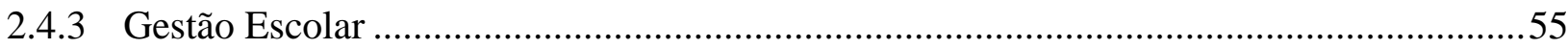

2.4.4 Remuneração e responsabilização docente .....................................................................58

2.5 Avaliação de desempenho escolar............................................................................... 59

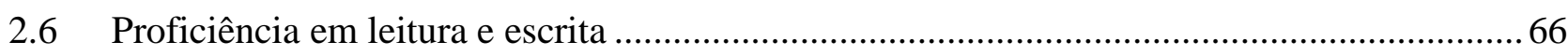

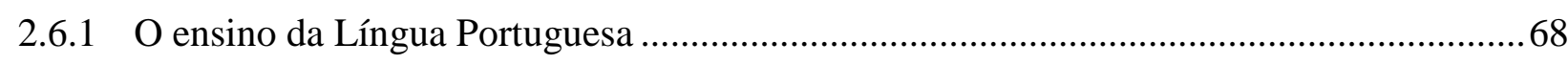

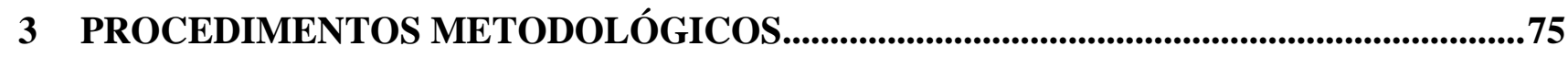

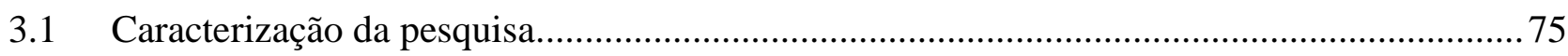

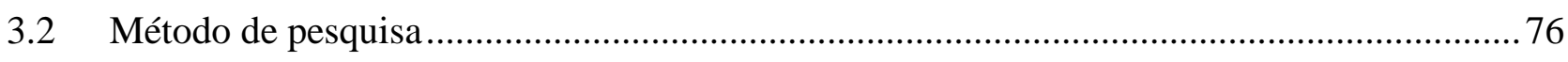

3.2.1 Base de dados e definição da amostra ..................................................................... 79

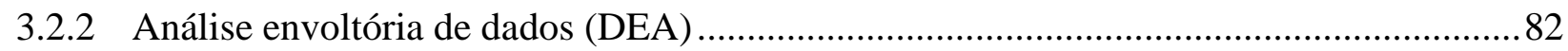

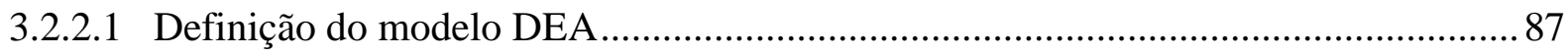

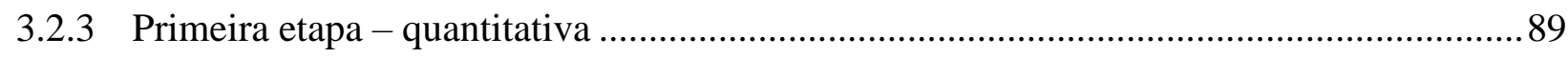

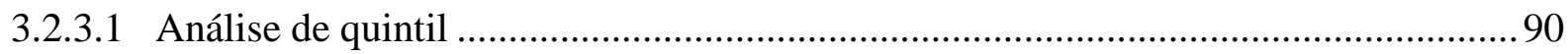

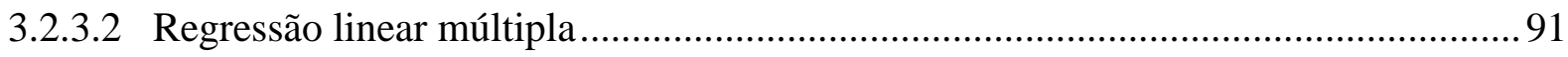

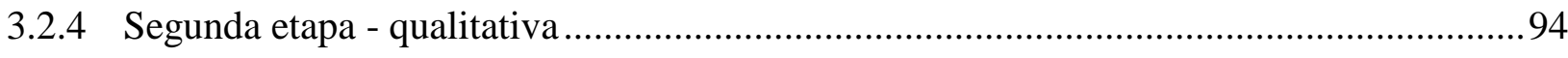

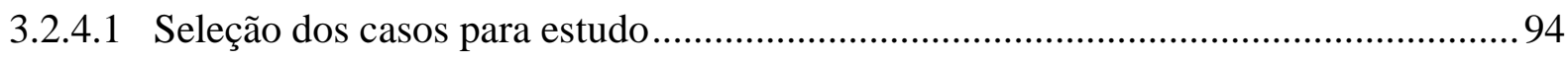




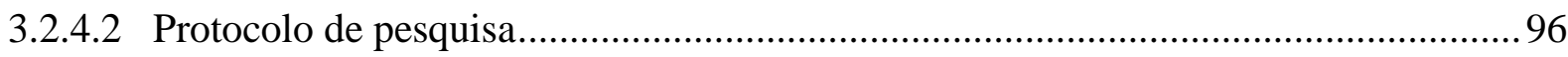

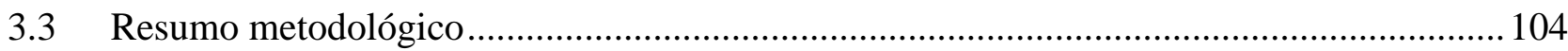

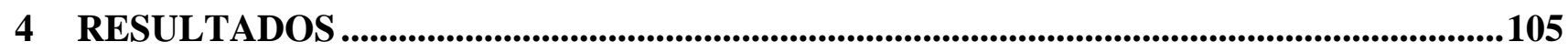

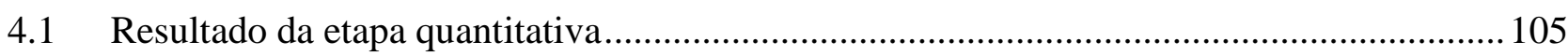

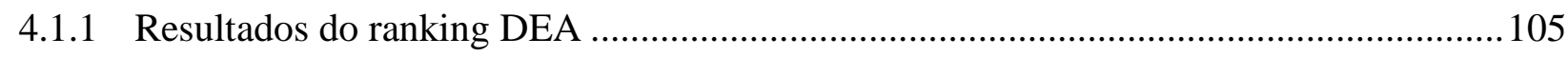

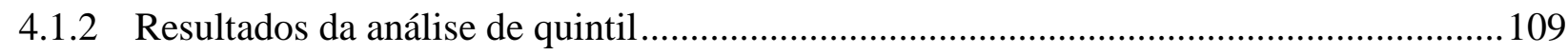

4.1.3 Resultados da regressão linear múltipla .............................................................. 110

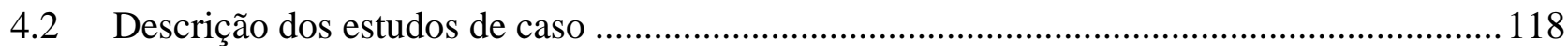

4.2.1 Análise do município “A” - alto desempenho ......................................................... 119

4.2.1.1 Análise Secretaria Municipal de Educação - município A.................................... 120

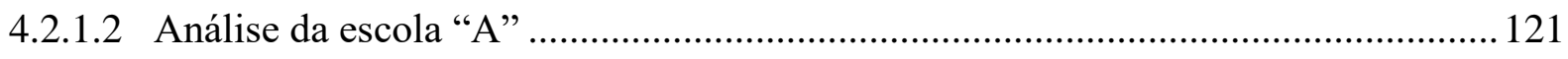

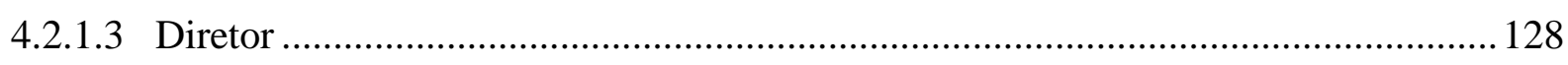

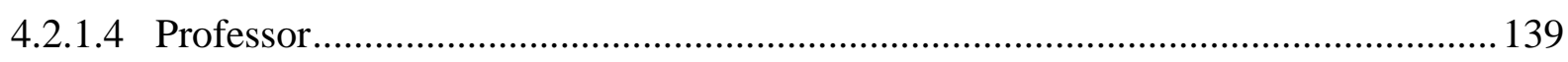

4.2.1.5 Alunos e Família .......................................................................................... 144

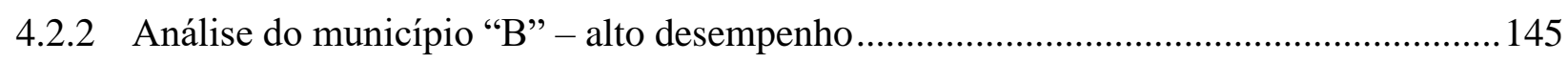

4.2.2.1 Análise da Secretaria Municipal de Educação ..................................................... 147

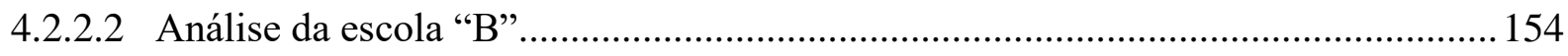

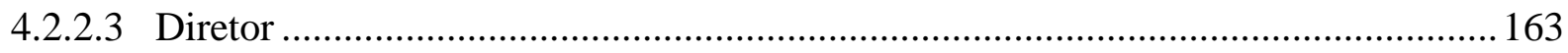

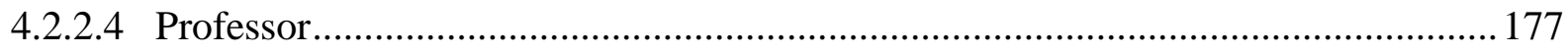

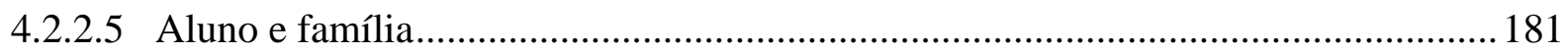

4.2.3 Análise do município C - baixo desempenho ....................................................... 182

4.2.3.1 Análise da Secretaria Municipal de Educação ..................................................... 183

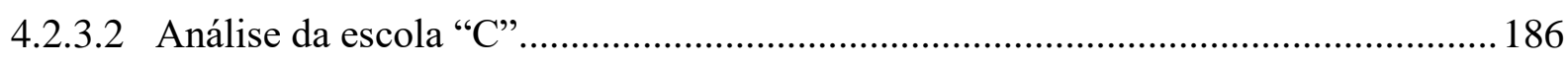

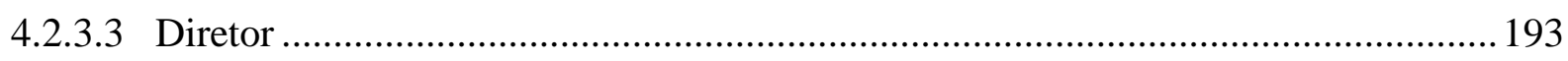

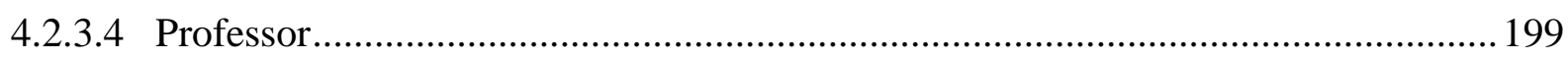

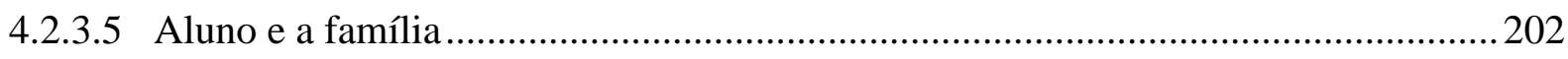

4.2.4 Análise do município D - baixo desempenho .......................................................204

4.2.4.1 Análise da Secretaria Municipal de Educação ....................................................... 205

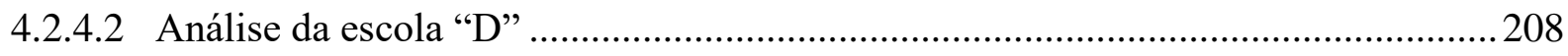




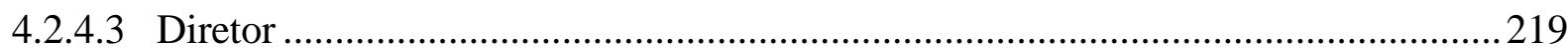

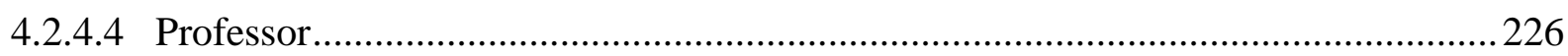

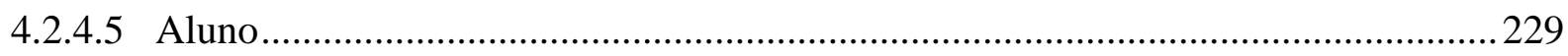

4.3 Análise quali-quantitativa e discussão dos resultados................................................... 231

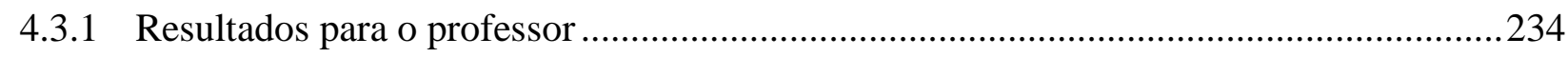

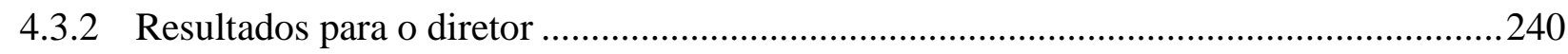

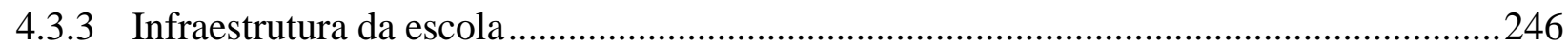

4.3.4 Resultados para o aluno e a família .....................................................................248

4.3.5 Evidências exclusivamente qualitativas oriundas dos estudos de caso ..........................250

5 CONCLUSÃO...........................................................................................................................254

5.1 Limitação e sugestão para trabalhos futuros ……........................................................ 255

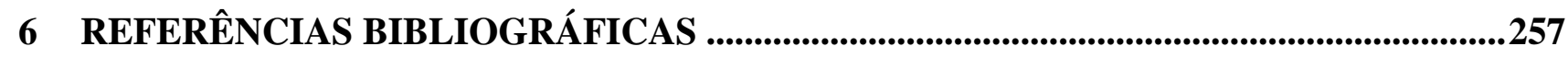

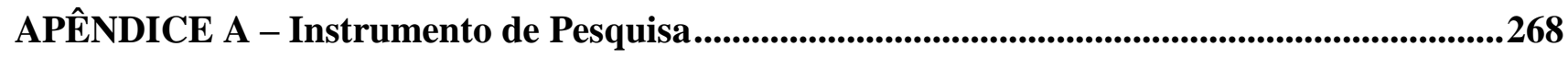

APÊNDICE B - Roteiro de Entrevista - Professor (A) .................................................................2274

APÊNDICE C - Roteiro de Entrevista - Diretor $(\mathrm{B})$...........................................................278

APÊNDICE D - Roteiro de Entrevista - Secretário Municipal De Educação (C) .....................282

ANEXO A - Questionário da Escola - Prova Brasil..............................................................285

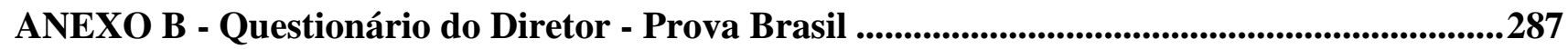

ANEXO C - Questionário do Professor - Prova Brasil.............................................................................295

ANEXO D - Questionário do Aluno - Prova Brasil ...........................................................................303

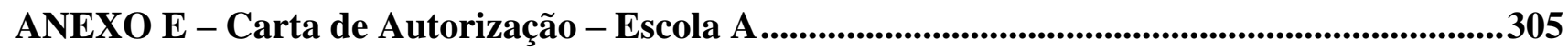

ANEXO F - Carta de Autorização - Escola B ..................................................................................306

ANEXO G - Carta de Autorização - Escola C .................................................................................307

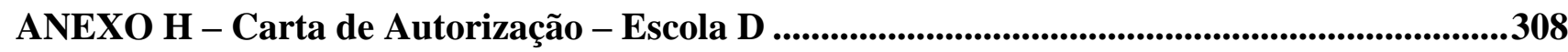





\section{INTRODUÇÃO}

A educação tem sido frequentemente vinculada ao desenvolvimento dos países, tanto no âmbito social quanto no econômico. Diversos autores e estudos, elaborados e patrocinados por entidades governamentais e não governamentais, corroboram com esta afirmação e reconhecem a educação como fator preponderante para o progresso. Este fator, aliado aos altos valores investidos pelos governos e pelas famílias ao redor do mundo, tem feito com que o interesse pela área extrapole o campo da educação, suscitado estudos e debates nos campos das ciências econômicas e da administração (CARDOSO GOMES; BRESCIANI; AMORIM, 2016; DUMCIUVIENE, 2015; GLEWWE; ZHENG, 2014; KRUSS et al., 2015; MELHUISH, 2013; NEAMTU, 2015; PANA; MOSORA, 2013; SALGADO JUNIOR; NOVI, 2015; SALGADO JUNIOR; NOVI; FERREIRA, 2016).

Dada a sua importância, os resultados relativos aos serviços educacionais não devem avaliar apenas os números em relação ao investimento e ao total da população atendida, devese considerar, principalmente, a qualidade do serviço educacional prestado (SALGADO JUNIOR; NOVI, 2015).

Corroborando com esta afirmação, Wu, Liu e Zhang (2017), em sua pesquisa sobre a mobilidade social entre os chamados "Novos trabalhadores do colarinho branco" na China, verificaram significativa diferença salarial entre os trabalhadores formados nas instituições consideradas de melhor qualidade do país em relação àqueles formados em instituições de menos prestígio, evidenciando o importante papel da qualidade da educação na vida do trabalhador (WU; LIU; ZHANG, 2017).

Nas áreas da economia e da administração, os estudos têm focado o debate em termos da eficiência do setor público na oferta do serviço educacional, especialmente em razão dos crescentes custos e investimentos realizados na área, que é uma das mais dispendiosas na maioria dos países (DE WITTE; LÓPEZ-TORRES, 2015). E em razão da necessidade de os governos equilibrarem os investimentos realizados na área da educação com os demais serviços públicos como saúde, transporte, entre outros, é necessário que estes sejam feitos da forma mais eficiente possível (JOHNES; PORTELA; THANASSOULIS, 2017).

Evidências apontam que as experiências de uma criança durante o ensino fundamental trazem consequências importantes para o restante de sua vida acadêmica, sendo aconselhável que os estudos foquem a avaliação desta etapa educacional (MELHUISH, 2013). 
E, neste sentido, as competências de leitura e escrita são primordiais, pois há forte relação entre a compreensão em leitura e o desempenho escolar. Os alunos que possuem melhor compreensão textual, comumente também apresentam desempenho escolar mais satisfatório nas demais disciplinas (OLIVEIRA; BORUCHOVITCH; SANTOS, 2008).

Segundo Oliveira, Boruchovitch e Santos (2008), a habilidade de compreensão é cada vez mais aprimorada em razão do contato que se tem com a leitura, uma vez que há o desenvolvimento e a ampliação dos conhecimentos prévios que basearão a compreensão de novas informações.

Além dos benefícios no campo educacional, o adequado letramento, isto é, a capacidade de entender e usar as formas da linguagem, ainda proporciona ao indivíduo outros ganhos. Para Bray, Adamson e Mason (2014), diversos estudos neste campo relacionaram ganhos sociais advindos do letramento. Em seu trabalho os autores citam dois estudos a respeito: primeiro, apontam que estudo realizado com mulheres nepalenses identificou que elas sentiram que ganharam uma nova forma de identidade pública como 'educada', ao mesmo tempo em que ganharam um espaço social e voz individual, em razão de sua escrita; a seguir apresentam estudo que realizado junto a mulheres em Bangladesh o qual interpretou que sua alfabetização representava um desafio ao patriarcado, pois fortaleceu a sua posição em relação aos homens e lhes permitiu estabelecer seus direitos. Ainda verificaram que trabalhadores com maior alfabetização geralmente ganham mais do que aqueles com níveis de alfabetização menores (BRAY; ADAMSON; MASON, 2014).

A qualidade da educação tem sido medida por meio de avaliações em larga escala. Apesar de questionamentos encontrados na literatura, é consenso de que esta ainda é a melhor ferramenta para a obtenção de um quadro comparativo do desempenho dos diversos sistemas e métodos educacionais e de gestão, fornecendo aos gestores e fomentadores de políticas públicas importante ferramental de trabalho em busca da melhoria da qualidade (BAUER; ALAVARSE; OLIVEIRA, 2015).

No Brasil, a educação básica é um direito garantido pela Constituição Federal, sendo um dever do estado proporcionar o acesso ao ensino de qualidade aos seus cidadãos. Porém, apesar dos crescentes investimentos no setor e da ampliação da oferta, a qualidade do serviço educacional brasileiro não tem acompanhando o ritmo de seu crescimento (ALVES; SILVA, 2013; DUARTE, 2013; GOUVEIA; SOUZA, 2013; LÚCIO; PINHEIRO; NASCIMENTO, 2010; SALGADO JUNIOR; NOVI; FERREIRA, 2016; SOARES; ALVES, 2013; ZOGHBI et al., 2009). 
Os resultados do Brasil em avaliações padronizadas, como o Programme for International Students Assessment (PISA), promovido pela Organização de Cooperação e Desenvolvimento Econômico (OCDE), que avalia internacionalmente alunos de 15 anos de 72 países, evidenciam o problema. Em estudo que comparou os resultados do PISA entre Brasil, Chile, Colombia, México e Uruguai, Deutsch, Dumas e Silber (2013) verificaram que o Brasil é o país com piores resultados médios entre cinco países considerando-se o desempenho em todas as áreas - leitura, matemática e ciências. Na última edição do teste, aplicado em 2015, o Brasil pontuou abaixo da média dos países da OCDE em praticamente todas as áreas. Em leitura, alcançou média de apenas 407 pontos, ante a uma média de 493 pontos dos demais países. O quadro se torna ainda mais alarmante ao verificar que esta média apresentou decréscimo de 2 pontos em relação aos últimos 3 anos.

No âmbito nacional, o Índice de Desenvolvimento da Educação Básica (IDEB) é o principal indicador de qualidade disponível. Entre outros fatores, este índice é composto pelos resultados obtidos pelos alunos na Prova Brasil, teste nacional padronizado que avalia os conhecimentos e habilidades dos estudantes brasileiros em matemática e língua portuguesa. Também nesta avaliação os resultados são insatisfatórios, estando a média nacional dos estudantes abaixo da média projetada pelo Ministério da Educação (MEC) para cada nível educacional. Destaca-se que, apesar da tendência de melhoria apresentada nas últimas edições da avaliação, a nota média em língua portuguesa foi de 252 pontos, valor abaixo, por exemplo, da nota obtida pelos estudantes em 1995, quando se atingiu 256 pontos de média.

Utilizando-se destes dados, diversas pesquisas têm procurado identificar e compreender as razões pelas quais os sistemas educacionais dos países apresentam ineficiências na gestão dos recursos públicas e na entrega de bons resultados à sociedade, de forma a compreender melhor este fenômeno para encontrar as medidas mais adequadas para mitigar o problema (AMÂNCIO-VIEIRA et al., 2015).

Para além dos fatores extraescolares e daqueles estritamente ligados ao processo de ensino-aprendizagem, diversos estudos apontam que as práticas de gestão adotas nas escolas têm papel decisivo na qualidade do serviço educacional. (ALVES; SOARES, 2007a; BLOOM et al., 2015; GONÇALVES; FRANÇA, 2013; GOUVEIA; SOUZA, 2013; SALGADO JUNIOR; NOVI, 2015; SALGADO JUNIOR; NOVI; FERREIRA, 2016; ZOGHBI et al., 2009).

Porém, as pesquisas realizadas no âmbito da gestão da educação deixam algumas lacunas, como a falta de consenso sobre sua eficácia em razão dos métodos utilizados para sua identificação. Segundo Salgado Junior e Novi (2015, p. 632), “as pesquisas já realizadas se 
dividem, basicamente, em dois grupos: quantitativas e qualitativas". As quantitativas, embora se utilizem de variadas técnicas estatísticas, em geral, se limitam a relacionar os insumos utilizados no setor (recursos humanos e materiais) aos resultados dos estudantes sem, no entanto, investigar as práticas administrativas e pedagógicas adotadas pelas escolas de melhor desempenho (FARIA; JANNUZZ; SILVA, 2008). Nesta abordagem o 'efeito escola', ou seja, o efeito gerado no aluno em razão das atividades realizadas pela escola (BROOKE; SOARES, 2011; CAVALIERE, 2007) é desconsiderado, uma vez que não se verifica o que acontece dentro das unidades escolares.

Ainda, naquelas de abordagem qualitativas, a limitação, em geral, ocorre na seleção das escolas, uma vez que nem sempre se utilizam instituições com características similares e com resultados diferentes, que permitam generalizar os resultados das práticas identificadas (SALGADO JUNIOR; NOVI, 2015).

Pesquisas que identifiquem atividades praticadas no âmbito escolar que possam contribuir para a melhoria do desempenho dos alunos nos testes padronizados e que envolvam uma visão sistêmica da educação, englobando tanto os aspectos pedagógicos quanto aqueles ligados às atividades de gestão são fundamentais, à medida que fornecem subsídio para o planejamento das Secretarias Municipais de Educação (SME), diretores e escolas (SALGADO JUNIOR; NOVI, 2015). Estas pesquisas possibilitam a adoção de um novo modelo de Administração Pública, voltado à implementação de políticas, estratégias e práticas gerenciais modernas, anseio da sociedade na busca pela eficiência do uso dos recursos e pela oferta de serviços de melhor qualidade (BLIACHERIENE, 2015).

Assim, o presente trabalho se propõe a preencher estas lacunas, propondo boas práticas administrativas e pedagógicas que possam colaborar para a melhoria do desempenho dos estudantes de escolas públicas municipais de ensino fundamental II em avaliações padronizadas de leitura e escrita, identificadas pelo método quali-quantitativo proposto por Salgado Junior e Novi (2014). A utilização desta metodologia contribui para a obtenção de respostas mais completas, uma vez que, apesar das diferenças, dos pontos fortes e fracos de cada abordagem, o uso combinado de ambas as abordagens permite aos estudiosos entender melhor os importantes problemas educacionais (BRAY; ADAMSON; MASON, 2014).

$\mathrm{Na}$ etapa quantitativa, com o uso de dados do IDEB (nota em teste padronizado de língua portuguesa e indicador de rendimento escolar [reprovações e evasão escolar]), as escolas serão classificadas por meio da Análise Envoltória de Dados (DEA), de acordo com seu desempenho em agregar aos alunos melhoria nas notas de português do IDEB. Para isso serão considerados como input os resultados obtidos pelos estudantes na Prova Brasil da 
quinta série, realizada em 2011 e como outputs o desempenho destes mesmos alunos na Prova Brasil da nona série, realizada em 2015, bem como o indicador de rendimento da escola. Em seguida, a partir dos dados obtidos no Censo Escolar e no questionário contextual da Prova Brasil, e por meio das técnicas de regressão linear múltipla e da análise de quintil, serão identificadas as variáveis potencialmente relacionadas ao bom desempenho. Os resultados obtidos na primeira etapa - quantitativa - são utilizados para a etapa seguinte - qualitativa -, na qual são realizadas visitas a escolas selecionadas (duas de alto desempenho e duas de baixo desempenho) para um estudo em profundidade para a identificação das práticas de gestão adotadas pelas escolas de alto desempenho.

\subsection{Problema de pesquisa}

Com base no referencial teórico já citado, este trabalho busca responder ao seguinte problema de pesquisa: Quais práticas administrativo-pedagógicas podem colaborar para a melhoria do desempenho de leitura e escrita de alunos de escolas municipais do ensino fundamental II?

\subsection{Objetivos}

O objetivo geral deste trabalho será:

- Propor práticas administrativas e pedagógicas que colaborem para a melhoria do desempenho dos alunos de escolas de ensino fundamental II em avaliações padronizadas de língua portuguesa.

Para isso, alguns objetivos específicos serão alcançados previamente:

- Compreender o conceito de eficiência em educação;

- Identificar os fatores internos e externos às escolas que influenciam no desempenho escolar;

- Identificar o nível de eficiência das escolas de ensino fundamental II em agregar desempenho aos estudantes em avaliações padronizadas de língua portuguesa; 
- Agrupar as práticas administrativas e pedagógicas de acordo com o agente responsável (diretor, professor ou aluno e família), área e tema relacionados.

\subsection{Contribuição}

Espera-se que os resultados encontrados possam auxiliar na melhoria do ensino de língua portuguesa nas escolas públicas de ensino fundamental II, por fornecer um referencial de boas práticas que possam ser utilizados no planejamento das unidades escolares pelas Secretarias Municipais de Educação, diretores escolares, professores da disciplina de língua portuguesa, bem pelos alunos e seus familiares na adoção de rotinas que favoreçam o aprendizado do estudante. 


\section{REFERENCIAL TEÓRICO}

Neste capítulo são apresentados os principais conceitos que norteiam o desenvolvimento desta dissertação. Inicialmente é analisada a importância da educação no desenvolvimento social e econômico, tanto das pessoas quanto das nações à luz da literatura acadêmica, justificando-se, assim, a importância de pesquisas sobre o tema. A seguir o sistema educacional brasileiro é caracterizado, fornecendo um panorama geral sobre seu funcionamento, características organizacionais e resultados qualitativos obtidos em avaliações de desempenho dos estudantes. Em seguida é apresentada uma revisão sobre os principais e mais recentes estudos relacionados à eficiência em educação e suas abordagens metodológicas, importante etapa para a compreensão da metodologia utilizada nesta dissertação. Posteriormente se apresentam os fatores de maior influência indicados pela literatura acadêmica para o desempenho escolar: a influência dos fatores socioeconômicos do aluno; o chamado 'efeito escola', que congrega as atividades realizadas dentro do ambiente escolar e que resultam em ganhos de aprendizado ao aluno; a gestão escolar e as políticas de remuneração e responsabilização docente. Na sequência são revisados os trabalhos acerca da utilização de avaliações padronizadas em larga escala para a avaliação da qualidade da educação. E, por fim, são abordadas a importância da proficiência em leitura e escrita e os métodos de letramento.

\subsection{A educação e o desenvolvimento social e econômico}

Diversos autores e pesquisadores têm defendido o papel e a importância da educação tanto para o desenvolvimento do cidadão, quanto para o desenvolvimento social e econômico das nações (CARVALHO; SOUSA, 2014; GOMES, 2010; POKER JUNIOR; NUNES; NUNES, 2013).

A educação influencia a determinação e a distribuição da renda. Ela é essencial para a formação de Capital Humano que, consequentemente, possibilita o aumento da produtividade e o crescimento econômico de um país (GOMES, 2010; NEAMTU, 2015).

A Teoria do Capital Humano, formulada na década de 1950 pelo então professor da universidade de Chicago, Theodore W. Schultz, é precursora deste conceito. Segundo esta 
teoria, "o trabalho humano, quando qualificado pela educação, é uma das fontes mais importantes de ampliação da produtividade econômica e das taxas de lucro. A educação passou a ser vista como um pressuposto do desenvolvimento econômico" (ANDRADE, 2010, p. 7).

As políticas públicas de diversos países têm sido influenciadas por esta teoria e por outras que com ela corroboram, gerando maiores investimentos em educação. "No Brasil o investimento está atrelado ao PIB, e pode chegar a alcançar, de acordo com propostas, até 10\% deste montante" Poker Junior, Nunes e Nunes (2013, p. 264). Assim, a educação adquiriu um valor econômico, sendo considerado um fator de produção, com critérios de investimento (ANDRADE, 2010).

Além de cumprir importante papel na formação de mão de obra qualificada necessária ao desenvolvimento, a educação proporciona a disseminação do conhecimento, incentivando os países a desenvolver tecnologias, contribuindo para a melhoria da produtividade e para o aumento dos ganhos individuais, como melhores salários e empregabilidade. Por esta razão, a diferença de performance econômica entre os países está diretamente ligado às diferenças nos níveis de educação entre eles (MERCAN; SEZER, 2014).

O Japão tem em sua história a forte preocupação com a educação. Ele se tornou um dos países mais desenvolvidos, mesmo com escassos recursos naturais, por ter formado um sistema educacional de sucesso antes de ter uma economia de sucesso. Durante um longo período os japoneses chegaram a investir um terço de seu orçamento na consolidação da educação e na formação de capital humano (NEAMTU, 2015).

Segundo Carvalho e Sousa (2014), outros benefícios advêm de um maior nível de escolaridade da população, como a redução da criminalidade, maior harmonia social e, inclusive, a melhoria nas condições de saúde da população. Em seu estudo sobre a avaliação da efetividade e eficiência do gasto público em educação em municípios brasileiros, Poker Junior, Nunes e Nunes (2013) destacam que a educação proporciona resultados positivos não apenas para quem a recebe, mas também para a sociedade de forma geral. Segundo eles

[...] outra especificidade do mercado educacional seria a produção de externalidades positivas, gerando benefícios coletivos até maiores que os individuais, inclusive para quem não está inserido no processo educativo, influenciando na renda per capita, na expectativa de vida, na mortalidade infantil e até nas exportações. Assim, o investimento em educação seria capaz de explicar não só o crescimento do PIB, mas também a melhoria do padrão de vida da população em geral (POKER JUNIOR; NUNES; NUNES, 2013, p. 268). 
Os investimentos na área da educação, de forma geral, são os que mais geram crescimento quando comparados a outros tipos de gastos públicos (ZOGHBI et al., 2009).

Estes fatores têm feito com que a educação seja considerada um dos mais relevantes serviços públicos, o que tem atraído a atenção tanto dos governantes, quanto dos pesquisadores em todo o mundo (AMÂNCIO-VIEIRA et al., 2015).

Mas ao se avaliar a educação, é necessário compreender que a qualidade é a variável mais importante para explicar o desenvolvimento econômico, e não a quantidade (SALGADO JUNIOR; NOVI, 2014). Em sua pesquisa sobre a mobilidade social entre os chamados "Novos trabalhadores do colarinho branco" na China, Wu, Liu e Zhang (2017), verificaram significativa diferença salarial entre os trabalhadores formados nas melhores instituições do país em relação àqueles formados em instituições de menos prestígio, evidenciando, assim, o importante papel da educação na vida do trabalhador (WU; LIU; ZHANG, 2017).

Poker Junior, Nunes e Nunes (2013), corroboram com esta afirmação. Para os autores, deve-se considerar a qualidade do gasto na educação, uma vez que investimentos maiores não estão necessariamente atrelados ao aumento de produtividade, podendo, inversamente, afetar de maneira negativa a gestão dos recursos públicos (POKER JUNIOR; NUNES; NUNES, 2013).

Apesar dos altos investimentos no setor, nos países em desenvolvimento o esforço ainda parece ser insuficiente para prover uma educação de qualidade em níveis de eficiência (RAMZI; AFONSO; AYADI, 2016).

\subsection{A educação no Brasil}

No Brasil, a educação pública, gratuita e de qualidade, é uma garantia do cidadão e um dever do Estado. A Constituição Federal preconiza:

Art. 205 - A educação, direito de todos e dever do Estado e da família, será promovida e incentivada com a colaboração da sociedade, visando ao pleno desenvolvimento da pessoa, seu preparo para o exercício da cidadania e sua qualificação para o trabalho.

Art. 206 - O ensino será ministrado com base nos seguintes princípios: I - igualdade de condições para o acesso e permanência na escola; [...] IV - gratuidade do ensino público em estabelecimentos oficiais; [...] VII - garantia de padrão de qualidade. (BRASIL, 1988) 
O sistema educacional brasileiro é dividido em 03 etapas principais: ciclo básico, profissionalizante e superior. O maior deles, o básico, é composto pela educação infantil (3 a 5 anos), fundamental (6 a 14 anos) e pelo ensino médio (15 a 17 anos), concentrando o maior volume de alunos (QUADRO 1).

\section{QUADRO 1 - ESTRUTURA EDUCACIONAL BRASILEIRA}

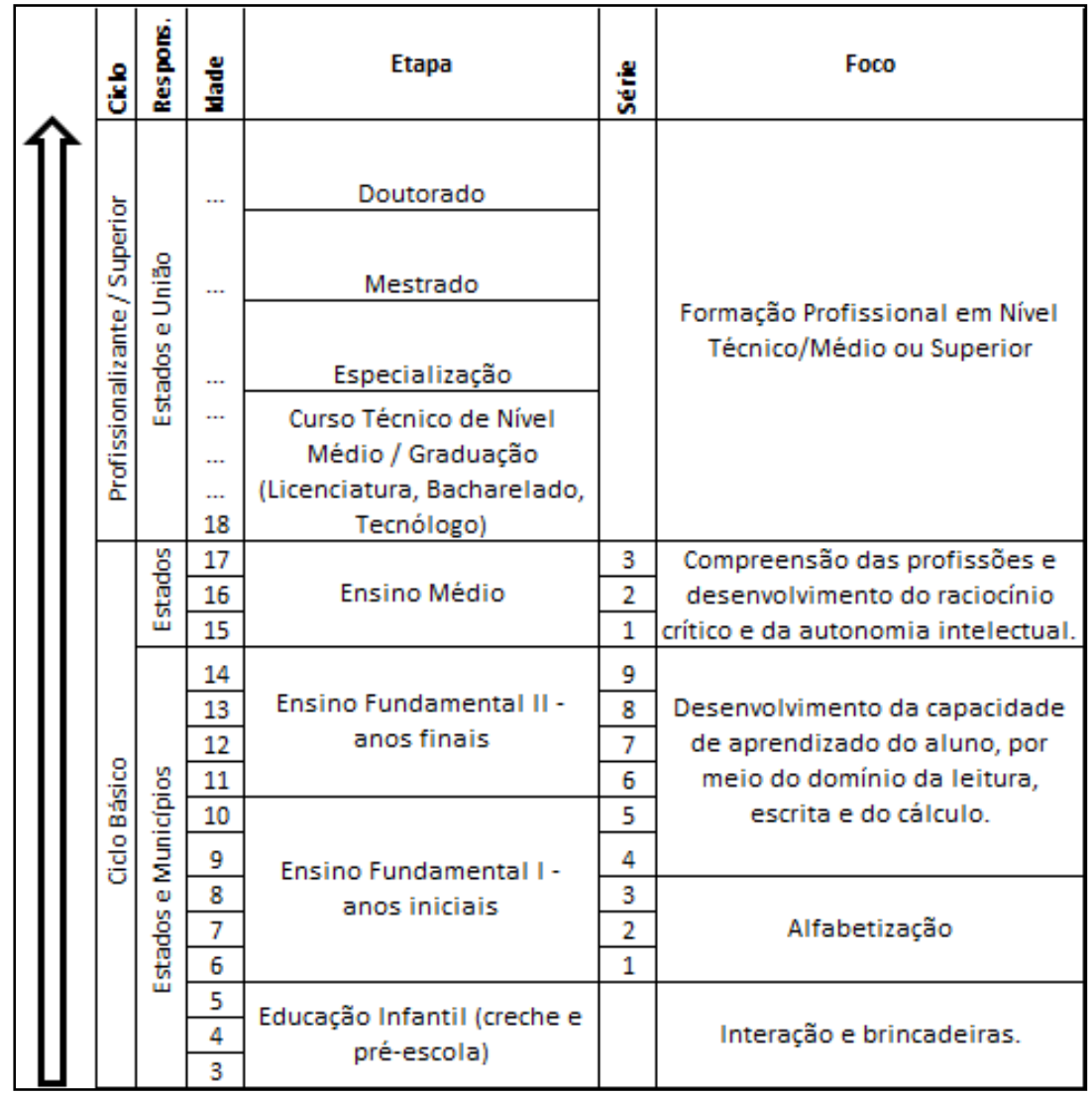

Fonte: Elaborado pelo autor. Base: (BRASIL, 2014)

Em todos os ciclos, além da educação pública gratuita, há, também, a oferta por meio de instituições privadas, as quais possuem concessão do estado para operar, estando subordinadas à regulação de acordo com o nível em que atua, conforme estabelecido na Lei $\mathrm{n}^{\circ}$ 9.394/1996 - Lei de Diretrizes e Bases para a Educação (LDB).

A organização dos sistemas educacionais no Brasil, como hoje se apresenta, teve como ponto de partida a Constituição Federal de 1988, que previu em seu ordenamento o compartilhamento do poder e a autonomia dos entes federados, estabelecendo entre eles um Regime de Colaboração. A partir de sua promulgação, os municípios que antes podiam atuar apenas na esfera administrativa da educação, passaram a gozar de autonomia para a 
formulação das políticas educacionais da educação infantil e básica (SOUZA; FARIA, 2004). Porém, foi a partir de 1996, com o advento da LDB que se definiu com maior clareza o papel dos municípios. A partir de então houve a expansão do sistema educacional brasileiro, bem como o início do processo de descentralização dos recursos educacionais, o que fez com que os estudantes do ensino fundamental migrassem das escolas estaduais para as municipais (SOUZA; FARIA, 2004). Para Gonçalves e França (2013, p. 272), “o processo de descentralização pode resultar em acréscimos de eficiência devido ao maior controle social existente sobre os gestores da política pública".

Quanto à competência para realizar os gastos com educação, cabe à União financiar as instituições de ensino públicas federais e garantir a equalização de oportunidades educacionais e padrão mínimo de qualidade do ensino mediante assistência técnica e financeira aos estados, ao Distrito Federal e aos municípios. Os municípios, por sua vez, devem atuar prioritariamente na educação infantil e no ensino fundamental, enquanto os estados têm como prioritários os ensinos fundamental e médio. Já o Distrito Federal, por acumular competências dos estados e dos municípios, deve atuar na educação infantil e nos ensinos fundamental e médio com prioridade (POKER JUNIOR; NUNES; NUNES, 2013, p. 273).

Para garantir a execução deste processo, foi instituído no mesmo ano, o Fundo de Manutenção e Desenvolvimento da Educação Fundamental e da Valorização do Magistério (Fundef), que vigorou no país de 1998 a 2006. O Fundef recebia e redistribuía aos entes da federação o equivalente a $15 \%$ de todas as receitas com impostos e transferências e a partilha era realizada com base no número de alunos atendidos no ensino fundamental em cada rede de ensino. A partir de 2007 foi criado o Fundo de Manutenção e Desenvolvimento da Educação Básica Fundamental e da Valorização dos Profissionais da Educação (Fundeb), ampliando sua atuação para toda a educação básica. Com sua instituição também foi ampliado o percentual de vinculação das receitas dos estados e municípios para $20 \%$ nestas etapas do ensino. A distribuição dos recursos pelo Fundeb se dá com base no número de alunos informados no censo escolar do ano calendário anterior, em seus âmbitos de atuação prioritários definidos pela LDB (municípios: alunos da educação infantil e do ensino fundamental; estados: alunos do ensino fundamental e médio), e a aplicação dos recursos é feita pelos gestores de cada ente, considerando suas responsabilidades constitucionais. (FNDE, 2017).

O processo de municipalização, porém, ainda não foi finalizado e não tem se desenvolvido na mesma velocidade em todos os estados da federação. O Gráfico 1 apresenta a distribuição das matrículas nos estados de acordo com a dependência administrativa. No país, 
$55,76 \%$ das matrículas do ensino fundamental estavam sob a tutela dos municípios no ano de 2018. Alguns estados apresentam índices bem inferiores, como o Acre e do Amapá, com, respectivamente, $36,91 \%$ e 36,98\%. Outros estados apresentam índices de municipalização mais elevados, como o Maranhão com 86,47\%, Piaúi com 77,88\%, Ceará com 77,38\% e o Pará, com $77,92 \%$. No estado de São Paulo, 42,87\% dos alunos nesta etapa do ensino já se encontram matriculados em escolas municipais.

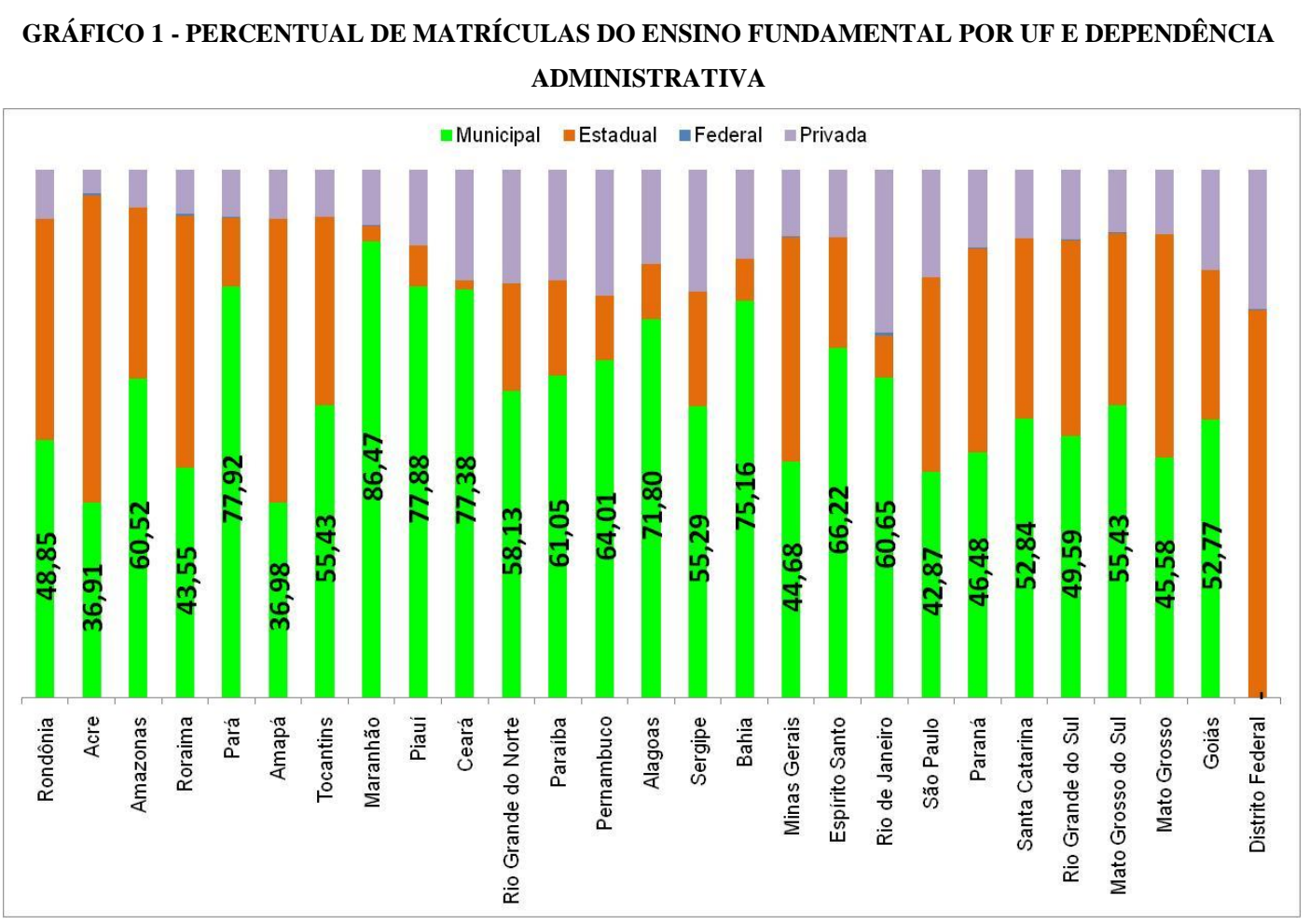

Fonte: Elaborado pelo autor. Base: (INEP, 2018).

Com cerca de 48,8 milhões de alunos somente na educação básica em 2016, segundo Resumo Técnico emitido pelo Instituto Nacional de Pesquisas Educacionais Anísio Teixeira (INEP), em 2017, o sistema educacional brasileiro é maior do que a população de diversas nações. O ensino fundamental é a etapa que concentra o maior número de alunos. São mais de 27 milhões de estudantes apenas nesta fase, o que compreende a mais da metade do alunado brasileiro (Tabela 1).

TABELA 1 - MATRÍCULAS BRASIL - CENSO DA EDUCAÇÃO BRASILEIRA 2016

\begin{tabular}{|c|c|c|c|c|c|c|c|}
\hline \multirow{2}{*}{ Creche } & \multirow{2}{*}{ Pré-escola } & \multicolumn{3}{|c|}{ Ensino Fundamental } & \multicolumn{3}{c|}{ Ensino Médio } \\
\cline { 3 - 8 } & & Total & Fund. 1 & Fund. 2 & \multirow{2}{*}{ Total } & Integrado - profissional & \multirow{2}{*}{ Normal } \\
\hline 3.233 .739 & 5.034 .353 & 27.588 .905 & 15.346 .008 & 12.242 .897 & 531.771 & 428.974 & 102.797 \\
\hline
\end{tabular}

Fonte: Elaborado pelo autor. Base: INEP (2017) 
Estas proporções trazem ao dia-a-dia dos órgãos responsáveis pelo estabelecimento das diretrizes e aos gestores, dificuldades e desafios que impactam diretamente a sua gestão, bem como a implementação das políticas públicas emanadas dos órgãos competentes.

O país conta com mais de 186 mil escolas de educação básica entre todas as esferas pública e privada, de acordo com os dados do Censo Escolar 2016, divulgados pelo INEP em 2017. Deste total, a rede pública municipal é a que detém o maior volume com 114, 7 mil escolas, correspondendo a 2/3 do total, conforme Gráfico 2.

\section{GRÁFICO 2 - PERCENTUAL DE ESCOLAS BÁSICAS POR CATEGORIA ADMINISTRATIVA - BRASIL 2016}

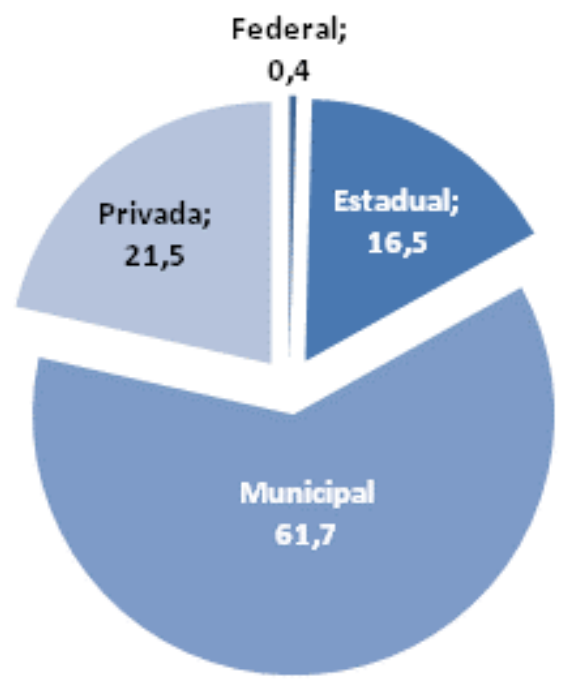

Fonte: INEP (2017)

Entre as escolas de educação básica, 71,3\%, ou seja, 132,7mil oferecem alguma etapa do ensino fundamental, sendo que destas, 116,3 mil oferecem os anos iniciais.

Ao se analisar os números sob a ótica da dependência administrativa, pode-se observar que o processo de descentralização está caminhando. Assim, verifica-se que a rede municipal é a que detém o maior número de matrículas, totalizando mais de 22 milhões de alunos, o que corresponde a 46,8\% do total de alunos registrados no ano de 2016, conforme Tabela 2.

TABELA 2 - MATRÍCULAS POR DEPENDÊNCIA ADMINSITRATIVA - 2016

\begin{tabular}{|c|c|c|c|c|c|c|}
\hline \multirow{2}{*}{ Total } & \multicolumn{3}{|c|}{ Dependência Administrativa } & \multicolumn{2}{c|}{ Localização } \\
\cline { 2 - 7 } & Federal & Estadual & Municipal & Privada & Urbana & Rural \\
\hline 48.817 .479 & 392.565 & 16.595 .631 & 22.846 .182 & 8.983 .101 & 42.236 .458 & 5.581 .021 \\
\hline
\end{tabular}

Fonte: Elaborado pelo autor. Base: INEP (2017) 
O sistema educacional brasileiro conta, ainda, com 2,2 milhões de professores, somente na educação básica, conforme dados oficiais obtidos do INEP, sendo que destes, $75,6 \%$ trabalham exclusivamente na rede pública de ensino, considerando-se todas as esferas (municipal, estadual e federal) e a maior parte, $84 \%$, possui formação superior completa ou em andamento (Gráfico 3).

GRÁFICO 3 - DISTRIBUIÇão DE DOCENTES EDUCAÇão BÁSICA POR NÍVEL DE ESCOLARIDADE - BRASIL 2016

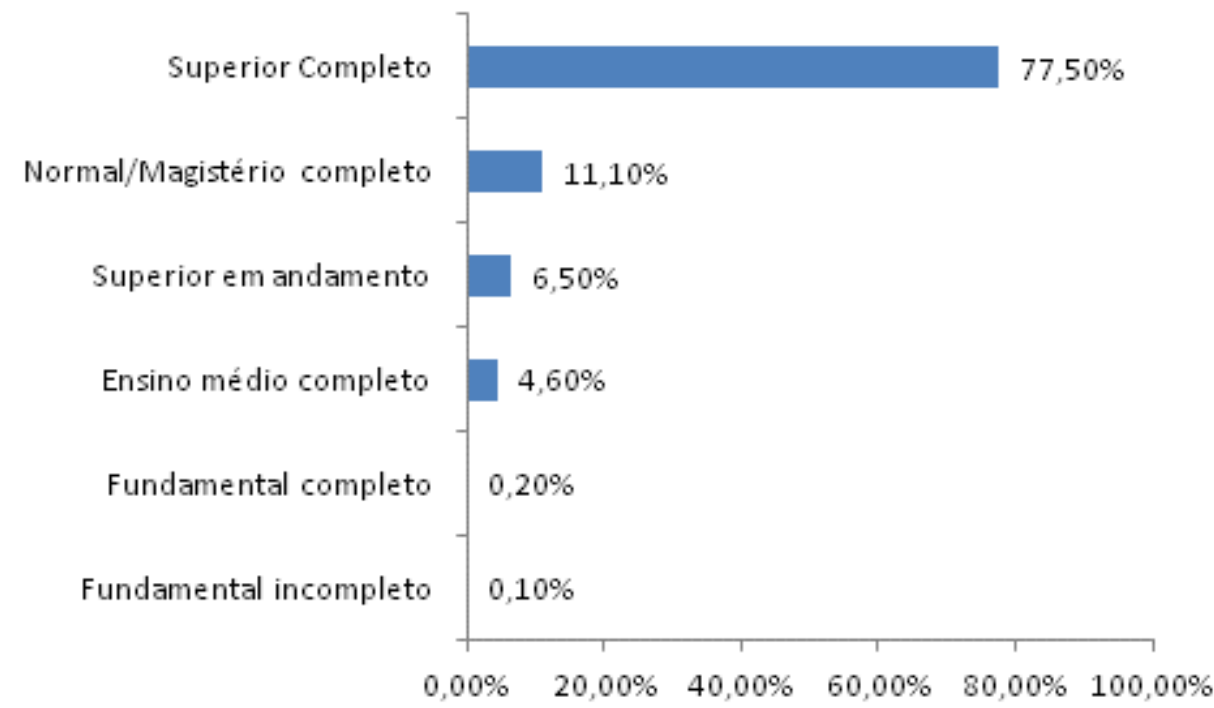

Fonte: Elaborado pelo autor. Base: INEP (2017)

Outro ponto a se observar é Indicador de Adequação da Formação Docente. Este indicador "sintetiza a relação entre a formação inicial dos docentes de uma escola e as disciplinas que eles lecionam, considerando o ordenamento legal vigente" (INEP, 2017a).

Segundo os dados do censo obtidos junto ao INEP, verifica-se que apenas um pouco mais da metade dos professores da educação básica, tanto nos anos iniciais, quanto nos anos finais estão incluídos no Grupo $1^{1}$, ou seja, ministram aquelas disciplinas para as quais possuem formação superior de licenciatura (ou bacharelado com complementação pedagógica) na mesma área. Pelos dados é possível identificar que a disciplina de Língua Portuguesa é uma das que apresenta maior proporção de adequação de formação docente, mas, ainda assim, possui apenas 62,5\% dos docentes dos anos iniciais no Grupo 1 (Gráfico 4).

\footnotetext{
${ }^{1}$ Grupo 1 - Percentual de disciplinas que são ministradas por professores com formação superior de licenciatura (ou bacharelado com complementação pedagógica) na mesma área da disciplina que leciona; Grupo 2 -
} 
GRÁFICO 4 - INDICADOR DE ADEQUAÇÃO DA FORMAÇÃO DOCENTE DOS ANOS INICIAIS DO ENSINO FUNDAMENTAL POR DISCIPLINA - BRASIL 2016

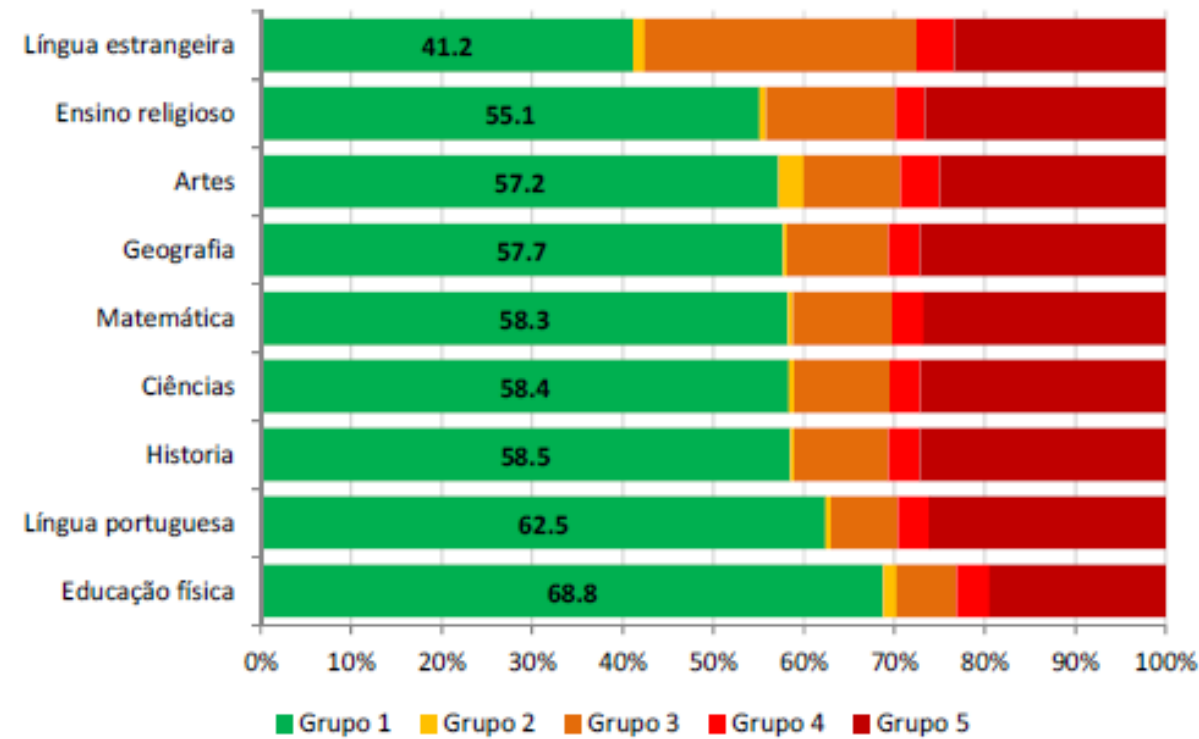

Fonte: INEP (2017)

Nos anos finais, apenas 63,7\% dos docentes estão neste grupo (Gráfico 5), o que claramente não se apresenta como o quadro ideal.

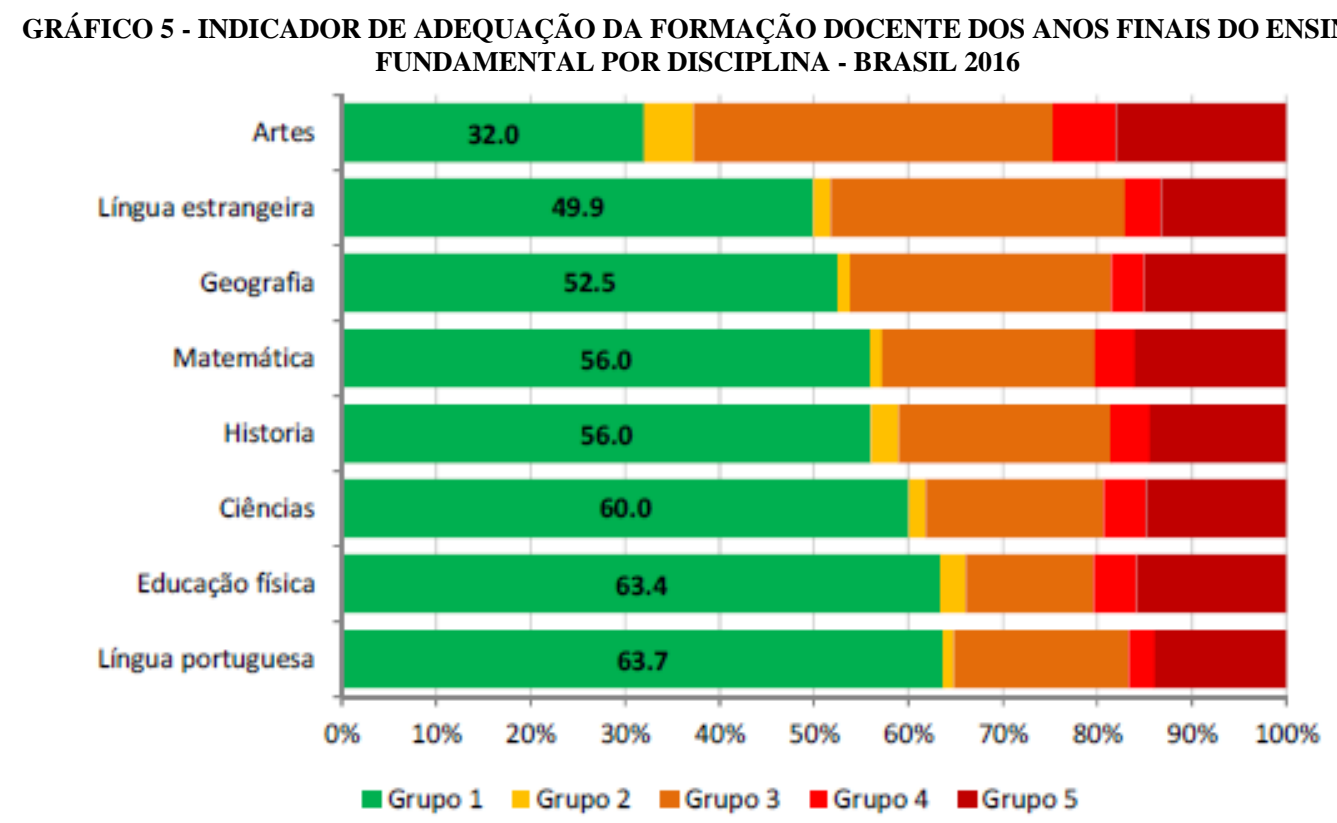

Fonte: INEP (2017)

Porém, o ensino fundamental no Brasil parece que sempre foi polarizado entre quantidade e qualidade, e, como resultado, geram-se grandes desigualdades (GOUVEIA; SOUZA, 2013). 
O expressivo crescimento da educação básica no Brasil não foi acompanhado pela melhoria da qualidade, o que se comprova com os baixos índices de desempenho dos estudantes quando comparado aos resultados de outros países (SALGADO JUNIOR; NOVI; FERREIRA, 2016).

Os dados do Censo 2016 mostram que, apesar das melhorias apresentadas nos últimos anos, ainda persiste uma significativa taxa de distorção idade $\mathrm{x}$ série em praticamente todas as etapas de ensino, em especial nos anos finais do ensino fundamental (Gráfico 6), com cerca de $26,3 \%$ dos alunos em atraso escolar.

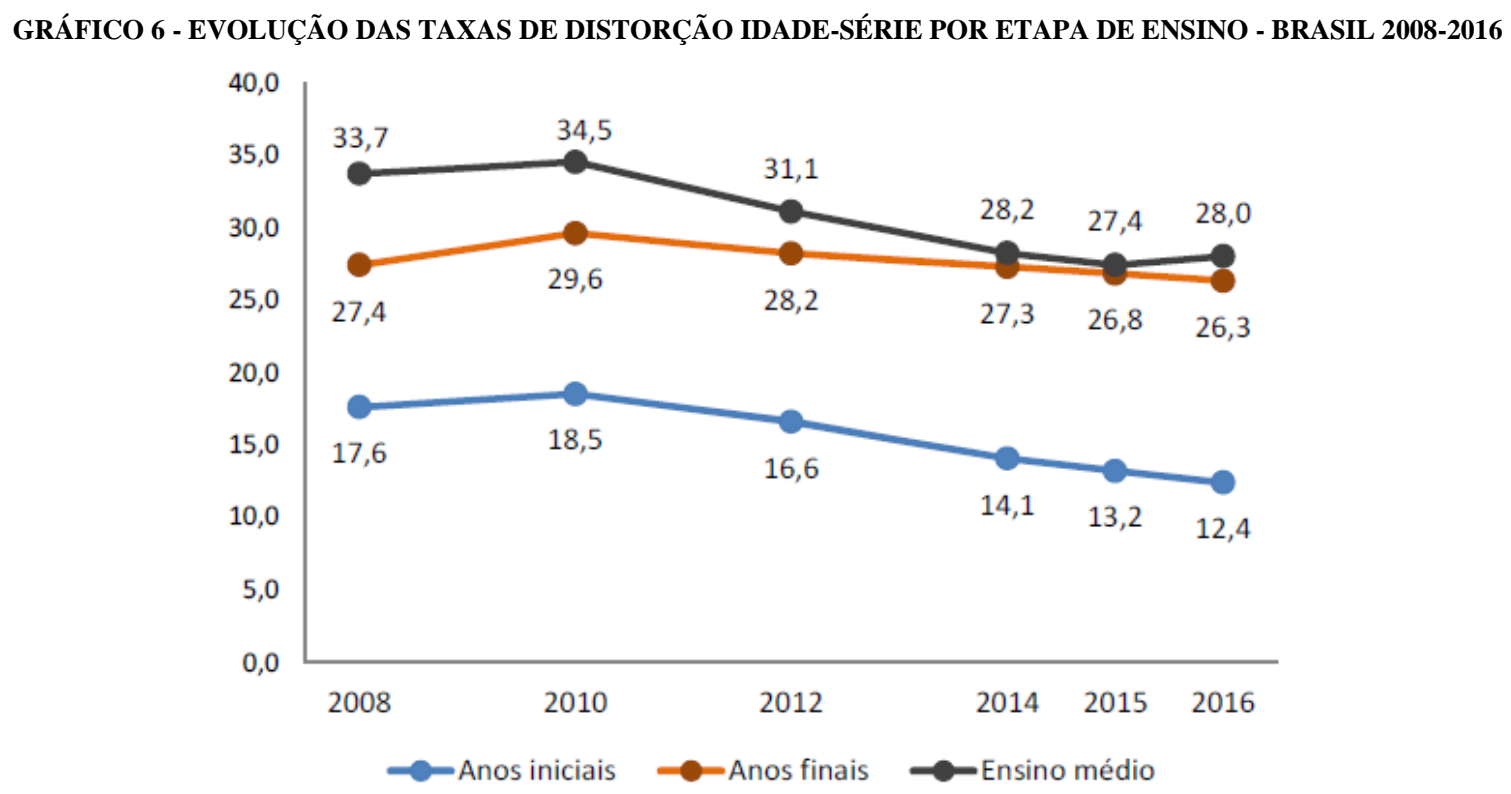

Fonte: INEP (2017)

Também é relevante a taxa de não aprovação dos estudantes. Este índice se constitui da soma das taxas de reprovação e de abandono escolar. Os dados do censo (Gráfico 7) revelam que a maior parte das taxa de não aprovação está concentrada em escolas da rede pública, alcançando a marca de $19,2 \%$ somente nas turmas de $6^{\circ}$ ano do ensino fundamental. Este elevado índice se constitui um fator relevante para a não continuidade dos estudos nas etapas posteriores. 
GRÁFICO 7 - TAXA DE NÃO APROVAÇÃO POR SÉRIES DO ENSINO FUNDAMENTAL E MÉDIO SEGUNDO REDE DE ENSINO (PÚBLICA/PRIVADA) - BRASIL 2015

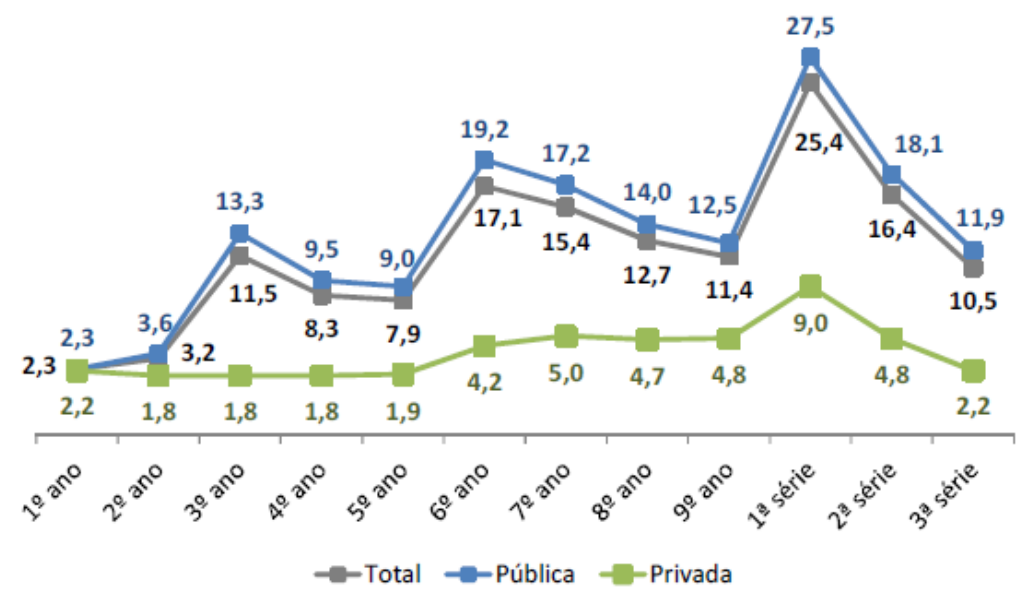

Fonte: INEP (2017)

Visando à melhoria da qualidade, várias mudanças foram realizadas no sistema educacional brasileiro nos últimos anos, como a centralização dos mecanismos de avaliação, que passaram a se tornar ferramentas de gestão e de definição das políticas públicas; a descentralização dos processos de gestão, fornecendo maior autonomia às escolas e às redes; e a valorização dos bons resultados nas avaliações padronizadas (BAUER; ALAVARSE; OLIVEIRA, 2015).

Para Bauer, Alavarse e Oliveira (2015, p. 1367), as reformas no setor educacional “implantadas nas últimas décadas caracterizam-se [...] pela utilização de avaliações em larga escala como instrumento de gestão de redes de ensino e de responsabilização de profissionais da educação".

A avaliação do nível de eficiência do setor educacional deve considerar a conexão entre as entradas e saídas do sistema. A medida da eficiência é obtida por meio da relação entre inputs e outputs na execução de certa atividade, comparados aos seus valores ótimos (MARQUES; SILVA, 2006). Em razão da alocação de recursos nas escolas, é necessário criar uma medida de performance que conecte estes recursos (humanos, materiais e financeiros) às saídas dos estudantes e seus resultados (RAMZI; AFONSO; AYADI, 2016).

Os investimentos financeiros são frequentemente apontados como importante variável para a qualidade do serviço educacional. Buscando melhorar os índices de inserção da população, bem como de qualidade da oferta do serviço educacional, o país tem aumentado os gastos no setor. O relatório Education at a Glance 2017, da OCDE, mostra que o país está entre as nações que apresentou maior crescimento de investimento em relação ao seu Produto Interno Bruto (PIB), no período de 2008 a 2014 (Gráfico 8). 
GRÁFICO 8 - ÍNDICE DE GASTO PÚBLICO EM EDUCAÇÃO EM RELAÇÃO AO PIB (VARIAÇÃO 2008 - 2014)

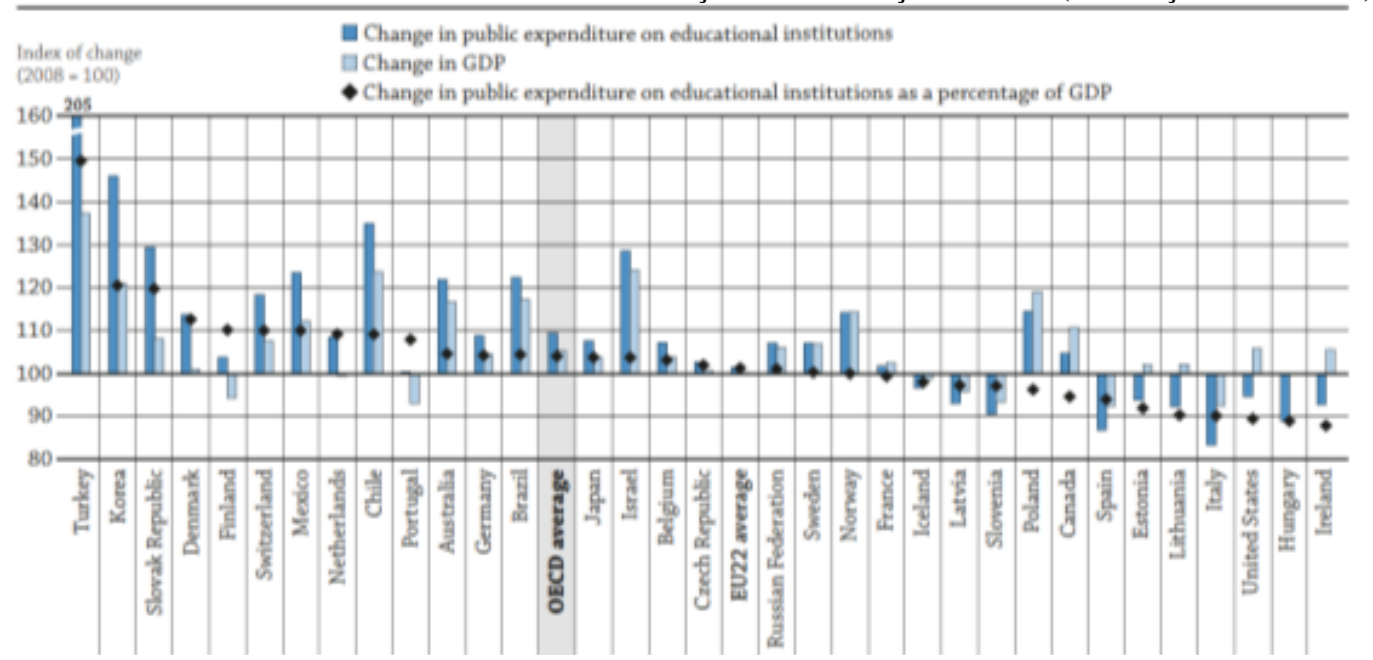

Fonte: OCDE (2017)

No entanto, apesar do crescimento no investimento total, o país ainda apresenta um baixo índice de investimento por aluno na educação pública, quando comparado a outros membros da OCDE. Enquanto que em 2014 o Brasil investiu cerca de U\$ 3.799 dólares por aluno, por ano, na educação primária, a média dos países da OCDE foi de U\$ 8.733 dólares por aluno, por ano (Gráfico 9).

\section{GRÁFICO 9 - INVESTIMENTO ANUAL POR ALUNO 2014 - EDUCAÇÃO PRIMÁRIA - US\$/ANO²} Expenditure per student (equivalent USD converted using PPPs)

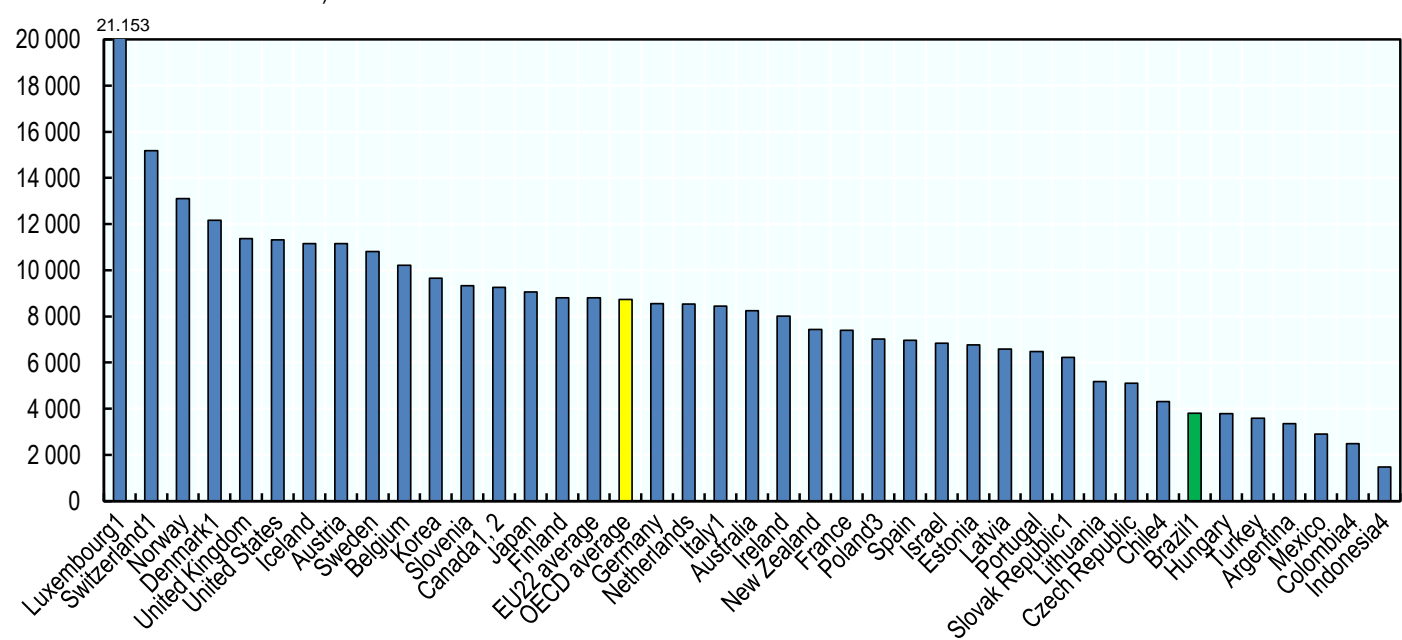

Fonte: OCDE (2017)

${ }^{2}$ Nota: PPP e USD representam Paridade de Poder de Compra (Purchasing Power Parity) e Dólares dos Estados Unidos, respectivamente. 1. Apenas instituições públicas (para Itália; Canadá e Luxembourgo); 2. Educação primária inclui dados da educação infantil e anos iniciais do ensino fundamental; 3. O ensino médio superior inclui informação de programas vocacionais no ensino secundário inferior; 4. Ano de referência 2015; Os países são classificados em ordem decrescente das despesas com instituições educacionais por aluno no ensino primário; Fonte: OECD / UIS / Eurostat (2017, tradução nossa). 
Porém, verificando-se os gráficos de desempenho em leitura dos estudantes no PISA em relação ao investimento por aluno, é possível verificar que alguns países têm conseguido desempenho significativamente superior ao do Brasil, com investimentos similares ou inferiores aos atualmente praticados. Observando-se o Gráfico 10, é possível verificar que, apesar de possuir um valor de investimento acumulado por aluno de 6 a $15^{3}$ anos superior ao do Uruguai, México, Turquia, Colômbia, Bulgária, Monte Negro e Tailândia, o Brasil possui escores inferiores em leitura.

\section{GRÁFICO 10 - INVESTIMENTO ACUMULADO POR ALUNO (6 A 15 ANOS) VERSUS DESEMPENHO EM LEITURA - PISA} 2015

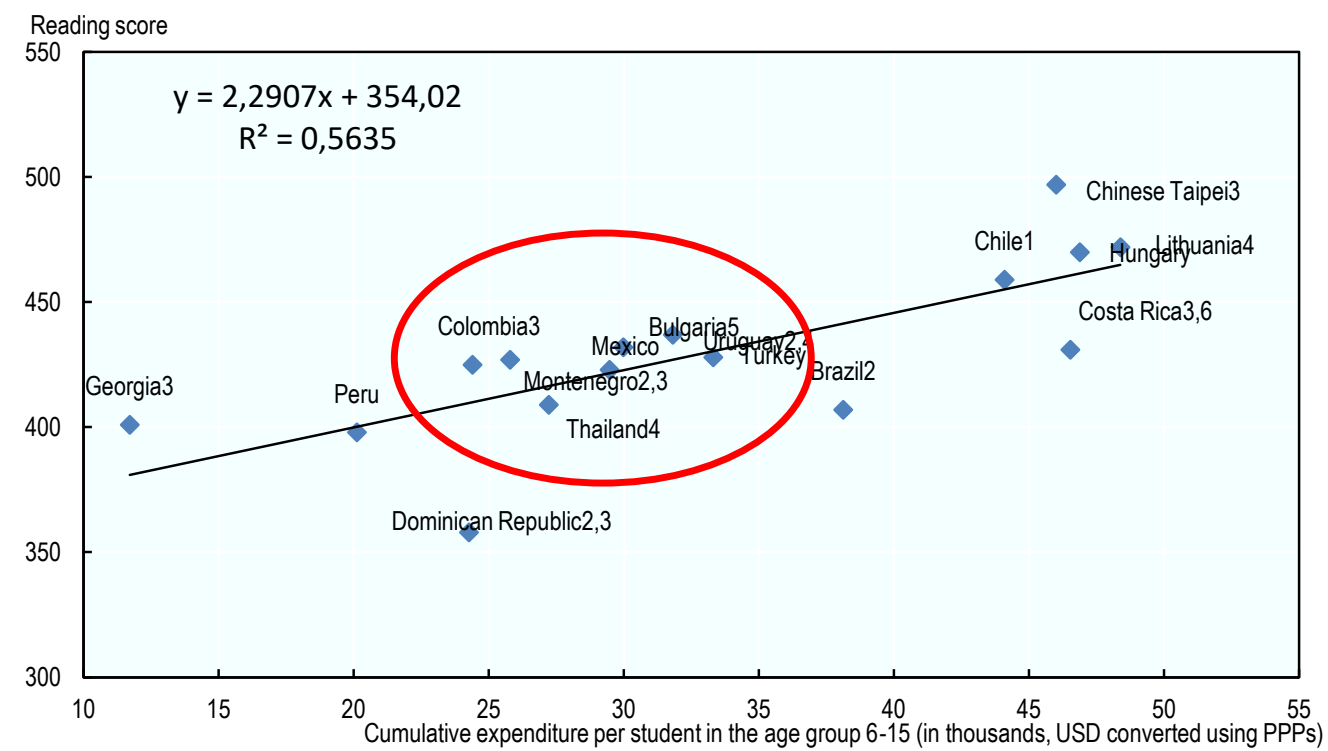

Fonte: OCDE (2017)

Assim, "temos, então, indícios para questionar se o problema da educação no Brasil se deve apenas ao volume insuficiente de investimentos na área, como afirmam alguns, ou também à má qualidade do gasto nessa área” (CARVALHO; SOUSA, 2014, p. 650).

\subsection{Eficiência em educação}

Antes de adentrar a seara da eficiência em educação, faz-se necessário compreender o conceito amplo de "eficiência".

\footnotetext{
${ }^{3}$ Nota: A despesa acumulada por aluno é calculada utilizando a duração teórica dos estudos. USD significa dólar dos Estados Unidos. 1. Ano de referência 2015; 2. Apenas instituições públicas; 3. Ano de referência 2013; 4. Os dados de despesas totais incluem educação pré-primária; 5. Ano de referência 2012; 6. Instituições privadas combinadas públicas e dependentes do governo; Fonte: OCDE / UIS / Eurostat (2017, tradução nossa).
} 
Segundo o dicionário Houaiss (2001), eficiência é a "característica de conseguir o melhor rendimento com o mínimo de erros, dispêndio de energia, tempo, dinheiro ou meios". Para Meza et al. (2005), trata-se de um conceito relativo, que compara aquilo o que foi produzido, considerando-se os recursos disponíveis (entradas), com o que poderia ter sido produzido (saída) com os mesmos recursos.

Pode-se obter um índice de eficiência ao se comparar um indicador de desempenho desejado de um determinado grupo (máquinas, organizações, pessoas), com o valor ótimo que esse indicador pode alcançar, a partir da definição de algumas condições de ambiente e recursos disponíveis (MARIANO, 2007). Em resumo, a eficiência é estabelecida pela comparação da razão da produção pelo montante de recursos utilizados em uma determinada atividade, em um determinado grupo ou amostra. E mesmo no campo educacional público, a discussão da eficiência na prestação do serviço tem espaço.

Em seu artigo 37, a Constituição Federal do Brasil subordina o exercício da administração pública ao princípio da eficiência. Assim, espera-se que os serviços públicos sejam ofertados de forma a obter o melhor desempenho, satisfazendo as necessidades da sociedade, ao menor custo possível (BLIACHERIENE, 2015).

Porém, a definição do conceito de eficiência passa, obrigatoriamente, pela compreensão do 'processo produtivo' a ser avaliado, bem como pela identificação das entradas e saídas a serem considerados, uma vez que a inadequada definição desta relação pode gerar resultados inadequados. Para isso, este capítulo apresenta uma revisão da literatura sobre "Eficiência em Educação", que baliza a definição de eficiência utilizada neste trabalho.

De Witte e López-Torres (2015) revisaram 223 trabalhos internacionais disponíveis nas ferramentas de busca Educational Resources Information Center (ERIC) e ISI Web of Science (WOS), produzidos de 1977 a 2014, a partir do termo de busca "Efficiency in education", fornecendo um importante material para a compreensão da evolução dos estudos sobre eficiência em educação. Em seu artigo os autores compararam e sumarizaram as principais técnicas, níveis de abordagem, insumos e produtos do serviço educacional, permitindo uma visão ampla dos estudos na área.

Para os autores, a eficiência em educação tem sido amplamente estudada na área da economia da educação em razão dos crescentes investimentos realizados no setor. A pesquisa verificou que são relativamente poucos os estudos que avaliam o nível escola - apenas 58 do total - incluindo-se neste número escolas de ensino básico e ensino médio (QUADRO 2). A maioria dos estudos - 89 - focam seus esforços no nível das universidades, avaliando os resultados de suas pesquisas científicas, enquanto que os demais avaliam o desempenho nos 
níveis de estados e municípios, por exemplo, o que não permite captar o chamado "efeito escola", não sendo possível, nestes casos, a identificação dos fatores intraescolares que afetam o desempenho dos estudantes.

QUADRO 2 - TRABALHOS INTERNACIONAIS - EFICIÊNCIA EM EDUCAÇÃO - NÍVEL ESCOLA

\begin{tabular}{|c|c|}
\hline $\begin{array}{l}\text { Trabalhos } \\
\text { em nível } \\
\text { escola / } \\
\text { ensino } \\
\text { médio }\end{array}$ & $\begin{array}{l}\text { Bessent and Bessent (1980), Charnes et al. (1981), Bessent et al. (1982), Diamond and Medewitz } \\
\text { (1990), Ray (1991), Deller and Rudnicki (1993), Bonesrønning and Ratts } \varnothing \text { (1994), Thanassoulis } \\
\text { and Dustan (1994), Jimenez and Paqueo (1996), Thanassoulis (1996), Kirjavainen and Loikkanen } \\
\text { (1998), Mancebón and Bandres (1999), Mancebón and Mar-Molinero (2000), McEwan and Carnoy } \\
\text { (2000), Bradley et al. (2001) (2010), Daneshvary and Clauretie (2001), Muñiz (2002), Wang } \\
\text { (2003), Kiong et al. (2005), Oliveira and Santos (2005), Ouellette and Vierstraete (2005), Waldo } \\
\text { (2007b), Conroy and Arguea (2008), Cordero- Ferrera et al. (2008) (2010) (2015), Mancebón and } \\
\text { Muñiz (2008), Millimet and Collier (2008), Grosskopf et al. (2009), Hu et al. (2009), Kantabutra } \\
\text { (2009), Sarrico and Rosa (2009), Alexander et al. (2010), Carpenter and Noller (2010), Essid et al. } \\
\text { (2010) (2013) (2014), Khalili et al. (2010), Naper (2010), Sarrico et al. (2010), Agasisti (2011a) } \\
\text { (2013), Mongan et al. (2011), Gronberg et al. (2012), Haelermans and Blank (2012), Haelermans } \\
\text { and De Witte (2012), Haelermans et al. (2012), Johnes et al. (2012), Kirjavainen (2012), Mancebón } \\
\text { et al. (2012), Misra et al. (2012), Portela et al. (2012), Burney et al. (2013), Haelermans and } \\
\text { Ruggiero (2013), Aristovnik and Obadic (2014), Blackburn et al. (2014), Brennan et al. (2014). }\end{array}$ \\
\hline
\end{tabular}

Fonte: adaptado de De Witte e López-Torres (2015)

Outra característica é a diversidade de formas e métodos utilizados. Para os autores,

o setor de educação fornece um excelente contexto para a avaliação da eficiência, pois suas instituições são sem fins lucrativos, produzem múltiplos resultados e há uma ausência de preços de produção e insumos. Consequentemente, definir e estimar a tecnologia de produção que os alunos usam para adquirir conhecimento é uma tarefa complexa (DE WITTE; LÓPEZ-TORRES, 2015, p. 03, tradução nossa).

Corroboram com esta afirmação Johnes, Portela, Thanassoulis (2017), para quem a identificação do nível de eficiência com que a educação tem sido provida tem um desafio aos pesquisadores nas últimas décadas. E esta complexidade pode ser observada nas diferentes abordagens adotadas para a medição da função de produção adotada pelos diversos pesquisadores, bem como pelos insumos e produtos utilizados para estas medições.

Segundo De Witte e López-Torres (2015), de modo geral os modelos de fronteira são os que mais têm atraído a atenção dos pesquisadores e, dentre os métodos existentes, a Análise Envoltória de Dados (DEA) é a que tem sido mais amplamente aplicada. No Brasil esta técnica também tem sido amplamente aplicada. O QUADRO 3 apresenta alguns trabalhos recentes e suas respectivas abordagens. 
QUADRO 3 - TRABALHOS SOBRE EFICIÊNCIA EM EDUCAÇÃO NO BRASIL

\begin{tabular}{|c|c|c|c|}
\hline Autor & Título & $\begin{array}{l}\text { Nível de } \\
\text { Análise }\end{array}$ & Técnica \\
\hline $\begin{array}{l}\text { Zogbhi et al } \\
(2009)\end{array}$ & $\begin{array}{l}\text { Mensurando o Desempenho e a Eficiência dos Gastos Estaduais } \\
\text { em Educação Fundamental e Média }\end{array}$ & Brasil - Estados & $\begin{array}{l}\text { FDH (free } \\
\text { disposable } \\
\text { hull) }\end{array}$ \\
\hline $\begin{array}{l}\text { Delgado e } \\
\text { Machado (2007) }\end{array}$ & Eficiência das Escolas Públicas Estaduais de Minas Gerais & $\begin{array}{l}\text { Minas Gerais - } \\
\text { Escolas } \\
\text { Estaduais }\end{array}$ & $\begin{array}{l}\text { DEA CCR } \\
\text { com } \\
\text { bootstrap }\end{array}$ \\
\hline $\begin{array}{l}\text { Zogbhi, Rocha e } \\
\text { Matos (2013) }\end{array}$ & $\begin{array}{l}\text { Education production efficiency: Evidence from Brazilian } \\
\text { universities }\end{array}$ & $\begin{array}{l}\text { Faculdades } \\
\text { Brasileiras }\end{array}$ & $\begin{array}{l}\text { Fronteira } \\
\text { estocástica }\end{array}$ \\
\hline $\begin{array}{l}\text { Gonçalves e } \\
\text { França (2013) }\end{array}$ & $\begin{array}{l}\text { Eficiência na Provisão de Educação Pública Municipal: Uma } \\
\text { Análise em três Estágios dos Municípios Brasileiros }\end{array}$ & $\begin{array}{l}\text { Brasil - } \\
\text { Municípios }\end{array}$ & DEA SBM \\
\hline Flach et al (2017) & $\begin{array}{l}\text { Efficiency of expenditure on education and learning by Brazilian } \\
\text { states : A study with Data Envelopment Analysis }\end{array}$ & Brasil - Estados & DEA BCC \\
\hline $\begin{array}{l}\text { Carvalho e Souza } \\
(2014)\end{array}$ & $\begin{array}{l}\text { Eficiência das Escolas Públicas Urbanas das Regiões Nordeste e } \\
\text { Sudeste do Brasil: Uma Abordagem em três Estágios }\end{array}$ & $\begin{array}{l}\text { Brasil - Regiões } \\
\text { NE e SE - } \\
\text { Escolas Públicas }\end{array}$ & DEA BCC \\
\hline $\begin{array}{l}\text { Salgado Junior e } \\
\text { Novi (2014) }\end{array}$ & $\begin{array}{l}\text { Proposta metodológica: avaliação externa e desempenho dos } \\
\text { alunos }\end{array}$ & $\begin{array}{l}\text { Brasil - Escolas } \\
\text { Municipais }\end{array}$ & DEA BCC \\
\hline Ferreira (2015) & $\begin{array}{l}\text { Boas práticas administrativo-pedagógicas que colaboram para o } \\
\text { desempenho dos alunos de escolas municipais de ensino } \\
\text { fundamental do estado de São Paulo no IDEB }\end{array}$ & $\begin{array}{l}\text { São Paulo - } \\
\text { Escolas } \\
\text { municipais }\end{array}$ & DEA BCC \\
\hline Soriano (2017) & $\begin{array}{l}\text { Proposta de práticas administrativo-pedagógicas que colaborem } \\
\text { para o desempenho das escolas municipais do ensino } \\
\text { fundamental, de baixo nível socioeconômico, no IDEB: um } \\
\text { estudo multicaso no estado do Ceará (CE) }\end{array}$ & $\begin{array}{l}\text { Ceará - Escolas } \\
\text { Municipais }\end{array}$ & DEA CCR \\
\hline
\end{tabular}

Fonte: Elaborado pelo autor.

Quanto às fontes de dados utilizadas, os autores verificaram que a maioria dos trabalhos (143), subsidiaram suas análises com bases de dados nacionais, uma vez que permitem melhor nível de comparabilidade entre as instituições avaliadas e uma redução nos níveis de erro. Poucos se utilizam de bases de dados internacionais, uma vez que as poucas existentes como o PISA, por exemplo, fornecem apenas dados a nível país, o que permite apenas análises macro em relação à estrutura educacional dos países e políticas nacionais de educação, sem permitir, no entanto, captar as diferenças internas das escolas ou, ainda, estudos mais aprofundados que verifiquem as práticas adotadas na gestão.

No Brasil, a conjuntura econômica e política a partir dos anos de 1980 favoreceram o desenvolvimento de estudos nesta área, uma vez que havia a busca pela sociedade por mais “transparência no uso dos recursos públicos" (COTTA, 2001) e se questionava "o que e o quanto os alunos estavam realmente aprendendo". Assim, diversos estudos enveredaram para a compreensão dos fatores ligados à eficiência do setor educacional. Em tempos mais recentes, Delgado e Machado (2007), avaliaram a eficiência das escolas públicas estaduais de Minas Gerais de nível fundamental e de nível médio, por meio do uso da técnica DEA CCR 
em dois estágios. Zoghbi et al. (2009) avaliaram a eficiência dos estados brasileiros nos gastos com a educação nos níveis fundamental e médio.

Gonçalves e França (2013), analisaram as características dos municípios brasileiros que afetavam sua eficiência no ano de 2005, por meio de uma abordagem em três estágios, com uso da técnica DEA Slacks-Based Measure (SBM), Regressão Tobit e, por fim, o modelo de misturas finitas (MMF). Para isso se utilizaram de dados do Censo Escolar, da Prova Brasil e os dados de investimento no relatório Finanças do Brasil (FINBRA) e da Secretaria do Tesouro Nacional. O trabalho que focou exclusivamente os aspectos de disputa política dos municípios, verificou que o processo de descentralização da educação colaborou para a melhoria do desempenho, assim como o recebimento de recursos do Fundef pelos municípios. Zoghbi, Rocha e Mattos (2013) realizaram uma avaliação da eficiência das universidades brasileiras. Para isso se utilizaram das notas do Exame Nacional de Desempenho de Estudantes (ENADE) do ano de ingresso e do ano de conclusão da graduação, e da técnica de fronteira estocástica.

Já Carvalho e Sousa (2014), estudaram a eficiência das escolas públicas das regiões nordeste e sudeste do Brasil, a partir dos resultados da Prova Brasil para o $5^{\circ}$ e $9^{\circ}$ anos de 2007, que, juntamente com o número de matrículas compunham os resultados (outputs), e como insumos (inputs), o número de funcionários da escola e a Taxa de Distorção Série-Idade (TDI) do Ensino Fundamental (\%). Flach et al. (2017), avaliaram a eficiência dos estados brasileiros no período de 2001 a 2011, também por meio da técnica DEA BCC. Os autores utilizaram como input a média de investimento em educação, obtidos a partir da divisão dos gastos informados pelos estados no sistema da Secretaria do Tesouro Nacional, divididos pelo número de habitantes de cada estado e, como outputs, os resultados do SAEB para os anos de 2005, 2007, 2009 e 2011, verificando quais os entes da federação mais eficientes em transformar investimento em educação em resultados em testes padronizados de português e matemática. O QUADRO 4 apresenta um resumo dos trabalhos encontrados no Brasil sobre o tema, com a relação de unidades de avaliação, bases dados e modelo de eficiência adotado, sendo este último composto pela relação de inputs e outputs considerados nos estudos. 
QUADRO 4 - TRABALHOS SOBRE EFICIÊNCIA EM EDUCAÇÃO NO BRASIL - BASES DE DADOS, INPUTS E OUTPUTS

\begin{tabular}{|c|c|c|c|c|}
\hline Autor & $\begin{array}{l}\text { Unidade de } \\
\text { Avaliação }\end{array}$ & Base de Dados & Inputs & Outputs \\
\hline $\begin{array}{l}\text { Zoghbi et al } \\
(2009)\end{array}$ & Estados Brasileiros & $\begin{array}{l}\text { SAEB,Censo } \\
\text { Escolar MEC, } \\
\text { PNAD }^{4} \text {, Balanço } \\
\text { dos governos } \\
\text { Estaduais - STN }\end{array}$ & - Gasto por aluno & - Nota SAEB \\
\hline $\begin{array}{l}\text { Delgado e } \\
\text { Machado } \\
(2007)\end{array}$ & $\begin{array}{l}\text { Escolas estaduais de } \\
\text { Minas Gerais }\end{array}$ & $\begin{array}{l}\text { SIMAVE }^{5}, \text { SICA } \\
6 \text { e Censo Escolar } \\
\text { MEC }\end{array}$ & $\begin{array}{l}\text { - Variáveis Socioeconômicas } \\
\text { do aluno } \\
\text { - Gasto por Aluno } \\
\text { - Infraestrutura escolar }\end{array}$ & $\begin{array}{l}\text {-Nota Português e } \\
\text { Matemática no } \\
\text { SIMAVE }\end{array}$ \\
\hline $\begin{array}{l}\text { Zogbhi, Rocha } \\
\text { e Matos (2013) }\end{array}$ & $\begin{array}{l}\text { Universidades } \\
\text { Brasileiras }\end{array}$ & ENADE & $\begin{array}{l}\text { Proporção professor/aluno, } \\
\text { computador/aluno, } \\
\text { gastos/aluno, gasto com } \\
\text { professor x aluno, estudantes } \\
\text { que trabalham mais de } 20 \mathrm{~h}, \\
\text { escolaridade dos pais, } \\
\text { estudantes não brancos }\end{array}$ & - Nota ENADE \\
\hline $\begin{array}{l}\text { Gonçalves e } \\
\text { França (2013) }\end{array}$ & $\begin{array}{l}\text { Municípios } \\
\text { Brasileiros }\end{array}$ & $\begin{array}{l}\text { Prova Brasil, Censo } \\
\text { Escolar, Finbra e } \\
\text { STN }\end{array}$ & $\begin{array}{l}\text { Razão alunos x professores, } \\
\text { proporção de professores com } \\
\text { curso superior, razão alunos x } \\
\text { sala, índice de programas } \\
\text { governamentais, infraestrutura } \\
\text { física, equipamentos, PIB } \\
\text { municipal / alunos }\end{array}$ & $\begin{array}{l}\text { - Notas médias: } \\
\text { em língua } \\
\text { portuguesa e } \\
\text { matemática, a } \\
\text { taxa de aprovação } \\
\text { média na Prova } \\
\text { Brasil }\end{array}$ \\
\hline $\begin{array}{l}\text { Flach } \text { et al } \\
(2017)\end{array}$ & Estados Brasileiros & STN, Censo IBGE, & Gasto por aluno & Resultados SAEB \\
\hline $\begin{array}{l}\text { Carvalho e } \\
\text { Souza (2014) }\end{array}$ & $\begin{array}{l}\text { Escolas municipais } \\
\text { do Nordeste e } \\
\text { Sudeste }\end{array}$ & $\begin{array}{l}\text { Censo Escolar, } \\
\text { Prova Brasil }\end{array}$ & $\begin{array}{l}\text { Número de funcionários da } \\
\text { escola, Taxa de Distorção } \\
\text { Série Idade }\end{array}$ & $\begin{array}{l}\text { Prova Brasil - } \\
\text { mediana de } \\
\text { matemática por } \\
\text { escola }\end{array}$ \\
\hline
\end{tabular}

Fonte: Elaborado pelo autor.

O que têm em comum os trabalhos apresentados, é que a maioria das pesquisas sobre o tema utiliza-se exclusivamente de abordagens quantitativas, limitando-se a compreender as diferenças entre os inputs das escolas, como a qualidade dos professores, características sociais do aluno e da família, tamanho de classes e recursos disponíveis e forma de admissão de alunos por meio das bases de dados disponíveis, e poucos estudos se aprofundam em explorar os processos de gestão das escolas, considerando o contexto escolar e a execução dos serviços prestados nas unidades escolares (AMÂNCIO-VIEIRA et al., 2015; BLOOM et al., 2015).

Assim, pesquisas de caráter instrumental, que sirvam de base para orientar intervenções no microambiente das escolas e que avaliem as políticas públicas devem ser fomentadas (AMÂNCIO-VIEIRA et al., 2015).

\footnotetext{
${ }^{4}$ PNAD - Pesquisa Nacional por Amostra de Domicílios.

${ }^{5}$ SIMAVE - Sistema Mineiro de Avaliação da Educação Pública.

${ }^{6}$ SICA - Sistema Informacional de Custo Aluno.
} 
Neste sentido, o artigo de Salgado Junior e Novi (2014), propôs a metodologia qualiquantitativa que serve de base para esta pesquisa. No trabalho, os autores sugerem a realização da pesquisa em duas etapas: a primeira, quantitativa, utiliza-se da técnica DEA para identificar as escolas mais eficientes. Nela se sugere como input, entre outros, o uso do investimento médio por aluno e, como output o desempenho dos estudantes em avaliações padronizadas. A partir desta análise, selecionam-se as escolas com Nível Socioeconômico (NSE) similares, classificadas como eficientes e ineficientes no escore DEA, para a realização da segunda etapa, a qualitativa. Na segunda etapa são realizados estudos de múltiplos casos nas escolas selecionadas para verificar as frequências com que são realizadas as práticas administrativas e pedagógicas nos diferentes grupos, identificando, assim, aquelas que podem influenciar no desempenho dos estudantes.

A metodologia proposta se mostra vantajosa em relação às demais abordagens utilizadas por dois fatores principais: primeiro, em relação às pesquisas exclusivamente quantitativas, ela fornece a vantagem de permitir a verificação in loco das diferenças entre as instituições mais e menos eficientes, de forma a validar, ou não, os resultados da primeira etapa, bem como por permitir identificar fatores inicialmente não observados nos dados quantitativos, assim como os fatores ambientais e comportamentais dentro de cada escola que influenciam em seu desempenho; e em segundo lugar, em relação às qualitativas, ela representa uma melhoria uma vez que se adota um critério lógico para a definição da amostra a ser estudada em profundidade, sendo, portanto, um critério mais bem embasado do que a escolha por conveniência, comumente encontrada em trabalhos acadêmicos (SORIANO, 2017), eliminando-se, assim, a subjetividade na escolha dos estudos de caso.

A partir deste trabalho, foram desenvolvidas outras pesquisas no âmbito do Grupo de Estudos em Eficiência (GREFIC), vinculado ao Departamento de Administração da Faculdade de Economia, Administração e Contabilidade da Universidade de São Paulo campus de Ribeirão Preto-SP, como Ferreira (2015), Salgado Junior, Novi e Ferreira (2016) e Soriano (2017).

Em sua dissertação de mestrado, Ferreira (2015), utilizou-se da metodologia proposta por Salgado Junior e Novi (2014) para avaliar o desempenho de escolas públicas municipais de ensino fundamental do estado de São Paulo, que somavam, à época, 1.298 unidades. Para isso adotou a técnica DEA BCC, tendo como inputs o investimento anual do município por aluno, o NSE da escola e a infraestrutura disponível, sendo esta última composta pelo número de computadores por aluno e pelo número de salas de aula por aluno, fornecidos pelo INEP. Como output adotou-se a média do IDEB de 2011 de cada escola. Na etapa qualitativa, 
realizou-se o estudo de múltiplos casos com cinco escolas de alto desempenho e cinco escolas de baixo desempenho. Como resultado o pesquisador identificou 23 práticas (20 pedagógicas e 03 administrativas), ligadas à melhoria do desempenho dos estudantes, fornecendo importante referencial sobre o assunto.

As limitações encontradas em sua pesquisa também permitiram o aprimoramento da metodologia. Uma limitação diz respeito à utilização de escolas com NSE muito diversos para a realização dos estudos de caso. Foram visitadas escolas com NSE variando de 3 a 6 , conforme critério de classificação apresentado no capítulo 2.4.1.Este é um ponto relevante a ser observado, por duas razões: 1) a técnica DEA pressupõe a homogeneidade das DMUs, e, como apresentado anteriormente, o contexto socioeconômico é um dos fatores de maior influência sobre os resultados das escolas, e 2) as escolas visitadas apresentavam condições de infraestrutura bem como características sociais da população atendida muito distantes, itens apresentados como fortemente influentes nos resultados educacionais, não possível isolar seus efeitos e, por consequência, assumir a proposição de que apenas as práticas administrativas e pedagógicas adotadas por estas escolas estavam relacionadas aos seus desempenhos.

Assim, o NSE deveria ser utilizado para a seleção inicial das escolas para o cálculo da fronteira de eficiência. Também se destaca a utilização do item infraestrutura como input. Ao incluir este item como insumo, pressupõe-se, antecipadamente, que este seja um item relevante para o desempenho do estudante. Porém, a literatura não apresenta consenso sobre a relação entre o uso destes recursos e a melhoria do desempenho dos estudantes. Desta forma, este item deveria ser fruto da investigação enquanto variável explicativa para o resultado, verificando-se a diferença de sua disponibilidade e utilização entre os grupos estudados.

Utilizando-se da mesma metodologia, Soriano (2017), que investigou a eficiência das escolas municipais de ensino fundamental do estado do Ceará. Em sua tese de doutorado, foi adotada a técnica DEA CCR, com orientação output. O modelo definia como inputs o investimento médio anual municipal por aluno e o NSE, e, como output, o desempenho médio das escolas no IDEB de 2013. Este novo trabalho trouxe como avanços a eliminação do item infraestrutura como input, bem como a separação prévia das escolas pelo seu NSE, mantendose para o estudo apenas as escolas de NSE 2 e 3 de Alves, Soares e Xavier (2014). Esta separação inicial garantiu a homogeneidade da amostra, pré-requisito para a aplicação da técnica DEA, bem como permitiu verificar na etapa qualitativa, escolas com contextos socioeconômicos similares, suavizando, assim, os efeitos deste fator nos resultados encontrados. Além da evolução na aplicação do modelo, o trabalho de Soriano (2017), 
também contribui para pesquisas na área pela proposição de um modelo de roteiro de entrevista semiestruturado para a etapa qualitativa.

Porém, apesar do significativo avanço deste trabalho em relação ao de Ferreira (2015), observa-se uma importante restrição: a não consideração dos resultados anteriores obtidos pelos alunos como input. A ausência desta variável pode implicar em uma distorção da eficiência, uma vez que escolas que recebam alunos com melhor desempenho inicial tendem a apresentar melhores resultados (DE WITTE; LÓPEZ-TORRES, 2015). O QUADRO 5 apresenta a relação inputs e outputs utilizados nos trabalhos realizados pelo GREFIC.

QUADRO 5 - HISTÓRICO DE PESQUISAS DO GREFIC

\begin{tabular}{|l|l|l|}
\hline Autor & Input & Output \\
\hline $\begin{array}{l}\text { (SALGADO JUNIOR; } \\
\text { NOVI, 2015) }\end{array}$ & Investimento financeiro por aluno & Nota na Prova Brasil \\
\hline (FERREIRA, 2015) & $\begin{array}{l}\text { - Investimento anual por aluno } \\
- \text { Nível Socioeconômico da Escola } \\
\text { - Infraestrutura (número de computadores } \\
\text { e de salas por aluno) }\end{array}$ & Nota média do IDEB por escola \\
\hline (REGALO et al., 2016) & $\begin{array}{l}\text { - Investimento anual por aluno } \\
\text { - Nível Socioeconômico da Escola }\end{array}$ & Nota média do IDEB por município \\
\hline (SORIANO, 2017) & $\begin{array}{l}\text { - Investimento anual por aluno } \\
\text { - Nível Socioeconômico da Escola }\end{array}$ & Nota média do IDEB por escola \\
\hline
\end{tabular}

Fonte: Elaborado pelo autor.

Assim, o presente trabalho se constitui da aplicação da metodologia sugerida por Salgado Junior e Novi (2014), para escolas municipais de ensino fundamental do estado de São Paulo, de NSE 5 e 6 Alves, Soares e Xavier (2014), beneficiando-se dos aprendizados observados a partir das pesquisas anteriores.

\subsection{Fatores para o desempenho escolar}

O desempenho dos estudantes advém de uma "complexa interação de vários fatores" (BARBOSA; FERNANDES, 2001). Estes fatores podem ser intra ou extraescolares e devem ser considerados ao se avaliar a eficiência das instituições, sob o risco de penalizar ou privilegiar determinadas unidades, não pela sua capacidade ou incapacidade de produzir resultados, mas sim por fatores que, apesar de exercerem efeito direto, eventualmente não estão sob o controle da escola. Nesta seção abordaremos alguns destes fatores. 


\subsubsection{Nível socioeconômico (NSE)}

Para Haelermans e Ruggiero (2013, p. 227, tradução nossa) "a provisão de produção do setor público é influenciada não apenas por insumos discricionários, mas também por fatores ambientais exógenos”. Para Soares et al. (2017), a desconsideração destes fatores tem sido uma das principais críticas da literatura sobre os trabalhos que comparam o desempenho das escolas. Para os autores, os modelos de avaliação do "valor agregado" das escolas devem considerar o seu contexto social bem como o de seus alunos.

O nível socioeconômico das famílias dos alunos tem apresentado grande poder explicativo nas grandes pesquisas educacionais realizadas em outros países (ALVES; SOARES, 2007a).

Desde a divulgação do chamado 'Relatório Coleman', em 1966, é sabido que as variáveis relacionadas à família têm muito mais influência sobre o desempenho dos alunos do que aquelas relacionadas exclusivamente à escola (FERNANDES et al., 2014).

Para Coleman et al. (1966), os fatores socioeconômicos têm forte relação com o desempenho acadêmico. Este fator tem sido apontado por diversas pesquisas como uma das variáveis de maior influência no processo educacional (SORIANO, 2017), devendo ser considerado em qualquer análise de eficiência no segmento (HAELERMANS; RUGGIERO, 2013).

Para Duarte (2013, p.343), “a presença de alunos em situação de pobreza tem efeito negativo bastante considerável no IDEB da escola”. Em pesquisa realizada com 299 alunos do ensino fundamental, Alves et al. (2013), também observaram a influência do NSE nos resultados: escolas com alunos de menor nível socioeconômico apresentam resultados piores. "Há uma relação linear positiva entre as variáveis, uma vez que a proficiência (em língua portuguesa) aumenta à medida que cresce o NSE (do aluno)" (ALVES et al., 2013, p. 575). Escolas cujo corpo discente é composto por alunos em situação de pobreza tendem a ter piores resultados em termos de desempenho (JOHNSON; RUGGIERO, 2014).

Em levantamento realizado por De Witte e López-Torres (2015), verifica-se que diversos estudos têm relacionado fatores socioeconômicos às diferenças de desempenho dos alunos e escolas (QUADRO 6), sendo necessário, portanto, realizar a análise considerando-se esta variável. 
QUADRO 6 - REVISÃO DE INPUTS: VARIÁVEIS RELACIONADAS À FAMÍLIA

\begin{tabular}{|l|l|}
\hline Inputs & Estudos \\
\hline $\begin{array}{l}\text { Necessidades } \\
\text { econômicas }\end{array}$ & $\begin{array}{l}\text { Bessent and Bessent (1980), Denaux (2009), Grosskopf et al. (2009), Sarrico } \\
\text { and Rosa (2009), Sarrico et al. (2010), Mongan et al. (2011). }\end{array}$ \\
\hline $\begin{array}{l}\text { Situação } \\
\text { Socioeconômica (renda } \\
\text { e emprego) }\end{array}$ & $\begin{array}{l}\text { Charnes et al. (1981), Smith and Mayston (1987), Sengupta and Sfeir (1988), } \\
\text { Barrow (1991),Ganley and Cubbin (1992), Deller and Rudnicki (1993), } \\
\text { Ruggiero (1996b), Thanassoulis (1996), Bates (1997), Cooper and Cohn } \\
\text { (1997), Heshmati and Kumbhakar (1997), Mancebón and Bandres (1999), } \\
\text { Fukuyama and Weber (2002), Mizala et al. (2002), Dolton et al. (2003), } \\
\text { Mancebón and Muñiz (2008), Denaux (2009), Kantabutra (2009), Agasisti } \\
\text { (2011a) (2013), Cordero-Ferrera et al. (2011), Perelman and Santín (2011a), } \\
\text { Kirjavainen (2012), Mancebón et al. (2012), Thieme et al. (2013), Crespo- } \\
\text { Cebada et al. (2014), Podinovski et al. (2014). }\end{array}$ \\
\hline
\end{tabular}

Fonte: adaptado de De Witte; López-Torres (2015).

Para que as pesquisas no âmbito educacional consigam isolar o efeito da escola no desempenho dos estudantes, elas devem adotar medidas para o controle das externalidades que a afetam, como o seu nível socioeconômico (ALVES; SOARES, 2009).

Antes de examinar a relação das características da escola com a realização do aluno, é útil examinar a influência das características de histórico do aluno. Como essas diferenças de antecedentes são anteriores à influência da escola e moldam a criança antes de chegar à escola, elas poderão, na medida em que conseguimos medi-las, ser controladas ao examinar o efeito dos fatores escolares. Isto significa que as diferenças de realização entre as escolas que são devidas apenas a diferenças entre os alunos podem ser parcialmente controladas, para permitir um exame mais preciso dos efeitos aparentes das diferenças nos próprios fatores escolares ou professores. (COLEMAN et al., 1966, p. 298, tradução nossa)

Para Alves e Soares, (2009, p. 2), apesar de o NSE estar presente em inúmeros estudos como "variável explicativa ou de controle para a análise de diversos fenômenos sociais", ainda não há consenso sobre seu conceito e sobre como efetuar sua medição. A despeito disto, a maioria dos estudos que tentam conceituá-lo utilizam como base as posições de trabalho do indivíduo.

Uma metodologia para a definição do NSE foi proposta por Alves e Soares (2009), por meio da Teoria da Resposta ao Item (TRI), com uso dos dados da Pesquisa Longitudinal da Geração Escolar de 2005 - GERES (SALGADO JUNIOR; NOVI; FERREIRA, 2016).

O NSE é tomado como um construto teórico, ou seja, uma variável latente (não diretamente observada) cuja medida é feita pela agregação de informações sobre: a educação, a ocupação e a riqueza ou rendimento dos indivíduos (ALVES; SOARES, 2009, p. 2).

Ainda, para os autores, a educação e a renda são tanto causa quanto efeito do status ocupacional, pois, para eles, a hipótese é que a qualificação para a ocupação ocorre pela 
educação, e a remuneração é consequência da ocupação (ALVES; SOARES, 2009). A partir dos questionários contextuais respondidos pelos alunos submetidos à Prova Brasil nos anos de 2005, 2007, 2009 e 2011; dos dados do SAEB de 2003, 2005 e 2011 e do Exame Nacional do Ensino Médio - Enem, de 2007, 2008, 2009 e 2011, os autores desenvolveram a classificação do nível socioeconômico das escolas brasileiras, de acordo com o nível socioeconômico médio dos alunos (tendo sido consideradas apenas aquelas escolas com, pelo menos, 15 estudantes), as quais podem ser divididas em 07 grupos, conforme QUADRO 7 (ALVES; SOARES; XAVIER, 2014).

QUADRO 7 - ESCALA DE NÍvEL SóCIOECONÔMICO DE ALVES E S
\begin{tabular}{|l|l|}
\hline Faixa & Grupo do Nível Socioeconômico \\
\hline 1 & Mais Baixo \\
\hline 2 & Baixo \\
\hline 3 & Médio Baixo \\
\hline 4 & Médio \\
\hline 5 & Médio Alto \\
\hline 6 & Alto \\
\hline 7 & Mais Alto \\
\hline
\end{tabular}

Fonte: Elaborado pelo autor.

Desta forma, a metodologia para medição do NSE proposta por consegue captar, além das características meramente econômicas, aquelas relacionadas ao background educacional do aluno, assim compreendido pelos níveis de escolaridade dos pais, podendo servir, portanto, como base para a estratificação das amostras em pesquisas de âmbito educacional.

\subsubsection{Efeito escola}

Nas décadas de 50 e 60 houve um crescimento das pesquisas no campo da Sociologia da Educação em razão da maior disponibilidade das fontes de dados empíricos sobre a educação em países como Inglaterra, Estados Unidos e França, cuja "principal motivação era investigar os problemas das desigualdades de acesso e de resultados escolares" (ALVES; SOARES, 2007b). Foi neste período que surgiu a Sociologia da Educação. Os estudos da 
época "buscavam correlacionar uma série de indicadores sociais do grupo familiar, como por exemplo, a ocupação do pai, a renda, a cor, o número de filhos e/ou o local de moradia" para tentar explicar o fracasso escolar (PENA, 2012).

Segundo Alves e Soares (2007b), durante este período e pela década seguinte, as pesquisas reproduziam resultados similares, dando ênfase à influência da origem social dos alunos sobre o seu desempenho, minimizando a importância da escola neste processo, o que, "de certa forma, condenava à esterilidade qualquer política pública voltada para as escolas". Ainda, segundo os autores, a despeito das evidências acerca da influência dos fatores socioeconômicos no desempenho dos estudantes, não se poderia renegar o papel fundamental da escola neste processo, uma vez que eram encontradas variações nos resultados por elas obtidos, mostrando que seria possível reduzir os efeitos de ordem socioeconômica por meio de políticas e práticas e pedagógicas. Com este pensamento novos estudos passaram a ser realizados, desta vez considerando novos fatores, como a trajetória escolar, o papel dos professores, as salas de aula e as escolas.

Neste sentido, a década de 80 se mostrou produtiva, em especial pela autonomia concedida às escolas, que permitiu a maior diferenciação entre elas. "A principal diferença desses estudos em relação aos da geração anterior era o foco no contexto e nos processos escolares que ocorriam dentro da caixa-preta da escola" (ALVES; SOARES, 2007b), e que buscavam compreender as características daquelas que apresentavam melhor desempenho. Em resumo, a partir deste período é que, além dos efeitos do nível socioeconômico, os estudos também passaram a avaliar o 'efeito-escola'.

Pode-se definir o efeito-escola como "o quanto um dado estabelecimento escolar, pelas suas políticas e práticas internas, acrescenta ao aprendizado do aluno" (BROOKE; SOARES, 2008, p. 10). O estudo do "efeito-escola" também tem sido referenciado na literatura como Modelo de Valor Adicionado, ou seja, a avaliação da porção dos resultados educacionais que podem ser atribuídos aos esforços e práticas da escola (FERNANDES; GREMAUD, 2009).

Segundo Soares et al. (2017), os "Modelos de Valor Agregado (ou Adicionado)", podem ser definidos como um conjunto de procedimentos estatísticos capazes de inferir sobre a eficácia das escolas. Seu objetivo é estimar o quanto uma escola e capaz de contribuir para a melhoria do desempenho de seus alunos durante um determinado ciclo, utilizando-se de resultados em testes passíveis de medição. Uma vez que o cálculo do valor agregado se fundamenta nas relações de causa e efeito dos processos escolares e seus resultados, estes 
modelos têm sido utilizados para identificar os fatores que diferenciam escolas e sistemas educacionais no alcance dos resultados de seus alunos (SOARES et al., 2017).

As pesquisas sobre o efeito-escola no Brasil são recentes relativamente aos demais países, datando do ano de 1990, quando o INEP passou a disponibilizar publicamente os dados do SAEB (ALVES; SOARES, 2007a). Segundo Gremaud, Felício e Biondi (2007), desde a divulgação do Relatório Coleman, "diversos estudos surgiram na tentativa de explicar melhor a relação entre a qualidade da escola e o aprendizado dos alunos", tendo em comum a identificação da forte relação dos fatores socioeconômicos do aluno e da família com os resultados educacionais, que aparecem como mais relevantes do que aqueles inerentes à própria escola (GREMAUD; FELÍCIO; BIONDI, 2007).

Felício e Fernandes (2005), acreditam que a verificação de maior influência dos fatores socioeconômicos no desempenho escolar em detrimento das diferenças ligadas à qualidade da escola possa estar relacionada à escolha dos insumos que definam este último conceito nas pesquisas sobre a eficácia escolar. Para os autores:

Enquanto as variáveis relacionadas à família do aluno como, por exemplo, renda e escolaridade dos pais dariam um bom indicador das condições de aprendizado extra-escola, as variáveis relacionadas à escola forneceriam um indicador pobre de qualidade da escola. Assim, a fraca relação entre insumos escolares e desempenho dos estudantes não seria uma evidência de que a escola não importa, mas uma consequência da fraca relação entre os insumos escolares considerados e a qualidade da escola (FELÍCIO; FERNANDES, 2005).

Corroboram com esta afirmação Gremaud, Felício e Biondi (2007), para quem:

A dificuldade em demonstrar a relação entre qualidade da escola e desempenho escolar pode estar relacionada ao fato de que os dados disponíveis para representar a qualidade da escola podem ser inadequados, ou seja, os atributos escolares importantes para a aprendizagem podem ser não observáveis ou não mensuráveis pelos métodos tradicionais. $\mathrm{O}$ mesmo não ocorre com os atributos familiares. Ao contrário disso, o efeito do background familiar é bem identificado por meio de bons indicadores das condições de vida das crianças (renda familiar, escolaridade dos pais, etc.). Como consequência, o efeito da escola sobre o aprendizado acaba sendo subestimado relativamente ao efeito da família e do meio.

Além disso, o uso dos insumos escolares nas investigações da relação entre qualidade da escola e desempenho escolar ignora o grau de eficiência na utilização de tais recursos para a melhoria da aprendizagem e, portanto, desconsidera as diferentes aplicações que cada escola pode dar aos mesmos insumos disponíveis (GREMAUD; FELÍCIO; BIONDI, 2007). 
Brooke e Soares (2011, p. 595), afirmam que "embora os efeitos do nível socioeconômico dos alunos não sejam desprezíveis, não se pode admitir que a escola faça pouca ou nenhuma diferença no sucesso escolar de sua clientela”.

Para os autores, "há uma enorme variação entre resultados de escolas de um mesmo sistema que atendem alunos muito similares em termos socioeconômicos. Ou seja, a unidade escolar frequentada pelo aluno pode fazer diferença significativa na sua vida escolar", não podendo, portanto, ser imputado apenas às diferenças de NSE o desempenho das escolas (BROOKE; SOARES, 2008, p. 9). Em seu trabalho, Felício e Fernandes (2005) identificaram que o efeito escola é capaz de explicar até $28,4 \%$ da desigualdade total de notas de Língua Portuguesa e até 34,4\% para Matemática nas escolas de São Paulo.

Assim, pode-se afirmar que a escola é fator preponderante para o aprendizado do aluno, ainda que outros fatores também o influenciem (ANDRADE; SOARES, 2008).

As pesquisas sobre o efeito das escolas buscam investigar "o impacto das escolas para desempenho acadêmico dos alunos, após o controle das características de origem social dos alunos e do contexto das escolas" (ALVES; SOARES, 2007b).

No Brasil, Gremaud, Felício e Biondi (2007), propuseram uma metodologia para a identificação e mensuração do efeito escola: o Indicador de Efeito Escola (IEE), que se utiliza dos resultados da Prova Brasil. Para tanto, os autores definiram tecnicamente o "efeito escola" como "a parcela residual da estimativa da nota média das escolas, controlando-se as características socioeconômicas dos alunos e as características dos municípios”. Ou seja, por meio da metodologia proposta, pode-se capturar a parte da nota do aluno que não está relacionada ao nível socioeconômico (identificado pelo questionário socioeconômico respondido pelo aluno na Prova Brasil) e da localidade onde está inserido (por meio de dados obtidos para cada município no IBGE), permitindo verificar a real contribuição da escola para a nota média de seus estudantes.

Além dos aspectos pedagógicos inerentes ao processo ensino-aprendizado, várias pesquisas têm apontado à relevância da gestão administrativa no impacto dos resultados das avaliações de desempenho das escolas (BLOOM et al., 2015; SALGADO JUNIOR; NOVI, 2015; SALGADO JUNIOR; NOVI; FERREIRA, 2016).

Em pesquisa realizada com 1800 escolas em 8 países, Bloom et al. (2015) identificaram práticas administrativas comumente aplicadas em organizações de todos os tipos e que foram consideradas relevantes para a gestão escolar. Para os autores, altos níveis de gestão estão fortemente relacionados à melhores resultados educacionais. Elas foram 
divididas em quatro áreas: 1) Operações; 2) Monitoramento; 3) Definição de Metas; e 4) Gestão de Pessoas.

Em sua pesquisa que avaliou a eficiência de escolas públicas das regiões Nordeste e Sudeste do Brasil com base nos resultados da Prova Brasil de 2007, Carvalho e Sousa (2014), verificaram que são necessárias melhorias ligadas à gestão, mesmo descontando-se os fatores ambientais e aleatórios. Esta diferença observada entre as escolas pode ser atribuída ao "efeito da escola", que, segundo Andrade e Soares (2008, P. 381) "é utilizado para medir a capacidade de as escolas, por meio de seu projeto pedagógico e de suas políticas internas, influenciarem o desempenho cognitivo de seus alunos".

O efeito da escola também pode ser avaliado pela sua capacidade de agregação de valor. Neste sentido, pode-se considerar que uma escola é eficaz se ela consegue proporcionar ao aluno um nível de conhecimento tal, que seu desempenho final seja acima do esperado, considerando-se seu desempenho inicial e seu nível socioeconômico (BROOKE; SOARES, 2008).

Diversos estudos têm relacionado o desempenho dos alunos com os recursos disponíveis nas escolas. Foram encontradas relações entre o tamanho das escolas e classes escolas menores e classes menores também têm impacto positivo sobre os estudantes -, assim como o investimento por aluno. Fatores como a formação e experiência dos professores também são preponderantes para o bom desempenho (RAMZI; AFONSO; AYADI, 2016).

Sendo a educação basicamente a 'prestação de serviço', um dos fatores de maior impacto, e que está diretamente ligado à gestão, é o fator humano. Os problemas ligados à baixa remuneração dos profissionais, falta de capacitação e ambiente de trabalho inadequado afetam diretamente o desempenho do ensino (AMÂNCIO-VIEIRA et al., 2015).

[...] na literatura, há duas definições do conceito de efeito da escola. A primeira refere-se a uma medida específica para cada escola que registra o efeito daquela unidade escolar sobre o aprendizado de seus alunos; consiste na parcela da proficiência do aluno que pode ser atribuída às práticas da escola. A segunda é uma medida do efeito global das escolas de um determinado grupo de referência, com base numa partição da variância dos resultados dos alunos, isto é, se esse efeito é grande, há diferenças entre estudar em uma ou outra escola (ANDRADE; SOARES, 2008).

Então, as pesquisas que buscam identificar dentro do universo escolar as práticas que possam colaborar para a melhoria do desempenho dos alunos se justificam (SALGADO JUNIOR; NOVI, 2015), pois permitem compreender os processos escolares e os fatores que influem na efetividade das ações públicas e podem fornecer subsídios para o planejamento, sendo, portanto, de interesse dos gestores (ALVES; SOARES, 2007a; AMÂNCIO-VIEIRA et 
al., 2015), o que pode gerar ganhos de desempenho ao se repetir as experiências das melhores escolas (FELÍCIO; FERNANDES, 2005).

\subsubsection{Gestão Escolar}

A escola é um ambiente complexo. Sua gestão é igualmente complexa, pois envolve a atuação com partes fortemente interligadas - como professores, alunos, familiares e as instâncias do poder público -, ciclos de retroalimentação, auto-organização, não linearidade das condições de operação e a atuação em situações emergenciais (MITAL; MOORE; LLEWELLYN, 2014).

O trabalho de Bloom et al., (2015), mostrou que a alta qualidade da gestão escolar está fortemente ligada à melhoria dos resultados educacionais. Segundo os autores, as práticas de gestão são capazes de explicar a maioria das diferenças de resultados entre os países nas avaliações padronizadas internacionais como o PISA.

Masci, De Witte e Agasisti (2018) investigaram a influência das características dos diretores escolares e das práticas de gestão por ele nos resultados em avaliações padronizadas de leitura e de matemática aplicadas em escolas italianas. O trabalho identificou que as práticas de gestão são uma variável importante e que influenciam diretamente os resultados dos estudantes.

Os autores também apresentam em seu estudo uma ampla revisão da literatura sobre o tema. Segundo eles, algumas práticas foram identificadas por estudos anteriores e relacionadas à melhoria do desempenho dos estudantes, como, por exemplo: o foco nos resultados dos estudantes; bom relacionamento com as instâncias superiores (no sistema educacional brasileiro, representado pelos(as) Secretários(as) Municipais de Educação); liderança; gestão orçamentária e políticas adequadas de avaliação e treinamento. A existência de um plano de metas e objetivos, com a definição dos responsáveis e de indicadores para a avaliação do sucesso também é fundamental (MASCI; DE WITTE; AGASISTI, 2018).

Outros aspectos também são apresentados nesta revisão. Em relação ao perfil, os estudos avaliados apontaram para o melhor desempenho de mulheres no cargo de direção, com destaque para sua capacidade na implementação de modelos de gestão democráticos e orientados à execução. A experiência no cargo e o tempo de permanência do dirigente na escola também foram citados como variáveis relevantes: enquanto alguns estudos apontam 
para a piora na adoção de práticas de gestão à medida que aumenta o tempo no cargo de diretor (DI LIBERTO; SCHIVARDI; SULIS, 2014), outros mostram que diretores com mais de 6 anos de atuação na mesma escola, em geral, apresentam resultados melhores (BRANCH et al., 2012). Os autores ainda apresentam estudos que relacionam o aumento dos resultados dos estudantes em leitura à formação do diretor: quanto mais elevado o nível de formação do diretor, melhor o desempenho dos estudantes nesta habilidade.

Dada a importância deste aspecto, o INEP lançou, em 2014, um indicador para mensurar a complexidade da gestão nas escolas básicas brasileiras, a partir dos dados do Censo Escolar da Educação Básica. O indicador classifica a complexidade da gestão das escolas a partir de quatro características: “(1) porte da escola; (2) número de turnos de funcionamento; (3) complexidade das etapas ofertadas pela escola e (4) número de etapas/modalidades oferecidas" (INEP, 2014).

A variável "porte da escola" se refere ao número e alunos matriculados, assumindo que escolas com maior número de alunos apresentam mais complexidades do que as com menor número. A variável "número de etapas" diz respeito à variedade de etapas educacionais ofertadas pela escola, como educação infantil, anos iniciais do ensino fundamental, anos finais do ensino fundamental, ensino médio, Ensino de Jovens e Adultos - EJA, educação especial e educação profissional. Quanto mais etapas ofertadas, mais complexa é a gestão da escola (INEP, 2014).

Em relação à "complexidade das etapas", o indicador considera que as escolas que atendem a alunos mais velhos, em tese, seriam mais complexas do que aquelas que atendem alunos mais jovens. A hipótese é que quanto mais avançadas as etapas do ensino, ampliam-se as exigências, envolvendo a gestão de um número maior de professores, a organização das grades curriculares, além de desafios relacionados à manutenção do aluno na escola, como as distorções idade-série, entre outros. E, por fim, o "número de turnos", que diz respeito aos horários de oferta de turmas (matutino, vespertino e noturno), sendo consideradas mais complexas aquelas escolas com maior oferta de turnos (INEP, 2014). O resultado da composição destas variáveis é um indicador com 6 níveis de complexidade, sendo as de nível 1 as de menor e as de nível 6 as de maior complexidade. O QUADRO 8 apresenta a descrição dos níveis de complexidade de gestão das escolas. 
QUADRO 8 - DESCRIÇÃO DOS NÍVEIS DE COMPLEXIDADE DE GESTÃo

\begin{tabular}{|c|c|}
\hline Niveis & Descrição' \\
\hline Nivel 1 & $\begin{array}{l}\text { Porte inferior a } 50 \text { matrículas, operando em único turno e etapa e apresentando a } \\
\text { Educação Infantil ou Anos Iniciais como etapa mais elevada*. }\end{array}$ \\
\hline Nivel 2 & $\begin{array}{l}\text { Porte entre } 50 \text { e } 300 \text { matrículas, operando em } 2 \text { turnos, com oferta de até } 2 \text { etapas e } \\
\text { apresentando a Educação Infantil ou Anos Iniciais como etapa mais elevada*. }\end{array}$ \\
\hline Nivel 3 & $\begin{array}{l}\text { Porte entre } 50 \text { e } 500 \text { matriculas, operando em } 2 \text { turnos, com } 2 \text { ou } 3 \text { etapas e } \\
\text { apresentando os Anos Finais como etapa mais elevada*. }\end{array}$ \\
\hline Nivel 4 & $\begin{array}{l}\text { Porte entre } 150 \text { e } 1000 \text { matrículas, operando em } 2 \text { ou } 3 \text { turnos, com } 2 \text { ou } 3 \text { etapas, } \\
\text { apresentando Ensino Médio/profissional ou a EJA como etapa mais elevada*. }\end{array}$ \\
\hline Nível 5 & $\begin{array}{l}\text { Porte entre } 150 \text { e } 1000 \text { matrículas, operando em } 3 \text { turnos, com } 2 \text { ou } 3 \text { etapas, } \\
\text { apresentando a EJA como etapa mais elevada*. }\end{array}$ \\
\hline Nivel 6 & $\begin{array}{l}\text { Porte superior à } 500 \text { matrículas, operando em } 3 \text { turnos, com } 4 \text { ou mais etapas, } \\
\text { apresentando a EJA como etapa mais elevada*. }\end{array}$ \\
\hline
\end{tabular}

Fonte: INEP (2014)

O Gráfico 11 apresenta o histograma do escore de complexidade e as respectivas mas de delimitação dos níveis, obtido a partir dos dados do Censo Escolar de 2013.

\section{GRÁFICO 11 - HISTOGRAMA DO ESCORE DE COMPLEXIDADE DA GESTÃO DA ESCOLA}

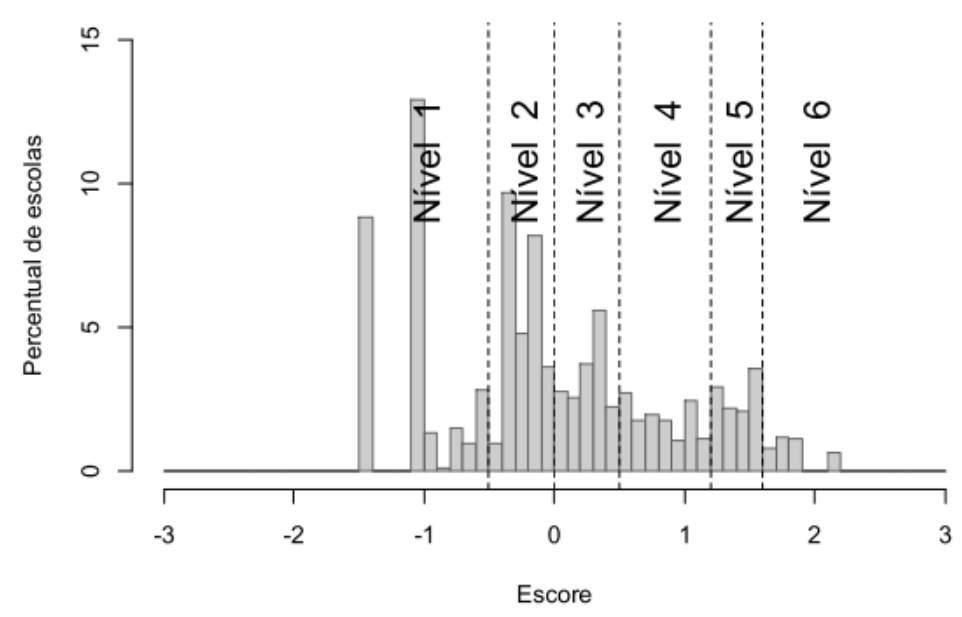

Fonte: (INEP, 2014).

Apesar de a gestão envolver outros aspectos não compreendidos pelas quatro variáveis analisadas, o indicador permite obter alguma contextualização das características das escolas e dos desafios envolvidos, destacando a importância desta variável no contexto educacional (INEP, 2014). 


\subsubsection{Remuneração e responsabilização docente}

Ator chave no processo de ensino, o professor tem recebido boa parte das atenções nas políticas públicas para a melhoria dos resultados educacionais. $\mathrm{O}$ incentivo à educação continuada e as políticas de remuneração e premiação têm se destacado entre as ações de valorização do docente. Apesar de não haver consenso sobre os resultados, diversos países do mundo, assim como o Brasil, "têm adotado políticas de pagamento por mérito" (OSHIRO; SCORZAFAVE; DORIGAN, 2015).

Oshiro, Scorzafave e Dorigan (2015) avaliaram os efeitos desta política em escolas estaduais de São Paulo. Em sua ampla revisão da literatura, os autores identificaram defensores e críticos desta prática na literatura. $\mathrm{O}$ argumento daqueles favoráveis à adoção deste tipo de medida é de que a oferta da recompensa seria uma forma de incentivo aos professores para despenderem maior esforço na promoção da melhoria da proficiência dos estudantes. Porém, os autores também destacam como contraponto recorrente entre os críticos a existência de um possível resultado negativo, que seria o foco dos docentes na melhoria de aspectos passíveis de mensuração por meio de testes padronizados, não privilegiando competências e habilidades igualmente importantes, mas não passíveis de avaliação, como a criatividade e habilidades não cognitivas, por exemplo.

Os resultados de seu trabalham identificaram um resultado positivo entre os alunos da quinta série no ano de 2009, tanto nas disciplinas de matemática quanto de língua portuguesa. Porém, os pesquisadores verificaram um declínio deste resultado para o ano de 2011 nesta mesma série. Em relação aos resultados do nono ano, identificaram efeito negativo no ano de 2009 e ausência de efeito sobre os resultados de 2011.

Monteiro (2015) corrobora com estes achados. Para a autora, os estudos mais recentes não foram capazes de estabelecer uma clara relação entre maiores salários e a melhora dos resultados educacionais. Em seu estudo sobre a relação dos gastos públicos com o desempenho escolar, realizado junto a municípios do Rio de Janeiro beneficiados por royalties advindos da produção petróleo, a autora não identificou correlação entre o aumento dos salários dos professores e a melhoria do desempenho dos estudantes.

Mello e Souza (2005) reforçam as teorias anteriores. Os autores investigaram os fatores determinantes para o desempenho de alunos em três municípios do Rio de Janeiro. Para isto os autores aplicaram testes de língua portuguesa e matemática aos estudantes da quarta e oitava séries. Os participantes da pesquisa (alunos das escolas selecionadas, 
professores, diretores e secretários de educação municipais) responderam a outros instrumentos para identificar as características destas escolas. Os resultados das provas foram utilizados como variáveis dependentes e os dados coletados nos instrumentos como variáveis dependentes de um modelo de regressão. Ao final os autores verificaram que a remuneração docente apresenta, na verdade, um resultado negativo. Ou seja, maiores salários não estavam se revertendo em melhores resultados aos alunos. Para os autores parte da justificativa para este resultado se deve à política de progressão salarial adotada pelos municípios avaliados, que se baseiam em tempo de serviço e formação, fatores que não estão diretamente associados à obtenção de desempenho dos estudantes.

\subsection{Avaliação de desempenho escolar}

A utilização das avaliações em larga escala é uma resposta à demanda de que os sistemas públicos adotem sistemas e níveis de gestão que se assemelhem àqueles aplicados nas organizações de forma geral, permitindo, assim, o seu aprimoramento. Elas permitem ao gestor obter informações comparativas sobre seu desempenho ao longo do tempo, sendo um instrumento neutro, uma vez que se utiliza de critérios únicos e objetivos em sua correção, sem vieses. Desta forma, cria-se um "indicador de qualidade" que, mesmo limitado, fornece algum direcionamento, ao mesmo tempo em que se permite maior autonomia às redes e escolas na busca dos resultados desejados, possibilitando a estas a adoção de medidas mais adequadas à sua realidade local. Com isso, se contribui para a pluralidade de abordagens e métodos que, se bem estudados, podem ser difundidos visando à melhoria do sistema como um todo (BAUER; ALAVARSE; OLIVEIRA, 2015).

Segundo Fernandes e Gremaud (2009), inicialmente as avaliações restringiam-se às salas de aula, por meio de provas elaboradas pelos próprios docentes, cujo objetivo era verificar se um estudante tinha, ou não, condições de prosseguir seus estudos para as etapas seguintes, tomando-se por base critérios por eles mesmos impostos. Foi a partir da década de 1950 que as avaliações aplicadas em larga escala passaram a ser utilizadas para diagnosticar a qualidade das escolas e dos sistemas educacionais.

Porém, o uso de avaliações em larga escala para a mensuração dos níveis de qualidade na educação abre espaço para conclusões controversas. 
É preciso reconhecer que todas as medidas utilizadas em avaliações educacionais são imperfeitas, por não levarem em conta todos os aspectos que se gostaria de considerar e por medir com erros (sistemáticos e/ou aleatórios) os aspectos que elas se propõem avaliar (FERNANDES; GREMAUD, 2009).

A validade destas avaliações foi alvo de desconfiança no Brasil entre os pedagogos e demais educadores que questionavam sua legitimidade, encarando-as como uma simples tentativa de controle e não como ferramenta de auxílio para o aprimoramento do serviço educacional (COTTA, 2001).

Entre as críticas a este modelo de avaliação estão: o foco limitado, que restringe a avaliação de um sistema de múltiplos contextos e facetas a algumas disciplinas (em geral leitura e matemática), em detrimento de outros objetivos esperados das escolas como, por exemplo, a ética e algumas habilidades não cognitivas; e a não identificação de outros fatores de desenvolvimento social relacionados à educação (COTTA, 2001; FERNANDES; GREMAUD, 2009).

Mesmo assim, "há certo consenso de que o tema da avaliação da qualidade da escola precisa ser enfrentado e que a mensuração da qualidade deve passar necessariamente pelo uso de diferentes instrumentos" (GOUVEIA; SOUZA, 2013, p. 841). As evidências relacionam positivamente os resultados dos testes padronizados com a renda individual, a produtividade e o crescimento econômico (FERNANDES et al., 2014; FERNANDES; GREMAUD, 2009) e os estudos na área apontam para um rápido crescimento no desempenho dos alunos nos locais onde este tipo de avaliação foi implantada (FERNANDES; GREMAUD, 2009).

Para Bauer, Alavarse e Oliveira (2015), vários benefícios advêm do uso destas avaliações, tais como:

- responsabilização dos gestores e professores pelos resultados, aumentando seu comprometimento;

- a criação de uma cultura avaliativa e a transparência sobre os resultados da educação pública;

- o direcionamento dos pais na escolha das escolas melhor avaliadas, por meio dos rankings divulgados;

- fornece informação comparativa a toda a comunidade, em especial à equipe gestora e aos professores, que podem buscar aprimorar seus processos;

- permitem a comparação dos resultados através de recortes e perfis, tanto de alunos e escolas, quanto de outros fatores externos, possibilitando a identificação de características que influenciem no desempenho dos estudantes, fornecendo informações que subsidiem a adoção de políticas educacionais; 
- $\quad$ sugerem melhorias nos currículos;

- dão ao aluno estímulo para a competição saudável por melhores resultados.

(BAUER; ALAVARSE; OLIVEIRA, 2015)

A OCDE promove trienalmente a principal avaliação internacional de educação, o PISA. Aplicado a estudantes com 15 anos de idade dos países membros, o teste avalia as habilidades e conhecimentos proporcionados pelos sistemas educacionais dos países nas áreas de ciências, matemática e leitura.

Historicamente o Brasil tem pontuado abaixo da média dos países da OCDE, resultado que se repetiu na edição de 2015, como se pode observar na Figura 1 e no Gráfico 12.
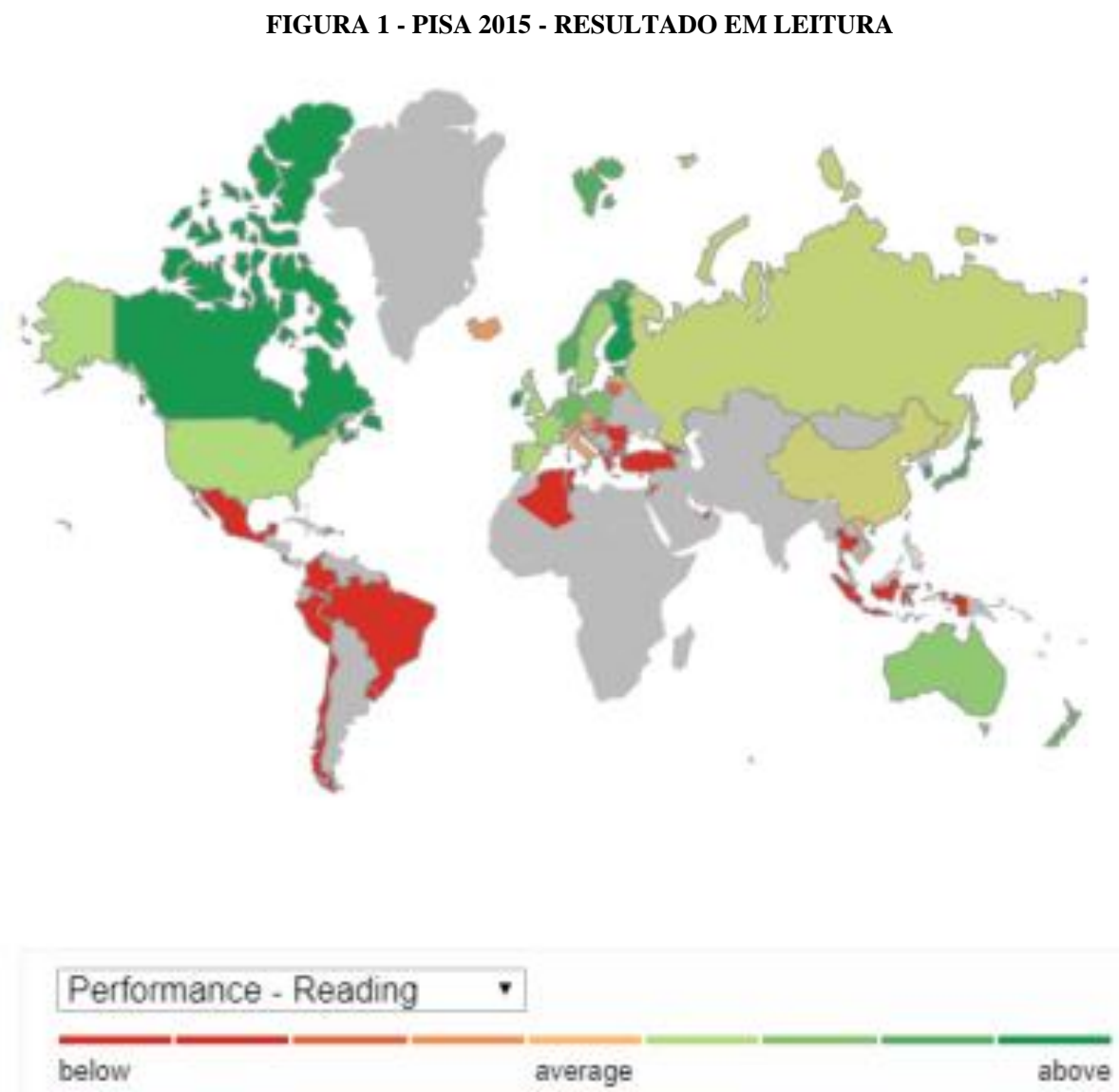

Fonte: OECD (2016) 
GRÁFICO 12 - PISA - DESEMPENHO EM LEITURA - BRASIL VERSUS MÉDIA OCDE - EVOLUÇÃO 2000 - 2015

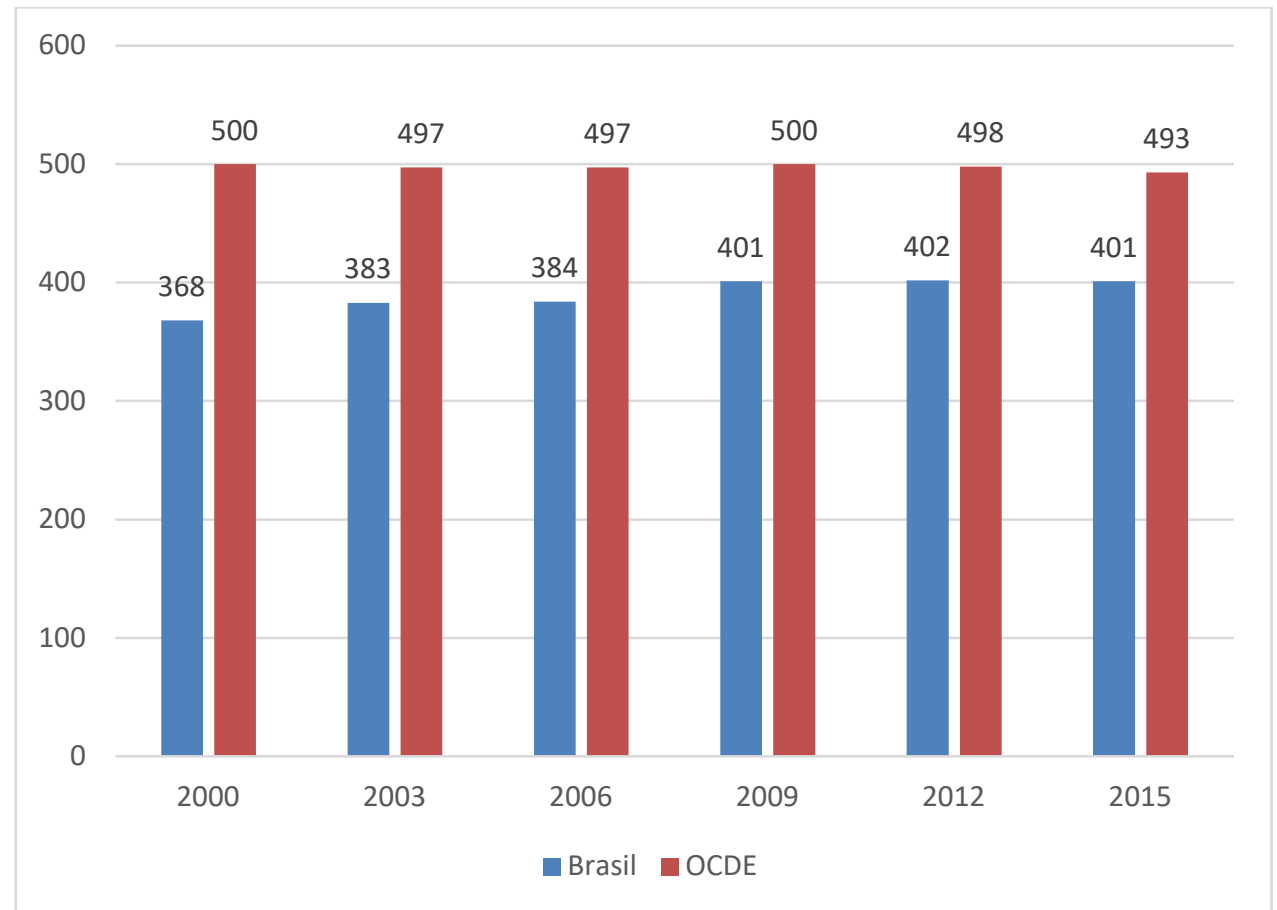

Fonte: Elaborado pelo autor. Base: OCDE (2016)

No Brasil, as avaliações externas são aplicadas desde a década de 1990, quando foi desenvolvido pelo INEP, o Sistema de Avaliação da Educação Básica (SAEB) (ALVES; SOARES, 2013).

Composto por avaliações em larga escala, o SAEB fornece um diagnóstico da educação básica no país. Seu resultado é um importante instrumento para o poder público na formulação e monitoramento das políticas públicas em educação em todas as esferas do governo - federal, estadual e municipal - visando à qualidade no serviço educacional. $\mathrm{O}$ SAEB também oferece dados e indicadores acerca de fatores que influenciaram no desempenho dos estudantes avaliados (FERNANDES; GREMAUD, 2009).

O SAEB é composto por três instrumentos (Figura 2): Avaliação Nacional da Educação Básica (ANEB); Avaliação Nacional do Rendimento Escolar (ANRESC), conhecida como Prova Brasil e a Avaliação Nacional da Alfabetização (ANA ). 
FIGURA 2 - SISTEMA DE AVALIAÇÃO DA EDUCAÇÃO BÁSICA BRASILEIRA

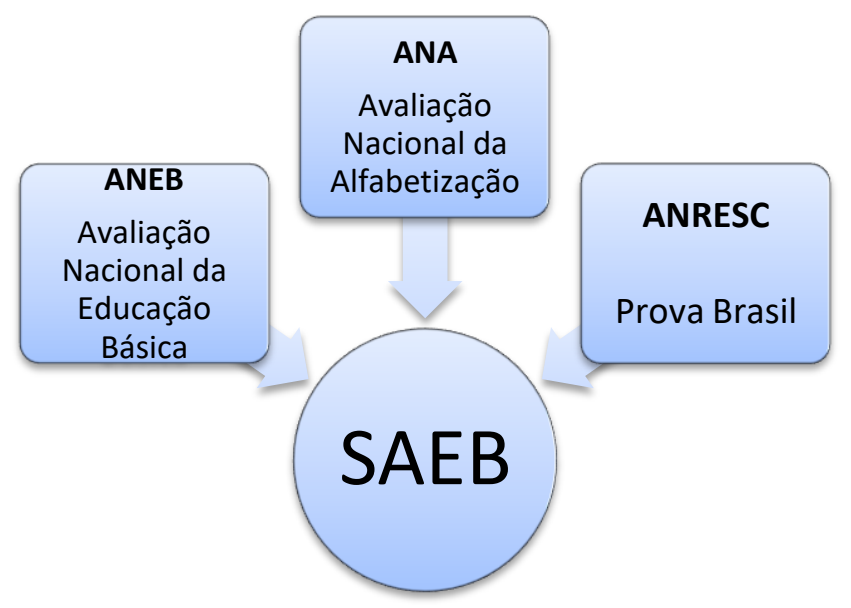

Fonte: Elaborado pelo autor.

A Prova Brasil é aplicada de forma censitária aos alunos do quinto e do nono ano do ensino fundamental das escolas públicas brasileiras, e de forma amostral entre as escolas privadas. Ela é formulada para avaliar competências, conteúdos curriculares e operações mentais, abordando as disciplinas de português e matemática (INEP, [s.d.]).

Porém, a avaliação dos sistemas educacionais baseado exclusivamente no desempenho dos estudantes nas avaliações também seria equívoco. A adoção de um sistema que considerasse apenas este resultado poderia trazer consigo a ação de práticas indesejáveis, com consequências negativas. Uma possível consequência seria, por exemplo, a elevação dos padrões para a aprovação dos estudantes, sem, necessariamente, a implementação de ações de auxílio à melhoria do desempenho dos alunos. Desta forma, aqueles com desempenho abaixo do esperado seriam excluídos do sistema educacional, reduzindo-se, assim, as taxas de aprovação. Por outro lado, um modelo de avaliação que considerasse apenas os números gerais de atendimento à população, como, por exemplo, a taxa de escolarização e o percentual de aprovações, poderia incentivar a adoção de padrões inferiores de aprovação, gerando altos índices de conclusão, sem, no entanto, apresentarem a qualidade adequada (FERNANDES; GREMAUD, 2009).

Em 2007, foi criado no Brasil o IDEB, cujo objetivo é diagnosticar as escolas e sistemas educacionais do país considerando os aspectos anteriormente apresentados. Este indicador agrega dois importantes itens para a educação: o desempenho nas avaliações padronizadas, obtido a partir das médias das avaliações do SAEB e da Prova Brasil, e o fluxo escolar, fator que avalia os dados de aprovação escolar. Desta forma, o IDEB permite uma avaliação mais realística do nível de qualidade da educação pois, 
"se um sistema de ensino retiver seus alunos para obter resultados de melhor qualidade no SAEB ou Prova Brasil, o fator fluxo será alterado, indicando a necessidade de melhoria do sistema. Se, ao contrário, o sistema apressar a aprovação do aluno sem qualidade, o resultado das avaliações indicará igualmente a necessidade de melhoria do sistema" (INEP, [s.d.]).

O IDEB é calculado para cada escola do país considerando-se os desempenhos médios de seus alunos e a taxa média de aprovação, sendo este último índice a o quociente entre o total de alunos matriculados na $8^{\text {a }}$ série de uma escola em razão daqueles que estavam matriculados na $5^{a}$ série há quatro anos, considerando-se, assim, a mesma geração de estudantes.

A média de proficiência dos estudantes combina as notas de matemática e português e a proficiência média é padronizada para estar entre zero e dez, enquanto que a taxa de aprovação se situa entre zero e um, de modo que o IDEB também se situa entre zero e 10 (FERNANDES; GREMAUD, 2009).

Assim, o cálculo deste indicador pode ser escrito como:

$\mathrm{IDEB}=\mathrm{N} \times \mathrm{P}$

em que,

$\mathrm{N}$ = proficiência média padronizada dos alunos da escola; $\mathrm{e}$

$\mathrm{P}=$ taxa média de aprovação.

A introdução deste índice pelo governo federal representou uma mudança significativa na forma como a educação passou a ser acompanhada no Brasil. Por meio dele se passou a acompanhar a evolução dos índices de qualidade dos serviços educacionais oferecidos no país, sendo possível acompanhar os resultados por estado, município e escola, oferecendo um valor comparativo em relação às metas, mas, também, em relação a outras escolas e municípios do sistema (ALVES; SOARES, 2013).

Dada a sua importância, esse indicador foi introduzido na política educacional pelo Plano de Metas Compromisso Todos pela Educação (ALVES; SOARES, 2013).

Ele é calculado, a cada dois anos, pelo Instituto Nacional de Estudos e Pesquisas Educacionais Anísio Teixeira - Inep, do Ministério da Educação (MEC), combinando dados de rendimento escolar obtidos pelo Censo Escolar com dados do desempenho dos alunos nas avaliações externas nacionais (ALVES; SOARES, 2013). 
E, “apesar das críticas, o IDEB continua sendo uma das principais medidas de desempenho escolar e, ainda, possui como ponto positivo sua abrangência, pois é mensurado tanto em níveis nacional e estadual quanto em nível escolar" (AMÂNCIO-VIEIRA et al., 2015, p. 175).

O IDEB também tem sido utilizado para a estipulação de metas de desempenho para os diversos sistemas de ensino e para cada escola. Desta forma, contemplou-se, no âmbito do Plano de Desenvolvimento da Educação - PDE, a criação de uma meta nacional para o ano de 2021 e metas intermediárias para serem cumpridas a cada dois anos pelos componentes do sistema educacionais brasileiro (FERNANDES; GREMAUD, 2009). Para isso, utilizou-se um comparativo com países da OCDE.

A meta para a média do Brasil foi estabelecida a partir de um indicador externo. Ou seja, procurou-se simular o cálculo do IDEB para os países da OCDE e verificar qual seria o desempenho médio desses no indicador. Para isso foi utilizada a ordenação dos alunos brasileiros no PISA e no SAEB e a ordenação dos alunos da OCDE no PISA. Admitiu-se que os exames ordenam os alunos de forma similar e, assim, fez-se a conversão das escalas.32 Para o cálculo do IDEB dos países da OCDE, supôs-se uma taxa de aprovação de 96\% (FERNANDES; GREMAUD, 2009).

Os resultados do IDEB têm mostrado que, apesar dos esforços e altos investimentos, o país está longe de alcançar a meta estipulada, como se pode observar no Gráfico 13. E o baixo desempenho se agrava nos resultados dos anos finais que obtêm rendimento inferior ao observado nos anos iniciais, demonstrando-se claramente a necessidade de melhorias nesta fase do ensino e justificando a realização de pesquisas sobre o tema.

GRÁFICO 13 - IDEB - DESEMPENHO VERSUS META

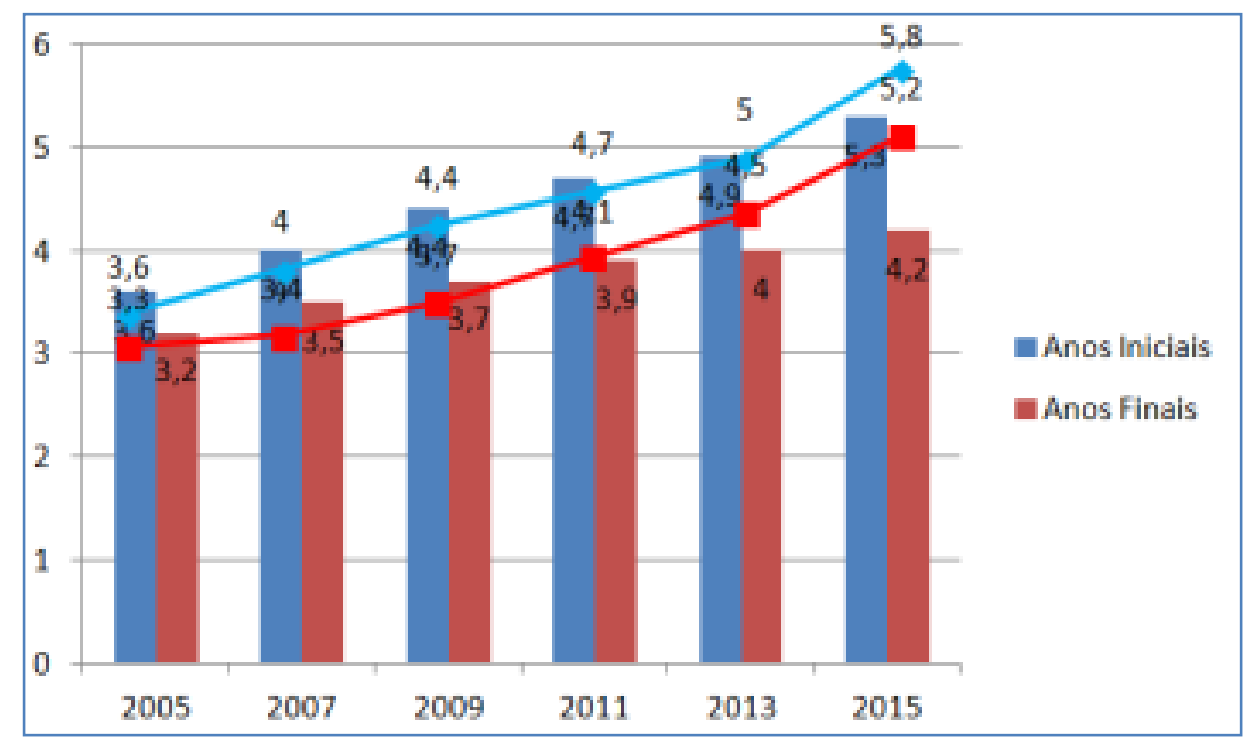

Fonte: Elaborado pelo autor. Base Inep. 


\subsection{Proficiência em leitura e escrita}

Dentre as habilidades adquiridas durante o ensino fundamental, certamente as de leitura e escrita estão entre as mais importantes e necessários à vida em sociedade e ao desenvolvimento dos indivíduos, uma vez que se relacionam à comunicação. A Língua Portuguesa é o "veículo de todos os conhecimentos" uma vez que o ensino dos demais conteúdos da escola passa obrigatoriamente por ela, exigindo do aluno a compreensão mínima da língua para que seja capaz de assimilar os demais saberes e desenvolver um pensamento lógico (LIMA, 1985).

Ser capaz de ler e escrever com proficiência em língua materna é imprescindível para o desenvolvimento de qualquer pessoa inserida em uma cultura letrada. Além disso, o domínio da leitura e da escrita ajuda o sujeito a desenvolver autonomia e a superar barreiras sociais, culturais e econômicas que podem the ser impostas ao longo da vida (PARISOTTO; RINALDI, 2016).

“A leitura é vital não só por trazer conhecimento e cultura a quem lê, mas por ampliar sua visão do mundo. Em nossa sociedade, podemos dizer, de maneira exagerada, mas enfática, que uma pessoa que não lê porta uma espécie de cegueira" (LITRON, 2014). Para Lima (1985) a leitura é um "instrumento de libertação" à medida que possibilita ao cidadão conscientizar-se, interpretando e refletindo de forma autônoma, tornando-o um pensador, capaz de compreender melhor o mundo e de comunicar-se.

É importante destacar que, como explicam Parisotto e Rinaldi (2016), ler não se trata da simples "decodificação das palestras escritas", mas sim da "atribuição de sentido, ou sentidos, que as palavras podem assumir, de acordo com as situações de interação verbal". Portanto, para os autores, focar tão somente na alfabetização, dissociando-se do letramento, impõe restrições ao processo de aquisição das competências de leitura e escrita, deixando de lado as necessidades essenciais destas habilidades, que serão utilizadas na vida extraescolar.

Além das questões sociais, o desempenho escolar também possui grande relação com as habilidades de escrita, leitura e compreensão. Os efeitos decorrentes da adequada habilidade de leitura podem ser observados nas outras disciplinas, sendo que alunos que apresentam melhor desempenho neste quesito tendem a repeti-lo nas demais matérias (OLIVEIRA; BORUCHOVITCH; SANTOS, 2008). No ensino fundamental, em especial, 
sabe-se que o fracasso escolar tem relação direta ao domínio destas habilidades. "A leitura serve de base para a aquisição de novos conhecimentos por permitir a ampliação dos conhecimentos já armazenados na memória de longa duração" (OLIVEIRA; BORUCHOVITCH; SANTOS, 2008, p. 537).

Ainda, segundo Fernandes e Gremaud (2009), alunos que apresentam bons resultados nos exames de leitura nos anos iniciais tendem a acumular mais anos de estudos. Para os autores "dado o conhecimento disponível, somos levados a considerar que escolas que, nos anos iniciais de escolarização, orientem seus esforços para o aprendizado de leitura e matemática estão, provavelmente, fazendo a coisa certa”.

Porém, a Prova Brasil torna clara a inoperância do ensino da disciplina de Língua Portuguesa (LIMA, 1985). Os resultados referentes a 2015 mostram que, apesar dos recentes avanços no desempenho, as notas atuais ainda são inferiores às observadas em 1995 para os anos finais do ensino fundamental, como se pode observar no Gráfico 14.

\section{GRÁFICO 14 - EVOLUÇão DOS RESULTADOS EM LÍNGUA PORTUGUESA NO SAEB (1995 A 2015)}
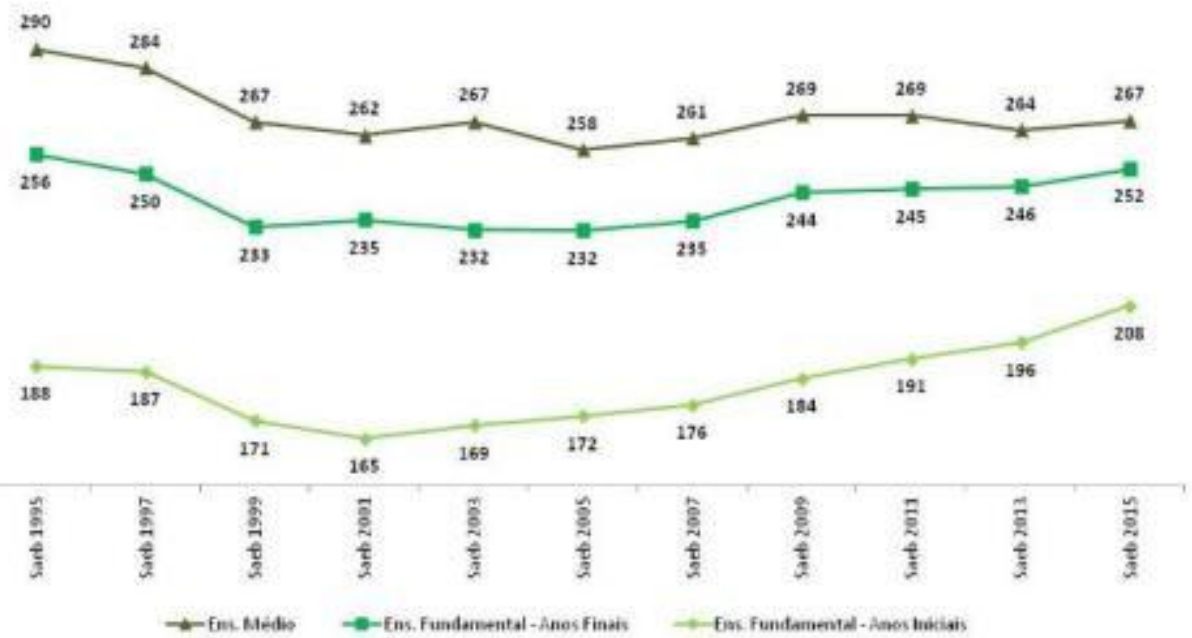

Fonte: (INEP, 2016)

Segundo Oliveira, Boruchovitch e Santos (2008), é comum que os estudantes concluam o nível fundamental sabendo ler, porém, não possuem a capacidade de abstrair as ideias mais relevantes do texto. Em geral são capazes de tão somente decodificar de forma simples o conteúdo, sem, no entanto, compreendê-lo de forma integral.

A habilidade de leitura e compreensão ainda desempenha outro papel importante para o desempenho do aluno. 
"Como fator de retroalimentação e de forma macroestrutural, ainda contribuiria para a aprendizagem de diferentes conteúdos escolares. Assim, facilitaria a utilização de processos cognitivos complexos, tais como o raciocínio analógico e o analítico, exigidos pela disciplina de matemática, por exemplo" (OLIVEIRA; BORUCHOVITCH; SANTOS, 2008, p. 538).

Em resumo, estas importantes habilidades devem receber maior atenção por parte das escolas e das políticas públicas de educação, uma vez que pode colaborar fortemente para que sejam evitados problemas ligados ao desempenho escolar (OLIVEIRA; BORUCHOVITCH; SANTOS, 2008).

\subsubsection{O ensino da Língua Portuguesa}

Ao ingressar na segunda etapa do ensino fundamental, quinta a oitava séries, o aluno experimenta uma mudança significativa na forma com que se relaciona com os professores. A partir da quinta série, ao invés de ter aulas com uma única professora, como ocorria nos anos iniciais (exceto nos casos de atividades específicas como música e educação física, por exemplo), o aluno se depara com um número de professores ampliado, e, à medida que avança para os anos seguintes, se depara com abordagens diversificadas adotadas pelos docentes.

Porém, resultado de um 'ciclo vicioso' em que o professor leciona da forma que aprendeu, o ensino da Língua Portuguesa no Brasil sido reduzido ao ensino gramatical, prática reforçada ao longo do tempo por regulamentações governamentais, sendo este um fator importante para o relativo insucesso dos estudantes.

Estudo realizado por Gatti e Nunes (2009), avaliou o currículo de 32 cursos de Licenciatura em Letras no país. Ao analisar as disciplinas ofertadas, as pesquisadoras identificaram uma discrepância entre a carga horária estipulada nos cursos para as disciplinas de formação profissional e o que se julga adequado. Elas verificaram que apenas 10,5\% estavam direcionadas aos "Conhecimentos Específicos para a Docência", conforme Gráfico 15, o que deixa evidente a carência da ligação teoria-prática para a docência. E, ao analisar a distribuição dos conteúdos dentro da categoria "Conhecimentos Específicos para a Docência", verificou-se, novamente, uma deficiência em relação à apresentação de novas tecnologias educacionais aos futuros docentes. Neste núcleo, 50,4\% estava destinado aos "Conteúdos Dirigidos à Escola Básica", 47,2\% às "Didáticas Específicas, Metodologias e Práticas de 
Ensino" e apenas 2,4\% destinava-se aos "Saberes Relacionados à Tecnologia" (GATTI; NUNES, 2009).

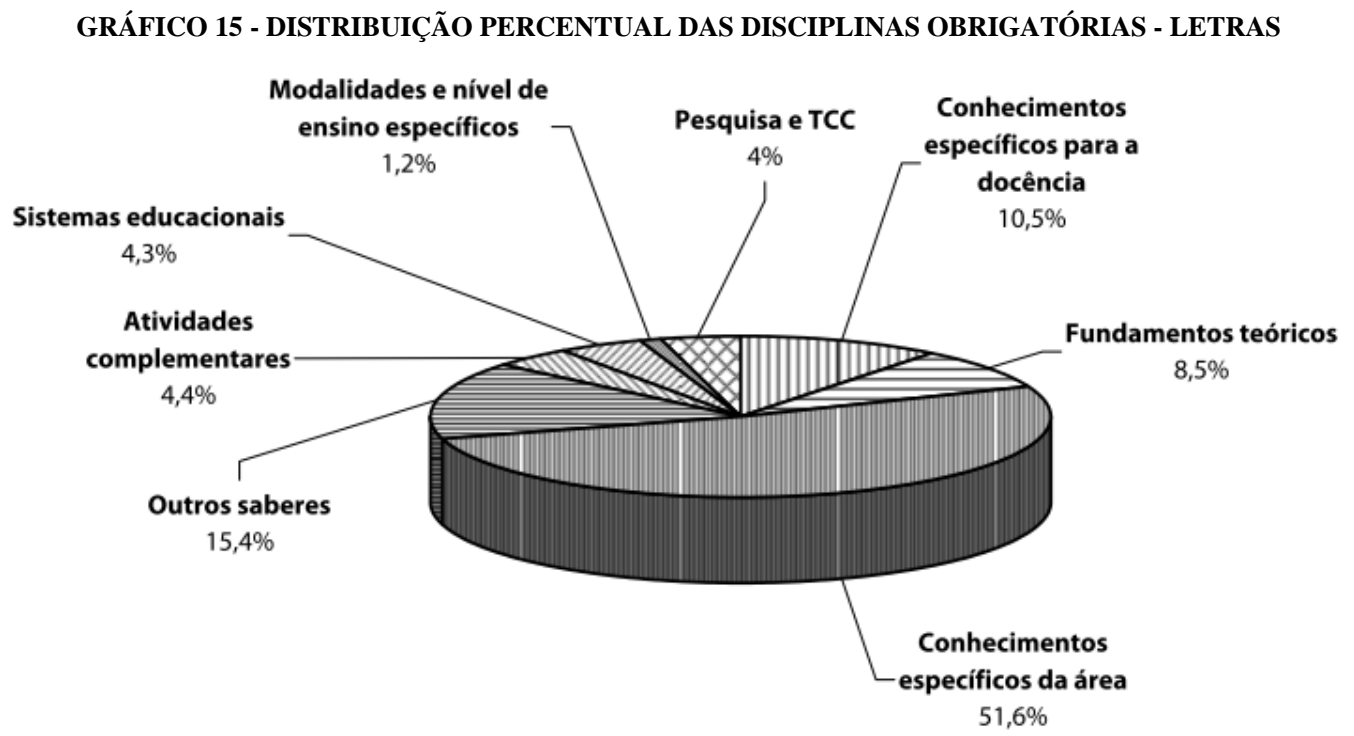

Fonte: Gatti e Nunes (2009, p. 64)

Ademais, pesam outros dois fatores contra o ensino da Língua Portuguesa focado exclusivamente na gramática tradicional - a imprecisão da teoria gramatical ensinada e o fato de que o sujeito é capaz de compreender a língua, mesmo sem conhecimento aprofundado da gramática (LIMA, 1985).

Assim, o ensino da Língua Portuguesa pode adotar dois caminhos - mais prático ou mais teórico - a depender de seus objetivos, não sendo um excludente do outro: o primeiro, desenvolver no indivíduo a capacidade de compreender e se expressar e, o segundo, fornecer o conhecimento do sistema linguístico. Neste sentido, é importante compreender que inicialmente o aluno deve ser capaz de compreender e decodificar mensagens verbais para sua utilização em situações reais do cotidiano, usando apropriadamente a língua. Estas habilidades deveriam ser o foco da disciplina com os alunos do ensino fundamental. Adquiridas estas habilidades iniciais, o aluno está apto a compreender os aspectos formais do sistema linguístico (LIMA, 1985).

Para GERALDI et al. (2013), as práticas de ensino de Língua Portuguesa podem ser divididas em três: análise linguística; leitura e escuta; produção de textos (Figura 3). 


\section{FIGURA 3 - PRÁTICAS PARA LETRAMENTO}

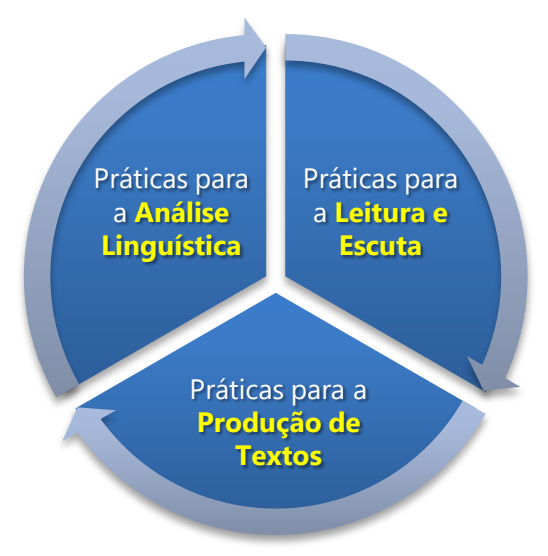

Fonte: Elaborado pelo autor.

Os conteúdos curriculares das disciplinas oferecidas no ensino básico são definidos no âmbito nacional pela Base Nacional Comum Curricular - BNCC, e, sob sua égide, são formuladas os currículos escolares dos estados e municípios, em cada etapa do ensino.

A BNCC é um documento de caráter normativo que define o conjunto orgânico e progressivo de aprendizagens essenciais que todos os alunos devem desenvolver ao longo das etapas e modalidades da Educação Básica, de modo a que tenham assegurados seus direitos de aprendizagem e desenvolvimento, em conformidade com o que preceitua o Plano Nacional de Educação - PNE (BRASIL, 2017).

A BNCC preconiza que nos anos finais do ensino fundamental as estratégias de ensino da língua portuguesa atuem sobre os eixos das práticas da leitura, oralidade, produção de textos, análise linguística/semiótica e educação literária (Figura 4).

FIGURA 4 - BNCC - LÍNGUA PORTUGUESA - EIXOS ORGANIZADORES

\begin{tabular}{|c|c|c|c|c|}
\hline \multicolumn{5}{|c|}{ LINNGUA PORTUGUESA } \\
\hline \multicolumn{5}{|c|}{ EIXOS ORGANIZADORES } \\
\hline ORALIDADE & LETTURA & ESCRTIA & $\begin{array}{l}\text { CONHECIMENTOS } \\
\text { UNGUISTICOS E GQAMATICAIS }\end{array}$ & EDUCACAO UTTERARIA \\
\hline UNIOADES TEMATICAS & UNIDADES TEMATICAS & UNIDADES TEMATICAS & UNIDAOES TEMATICAS & UNDADES TEMATICAS \\
\hline 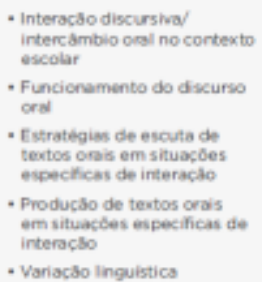 & $\begin{array}{l}\text { - Construcaso da autonomia de } \\
\text { leiturs } \\
\text { - Estratigias de lentura }\end{array}$ & 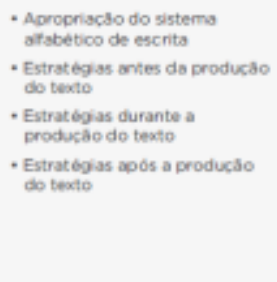 & 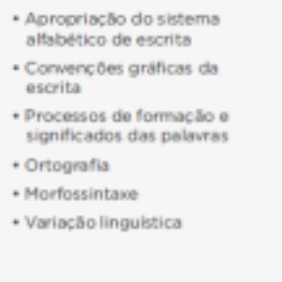 & $\begin{array}{l}\text { - Categorias do discurso } \\
\text { literario } \\
\text { - Reconstrucalo do sentido do } \\
\text { texto literario } \\
\text { - Experiencias estuticas } \\
\text { - O terto irerario no contexto } \\
\text { sociocultural } \\
\text { - Interesse pela leitura iteraria }\end{array}$ \\
\hline
\end{tabular}

Fonte: Brasil (2017) 
Neste sentido, também é necessário compreender um conceito bastante difundido na área: o letramento. Para Litron (2014),

O conceito de letramento considera os níveis de intimidade do indivíduo com usos e funções da escrita e da leitura. Quando alguém sabe ler, mas só compreende textos elementares, tal pessoa é alfabetizada, mas tem um baixo grau de letramento. Esse grau aumenta à medida que se aprende a lidar com variados materiais de leitura e de escrita, dos simples aos complexos. Quanto mais textos alguém é capaz de ler e entender, mais letrado se torna (LITRON, 2014).

Assim, a prática do letramento permeia todos os anos da educação escolar, "constituindo-se num conceito complexo, que abarca uma ampla gama de conhecimentos, habilidades, técnicas, valores e usos sociais" (PARISOTTO; RINALDI, 2016).

Em pesquisa realizada junto a professores de ensino fundamental de município localizado no estado de São Paulo, Parisotto e Rinaldi (2016), procuraram, por meio de entrevistas, identificar as dificuldades encontradas pelos docentes no ensino da língua portuguesa. No trabalha verificaram que os professores manifestam dificuldades no ensino da produção de textos que estavam relacionadas à proposição de práticas que tivessem algum significado para os estudantes, assim como no processo de correção. Neste sentido, as autoras destacam que "a metodologia para o trabalho com a produção de texto na sala de aula prevê somente os passos para uma abordagem artificial do texto". Também houve relatos de dificuldades com a influência da oralidade na produção dos textos escritos pelos estudantes o que, para as autoras, sinaliza uma dificuldade no ensino de ortografia. Em relação ao ensino da gramática, pouca dificuldade foi levantada.

No mesmo trabalho os professores foram convidados a informar em quais conhecimentos / temas sentiam necessidade de complementar sua formação. Pela ordem, foram citados os seguintes temas: 1) Produção de Textos; 2) Alfabetização e Letramento; 3) Análise Linguística e Normatividade; 4) Reescrita das Produções dos Alunos e, 5) Leitura e Interpretação de Textos.

Os resultados de sua pesquisa apontam para uma direção preocupante: a dificuldade dos professores está diretamente relacionada na transmissão das habilidades ligadas à proficiência da língua materna, apresentadas no capítulo anterior como fundamentais ao desenvolvimento social e educacional dos estudantes. Isto alerta para a necessidade de se encontrar metodologias que auxiliem os professores nesta tarefa. Na literatura, encontramos algumas sugestões de práticas / metodologias para o ensino da língua portuguesa. 
Angelo e Menegassi (2016) avaliaram a prática da Leitura Compartilhada aplicada em Salas de Apoio à Aprendizagem de Língua Portuguesa (SAALP), projeto desenvolvido pela Secretaria Estadual de Educação do Paraná em 2004 para auxiliar alunos em situação de dificuldade de aprendizagem. Para os autores, a principal dificuldade dos alunos está na localização de informações textuais, no estabelecimento de inferências e na sua interpretação, problemas que, segundo eles, podem ser solucionados por meio da Leitura Compartilhada.

Na leitura compartilhada ou leitura colaborativa, os alunos são ativos no processo de aprendizado por ler, interpretar, formular hipóteses e verifica-las. É o aluno quem controla a leitura e cada leitor deve apresentar as estratégias que utilizou para a sua compreensão. Este processo permite que os demais possam se apropriar deste aprendizado, fazendo com que um auxilie o outro em seu desenvolvimento. Neste tipo de estratégia, a escolha do texto também é importante. Recomenda-se a leitura de conteúdos desafiadores, com os quais os alunos não possuam proficiência autônoma, para que a colaboração se faça necessária (ANGELO; MENEGASSI, 2016).

Esta estratégia se contrapõe à leitura dirigida, metodologia em que o professor lê e expõe suas ideias e interpretações do texto, sendo o aluno passivo no processo de aprendizagem com papel de expectador que, ao final, deve apenas responder eventuais perguntas sobre o que foi apresentado (ANGELO; MENEGASSI, 2016).

Outra abordagem identificada por Angelo e Menegassi (2016) é a da 'leitura tutorial'. Nesta prática, o professor atua como mediador ou 'tutor' do aluno, guiando-o pela leitura, mas sem, no entanto, tirar do aluno o seu papel ativo no processo. Esta abordagem utiliza como pressuposto o conceito de "andaimagem", do inglês "scaffolding", assim chamado em alusão aos andaimes que fornecem suporte, comumente utilizados na construção civil. No scaffolding, utilizando-se de contextos divertidos, o professor deixa a criança trabalhar com uma tarefa acima da sua habilidade, mas dentro de sua capacidade, por um tempo, e só intervém quando ela tem dificuldade e precisa de assistência (KHALILIAQDAM, 2014; SALEM, 2016).

Esta abordagem desperta o interesse do aluno pela tarefa e encara o erro como uma oportunidade de aprendizado, criando um ambiente seguro, mas desafiador ao aluno, que assume um papel cada vez maior no processo à medida que aumentam seu conhecimento e confiança. A técnica ainda favorece a comunicação entre os participantes, que acontece de forma natural e estimulada pelo desafio. Neste processo o professor mantém a direção do objetivo e auxilia na definição dos limites de liberdade, atuando de acordo com a reação dos alunos (KHALILIAQDAM, 2014; SALEM, 2016). 
Angelo e Menegassi (2016) chamam de "estratégias basilares" uma sequência de atividades que garantem a leitura produtiva. São elas: a formulação de previsões sobre o texto a ser lido; a formulação de perguntas sobre o que foi lido; o esclarecimento de possíveis dúvidas sobre o texto; o resumo das ideias do texto.

Azizifar et al. (2015) defendem a prática das atividades de pré-leitura como estratégica para o ensino. A realização de discussões prévias com os estudantes abordando o assunto a ser lido, a realização de perguntas sobre o assunto, bem como a introdução prévia dos novos vocábulos empregados auxiliam na compreensão, tornam mais eficiente o processo. Para que seja efetiva, esta prática deve ser balanceada pelo professor de forma que tome apenas o tempo necessário para a introdução do assunto, não se ocupando o espaço que deveria ser destinado à leitura dos conteúdos em si (AZIZIFAR et al., 2015).

As discussões de texto também se mostram como uma técnica importante. Para Johnson (2017), elas incentivam a comunicação e a análise cooperativa das interpretações entre os estudantes, além de permitir que adquiram independência na leitura. Este tipo de abordagem também favorece que o aluno se desenvolva enquanto leitor, permitindo a construção de conteúdos e a verificação de interpretações diversas das suas, além de auxiliar na prática da oralidade e do pensamento, habilidades essenciais à leitura (JOHNSON, 2017).

Em sua pesquisa, Ardoin et al. (2016), compararam outras duas técnicas para aprimoramento da leitura: Repeated Reading ou Leitura Repetida, e Wide Reading ou Leitura Ampla. Os autores verificaram através de seus experimentos que ambas as metodologias apresentam ganhos ao aluno, embora os resultados tenham sido similares entre os grupos de cada modalidade. A prática da Repeated Reading consiste na leitura de um determinado texto por um número pré-estabelecido de vezes, e auxilia no desenvolvimento da fluência e da velocidade de leitura, sendo indicada para alunos com dificuldades neste quesito. Porém, esta técnica apresenta limitações, uma vez que os estudantes são expostos ao mesmo conteúdo, o que reduz a amplitude do vocabulário trabalhado. Em contrapartida, a Wide Reading consiste na oferta de materiais diversos, sendo recomendado ao estudante que já apresenta nível de fluência adequado, e oportuniza ampliar seu vocabulário pelo contato com conteúdo diversificado. (ARDOIN et al., 2016).

Sardinha, Azevedo e Rato (2015), também encontraram uma gama de atividade pré e pós-leitura aplicada nas escolas portuguesas. Entre as técnicas pós-leitura mais utilizadas pelos docentes identificou-se a técnica de resumo, a técnica do reconto escrito, a criação de diagramas e o desenho das partes que mais gostaram. Entre as atividades pré-leitura, as de maior frequência foram a apresentação da 'motivação para o estudo da obra', que apresenta ao 
estudante a importância do material; a 'ativação do conhecimento temático', que consiste na apresentação e discussão prévia do assunto a ser abordado pelo texto e a 'adivinhação sobre o conteúdo da obra', que objetiva despertar a curiosidade prévia dos estudantes (SARDINHA; AZEVEDO; RATO, 2015).

Outra técnica de letramento é o PQ4R (Preview, Question, Read, Reflect, Recite and Review), que consiste de uma estratégia passo a passo aplicada à leitura de um texto. Trata-se de um procedimento analítico para a leitura. Inicialmente, como atividades pré-leitura, o conteúdo é apresentado pelo professor ao aluno, para que compreenda o contexto do que será lido. Também são levantadas questões a respeito. Estas questões devem suscitar o interesse e curiosidade do leitor, sendo elaboradas de forma a conduzir o aluno ao ponto principal. A seguir procede-se à leitura. As atividades pós-leitura consistem na reflexão dirigida pelo professor, que promove o debate em sala. Os alunos devem, então, recitar partes do texto e, ao final, realiza-se uma revisão geral do que foi lido e discutido. Esta metodologia auxilia o estudante a organizar as informações e a encontrar os significados do texto (RODLI, 2015).

Além das metodologias, também é importante destacar a escolha, pelo professor, dos materiais a serem utilizados. Também devem ser inseridos no cotidiano do aluno diversos tipos textuais, de forma a aumentar seu repertório. Isto é importante porque a leitura de gêneros diferentes, como romances, manuais de instruções e notícias de jornal, por exemplo, se utilizam de processos distintos de compreensão (LITRON, 2014).

Assim, conhecer as diversas metodologias empregadas para o ensino de Língua Portuguesa é um passo essencial desta pesquisa, uma vez que se procurará verificar in loco nas escolas de alto desempenho, aquelas que colaboram para a melhoria dos resultados dos alunos nas avaliações padronizadas de leitura. 


\section{PROCEDIMENTOS METODOLÓGICOS}

O método científico compreende os procedimentos, técnicos e intelectuais, utilizados para se atingir o objetivo de uma pesquisa: a aquisição de novos conhecimentos. "Pode-se definir pesquisa como o processo formal e sistemático de desenvolvimento do método científico (GIL, 1999, p. 42). Nesta seção serão apresentados a classificação da pesquisa, o método, os dados e as técnicas de análise utilizadas.

\subsection{Caracterização da pesquisa}

As pesquisas científicas podem ser classificadas segundo critérios, os quais estão ligados ao processo lógico adotado - abordagem -, aos métodos empregados e ao seu nível. Esta pesquisa se caracteriza como descritivo-explicativa, com o uso da metodologia mista (quali-quantitativa), proposta por Salgado Junior e Novi (2014).

As pesquisas descritivas, segundo Gil (1999, p. 44) "têm como objetivo primordial a descrição das características de determinada população ou fenômeno ou o estabelecimento de relações entre variáveis". Já as pesquisas explicativas, "têm como preocupação central identificar os fatores que determinam ou contribuem para a ocorrência de fenômenos" (GIL, 1999, p. 44). Para o autor "este é o tipo de pesquisa que mais aprofunda o conhecimento da realidade, por explicar a razão, o porquê das coisas" (GIL, 1999, p. 44).

O enquadramento desta pesquisa neste modelo - descritivo-explicativa - é aderente aos seus objetivos, que são: inicialmente caracterizar as escolas municipais de ensino fundamental II, segundo sua capacidade de agregar conhecimento e desempenho aos seus alunos em avaliações de língua portuguesa e, posteriormente identificar os fatores ou práticas que aquelas mais eficientes adotam e que as diferenciam das demais.

Segue-se aqui a lógica indutiva, método "que passou a ser proposto como o método mais adequado para investigação nas ciências sociais" (GIL, 1999, p. 29). Este método tem como base a generalização dos resultados a partir da análise dos dados particulares, ou seja, do particular para o todo (RUDIO, 2007), sendo o responsável pelo movimento que trouxe os estudiosos das ciências sociais de sua postura meramente especulativa para a adoção da observação como procedimento para se atingir o conhecimento científico (GIL, 1999). 
Corroboram com esta visão Bray, Adamson e Mason (2014, p. 75), para quem "a pesquisa qualitativa pode, portanto, ser mais facilmente caracterizada como indutiva e exploratória, ao invés de dedutiva e confirmatória".

Trata-se de uma pesquisa ex-post-facto, ou seja, "a manipulação da variável independente é impossível" uma vez que "chegam ao pesquisador já tendo exercido os seus efeitos" (GIL, 1999, p. 69). Ela se utiliza da pesquisa bibliográfica e do estudo de múltiplos casos para tentar responder à questão de pesquisa.

Para Gil (1999, p. 72), “o estudo de caso é caracterizado pelo estudo profundo e exaustivo de um ou de poucos objetos, de maneira a permitir o seu conhecimento amplo e detalhado" e envolve a "observação direta e série sistemática de observações" (YIN, 2001, p 27).

Em geral, os estudos de caso representam a estratégia preferida quando se colocam questões do tipo "como" e "por que", quando o pesquisador tem pouco controle sobre os eventos e quando o foco se encontra em fenômenos contemporâneos inseridos em algum contexto da vida real. Pode-se complementar esses estudos de casos "explanatórios" com dois outros tipos estudos "exploratórios" e "descritivos" (YIN, 2001, p. 19).

\subsection{Método de pesquisa}

A metodologia da pesquisa diz respeito ao conjunto de procedimentos utilizados para a condução de um estudo, caracterizados pela presença de rigor científico (ALMEIDA, 2011).

A presente dissertação utiliza-se da metodologia quali-quantitativa proposta por Salgado Junior e Novi (2014).

Este modelo permite

"explorar melhor as questões pouco estruturadas, os territórios ainda não mapeados, os horizontes inexplorados, problemas que envolvem atores, contextos e processos [..] Os modelos quali-quantitativos são, portanto, uma evolução dos modelos meramente qualitativos ou quantitativos" (ENSSLIN; VIANNA, 2008, p. 7).

A utilização de métodos mistos de pesquisa permite a abordagem de questões de pesquisa mais complexas e a coleta de evidências mais fortes e ricas, que não poderiam ser obtidos a partir de métodos únicos e isolados (YIN, 2010). 
A combinação dos métodos quali-quantitativos pode ser altamente sinérgica,

as evidências quantitativas podem indicar relacionamentos que podem não ser evidentes para o pesquisador. Também pode impedir que os pesquisadores sejam levados por impressões vívidas, mas falsas, em dados qualitativos, e pode reforçar as descobertas quando corrobora esses achados de evidências qualitativas. Os dados qualitativos são úteis para entender a lógica ou a teoria das relações subjacentes reveladas nos dados quantitativos ou sugerem uma teoria direta que pode então ser fortalecida pelo suporte quantitativo (EISENHARDT, 1989, p. 538, tradução nossa).

Este método se apresenta adequado à presente pesquisa, uma vez que permite compreender fenômenos que apresentem alto grau de complexidade interna bem como estejam em ambiente de incertezas (ENSSLIN; VIANNA, 2008), o que corresponde às características do serviço educacional, que é influenciado por diversos atores e condições externas à sua execução.

Goldenberg, Marsiglia e Gomes (2003, p. 168) sugerem que este tipo de abordagem podem ter quatro modelos de integração: 1) Qualitativa no início; 2) Quantitativa no início; 3) Execução paralela e 4) Técnicas Alternadas. O modelo quantitativo no início é particularmente útil quando se "quer realizar uma prova dos pressupostos que sustenta um tema da investigação" (GOLDENBERG; MARSIGLIA; GOMES, 2003, p. 171), sendo este o método adotado no presente trabalho.

A primeira etapa, quantitativa, é fundamentalmente descritiva, com a utilização da técnica DEA, em dois estágios. Inicialmente atribui-se um escore para cada escola, criando um ranking de eficiência relativa entre elas, de modo a se identificar as de alto desempenho e as de baixo desempenho em agregar performance aos alunos em avaliações de língua portuguesa. A partir deste ranking, se buscou por outras técnicas estatísticas (Regressão Linear Múltipla e Análise de Quintis), identificar as variáveis explicativas para o escore e que estão contribuindo para as diferenças entre as escolas.

O chamado método de dois estágios é popular e amplamente empregado. Nesta abordagem, o primeiro estágio inclui apenas insumos discricionários e, em uma segunda etapa, as variáveis não criticas são regredidas nos escores de eficiência da primeira etapa (DE WITTE; LÓPEZ-TORRES, 2015, p. 18, tradução nossa)

Ainda na etapa quantitativa, o investimento anual médio por aluno das escolas obtido a partir dos dados do FINBRA para os anos de 2012 a 2014 - é utilizado para verificar a eventual de correlação desta variável com os resultados do escore DEA e o IDEB de cada escola. 
Na segunda etapa, a qualitativa, são realizados estudos de múltiplos casos. Para isso foram escolhidas 02 escolas de alto desempenho e 02 de baixo desempenho com base no escore DEA (Figura 5). Por meio de roteiros de entrevista semiestruturados, elaborados a partir dos dados identificados na etapa quantitativa, são realizadas entrevistas junto aos atores envolvidos no processo educacional, a saber: corpo docente da disciplina de português, coordenadores pedagógicos, diretores e secretários de educação, bem como a observação direta. Com isso, se busca verificar in loco as práticas administrativas e pedagógicas adotadas pelas escolas que tenham relação com a melhoria do desempenho dos estudantes nos testes padronizados de língua portuguesa, de forma a permitir a triangulação dos dados para se confirmar ou refutar os resultados encontrados na primeira etapa, bem como identificar os fatores que não são passíveis de interpretação baseados exclusivamente nos dados inicialmente utilizados.

FIGURA 5 - ETAPAS DO MÉTODO DE PESQUISA

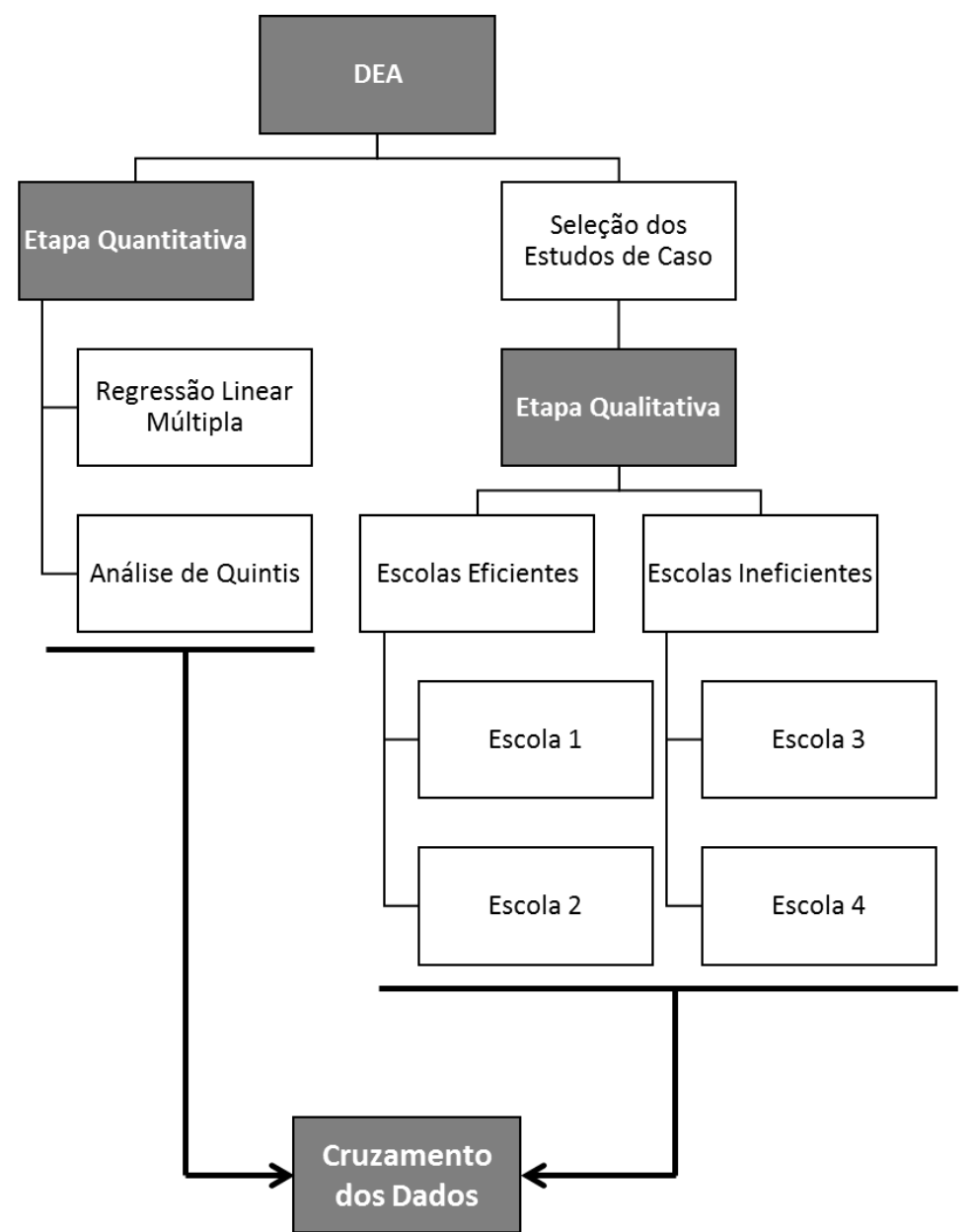

Fonte: Elaborado pelo autor. 


\subsubsection{Base de dados e definição da amostra}

Para a aplicação da técnica DEA no modelo proposto foram utilizados os dados das escolas municipais de ensino fundamental da Prova Brasil, disponível no site do INEP, que é aplicada a cada período de 02 anos, sendo a última edição disponível na data de execução desta pesquisa a de 2015. Os resultados não estão disponíveis para consulta a nível aluno, sendo o menor nível informado o da escola. Assim, foram utilizados os dados das notas médias das escolas em língua portuguesa, sendo que da base de 2011 foram utilizados as notas do $5^{\circ}$ ano e da base de 2015 as notas do $9^{\circ}$ ano, bem como o Indicador de Rendimento do IDEB de 2015. O uso dos dados dos anos base 2011 e 2015 foi adotado visando captar a evolução do desempenho do mesmo ciclo de alunos, uma vez há alta probabilidade daqueles que realizaram a prova no $9^{\circ}$ ano em 2015 sejam os mesmos que a realizaram em 2011, durante o $5^{\circ}$ ano.

Em razão do formato de dados disponibilizado pelo INEP, seu uso direto na ferramenta Microsoft Excel não é possível. Desta forma, procedeu-se à sua extração por meio da elaboração de um programa SQL para que os dados pudessem, então, ser convertidos. O software utilizado para esta finalidade foi o Postgre SQL.

A base de dados inicial contou com os dados de desempenho de 40.957 escolas municipais de ensino fundamental de todo o país. Sendo o menor nível de informação disponível o da escola e em razão do modelo adotado, em que se emprega a média da Nota de Português do $5^{\circ}$ ano de 2011 como input e a média Nota de Português do $9^{\circ}$ ano de 2015 de cada escola como um dos outputs, foi realizado corte na amostra, selecionando-se apenas aquelas escolas que oferecem tanto os anos iniciais quanto os anos finais do ensino fundamental, admitindo-se que, de maneira geral, os estudantes tendem a prosseguir seus estudos na mesma instituição, permanecendo na base, portanto, 13.798 escolas. A seguir foi realizado novo corte, de forma a manter apenas escolas que possuíam todos os dados necessários para a execução do DEA (notas 2011 e 2015 e Indicador de Desempenho 2015), ficando a base com 9.170 unidades. Foram então eliminados da base os outliers, sendo considerado outlier para este estudo aquelas escolas que obtiverem Indicador de Rendimento 2015 menor do que 0,50 (50 registros), restando 9.120 escolas.

Na sequência as escolas foram classificadas de acordo com seu nível socioeconômico. Uma vez que o INEP não disponibiliza este tipo de informação, utilizou-se da classificação proposta por Alves, Soares e Xavier (2014), já apresentada anteriormente. As escolas foram 
agregadas, então, em 03 grupos, segundo NSE: grupo 01: NSE 2 e 3, grupo 2: NSE 4 e grupo 3: NSE 5 e 6. Para o presente trabalho, optou-se pela utilização de escolas dos níveis 5 e 6, de forma a complementar os resultados dos trabalhos anteriores realizados pelo GREFIC, que avaliaram escolas dos demais NSE, sendo esta, também, uma das contribuições desta dissertação. Assim, foi realizado recorte na base, restando, então, 3330 escolas dos NSE 5 e 6, conforme Figura 6, sendo esta a amostra utilizada para a geração do ranking de eficiência com a técnica DEA. Os dados das bases de 2011 e 2015 foram, então, consolidados em planilha única para a elaboração do ranking. O software utilizado foi o PIM DEA, versão 3.2.

\section{FIGURA 6 - DEFINIÇÃO DA AMOSTRA}

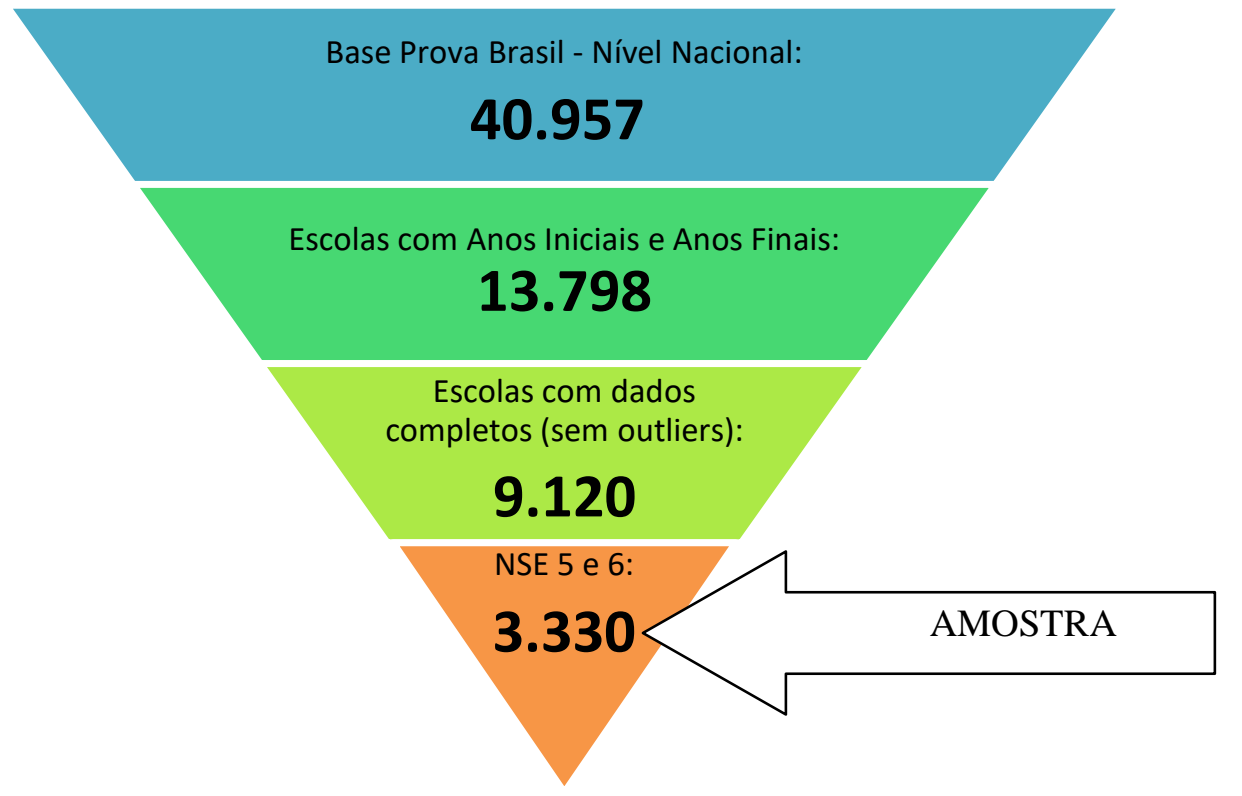

Fonte: Elaborado pelo autor.

A seguir, foram inseridos na planilha os dados dos questionários contextuais da Prova Brasil e os dados do Censo Escolar. Os dados referentes à escola e ao diretor foram extraídos das bases do Censo Escolar e da Prova Brasil de 2013, de forma a permitir identificar a estrutura disponível durante o período em que o aluno estava em curso, bem como as características do diretor e as ações de gestão por ele implantadas, cujo efeito pode ser observado ao longo de um período de tempo maior. Para os alunos e professores, optou-se pelo uso da base de dados de 2015, uma vez que retratam com maior precisão as características destes atores à época da realização da Prova Brasil, entendendo que estas características têm influência direta sobre o resultado da avaliação. A Prova Brasil coleta por meio de questionário contextual, dados detalhados sobre os professores, como a formação, experiência e condições de trabalho (ALVES; SOARES, 2013). Ela é composta por 04 
questionários de contexto (Figura 7) que "coletam informações sobre fatores socioeconômicos e de contexto que podem auxiliar a compreender o desempenho nos testes" (INEP, 2017b). O questionário da escola possui 74 questões, sendo preenchido pelo aplicador da prova (Anexo A); o questionário do diretor possui 111 questões (Anexo B), o questionário do professor, com 125 perguntas (Anexo C), e, por fim, o questionário do aluno, com 57 questões (Anexo D). Há ainda o questionário da escola, que deve ser preenchido pelo aplicador. Pela sua completude, os questionários de contexto da Prova Brasil permitem uma leitura mais ampla do sistema educacional brasileiro (GOUVEIA; SOUZA, 2013).

FIGURA 7 - QUESTIONÁRIOS CONTEXTUAIS PROVA BRASIL
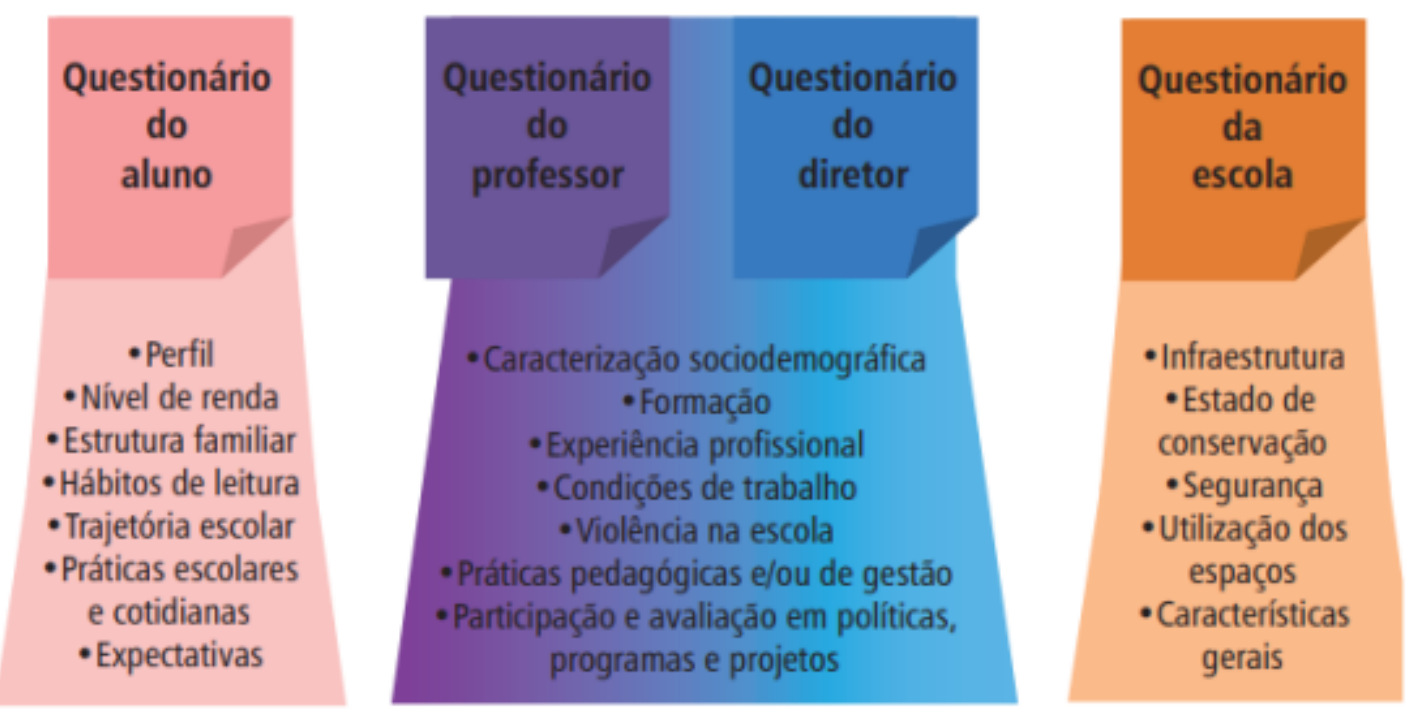

Fonte: (INEP, 2017b).

Já o Censo Escolar é o mais importante instrumento de coleta de informações da educação básica. Por meio da colaboração das secretarias municipais e estaduais de educação é realizado levantamento de dados em âmbito nacional e, em todos os anos, com informações sobre as escolas e suas características, considerando-se, por exemplo, os dados referentes ao corpo docente, sua composição e caracterização e dados de infraestrutura física da escola, como a disponibilidade de equipamentos multimídia, pessoal de apoio pedagógico e administrativo, qualidade das instalações físicas, entre outros. Os dados ainda são divididos segundo o município sede, a dependência administrativa (estadual, municipal, federal e privada), o nível de ensino, o número de matriculados, concluintes, reprovados e evadidos (movimento e rendimento escolar) (GONÇALVES; FRANÇA, 2013). 


\subsubsection{Análise envoltória de dados (DEA)}

Para a estimação da eficiência, os principais métodos encontrados na literatura são os métodos paramétricos e não-paramétricos (BARRA; ZOTTI, 2016; MARQUES; SILVA, 2006). Entre os métodos não-paramétricos está a Análise DEA, proposta por Charnes, Cooper e Rhodes (1978) a partir da contribuição original de Farrell (1957), sendo uma técnica baseado nos modelos de fronteira (BARRA; ZOTTI, 2016, p. 14, tradução nossa).

Para Marques e Silva (2006), apesar de os métodos paramétricos terem como vantagem a possibilidade de medição do erro, apresentam como dificuldade de conhecer a especificação associada ao comportamento admitido. Em consonância com os autores, Barra e Zotti (2016), indicam o uso de métodos não-paramétricos para o setor educacional como mais adequados pois "não exigem a construção de uma fronteira teórica de produção", ao contrário das técnicas paramétricas, como, por exemplo, a Stochastic Frontier Approach (SFA), Distribution-Free Approach (DFA) e a Thick Frontier Approach (TFA) (BARRA; ZOTTI, 2016, p. 14, tradução nossa).

[...] métodos não-paramétricos podem lidar com múltiplas entradas e saídas de forma simples, enquanto a maioria das abordagens estocásticas requer a escolha de uma única variável explicativa. Em segundo lugar, abordagens não-paramétricas não requerem quaisquer suposições sobre a forma funcional ou a especificação do termo de erro, enquanto os métodos estocásticos precisam desses pressupostos. Além disso, abordagens nãoparamétricas assumem que todos os desvios da fronteira são devidos à ineficiência. Isso significa que os limites das estimativas não podem ser facilmente determinados, e a significância estatística não está disponível nos modelos tradicionais (DE WITTE; LÓPEZ-TORRES, 2015, p. 15, tradução nossa).

O desenvolvimento das técnicas de estimação de fronteiras, como a DEA, ocorridas no final dos anos 1970, permitiram a expansão das pesquisas sobre eficiência em educação (JOHNES; PORTELA; THANASSOULIS, 2017). Segundo os autores, "estes métodos podem ser utilizados para estimar as fronteiras de produção para as instituições a partir das quais pode-se derivar sua eficiência" (JOHNES; PORTELA; THANASSOULIS, 2017, p. 332, tradução nossa).

A técnica DEA foi escolhida por permitir que se obtenha uma comparação de eficiência relativa entre os grupos de escolas a serem estudados, passo necessário para o desenvolvimento desta pesquisa (SALGADO JUNIOR; NOVI, 2015). 
O modelo DEA proposto por Banker, Charnes e Cooper em seu trabalho no ano de 1984 "é especialmente adequado para avaliar a eficiência de entidades sem fins lucrativos que operam fora do mercado, uma vez que, para eles, indicadores de desempenho, como renda e rentabilidade, não funcionam de forma satisfatória" (BARRA; ZOTTI, 2016, p. 14, tradução nossa).

Para Flach et al. (2017, p. 113, tradução nossa), “o conceito de eficiência usualmente utilizado em DEA é a melhor forma de transformar inputs em outputs" (Figura 8). O objetivo da DEA é permitir a comparação de Decision Making Units (DMUs), ou, Unidades Tomadoras de Decisão, que realizam tarefas similares e que obtém resultados diferentes na relação entre a quantidade de entradas utilizadas e a quantidade de saídas produzidas (MEZA et al., 2005).

\section{FIGURA 8 - MODELO DE EFICIÊNCIA DEA}

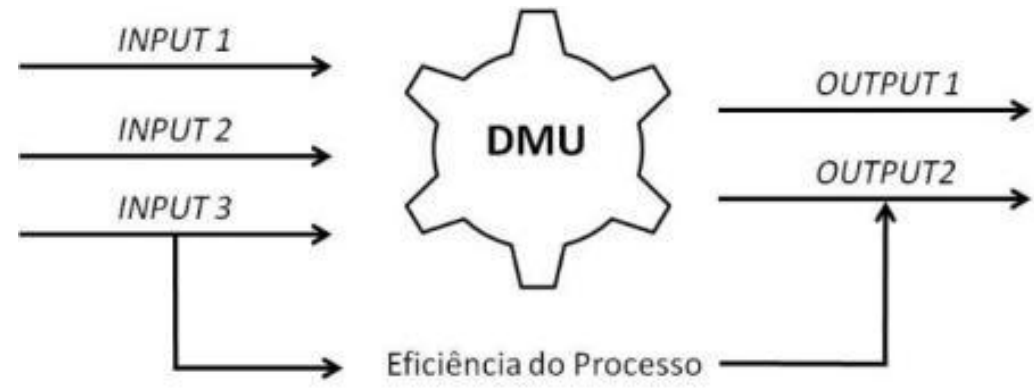

Fonte: Elaborado pelo autor.

A fronteira de eficiência resultante da aplicação da técnica DEA (Figura 9) indica as DMUS eficientes, ou benchmarking, que podem ser estudadas e comparadas para encontrar as melhores práticas (FLACH et al., 2017).

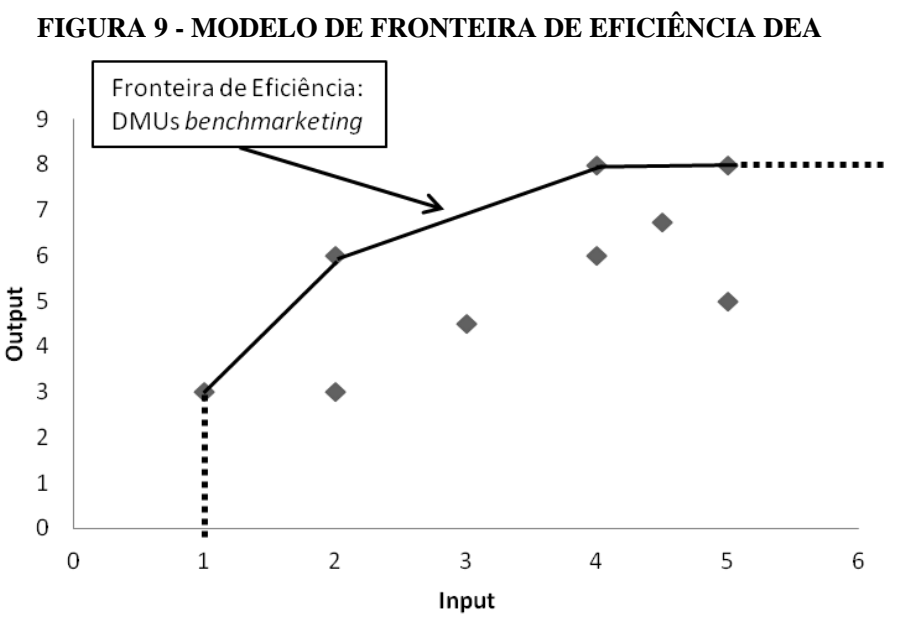

Fonte: Elaborado pelo autor. 
Ainda,

a produção dos primeiros trabalhos sobre eficiência na área educacional se confunde com a origem do método DEA. O aspecto essencial desse método consiste na construção de uma fronteira, formada pelas Unidades Tomadoras de Decisão (DMUs) mais eficientes, que, assim, passam a delimitar as demais unidades, de forma que aquelas mais eficientes estejam localizadas na fronteira, ou próximas a ela, e as menos eficientes, em posição mais afastada (CARVALHO; SOUSA, 2014, p. 651).

A técnica DEA tem sido amplamente aplicada por pesquisadores que avaliam a eficiência na prestação de serviços da área da educação, como se pode observar no QUADRO 9. “A razão é que o conceito de fronteira ilustra fielmente as características essenciais da eficiência de medição, pois procura avaliar o quão bem uma organização está alcançando a produção máxima com o mínimo de consumo de insumos" (DE WITTE; LÓPEZ-TORRES, 2015, p. 15, tradução nossa).

\section{QUADRO 9 - TRABALHOS COM USO DA TÉCNICA DEA EM EDUCAÇÃO}

\begin{tabular}{|c|c|}
\hline Técnicas & Estudos \\
\hline $\begin{array}{l}\text { 1.1. DEA } \\
\text { (Estatísticas } \\
\text { Descritivas, } \\
\text { Folgas, Testes } \\
\text { de } \\
\text { Significância, } \\
\text { etc.) }\end{array}$ & $\begin{array}{l}\text { Bessent and Bessent (1980), Charnes et al. (1981), Bessent et al. (1982), Jesson et al. (1987), Smith } \\
\text { and Mayston (1987), Sengupta and Sfeir (1988), Färe et al. (1989), Beasley (1990), Ganley and } \\
\text { Cubbin (1992), Kao and Yang (1992), Johnes and Johnes (1993) (1995), Bonesrønning and Rattsø } \\
\text { (1994), Breu and Raab (1994), Sinuany et al. (1994), Thanassoulis and Dustan (1994), Beasley } \\
\text { (1995), Chalos and Cherian (1995), Ruggiero et al. (1995), Engert (1996), Mar-Molinero (1996), } \\
\text { Ruggiero (1996a) (1999) (2007), Thanassoulis (1996), Athanassopoulos and Shale (1997), Chalos } \\
\text { (1997), Madden et al. (1997), Haksever and Muragishi (1998), McMillan and Datta (1998), Ray and } \\
\text { Mukherjee (1998), Mancebón and Bandres (1999), Thanassoulis (1999), Colbert et al. (2000), } \\
\text { Sarrico and Dyson (2000), Thursby (2000), Ying and Sung (2000), Avkiran (2001), Korhonen et al. } \\
\text { (2001), Portela and Thanassoulis (2001), Fukuyama and Weber (2002), Moreno and Tadepali } \\
\text { (2002), Abbott and Doucouliagos (2003), Banker et al. (2004), Emrouznejad and Thanassoulis } \\
\text { (2005), Joumady and Ris (2005), Kiong et al. (2005), Agasisti and Dal Bianco (2006), Bougnol and } \\
\text { Dulá (2006), Casu and Thanassoulis (2006), Kocher et al. (2006), Giménez and Martínez (2006), } \\
\text { Johnes (2006c), Fandel (2007), Giménez et al. (2007), Tauer et al. (2007), Mancebón and Muñiz } \\
\text { (2008), Ray and Jeon (2008), Abramo and D'Angelo (2009), Cokgezen (2009), Colin-Glass et al. } \\
\text { (2009), Kantabutra (2009), Sarrico and Rosa (2009), Tyagi et al. (2009), Dehnokhalaji et al. (2010), } \\
\text { Kantabutra and Tang (2010), Katharaki and Katharakis (2010), Portela and Camanho (2010), } \\
\text { Sarrico et al. (2010), Eff et al. (2012), Portela et al. (2012), Agasisti et al.(2012), Montoneri et al. } \\
\text { (2012), Sexton et al.(2012), Aristovnik (2013), Aristovnik and Obadic (2014), Mainardes et al. } \\
\text { (2014), Mayston (2014), Nazarko and Saparauskas (2014), Miranda e Rodrigues (2010), Miranda } \\
\text { (2008), Salgado Junior e Novi (2014), Salgado Junior e Novi (2015), Ferreira (2015), Silva, Souza e } \\
\text { Araújo (2013), Peña, Albuquerque e Daher (2012), Carvalho e Sousa (2014), Gomes (2010), } \\
\text { Delgado e Machado (2007), Barbosa e Wilhlm (2009), Giacomello e Oliveira (2014), Cavalcante e } \\
\text { Andriola (2012), Gramani e Duarte(2011), Machado Junior, Irffi e Benegas(2011), Faria, Jannuzzi e } \\
\text { Silva (2008), Jubran (2006). }\end{array}$ \\
\hline $\begin{array}{l}\text { DEA } \\
\text { Multiestágio } \\
\text { (OLS, } \\
\text { Regressão } \\
\text { Canônica, } \\
\text { HLM, Tobit, } \\
\text { Truncada, com } \\
\text { ou sem } \\
\text { bootstrapping) }\end{array}$ & $\begin{array}{l}\text { Mayston and Jesson (1988), Ray (1991), McCarty and Yaisawarng (1993), Ruggiero (1996b), } \\
\text { Duncombe et al. (1997), Kirjavainen and Loikkanen (1998), McMillan and Datta (1998), Ruggiero } \\
\text { and Bretschneider (1998), Mancebón and Mar-Molinero (2000), Bradley et al. (2001) (2010), } \\
\text { Abbott and Doucouliagos (2002), Muñiz (2002), Cherchye and Vanden Abeele (2005), Ouellette } \\
\text { and Vierstraete (2005), Afonso and Aubyn (2006), Primont and Domazlicky (2006), Agasisti and } \\
\text { Salerno (2007), Anderson et al. (2007), Rassouli-Currier (2007), Waldo (2007b), Cordero-Ferrera et } \\
\text { al. (2008) (2010), Denaux (2009), Hu et al. (2009), Alexander et al. (2010), Houck et al. (2010), } \\
\text { Naper (2010), Agasisti (2011a) (2011b) (2013) (2014), Kounetas et al. (2011), Lee (2011), } \\
\text { Wolszczak-Derlacz and Parteka (2011), Johnes et al. (2012), Mancebón et al. (2012), Burney et al. } \\
\text { (2013), Duh et al. (2014). }\end{array}$ \\
\hline
\end{tabular}

Fonte: Adaptado de DE WITTE; LÓPEZ-TORRES (2015) e (SORIANO, 2017) 
Porém, a técnica DEA apresenta como restrição a incapacidade de distinguir a ineficiência atribuída às más práticas gerenciais daquelas decorrentes de diferenças socioeconômicas ou de outros fatores não controláveis pelos gestores (CARVALHO; SOUSA, 2014). Ainda, segundo Duarte (2013), o IDEB das escolas sofre efeito negativo considerável à medida que se incluem alunos em situação de pobreza.

Ainda, é apresentado como pré-suposto para a sua utilização a homogeneidade das DMUs, ou seja, as unidades devem realizar tarefas iguais, com objetivos similares, atuando nas mesmas condições de mercado, além de ter autonomia para a tomada de decisões (MEZA et al., 2005).

A preocupação com a seleção das DMUs e a garantia de sua homogeneidade é item essencial para que a escala de eficiência obtida reflita apenas as diferenças entre as práticas adotadas pelas escolas e não a interferência de fatores externos. Em sua dissertação, Ferreira (2015), comparou escolas eficientes e ineficientes para encontrar práticas que poderiam estar relacionadas ao desempenho dos alunos no IDEB. No entanto, não se discriminou no modelo o NSE das escolas e, como consequência, foram visitadas escolas de alto e baixo NSE, com infraestrutura e clientela heterogêneas, o que tornam questionáveis as análises acerca das práticas identificadas, uma vez que os resultados de desempenho do IDEB utilizados como output em seu modelo poderiam estar associados, em parte, às condições socioeconômicas dos alunos, uma vez que este fator tem influência direta no desempenho.

Assim, inicialmente as escolas são separadas de acordo com o Nível Socioeconômico - NSE de forma a permitir uma comparação mais justa entre elas (ANDRADE; SOARES, 2008), sendo utilizada para a geração do ranking apenas aquelas pertencentes às classes 5 e 6 de Alves, Soares e Xavier (2014), cuja justificativa para a escolha já foi abordada no item 3.2.1.

Outro importante aspecto na definição do modelo de eficiência e na escolha das variáveis segundo De Witte e López-Torres (2015), é que a maioria dos estudos sobre o tema ignora os resultados anteriores obtidos pelos alunos, e, como consequência não é possível estimar a eficiência de forma imparcial (DE WITTE; LÓPEZ-TORRES, 2015).

Para Soares et al. (2017), inclusão da proficiência prévia do aluno permite "medir o ganho de aprendizado atribuível ao trabalho da escola ao longo das etapas escolares". A adoção de um modelo comparativo que considere esta informação permite a formulação de um "Modelo de Valor Agregado", segundo os autores, fazendo com que os resultados comparativos encontrados estejam mais próximos da mensuração real das diferenças entres os processos realizados pelas unidades escolares 
Assim, o modelo de eficiência proposto neste trabalho se beneficia destas observações e tem como objetivo identificar as escolas que conseguiram agregar mais desempenho nos resultados de língua portuguesa na Prova Brasil ao mesmo grupo de estudantes. Para isto este trabalho toma como input a média por escola do desempenho dos estudantes em português na Prova Brasil, aplicada ao final do quinto ano (quarta série), e, como outputs o desempenho médio nesta avaliação ao final do nono ano (oitava série), bem como o indicador de rendimento de cada escola neste período, conforme QUADRO 10 e Figura 11.

\begin{tabular}{|l|l|l|c|}
\hline \multicolumn{1}{|c|}{ QUADRO 10 - VARIÁVEIS MODELO DEA } \\
\hline \multicolumn{1}{|c|}{ TIPO } & \multicolumn{1}{|c|}{ DARIÁVEL } & \multicolumn{1}{|c|}{ DESCRIÇÃO } & FONTE \\
\hline Input & $\begin{array}{l}\text { Nota de Português do } 5^{\circ} \text { ano }\left(4^{\mathrm{a}}\right. \\
\text { série })\end{array}$ & Média por escola na edição de 2011 \\
\hline Output & $\begin{array}{l}\text { Nota de Português do } 9^{\circ} \text { ano }\left(8^{\mathrm{a}}\right. \\
\text { série })\end{array}$ & Média por escola na edição de 2015 & Prova Brasil - INEP \\
\hline Output & $\begin{array}{l}\text { Indicador de Rendimento } \\
\text { Taxa de aprovação da etapa de ensino por } \\
\text { escola }\end{array}$ & IDEB - INEP \\
\hline
\end{tabular}

Fonte: Elaborado pelo autor.

O modelo proposto tem como premissa a necessidade de se avaliar o mesmo ciclo de alunos, conforme Figura 10, o que permite verificar a escola que mais agregou resultado. Para isto, somente escolas que oferecem os dois ciclos do ensino fundamental (fundamental I e fundamenta II) são selecionadas, uma vez que se supõe que, em sua maioria, os estudantes permanecem na mesma instituição durante todo o ensino fundamental.

Também colaboram para o modelo as taxas de aprovação dos estudantes. Segundo dados do Censo Escolar 2016 (com dados referentes ao ano de 2015), a taxa de aprovação no segundo ciclo do ensino fundamental foi de $85,7 \%$, o que garante a representatividade da amostra de estudantes nas unidades escolares avaliadas (INEP, 2017a).

FIGURA 10 - CICLO DE AVALIAÇÃo PROVA BRASIL - MODELO DE EFICIÊNCIA

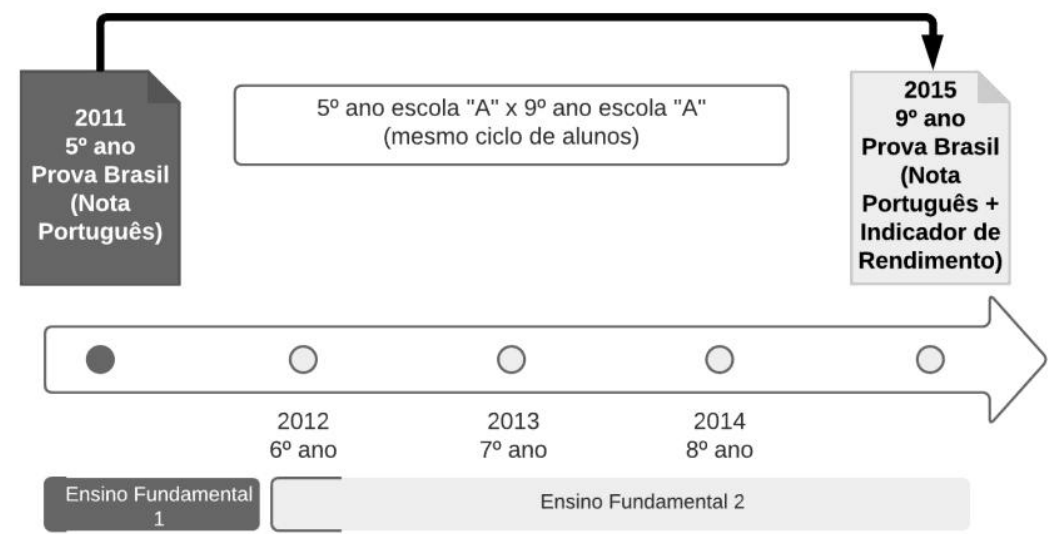

Fonte: Elaborado pelo autor 


\subsubsection{Definição do modelo DEA}

Definidas as variáveis, necessita-se definir a orientação (para redução de inputs ou incremento dos outputs) e o modelo a ser utilizado pela técnica DEA, para a obtenção do ranking de eficiência.

A sua obtenção pode ser efetuada numa perspectiva de minimização de
inputs, isto é, do coeficiente entre a quantidade observada de inputs
consumidos e a quantidade mínima de inputs para uma quantidade idêntica
de outputs produzida ou, numa lógica complementar, de maximização de
outputs, do coeficiente entre os outputs observados e os outputs máximos
possíveis para uma quantidade fixa de inputs utilizados. (MARQUES;
SILVA, 2006, p. 90)

Segundo Flach et al. (2017), a orientação a outputs é a mais adequada pois o objetivo do serviço público não é a redução dos insumos, mas sim, a melhor aplicação destes de forma a se obter resultados melhores para a sociedade (FLACH et al., 2017).

Em nosso estudo, uma vez que o objetivo é melhorar o desempenho do aluno na prova de saída do modelo (Prova Brasil da $8^{\mathrm{a}}$ série), e não reduzir a sua nota de entrada (Prova Brasil da $4^{\mathrm{a}}$ série) será utilizada a orientação output, com o modelo BCC com Bootstrap (Figura 11).

FIGURA 11 - MODELO DE EFICIÊNCIA

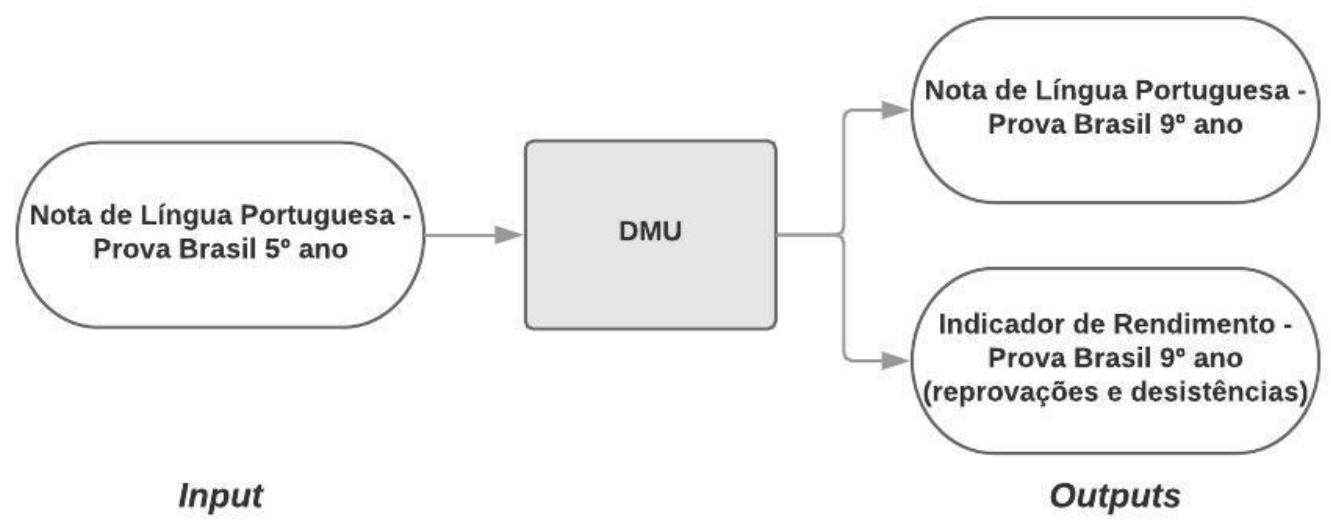

Fonte: Elaborado pelo autor.

Segundo Meza et al. (2005), dentre as várias formas da fronteira os dois modelos que são considerados clássicos são o CCR e o BCC. 
O modelo CCR, apresentado por Charnes, Cooper e Rhodes (1978), também conhecido como modelos Constant Returns to Scale (CRS), "considera retornos constantes de escala, isto é, qualquer variação nas entradas (inputs) produz variação proporcional nas saídas (outputs)" (MEZA et al., 2005, p. 2525).

Já o modelo BCC, assim denominado em razão do trabalho de Banker, Charnes e Cooper (1984), considera retornos variáveis de escala, sendo conhecido, também, como Variable Returns do Scale (VRS). Nesta abordagem, a DEA

[...] substitui o axioma da proporcionalidade entre inputs e outputs pelo axioma da convexidade. Ao obrigar que a fronteira seja convexa, o modelo BCC permite que DMUs que operam com baixos valores de inputs tenham retornos crescentes de escala e as que operam com altos valores tenham retornos decrescentes de escala" (MEZA et al., 2005, p. 2531).

Assim, segundo Marques e Silva (2006, p. 93), "no modelo CCR, a eficiência técnica obtida poderia dever-se à ineficiência técnica propriamente dita ou à operação a uma escala não ótima, não se distinguindo esse efeito”. Em contrapartida, o modelo BCC pode assegurar que as DMU só sejam comparadas com DMU de tamanho equivalente (MARQUES; SILVA, 2006).

Sobre a orientação da técnica DEA, a utilização do modelo BCC (Banker, Charnes e Cooper), com orientação a output, é considerada a mais adequada por dois fatores principais. O primeiro deles é pela impossibilidade de se estabelecer uma relação de proporcionalidade entre inputs e outputs [...] Desta forma, recomenda-se o modelo BCC [...]. O segundo fator, relacionado à orientação aos outputs, que consiste em encontrar a escola com maior capacidade de gerar melhores resultados nos testes padronizados, em avaliações de larga escala [...] (SALGADO JUNIOR; NOVI, 2015, p. 637)

Ainda, para Ramzi, Afonso e Ayadi (2016), o modelo BCC é mais adequado em relação ao CCR, por produzir DMUs mais eficiente. Para os autores, "este resultado pode ser explicado pelo fato de que a não assunção na restrição de convexidade amplia a região viável para o modelo CCR e reduz as DMUs eficientes em comparação com o modelo BCC" (RAMZI; AFONSO; AYADI, 2016, p.72, tradução nossa).

Sendo a DEA uma técnica não-paramétrica, ela não é passível de inferência estatística, apresentando grande dependência da qualidade da amostra e da especificação do modelo de eficiência adotado, sendo este um dos principais apontamentos dos críticos à técnica (BARRA; ZOTTI, 2016; MARQUES; SILVA, 2006).

Em razão disto, para este estudo, optou-se pela aplicação do DEA com boostrap, que fornece intervalos de confiança aos escores de eficiência e permite estimativas corrigidas de 
viés. Por meio dela "são obtidas estimativas corrigidas por polarização ajustadas, indicando a sensibilidade dos escores de eficiência em relação às variações de amostragem da fronteira estimada" (BARRA; ZOTTI, 2016, p. 13, tradução nossa). Este procedimento também foi utilizado por Gonçalves e França (2013) para a identificação de fatores que influenciam a eficiência da gestão educacional dos municípios brasileiros.

O bootstrap é uma maneira de aproximar assintoticamente a distribuição dos estimadores. A partir da técnica proposta, é possível se obter uma série de estimativas mais confiáveis para os índices de eficiência, assim como construir intervalos de confiança, impossíveis de serem obtidos sem a nova técnica (DELGADO; MACHADO, 2007, p. 435).

A aplicação da metodologia de bootsrap - introduzida por Bradley Efron em 1979 -, aos estimadores do DEA permite a inferência estatística por "avaliar a robustez das medidas de eficiência obtidas pela DEA às variações da amostra e das variáveis não observáveis" (MARQUES; SILVA, 2006, p. 104).

\subsubsection{Primeira etapa - quantitativa}

Nesta primeira etapa foram utilizadas técnicas estatísticas paramétricas e nãoparamétricas com o objetivo de se diferenciar as escolas de alto e baixo desempenho por meio da atribuição de um escore de eficiência para cada uma delas, de acordo com o objetivo da pesquisa, qual seja - proporcionar melhor desempenho em língua portuguesa aos alunos -, bem como identificar, por meio dos dados educacionais disponíveis, as variáveis associadas àquelas mais eficientes.

As respostas dos questionários da Prova Brasil e do Censo Escolar foram 'convertidos' em variáveis de forma que se chegou ao número de 1392 variáveis. Para cada alternativa de cada questão, foi-se nomeada uma variável. Por exemplo: no questionário da Prova Brasil preenchido pelos professores, a questão sobre a Idade apresentava as seguintes alternativas: a) até 24 anos; b) 25 a 29 anos; c) 30 a 39; d) 40 a 49; e) 50 a 54 e f) 55 anos ou mais. Esta questão deu, então, origem, a 06 variáveis, conforme QUADRO 11. 
QUADRO 11 - ORGANIZAÇÃO DAS VARIÁVEIS

\begin{tabular}{|c|c|c|c|}
\hline Questionário & Questão & Alternativas & Variável \\
\hline \multirow{6}{*}{$\begin{array}{l}\text { Prova Brasil / } \\
\text { Professor }\end{array}$} & \multirow{6}{*}{ Idade } & A) até 24 anos & PB_PROF_V01 \\
\hline & & B) 25 a 29 & PB_PROF_V02 \\
\hline & & C) 30 a 39 & PB_PROF_V03 \\
\hline & & D) 40 a 49 & PB_PROF_V04 \\
\hline & & E) 50 a 54 & PB_PROF_V05 \\
\hline & & F) 55 ou mais & PB_PROF_V06 \\
\hline
\end{tabular}

Fonte: Elaborado pelo autor.

\subsubsection{Análise de quintil}

Inicialmente foi realizado teste de normalidade (Kolmogorov-Smirnov) para cada uma das 1392 variáveis, para orientar a próxima etapa da análise - a análise de quintil. A partir destes resultados foi efetuado o cálculo das médias e/ou medianas destas variáveis, de forma a permitir a verificação das diferenças encontradas entre as escolas constantes dos quintis inferior e superior. Esta análise se deu pelo uso do teste de Mann-Whitney, que identificou a significância das diferenças entre os quintis inferior e superior.

A partir desta primeira análise, restaram, então, 554 variáveis com diferença significativa de média ou mediana entre os quintis. Sendo este um número ainda elevado, foi realizada nova análise por julgamento visando à redução. Inicialmente foram removidas aquelas que apareciam em duplicidade entre as bases, como, por exemplo, a idade e nível de escolaridade dos professores, presentes tanto na base do Censo quando da Prova Brasil. Também se verificou que um elevado número de variáveis com diferença significativa estava relacionado à mesma questão. Por exemplo, na questão sobre o tipo de instituição de ensino superior frequentado pelo professor, tanto as opções "pública” quanto "privada" apresentaram diferença significativa na análise. No entanto, sendo esta uma variável dicotômica, elas claramente oferecem a mesma resposta ao pesquisador, sendo possível, portanto, optar-se pela manutenção de uma única variável. Após esta última análise restou 162 variáveis, que foram utilizadas para as etapas seguintes. 


\subsubsection{Regressão linear múltipla}

Dada a quantidade de variáveis restante, fez-se necessária a utilização de uma técnica de análise multivariada de dados. "A análise multivariada refere-se a um conjunto de métodos estatísticos que torna possível a análise simultânea de medidas múltiplas para cada indivíduo, objeto ou fenômeno observado" (CORRAR; PAULO; DIAS FILHO, 2009, p. 02).

A escolha da técnica a ser utilizada leva em consideração os tipos de variáveis a serem analisadas, bom como a eventual relação de dependência entre elas (Figura 12), sendo este o principal elemento na estatística multivariada (CORRAR; PAULO; DIAS FILHO, 2009).

Entre as técnicas de análise multivariada, a Análise de Regressão "é a técnica de análise de dados mais amplamente aplicada para mensurar relações lineares entre duas ou mais variáveis" (HAIR JR et al., 2005, p. 341). A Regressão Linear Múltipla tem sido amplamente aplicada a pesquisas em educação (ALVES; SOARES, 2013; AMâNCIOVIEIRA et al., 2015; ANDRADE; SOARES, 2008), e permite identificar a existência de relação de dependência entre a variável dependente, ou seja, aquela a que se deseja explicar no caso deste estudo, o escore de eficiência de cada escola gerado pela técnica DEA -, e as independentes, ou seja, aquelas que podem estar relacionadas a este desempenho, neste trabalho aquelas disponíveis nas bases do Censo Escolar e da Prova Brasil (CORRAR; PAULO; DIAS FILHO, 2009, p. 132).

Equação da Regressão Linear Múltipla:

$Y=\beta_{0}+\beta_{1} x_{1}+\beta_{2} x_{2}+\ldots .+\beta_{n} x_{n}+\varepsilon$

Em que:

$\mathrm{Y}=$ variável dependente (escore DEA BCC);

$\beta_{0}=$ intercepto (valor de $Y$ quando $X=0$ );

$X_{1}, X_{2}, \ldots X_{n}=$ variáveis independentes (variáveis identificadas na análise de quintil);

$\beta_{1}, \beta_{2}, \ldots \beta_{\mathrm{n}}=$ parâmetros da regressão;

$\varepsilon=$ resíduo ou erro da regressão. 
FIGURA 12 - TÉCNICAS MULTIVARIADAS MAIS COMUNS

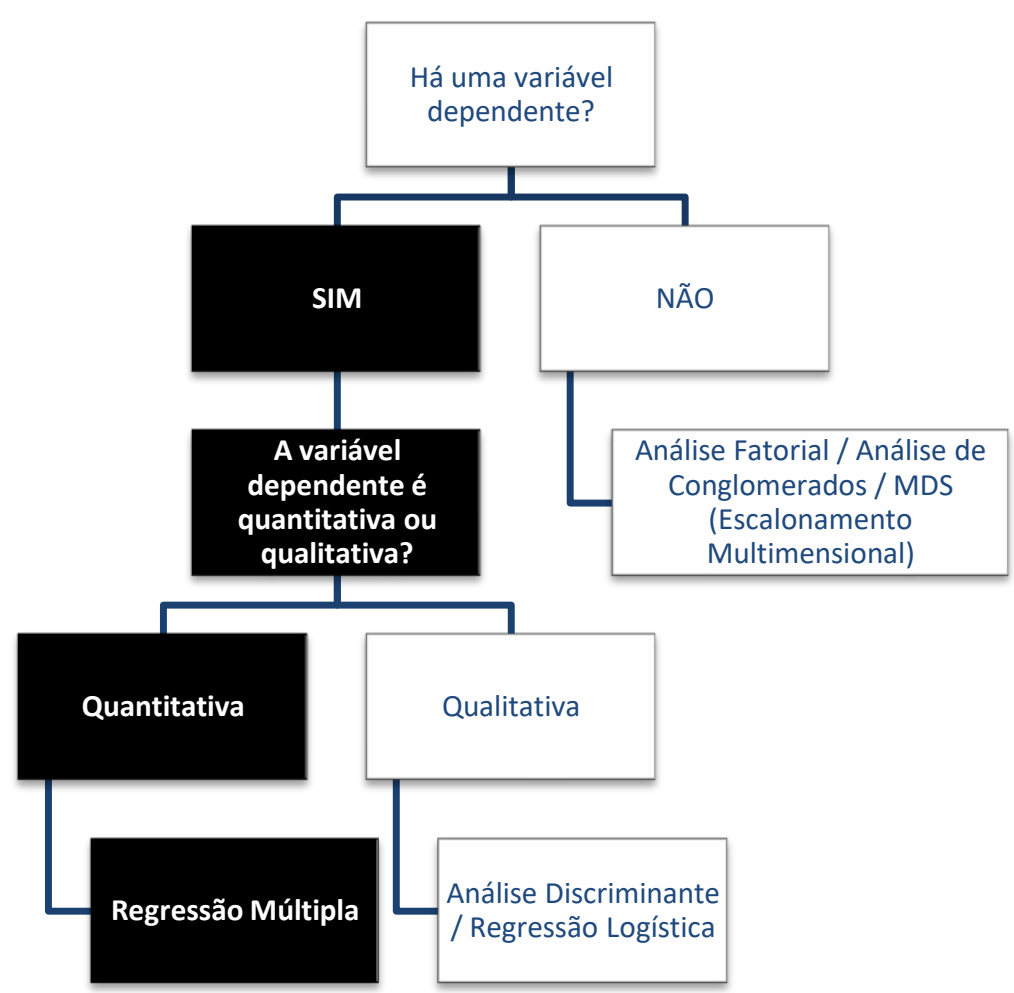

Fonte: Adaptado de Corrar, Paulo e Dias Filho (2009, p. 05).

Para o modelo regressão linear múltiplo adotado, foram utilizadas as variáveis identificadas na análise de quintil que, como já abordado, se apresentam em número elevado, e "a etapa de seleção de quais variáveis farão parte do modelo se constitui num ponto importante do processo de estimação do modelo" (CORRAR; PAULO; DIAS FILHO, 2009, p. 158).

O método utilizado foi o de busca sequencial. Segundo Corrar, Paulo e Dias Filho (2009, p. 160), "este método realiza uma estimação inicial com um conjunto de variáveis independentes e acrescentam ou eliminam variáveis até alcançarem a melhor medida dentro do critério utilizado". Optou-se pela estimação stepwise (também chamado de passo a passo), o mais comum entre os métodos de busca sequencial. Este método analisa a contribuição adicional proporcionada por cada nova variável independente incluída no modelo, conforme ilustrado na Figura 13. 
FIGURA 13 - ETAPAS DA ESTIMAÇÃO STEPWISE

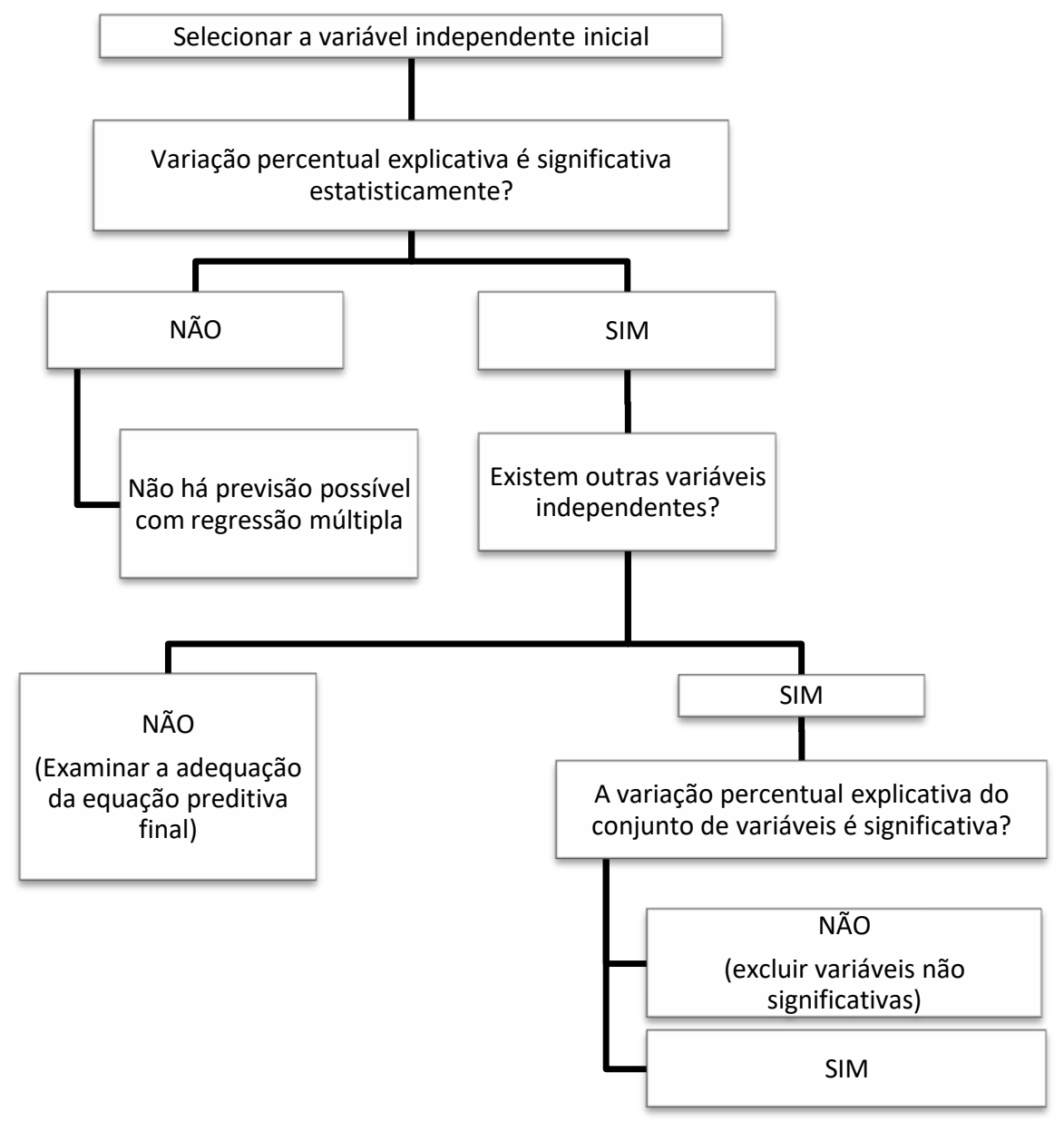

Fonte: Adaptado de Corrar, Paulo e Dias Filho (2009, p. 160)

Os resultados obtidos na análise de quintis e da Regressão Linear Múltipla foram utilizados para a elaboração dos roteiros de entrevista semiestruturados que servirão de base para a segunda etapa da pesquisa, a qualitativa. A Figura 14 sintetiza as fases da etapa quantitativa.

FIGURA 14 - FASES DA FASE QUANTITATIVA

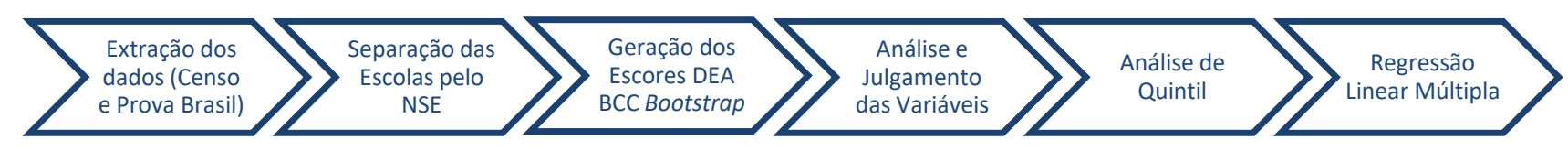

Fonte: Elaborado pelo autor. 


\subsubsection{Segunda etapa - qualitativa}

A etapa qualitativa consiste na realização de estudos de múltiplos casos visando à confirmação ou refutação dos achados na etapa quantitativa, bem como à identificação de fatores inicialmente não encontrados, uma vez que, "ao invés de ser limitada a variáveis particulares de interesse, [...] é mais holística e naturalista, examinando entidades sociais inteiras, como escolas ou comunidades em vários níveis e ao longo de muitas dimensões" (BRAY; ADAMSON; MASON, 2014, p. 75, tradução nossa). Para estes autores, a pesquisa qualitativa tem o importante papel de complementar a pesquisa quantitativa, uma vez que esta última, em geral, desconsidera os eventual vieses implícitos nas grandes bases de dados, uma vez que a educação não pode ser descontextualizada de sua cultura local, dos aspectos políticos e sociais.

O estudo de caso, por sua vez,

permite que os investigadores retenham as características holísticas e significativas dos eventos da vida real - como [...], o comportamento dos pequenos grupos, os processos organizacionais e administrativos, [...], o desempenho escolar" (YIN, 2010, p. 24).

Para Eisenhardt (1989, p. 532, tradução nossa), "o estudo de caso é uma estratégia de pesquisa que se concentra na compreensão da dinâmica presente em um único cenário", permitindo "explicar as variáveis causais de determinado fenômeno em situações muito complexas que não possibilitam a utilização de levantamentos e experimentos" (GIL, 1999, p.73), por exemplo, razão pela qual tem sido utilizado com frequência nas pesquisas sociais, assim como esta.

\subsubsection{Seleção dos casos para estudo}

Para esta etapa foi realizado novo corte na base, optando-se pela realização dos estudos de caso da etapa qualitativa em um único estado. Desta forma, buscou-se garantir maior homogeneidade entre as DMUs a serem comparadas uma vez que, além de compartilharem dos mesmos NSEs, também estavam inseridas em realidades regionais um pouco mais próximas. É sabido que no Brasil, dadas as suas dimensões, as diferenças 
culturais, geográficas e econômicas entre os estados variam consideravelmente e que, mesmo dentre de uma mesma classificação de NSE, uma escola de nível 5 ou 6 em estados da região norte, por exemplo, podem sofrer interferências de fatores externos diferentes daqueles da região Sul e Sudeste. Assim, este novo recorte, realizado por julgamento e conveniência, selecionou apenas as escolas do estado de São Paulo. A escolha por São Paulo considerou, inicialmente, o fato de que se concentra neste estado o maior volume de escolas nos níveis socioeconômicos estudados (5 e 6), conforme Gráfico 16. Complementarmente, esta opção também se mostrou a mais conveniente em razão da proximidade e da necessidade de deslocamento às localidades para a realização dos estudos de caso.

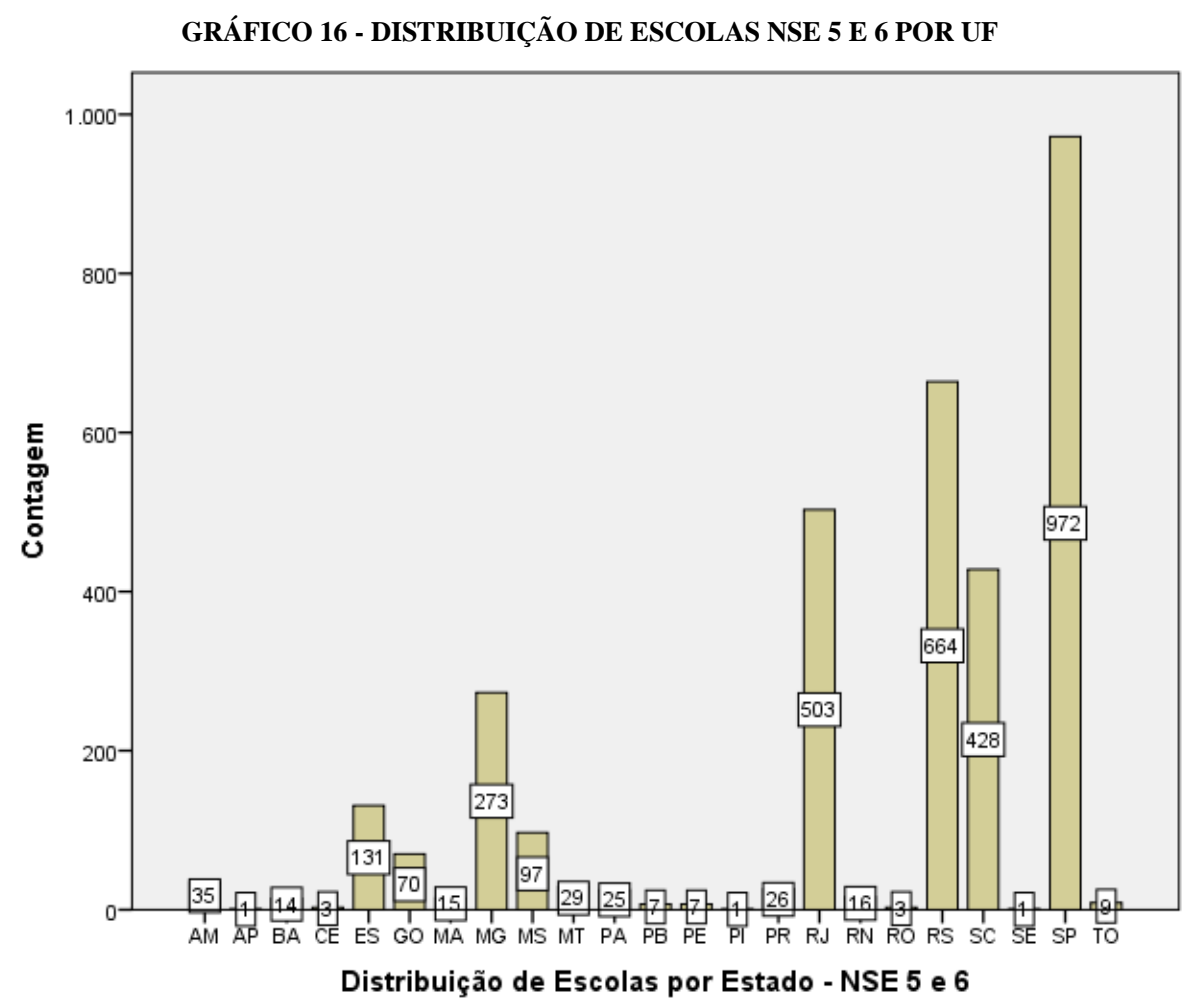

Fonte: Elaborado pelo autor.

Dentre estas escolas foram escolhidas duas classificadas como de alto desempenho e duas classificadas como de baixo desempenho, selecionadas a partir do ranking DEA para a realização do estudo de múltiplos casos. Esta lógica de seleção dos estudos de caso polares alto $\mathrm{x}$ baixo desempenho - permite estabelecer as teorias de sucesso e insucesso (EISENHARDT, 1989), objetivo buscado neste trabalho. É importante destacar que a classificação como alto ou baixo desempenho não está relacionada apenas à nota média obtida pela escola na Prova Brasil. Esta classificação refere-se à sua capacidade de agregar 
conhecimento e desempenho aos estudantes, considerando-se sua nota de entrada ( $4^{\mathrm{a}}$ série $/ 5^{\circ}$ ano) e sua nota de saída ( $8^{\mathrm{a}}$ série $/ 9^{\circ}$ ano), controlados pelo indicador de rendimento. Assim, é possível, portanto, a classificação de escolas com notas mais altas na $8^{\text {a }}$ série como de baixo desempenho, por terem agregado proporcionalmente pouco desempenho aos estudantes em relação à sua nota média na $4^{\mathrm{a}}$ série, e escolas com notas baixas como de alto desempenho, por conseguirem aumentos relativamente maiores nas notas médias dos estudantes.

Identificadas as escolas a serem utilizadas para esta etapa, procedeu-se à verificação da recondução da equipe gestora da SME, uma vez que o objetivo é compreender as práticas aplicadas durante o período de 2011 a 2015 e, posteriormente, ao contato telefônico junto às respectivas Secretarias Municipais de Educação de cada município, visando-se à solicitação de autorização para a realização das visitas in loco. Depois de esclarecidos os objetivos da pesquisa e as ações a serem realizadas, a saber, as entrevistas e a observação em campo, as autorizações foram concedidas por meio de ofício modelo a elas encaminhadas. Os ofícios com as respectivas autorizações encontram-se nos Anexos E, F, G e H.

Para garantia do sigilo das informações, as escolas de alto desempenho serão chamadas de Escola A e Escola B, e as de baixo desempenho serão chamadas de Escola C e Escola D. Os dados das escolas são apresentado na Tabela 3.

TABELA 3 - ESTUDOS DE CASO

\begin{tabular}{|c|c|c|c|c|c|c|}
\hline 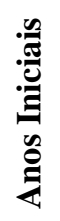 & 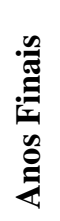 & 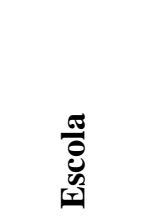 & 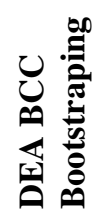 & 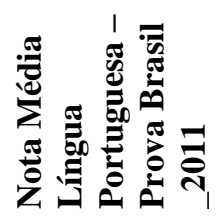 & 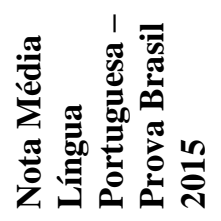 & 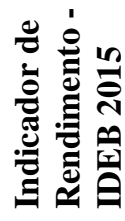 \\
\hline $\mathrm{X}$ & $X$ & Escola A & 100 & 207,51 & 246,28 & 1 \\
\hline $\mathrm{X}$ & $X$ & Escola B & 99,01 & 227,53 & 285,98 & 0,99 \\
\hline $\mathrm{X}$ & $X$ & Escola C & 82,53 & 184,76 & 225,13 & 0,82 \\
\hline $\mathrm{X}$ & $\mathrm{X}$ & Escola D & 85,00 & 185,80 & 235,14 & 0,84 \\
\hline
\end{tabular}

Fonte: Elaborado pelo autor.

\subsubsection{Protocolo de pesquisa}

A elaboração de um protocolo de pesquisa é importante para se garantir a confiabilidade do estudo de caso e auxilia o pesquisador na sua condução. O protocolo 
contém, além do instrumento de pesquisa, as regras a serem seguidas ao utilizá-lo, sendo essencial para os projetos que envolvem estudos de múltiplos casos (YIN, 2001, p. 89).

O protocolo ainda auxilia na manutenção do foco da pesquisa. Em pesquisas qualitativas, que envolvam entrevistas de campo e observações, é possível que o pesquisador perca seu foco e fique sobrecarregado de dados, muitas vezes desnecessários à pesquisa (EISENHARDT, 1989). Assim, esta seção apresentará os procedimentos adotados para a etapa qualitativa.

\subsection{Proposições de estudo}

A definição inicial das proposições ajuda a organizar o estudo de caso, colocando o foco nos dados chave e na definição de explanações alternativas (YIN, 2001, p. 133). Ainda, segundo Yin (2001, p. 42), “cada proposição destina atenção a alguma coisa que deveria ser examinada dentro do escopo do estudo".

Desta forma, a partir da análise dos resultados da etapa quantitativa e da revisão da literatura, procedeu-se ao estabelecimento das proposições que serão abordadas nos estudos de caso, conforme QUADRO 12.

QUADRO 12 - PROPOSIÇÕES PARA O ESTUDO DE CASO

\begin{tabular}{|llll|}
\hline Questão de Estudo & Proposições & $\begin{array}{c}\text { Result. } \\
\text { Quant. }\end{array}$ & Literatura \\
\hline Quais práticas & A infraestrutura da escola (salas de aula, & (CARVALHO; & SOUSA, \\
administrativo- & recursos para alunos PNE, biblioteca, & 2014; DE WITTE; LÓPEZ- \\
pedagógicas podem & laboratório de informática, disponibilidade de & TORRES, \\
colaborar para a & internet, instalações administrativas, & DELGADO; MACHADO, \\
melhoria do & equipamentos multimídia, máquina de & $\sqrt{ }$ & 2007) \\
desempenho em & fotocópia, professores e funcionários & \\
Língua Portuguesa & administrativos, etc) pode influenciar nos & \\
de alunos de escolas & resultados. & \\
\cline { 2 - 3 } & Oferta de merenda de qualidade em quantidade & & \\
munsino fundamental & adequada e infraestrutura adequada para sua & $\sqrt{ }$ & SALGADO \\
II? & preparação. & JUNIOR; \\
\hline
\end{tabular}


continuação

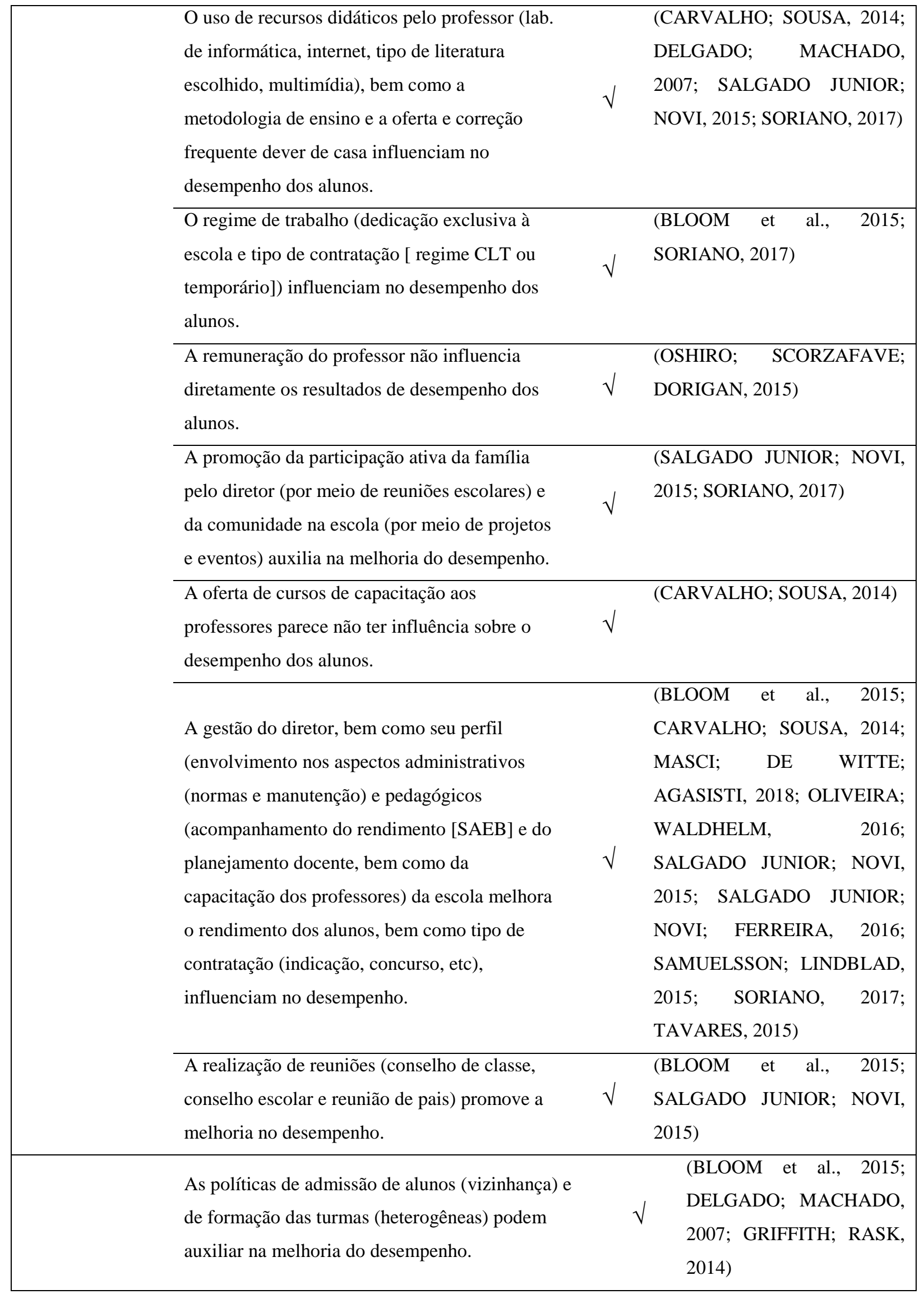


continuação

\begin{tabular}{|c|c|c|}
\hline $\begin{array}{l}\text { Ações de combate à evasão (acompanhamento de } \\
\text { frequência) e repetência (reforço no contra turno) } \\
\text { melhoram os resultados dos alunos. }\end{array}$ & $\sqrt{ }$ & $\begin{array}{l}\text { (SALGADO JUNIOR; NOVI, } \\
\text { 2015) }\end{array}$ \\
\hline $\begin{array}{l}\text { A disponibilização de biblioteca com infraestrutura } \\
\text { e acervos em boas condições e de fácil acesso aos } \\
\text { alunos e à comunidade influenciam positivamente } \\
\text { os resultados. }\end{array}$ & $\sqrt{ }$ & $\begin{array}{l}\text { (SALGADO JUNIOR; NOVI, } \\
2015 \text { ) }\end{array}$ \\
\hline $\begin{array}{l}\text { O perfil social do aluno (escolaridade dos pais, } \\
\text { interesse pela leitura e participação na vida escolar), } \\
\text { bem como a disponibilidade de computadores em } \\
\text { casa tem influência direta sobre o seu desempenho. }\end{array}$ & $\sqrt{ }$ & $\begin{array}{l}\text { (APARICIO et al., } 2017 \text {; } \\
\text { DELGADO; } \text { MACHADO, } \\
\text { 2007; MATOS et al., 2017) }\end{array}$ \\
\hline $\begin{array}{l}\text { Os hábitos de estudo (realização das tarefas de casa, } \\
\text { gostar da disciplina de língua portuguesa) e de } \\
\text { leitura dos alunos (frequência de leitura, utilização } \\
\text { da biblioteca, tipo de leitura) influenciam no } \\
\text { rendimento. }\end{array}$ & $\sqrt{ }$ & $\begin{array}{l}\text { (DEUTSCH; } r \text { DUMAS; } \\
\text { SILBER, 2013; SORIANO, } \\
2017 ; \quad \text { THANASSOULIS; } \\
\text { PORTELA, 2010) }\end{array}$ \\
\hline $\begin{array}{l}\text { Altas taxas de absenteísmo, evasão e retenção e } \\
\text { problemas de indisciplina colaboram para o baixo } \\
\text { desempenho da escola. }\end{array}$ & $\sqrt{ }$ & $\begin{array}{l}\text { (HOROI; OST, } 2015 ; \\
\text { SALGADO JUNIOR; NOVI, } \\
\text { 2015; SORIANO, 2017) }\end{array}$ \\
\hline
\end{tabular}

Fonte: Elaborado pelo autor.

\subsection{Procedimentos de campo}

As entrevistas, realizadas pessoalmente e conduzidas pelos roteiros semiestruturados, elaborados a partir dos dados identificados na etapa quantitativa, são realizadas com os informantes chave - diretores, professores e secretários municipais de educação - das escolas selecionadas, conforme Figura 15, mediante agendamento prévio junto à Secretaria Municipal de Educação a que a escola está subordinada. Para a garantia da veracidade das informações e para que seja possível a posterior triangulação dos dados, cada entrevista é realizada de forma independente, em locais e horários diferentes ao longo do período da visita in loco. Os informantes não têm acesso prévio ao roteiro de entrevistas, de forma a garantir a espontaneidade das respostas. O Secretário de Educação deve ser entrevistado em ambiente externo ao da escola, e o diretor, coordenador e professores, no ambiente escolar, mas de forma isolada. Os resultados das entrevistas são transcritos nos respectivos formulários e 
gravados, com anuência dos entrevistados, para garantia da credibilidade dos dados e análise posterior.

\section{FIGURA 15 - ESTUDOS DE CASO - INFORMANTES CHAVE}

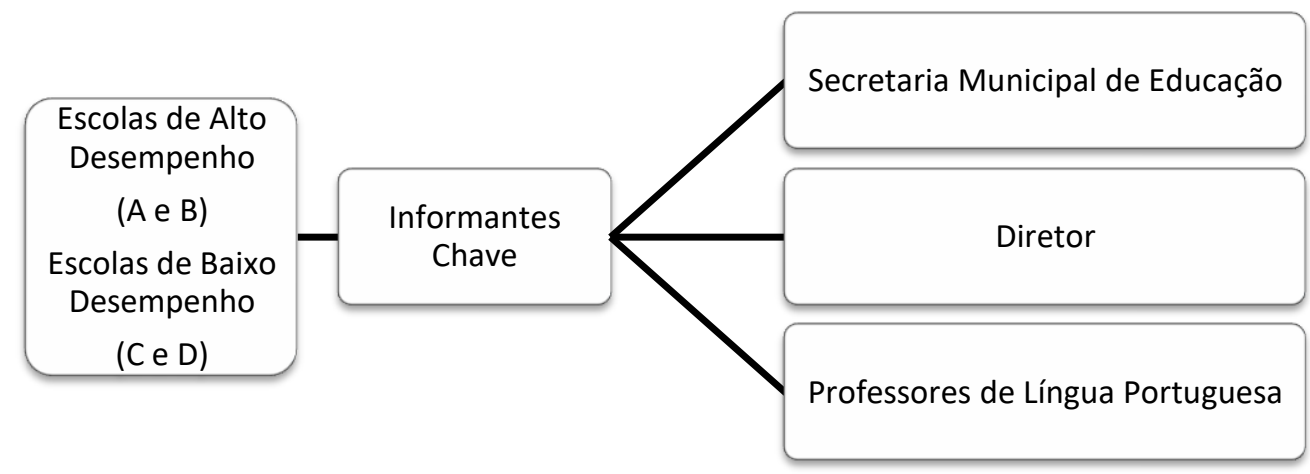

Fonte: Elaborado pelo autor.

Complementarmente, realizar-se-á a análise de arquivos escolares, conforme disponibilidade e autorização, e a observação direta do ambiente escolar, conforme QUADRO 13, que fornecem dados relevantes uma vez que os estudos de caso se utilizam da combinação de métodos de coleta de dados como arquivos, entrevistas, questionários e observações (EISENHARDT, 1989). Este tipo de observação colabora para a qualidade do estudo de caso, sendo "um ponto forte muito importante da coleta de dados" e "a oportunidade de utilizar muitas fontes diferentes para a obtenção de evidências" (YIN, 2001, p. 120).

\section{QUADRO 13 - COLETA DE DADOS}

\begin{tabular}{|c|c|c|}
\hline Entrevistas & Documentos Pretendidos & Observação \\
\hline $\begin{array}{l}\text { - Secretário(a) Municipal } \\
\text { de Educação }\end{array}$ & $\begin{array}{l}\text { - } \text { Organograma setorial } \\
\text { - } \quad \text { Procedimentos diversos }\end{array}$ & $\begin{array}{l}\text { - Estrutura da Secretaria de Educação } \\
\text { - Estrutura de Pessoal }\end{array}$ \\
\hline - Diretor(a) Escolar & $\begin{array}{l}\text { - Cronogramas de Reuniões (conselho de } \\
\text { classe, conselho escolar, reuniões de pais, } \\
\text { etc) } \\
\text { - Atas de registros de reuniões } \\
\text { - Registros de leitura de livros da biblioteca }\end{array}$ & $\begin{array}{l}\text { - Observação da estrutura da escola } \\
\text { quanto a: biblioteca; refeitório; } \\
\text { cozinha; salas de recursos; } \\
\text { laboratórios de informática; internet; } \\
\text { dependências administrativas }\end{array}$ \\
\hline $\begin{array}{l}\text { Professores(as) de } \\
\text { Língua Portuguesa }\end{array}$ & $\begin{array}{ll}\text { - } & \text { Registros de aulas } \\
\text { - } & \text { Materiais didáticos utilizados }\end{array}$ & $\begin{array}{l}\text { - } \text { Estrutura das salas de aula } \\
\text { - Disponibilidade dos livros aos } \\
\text { alunos } \\
\text { - Observação de aulas. }\end{array}$ \\
\hline
\end{tabular}

Fonte: Elaborado pelo autor. 
Sobre os resultados das entrevistas são gerados relatórios individuais para cada uma das escolas com a transcrição precisa das informações coletadas, de forma a permitir as análises individuais e a posterior verificação das frequências das práticas identificadas nestas escolas. Na sequência os dados são agregados e organizados para permitir a análise contextual e a comparação e identificação de frequência e padrões entre os grupos - alto x baixo desempenho. Estes resultados são ainda comparados com os obtidos na etapa quantitativa, permitindo, assim, a triangulação dos dados para a confirmação ou refutação das proposições identificadas na etapa quantitativa. "A triangulação é tornada possível por múltiplos métodos de coleta de dados e fornece uma base mais sólida de construções e hipóteses" (EISENHARDT, 1989, p. 536, tradução nossa).

\subsection{Elaboração do instrumento e dos roteiros de entrevista}

Ao se elaborar o instrumento de pesquisa e os roteiros de entrevista para trabalhos qualitativos, deve-se ter em mente os objetivos principais da pesquisa para que se oriente o pesquisador em campo, de tal forma que este não os perca de vista, deixando de coletar dados essenciais e/ou coletando um volume excessivo de dados não necessários, sobrecarregando-o na etapa de análise (EISENHARDT, 1989).

Em sua tese de doutorado, Soriano (2017) procurou identificar, utilizando-se de metodologia similar à aplicada neste trabalho, as práticas administrativas e pedagógicas utilizadas por escolas de NSE 3 e 4 localizadas no estado do Ceará, que contribuíam para o melhor desempenho geral destas no IDEB. Para isso, o pesquisador desenvolveu modelos de roteiros de entrevista semiestruturados para a condução de suas entrevistas junto às secretarias de educação, professores de Língua Portuguesa e Matemática, bem como com diretores e coordenadores pedagógicos.

Neste trabalho, o instrumento de pesquisa, bem como os roteiros de entrevista semiestruturados propostos por Soriano (2017) foram utilizados como base para o desenvolvimento dos instrumentos de estudo de caso. A opção pelo uso deste instrumento se deu em razão de sua utilização em pesquisas anteriores, que permitiram verificar sua aplicabilidade. Cabe ressaltar que o instrumento proposto por Soriano (2017), se trata de uma adaptação dos instrumentos por Salgado Junior e Novi (2014) e Ferreira (2015), o que lhe confere maior grau de refinamento. $\mathrm{O}$ instrumento original foi alterado visando-se sua adequação aos achados nesta pesquisa durante a fase quantitativa, por meio dos resultados da análise de quintil e da regressão, e considerando-se o seu foco exclusivo na disciplina de 
Língua Portuguesa. Também foi realizada ampla discussão junto aos membros do GREFIC, bem como o levantamento de questões relevantes junto à literatura sobre o tema, identificados durante a etapa de revisão bibliográfica (Figura 16). A partir deste processo foram elaborados o Instrumento de Pesquisa (Apêndice A) e os roteiros semiestruturados para a entrevista de professores (Apêndice B), diretor (Apêndice C) e secretário de educação (Apêndice D).

FIGURA 16 - PROCESSO DE ELABORAÇÃO DOS ROTEIROS DE ENTREVISTA

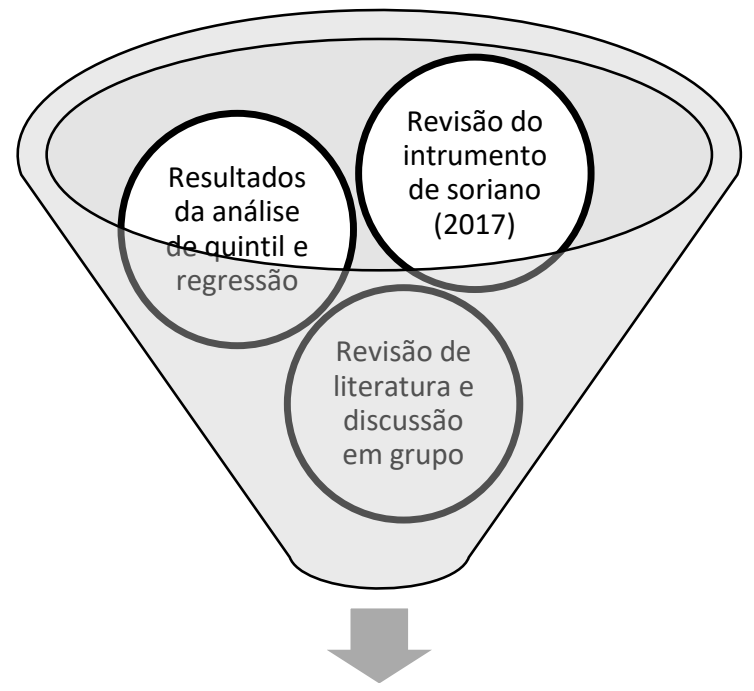

Instrumento de pesquisa e roteiros de entrevista e observação

Fonte: Elaborado pelo autor. 
QUADRO 14 - RESUMO DO PROTOCOLO DE ESTUDO DE CASO

\begin{tabular}{|l|l|}
\hline Questão de Pesquisa & $\begin{array}{l}\text { Quais práticas administrativo-pedagógicas podem colaborar } \\
\text { para a melhoria do desempenho de leitura escrita de alunos } \\
\text { de escolas municipais do ensino fundamental II? }\end{array}$ \\
\hline Unidade de Análise & $\begin{array}{l}\text { Frequência de práticas administrativas e pedagógicas adotadas por } \\
\text { escolas municipais, de NSE 5 e 6 do estado de São Paulo, } \\
\text { eficientes em melhorar o desempenho dos alunos de ensino } \\
\text { fundamental II em exames padronizados de Língua Portuguesa. }\end{array}$ \\
\hline Estudos de Caso & $\begin{array}{l}\text { Escolas municipais de ensino fundamental (com oferta dos anos } \\
\text { iniciais e anos finais desta etapa) do estado de São Paulo, dos NSE } \\
5 \text { e 6, sendo duas de alto desempenho e duas de baixo } \\
\text { desempenho, assim classificadas por meio da técnica DEA BCC } \\
\text { com Bootstraping, considerando-se como input a Média da Nota } \\
\text { de Língua Portuguesa na Prova Brasil de 2011 e como outputs a } \\
\text { Média da Nota de Língua Portuguesa na Prova Brasil de 2015 e o } \\
\text { Indicador de Rendimento do IDEB 2015. }\end{array}$ \\
\hline Métodos de Coleta de \\
Dados
\end{tabular}

Fonte: Adaptado de Jabbour et al. (2015). 


\subsection{Resumo metodológico}

A Figura 17 sintetiza os procedimentos metodológicos adotados nesta pesquisa.

FIGURA 17 - QUADRO METODOLÓGICO

\begin{tabular}{|c|c|c|c|c|}
\hline $\begin{array}{c}\text { Pergunta de } \\
\text { Pesquisa }\end{array}$ & Objetivo Geral & Objetivos Específicos & $\begin{array}{c}\text { Métodos de } \\
\text { Coleta }\end{array}$ & $\begin{array}{c}\text { Métodos de } \\
\text { Análise de Dados }\end{array}$ \\
\hline \multirow{5}{*}{$\begin{array}{l}\text { Quais práticas } \\
\text { administrativo- } \\
\text { pedagógicas } \\
\text { podem } \\
\text { colaborar para } \\
\text { a melhoria do } \\
\text { desempenho } \\
\text { em Língua } \\
\text { Portuguesa de } \\
\text { alunos de } \\
\text { escolas } \\
\text { municipais do } \\
\text { ensino } \\
\text { fundamental } \\
\text { II? }\end{array}$} & \multirow{5}{*}{$\begin{array}{l}\text { Identificar práticas } \\
\text { administrativas e } \\
\text { pedagógicas que } \\
\text { colaborem para a } \\
\text { melhoria do } \\
\text { desempenho dos } \\
\text { alunos de escolas } \\
\text { de ensino } \\
\text { fundamental II em } \\
\text { avaliações } \\
\text { padronizadas de } \\
\text { língua portuguesa }\end{array}$} & $\begin{array}{l}\text { Compreender o conceito } \\
\text { de eficiência em } \\
\text { educação; }\end{array}$ & $\begin{array}{l}\text { Revisão da } \\
\text { Literatura }\end{array}$ & - \\
\hline & & $\begin{array}{l}\text { Identificar os fatores } \\
\text { internos e externos às } \\
\text { escolas que influenciam } \\
\text { no desempenho escolar; }\end{array}$ & $\begin{array}{l}\text { Dados } \\
\text { Secundários da } \\
\text { Prova Brasil e } \\
\text { (2015) Censo } \\
\text { Escolar (2013) }\end{array}$ & $\begin{array}{l}\text { Regressão Linear } \\
\text { Múltipla }\end{array}$ \\
\hline & & $\begin{array}{l}\text { Identificar o nível de } \\
\text { eficiência das escolas de } \\
\text { ensino fundamental II } \\
\text { em agregar desempenho } \\
\text { aos estudantes em } \\
\text { avaliações padronizadas } \\
\text { de língua portuguesa; }\end{array}$ & $\begin{array}{l}\text { Dados } \\
\text { Secundários da } \\
\text { Prova Brasil } \\
2011 \text { e } 2015\end{array}$ & $\begin{array}{c}\text { Análise } \\
\text { Envoltória de } \\
\text { Dados - DEA }\end{array}$ \\
\hline & & $\begin{array}{l}\text { Compreender como as } \\
\text { práticas administrativas } \\
\text { e pedagógicas adotadas } \\
\text { pelas escolas de alto } \\
\text { desempenho colaboram } \\
\text { para o seu resultado. }\end{array}$ & $\begin{array}{c}\text { Estudo de } \\
\text { múltiplos casos: } \\
\text { Entrevista com } \\
\text { Roteiro } \\
\text { Semiestruturado }\end{array}$ & $\begin{array}{l}\text { Estatística } \\
\text { Descritiva }\end{array}$ \\
\hline & & & $\begin{array}{l}\text { Observação } \\
\text { Análise de } \\
\text { Documentos }\end{array}$ & $\begin{array}{l}\text { Análise de } \\
\text { conteúdo }\end{array}$ \\
\hline
\end{tabular}

Fonte: Elaborado pelo autor.

Na seção a seguir são apresentados os resultados. 


\section{RESULTADOS}

Nesta seção serão apresentados os resultados obtidos na etapa quantitativa e que serviram de base para a etapa qualitativa.

\subsection{Resultado da etapa quantitativa}

Neste item serão apresentadas as estatísticas descritivas obtidas na etapa quantitativa a partir da amostra adotada, a saber, 3.330 escolas pertencentes aos NSEs 5 e 6, presentes em 685 municípios brasileiros.

\subsubsection{Resultados do ranking DEA}

A seleção das técnicas estatísticas a serem utilizadas está ligada ao tipo de distribuição dos dados. Inicialmente apresentamos a análise dos escores DEA BCC para verificar se estes apresentam distribuição normal.

O teste de normalidade pode ser realizado pela análise gráfica de um histograma, sendo esta a forma mais simples, ou por testes de normalidade específicos, como, por exemplo, o teste Kolmogorov-Smirnov com correção de significância de Lilliefors (CORRAR; PAULO; DIAS FILHO, 2009).

A análise visual do Gráfico 17 parece indicar que o escore DEA BCC não apresenta distribuição normal, o que pode ser confirmado pelo teste estatístico Kolmogorov-Smirnov, conforme Tabela 4, uma vez que a sua Sig foi de 0,000 ( $\mathrm{Sig}<0,05)$. 
GRÁFICO 17 - HISTOGRAMA DEA BCC - ESCOLAS DE NSE 5 E 6 - BRASIL

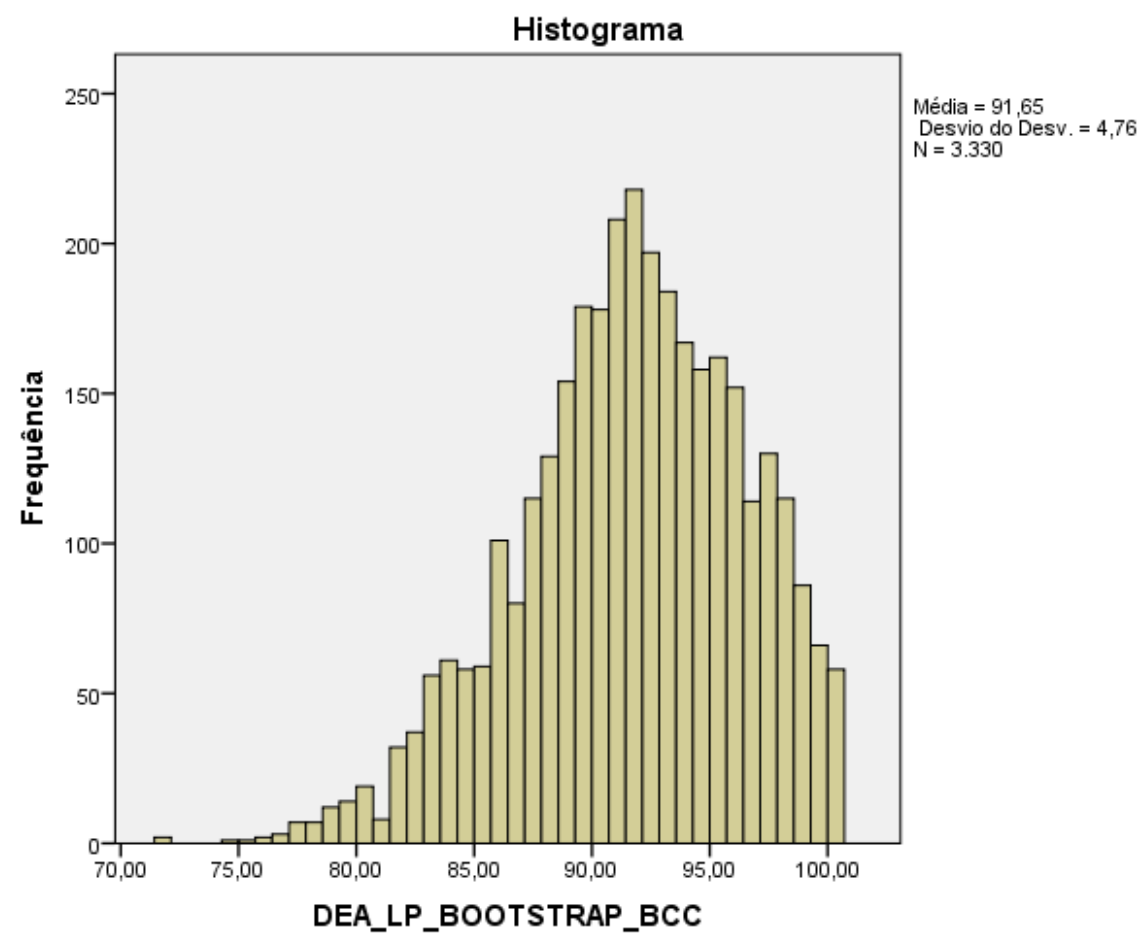

Fonte: Elaborado pelo autor.

TABELA 4 - TESTE DE NORMALIDADE - RANKING DEA BCC - NSE 5 E 6 - BRASIL

Testes de Normalidade

\begin{tabular}{|l|r|r|r|}
\hline \multirow{2}{*}{} & \multicolumn{4}{|c|}{ Kolmogorov-Smirnov $^{\mathrm{a}}$} \\
\cline { 2 - 4 } & Estatística & \multicolumn{1}{c|}{$\mathrm{df}$} & \multicolumn{1}{c|}{ Sig. } \\
\hline DEA_LP_BOOTSTRAP_BCC &, 040 & 3330 &, 000 \\
\hline
\end{tabular}

a. Correlação de Significância de Lilliefors

Fonte: Elaborado pelo autor.

A seguir é apresentada a estatística descritiva para os quintis com escore DEA, desempenho em Português na Prova Brasil, edições 2011 e 2015 e Indicador de Rendimento 2015 (Tabela 5).

TABELA 5 - ESTATÍSTICA DESCRITIVA PARA O ESCORE DEA

\begin{tabular}{|c|c|c|c|c|c|c|c|c|}
\hline & \multicolumn{4}{|c|}{ Média da Escola em Língua Portuguesa } & \multirow{2}{*}{\multicolumn{2}{|c|}{$\begin{array}{c}\text { Indicador de } \\
\text { Performance } 2015\end{array}$}} & \multirow{2}{*}{\multicolumn{2}{|c|}{ Escore DEA }} \\
\hline & \multicolumn{2}{|c|}{2011} & \multicolumn{2}{|c|}{2015} & & & & \\
\hline & Q1 & Q5 & Q1 & Q5 & Q1 & Q5 & Q1 & Q5 \\
\hline Minimo & 152,74 & 155,22 & 205,13 & 176,83 & 0,62 & 0,50 & 95,96 & 71,62 \\
\hline Média & 202,12 & 192,20 & 265,42 & 240,67 & 0,96 & 0,78 & 97,91 & 84,54 \\
\hline Máximo & 258,38 & 236,70 & 315,79 & 271,59 & 1,00 & 0,88 & 100,00 & 87,75 \\
\hline Desvio Padrão & 19,16 & 13,47 & 18,72 & 12,98 & 0,05 & 0,07 & 1,24 & 2,66 \\
\hline
\end{tabular}

Fonte: Elaborado pelo autor. 
A Tabela 6 apresenta a estatística descritiva para os estados. É possível verificar que São Paulo possui a maior quantidade de escolas no quintil superior dentre todos os estados, 260 escolas, além de possuir a maior concentração relativa de escolas nesta condição $38,98 \%$. Ainda é possível observar que o estado ocupa a terceira posição quando considerada a relação de diferença entre o Escore DEA máximo (100) e o mínimo $(77,5)$, ficando, neste quesito, atrás dos estados do Rio Grande do Sul, com 100 e 71,62, e do Rio de Janeiro, com 100 e 72,06 , respectivamente.

TABELA 6 - ESTATÍSTICA DESCRITIVA - ANÁLISE DOS ESCORES DEA POR ESTADO (UF)

\begin{tabular}{|c|c|c|c|c|c|c|c|c|c|}
\hline UF & $\begin{array}{c}\text { Número } \\
\text { de } \\
\text { Escolas }\end{array}$ & $\begin{array}{c}\% \text { de } \\
\text { Escolas }\end{array}$ & $\begin{array}{l}\text { Número } \\
\text { de } \\
\text { Escolas } \\
\text { Quintil } \\
\text { Superior }\end{array}$ & $\begin{array}{c}\% \text { de } \\
\text { Escolas } \\
\text { Quintil } \\
\text { Superior }\end{array}$ & $\begin{array}{c}\text { Mediana } \\
\text { do Escore } \\
\text { das } \\
\text { Escolas }\end{array}$ & $\begin{array}{c}\text { Média do } \\
\text { Escore } \\
\text { das } \\
\text { Escolas }\end{array}$ & $\begin{array}{l}\text { Escore } \\
\text { Mínimo } \\
\text { das } \\
\text { Escolas }\end{array}$ & $\begin{array}{c}\text { Escore } \\
\text { Máximo } \\
\text { das } \\
\text { Escolas }\end{array}$ & $\begin{array}{c}\text { Desvio } \\
\text { Padrão } \\
\text { dos } \\
\text { Escores } \\
\text { das } \\
\text { Escolas }\end{array}$ \\
\hline SP & 972 & 29,19 & 260 & 38,98 & 93,19 & 93,07 & 77,5 & 100 & 3,94 \\
\hline $\mathrm{SC}$ & 428 & 12,85 & 134 & 20,09 & 94,32 & 93,72 & 81,24 & 100 & 4,02 \\
\hline $\mathrm{RS}$ & 664 & 19,94 & 77 & 11,54 & 90,61 & 90,33 & 71,62 & 100 & 4,65 \\
\hline MG & 273 & 8,20 & 51 & 7,65 & 92,66 & 92,46 & 79,47 & 100 & 3,96 \\
\hline MS & 97 & 2,91 & 33 & 4,95 & 93,28 & 93,57 & 83,91 & 100 & 3,70 \\
\hline $\mathrm{RJ}$ & 503 & 15,11 & 32 & 4,80 & 88,40 & 88,11 & 72,06 & 100 & 4,95 \\
\hline MT & 29 & 0,87 & 17 & 2,55 & 97,21 & 95,81 & 86,55 & 100 & 4,21 \\
\hline GO & 70 & 2,10 & 16 & 2,40 & 93,93 & 93,38 & 85,59 & 100 & 3,59 \\
\hline ES & 131 & 3,93 & 11 & 1,65 & 89,47 & 89,40 & 77,58 & 100 & 4,73 \\
\hline $\mathrm{AM}$ & 35 & 1,05 & 10 & 1,50 & 92,24 & 93,57 & 85,27 & 100 & 3,89 \\
\hline PA & 25 & 0,75 & 7 & 1,05 & 92,49 & 92,44 & 82,24 & 99,6 & 4,88 \\
\hline TO & 9 & 0,27 & 6 & 0,90 & 97,88 & 97,25 & 93,15 & 100 & 2,75 \\
\hline PR & 26 & 0,78 & 5 & 0,75 & 90,19 & 91,30 & 82,24 & 98,84 & 4,23 \\
\hline $\mathrm{RN}$ & 16 & 0,48 & 3 & 0,45 & 90,94 & 90,47 & 80,09 & 100 & 4,96 \\
\hline MA & 15 & 0,45 & 2 & 0,30 & 93,05 & 92,86 & 86,27 & 100 & 3,94 \\
\hline BA & 14 & 0,42 & 1 & 0,15 & 89,75 & 89,20 & 79,32 & 96,16 & 4,88 \\
\hline $\mathrm{CE}$ & 3 & 0,09 & 1 & 0,15 & 94,36 & 95,11 & 91,55 & 99,41 & 3,98 \\
\hline PI & 1 & 0,03 & 1 & 0,15 & 99,27 & 99,27 & 99,27 & 99,27 & - \\
\hline $\mathrm{PB}$ & 7 & 0,21 & 0 & - & 85,25 & 85,85 & 83,71 & 90,44 & 2,17 \\
\hline PE & 7 & 0,21 & 0 & - & 90,32 & 88,13 & 79,95 & 94,91 & 5,39 \\
\hline RO & 3 & 0,09 & 0 & - & 90,51 & 90,32 & 87,5 & 92,94 & 2,73 \\
\hline AP & 1 & 0,03 & 0 & - & 92,32 & 92,32 & 92,32 & 92,32 & - \\
\hline SE & 1 & 0,03 & 0 & - & 88,87 & 88,87 & 88,87 & 88,87 & - \\
\hline TOTAL & 3330 & 100 & 667 & 20,03 & - & - & - & - & - \\
\hline
\end{tabular}

Fonte: Elaborado pelo autor. 
O Gráfico 18 apresenta a correlação entre os investimentos anuais médios ${ }^{7}$ por aluno realizados pelos municípios objeto deste estudo (municípios brasileiros de NSE 5 e 6) em educação fundamental no período de 2012 a 2014, e seu desempenho no IDEB 2015. Nota-se que, apesar da grande variância entre os valores empenhados, não há uma relação direta com os resultados observados, reforçando a suposição deste estudo de que o simples incremento de recursos financeiros não é capaz de gerar diferenças significativas.

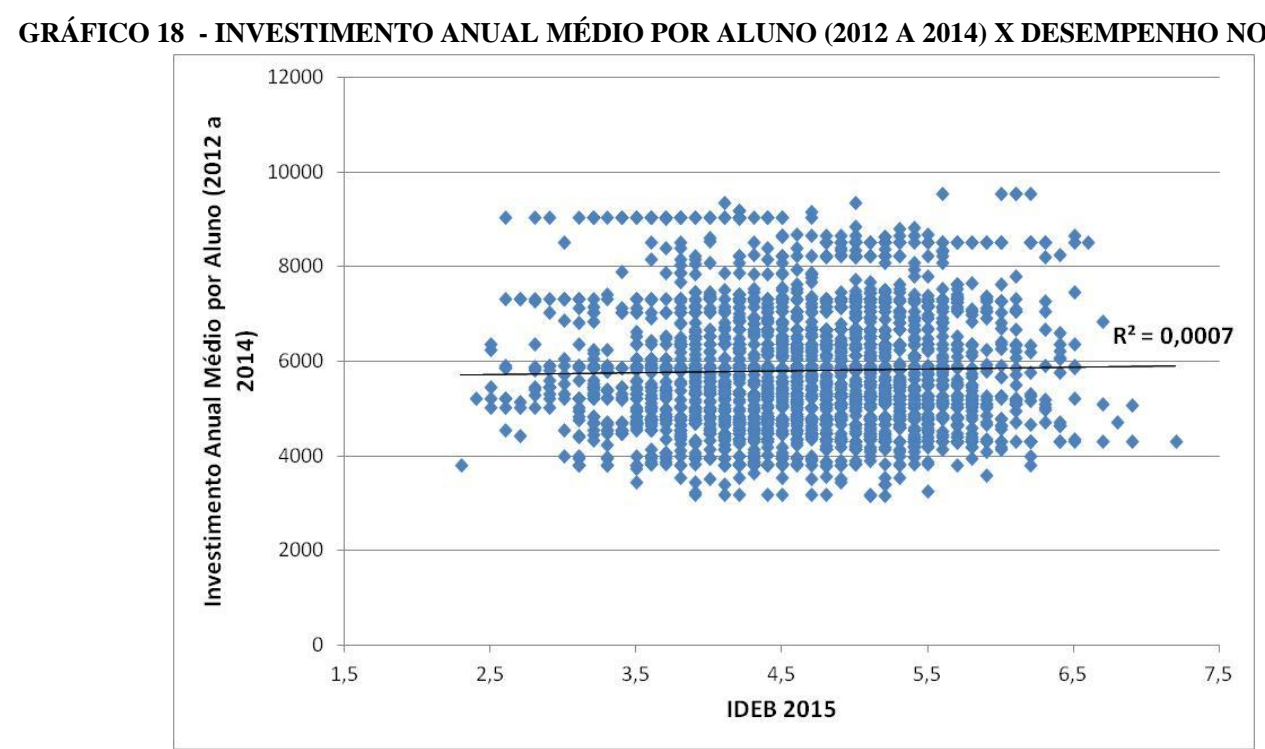

Fonte: Elaborado pelo autor.

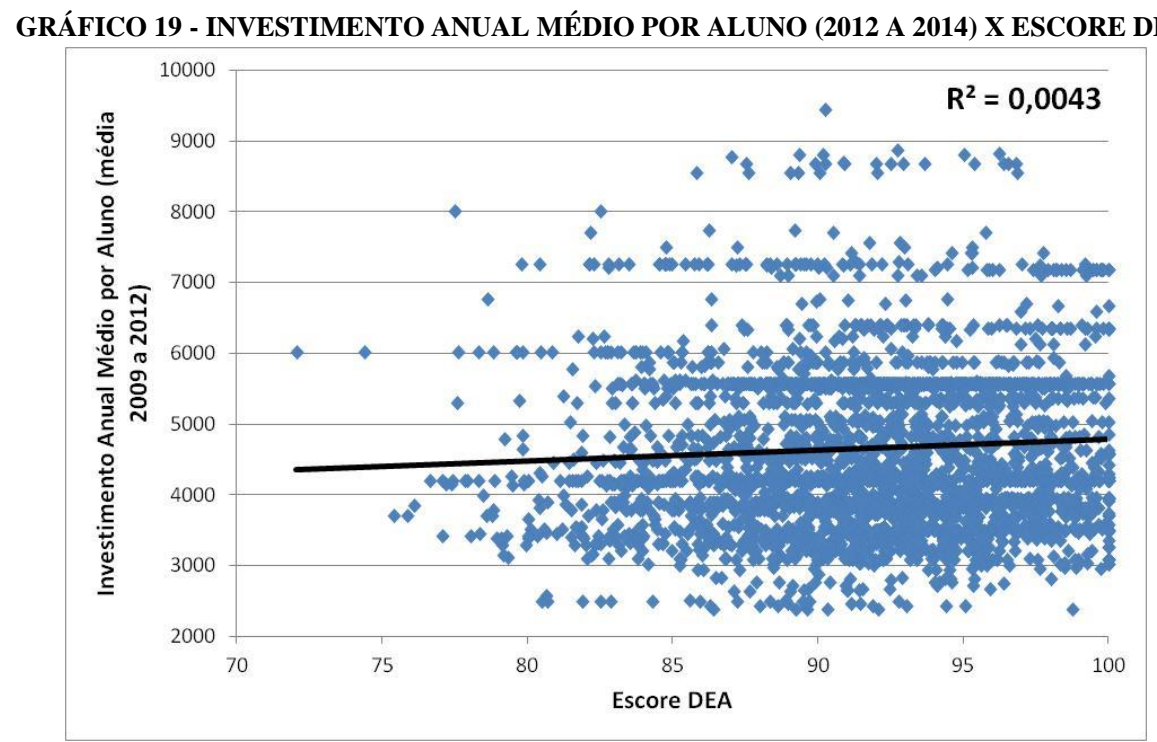

Fonte: Elaborado pelo autor.

\footnotetext{
${ }^{7}$ Os investimentos médios por aluno no período de 2012 a 2014 foram obtidos pela média dos investimentos anuais de cada município, calculados a partir do investimento total em educação fundamental informado pelos municípios no FINBRA, divididos pelo número de alunos matriculados em cada ano em cada município, informados no Censo Escolar.
} 
Da mesma forma, verifica-se no Gráfico 19 a inexistência de correlação entre o investimento anual médio por aluno e o escore DEA. Estas constatações reforçam os pressupostos deste trabalho, de que o mero gasto público não é capaz de gerar, por si só, melhoria na oferta dos serviços educacionais. Neste contexto, a adoção de práticas de gestão adequadas pode auxiliar na melhoria da eficiência do uso do recurso público e do desempenho dos estudantes.

\subsubsection{Resultados da análise de quintil}

A partir das bases de dados do Censo (2013) e da Prova Brasil (2015), que juntas continham 1.391 variáveis com informações sobre a escola, o diretor, os professores e os alunos, procedeu-se à análise de quintil para identificar aquelas que apresentavam diferença de média ou mediana estatisticamente significativa entre o quintil superior (escolas consideradas de alto desempenho no ranking DEA) e o quintil inferior (escolas consideradas de baixo desempenho no ranking DEA).

Da análise restaram 554 variáveis, as quais foram agrupadas e analisadas novamente, visando à eliminação de duplicidades uma vez que a mesma variável poderia fazer parte das duas bases (Censo e Prova Brasil). Após esta última etapa, realizada por julgamento, restaram 161 variáveis únicas com diferença estatística significativa entre os grupos de alto e baixo desempenho. A partir destes dados, percebeu-se que ainda seria possível realizar nova redução por meio do agrupamento de itens que tratam da mesma temática, como, por exemplo, a "oferta de língua e literatura inglesa" e "oferta de língua e literatura espanhola", que foram agrupadas para "oferta de língua estrangeira", uma vez que apresentam comportamento similar e tratam da mesma prática. Desta forma, procedeu-se à sua consolidação, obtendo-se, então, 141 variáveis nesta análise preliminar.

Também foram mantidas algumas variáveis que, apesar de não apresentarem diferença entre as escolas de alto e baixo desempenho, foram compreendidas como relevantes, sendo, inclusive, objeto de outros estudos identificados durante o levantamento do referencial teórico. Estas foram classificadas como "neutras" e são aquelas cuja média ou mediana não apresentaram diferença estatística significante entre os quintis superior e inferior, como: “A oferta de capacitações, oficinas e especializações aos professores", "Remuneração docente" e o "Uso de jornais, filmes, documentários e desenhos" pelos professores. 
Destaca-se, ainda, que estes são resultados preliminares e serviram de base para a próxima fase da etapa quantitativa, a análise de Regressão Lineal Múltipla, cujos resultados são apresentados a seguir.

\subsubsection{Resultados da regressão linear múltipla}

A partir das 161 variáveis identificadas na análise de quintil, procedeu-se à análise por meio da Regressão Linear Múltipla, tendo sido realizadas três simulações de busca sequencial de variáveis pelos métodos de estimação stepwise, adição forward e eliminação backward, utilizando-se o software IBM SPSS Statistics versão 22. O modelo que apresentou melhor discriminação foi o stepwise, com 39 variáveis independentes selecionadas e $\mathrm{R}^{2}$ de 0,248 , conforme Tabela 7. Este valor pode ser considerado relevante em razão da complexidade envolvida no serviço educacional, que sofre influência de fatores externos às resultados dos estudantes, e dos dados utilizados, que se limitam àqueles disponibilizados nos microdados do Censo e da Prova Brasil, sendo esta, inclusive, uma limitação da própria pesquisa.

O teste de significância também deve ser considerado, uma vez que determina a existência de relação linear entre a variável resposta. É possível verificar que todas as variáveis identificadas possuem nível de significância $<0,1$, reforçando o poder explicativo do modelo (Tabela 9).

Ademais, sendo atendidos os pressupostos da técnica, podemos utilizar seus resultados para reforçar a análise sobre os itens por ela destacados.

TABELA 7 - RESUMO DO MODELO DE REGRESSÃO LINEAR MÚLTIPLA

\begin{tabular}{|l|r|r|r|r|r|}
\hline Modelo & $\mathrm{R}$ & $\mathrm{R}$ quadrado & \multicolumn{1}{c|}{$\begin{array}{c}\text { R quadrado } \\
\text { ajustado }\end{array}$} & $\begin{array}{c}\text { Erro padrão da } \\
\text { estimativa }\end{array}$ & Durbin-Watson \\
\hline 39 &, $498^{\mathrm{am}}$ &, 248 &, 239 & 4,17785 & 1,721 \\
\hline
\end{tabular}

Fonte: Elaborado pelo autor.

Sendo a análise de Regressão Linear Múltipla uma técnica estatística paramétrica, ela está sujeita a "suposições subjacentes a respeito dos dados" (HAIR JR et al., 2005, p. 289). Segundo Corrar, Paulo e Dias Filho (2009), os principais pressupostos para a análise de regressão são: a normalidade e a homocedasticidade dos resíduos, bem como a ausência de 
multicolinearidade entre as variáveis independentes, isto é, não se pode haver correlação entre elas.

A análise do histograma dos resíduos (Gráfico 20) parece indicar a normalidade, o que é confirmado pelo teste Kolmogorov-Smirnov (Tabela 8), cumprindo um dos requisitos para a validade da regressão.

GRÁFICO 20 - HISTOGRAMA DOS RESÍDUOS DA REGRESSÃo

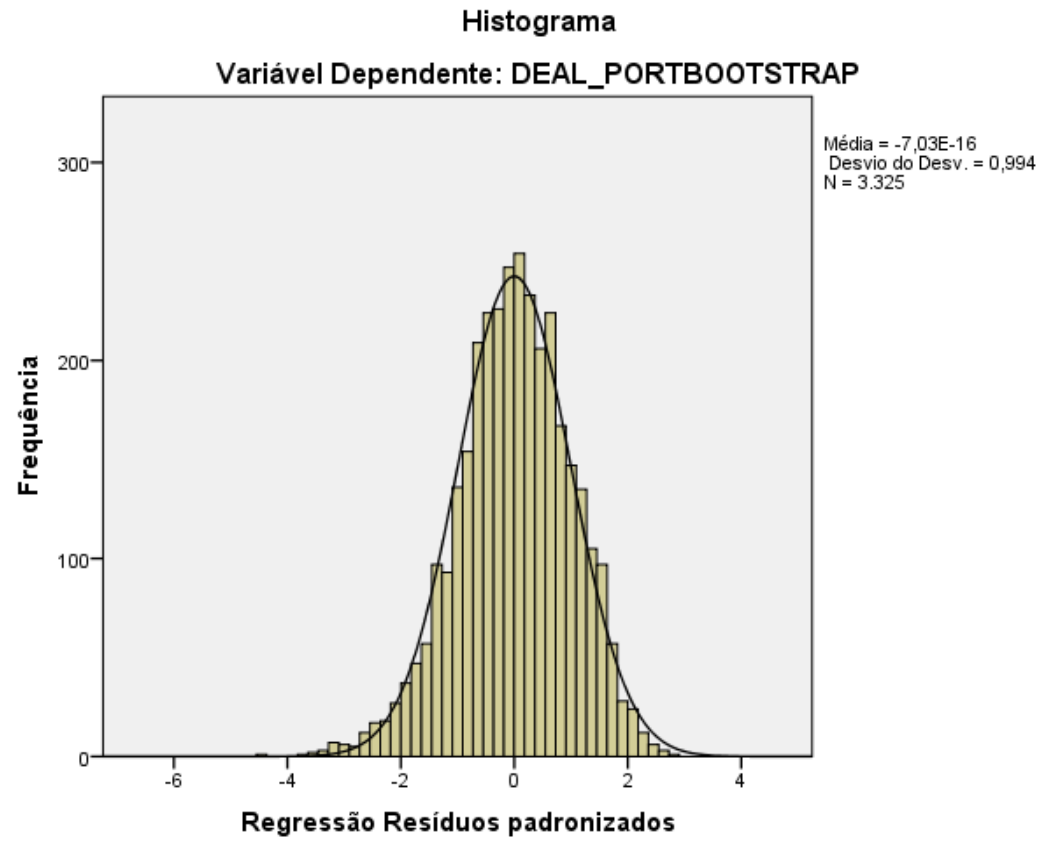

Fonte: Elaborado pelo autor.

TABELA 8 - TESTE DE NORMALIDADE KOLMOGOROV-SMIRNOV DOS RESÍDUOS DA REGRESSÃO

\begin{tabular}{|ll|r|}
\hline & & Standardized Residual \\
\hline N & & 3325 \\
Parâmetros normais $^{\text {a,b }}$ & Média &, 0000000 \\
& Erro Desvio &, 99411626 \\
Diferenças Mais Extremas & Absoluto &, 018 \\
& Positivo &, 013 \\
& Negativo &,- 018 \\
Estatística de teste & &, 018 \\
Significância Sig. (2 extremidades) & &, $014^{c}$ \\
\hline
\end{tabular}

a. A distribuição do teste é Normal. b. Calculado dos dados. c. Correção de Significância de Lilliefors

Fonte: Elaborado pelo autor.

A verificação da multicolinearidade pode ser realizada por meio de testes estatísticos como o Fator de Inflação da Variância - VIF e o Tolerance. Segundo Corrar, Paulo e Dias Filho (2009), na escala VIF, até 1 não há multicolinearidade e de 1 ate 10 , a multicolinearidade é aceitável. Já no índice Tolerance, até 1 , sem multicolinearidade e de 1 
até 0,10 , a multicolinearidade é aceitável. Por estes índices, se pode observar na Tabela 9 que não há multicolinearidade entre as variáveis independentes que permaneceram no modelo, uma vez tanto o VIF quanto o Tolerance se encontram dentro das faixas aceitáveis.

TABELA 9 - RESULTADOS DA REGRESSÃO

\begin{tabular}{|c|c|c|c|c|c|c|c|c|}
\hline & & \multicolumn{2}{|c|}{ Coeficientes não padronizados } & \multirow{2}{*}{$\begin{array}{c}\begin{array}{c}\text { Coeficientes } \\
\text { padronizados }\end{array} \\
\text { Beta } \\
\end{array}$} & & \multirow[t]{2}{*}{ Sig. } & \multicolumn{2}{|c|}{$\begin{array}{l}\text { Estatísticas de } \\
\text { colinearidade }\end{array}$} \\
\hline \multicolumn{2}{|c|}{ Modelo } & $\mathrm{B}$ & Erro Padrão & & & & Tolerância & VIF \\
\hline 39 & (Constante) & 76,904 & 2,098 & & 36,657 & 0 & & \\
\hline & PB_ALUNO_V04 & 4,672 & 1,4 & 0,073 & 3,336 & 0,001 & 0,477 & 2,098 \\
\hline & PB_ALUNO_V29 & 3,264 & 0,546 & 0,1 & 5,982 & 0 & 0,823 & 1,215 \\
\hline & PB_PROFESSOR_V10 & $-1,037$ & 0,214 & $-0,077$ & $-4,839$ & 0 & 0,901 & 1,109 \\
\hline & PB_ALUNO_V17 & $-4,674$ & 1,143 & $-0,071$ & $-4,091$ & 0 & 0,768 & 1,302 \\
\hline & PB_ALUNO_V26 & 4,138 & 0,618 & 0,113 & 6,694 & 0 & 0,81 & 1,235 \\
\hline & PB_ALUNO_V08 & 8,919 & 1,915 & 0,077 & 4,658 & 0 & 0,835 & 1,197 \\
\hline & PB_PROFESSOR_V48 & 1,114 & 0,266 & 0,065 & 4,184 & 0 & 0,934 & 1,07 \\
\hline & PB_ALUNO_V15 & $-5,227$ & 1,025 & $-0,086$ & $-5,1$ & 0 & 0,803 & 1,246 \\
\hline & PB_ALUNO_V14 & 2,259 & 0,505 & 0,074 & 4,473 & 0 & 0,828 & 1,207 \\
\hline & PB_DIR_V30 & 0,336 & 0,093 & 0,061 & 3,627 & 0 & 0,82 & 1,219 \\
\hline & PB_ESCOLA_V14 & $-0,33$ & 0,079 & $-0,067$ & $-4,153$ & 0 & 0,892 & 1,121 \\
\hline & PB_ALUNO_V20 & $-2,768$ & 0,966 & $-0,05$ & $-2,866$ & 0,004 & 0,739 & 1,353 \\
\hline & C_TURM_V08 & $-1,442$ & 0,319 & $-0,069$ & $-4,518$ & 0 & 0,992 & 1,008 \\
\hline & PB_PROFESSOR_V27 & 0,991 & 0,272 & 0,056 & 3,64 & 0 & 0,955 & 1,047 \\
\hline & PB_PROFESSOR_V03 & 0,628 & 0,211 & 0,047 & 2,976 & 0,003 & 0,901 & 1,11 \\
\hline & PB_DIR_V53 & $-0,242$ & 0,081 & $-0,048$ & $-3,005$ & 0,003 & 0,881 & 1,135 \\
\hline & PB_PROFESSOR_V18 & $-1,545$ & 0,55 & $-0,043$ & $-2,806$ & 0,005 & 0,976 & 1,024 \\
\hline & PB_DIR_V10 & 0,187 & 0,035 & 0,102 & 5,303 & 0 & 0,62 & 1,612 \\
\hline & PB_DIR_V18 & $-0,308$ & 0,062 & $-0,083$ & $-4,939$ & 0 & 0,819 & 1,222 \\
\hline & PB_PROFESSOR_V11 & 0,697 & 0,194 & 0,057 & 3,587 & 0 & 0,897 & 1,115 \\
\hline & PB_ALUNO_V24 & 3,589 & 1,135 & 0,049 & 3,161 & 0,002 & 0,942 & 1,061 \\
\hline & PB_PROFESSOR_V23 & $-0,796$ & 0,243 & $-0,052$ & $-3,273$ & 0,001 & 0,901 & 1,11 \\
\hline & PB_PROFESSOR_V37 & 0,535 & 0,217 & 0,039 & 2,458 & 0,014 & 0,926 & 1,079 \\
\hline & PB_ALUNO_V27 & 1,352 & 0,583 & 0,04 & 2,319 & 0,02 & 0,766 & 1,305 \\
\hline & PB_PROFESSOR_V32 & $-1,725$ & 0,572 & $-0,046$ & $-3,014$ & 0,003 & 0,977 & 1,023 \\
\hline & PB_DIR_V41 & 0,181 & 0,094 & 0,03 & 1,916 & 0,055 & 0,935 & 1,07 \\
\hline & PB_PROFESSOR_V12 & 0,529 & 0,199 & 0,042 & 2,662 & 0,008 & 0,937 & 1,067 \\
\hline & PB_ALUNO_V07 & 4,94 & 1,699 & 0,063 & 2,907 & 0,004 & 0,482 & 2,075 \\
\hline & PB_ALUNO_V22 & $-2,898$ & 0,89 & $-0,058$ & $-3,257$ & 0,001 & 0,721 & 1,386 \\
\hline & PB_ALUNO_V02 & $-3,874$ & 1,3 & $-0,053$ & $-2,98$ & 0,003 & 0,711 & 1,407 \\
\hline & PB_DIR_V14 & $-0,142$ & 0,049 & $-0,052$ & $-2,918$ & 0,004 & 0,734 & 1,363 \\
\hline & PB_DIR_V50 & $-0,19$ & 0,08 & $-0,037$ & $-2,365$ & 0,018 & 0,916 & 1,091 \\
\hline & PB_PROFESSOR_V33 & 0,503 & 0,204 & 0,039 & 2,469 & 0,014 & 0,9 & 1,112 \\
\hline & PB_ESCOLA_V23 & 0,493 & 0,169 & 0,052 & 2,918 & 0,004 & 0,729 & 1,372 \\
\hline & PB_DIR_V42 & 0,231 & 0,105 & 0,034 & 2,208 & 0,027 & 0,975 & 1,026 \\
\hline & PB_ESCOLA_V22 & $-0,294$ & 0,134 & $-0,038$ & $-2,191$ & 0,029 & 0,763 & 1,31 \\
\hline & PB_DIR_V32 & 0,269 & 0,126 & 0,036 & 2,13 & 0,033 & 0,795 & 1,258 \\
\hline & PB_ALUNO_V23 & $-3,274$ & 1,634 & $-0,031$ & $-2,003$ & 0,045 & 0,929 & 1,077 \\
\hline & PB_PROFESSOR_V50 & 0,434 & 0,217 & 0,031 & 2,001 & 0,045 & 0,926 & 1,08 \\
\hline
\end{tabular}

a Variável Dependente: DEAL_PORTBOOTSTRAP

Fonte: Elaborado pelo autor.

A partir das variáveis encontradas nas análises quantitativas (análise de quintis e Regressão Linear Múltipla), os fatores que afetam o desempenho escolar puderam ser 
divididos em quatro categorias, conforme Figura 18: a escola e sua estrutura; o aluno e a participação da família; o professor e o diretor.

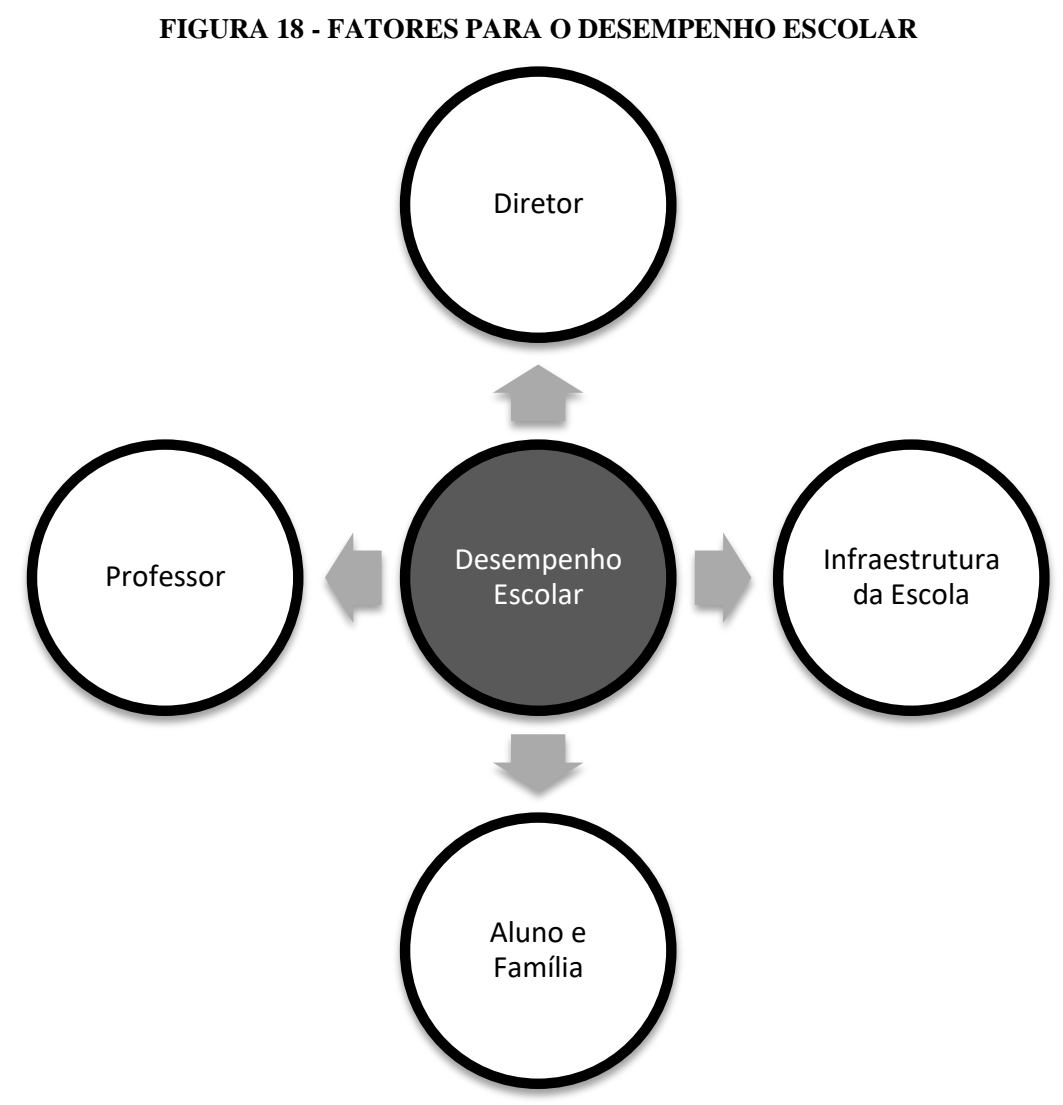

Fonte: Elaborado pelo autor.

As variáveis foram inicialmente agrupadas pelo sujeito responsável (diretor, professor e aluno e sua família), a seguir realizou-se o agrupamento por temas ou áreas. Para o professor, foram realizados os seguintes agrupamentos de variáveis: Perfil Pessoal; Regime de Trabalho; Planejamento Docente; Prática Docente. Para o Diretor, chegou-se ao seguinte agrupamento: Regime de Trabalho, Formação e Experiência; Atuação com a Família e a Comunidade; Práticas de Gestão; Práticas Pedagógicas. Em relação aos Alunos, as variáveis foram agrupadas em: Participação da Família; Aspectos Familiares; Hábitos do Aluno.

$\mathrm{Na}$ sequência as variáveis foram classificadas de acordo com seu efeito nas escolas negativo ou positivo. Foram consideradas variáveis com efeito negativo aquelas que, apresentando diferença estatística significativa, estavam mais presentes nas escolas de baixo desempenho, como, por exemplo, o "Percentual de tempo da aula gasto fazendo com que os alunos copiem a matéria da lousa", e positivo, aquelas que, também apresentando diferença 
estatística significativa, apresentavam maior frequência nas escolas consideradas eficientes pelo modelo, como, por exemplo "Realizar a correção diária do deve de casa".

Para cada variável estipulou-se como meta o valor constante do quintil superior e sua respectiva tendência (para mais ou para menos). A meta pode ser compreendida como valor ideal de cada variável para que as escolas sejam enquadradas no grupo de alto desempenho. Este resultado, além de permitir a identificação das práticas nas escolas de alto desempenho, também serve de guia para a coleta de informações em profundidade nos estudos de campo.

Alguns achados merecem destaque por apresentarem resultados contraditórios aos tradicionalmente apresentados na literatura e pelas ideias amplamente difundidas no setor. Em relação às práticas pedagógicas, verificou-se que a utilização de jornais, filmes, documentários e desenhos pelos professores não se mostra efetivo para a melhoria do desempenho dos estudantes em leitura e escrita.

Outras duas constatações são especialmente relevantes, uma vez que impactam diretamente os investimentos públicos no setor. Primeiramente observou-se que a participação dos professores em capacitações, oficinas e especializações não apresentou diferenças significativas entre os quintis superior e inferior, sugerindo que esta prática, por si só, não é capaz de produzir melhorias nos resultados dos estudantes, abrindo questionamento sobre a real efetividade dos programas até então oferecidos.

Outro importante achado diz respeito à remuneração docente, tema recorrente na literatura e no meio. Profissional essencial à promoção do desenvolvimento pessoal, social e econômico dos indivíduos, os professores enfrentam desafios complexos em sua jornada diária de trabalho e fazem jus a remunerações dignas, que devem ser capazes de tornar a profissão atraente. Porém, os dados mostram que não existem diferenças significativas entre o salário dos docentes das escolas de alto e baixo desempenho. Esta constatação, em particular, deve ser analisada cuidadosamente pelos gestores municipais, uma vez que o simples acréscimo do valor da remuneração docente não é capaz de produzir melhorias nos resultados educacionais se não estiverem acompanhadas de outras práticas administrativas e pedagógicas eficazes.

O QUADRO 15 apresenta os resultados compilados da etapa quantitativa, bem como os valores observados em cada uma das variáveis nas escolas selecionadas para as visitas. 
QUADRO 15 - RESULTADOS DA ETAPA QUANTITATIVA

\begin{tabular}{|c|c|c|c|c|c|c|c|c|c|c|c|c|c|}
\hline$\frac{2}{2}$ & 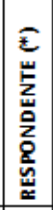 & 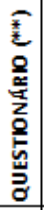 & GRUPO & 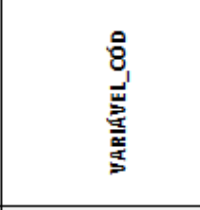 & VARIÁVEL_DESCRIÇÃO & $\underset{\underline{z}}{\underline{z}}$ & 足 & 을 & $\frac{5}{5}$ & 遌 & $\begin{array}{l}\infty \\
\stackrel{\pi}{0} \\
\ddot{4}\end{array}$ & 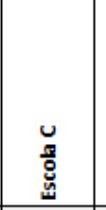 & 品 \\
\hline P & $\mathrm{P}$ & c & \multirow{5}{*}{ Perfil Pessoal } & C_PROF_CONS_V03 & Percentual de professores do sexo feminino & $\mathrm{x}$ & & 0 & 仓 $71,70 \%$ & $63,60 \%$ & $84,80 \%$ & $58,80 \%$ & $85,70 \%$ \\
\hline $\mathrm{P}$ & $\mathrm{P}$ & $\mathrm{C}$ & & PB_PROF_V142 & Frequência com que vai ao cinema & $\mathrm{x}$ & $x$ & 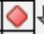 & $20,11 \%$ & $0,00 \%$ & $0,00 \%$ & $0,00 \%$ & $0,00 \%$ \\
\hline P & P & $\mathrm{P}$ & & PB_PROF_V270 & $\begin{array}{l}\text { Insatisfação e desestímulo do professor } \\
\text { com a carreira docente }\end{array}$ & $\mathrm{x}$ & & Or & \& $29,98 \%$ & $0,00 \%$ & $0,00 \%$ & $0,00 \%$ & $0,00 \%$ \\
\hline$P$ & P & $\mathrm{P}$ & & PB_PROF_V10 & Ensino Superior em Pedagogia & $\mathrm{x}$ & & 0 & 个 $0,10 \%$ & $0,00 \%$ & $0,00 \%$ & $0,00 \%$ & $0,50 \%$ \\
\hline $\mathrm{P}$ & $\mathrm{P}$ & $\mathrm{C}$ & & PB_PROF_V17 & Tipo de IES que cursou: pública (-) ou & $\mathrm{x}$ & & 안 & 个 $57,00 \%$ & $100,00 \%$ & $81,80 \%$ & $76,50 \%$ & $21,04 \%$ \\
\hline$P$ & $\mathrm{P}$ & $\mathrm{P}$ & \multirow{4}{*}{$\begin{array}{l}\text { Regime de } \\
\text { Trabalho }\end{array}$} & PB_PROF_V71 & Tipo de contratação: Estatutário & $\mathrm{x}$ & \begin{tabular}{l|l}
$x$ & \\
\end{tabular} & $>$ & $68,19 \%$ & $0,00 \%$ & $0,00 \%$ & $0,00 \%$ & $50,00 \%$ \\
\hline $\mathrm{P}$ & P & $\mathrm{P}$ & & PB_DIR_V151 & $\begin{array}{l}\text { Menos de } 25 \% \text { dos professores da escola } \\
\text { com vínculo estável. }\end{array}$ & $\mathrm{x}$ & $\mathrm{x}$ & 0) & SIM & NÃO & NÃO & NÃO & NÃO \\
\hline$P$ & D & $\mathrm{P}$ & & PB_PROF_V78 & $\begin{array}{l}\text { Professores com maior carga horária na } \\
\text { escola (acima de } 20 \text { horas) apresentam } \\
\text { melhor desepenho. }\end{array}$ & $\mathrm{x}$ & $\mathrm{x}$ & 0 & 个 $61,99 \%$ & $100,00 \%$ & $50,00 \%$ & $100,00 \%$ & $33,33 \%$ \\
\hline$P$ & P & $\mathrm{P}$ & & PB_PROF_V80 & Atuar em apenas 01 escola melhora o & $\mathrm{x}$ & $\mathrm{x}$ & 이 & 个 $42,48 \%$ & $0,00 \%$ & $100,00 \%$ & $0,00 \%$ & $66,67 \%$ \\
\hline$P$ & $\mathrm{P}$ & $\mathrm{P}$ & \multirow{6}{*}{$\begin{array}{l}\text { Planejamento } \\
\text { Docente }\end{array}$} & PB_PROF_V178 & $\begin{array}{l}\text { Projeto Pedagógico Pronto e Adaptado Sem } \\
\text { Discussão com os Professores }\end{array}$ & $\mathrm{x}$ & $\mathrm{x}$ & $\diamond$ & ? $0,02 \%$ & $0,00 \%$ & $0,00 \%$ & $0,00 \%$ & $0,00 \%$ \\
\hline $\mathrm{P}$ & P & $\mathrm{P}$ & & PB_PROF_V264 & $\begin{array}{l}\text { Conteúdos curriculares inadequados às } \\
\text { necessidades dos alunos }\end{array}$ & $\mathrm{x}$ & & 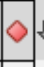 & 及 $14,52 \%$ & $0,00 \%$ & $0,00 \%$ & $0,00 \%$ & $0,00 \%$ \\
\hline $\mathrm{P}$ & P & $\mathrm{P}$ & & PB_PROF_V196 & $\begin{array}{l}\text { A troca semanal de materiais didáticos com } \\
\text { os colegas }\end{array}$ & $x$ & & 0 & 个 $20,77 \%$ & $0,00 \%$ & $50,00 \%$ & $0,00 \%$ & $0,00 \%$ \\
\hline$P$ & P & $P$ & & PB_PROF_V201 & $\begin{array}{l}\text { Reuniões semanais com professores que } \\
\text { trabalham na mesma }\end{array}$ & $\mathrm{x}$ & & 0 & 个 $27,30 \%$ & $0,00 \%$ & $50,00 \%$ & $100,00 \%$ & $100,00 \%$ \\
\hline $\mathrm{P}$ & $\mathrm{P}$ & $\mathrm{P}$ & & PB_PROF_V206 & $\begin{array}{l}\text { Participar em discussões semanais sobre } \circ \\
\text { desenvolvimento da aprendizagem }\end{array}$ & $\mathrm{x}$ & $\mathrm{x}$ & $0 \hat{r}$ & 个 $32,22 \%$ & $0,00 \%$ & $50,00 \%$ & $100,00 \%$ & $83,33 \%$ \\
\hline$P$ & $\mathrm{P}$ & $\mathrm{P}$ & & PB_PROF_V211 & $\begin{array}{l}\text { Desenvolvimento de atividades conjuntas } \\
\text { com outros docentes semanalmente }\end{array}$ & $\mathrm{x}$ & & $0 \mid k$ & \& $8,99 \%$ & $0,00 \%$ & $0,00 \%$ & $0,00 \%$ & $0,00 \%$ \\
\hline$P$ & $\mathrm{P}$ & $\mathrm{P}$ & \multirow{27}{*}{$\begin{array}{l}\text { Prática } \\
\text { Docente }\end{array}$} & PB_PROF_V153 & Uso de livros de literatura é bom & $\mathrm{x}$ & & O & 个 $39,37 \%$ & $0,00 \%$ & $50,00 \%$ & $0,00 \%$ & $50,00 \%$ \\
\hline$P$ & $\mathrm{P}$ & $\mathrm{P}$ & & PB_PROF_V157 & Uso do projetor & $\mathrm{x}$ & $\mathrm{x}$ & 인 & 个 $20,66 \%$ & $0,00 \%$ & $50,00 \%$ & $0,00 \%$ & $0,00 \%$ \\
\hline$P$ & $\mathrm{P}$ & $\mathrm{P}$ & & PB_PROF_V165 & Professor utiliza equipamento de fotocópia & $\mathrm{x}$ & & 안 & 仓 $59,48 \%$ & $0,00 \%$ & $100,00 \%$ & $0,00 \%$ & $33,33 \%$ \\
\hline$P$ & $\mathrm{P}$ & $\mathrm{P}$ & & PB_PROF_V169 & Professor utiliza aplicativos pedagógicos & $\mathrm{x}$ & & (1) & $21,88 \%$ & $0,00 \%$ & $50,00 \%$ & $100,00 \%$ & $0,00 \%$ \\
\hline$P$ & $\mathrm{P}$ & $\mathrm{P}$ & & PB_PROF_V173 & \begin{tabular}{|l|l|} 
Professor utiliza a internet \\
\end{tabular} & $\mathrm{x}$ & & ㅇ. & \& $12,25 \%$ & $0,00 \%$ & $0,00 \%$ & $0,00 \%$ & $33,33 \%$ \\
\hline $\mathrm{E}$ & AP & $\mathrm{P}$ & & PB_ESC_V91 & $\begin{array}{l}\text { Disponibilidade e número de computadores } \\
\text { para uso dos alunos (Bom) }\end{array}$ & $x$ & & O & SIM & SIM & SIM & NÃO & SIM \\
\hline $\mathrm{E}$ & AP & $\mathrm{P}$ & & PB_ESC_V97 & Acesso à internet banda-larga para os & $\mathrm{x}$ & & O & SIM & SIM & SIM & NÃO & SIM \\
\hline E & AP & P & & PB_ESC_V103 & $\begin{array}{l}\text { Disponibilidade de computadores para uso } \\
\text { dos professores (Bom) }\end{array}$ & $\mathrm{x}$ & $\mathrm{x}$ & 0 & SIM & $\operatorname{siM}$ & SIM & NÃO & SIM \\
\hline $\mathrm{P}$ & P & $\mathrm{P}$ & & PB_PROF_V321 & Mais tempo dedicado às aulas e menos a & $\mathrm{x}$ & & 0 & 个 $72,06 \%$ & $100,00 \%$ & $50,00 \%$ & $100,00 \%$ & $66,67 \%$ \\
\hline $\mathrm{P}$ & P & $\mathrm{P}$ & & PB_PROF_V84 & Horas dedicadas a atividades extraclasse & $\mathrm{x}$ & $\mathrm{x}$ & 唡 & \& $0,02 \%$ & $0,00 \%$ & $0,00 \%$ & $0,00 \%$ & $0,00 \%$ \\
\hline $\mathrm{P}$ & $\mathrm{P}$ & $P$ & & PB_PROF_V268 & $\begin{array}{l}\text { Sobrecarga de trabalho dos professores, } \\
\text { dificultando o planejamento e o preparo }\end{array}$ & $\mathrm{x}$ & & ৩) & $35,46 \%$ & $0,00 \%$ & $50,00 \%$ & $0,00 \%$ & $16,67 \%$ \\
\hline $\mathrm{P}$ & $\mathrm{P}$ & $\mathrm{P}$ & & PB_PROF_V310 & $\begin{array}{l}\text { Gastar menos de } 10 \% \text { do tempo garantindo } \\
\text { a disciplina na sala }\end{array}$ & $x$ & & 0 & 仓 $37,35 \%$ & $0,00 \%$ & $50,00 \%$ & $100,00 \%$ & $33,33 \%$ \\
\hline D & D & $P$ & & PB_DIR_V457 & $\begin{array}{l}\text { Funcionamento da Escola interrompido por } \\
\text { problemas de indisciplina }\end{array}$ & $x$ & $\mathrm{x}$ & 0 & NÃO & NÃO & NÃO & SIM & NÃO \\
\hline$P$ & $\mathrm{P}$ & $\mathrm{P}$ & & PB_PROF_V336 & Oferta de dever de casa diariamente & $\mathrm{x}$ & & 인 & 亿 $28,85 \%$ & $0,00 \%$ & $0,00 \%$ & $0,00 \%$ & $0,00 \%$ \\
\hline$P$ & A & $\mathrm{P}$ & & PB_PROF_V342 & Professor corrige dever de casa diariamente & $\mathrm{x}$ & & O & 个 $80,40 \%$ & $86,00 \%$ & $88,00 \%$ & $73,00 \%$ & $55,00 \%$ \\
\hline $\mathrm{P}$ & $\mathrm{P}$ & $P$ & & PB_PROF_V360 & $\begin{array}{l}\text { Cópia de conteúdos do livro ou lousa é } \\
\text { negativo }\end{array}$ & $\mathrm{x}$ & & $0 \mid k$ & $30,34 \%$ & $0,00 \%$ & $50,00 \%$ & $0,00 \%$ & $50,00 \%$ \\
\hline $\mathrm{P}$ & P & $P$ & & PB_PROF_V366 & \begin{tabular}{|l|} 
Atividades que estimulem aos alunos \\
expressar suas opiniões e a criarem
\end{tabular} & $\mathrm{x}$ & & 0 & 个 $65,17 \%$ & $100,00 \%$ & $100,00 \%$ & $0,00 \%$ & $50,00 \%$ \\
\hline$P$ & $\mathrm{P}$ & $P$ & & PB_PROF_V377 & $\begin{array}{l}\text { Promover discussões a partir de textos } \\
\text { (jornais e revistas) semanalmente }\end{array}$ & $\mathrm{x}$ & & $0 k$ & 个 $41,41 \%$ & $41,41 \%$ & $100,00 \%$ & $35,00 \%$ & $0,00 \%$ \\
\hline $\mathrm{P}$ & $\mathrm{P}$ & $\mathrm{P}$ & & PB_PROF_V402 & $\begin{array}{l}\text { Propor atividades gramaticais relacionadas } \\
\text { aos textos de jornais ou revistas }\end{array}$ & $\mathrm{x}$ & & $0 \mid k$ & ? $18,40 \%$ & $18,16 \%$ & $0,00 \%$ & $21,57 \%$ & $0,00 \%$ \\
\hline $\mathrm{P}$ & $P$ & $P$ & & PB_PROF_V389 & $\begin{array}{l}\text { Promover a leitura e discussão de contos, } \\
\text { crônicas, poesias ou romances }\end{array}$ & $\mathrm{x}$ & & 0 & 个 $48,02 \%$ & $47,97 \%$ & $0,00 \%$ & $42,95 \%$ & $33,33 \%$ \\
\hline$P$ & $\mathrm{P}$ & $P$ & & PB_PROF_V330 & $\begin{array}{l}\text { Garantir o cumprimento de, pelo menos, } \\
80 \% \text { dos conteúdos na trajetória escolar } \\
\end{array}$ & $\mathrm{x}$ & & 0 & 个 $57,35 \%$ & $100,00 \%$ & $87,50 \%$ & $100,00 \%$ & $33,33 \%$ \\
\hline $\mathrm{P}$ & P & $\mathrm{P}$ & & PB_PROF_V267 & $\begin{array}{l}\text { Cumprir o conteúdo curricular ao longo da } \\
\text { trajetória do aluno }\end{array}$ & $\mathrm{x}$ & $\mathrm{x}$ & 0 & 个 $74,46 \%$ & $100,00 \%$ & $100,00 \%$ & $100,00 \%$ & $100,00 \%$ \\
\hline $\mathrm{P}$ & P & $\mathrm{P}$ & & PB_PROF_V321 & $\begin{array}{l}\text { Mais tempo dedicado às aulas e menos a } \\
\text { questões administrativas }(80 \%+/ 10 \%-)\end{array}$ & $\mathrm{x}$ & & $0 k$ & 个 $72,06 \%$ & $100,00 \%$ & $50,00 \%$ & $100,00 \%$ & $66,67 \%$ \\
\hline$P$ & $P$ & $P$ & & PB_PROF_V268 & $\begin{array}{l}\text { Sobrecarga de trabalho dos professores, } \\
\text { dificultando o planejamento e o preparo } \\
\end{array}$ & $\mathrm{x}$ & & $0 \mid k$ & \& $35,46 \%$ & $0,00 \%$ & $50,00 \%$ & $0,00 \%$ & $16,67 \%$ \\
\hline $\mathrm{P}$ & $\mathrm{P}$ & $\mathrm{P}$ & & PB_PROF_V178 & \begin{tabular}{|l|} 
Projeto Pedagógico Pronto e Adaptado Sem \\
Discussão com os Professores \\
\end{tabular} & $\mathrm{x}$ & $\mathrm{x}$ & O & \& $0,02 \%$ & $0,00 \%$ & $0,00 \%$ & $0,00 \%$ & $0,00 \%$ \\
\hline$P$ & $P$ & $\mathrm{P}$ & & PB_PROF_V264 & $\begin{array}{l}\text { Conteúdos curriculares inadequados às } \\
\text { necessidades dos alunos }\end{array}$ & $\mathrm{x}$ & & 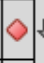 & \& $14,52 \%$ & $0,00 \%$ & $0,00 \%$ & $0,00 \%$ & $0,00 \%$ \\
\hline P & $\mathrm{P}$ & $\mathrm{P}$ & & PB_PROF_V310 & $\begin{array}{l}\text { Gastar menos de } 10 \% \text { do tempo garantindo } \\
\text { a disciplina na sala }\end{array}$ & $\mathrm{x}$ & & ok & 仓 $37,35 \%$ & $0,00 \%$ & $50,00 \%$ & $100,00 \%$ & $33,33 \%$ \\
\hline
\end{tabular}


Continuação

\begin{tabular}{|c|c|c|c|c|c|c|c|c|c|c|c|c|c|}
\hline$\frac{\tilde{z}}{2}$ & 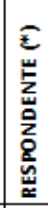 & 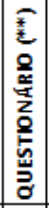 & GRUPO & 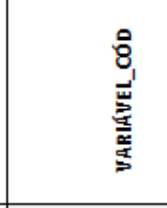 & VARIÁVEL_DESCRIÇÃo & 言 & 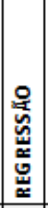 & 을 & 焉 & 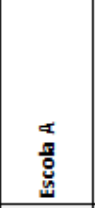 & 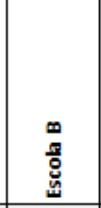 & $\begin{array}{l}u \\
\stackrel{\pi}{0} \\
\stackrel{4}{4} \\
\end{array}$ & 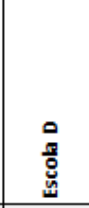 \\
\hline $\mathrm{D}$ & D & $\mathrm{P}$ & \multirow{6}{*}{$\begin{array}{l}\text { Regime de } \\
\text { Trabalho, } \\
\text { Formação e } \\
\text { Experiência }\end{array}$} & PB_DIR_V37 & Dedicação Exclusiva à Escola & $\mathrm{x}$ & & 0 & SIM & SIM & SIM & SIM & SIM \\
\hline$D$ & D & $\mathrm{P}$ & & PB_DIR_V54 & Possui 40 horas semanais oU + de carga & $\mathrm{x}$ & & o & SIM & SIM & SIM & SIM & SIM \\
\hline D & D & $\mathrm{P}$ & & PB_DIR_V61 & $\begin{array}{l}\text { Ingresso no cargo via Concurso Público ou } \\
\text { Indicacão Direta }\end{array}$ & $\mathrm{x}$ & & 0 & SIM & SIM & SIM & SIM & $\operatorname{sim}$ \\
\hline D & D & P & & PB_DIR_V30 & $\begin{array}{l}\text { Possuir Pós-graduação (Especial lização, no } \\
\text { mínimo) }\end{array}$ & $x$ & $\mathrm{x}$ & 0 & SIM & SIM & SIM & SIM & SIM \\
\hline $\mathrm{D}$ & D & $\mathrm{p}$ & & PB_DIR_V75 & Experiência anterior como professor $(+$ de 20 & $\mathrm{x}$ & $\mathrm{x}$ & 0 & NÃO & NÃO & NÃO & NÃo & NÃo \\
\hline$D$ & $\mathrm{D}$ & $\mathrm{p}$ & & PB_DIR_V90 & Diretor na mesma escola pelo período de 06 & $\mathrm{x}$ & & o & SIM & NÃO & NÃO & NÃ̃o & NÃO \\
\hline D & D & P & \multirow{9}{*}{$\begin{array}{l}\text { Atuação com } \\
\text { a Família e a } \\
\text { Comunidade }\end{array}$} & PB_DIR_V276 & $\begin{array}{l}\text { Frequência com que o Diretor comunica os } \\
\text { pais sobre problemas relacionados aos } \\
\text { aluno (Sempre ou Quase Sempre) }\end{array}$ & $\mathrm{x}$ & & 0 & SIM & NÃO & NÃO & NÃO & SIM \\
\hline A & A & $\mathrm{P}$ & & PB_ALUN_V29 & Participação dos pais em reuniões & $\mathrm{x}$ & & ㅇ․ & 仓 $55,40 \%$ & $86,00 \%$ & $67,00 \%$ & $69,00 \%$ & $64,00 \%$ \\
\hline D & D & P & & PB_DIR_V311 & $\begin{array}{l}\text { Diretor promover projetos temáticos (como } \\
\text { bullying, desigualdades e impactos } \\
\text { socioambientais) (Frequentemente) }\end{array}$ & $\mathrm{x}$ & & 0 & SIM & NÃO & NÃO & SIM & SIM \\
\hline D & D & P & & PB_DIR_V317 & $\begin{array}{l}\text { Diretor promover eventos para a } \\
\text { comunidade (Frequentemente) }\end{array}$ & $\mathrm{x}$ & & 0 & SIM & SIM & SIM & NÃO & SIM \\
\hline$D$ & D & P & & PB_DIR_V321 & $\begin{array}{l}\text { Diretor ceder o espaço escolar para eventos } \\
\text { realizados pela comunidade (Nunca) }\end{array}$ & $x$ & & 0 & NÃO & NÃO & NÃ̃o & NÃo & NÃo \\
\hline $\bar{E}$ & AP & $\mathrm{p}$ & & PB_ESC_V172 & Biblioteca permite acesso do acervo à & $\mathrm{x}$ & $\mathrm{x}$ & 0 & SIM & NÃO & SIM & NÃ̃o & SIM \\
\hline$D$ & D & $\mathrm{P}$ & & PB_DIR_V472 & Receber apoio da Comunidade. & $\mathrm{x}$ & & o & SIM & SIM & SIM & SIM & $\operatorname{SIM}$ \\
\hline D & D & P & & PB_DIR_V327 & $\begin{array}{l}\text { Diretor promover a participação da } \\
\text { comunidade realizando trabalhos }\end{array}$ & $\mathrm{x}$ & $\mathrm{x}$ & 0 & SIM & SIM & SIM & SIM & SIM \\
\hline D & D & P & & PB_DIR_V212 & $\begin{array}{l}\text { Adotar política de admissão de alunos pelo } \\
\text { local de residência (vizinhança da escola) }\end{array}$ & $x$ & & 0 & SIM & SIM & SIM & SIM & NÃO \\
\hline D & D & P & \multirow{25}{*}{$\begin{array}{l}\text { Práticas de } \\
\text { Gestão }\end{array}$} & PB_DIR_V232 & $\begin{array}{l}\text { Atribuição de aulas considerando a escolha } \\
\text { dos professores, de acordo com a } \\
\text { pontuação por tempo de serviço e formação. }\end{array}$ & $\mathrm{x}$ & & 0 & SIM & SIM & NÃO & SIM & NÃO \\
\hline D & D & $\mathrm{p}$ & & PB_DIR_V161 & $\begin{array}{l}\text { Diretor realiza e participa de reuniões de } \\
\text { Conselho Escolar por três vezes ou mais no }\end{array}$ & $\mathrm{x}$ & & 0 & SIM & NÃ̃o & - & SIM & NÃO \\
\hline D & D & P & & PB_PROF_V186 & $\begin{array}{l}\text { Diretor promover reuniões de conselho } \\
\text { classe (órgão formado por todos os } \\
\text { professores que lecionam em cada série) }\end{array}$ & $\mathrm{x}$ & $\mathrm{x}$ & 0 & ث $75,36 \%$ & $100,00 \%$ & $100,00 \%$ & $100,00 \%$ & $100,00 \%$ \\
\hline D & $\mathrm{p}$ & P & & PB_PROF_V222 & $\begin{array}{l}\text { O Diretor informa com frequência sobre } \\
\text { possibilidades de aperfeiçoamento aos } \\
\text { professores }\end{array}$ & $\mathrm{x}$ & & 0 & 4,17\% & $0,00 \%$ & $0,00 \%$ & $0,00 \%$ & $0,00 \%$ \\
\hline $\mathrm{D}$ & D & $\mathrm{P}$ & & PB_DIR_V464 & Receber apoio das instâncias superiores. & $\mathrm{x}$ & & . & SIM & SIM & SIM & SIM & $\operatorname{SIM}$ \\
\hline D & D & P & & PB_DIR_V368 & $\begin{array}{l}\text { Merenda escolar: Disponibilidade de } \\
\text { recursos financeiros (Bom ou acima) }\end{array}$ & $\mathrm{x}$ & & 0 & SIM & SIM & SIM & SIM & NÃ̃o \\
\hline$D$ & D & $\mathrm{P}$ & & PB_DIR_V376 & Merenda escolar: Quantidade de Alimentos & $\mathrm{x}$ & & 0 & SIM & SIM & NÃO & SIM & SIM \\
\hline$D$ & $\mathrm{D}$ & $\mathrm{P}$ & & PB_DIR_V383 & Merenda escolar: Qualidade dos Alimentos & $\mathrm{x}$ & & o & SIM & SIM & NÃO & SIM & SIM \\
\hline$D$ & $\mathrm{D}$ & $\mathrm{p}$ & & PB_DIR_V390 & Merenda escolar: Espaço Físico para & $\mathrm{x}$ & & a & SIM & NÃO & NÃO & NÃO & SIM \\
\hline D & D & $\mathrm{P}$ & & PB_PROF_V263 & Garantir que o quadro de pessoal de apoio & $\mathrm{x}$ & $\mathrm{x}$ & o] & 仓 $90,00 \%$ & $100,00 \%$ & $100,00 \%$ & $100,00 \%$ & $100,00 \%$ \\
\hline$D$ & D & $\mathrm{P}$ & & PB_DIR_V406 & Garantir que o quadro docente esteja & $x$ & & 0 & SIM & SIM & NÃO & NÃO & SIM \\
\hline D & D & P & & PB_DIR_V412 & $\begin{array}{l}\text { Garantir que o quadro de funcionários } \\
\text { administrativos seja adequado à estrutura }\end{array}$ & $\mathrm{x}$ & & 0 & NÃO & NÃO & NÃO & NÃO & NÃO \\
\hline D & D & P & & PB_DIR_V418 & $\begin{array}{l}\text { Garantir que o quadro de apoio pedagógico } \\
\text { (coordenador, supervisor, orientador) esteja }\end{array}$ & $x$ & $\mathrm{x}$ & 0 & 仓ि $90,06 \%$ & $100,00 \%$ & $100,00 \%$ & $100,00 \%$ & $100,00 \%$ \\
\hline E & AP & P & & PB_ESC_V14 & $\begin{array}{l}\text { Apresentar infraestrutura em boas } \\
\text { condições de conservação e em } \\
\text { funcionamento. }\end{array}$ & $\mathrm{x}$ & & 0 & 仓 $74,61 \%$ & $100,00 \%$ & $0,00 \%$ & $0,00 \%$ & $100,00 \%$ \\
\hline$E$ & AP & $P$ & & PB_ESC_V43 & Todas as salas são bem iluminadas. & $\mathrm{x}$ & & 0 & SIM & SIM & SIM & SIM & SIM \\
\hline $\mathrm{E}$ & AP & P & & PB_ESC_V61 & $\begin{array}{l}\begin{array}{l}\text { Controle de entrada de pessoas estranhas } \\
(\text { Bom })\end{array} \\
\end{array}$ & $\mathrm{x}$ & & 0 & SIM & $\operatorname{sIM}$ & SIM & SIM & SIM \\
\hline E & AP & P & & PB_ESC_V79 & $\begin{array}{l}\text { Sistema policiamento para inibição ao } \\
\text { tráfico de drogas dentro da escola e nas }\end{array}$ & $x$ & & 0 & SIM & SIM & NÃO & NÃO & NÃO \\
\hline E & AP & $\mathrm{p}$ & & PB_ESC_V91 & $\begin{array}{l}\text { Disponibilidade e número de computadores } \\
\text { para uso dos alunos (Bom) }\end{array}$ & $x$ & & 0 & SIM & SIM & SIM & NÃ̃o & SIM \\
\hline $\mathrm{E}$ & AP & $\mathrm{P}$ & & PB_ESC_V97 & Acesso à internet banda-larga para os & $\mathrm{x}$ & & 0 & SIM & SIM & SIM & NÃ̃o & SIM \\
\hline E & AP & $\mathrm{p}$ & & PB_ESC_V103 & $\begin{array}{l}\begin{array}{l}\text { Disponibilidade de computadores para uso } \\
\text { dos professores (Bom) }\end{array} \\
\end{array}$ & $x$ & $\mathrm{x}$ & 0 & SIM & SIM & SIM & NÃO & SIM \\
\hline E & AP & $\mathrm{P}$ & & PB_ESC_V109 & Acesso à internet banda-larga para os & $\mathrm{x}$ & & 0 & SIM & SIM & SIM & SIM & SIM \\
\hline $\mathrm{E}$ & AP & P & & C_ESC_V14 & $\begin{array}{l}\text { Disponibilidade de computadores para uso } \\
\text { dos funcionários administrativos }\end{array}$ & $\mathrm{x}$ & & 0 & 仓 $10,80 \%$ & $11,00 \%$ & $8,00 \%$ & $5,00 \%$ & $7,00 \%$ \\
\hline $\bar{E}$ & AP & c & & C_ESC_V09 & Escola possui impressora & $\mathrm{x}$ & & 0. & 个 $1,20 \%$ & $2,00 \%$ & $1,00 \%$ & $4,00 \%$ & $2,00 \%$ \\
\hline$D$ & $\mathrm{P}$ & $\mathrm{P}$ & & PB_PROF_V231 & O Diretor se envolve com frequência com as & $\mathrm{x}$ & & 0 & 仓 $50,54 \%$ & $0,00 \%$ & $50,00 \%$ & $100,00 \%$ & $50,00 \%$ \\
\hline D & P & P & & PB_PROF_V235 & $\begin{array}{l}\text { O Diretor se envolve com frequência na } \\
\text { manutenção da escola }\end{array}$ & $x$ & & 0 & 仓 $51,56 \%$ & $0,00 \%$ & $50,00 \%$ & $100,00 \%$ & $50,00 \%$ \\
\hline
\end{tabular}


Continuação

\begin{tabular}{|c|c|c|c|c|c|c|c|c|c|c|c|c|c|}
\hline$\underset{z}{E}$ & 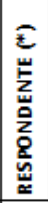 & 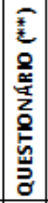 & GRUPO & 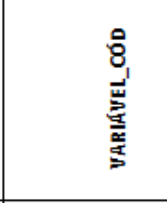 & VARIÁVEL_DESCRIÇÃO & 妾 & 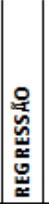 & 은 & $\frac{5}{\Sigma}$ & 造 & 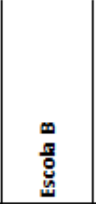 & $\begin{array}{l}u \\
\text { 吾 } \\
\ddot{u}\end{array}$ & 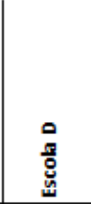 \\
\hline $\mathrm{D}$ & $D$ & $\mathrm{P}$ & & PB_DIR_V488 & Buscar apoio financeiro de empresas & $\mathrm{x}$ & & 0 & SIM & NÃO & NÃO & NÃO & SIM \\
\hline D & D & P & & PB_DIR_V400 & $\begin{array}{l}\text { Não haver interrupção das atividades } \\
\text { escolares por falta de recursos financeiros. }\end{array}$ & $x$ & & 0 & SIM & SIM & SIM & NÃO & SIM \\
\hline D & D & $P$ & $\begin{array}{l}\text { Práticas de } \\
\text { Gestão }\end{array}$ & PB_DIR_V342 & $\begin{array}{l}\text { Diretor garantir uma infraestrutura } \\
\text { adequada para atendimento às pessoas } \\
\text { com deficiência ou necessidades especiais. }\end{array}$ & $\mathrm{x}$ & $\mathrm{x}$ & 0 & $\operatorname{SIM}$ & NÃO & NÃO & NÃO & SIM \\
\hline$E$ & $\mathrm{AP}$ & $\mathrm{P}$ & & PB_ESC_V133 & Existência de sala de leitura para os & $\mathrm{x}$ & & O & $\operatorname{SIM}$ & SIM & NÃO & NÃO & SIM \\
\hline E & AP & P & & PB_ESC_V181 & $\begin{array}{l}\text { Existência de pessoa responsável pelo } \\
\text { atendimento na biblioteca }\end{array}$ & $x$ & $\mathrm{x}$ & 0 & SIM & SIM & NÃO & NÃO & $\operatorname{sIM}$ \\
\hline $\mathrm{E}$ & $\mathrm{AP}$ & $\mathrm{P}$ & & PB_ESC_V172 & Biblioteca permite acesso do acervo à & $\mathrm{x}$ & $\mathrm{x}$ & 0 & $\operatorname{SIM}$ & NÃO & $\operatorname{sim}$ & NÃO & SIM \\
\hline $\mathrm{E}$ & $\mathrm{AP}$ & $\mathrm{P}$ & & PB_ESC_V127 & Existência de Biblioteca em boas condições & $\mathrm{x}$ & & . & $\operatorname{sIM}$ & $\operatorname{sim}$ & NÃO & NÃO & SIM \\
\hline D & P & P & \multirow{14}{*}{$\begin{array}{l}\text { Práticas } \\
\text { Pedagógicas }\end{array}$} & PB_PROF_V219 & $\begin{array}{l}\text { O professor e o diretor compreenderem que } \\
\text { a qualidade é uma responsabilidade } \\
\text { coletiva auxilia na melhora do desempenho }\end{array}$ & $\mathrm{x}$ & & 0 & 个 $41,46 \%$ & $0,00 \%$ & $0,00 \%$ & $100,00 \%$ & $50,00 \%$ \\
\hline D & P & P & & PB_DIR_V264 & $\begin{array}{l}\text { Diretor discute com os professores medidas } \\
\text { com o objetivo de melhorar o ensino e a } \\
\text { aprendizagem dos alunos (Sempre ou }\end{array}$ & $\mathrm{x}$ & $\mathrm{x}$ & 0 & $\operatorname{SIM}$ & NÃO & NÃO & NÃO & NÃO \\
\hline $\mathrm{P}$ & P & P & & PB_PROF_V215 & $\begin{array}{l}\text { Discussão frequente com a Direção sobre as } \\
\text { metas educacionais melhora o }\end{array}$ & $x$ & & 0 & ß $3,97 \%$ & $0,00 \%$ & $0,00 \%$ & $0,00 \%$ & $0,00 \%$ \\
\hline $\mathrm{D}$ & P & P & & PB_DIR_V503 & $\begin{array}{l}\text { Escola receber os livros didáticos } \\
\text { escolhidos no início das aulas }\end{array}$ & $\mathrm{x}$ & & 0 & 个 $71,40 \%$ & $100,00 \%$ & $50,00 \%$ & $100,00 \%$ & $100,00 \%$ \\
\hline $\mathrm{D}$ & $\mathrm{P}$ & $\mathrm{P}$ & & PB_DIR_V509 & Todos os alunos terem o livro didático & $\mathrm{X}$ & & 0 & $66,72 \%$ & $100,00 \%$ & $50,00 \%$ & $100,00 \%$ & $100,00 \%$ \\
\hline $\mathrm{T}$ & AP & c & & C_TURM_V08 & $\begin{array}{l}\text { Oferta da disciplina Língua Estrangeira está } \\
\text { associada ao bom desempenho. }\end{array}$ & $\mathrm{x}$ & & 0 & $\operatorname{SIM}$ & SIM & SIM & SIM & SIM \\
\hline $\mathrm{D}$ & $\mathrm{D}$ & $\mathrm{P}$ & & PB_DIR_V196 & Diretor acompanhar os resultados do SAEB & $\mathrm{x}$ & & 0 & $\operatorname{SIM}$ & NÃO & SIM & SIM & SIM \\
\hline $\mathrm{D}$ & $\mathrm{D}$ & $\mathrm{P}$ & & PB_DIR_V201 & Diretor acompanhar os resultados do SAEB & $\mathrm{x}$ & & 0 & $\operatorname{SIM}$ & $\operatorname{sim}$ & SIM & SIM & SIM \\
\hline $\mathrm{D}$ & D & $\mathrm{P}$ & & PB_DIR_V206 & Diretor acompanhar os resultados do SAEB & $\mathrm{x}$ & & 0 & $\operatorname{sIM}$ & NÃO & SIM & SIM & SIM \\
\hline D & D & P & & PB_DIR_V226 & $\begin{array}{l}\text { Adotar critério de formação de turmas } \\
\text { heterogêneas em relação ao rendimento. }\end{array}$ & $x$ & & 0 & SIM & NÃO & NÃO & SIM & NÃO \\
\hline D & D & P & & PB_DIR_V246 & $\begin{array}{l}\text { Diretor realizar ações para redução das } \\
\text { taxas de abandono. }\end{array}$ & $x$ & & 0 & $\operatorname{SIM}$ & $\operatorname{SIM}$ & SIM & SIM & $\operatorname{siM}$ \\
\hline $\mathrm{A}$ & A & $P$ & & PB_ALUN_V38 & Cobrança dos pais para a frequência às & $\mathrm{x}$ & & 0 & $98,60 \%$ & $100,00 \%$ & $99,00 \%$ & $100,00 \%$ & $98,00 \%$ \\
\hline D & D & P & & PB_DIR_V253 & $\begin{array}{l}\text { Adoção de ações para a redução da } \\
\text { reprovação }\end{array}$ & $\mathrm{x}$ & $x$ & O & $\operatorname{SIM}$ & SIM & NÃO & NÃO & $\operatorname{siM}$ \\
\hline $\mathrm{D}$ & D & $\mathrm{P}$ & & PB_DIR_V258 & Oferta de reforço no contraturno & $x$ & & 0 & $\operatorname{sIM}$ & SIM & SIM & SIM & SIM \\
\hline A & A & P & \multirow{4}{*}{$\begin{array}{l}\text { Participação da } \\
\text { Familia }\end{array}$} & PB_ALUN_V29 & $\begin{array}{l}\text { Participação dos pais em reuniões } \\
\text { escolares }\end{array}$ & $x$ & & 0 & 个 $55,40 \%$ & $86,00 \%$ & $67,00 \%$ & $69,00 \%$ & $64,00 \%$ \\
\hline $\mathrm{A}$ & A & $\mathrm{P}$ & & PB_ALUN_V34 & Cobrança dos pais sobre os deveres de casa & $\mathrm{x}$ & & 0 & 个完 $95,10 \%$ & $100,00 \%$ & $98,00 \%$ & $92,00 \%$ & $95,00 \%$ \\
\hline $\mathrm{A}$ & A & P & & PB_ALUN_V38 & Cobrança dos pais para a frequência às & $\mathrm{x}$ & & 0 & 个 $98,60 \%$ & $100,00 \%$ & $99,00 \%$ & $100,00 \%$ & $98,00 \%$ \\
\hline A & A & $\mathrm{P}$ & & PB_ALUN_V36 & Incentivo dos pais à leitura & $\mathrm{x}$ & & 0 & 个 $88,40 \%$ & $95,00 \%$ & $91,00 \%$ & $88,00 \%$ & $86,00 \%$ \\
\hline $\mathrm{A}$ & A & $\mathrm{P}$ & \multirow{10}{*}{$\begin{array}{l}\text { Aspectos } \\
\text { Familiares }\end{array}$} & PB_ALUN_V07 & Mãe com ensino primário incompleto & $\mathrm{x}$ & $\mathrm{x}$ & 0 & $15,70 \%$ & $9,00 \%$ & $12,00 \%$ & $23,00 \%$ & $19,00 \%$ \\
\hline A & A & $\mathrm{P}$ & & PB_ALUN_V11 & Mãe com curso superior completo & $\mathrm{x}$ & $\mathrm{x}$ & 0 & 个 $12,30 \%$ & $5,00 \%$ & $12,00 \%$ & $8,00 \%$ & $5,00 \%$ \\
\hline $\mathrm{A}$ & A & $\mathrm{P}$ & & PB_ALUN_V22 & Pai com curso superior completo & $\mathrm{x}$ & $\mathrm{x}$ & 0 & ب $9,10 \%$ & $9,00 \%$ & $10,00 \%$ & $0,00 \%$ & $0,00 \%$ \\
\hline $\mathrm{A}$ & A & $\mathrm{P}$ & & PB_ALUN_V24 & Pai sabe ler e escrever & $\mathrm{x}$ & $\mathrm{x}$ & 0 & $95,70 \%$ & $95,00 \%$ & $100,00 \%$ & $92,00 \%$ & $98,00 \%$ \\
\hline $\mathrm{A}$ & A & $\mathrm{P}$ & & PB_ALUN_V44 & Mãe sabe ler e escrever & $\mathrm{x}$ & $\mathrm{x}$ & 0 & 个 $97,80 \%$ & $95,00 \%$ & $100,00 \%$ & $100,00 \%$ & $95,00 \%$ \\
\hline $\mathrm{A}$ & $\mathrm{P}$ & $\mathrm{P}$ & & PB_PROF_V272 & Influência do meio social do aluno & $\mathrm{x}$ & & 0 & 个 $23,13 \%$ & $0,00 \%$ & $50,00 \%$ & $0,00 \%$ & $33,33 \%$ \\
\hline $\mathrm{A}$ & $\mathrm{P}$ & $\mathrm{P}$ & & PB_PROF_V274 & Nivel cultural dos pais & $\mathrm{x}$ & & 0 & 个 $24,03 \%$ & $0,00 \%$ & $50,00 \%$ & $0,00 \%$ & $0,00 \%$ \\
\hline $\mathrm{A}$ & A & $\mathrm{P}$ & & PB_ALUN_V47 & Vê a mãe lendo & $\mathrm{x}$ & $x$ & 0 & 仓 $88,90 \%$ & $95,00 \%$ & $86,00 \%$ & $92,00 \%$ & $81,00 \%$ \\
\hline A & A & $P$ & & \begin{tabular}{|l|} 
PB_ALUN_V27 \\
\end{tabular} & Vê o pai lendo & $\mathrm{x}$ & & 0 & $74,60 \%$ & $90,00 \%$ & $79,00 \%$ & $69,00 \%$ & $71,00 \%$ \\
\hline A & A & P & & PB_ALUN_V02 & $\begin{array}{l}\text { Possui computador em casa tem efeito } \\
\text { positivo }\end{array}$ & $x$ & & 0 & \& $19,30 \%$ & $27 \%$ & $11 \%$ & 23 & 24 \\
\hline $\mathrm{A}$ & $\mathrm{P}$ & $\mathrm{P}$ & \multirow{7}{*}{ Hábitos do Aluno } & PB_PROF_V280 & Desinteresse e falta de esforço dos alunos & $\mathrm{x}$ & & 0 & ? $91,68 \%$ & $100,00 \%$ & $100,00 \%$ & $100,00 \%$ & $100,00 \%$ \\
\hline $\mathrm{A}$ & $\mathrm{P}$ & $\mathrm{P}$ & & PB_PROF_V278 & Baixa Autoestima do Aluno & $\mathrm{x}$ & & 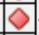 & $66,88 \%$ & $0,00 \%$ & $50,00 \%$ & $100,00 \%$ & $100,00 \%$ \\
\hline $\mathrm{A}$ & $\mathrm{P}$ & $P$ & & PB_PROF_V282 & Indisciplina dos alunos & $\mathrm{x}$ & & ㅇ․ & 2 $66,29 \%$ & $0,00 \%$ & $50,00 \%$ & $0,00 \%$ & $100,00 \%$ \\
\hline $\mathrm{A}$ & $\mathrm{P}$ & $\mathrm{P}$ & & PB_PROF_V284 & Alto índice de faltas do aluno (++) & $\mathrm{x}$ & & ㅇ. & $28,94 \%$ & $0,00 \%$ & $50,00 \%$ & $100,00 \%$ & $33,33 \%$ \\
\hline D & D & P & & PB_DIR_V457 & $\begin{array}{l}\text { Funcionamento da Escola interrompido por } \\
\text { problemas de indisciplina }\end{array}$ & $x$ & $\mathrm{x}$ & 0 & NÃO & NÃo & NÃo & SIM & NÃO \\
\hline $\mathrm{A}$ & A & $P$ & & PB_ALUN_V87 & Gosta da Disciplina de Língua Portuguesa & $\mathrm{x}$ & $x$ & 0 & 个 $72,70 \%$ & $73,00 \%$ & $79,00 \%$ & $81,00 \%$ & $67,00 \%$ \\
\hline A & A & P & & PB_ALUN_V107 & $\begin{array}{l}\text { Utilizar a biblioteca e sala de leitura da } \\
\text { escola (Sempre) }\end{array}$ & $\mathrm{x}$ & $\mathrm{x}$ & 0 & 个 $21,40 \%$ & $5,00 \%$ & $2,00 \%$ & $4,00 \%$ & $17,00 \%$ \\
\hline
\end{tabular}


Continuação

\begin{tabular}{|c|c|c|c|c|c|c|c|c|c|c|c|c|c|}
\hline 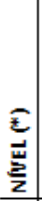 & 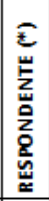 & 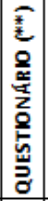 & GRUPO & 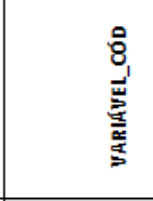 & VARIÁVEL_DESCRIÇÃO & $\underset{\mathrm{z}}{\mathrm{z}}$ & 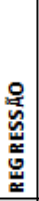 & 은 & $\frac{5}{5}$ & 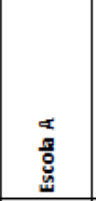 & 串 & 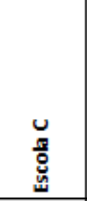 & 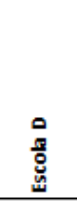 \\
\hline A & A & $\mathrm{P}$ & \multirow{14}{*}{ Hábitos do Aluno } & PB_ALUN_V66 & Frequência com que vai cinema (Sempre) & \begin{tabular}{l|l}
$\mathrm{x}$ & $\mathbf{n}$ \\
\end{tabular} & $\mathrm{x}$ & 0 & \& $15,90 \%$ & $14,00 \%$ & $31,00 \%$ & $8,00 \%$ & $0,00 \%$ \\
\hline A & A & $P$ & & PB_ALUN_V69 & $\begin{array}{l}\text { Frequência com que vai a espetáculos e } \\
\text { exposições (Sempre) }\end{array}$ & $\mathrm{x}$ & $\mathrm{x}$ & 0 & ? $7,20 \%$ & $5,00 \%$ & $6,00 \%$ & $0,00 \%$ & $14,00 \%$ \\
\hline A & A & P & & PB_ALUN_V74 & $\begin{array}{l}\text { Tempo gasto com tv, internet e jogos (uma a } \\
\text { duas horas/dia) }\end{array}$ & $\mathrm{x}$ & $\mathrm{x}$ & Or & 个 $19,90 \%$ & $18,00 \%$ & $16,00 \%$ & $15,00 \%$ & $14,00 \%$ \\
\hline A & A & P & & PB_ALUN_V89 & $\begin{array}{l}\text { Frequência com que faz o dever de casa de } \\
\text { Língua Portuguesa (Sempre) }\end{array}$ & $\mathrm{x}$ & $\mathrm{x}$ & Or & 个 $54,30 \%$ & $77,00 \%$ & $63,00 \%$ & $54,00 \%$ & $17,00 \%$ \\
\hline A & A & $\mathrm{P}$ & & PB_ALUN_V34 & Cobrança dos pais sobre os deveres de casa & $\mathrm{x}$ & & O & 个 $95,10 \%$ & $100,00 \%$ & $98,00 \%$ & $92,00 \%$ & $95,00 \%$ \\
\hline A & A & $\mathrm{P}$ & & PB_ALUN_V36 & Incentivo dos pais à leitura & $\mathrm{x}$ & & 0 & 个 $88,40 \%$ & $95,00 \%$ & $91,00 \%$ & $88,00 \%$ & $86,00 \%$ \\
\hline A & A & $\mathrm{P}$ & & PB_ALUN_V45 & Frequência de leitura de livros de interesse & $\mathrm{x}$ & & . & 个 $27,90 \%$ & $23,00 \%$ & $31,00 \%$ & $16,00 \%$ & $5,00 \%$ \\
\hline A & A & $\mathrm{P}$ & & PB_ALUN_V42 & Frequência de leitura de jornais (Sempre) & $\mathrm{x}$ & & 인. & \& $6,20 \%$ & $0,00 \%$ & $4,00 \%$ & $0,00 \%$ & $3,00 \%$ \\
\hline A & A & $\mathrm{P}$ & & PB_ALUN_V55 & Frequência de leitura de gibis (Algumas & $\mathrm{X}$ & & O & 亿 $44,10 \%$ & $45,00 \%$ & $48,00 \%$ & $38,00 \%$ & $47,00 \%$ \\
\hline A & A & $\mathrm{P}$ & & PB_ALUN_V48 & Frequência de leitura de livros de Literatura & $\mathrm{x}$ & & 용 & 仓 $24,10 \%$ & $23,00 \%$ & $31,00 \%$ & $13,00 \%$ & $13,00 \%$ \\
\hline A & A & $\mathrm{P}$ & & PB_ALUN_V57 & \begin{tabular}{|l|} 
Frequência de leitura de revistas de \\
comportamento (Sempre)
\end{tabular} & $\mathrm{x}$ & $\mathrm{x}$ & 0 & \& $27,40 \%$ & $36,00 \%$ & $19,00 \%$ & $8,00 \%$ & $28,00 \%$ \\
\hline A & A & $\mathrm{P}$ & & PB_ALUN_V51 & Frequência de leitura de revistas em geral & $\mathrm{x}$ & $\mathrm{x}$ & 0. & $15,70 \%$ & $10,00 \%$ & $16,00 \%$ & $22,00 \%$ & $5,00 \%$ \\
\hline $\mathrm{A}$ & A & $\mathrm{P}$ & & PB_ALUN_V60 & Frequência de leitura de notícias na & $\mathrm{x}$ & & 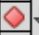 & $56,60 \%$ & $41,00 \%$ & $61,00 \%$ & $63,00 \%$ & $49,00 \%$ \\
\hline A & A & P & & PB_ALUN_V63 & Frequência de visitas à Biblioteca (Sempre) & $\mathrm{x}$ & & Or. & 仓 $11,40 \%$ & $0,00 \%$ & $6,00 \%$ & $0,00 \%$ & $7,00 \%$ \\
\hline \multicolumn{14}{|c|}{ Legenda: } \\
\hline \multicolumn{2}{|c|}{ Efeito: } & 8 & $\begin{array}{l}\text { Negativo } \\
\text { Positivo }\end{array}$ & & $\begin{array}{l}\left({ }^{*}\right) \mathrm{P}=\text { Professor } \mid \mathrm{A}=\text { Aluno } \mid \mathrm{D}=\text { Diretor } \mid \mathrm{T} \\
(* *) \mathrm{C}=\text { Censo Escolar } \mid \mathrm{B}=\text { Prova Brasil }\end{array}$ & & & & icola | & $A P=A p$ & dor a & va $\mathrm{B}$ & \\
\hline
\end{tabular}

Fonte: Elaborado pelo autor.

Os resultados desta etapa subsidiaram a elaboração dos roteiros de entrevista semiestruturados da etapa qualitativa, bem como para indicativos de itens a serem observados durante as visitas in loco. Na próxima seção serão apresentados os resultados encontrados nos estudos de caso.

\subsection{Descrição dos estudos de caso}

Neste tópico são apresentados os resultados da etapa qualitativa, realizada por meio do estudo de múltiplos casos. Foram visitadas duas escolas alto desempenho e duas escolas de baixo desempenho identificadas através de seu escore DEA.

Os dados a seguir são resultado de entrevistas realizadas junto aos Secretários Municipais de Educação dos municípios visitados, aos diretores escolares e professores de língua portuguesa, bem da observação da estrutura e de documentos e procedimentos apresentados pelos entrevistados. 
4.2.1 Análise do município "A" - alto desempenho

O Município “A” possuía, em 2010, 15 mil habitantes (IBGE, 2010), com PIB per capita de R\$ 16.058,64 (IBGE, 2015). Está localizado no interior do estado de São Paulo, próximo a importantes centros comerciais como Piracicaba, Limeira (Figura 19), para onde grande parte da força de trabalho se dirige, uma vez que o município não dispõe de grandes empreendimentos industriais, sendo sua economia basicamente direcionada à produção de cana-de-açúcar para abastecimento de usinas da região. O município também não possui escolas privadas de ensino básico.

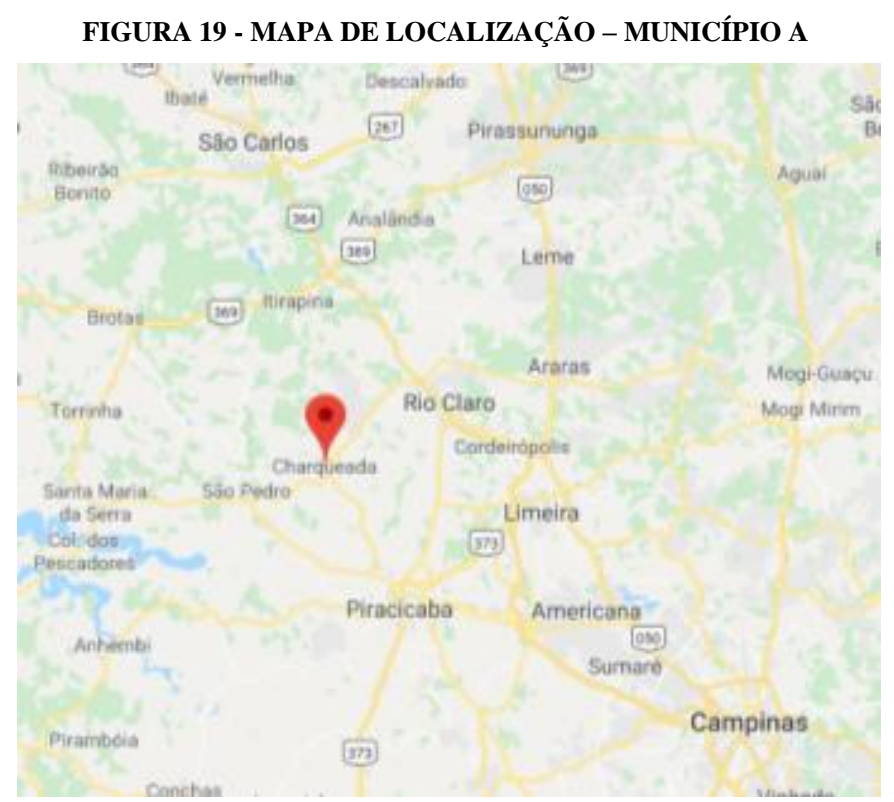

Fonte: Google Maps.

No setor educacional, o município apresenta taxa de escolarização da população de 06 a 14 anos de idade de 97,9\% (IBGE, 2010). A Tabela 10 apresenta a síntese dos dados do município.

TABELA 10 - DADOS DEMOGRÁFICOS - MUNICÍPIO A

\begin{tabular}{|l|l|l|l|l|l|}
\hline População $(*)$ & $\begin{array}{l}\text { IDH } \\
(*)\end{array}$ & $\begin{array}{l}\text { Renda Per Capita } \\
\text { Anual }(* *)\end{array}$ & $\begin{array}{l}\text { Número de } \\
\text { Escolas }(* * *)\end{array}$ & $\begin{array}{l}\text { Número } \\
\text { Alunos EF }\end{array}$ & $\begin{array}{l}\text { Investimento Anual Médio } \\
\text { por Aluno }(* * * *)\end{array}$ \\
\hline 15.085 & 0,736 & $\mathrm{R} \$ 16.058,64$ & 5 & 1.214 & $\mathrm{R} \$ 6354,11$ \\
\hline
\end{tabular}

Fonte: Elaborado pelo autor. | Base: (*) IBGE 2010; (**) IBGE 2015; (***) Censo Escolar 2015 (****); FINBRA - Investimento médio entre 2012, 2013 e 2014. 
Verificou-se pela Lei Orçamentária Anual de 2015 do município, que o maior investimento é realizado na educação infantil, que responde pelo uso de $74,78 \%$ de toda a verba destinada à pasta da educação, sendo que a maior parte do valor foi utilizada para a reforma de unidades escolares deste segmento. O Gráfico 21 apresenta a distribuição dos recursos do município na educação.

GRÁFICO 21 - DISTRIBUIÇÃO DO INVESTIMENTO EM EDUCAÇÃO - MUNICÍPIO A

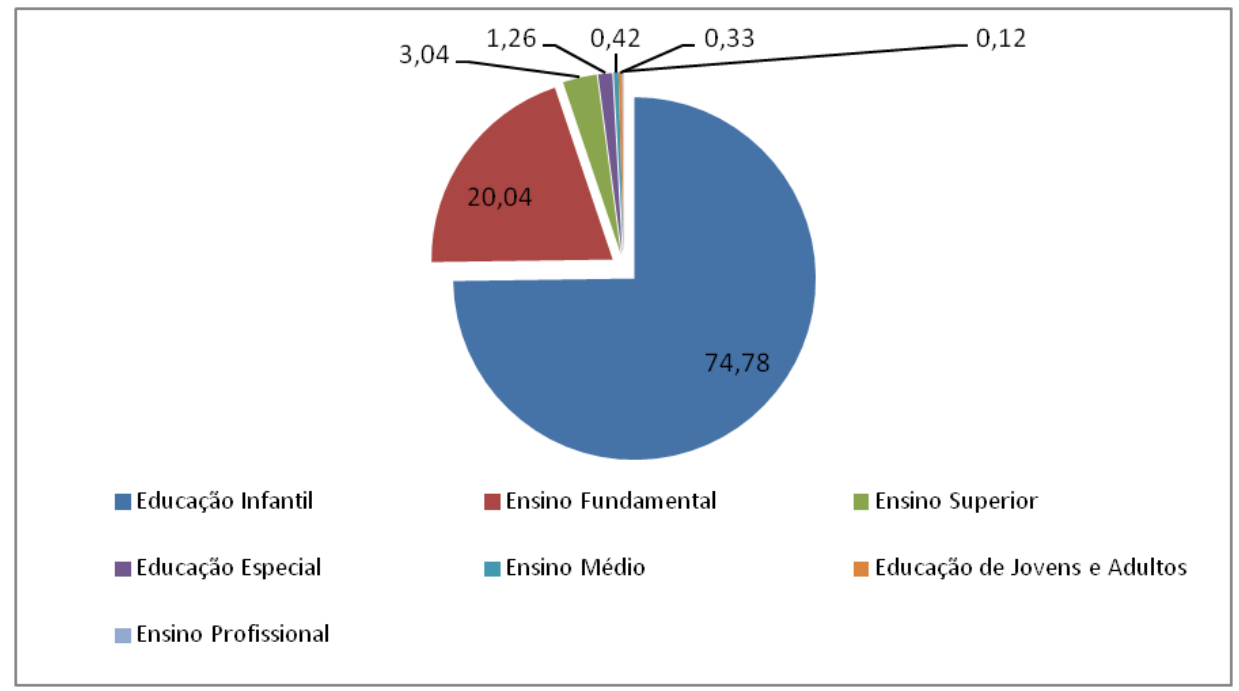

Fonte: Elaborado pelo autor. Base: Lei Orçamentária Anual 2015 do Município.

A visita ao município foi realizada no dia 11 de setembro de 2018, mediante prévio agendamento com a Secretaria Municipal de Educação. A seguir são apresentados os resultados das entrevistas realizadas com a Secretária Municipal de Educação, Diretora e Coordenadora Pedagógica e professora de Língua Portuguesa da escola selecionada.

\subsubsection{Análise Secretaria Municipal de Educação - município A}

\section{- Plano de Metas e Objetivos}

Segundo relato da Diretora, não há no município um plano com metas específicas a serem alcançadas, o que foi confirmado pela SME. Porém, nas reuniões realizadas quinzenalmente com a presença de todos os diretores da rede, a Secretária apresenta os 'resultados possíveis' para cada unidade escolar, com base nos resultados da avaliação padronizada realizada pelo município, a Avaliação de Aprendizagem e Processo (AAP). 


\section{- Trabalho com a SME e Autonomia do Diretor}

Foi relatado pela Diretora que, em geral, as decisões tomadas na escola recebem apoio da SME. Sua autonomia é razoável e pode decidir sobre a manutenção da escola, podendo realizar pequenos reparos com o uso caixa próprio, oriundo de doações da APM e de eventos realizados, sem necessidade de aprovação prévia. Também tem autonomia para a organização do transporte escolar e aceitação, ou não, de novas matrículas, de acordo com sua estrutura. As eventuais necessidades de alunos para a mudança de escola dependem de aval da SME.

Reportou, ainda, possuir acesso fácil à Supervisora Municipal de Educação e à própria Secretária Municipal de Educação, sempre que necessário. Apontou como ponto relevante para isso, o fato de que a ascensão ao cargo de diretor de escola no município se dá por meio de indicação, havendo, portanto, um contrato de confiança entre o Diretor e a Secretaria Municipal de Educação.

\section{- Política de Capacitação e Formação Continuada}

O Plano de Carreira Docente previa acréscimos de remuneração (de 5 a 10\%) aos professores, pela obtenção de certificados de pós-graduação, além de aumento na pontuação dos professores que realizavam cursos em áreas definidas como prioritárias pela SME. Porém, em razão de problemas de ordem orçamentária, o percentual foi reduzido (3\%). Em relação à formação continuada, não há programa específico. Fica a cargo dos professores identificar as necessidades e interesse.

\subsubsection{Análise da escola "A"}

Apesar de classificada como 'urbana' no Censo Escolar, a Escola A (Figura 20) está localizada em bairro rural, sendo assim também definida pela diretora, coordenadora e professores entrevistados. Seu acesso se dá por uma rodovia, ficando afastada cerca de $9 \mathrm{~km}$ do centro (Figura 21), atendendo a uma comunidade específica município. 
FIGURA 20 - FACHADA DA ESCOLA A

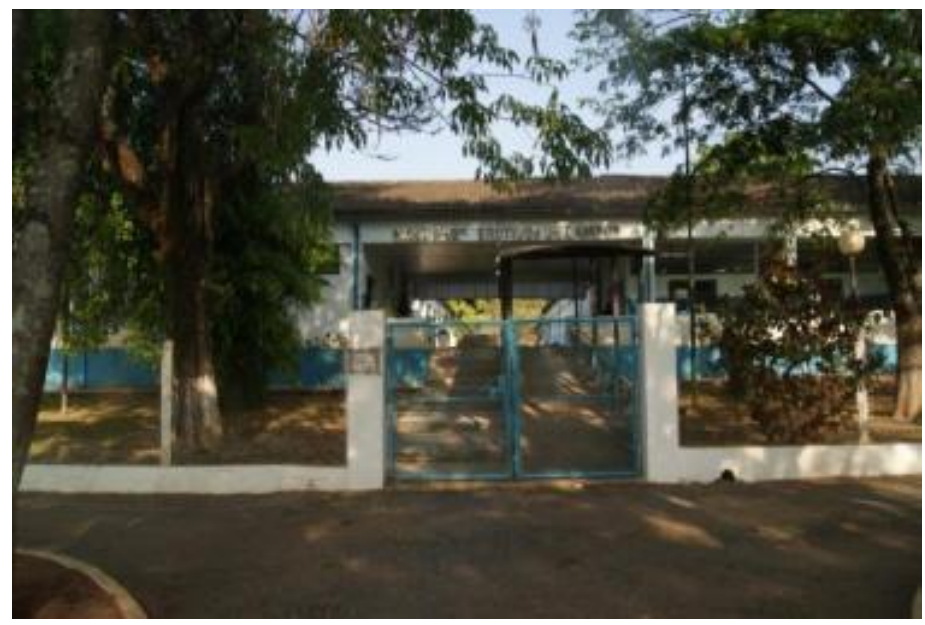

Fonte: arquivo pessoal do autor.

\section{FIGURA 21 - MAPA DE LOCALIZAÇÃO DA ESCOLA A}

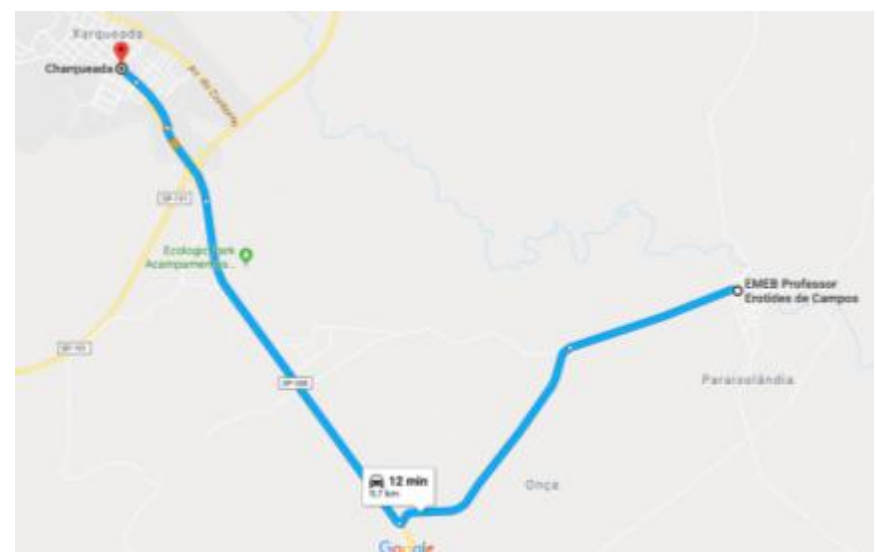

Fonte: Google Maps.

Segundo dados do Censo, a escola contava, em 2015, ano de realização da Prova Brasil, com 39 funcionários, responsáveis pelo atendimento de 139 estudantes do ensino fundamental I e 107 do ensino fundamental II. Dentre os alunos, 24 cursavam naquele ano a oitava série (nono ano) e participaram da avaliação.

Instalada em um prédio antigo, a escola foi 'reinaugurada' em 2002 e apresenta bom estado de conservação de sua infraestrutura física: paredes, telhados, piso, portas, janelas, corredores e pátio, não tendo sido relatados problemas pelos entrevistados. Instalações elétricas e hidráulicas também apresentam funcionamento adequado. Os banheiros se mostraram satisfatórios e limpos. No momento da visita foi constatada a existência de equipe de limpeza que, logo após o final das aulas do período matutino iniciaram a organização e limpeza das salas e demais instalações para a recepção dos estudantes do período vespertino. Na escola há a oferta da disciplina de Língua Inglesa. 
As salas de aula apresentam boa estrutura e mobiliário, com janelas amplas e ventiladores, garantindo, assim, boa luminosidade e ventilação. O mobiliário é novo, ergonômico e bem conservado (Figura 22).

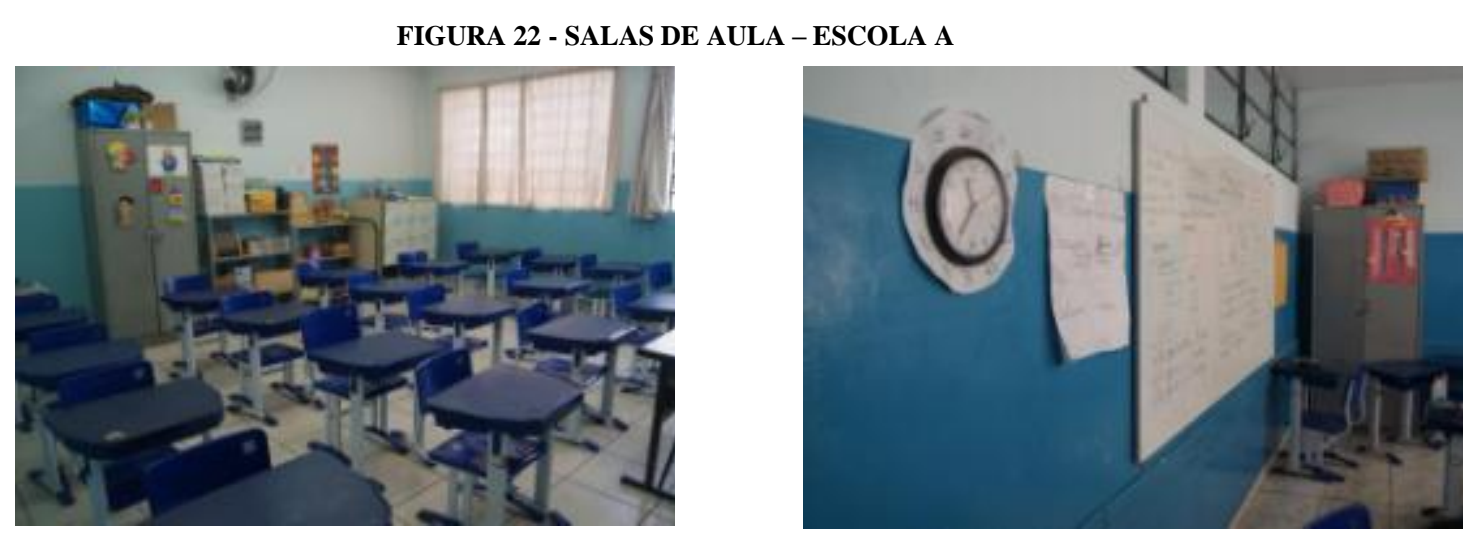

Fonte: arquivo pessoal do autor.

Segundo a direção, os tradicionais quadros negros estão sendo substituídos por lousas brancas com uso de canetas hidrográficas, uma vez que o pó do giz pode causar alergias tanto nos alunos quanto nos professores (Figura 22).

A escola dispõe de uma sala multimídia, com computador, projetor e equipamento de som em excelente estado de conservação e funcionamento (Figura 23). O recurso é utilizado com frequência pelos docentes das diversas disciplinas como forma de atrair a atenção dos estudantes aos conteúdos.

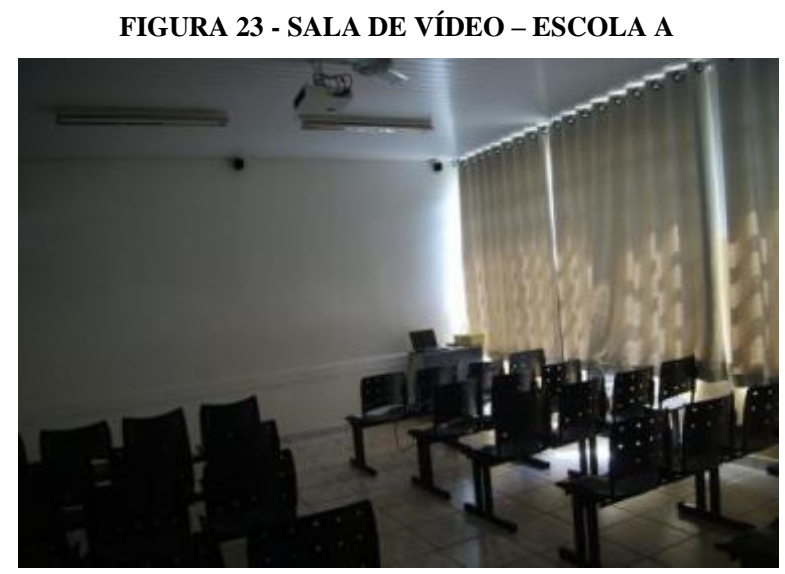

Fonte: arquivo pessoal do autor.

O laboratório de informática da escola passava por reforma no momento da visita. Os antigos computadores forem realocados na biblioteca da escola para uso temporário, uma vez que a SME havia recebido doação de equipamentos de uma empresa da cidade que fazia a troca de seu parque tecnológico à época (Figura 24). Os equipamentos, apesar de não serem 
novos, eram modernos e em excelente condição de uso de conservação, apresentando capacidade de processamento e armazenagem superiores aos já disponíveis na escola. Os equipamentos foram distribuídos entre as diversas escolas do município, sendo que treze foram destinados à escola visita.

A escola dispõe de dois serviços de internet disponíveis a funcionários, professores e alunos: um oferecido via link a partir da prefeitura, onde estão conectados os computadores administrativos, e outro contratado de provedor externo, acessível pelos computadores dos laboratórios de informática disponíveis aos estudantes.

Os laboratórios ficam à disposição dos alunos durante o período de aulas, para uso em atividades propostas pelos docentes, e fora do período para consulta e realização de pesquisas e trabalhos, mediante simples solicitação e agendamento com qualquer dos professores. A escola não dispõe de wifi e de aplicativos pedagógicos para ensino da língua portuguesa.

Foi relatado pelos professores entrevistados de que a escola dispõe de computadores e notebooks para uso dos docentes, tanto em aula quanto para a pesquisa, preparação das aulas e atividades. A escola também dispõe de impressora e copiadora para uso administrativo e pedagógico.

A SME dispõe de uma equipe própria que realiza os serviços de manutenção em todo o parque tecnológico da Secretaria.

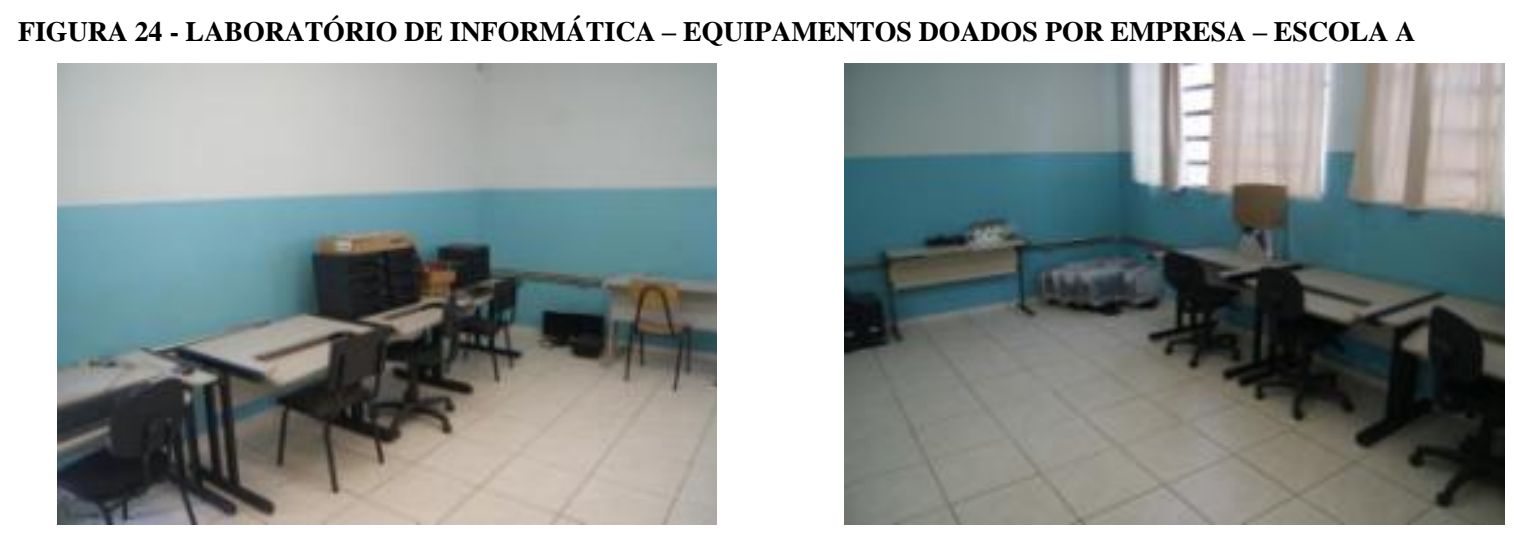

Fonte: arquivo pessoal do autor.

\section{- Acessibilidade}

Foi possível verificar que, apesar de constar no Censo Escolar que as dependências da escola não são acessíveis aos portadores de deficiência, a estrutura dispõe de rampas tanto para acesso externo à escola (embora não apresente a inclinação recomendada), quanto para as demais dependências como o pátio, refeitório e o Núcleo de Apoio Pedagógico (NAPE), 
conforme Figura 25. As salas de aula, biblioteca, secretaria e diretoria encontram-se no mesmo nível, não exigindo adaptações para este fim.
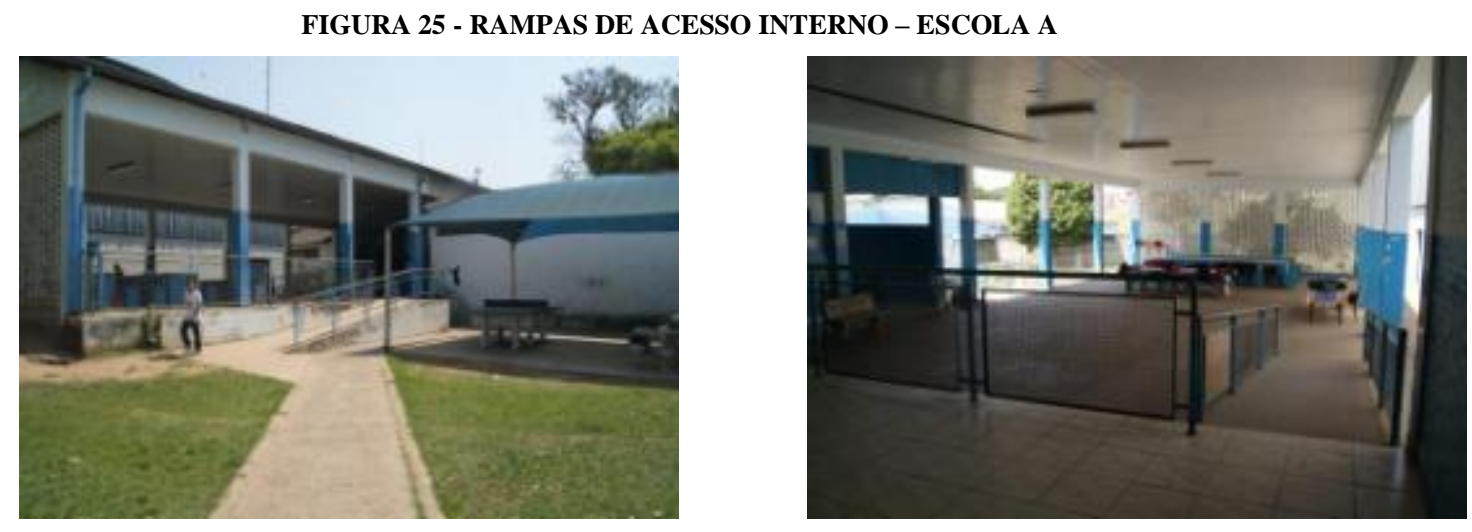

Fonte: arquivo pessoal do autor.

Os alunos ainda contam com um espaço para a prática de atividades recreativas com mesa de tênis de mesa e jogos de tabuleiro e de uma quadra coberta (Figura 26), utilizada para as aulas de educação física e para a prática de esportes. Esta estrutura é de uso exclusivo dos alunos, mas é eventualmente cedida para eventos do bairro e da igreja local.

FIGURA 26 - MESAS DE JOGOS E QUADRA POLIESPORTIVA- ESCOLA A
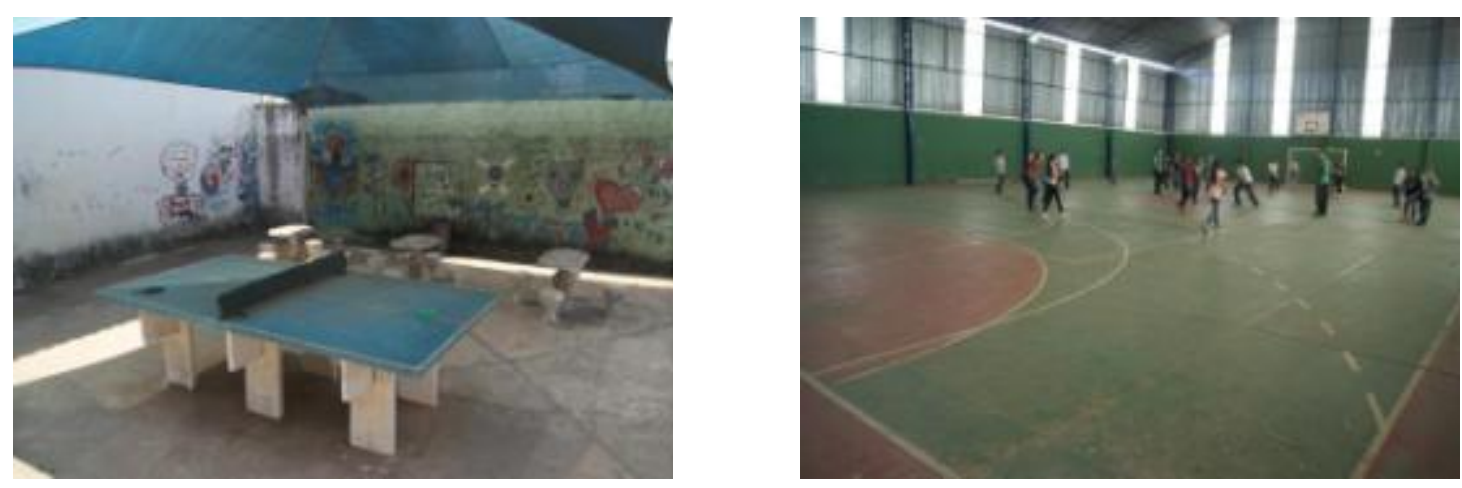

Fonte: arquivo pessoal do autor.

\section{- Merenda Escolar}

O cardápio da merenda escolar é elaborado por uma nutricionista do município e é preparada diariamente em uma Cozinha Modelo centralizada, que distribui as refeições para as escolas da rede.

A escola dispõe de uma pequena cozinha (Figura 27), limpa e equipada com uma geladeira, micro-ondas e água potável, destinada exclusivamente à armazenagem temporária e distribuição dos alimentos. Nesta cozinha, além do manuseio para distribuição dos alimentos, 
é feita a limpeza dos utensílios utilizados pelos alunos e a preparação de café e chá, servidos aos professores e funcionários na sala de docentes.

Segundo a diretora, a merenda é oferecida diariamente aos alunos sendo que, nos casos em que haja atividade no contraturno (ensaios para o desfile de 7 de setembro ou reforço escolar), também lhes é garantida a alimentação. Verificou-se que a merenda é entregue à escola em quantidade adequada para o número de estudantes atendido, não tendo havido casos de desabastecimento, bem como há uma variação de cardápio ao longo da semana.

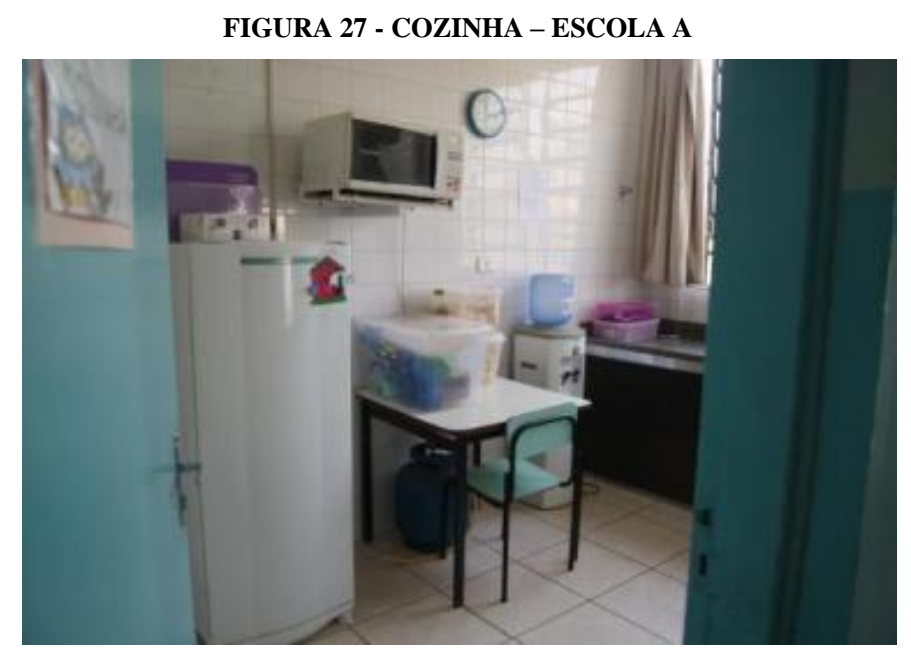

Fonte: arquivo pessoal do autor.

\section{- Biblioteca}

A biblioteca da escola (Figura 28) está localizada em sala próxima às salas de aula, o que facilita o acesso dos alunos. Sua infraestrutura é precária, contando com pouca variedade de títulos e baixo número de volumes para atender a todas as séries oferecidas na escola. Para a professora de Língua Portuguesa entrevistada ela 'não tem espaço e o acervo é pequeno e insuficiente'. A escola não dispõe de funcionário específico para a sua gestão, mas, segundo os entrevistados, ela permanece aberta durante todo o período das aulas, sendo acessível aos estudantes mediante simples solicitação aos professores que os acompanham para a escolha e retirada dos livros. 
FIGURA 28 - BIBLIOTECA - ESCOLA A
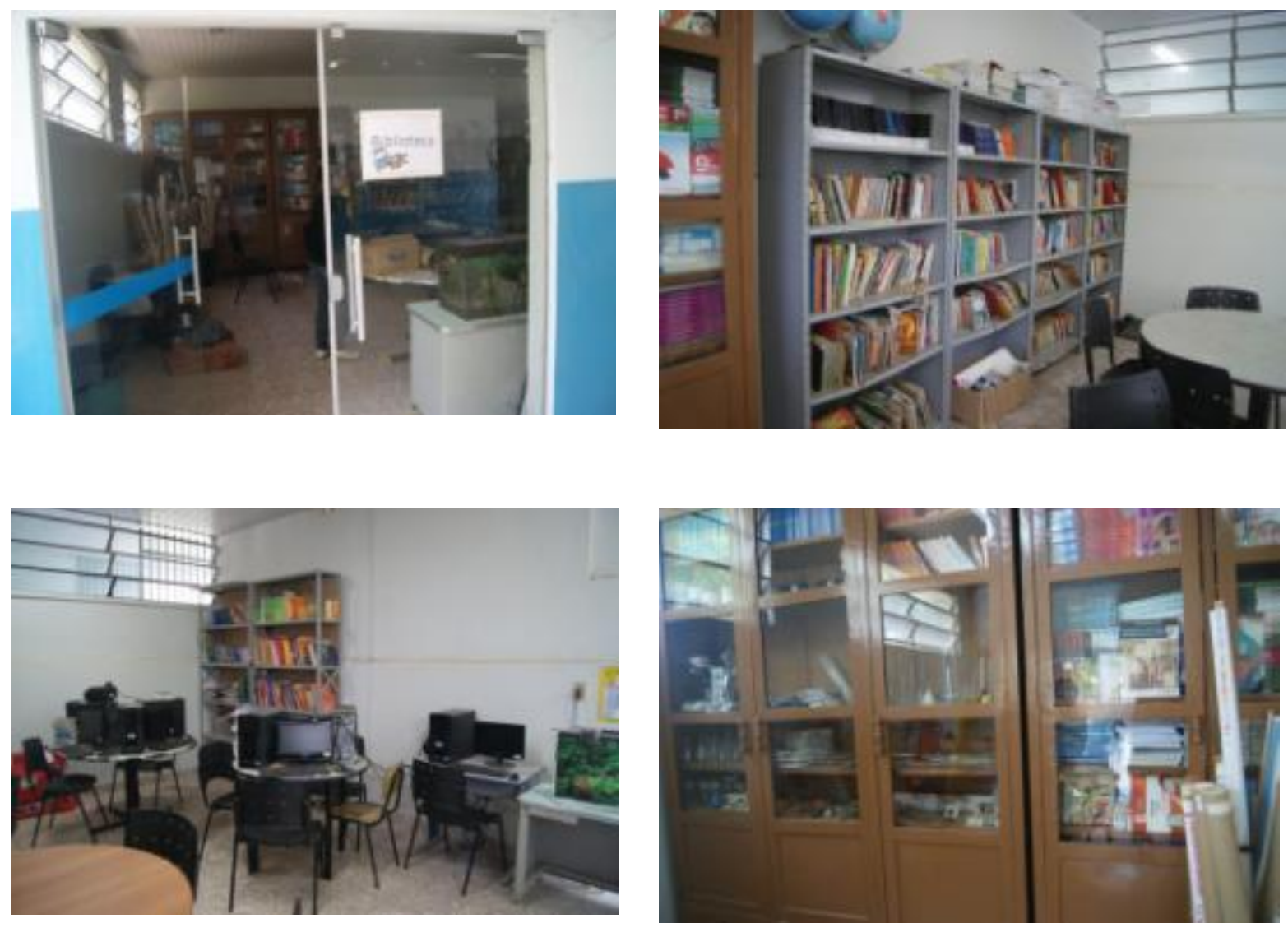

Fonte: arquivo pessoal do autor.

Apesar de não possuir uma sala de leitura, dispõe de mesas para leitura e trabalhos em grupo, que podem ser utilizadas pelos alunos, mesmo fora do horário das aulas. Compartilha o espaço da biblioteca uma estante onde são guardados equipamentos e vidrarias utilizadas em aulas de química e biologia, uma vez que a escola não possui laboratórios para esta finalidade, além de mapas.

\section{- Recursos para os Professores}

A sala dos professores (Figura 29) foi adaptada a partir de uma sala de aula, ficando localizada, portanto, próxima às demais salas e à sala da direção, facilitando o acesso pelos alunos. A estrutura conta com uma estante onde ficam disponíveis exemplares dos livros didáticos utilizados no ano letivo para cada série, duas mesas de reunião e uma mesa para trabalho individual e um quadro de avisos onde são afixados os comunicados oficiais. $\mathrm{Na}$ lousa são anotadas as datas importantes como avaliações e eventos previstos para o bimestre letivo em andamento. 
FIGURA 29 - SALA DOS PROFESSORES - ESCOLA A
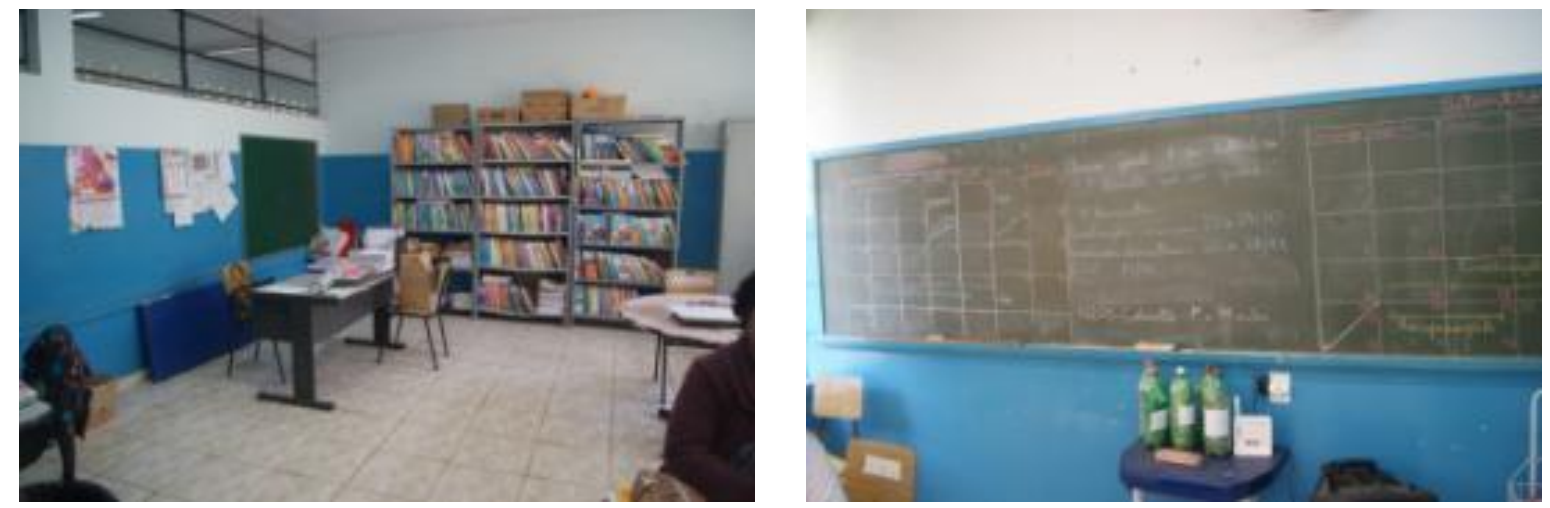

Fonte: arquivo pessoal do autor.

\section{- Disciplina discente e Regime Disciplinar}

Nas entrevistas, Diretora, Coordenadora e Professora relataram que a escola não possui problemas ligados à indisciplina dos alunos, que reconhecem e respeitam a autoridade dos professores e da equipe diretiva, sendo raríssimas as necessidades de intervenção da Direção neste quesito.

Para a garantia do amplo conhecimento das regras da escola, no início do ano letivo todos os alunos recebem uma cópia do Regimento Disciplinar, que é lido e explicado em sala, e encaminhado aos pais, que devem devolver uma cópia assinada do documento para arquivo na escola. Segundo a diretora, este documento é tratado pelos pais como um 'termo de compromisso' com a escola, os quais apoiam integralmente os seus termos.

Também foi relatado que, apesar de não haver ronda escolar, e as viaturas da Polícia Militar passarem eventualmente na região, a escola não enfrenta problemas relacionados ao tráfico de entorpecentes, tanto dentro quanto nas imediações.

\subsubsection{Diretor}

\subsection{Regime de trabalho, formação e experiência profissional}

Verificou-se que a Diretora possui carga horária semanal de 40 horas. Foi informado que o salário do município é maior da região, variando de $\mathrm{R} \$ 3.000,00$ (três mil reais) a $\mathrm{R} \$ 4.000,00$ (quatro mil reais), sendo superado apenas pelos valores pagos no município de Piracicaba (SP), o que permite ao profissional a manutenção de dedicação exclusiva à escola, sem necessidade de complementação de renda com atividades externas. 
O ingresso no cargo é feito por indicação da Secretaria Municipal de Educação o que, segundo a Diretora, resultando em um "contrato de confiança" com a equipe gestora, que realiza a cobrança da aplicação das políticas educacionais propostas. Para ser indicado o candidato deve apresentar, no mínimo, 05 (cinco) anos de experiência como professor. Esta experiência prévia foi apontada como 'essencial' pela Diretora - que reúne 09 (nove anos) como docente - para o exercício do cargo, uma vez que permite o conhecimento pleno do funcionamento da escola.

Além da graduação em Pedagogia, a Diretora possui, ainda, Especialização em Docência para o Ensino Fundamental e Especialização em Alfabetização e Letramento.

\section{- Transporte Escolar}

O transporte escolar é oferecido a todos os alunos, inclusive para a realização das atividades no contraturno, não tendo sido reportada interrupção dos serviços.

\subsection{Práticas de gestão}

\section{- Ações de Combate ao Abandono e à Evasão Escolar}

Verificou-se que o índice de evasão da escola visitada é baixo, o que é comprovado pelo Indicador de Rendimento 2015: 1,0 (um). Nas entrevistas, professora, coordenadora e diretora informaram ter, também, um baixíssimo índice de faltas e que, quando ocorrem, em geral estão relacionados a problemas de saúde, do aluno, ou de algum familiar. Foram relatados apenas dois casos recentes de faltas frequentes, pelo motivo já exposto, sendo que, em ambos os casos houve comunicado à escola pela família, uma vez que os estudantes necessitavam dar algum tipo de apoio ao familiar enfermo.

A escola adota um procedimento padrão para contato com os alunos faltantes. Ao identificar a falta, a Diretora realiza contato telefônico com a família para compreender o motivo da ausência. No caso de reincidência em falta por período superior a 5 (cinco) dias, e sem sucesso na tentativa de contato telefônico, é realizada uma visita pessoal pela diretora na residência do aluno, ocasião em que, além de identificar as razões da falta, a família é orientada sobre a importância da frequência e a obrigação legal dos responsáveis. Não sendo contornado o problema, e como última ação, o Conselho Tutelar do município é comunicado para que dê andamento aos processos legais cabíveis para a retomada dos estudos pelo aluno. Segundo os relatos, esta última instância praticamente não é utilizada uma vez que o contato 
próximo com as famílias permite a solução dos problemas mediante simples ação da própria escola.

Nos casos em que haja um afastamento por período prolongado (acima de 01 semana), os conteúdos e atividades são encaminhados ao responsável pelo aluno para efeito de reposição.

Adicionalmente, a escola desenvolve um projeto temático de "Combate ao Trabalho Infantil”, que visa à conscientização dos alunos e, em especial dos pais e responsáveis, uma vez que a está localizada em bairro rural, e grande parte dos estudantes é proveniente de famílias que têm como fonte de renda o trabalho no campo, submetendo os jovens, desde cedo a jornadas de trabalho que podem afastá-los das carteiras escolares.

\section{- Quadro Funcional da Escola}

A escola apresenta quadro funcional completo, em todos setores: corpo docente, secretaria, coordenação, merenda e limpeza. O preenchimento do quadro se dá via concurso público, o que reduz a rotatividade, uma vez que o funcionário é permanentemente lotado na unidade.

\section{- Atribuição de Aulas}

Os professores, assim como os funcionários administrativos, são contratados via concurso público. Os contratos de trabalho são regidos pela Consolidação das Leis Trabalhistas - CLT e os aprovados passam por um período probatório de 03 (três) anos.

A atribuição das aulas se dá de acordo com sua classificação no município, a qual é incrementada pelo tempo de trabalho do professor e número de aulas ministradas. Foi verificada a baixa rotatividade do corpo docente, sendo que a maioria atua na escola há vários anos. Segundo os entrevistados neste quesito (Diretora, Coordenadora Pedagógica e Professores de Língua Portuguesa), a baixa rotatividade favorece o ensino uma vez que o professor consegue acompanhar o desenvolvimento dos alunos, conhecendo suas características e eventuais necessidades pedagógicas, o que torna o trabalho em sala de aula mais produtivo desde o início do ano letivo e permite e continuidade de práticas implantadas. Segundo a Diretora, o prazo médio identificado na escola para que um professor ingressante na escola tome ciência das características da turma é de cerca de 2 (dois) meses. Neste período inicial, o professor ainda está em fase de diagnóstico junto à turma para a adaptação de sua trilha pedagógica. Assim, a manutenção de quadro docente permanente favorece, além 
da qualidade, a garantia do cumprimento integral dos conteúdos propostos para cada série e disciplina.

\section{- Estrutura para Alunos com Deficiência}

A escola possui rampas de acesso para todas as áreas, bem como banheiro adaptado. Os recursos para alunos com Necessidades Educacionais Especiais são fornecidos pela SME, mediante solicitação para cada caso específico.

A prefeitura também possui o Centro de Apoio à Pessoa Especial de Charqueada (CAPEC), além de duas pedagogas que fazem rodízio entre as escolas.

\section{- Captação de Recursos Externos}

O município destina $31 \%$ (trinta e um por cento) da receita total para a educação. Algumas ações são realizadas visando à captação de recursos externos adicionais, os quais são utilizados, principalmente, para a realização de pequenos reparos e adaptações da infraestrutura e a aquisição de materiais de consumo para os projetos pedagógicos.

A escola mantém um calendário de eventos onde são vendidos produtos, como pizzas, por exemplo, e montadas barracas para a venda de salgados e doces. Em geral se utilizam de ocasiões que fazem parte do calendário de atividades acadêmicas, como as reuniões de pais e Dia das Mães, o que aumenta a participação. Informaram que a realização de rifas não se mostra tão produtivo quanto a comercialização de itens, mesmo que a preço um pouco mais elevado, uma vez que quem os compra está consciente da destinação da arrecadação.

Não há projeto de captação de recursos diretamente com empresas, porém são recebidas doações esporádicas a partir de iniciativa destas instituições. Durante a visita verificou-se o recebimento de computadores provenientes de doação de organização local, que encontrava-se em período de renovação do parque tecnológico. Apesar de usados, verificou-se que os equipamentos recebidos eram mais novos e bem conservados do que aqueles já constantes da escola.

Outra importante fonte de arrecadação é a Associação de Pais e Mestres - APM da escola. Segundo a Direto é registrada Ata em cartório com a composição da APM a cada ano. Os pais auxiliam na organização dos eventos promovidos pela escola e contribuem com a APM frequentemente. A destinação dos valores arrecadados é definida de forma conjunta entre a direção e a APM, garantindo aos pais transparência no uso do recurso e fomentando sua atuação na preservação e melhoria das condições de infraestrutura da escola. 


\section{- Investimentos e Manutenção da Escola}

A SME confere às escolas autonomia para a gestão dos recursos financeiros disponibilizados, garantindo, assim, que o Diretor direcione os investimentos para o atendimento das necessidades locais. O acompanhamento das necessidades de manutenção também é de responsabilidade do Diretor que deve encaminhar à SME os pedidos de reparo e de eventuais adaptações, quando identificadas.

Semanalmente um funcionário da SME, responsável pelas obras de manutenção, faz visita à unidade escolar para realizar inspeção e verificar, junto à Diretora, as novas demandas. A prefeitura dispõe de equipe de manutenção própria que realiza pequenos reparos de forma rápida. Para grandes obras e/ou adaptações que não possam ser atendidas por esta equipe, é aberto edital para licitação do serviço desejado.

Durante a visita verificou-se que estava em andamento obra para a reforma da brinquedoteca da escola, conforme Figura 30.
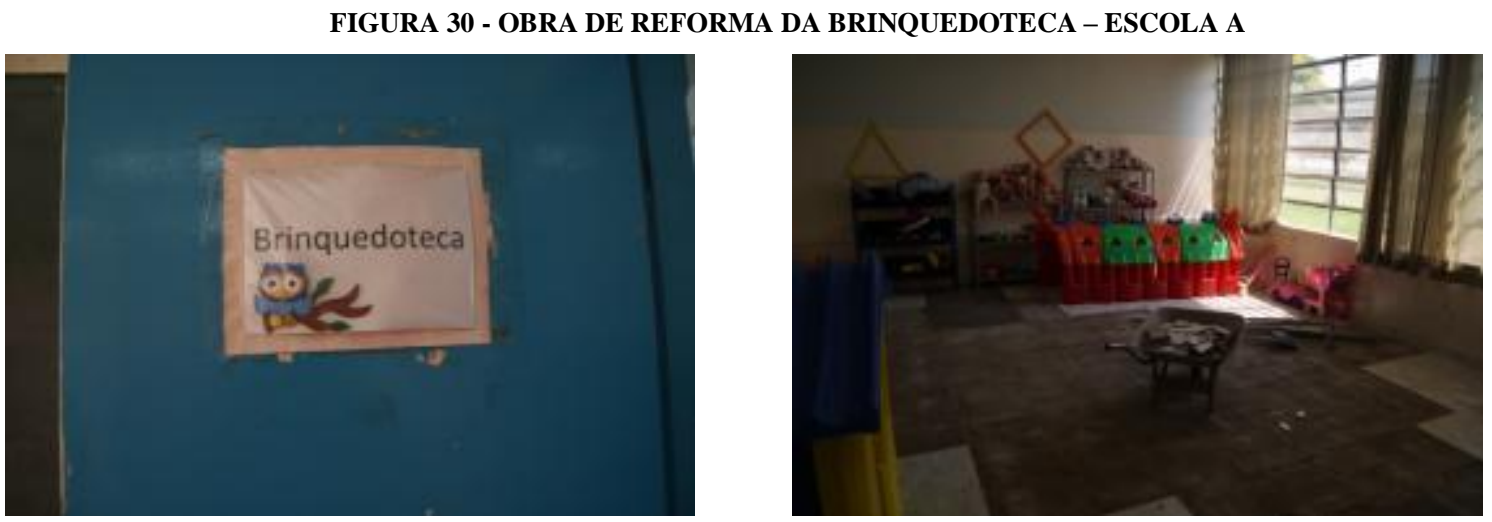

Fonte: arquivo pessoal do autor.

\subsection{Práticas pedagógicas}

\section{- Oferta de Reforço no Contraturno}

O município desenvolveu o Núcleo de Apoio Pedagógico - NAPE. Este núcleo, que fica em prédio anexo à escola (Figura 31 e Figura 32), oferece atividades no contraturno para alunos com dificuldades de aprendizagem. As atividades compreendem as disciplinas de Língua Portuguesa, Matemática, Língua Inglesa e incluem, ainda, Educação Física. Também são atendidos alunos que, mesmo sem dificuldades de aprendizagem, apresentam condições socioeconômicas que exigem a matrícula em tempo integral. 
FIGURA 31 - PRÉDIO DO NÚCLEO DE APOIO PEDAGÓGICO - NAPE - ESCOLA A

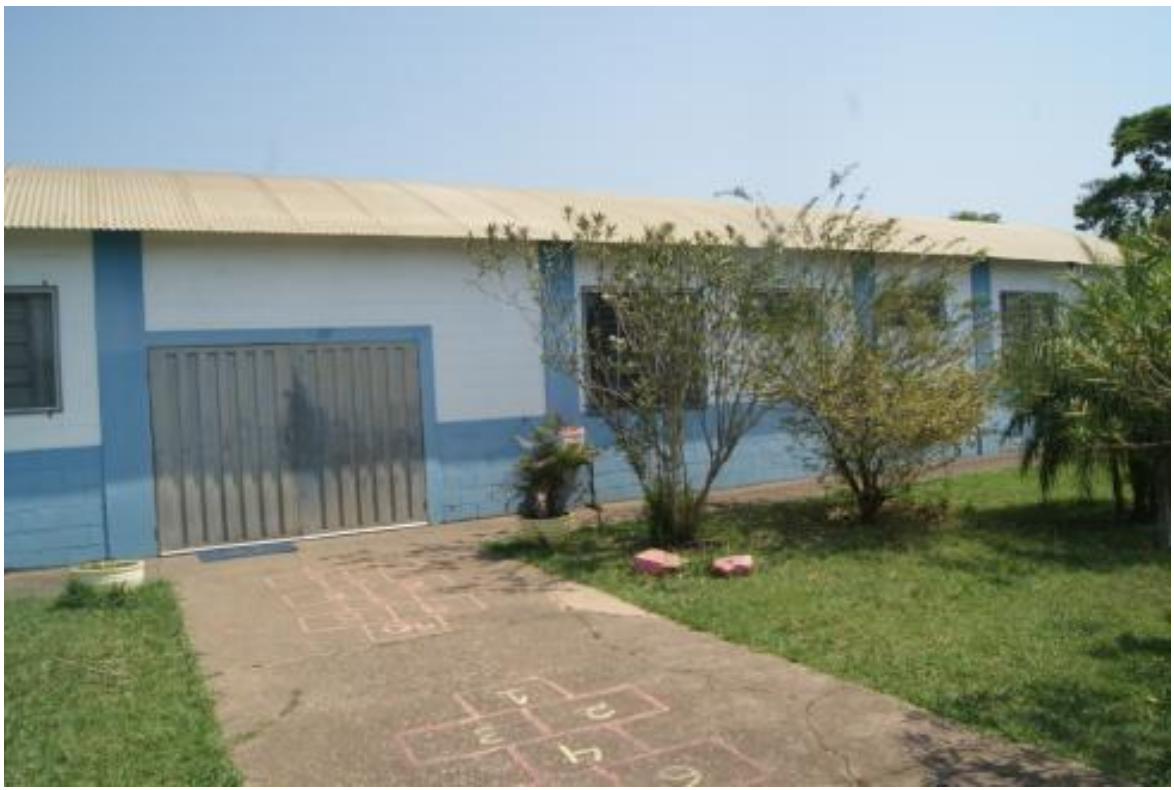

Fonte: arquivo pessoal do autor.

FIGURA 32 - SALAS DE AULA DO NAPE - ESCOLA A
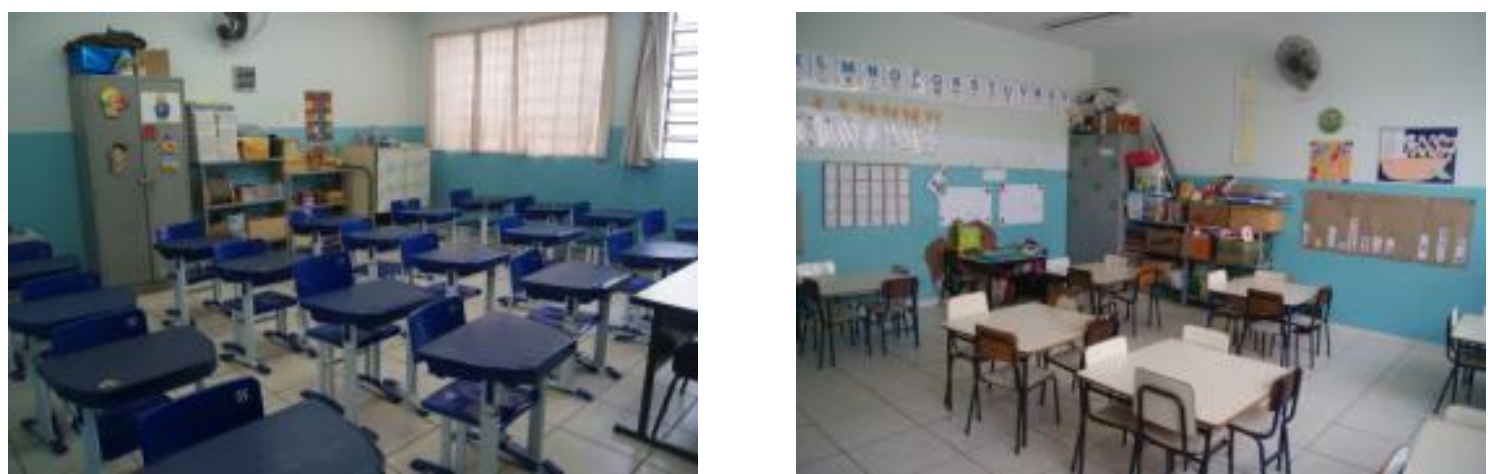

Fonte: arquivo pessoal do autor.

No NAPE, além das atividades de reforço, são utilizados jogos pedagógicos (Figura 33) e realizadas práticas de leitura e produção de texto. A Figura 34 apresenta cartaz referente à atividade 'Teatro de Leitores', promovido pela professora de Língua Portuguesa do NAPE. 
FIGURA 33 - JOGOS PEDAGÓGICOS E MATERIAIS DE APOIO - NAPE - ESCOLA A
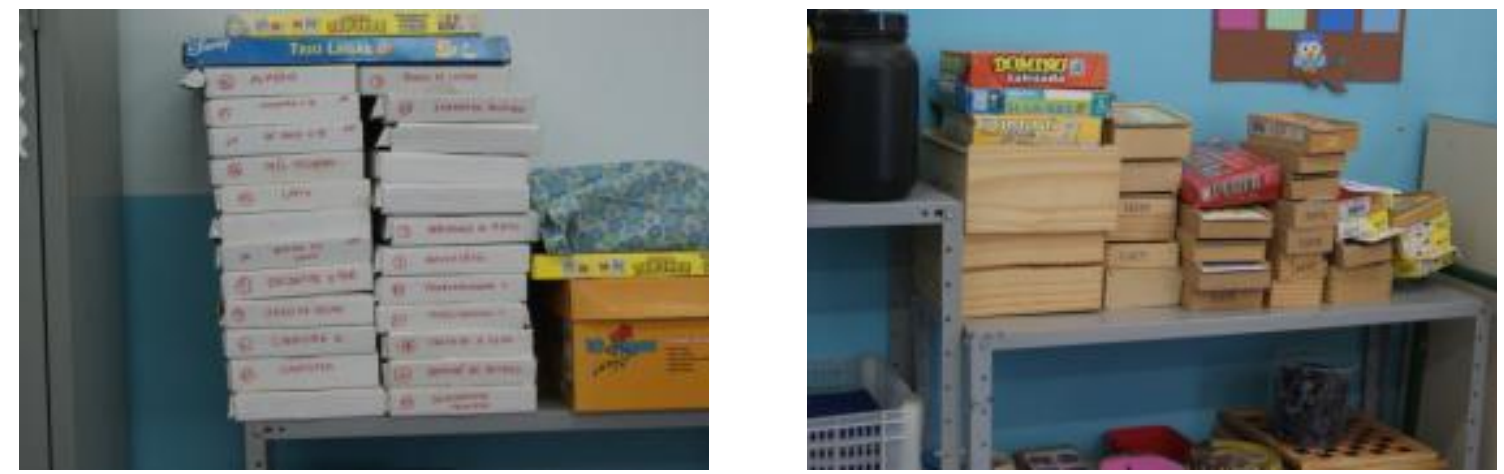

Fonte: arquivo pessoal do autor.

FIGURA 34 - CARTAZ ATIVIDADE “TEATRO DE LEITORES” - NAPE - ESCOLA A

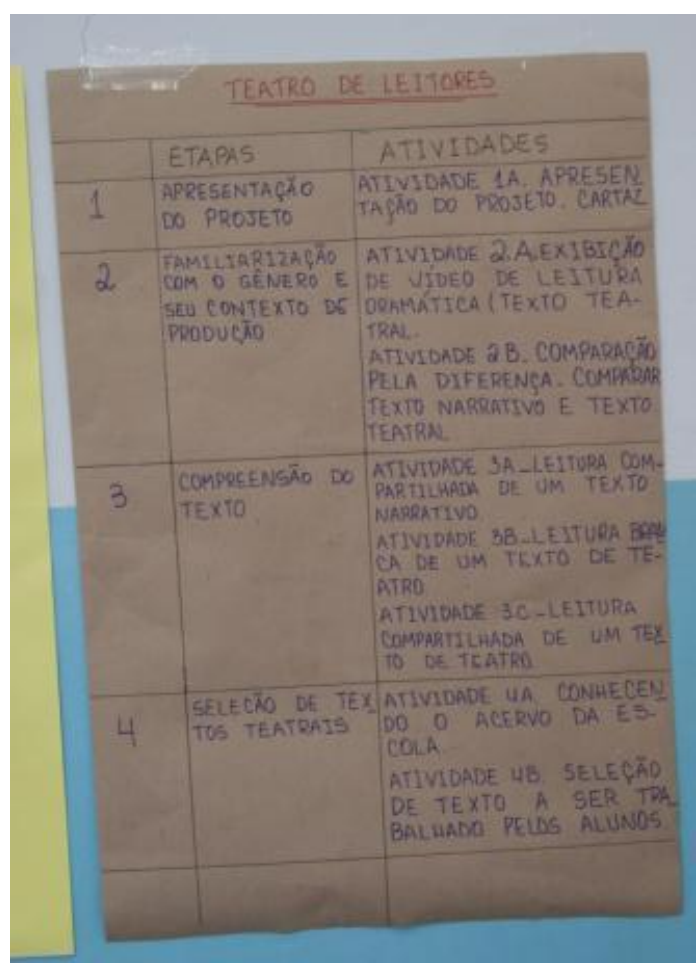

Fonte: arquivo pessoal do autor.

Além do transporte, o Núcleo também oferece refeição aos estudantes, que têm a opção de retornar para seus lares, com transporte escolar, ou almoçar no refeitório local (Figura 35). Os alunos são agrupados em turmas de acordo com as dificuldades identificadas pelos professores, e podem conter estudantes de séries diversas $\left(3^{\circ}\right.$ e $4^{\circ}$ anos, e $5^{\circ}$ e $6^{\circ}$ anos $)$. Apesar de estar disponível apenas a alunos até a $6^{\mathrm{a}}$ série, esta iniciativa, segundo depoimento da Diretora, Coordenadora Pedagógica e Professores, se mostra imprescindível para a melhoria do desempenho dos estudantes na etapa que qualificam como 'basilar' para o aprendizado da leitura e da escrita, uma vez que atua diretamente sobre o período da 
alfabetização e no período de transição entre o ensino fundamental I e o ensino fundamental II, em que o aluno experimenta uma relevante alteração no formato das aulas que, a partir deste momento, se diversifica pela existência de diversos professores, específicos para cada disciplina, ao contrário do que experimentavam durante o primeiro ciclo educacional.

Aos alunos das demais séries, são ofertadas listas de exercícios específicas, de acordo com as deficiências de aprendizagem observadas.

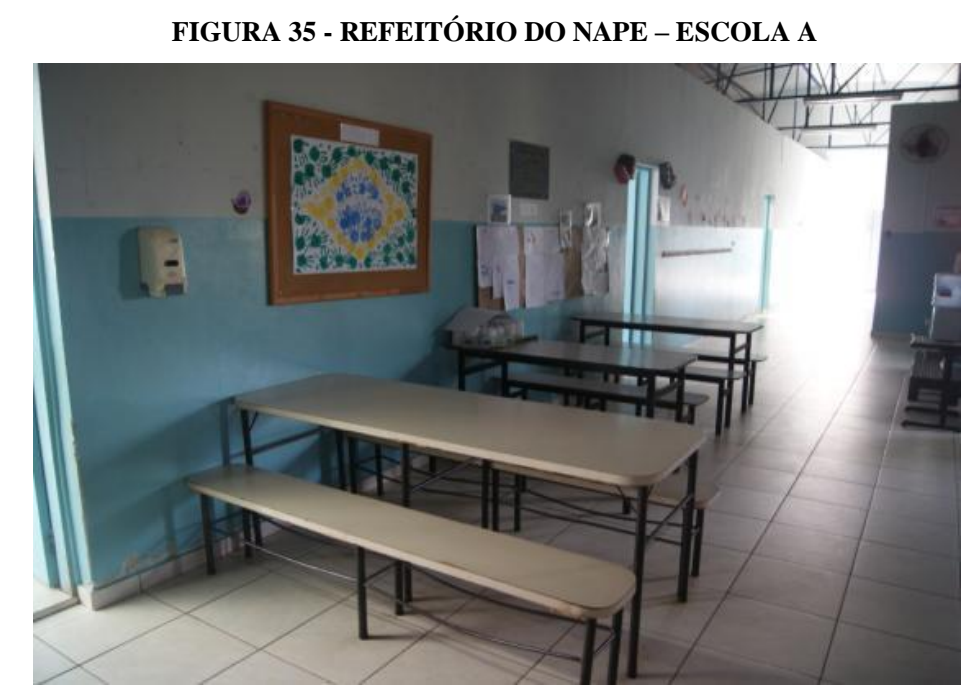

Fonte: arquivo pessoal do autor.

- Acompanhar a Aprendizagem dos Alunos e Promover Ações de Combate à Reprovação

O município adota o regime de Progressão Continuada por ciclos. Neste sistema os alunos somente podem ser reprovados ao final de cada ciclo. São adotados os seguintes ciclos:

- Primeiro ciclo: $1^{\mathrm{a}}, 2^{\mathrm{a}}$ e $3^{\mathrm{a}}$ séries

- Segundo ciclo: $4^{\mathrm{a}}$ e $5^{\mathrm{a}}$ séries

- Terceiro ciclo: $6^{\mathrm{a}}$ e $7^{\mathrm{a}}$ séries

- Quarto ciclo: $8^{\mathrm{a}}$ série

A adoção deste sistema, segundo a Diretora, se deve à crença de que a reprovação nesta etapa escolar pode trazer mais consequências ruins ao estudante, como, por exemplo, piora da autoestima, desestímulo pelos estudos e uma cobrança desproporcional pelo círculo familiar, do que os eventuais benefícios educacionais advindos da revisão dos conteúdos por mais um ano letivo. Assim, nas situações em que o professor identifica a necessidade de aplicar a reprova intermediária de um aluno, isto é, antes do final do ciclo, é realizada uma reunião conjunta entre professor, direção e pais ou responsáveis do aluno. Nesta reunião o 
professor apresenta as razões que justificam o pedido, bem como os planos de recuperação e reforço propostos e realizados para o aluno ao longo do período letivo para que, tanto a direção quanto os responsáveis a avaliem as alternativas. A partir desta reunião toma-se a decisão em conjunto com a família.

Nas entrevistas, a Diretora, Coordenadora e professora de Língua Portuguesa informaram que o acompanhamento da aprendizagem dos alunos é feita em diversos momentos. Semanalmente, nas reuniões de HTPC, os professores, coordenação pedagógica e direção discutem pontualmente os casos de estudantes em estando de dificuldade.

Especificamente em razão do modelo de progressão adotado, foram criados os chamados "Conselho de Ciclo". O Conselho de Ciclo é composto pelo coordenador pedagógico, professores e representantes dos alunos. Cada turma é representada no Conselho por dois alunos. Este conselho se reúne três vezes ao ano, ao final de cada bimestre letivo, para o acompanhamento do desempenho dos estudantes. Nas reuniões os professores apresentam os alunos em situação de possível reprova e elaboram, em conjunto, estratégias de recuperação, que são desenvolvidas dentro do próprio período das aulas. Os pais dos estudantes identificados nesta situação são notificados pela escola, para que auxiliem no processo de recuperação.

Adicionalmente, observou-se que o município adota um sistema de avaliação externa próprio, denominado Avaliação de Aprendizagem e Processo - AAP. Este instrumento foi indicado tanto pela Secretária Municipal de Educação, quanto para a Diretora, a Coordenadora Pedagógica e a Professora como a principal ferramenta de monitoramento do ensino do município. Ele é aplicado semestralmente aos estudantes e fornece informações diagnósticas nos níveis: aluno, turma, professor/disciplina, escola e, em último nível, do próprio município. Cada professor recebe o retorno sobre o desempenho dos alunos de suas turmas. Por meio deste instrumento são identificadas as deficiências, verificando, assim, as necessidades de reforço e capacitação docente.

\section{- Acompanhamento dos Resultados do SAEB}

Em relação aos resultados do $\mathrm{SAEB}$, os entrevistados informaram utilizar para o planejamento das ações de melhoria. Além da comparação com os resultados pregressos e aqueles alcançados pelas escolas que compõem a rede, a SME, juntamente com a equipe diretiva da escola, realiza um planejamento mediante análise das notas nas quarenta habilidades avaliadas, disponibilizadas nos Resultados Preliminares. 
Os entrevistados ainda informaram que não são realizadas preparações específicas com as turmas que participarão da prova.

\section{- Formação de Turmas}

Verificou-se que a escola dispõe de apenas uma turma de cada série, com média de 27 alunos por sala. Segundo a Direção, quando se faz necessária a divisão de turmas, esta é realizada de forma aleatória, de forma a permitir a alocação equilibrada de alunos alto e baixo desempenho em todas elas, se a adoção de sistema de divisão das turmas de acordo com o nível de desempenho.

\section{- Projetos Temáticos}

Foi relatado o incentivo à realização de projetos temáticos pelos professores junto aos alunos. Entre os projetos desenvolvidos estão:

- Projeto de Resgate Histórico do Bairro Paraisolândia - levantamento histórico sobre o bairro da escola e seus moradores;

- Projeto de Combate ao Trabalho Infantil - prevenção ao trabalho infantil. Realizado em parceria com o Ministério Público do Trabalho;

- Projeto Futuro Gênio - aulas online das diversas disciplinas;

- Projeto MobFogue (Mostra Brasileira de Foguetes) - elaboração e participação de competição de fabricação de foguetes com PET;

- Projeto para Catalogação dos Livros da Biblioteca da Escola;

- Olimpíada Brasileira de Astronomia (OBA) - participação na competição.

Os principais projetos, segundo as entrevistadas, são os dois primeiros. Segundo a Diretora, o resgate histórico do bairro permite a aproximação com a comunidade local, que se vê inserida no projeto e colaboram com informações, objetos e pesquisas; e o de Combate ao Trabalho Infantil, prática que, segundo elas, mostra-se relativamente frequente entre seus estudantes, uma vez que a escola se situa em região rural.

\subsection{Atuação com a família e a comunidade}

Os relatos, tanto de professores, quanto da Coordenadora Pedagógica e Diretora, apontam para uma forte conexão com a comunidade local, o que é reforçado pelo regime de matrículas que é realizada por zoneamento. 
- Realização de Eventos com a Comunidade e Cessão da Escola para Eventos da Comunidade

Em razão de se situar em bairro afastado 9 quilômetros da cidade, a escola é vista pelos moradores locais como o ponto de cultura do bairro, segundo a professora de língua portuguesa. A estrutura da escola é emprestada para a igreja do bairro, que lá realiza suas festividades, reforçando o vínculo com a comunidade.

Também são realizadas, anualmente, a Festa Juninha e a Festa da Primavera, que, além dos alunos e familiares, permite a participação de toda a comunidade. Estes eventos também são utilizados para a arrecadação de fundos para a escola por meio da venda de alimentos e brinquedos.

A quadra da escola também é aberta para a comunidade para a prática de esportes.

\section{- Projetos de Voluntariado}

A escola permite a participação, como voluntários, de alunos e pais na confecção dos uniformes utilizados para o desfile de 'Sete de Setembro'. Aqueles que comparecem à escola para isso recebem alimentação, juntamente com os alunos.

\section{- Estagiários do Ensino Médio}

Segundo relato da Diretora, a escola realiza a contratação de estagiários para auxílio aos professores. Trata-se de ação de âmbito municipal, custeado pela SME. No projeto são contratados alunos do ensino médio do município, que mediante recebimento de bolsa mensal no valor de $\mathrm{R} \$ 200,00$ (duzentos reais), atuam como inspetores durante o período de intervalo. Segundo o relato, a prática se mostra efetiva uma vez que os estudantes do ensino fundamental se mostram mais propensos a aderir à liderança destes jovens estagiários, que são responsáveis pelo auxílio à manutenção da disciplina e mediação, em primeira instância, de conflitos entre os estudantes. A maioria dos estagiários é composta por ex-alunos da escola, o que, segundo a Diretora, reforça o vínculo e aumenta o sentimento de propriedade da escola, assegurando, assim, o compromisso com sua manutenção.

\section{- Reuniões dos Conselhos de Classe e Conselho Escolar}

As reuniões dos Conselhos são realizadas quatro vezes ao ano, de forma ordinária. Também são convocadas reuniões extraordinárias, quando necessário e sempre conta com a presença dos docentes. 


\subsubsection{Professor}

\subsection{Perfil}

A professora entrevistada possuía, na data da entrevista, 10 (dez) anos de experiência como docente, profissão que adotou por desejo desde pequena. Possui licenciatura em Letras e em Pedagogia, além de especializações em Neuroaprendizagem e Orientação Educacional, todas realizadas em instituições de ensino superior privadas da região.

Em seu depoimento, destacou a importância do curso de Pedagogia para sua atuação em sala. Segundo ela, o curso de Letras focou, basicamente, nos conteúdos curriculares da disciplina, sem fornecer, no entanto, o ferramental didático necessário para a prática pedagógica. O curso de Pedagogia, por outro lado, lhe permitiu aprender a "lidar com o ser humano e ensinou a relação com o aluno e a compreender como se dá seu aprendizado, identificando os sinais do aluno". Em sua avaliação. Também classificou como importantes para sua atuação em sala a realização dos estágios de acompanhamento, que permitiu adquirir as competências práticas da profissão.

Ainda informou que não foram ofertados pelo município programas de capacitação e formação continuada para os docentes do ensino fundamental II, tendo sido ofertada exclusivamente para o ensino fundamental I.

\subsection{Regime de trabalho}

\section{- Contratação via CLT ou Contrato Temporário}

A contratação no município se dá mediante a aprovação em concurso público, sob o regime da Consolidação das Leis do Trabalho (CLT), que prevê um período probatório de 03 (três) anos. A escolha da escola e atribuição de aulas pelo sistema de pontos, onde o professor tem autonomia para escolher onde pretende atuar, sendo obedecida, para isso, a ordem de pontos de cada docente, calculada pelo tempo de experiência e cursos realizados.

\section{- Dedicação Exclusiva à Escola}

A professora informou possuir carga horária completa na escola, o que lhe permite a dedicação exclusiva. Também colabora para isso o Plano de Carreira do município que é "o 
melhor da região", em sua opinião, gerando interesse de professores de municípios vizinhos. Possui carga-horária semanal de 35 (trinta e cinco) aulas, mas que recebe adicional de 1/3 (um terço) para a realização de atividades extraclasse, como preparação e correção de provas e trabalhos, bem como pesquisa de conteúdos, o que lhe garante uma renda mensal de aproximadamente $\mathrm{R} \$ 4.200,00$ (quatro mil e duzentos reais). E o plano ainda prevê a progressão salarial por meio da realização de cursos de pós-graduação. A cada novo grau atingido (especialização, mestrado e doutorado), o salário é acrescido de 5\% (cinco por cento), sendo permitida a progressão a cada 03 (três) anos. Estes fatores foram apontados como relevantes pela entrevistada, que destacou como benefícios da atuação em uma única escola: a) melhoria na qualidade de vida, uma vez que há economia de tempo em razão da não necessidade de traslados para outras escolas ao longo do dia; b) a maior disponibilidade para a participação das atividades promovidas pela escola.

Também foi apresentado como relevante a sua atuação tanto no ensino fundamental I quanto no ensino fundamental II. Segundo a professora, isto lhe permite conhecer as características e dificuldades de aprendizagem de cada aluno desde cedo, o que lhe auxilia na composição das estratégias de ensino para cada caso particular.

\subsection{Planejamento docente}

\section{- Participação na Elaboração do Projeto Pedagógico}

A professora informou que há um Projeto Municipal, que deve ser adotado por todas as escolas, visando a garantia da mobilidade dos alunos entre as escolas, quando necessário. Porém, têm autonomia para planejar sua disciplina de acordo com a realidade local, não sendo obrigados a seguir linearmente os livros didáticos, sendo possível a inclusão de conteúdos onde julgam necessário. A escola elabora um planejamento semestral, com objetivos e metas de aprendizado para cada série, com a contribuição dos professores.

Os professores participam da escolha dos livros didáticos. Anualmente as editoras encaminham os materiais para as escolas, que discutem entre si para avaliar as propostas. Ao final, o material é escolhido por maioria de votos.

Também é permitida a participação dos professores na escolha do Coordenador Pedagógico da escola, que se dá por meio de eleição entre os docentes. 


\section{- Discussão Semanal das Metas}

Semanalmente é apresentado à Coordenadora Pedagógica da escola o semanário, documento que contém o registro dos conteúdos lecionados. Nestas ocasiões são discutidas as eventuais necessidades de ajuste do cronograma.

Também são realizadas as reuniões de HTPC, com a participação da Coordenadora e da Diretora. Também são utilizados os resultados da avaliação municipal semestral (AAP) para a discussão do alcance de resultados.

\subsection{Atividade docente}

\section{- Reuniões Semanais com Outros Professores}

A professora informou que são realizadas todas as semanas as reuniões de HTPC, sob responsabilidade da Coordenadora Pedagógica da escola. Nestas reuniões são discutidas as eventuais dificuldades de aprendizagem dos alunos e os professores aproveitam para traçar estratégicas conjuntas de ensino.

Ao final de cada bimestre também são realizadas as reuniões do Conselho de Ciclo, onde os professores têm a oportunidade de avaliar o desempenho dos estudantes em relação ao aprendizado e comportamento. Alguns projetos interdisciplinares são realizados, como, por exemplo, projeto entre a disciplina de Língua Portuguesa e de Geografia.

\section{- Dedicar mais Tempo às Aulas}

A professora informou que, além das horas-aula atribuídas para ministrar a disciplina, ainda dispõe de um terço de horas adicionais, as quais são utilizadas na preparação dos conteúdos, pesquisas, elaboração e correção de provas. Com isto, eventuais atividades de cunho administrativo e de planejamento podem ser realizadas nestas horas, sem interferir no horário das aulas.

\section{- Garantir o Cumprimento de Todo o Conteúdo}

São oferecidas 05 (cinco) aulas semanais da disciplina. Os professores devem preencher o semanário, que contém os registros dos conteúdos realizados. Este documento é apresentado semanalmente à Coordenadora Pedagógica, que acompanha a execução do cronograma proposto para o semestre, sendo realizados ajustes, quando necessário. 
Apesar de julgar adequada a carga-horária destinada à disciplina, a professora informou que seria necessária a inclusão de um conteúdo adicional voltado à "Produção de Texto", com carga-horária igualmente adicionada.

\section{- Oferta e Correção do Dever de Casa}

Nesta escola, a professora realiza a oferta semanal (às sextas-feiras) de dever de casa que, em geral, é voltado à interpretação de textos. Todos os trabalhos são vistados no dia programado para a entrega e a correção é feita em sala. Nos casos em que o aluno não o tenha realizado, é enviada mensagem de advertência no caderno, que deve ser assinada pelos pais do aluno. Segundo o depoimento, os pais acompanham, cobram e auxiliam na supervisão e realização do dever de casa.

Todos os alunos são incentivados a falar suas respostas, que, quando incorretas, são discutidas em sala. A professora informou que, nestas ocasiões, solicita a um colega da turma que saiba a resposta a esclarecer a questão.

\section{- Uso de Recursos Didáticos e Incentivo à Participação dos Alunos}

Semanalmente são realizadas aulas de leitura, que podem acontecer em espaços fora da sala de aula, como o pátio, a praça em frente à escola e o Centro Cultural do munícipio, prática observada na data da visita.

Para estas atividades a professora solicita inicialmente que os alunos façam a escolha dos livros, de acordo com sua preferência, sendo muito comum a leitura de obras mais recentes, como a série Harry Potter. Segundo depoimento, esta prática faz com que os estudantes 'tomem gosto pela leitura' para que, mais tarde, lhes sejam apresentadas as literaturas clássicas. A professora dispõe de um "Carrinho de Leitura", que consiste em um carrinho de feira que é levado para a sala de aula às sextas-feiras, com um conjunto de livros para a escolha dos estudantes, conforme Figura 36. Ao final da leitura são solicitadas a realização de uma ficha de leitura, que serve de avaliação. Neste documento é solicitado ao aluno informar aquilo que mais gostou, o que não gostou no livro e se o recomendaria a um amigo, com a exposição dos motivos para esta última resposta. Com isso, os alunos leem, ao menos 01 (um) livro por semana. 
FIGURA 36 - CARRINHO DA LEITURA - ESCOLA A
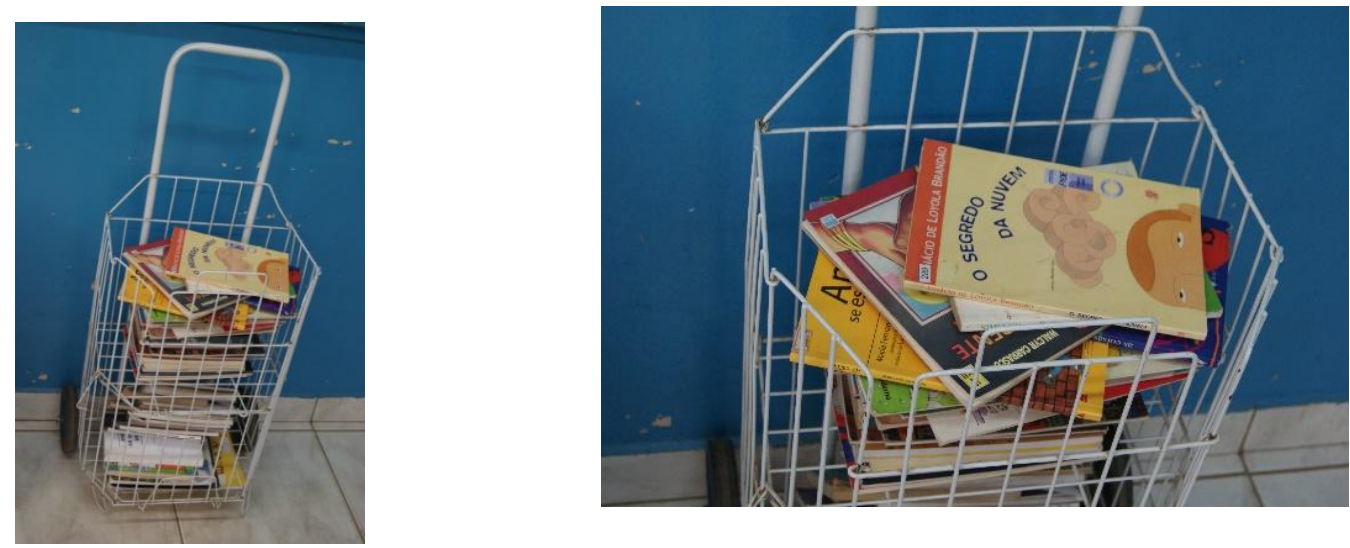

Fonte: arquivo pessoal do autor.

Apesar de dispor de computadores, a escola não possui aplicativos pedagógicos específicos para o ensino da Língua Portuguesa. Desta forma a professora o utiliza para a realização de pesquisas para os trabalhos solicitados.

Informou ainda que se utiliza da sala de vídeo da escola para a apresentação de filmes que, ao final, são discutidos em sala entre os alunos. E, na hipótese de haver um livro e um filme da mesma obra, os alunos são convidados a, primeiramente ler o livro e, então assistir ao filme, para discutir com a turma as diferenças encontradas.

Alguns projetos específicos são desenvolvidos para o ensino da leitura e da escrita:

Projeto Carta: consiste no envio de cartas manuscritas a colegas de outras escolas, que visam ao desenvolvimento da escrita. Estas cartas são trocadas pelas professoras das escolas participantes, e cada aluno deve responder ao colega que lhe escreveu. Uma vez que os estudantes sabem que haverá retorno, eles se empenham em elaborar boas cartas e estabelecer um vínculo com os colegas;

Literatura de Cordel: os estudantes devem escrever cordéis, os quais são expostos na escola para que outros possam ler;

Sarau: projeto sugerido pelos próprios alunos e adotado pela professora, em que são realizadas leituras de obras na praça em frente à escola para a população vizinha; 
Gêneros Textuais: os alunos realizam campanhas e peças publicitárias e elaboram artigos de opinião, de forma a conhecer os diversos gêneros textuais, identificando suas peculiaridades. Os materiais utilizados para a sua confecção são disponibilizados pela escola.

\subsubsection{Alunos e Família}

A investigação a respeito das práticas e comportamentos dos estudantes se deu por meio das entrevistas à Diretora, Coordenadora Pedagógica e Professora, que puderam apresentar suas impressões sobre o seu corpo discente. A seguir são listadas as principais impressões.

\subsection{Comportamento}

\section{- Manter a Disciplina e Frequência às Aulas}

Pelos depoimentos de todos os atores, a disciplina dos estudantes da escola visita é considerada adequada, não tendo sido reportadas ocorrências de indisciplina e interrupção das aulas por esta razão. A Diretora informou que, em razão do trabalho de prevenção ao abandono realizado pela escola, os pais comunicam a direção previamente nos casos em que o estudante necessite se ausentar por período prolongado, o que, em geral, está associado a problemas de saúde do aluno ou de familiar que necessite de seu apoio.

\section{- Realizar o Dever de Casa}

Foi reportado que os estudantes realizam os deveres de casa regularmente, participando ativamente do processo de correção em sala.

\section{- Leitura Frequente de Livros}

Em razão do projeto de leitura realizado toda sexta-feira, os alunos leem, pelo menos, 01 (um) livro por semana. 


\subsection{Ambiente familiar e social}

Por se estar localizada em bairro rural, os entrevistados informaram que, em geral, os pais dos estudantes têm poucos anos de estudos, mas que, todavia, valorizam a educação. Assim, acompanham a realização dos deveres de casa pelos alunos; participam com frequência das reuniões escolares e apoiam as decisões disciplinares da escola. Não souberam informar sobre os hábitos de leitura dos pais.

\section{- Possuir Computador em Casa}

A professora informou que, em sua opinião, a simples posse de um computador em casa não garante desempenho a seus estudantes. Alunos mais dedicados utilizam a ferramenta para a busca de conteúdos adicionais e aulas através do YouTube, sendo, portanto, um meio de revisão e expansão dos conhecimentos. Porém, também reportou que alguns estudantes utilizam a internet para a simples cópia de conteúdos, o que não contribui para o aprendizado. Somente é solicitado o uso deste equipamento para a realização de trabalhos.

4.2.2 Análise do município "B" - alto desempenho

O Município B possuía, em 2010, 137 mil habitantes (IBGE, 2010), com PIB per capita de R\$ 35.223,10 (IBGE, 2015), e está localizado no interior do estado de São Paulo, 60 quilômetros distante de Campinas e Limeira (Figura 37). O município possui forte atuação na citricultura, além de abrigar grandes empreendimentos industriais no ramo da metalmecânica e de fabricação de papel. O município possui uma grande rede de escolas privadas de ensino básico, além de instituições de ensino superior. 


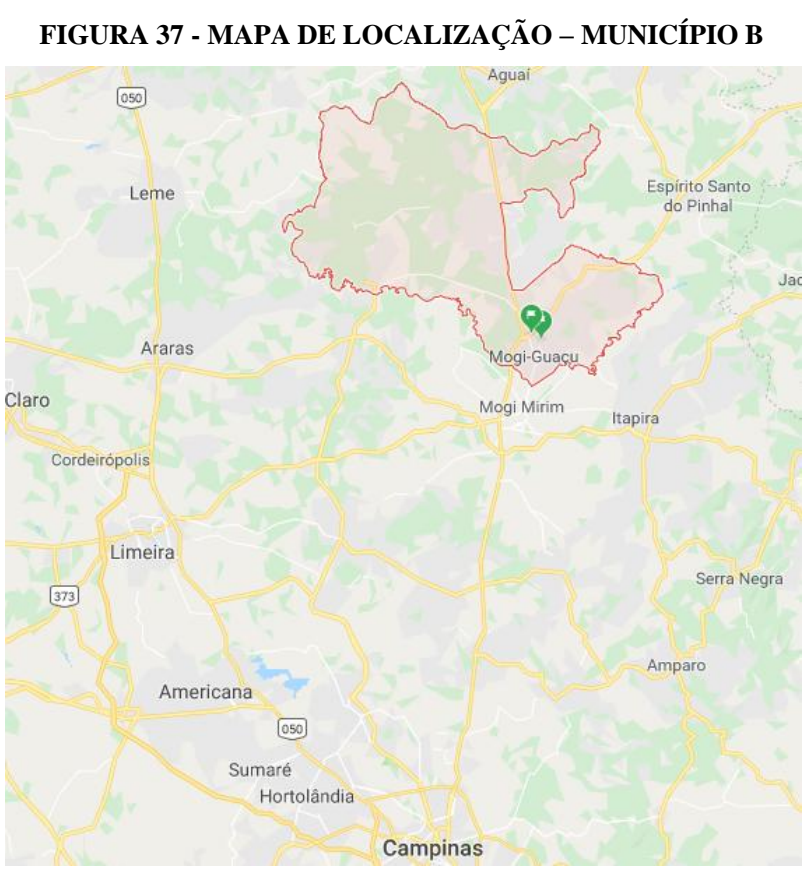

Fonte: Google Maps.

No setor educacional, o município apresenta taxa de escolarização da população de 06 a 14 anos de idade de 97,9\% (IBGE, 2010). A Tabela 11 apresenta a síntese dos dados do município.

TABELA 11 - DADOS DEMOGRÁFICOS - MUNICÍPIO B

\begin{tabular}{|l|l|l|l|l|l|}
\hline População $(*)$ & $\begin{array}{l}\text { IDH } \\
(*)\end{array}$ & $\begin{array}{l}\text { Renda Per Capita } \\
\text { Anual }(* *)\end{array}$ & $\begin{array}{l}\text { Número de } \\
\text { Escolas }(* * *)\end{array}$ & $\begin{array}{l}\text { Número } \\
\text { Alunos EF }\end{array}$ & $\begin{array}{l}\text { Investimento Anual Médio } \\
\text { por Aluno }(* * * *)\end{array}$ \\
\hline 137.245 & 0,774 & $\mathrm{R} \$ 35.223,10$ & 50 & 18.396 & $\mathrm{R} \$ 5.910,69$ \\
\hline
\end{tabular}

Fonte: Elaborado pelo autor.

Base: (*) IBGE 2010; (**) IBGE 2015; (***) Censo Escolar 2015 (****); FINBRA Investimento médio entre 2012, 2013 e 2014.

A análise da Lei Orçamentária Anual do município para o ano de 2015 permitiu verificar a relevância do investimento realizado no ensino fundamental: $60,88 \%$ de toda a verba municipal pra a educação é destinada à oferta e manutenção desta etapa de ensino. A seguir a educação infantil recebe a segunda maior parcela, com 26,96\% dos gastos, conforme Gráfico 22. 
GRÁFICO 22 - DISTRIBUIÇÃO DOS INVESTIMENTOS EM EDUCAÇÃO - MUNICÍPIO B

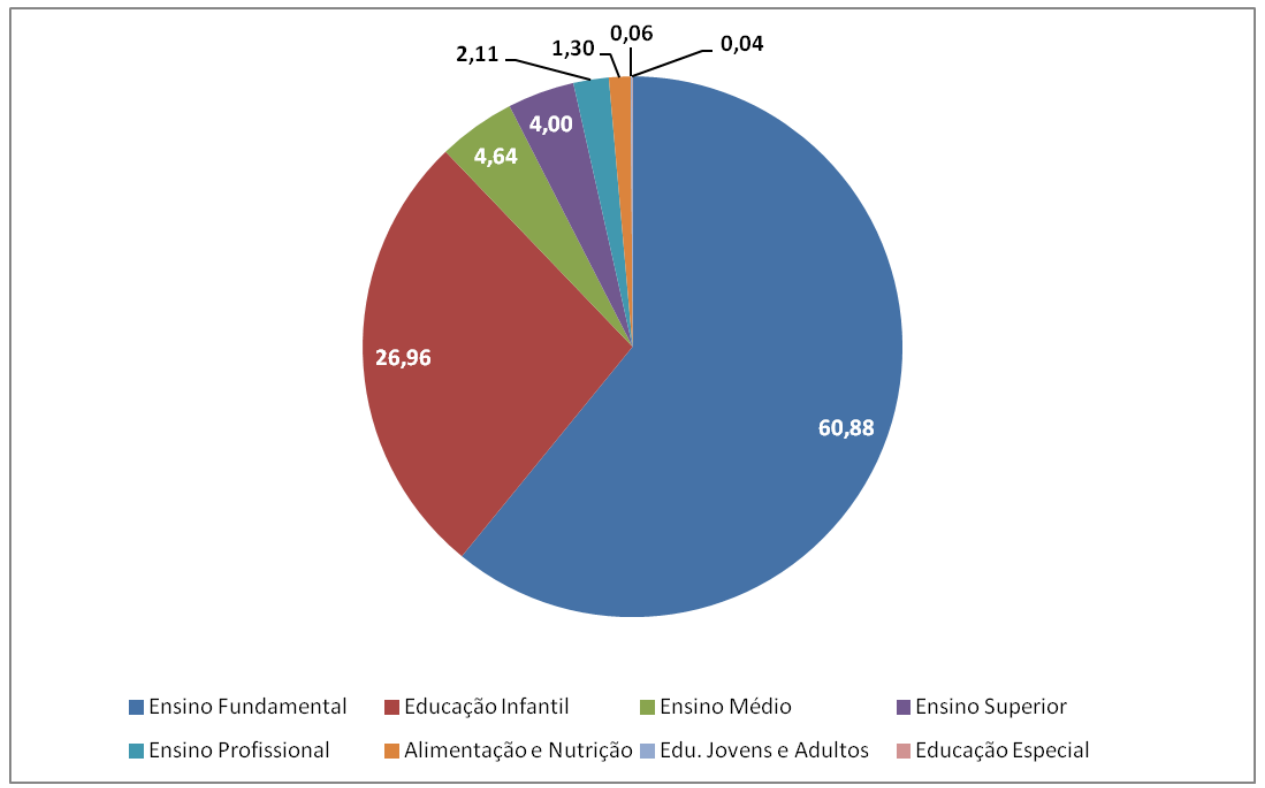

Fonte: Elaborado pelo autor. Base: Demonstrativo da Execução de Despesas por Função e Subfunção do Município 2015.

A visita ao município foi realizada no dia 20 de setembro de 2018, mediante prévio agendamento com a Secretaria Municipal de Educação. A seguir são apresentados os resultados das entrevistas realizadas com o Supervisor de Educação do Município, Diretora, Coordenadora Pedagógica e professora de Língua Portuguesa da escola selecionada.

\subsubsection{Análise da Secretaria Municipal de Educação}

A atual Secretária de Educação encontrava-se em seu quarto mandato consecutivo à época da visita, tendo mantido, da mesma forma, grande parte equipe gestora durante este período.

\section{- Estrutura da Secretaria Municipal de Educação}

A Secretaria Municipal de Educação (SME) dispõe de estrutura funcional clara e organizada, constante de organograma próprio (Figura 38), com 25 (vinte e cinco) funcionários. 


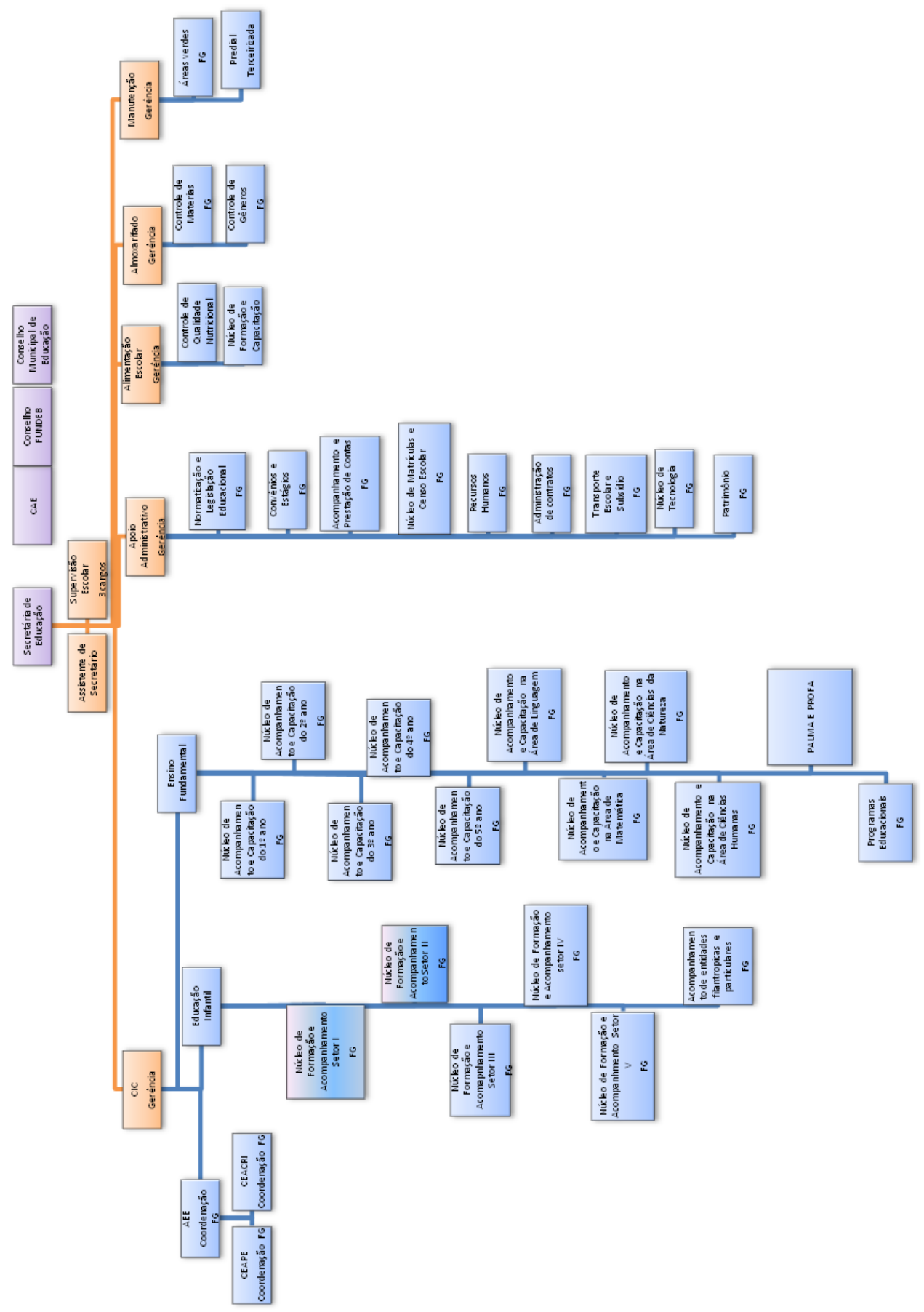

Fonte: Secretaria Municipal de Educação - Município B

Apoiam a Secretária Municipal 03 (três) Supervisores Escolares, cuja função é acompanhamento diário das escolas junto aos respectivos diretores. Foi possível verificar nas entrevistas um amplo conhecimento por parte dos entrevistados sobre os problemas e ações realizadas pela SME e pelas escolas. Também fazem parte da estrutura três conselhos 
consultivo-deliberativos: Conselho de Alimentação Escolar (CAE), Conselho do FUNDEB e Conselho Municipal de Educação.

Abaixo desta equipe estão 05 (cinco) gerências, que dividem responsabilidades administrativas e de gestão de pessoal. São elas:

\section{Centro de Inovação e Capacitação de Gestores Públicos (CIC):}

Esta gerência é responsável pela formação e capacitação dos docentes, coordenadores e dirigentes da rede. Sob sua gestão estão 03 (três) coordenações, a saber:

- Coordenação de Atendimento Educacional Especializado (AEE), cuja função é a capacitação, orientação e apoio permanente dos docentes para o atendimento de alunos com necessidades educacionais especiais. Esta coordenação conta com profissionais habilitados para o atendimento a todos os tipos de deficiências e dá apoio centralizado a todas as escolas;

- Coordenação da Educação Infantil, cuja função é capacitação dos docentes e profissionais das creches, com atendimento setorizado geograficamente. Cada setor é composto por um grupo de 06 a 10 escolas e possui uma Diretora responsável pelas questões administrativas e uma pedagoga;

- Coordenação do Ensino Fundamental, que se responsabiliza pela capacitação e acompanhamento dos docentes dos anos iniciais e finais do ensino fundamental. Para atendimento aos docentes dos anos iniciais, existem núcleos específicos para cada série/ano (do primeiro ao quinto ano), que reúnem todos os docentes da rede que atuam naquele segmento. Para o acompanhamento e capacitação dos professores dos anos finais do ensino fundamental, foram criados núcleos por área: Linguagem, Matemática, Ciências da Natureza e Ciências Humanas. Também compõe esta gerência um núcleo específico para o acompanhamento de Programas Educacionais; o Programa de Aperfeiçoamento da Linguagem Matemática (PALMA) e o Programa de Formação de Professores Alfabetizadores (PROFA).

\section{Gerência de Apoio Administrativo:}

É de responsabilidade desta gerência a gestão dos aspectos administrativos ligados à legislação administrativa e educacional; aspectos financeiros e prestação de contas; de recursos humanos; TI; transporte escolar; gestão de matrículas e censo.

\section{Gerência de Alimentação Escolar:}

Com equipe composta por nutricionistas, esta gerência é responsável pela elaboração dos cardápios semanais da merenda escolar e pelo controle de qualidade dos gêneros alimentícios. Os produtos são adquiridos, recebidos e armazenados no Centro de 
Armazenagem de Gêneros da SME (Figura 39), que realiza a distribuição semanal para as escolas, onde a merenda é preparada por pessoal próprio.
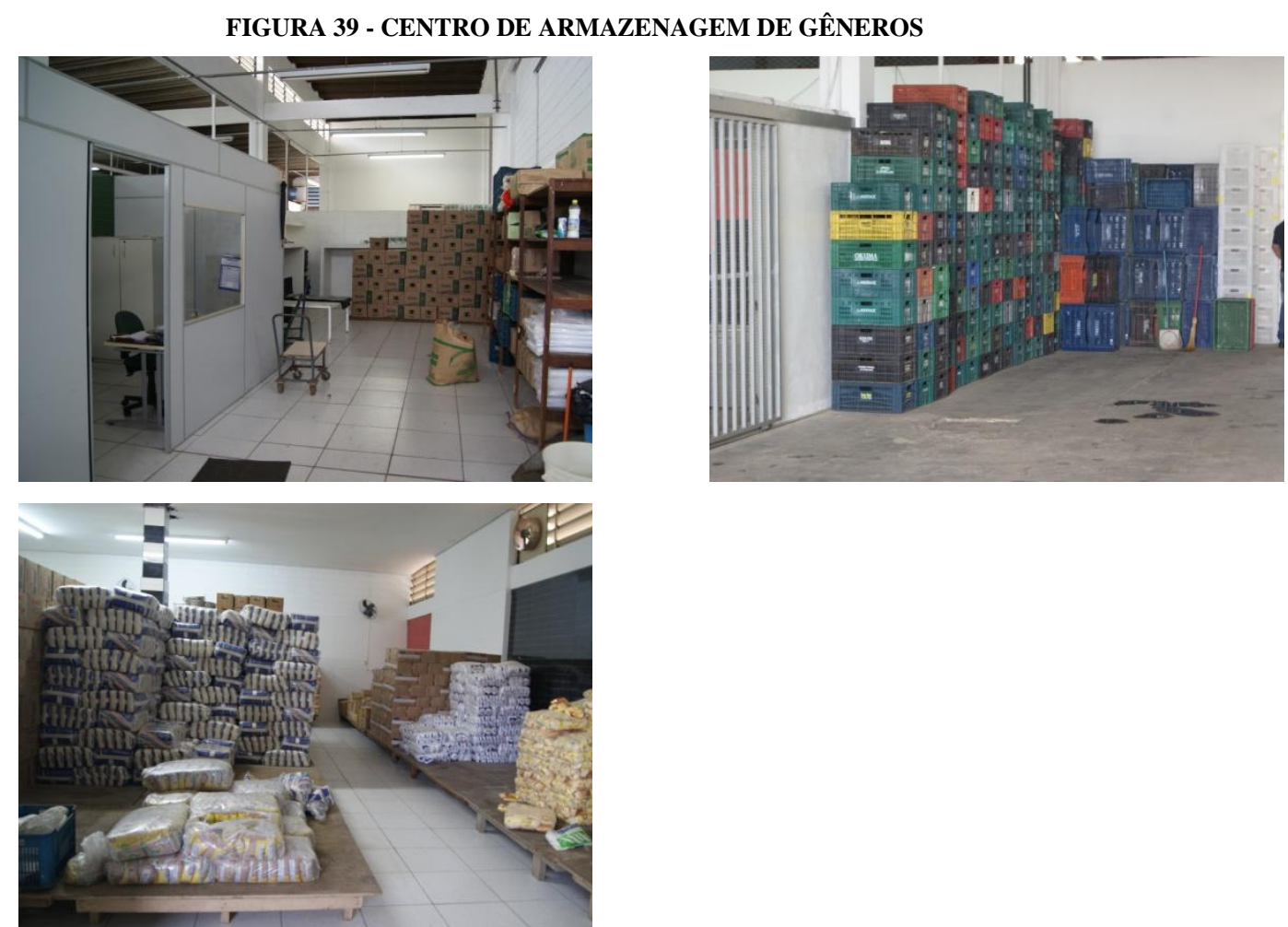

Fonte: arquivo pessoal do autor.

Gerência de Almoxarifado:

Realiza o controle de materiais de consumo e manutenção das escolas (Figura 40), bem como dos gêneros alimentícios destinados à merenda escolar.

FIGURA 40 - ALMOXARIFADO DA SME

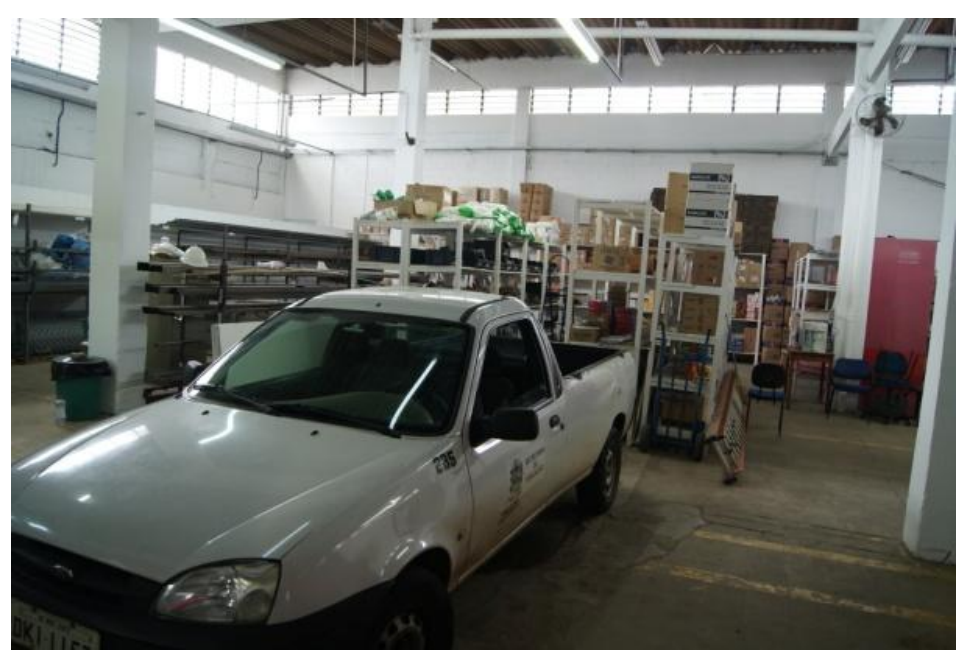

Fonte: arquivo pessoal do autor. 


\section{Gerência de Manutenção:}

Esta gerência possui pessoal e estrutura própria, que realiza pequenas manutenções nas escolas, mediante solicitação dos diretores. Também é de sua responsabilidade a coordenação de equipes terceirizadas contratadas para a realização de restaurações prediais e obras de médio e grande porte, quando necessárias.

\section{- Plano de Metas e Objetivos}

Segundo relato do Supervisor, a SME estabelece um plano de metas, o Plano Municipal de Educação. Este plano é realizado com a participação de representantes da comunidade, diretores e professores e estabelece metas para o IDEB, alfabetização, entre outras. O Plano é desdobrado em um Plano de Trabalho para sua consecução. Este Plano de Trabalho é proposto pela SME e pelos Centros de Apoio Pedagógico e Centro de Formação, o qual é repassado a cada ano aos Diretores em reunião realizada no início do primeiro semestre para análise e aprovação final, oportunidade em que também é feito levantamento das necessidades pedagógicas de cada escola. Apesar de não haver uma política de incentivo específica, são realizadas 03 (três) de acompanhamento ao longo do período com a participação da Secretária Municipal de Educação, além de reuniões específicas com os Supervisores Escolares, onde os resultados educacionais são cobrados individualmente. Ainda são realizadas reuniões mensais com os dirigentes escolares de cada segmento (educação infantil e fundamental, separadamente) para tratar de assuntos administrativos.

\section{- Captação de Recursos Financeiros}

A SME busca complementar os recursos por meio do Plano de Ações Articuladas (PAR). Foi relatado que o município não dispõe de uma política para a busca de apoio financeiro junto à iniciativa privada, mas que as escolas comumente o fazem, recebendo auxílio de grandes empresas locais para a reforma de bibliotecas, ações voltadas ao meio ambiente e até a construção de salas de aula.

\section{- Transporte Escolar}

A SME possui infraestrutura de transporte composta por 80 (oitenta) linhas de ônibus, atendendo, inclusive, estudantes que se encontram matriculados em escolas fora de sua região, havendo setor específico para a gestão deste serviço. Segundo relato das partes entrevistadas, 
não houve no município casos de interrupção do serviço aos estudantes nas últimas gestões municipais.

\section{- Manutenção das Escolas}

A manutenção corretiva da infraestrutura física da escola é realizada por empresa terceirizada, cuja agenda é coordenada por funcionário da SME. É de responsabilidade do Diretor de cada unidade o acompanhamento das condições da infraestrutura e as solicitações de reparo junto à SME.

\section{- Trabalho com a SME e Autonomia do Diretor}

Foi relatado pela Diretora que, de forma geral, as decisões são centralizadas na SME, que envolvem, inclusive, a discussão sobre a reprovação/ou não, dos estudantes. Esta afirmação é corroborada pelo Supervisor entrevistado. Segundo ele,as normas administrativas aplicadas nas escolas constam de um Regimental Geral do Município, sendo permitido ao Diretor a adoção de 'algo específico na escola', desde que subordinado a este Regimento, prática que relatou ser incomum. Entre as principais dificuldades encontradas para o exercício do cargo está a necessidade de equilibrar decisões administrativas com aspectos políticos. Também foi relatado que o acesso à equipe de Supervisores e à Secretária de Educação são fáceis, e os contatos frequentes por meio das reuniões periódicas organizadas pela SME.

\section{- Programas de Capacitação de Diretores e Professores}

A SME possui um centro de formação próprio, o CIC, onde professores da rede com melhor desempenho em determinados conteúdos ou metodologias atuam como multiplicadores de seu conhecimento para os demais colegas da rede. O principal foco deste centro é com a capacitação para a Alfabetização - programa desenvolvido desde 2004 pelo município e que lhes rendeu o reconhecimento, por três anos consecutivos, do Programa Além das Letras (Figura 41) - e o Acompanhamento Pedagógico pelos professores. 
FIGURA 41 - PLACAS DE RECONHECIMENTO DO PROGRAMA DE FORMAÇÃO CONTINUADA DE ALFABETIZADORES - MUNICÍPIO B

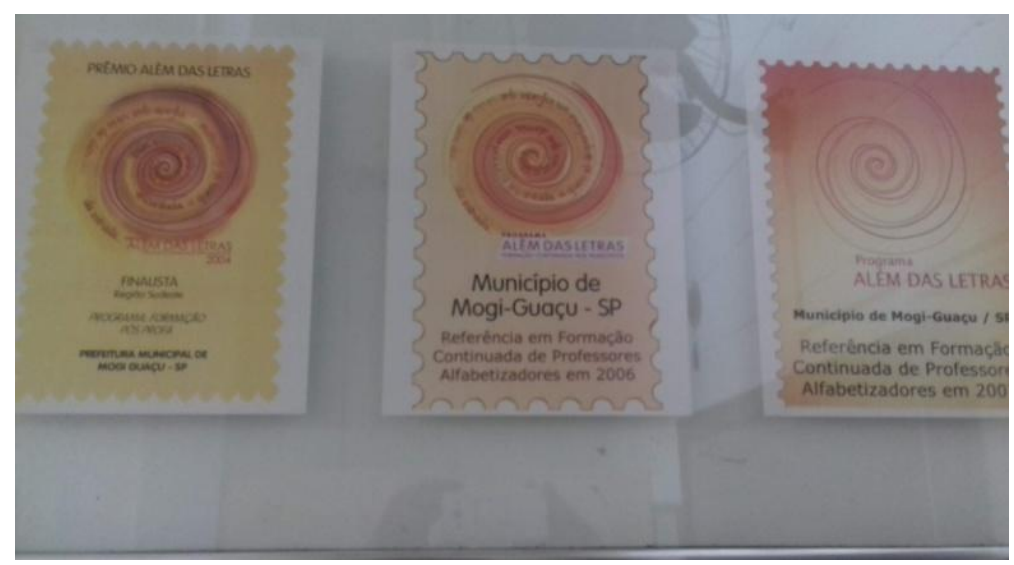

Fonte: arquivo pessoal do autor.

Após os treinamentos, os docentes multiplicadores assistem às aulas de seus 'alunos docentes' e dão feedback sobre o resultados. Neste centro também é realizada a integração entre as equipes do ensino fundamental I e fundamental II.

\section{- Estrutura para Atendimento Educacional Especializado (AEE)}

Foi relatado que a SME dispõe de uma gerência específica para o AEE. Subordinado a esta gerência estão:

- Centro de Apoio Pedagógico Especializado (CEAPE): este centro possui 20 (vinte) professores especializados no AEE os quais criam, a partir de um período de acompanhamento de 06 (seis) meses aos alunos nestas condições, um Plano de Ensino Individualizado (PEI). Este Plano é encaminhado ao(s) professor(es) da turma, com orientações sobre as abordagens a serem adotadas para cada um dos estudantes acompanhados. Este Centro ainda dispõe de brinquedoteca e sala de recursos para atendimento aos estudantes.

- Centro de Atendimento Especializado à Criança e Adolescente (CEACRI): composto por psicopedagogos (clínicos e institucionais), terapeutas ocupacionais, assistentes sociais e fonoaudiólogos, este centro auxilia os professores no desenvolvimento inicial dos alunos da educação infantil.

O município ainda possui parceria com a Associação de Pais e Amigos do Excepcional (APAE), que auxilia no atendimento de alunos com Transtorno do Espectro Autista (TEA), quando sua integração junto à escola regular não é possível. 
Nos casos em que são recomendados pelo CEAPE e pelo CEACRI o acompanhamento do aluno em AEE, a SME realiza sua contratação. No momento da visita foi informado haver 40 (quarenta) auxiliares e 30 (trinta) estagiários lotados nas diversas escolas do município com esta finalidade.

\subsubsection{Análise da escola "B"}

A escola está localizada em bairro distante do Centro apenas 1,5 quilômetros (Figura 42), classificado como de classe média baixa.

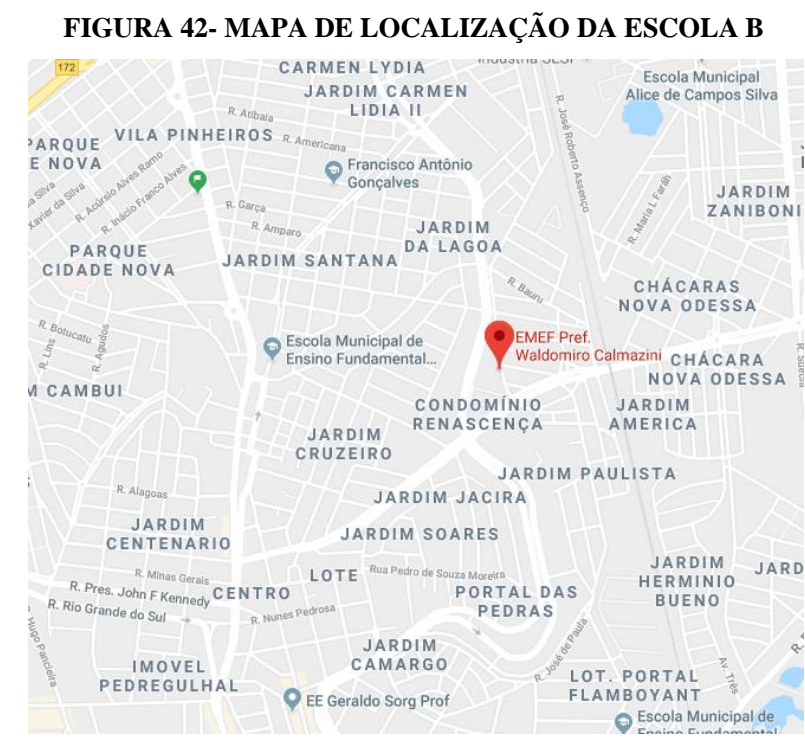

Fonte: Google Maps.

Segundo dados do Censo, a escola contava, em 2015, ano de realização da Prova Brasil, com 66 funcionários, responsáveis pelo atendimento de 460 estudantes do ensino fundamental I e 356 do ensino fundamental II.

As instalações foram recebidas do estado, durante o processo de municipalização da educação básica (Figura 43) e apresenta excelente estado de conservação: paredes, telhados, piso, portas, janelas, corredores, não tendo sido relatados problemas pelos entrevistados. Instalações elétricas e hidráulicas também apresentam funcionamento adequado. 


\section{FIGURA 43 - FACHADA DA ESCOLA B}

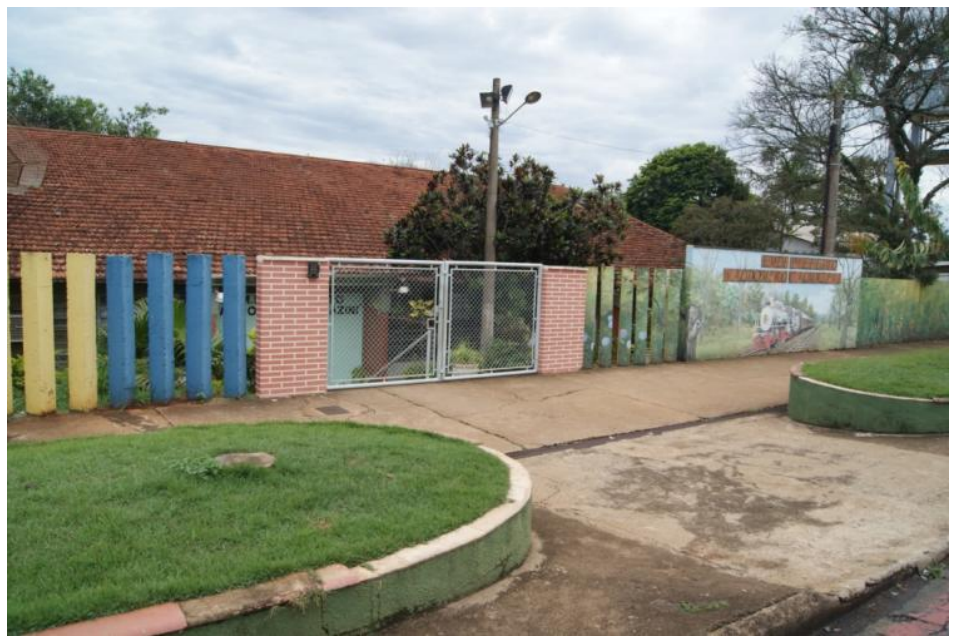

Fonte: arquivo pessoal do autor.

O pátio e as áreas externas são bem conservados e limpos (Figura 44). Há, junto ao pátio, uma pequena plantação de flores, que foi realizada e é mantida por alunos como parte da disciplina de língua estrangeira, que inserem placas de identificação nos espécimes, utilizando o que aprendem em aula.
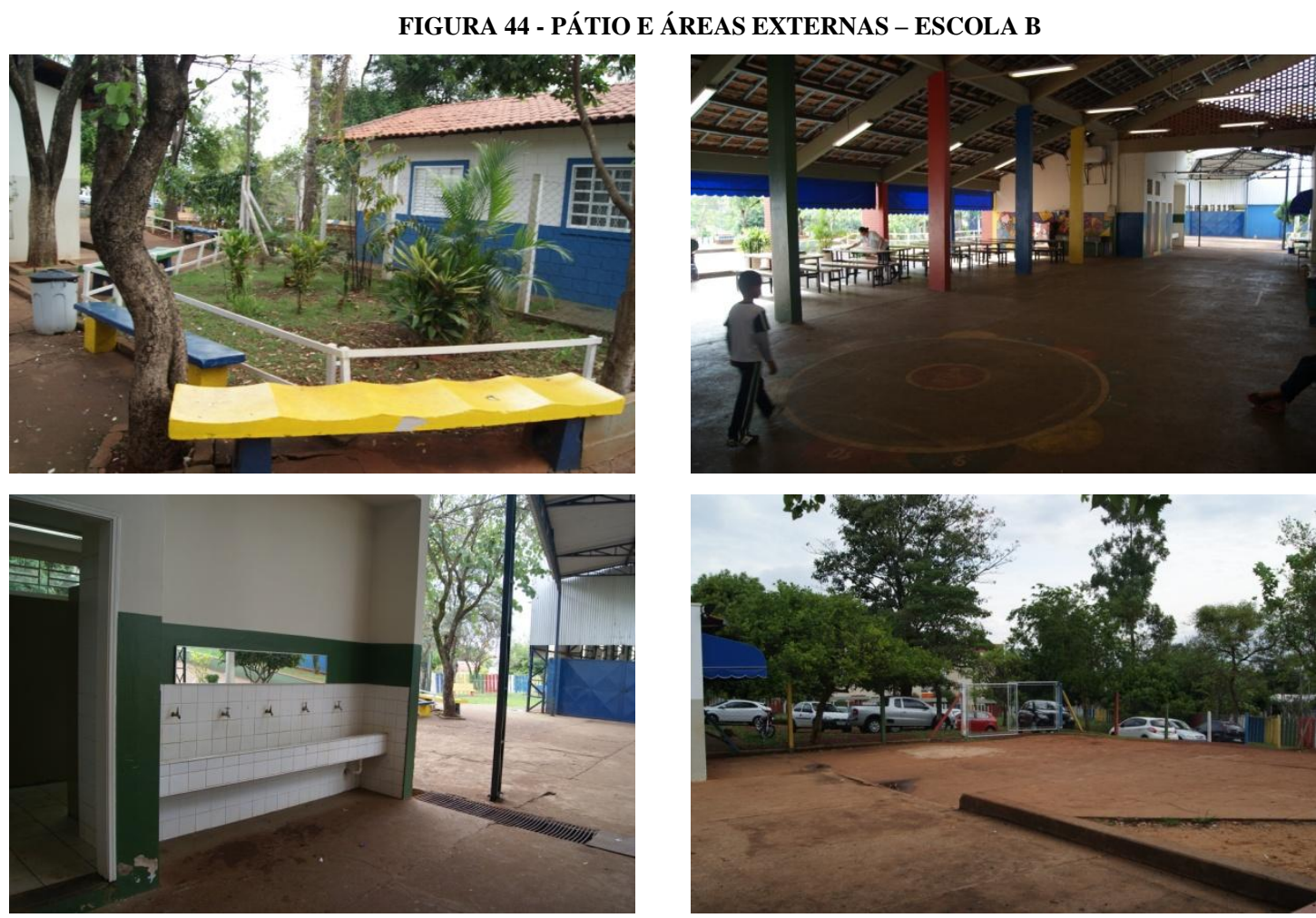

Fonte: arquivo pessoal do autor.

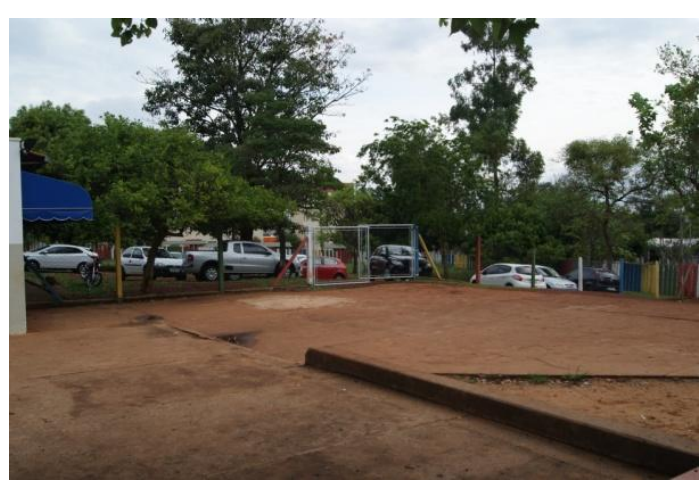


Os banheiros se mostraram satisfatórios e limpos, havendo, inclusive, instalações acessíveis, conforme Figura 45.

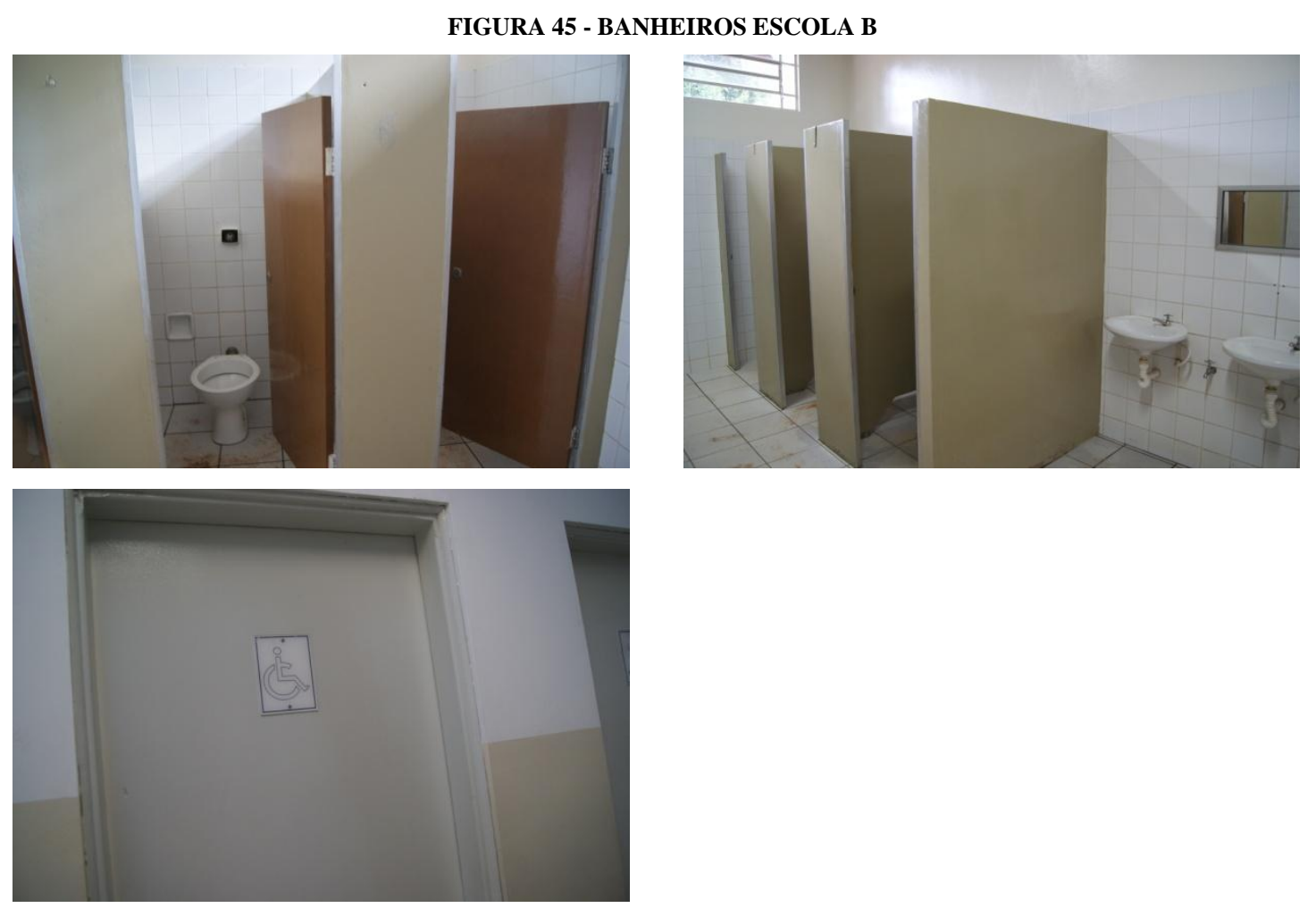

Fonte: arquivo pessoal do autor.

As instalações administrativas (salas de coordenação e direção) são conservadas e organizadas, com mobiliário novo e corredores decorados, proporcionando um ambiente agradável aos funcionários e estudantes (Figura 46).

FIGURA 46 - INSTALAÇÕES ADMINISTRATIVAS - ESCOLA B
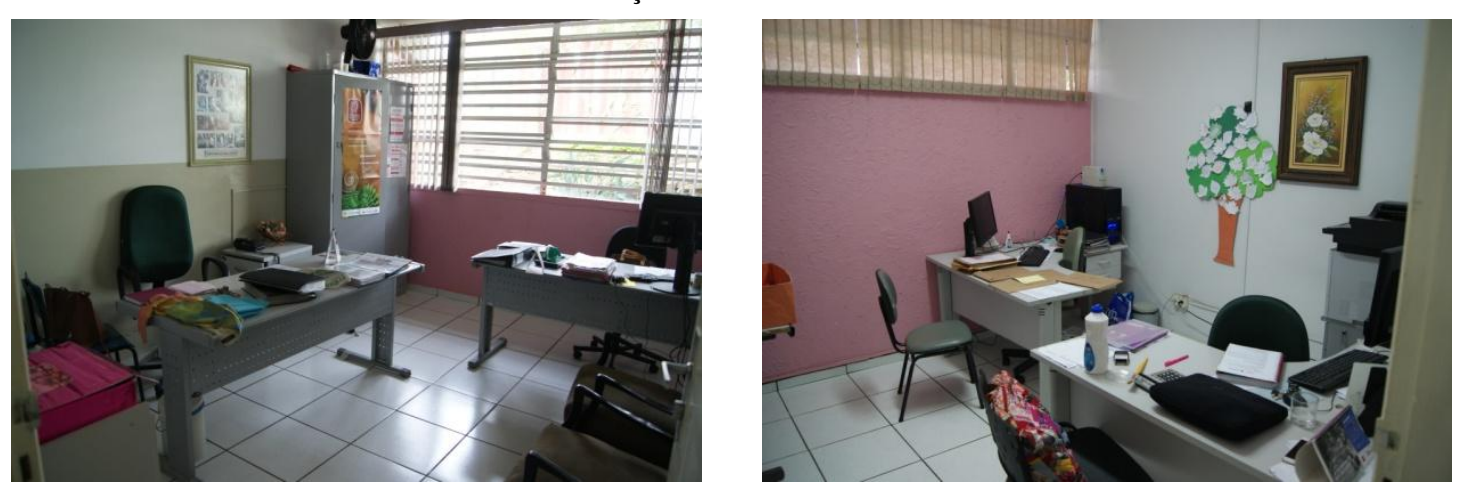

continua 


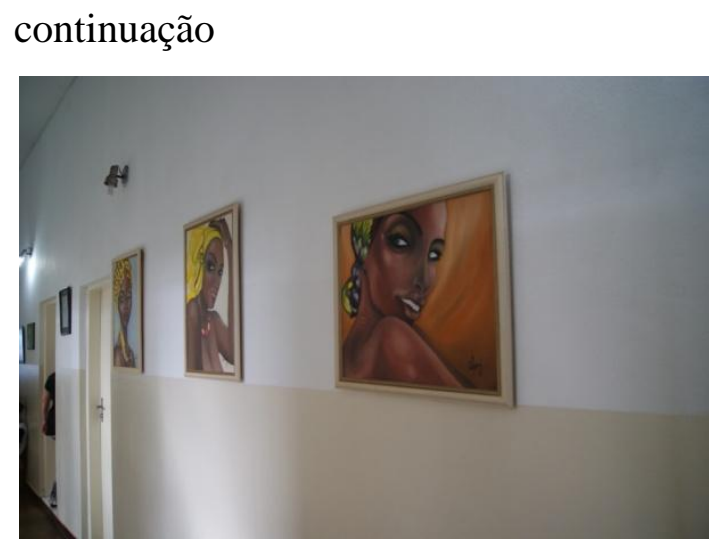

Fonte: arquivo pessoal do autor.

As salas de aula apresentam boa estrutura e mobiliário, com janelas amplas e ventiladores, garantindo, assim, boa luminosidade e ventilação.

A escola dispõe de uma sala de vídeo, com notebook, televisor de tela plana e arcondicionado, que foi adquirido mediante arrecadação entre professores e funcionários da escola, apresentando bom estado de conservação e funcionamento (Figura 47). O recurso é utilizado com frequência pelos docentes das diversas disciplinas como forma de atrair a atenção dos estudantes aos conteúdos, além de eventuais reuniões do corpo docente.

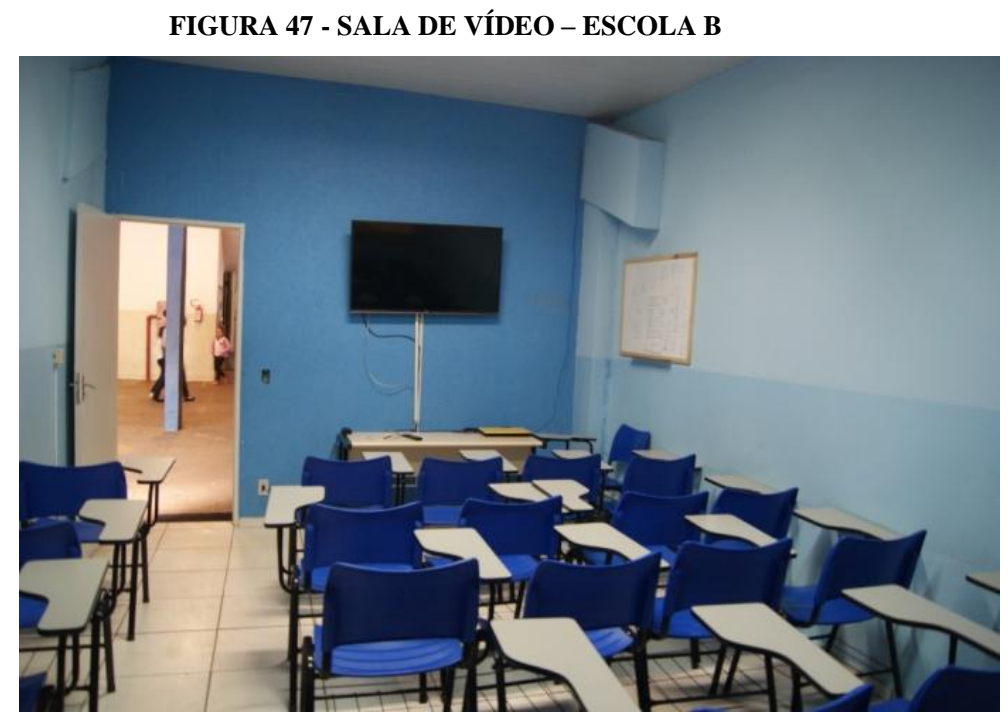

Fonte: arquivo pessoal do autor.

\section{- Oferta de Língua Estrangeira}

Verificou-se que o município oferece duas opções de língua estrangeira aos alunos Inglês e Espanhol -, desde o segundo ano, com materiais específicos adquiridos via processo licitatório. 


\section{- Recursos de Informática}

A escola dispõe de serviço de internet e computadores para uso dos funcionários e professores, mas não possui laboratório de informática para uso pelos estudantes. Foi relatado pela professora que este recurso é insuficiente para compartilhamento entre os docentes, uma vez que a escola somente dispõe de um computador para uso coletivo e com internet de baixa qualidade.

A escola também dispõe de impressora e copiadora para uso administrativo e pedagógico.

\section{- Acessibilidade}

Apesar de se tratar de prédio antigo, todas as instalações são acessíveis. A entrada e saída dos alunos é realizada por rampa em bom estado. A escola possui dois níveis, os quais são conectados por uma ampla rampa interna coberta, fazendo com que instalações administrativas, salas de aula e pátio possam ser acessadas sem obstáculos por pessoas com dificuldades de locomoção. Banheiro adaptado também está disponível, como abordado anteriormente.

\section{- Merenda Escolar}

Verificou-se que a escola possui cozinha e equipe própria (Figura 48) para o preparo da merenda, bem como equipamentos para a armazenagem dos gêneros alimentícios que são enviados semanalmente pela SME.
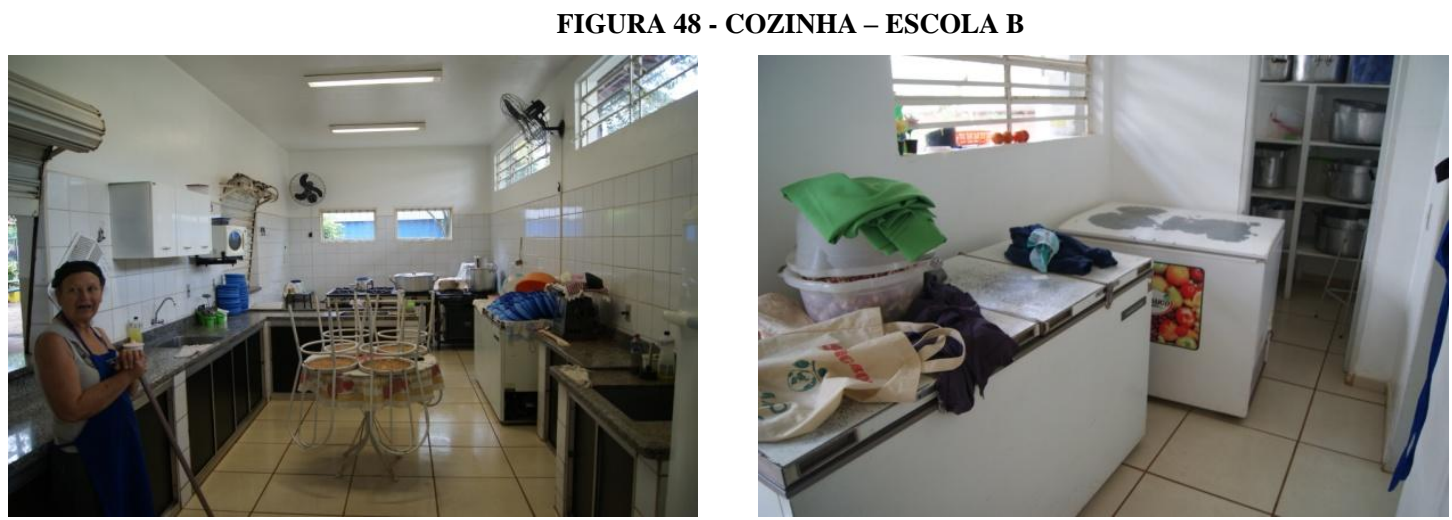

Fonte: arquivo pessoal do autor. 
O cardápio semanal (Figura 49) é preparado pela equipe de nutricionistas da SME e enviado às escolas, o qual é afixado em mural no pátio para consulta pelos alunos e pais. Alterações no cardápio somente podem ser realizadas mediante prévio comunicado e autorização da Direção.

FIGURA 49 - CARDÁPIO SEMANAL DA MERENDA - ESCOLA B
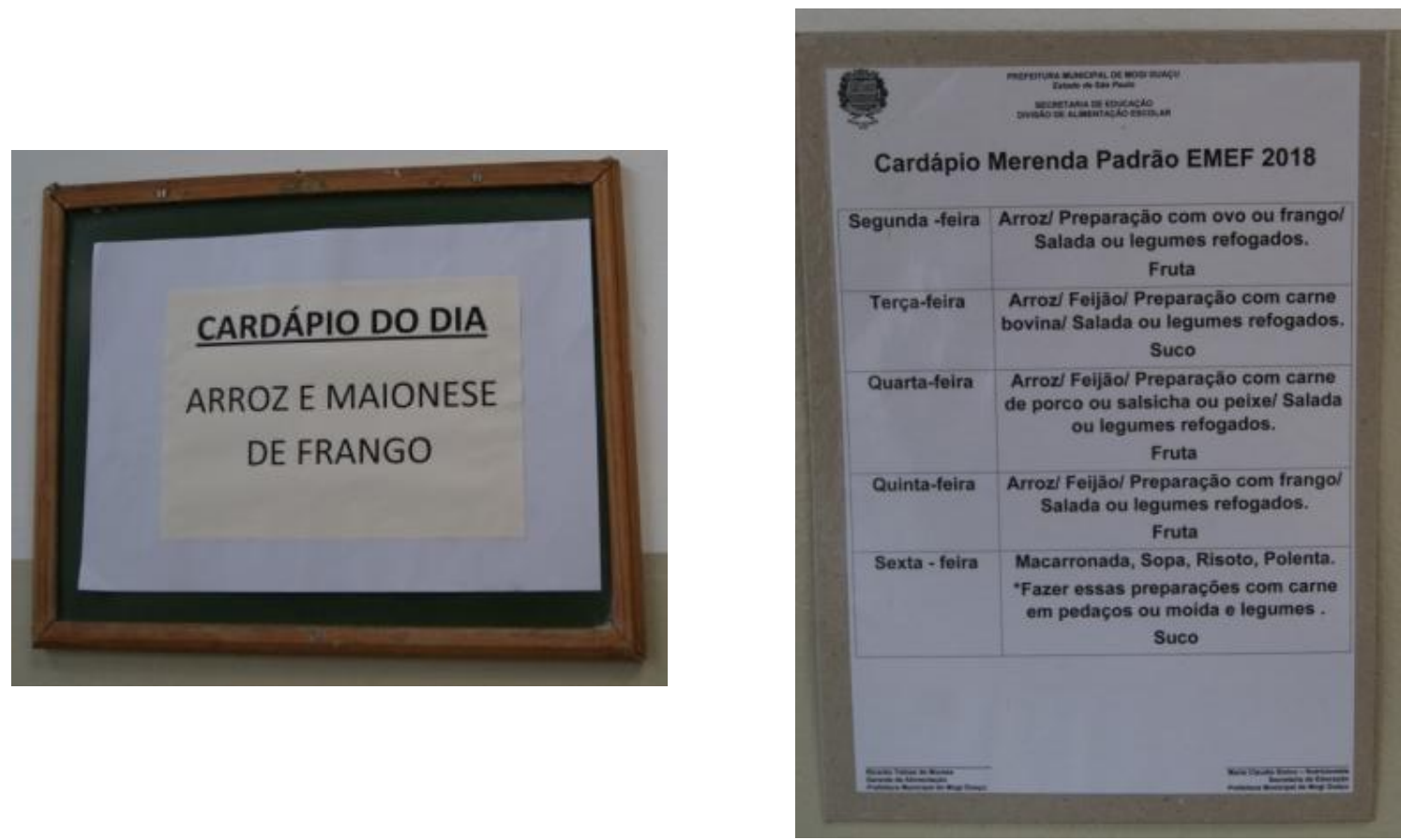

Fonte: arquivo pessoal do autor.

Os entrevistados (Supervisor, Diretora e Coordenadora Pedagógica), informaram que a merenda é enviada em quantidade e qualidade adequadas, não tendo ocorrido episódios de desabastecimento. Para sua manutenção, são utilizadas verbas do Programa Nacional de Alimentação Escolar (PNAE), verba da SME e um complemento é realizado pela Prefeitura, quando necessário.

Foi relatado que, além dos alunos, muitos funcionários e professores da rede usufruem da merenda, o que eventualmente gera a necessidade de complementação da verba pela Prefeitura mas, por outro lado, auxilia na avaliação periódica da qualidade, uma vez que estes são mais críticos do que os estudantes.

A escola criou o programa "Amigos da Merenda", por meio do qual, pais e qualquer membro da comunidade podem, sem necessidade de aviso prévio, solicitar para se servir da merenda e, ao final, preencher um relatório com suas impressões e opiniões (Figura 50). 
FIGURA 50 - FICHAS DE AVALIAÇÃO DA MERENDA - PROJETO AMIGOS DA MERENDA - ESCOLA B
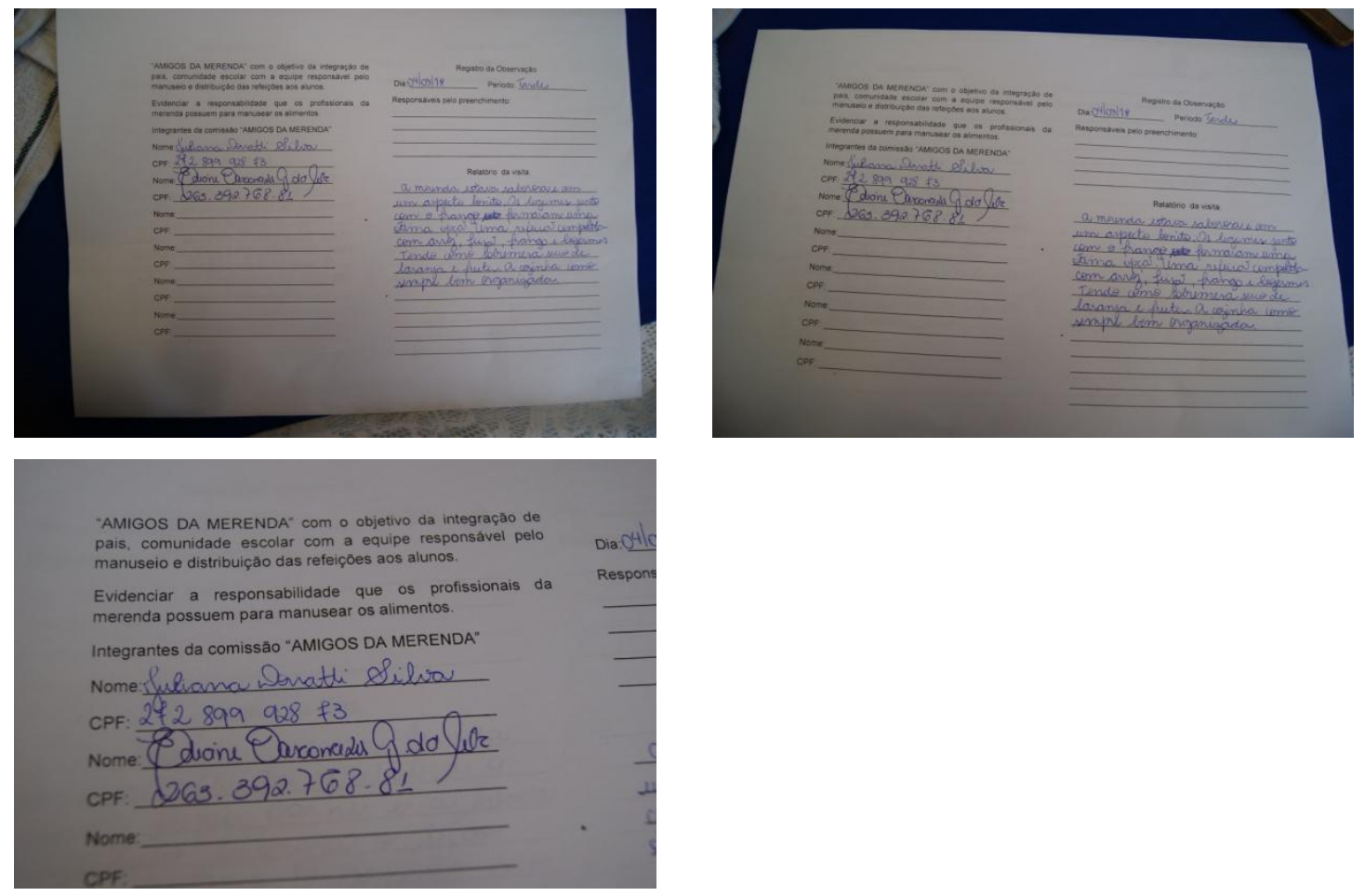

Fonte: arquivo pessoal do autor.

\section{- Biblioteca}

A escola não possui biblioteca, nem tão pouco sala de leitura. Foi relatado pela Diretora que a sala em que estava instalada foi utilizada para abrigar uma nova sala de professores. Como medida paliativa, o acervo foi dividido e guardado em 'caixas de leitura' (Figura 51). As caixas possuem livros agrupados por série e por tipo. Cada professor pode escolher uma caixa e levar para a sala de aula para que os alunos selecionem os livros que desejam ler. Os livros foram organizados nestas caixas pelos alunos que compõe o Grêmio Estudantil.

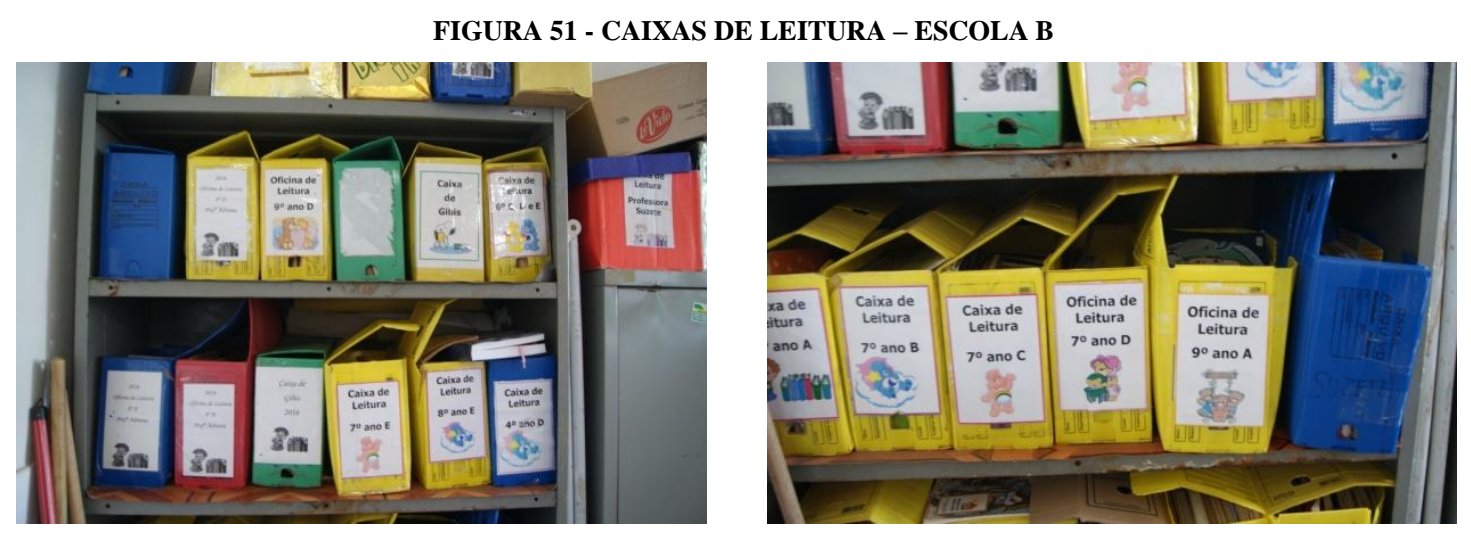

Fonte: arquivo pessoal do autor. 
Segundo relato (da professora, coordenadora e diretora), o volume e variedade de títulos são pequenos para o número de alunos. Segundo relato do Supervisor da SME há deficiência de acervo em toda a rede, em especial nas escolas mais novas, não havendo uma linha de recursos específicos para a aquisição de livros na SME.

Segundo a Diretora, a escola reduziu o número de itens de papelaria na lista de materiais solicitados aos pais no início do ano e incluiu a aquisição de obras literárias. A seleção dos títulos a serem adquiridos é de responsabilidade dos professores de língua portuguesa, que, para isso, verificam os valores das obras a serem solicitadas, para se adequar ao orçamento das famílias.

\section{- Recursos para os Professores}

Verificou-se que a escola dispõe de duas salas para uso dos professores (Figura 52). Ambas ficam localizadas nos corredores das salas de aula, permitindo o fácil acesso pelos alunos, quando necessário. A sala conta com computador com acesso à internet para uso no planejamento e pesquisa das aulas. Os docentes ainda contam com uma pequena copa, onde podem armazenar e preparar suas refeições e café (Figura 53).

FIGURA 52 - SALA DOS PROFESSORES - ESCOLA B
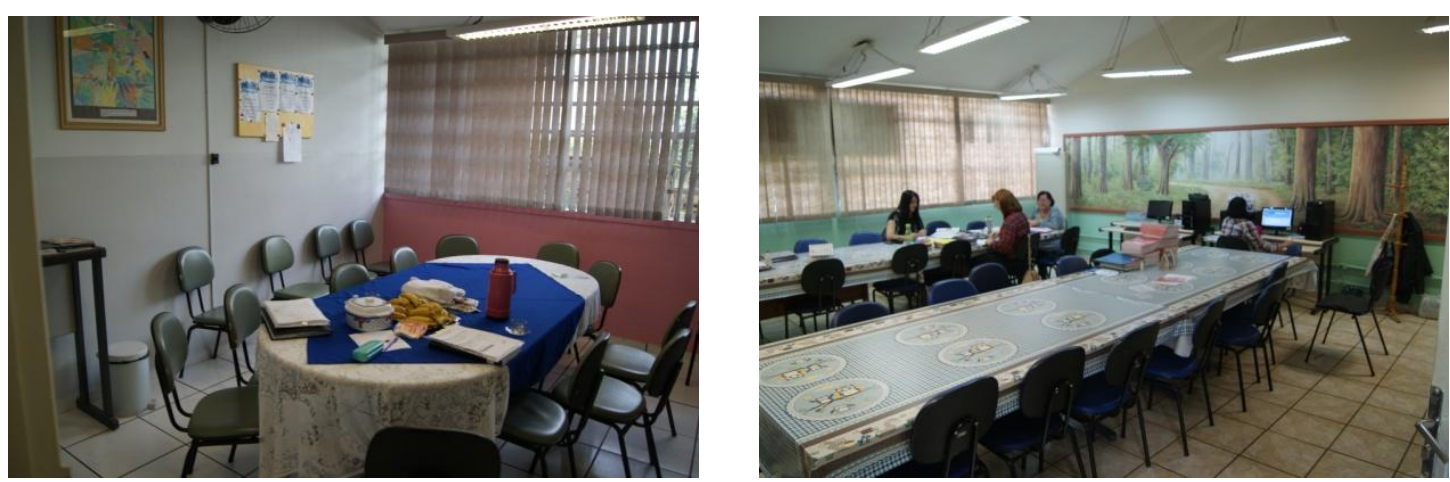

Fonte: arquivo pessoal do autor. 


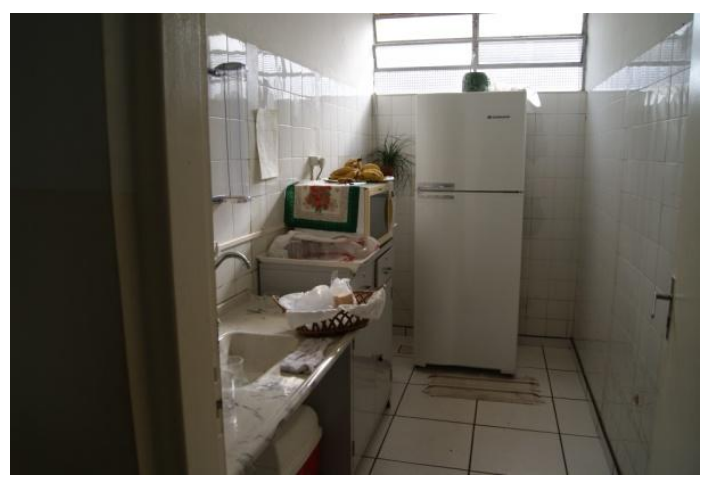

Fonte: arquivo pessoal do autor.

\section{- Disciplina discente e Regime Disciplinar}

Nas entrevistas, Diretora, Coordenadora e Professora relataram que a escola possui baixíssimo índice de indisciplina. A Diretora relatou que diariamente recebe os alunos na entrada, momento em que tem a oportunidade de encontrar e abordar alguns pais, verificar o atraso dos estudantes, o uso do uniforme correto e, em dias de frio ou chuva, a existência de crianças sem agasalho, sendo que, neste caso, a própria escola providencia blusas, a partir de um estoque de roupas e uniformes usados que mantém mediante doação de alunos e da comunidade. Logo após a entrada a Diretora e a Coordenadora passam em todas as turmas para verificar a disciplina.

Os entrevistados relataram que, em razão do longo tempo à frente da escola (26 anos), as regras disciplinares são antigas e de conhecimento geral, possuindo o apoio dos pais e da comunidade na sua aplicação, e envolve alunos, funcionários e professores. No início do ano as regras são apresentadas como um 'Contrato Pedagógico', e consta da Ata de Planejamento da escola. Cada possui um professor responsável pela elaboração de um conjunto de regras disciplinares juntamente com os alunos. Estas regras representam um contrato entre o docente os discentes que, tendo participado de sua elaboração, apresentam menor resistência ao 'combinado'.

Durante a visita uma prática chamou à atenção: dois alunos de $6^{\mathrm{a}}$ (sexta) série, que haviam se desentendido durante o intervalo, conversavam frente a frente e sozinhos em duas cadeiras instaladas ao lado da porta da Direção. Segundo a Diretora, trata-se de uma prática da escola para estes casos: os estudantes são convidados a dialogar entre si, antes da conversa com a Diretora, para compreender o porquê do desentendimento, de forma a buscarem, por conta própria, a solução do conflito. Pelo relato, esta prática auxiliou a reduzir o índice de 
conflitos entre os estudantes, além de incentivar a prática do diálogo para a solução dos problemas.

\subsubsection{Diretor}

4.2.2.3.1 Regime de trabalho, formação e experiência profissional

Verificou-se que a Diretora atua na escola há 26 (vinte e seis) anos, tendo atuado como docente por 6 (seis) anos, antes de assumir o cargo diretivo, experiência que informou julgar essencial para a assunção do cargo. Sua dedicação é exclusiva à escola, com carga horária semanal de 40 horas.

Os diretores são indicados pelo Prefeito, após aval da Secretária Municipal de Educação, sendo que $80 \%$ deles são professores com vínculo com o município, e $20 \%$ são cargos comissionados, porém com formação em Pedagogia.

Segundo relato obtido na SME, a remuneração dos diretores escolares é definida pela própria Secretaria, sem haver, no entanto, um plano de carreira para o cargo, ao contrário do que ocorre com os docentes. Ainda, foi informado de que a remuneração para o cargo de professor é proporcionalmente maior sendo que, professores com carga horária parcial já recebem salário superior.

\section{Transporte Escolar}

Foi relatado que o transporte escolar é oferecido a todos os alunos, sem ter ocorrido episódios de interrupção.

\subsection{Práticas de gestão}

\section{- Ações de Combate ao Abandono e à Evasão Escolar}

Verificou-se que o índice de evasão da escola visitada é baixo, o que é comprovado pelo Indicador de Rendimento 2015: 0,99. Nas entrevistas, professora, coordenadora e 
diretora informaram ter, também, um baixíssimo índice de faltas em razão do número de alunos.

Verificou-se a existência de uma lei municipal própria - Lei 4.914 de 2014 -, que obriga a escola a comunicar os pais em caso de falta. Todas as faltas são comunicadas por recado escrito encaminhado junto ao próprio aluno. Após 03 faltas consecutivas, o professor informa a Coordenadora Pedagógica que, então, liga para os pais. Havendo dificuldade de contato pelo prazo de 15 dias, um Assistente Social realiza visita à família e, nos casos em que se faz necessário, o Ministério Público (MP) é comunicado para que acione o Conselho Tutelar para os procedimentos cabíveis.

Segundo relatos, as faltas existentes, em geral, são em decorrência de problemas familiares. Nos casos em que seja necessária a intervenção de profissional especialista, os alunos faltosos são encaminhados ao Centro de Educação Especial, onde contam com o apoio de fonoaudiólogos, psicólogos, psicopedagogos, assistentes sociais ou terapeutas ocupacionais.

Também são aproveitados os momentos de entrada e saída dos estudantes para abordar os pais ou responsáveis dos alunos que apresentaram faltas no período.

\section{- Quadro Funcional da Escola}

A escola apresenta quadro funcional completo em todos setores: corpo docente, secretaria(Figura 54), coordenação, merenda e limpeza. O preenchimento do quadro se dá via concurso público, o que reduz a rotatividade, uma vez que o funcionário é permanentemente lotado na unidade.

Foi relatado baixa incidência de faltas docentes pela Diretora. As informações prestadas pela SME apontam para 33 (trinta e três) dispensas de aula em toda a rede para o ano corrente por faltas de professores, índice considerado baixo para o tamanho da rede, composta por 1200 (um mil e duzentos) professores. Entre os principais motivos para o afastamento constam as licenças médicas, em especial a licença gestante. 


\section{FIGURA 54 - EQUIPE DA SECRETARIA - ESCOLA B}

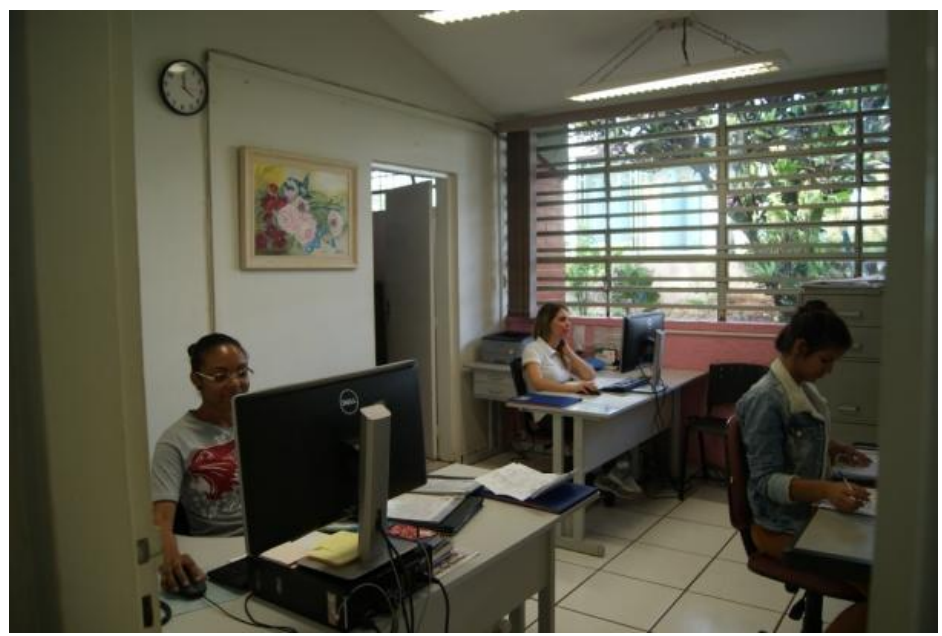

Fonte: arquivo pessoal do autor.

\section{- Atribuição de Aulas}

A contratação dos professores se dá por concurso público, e lhes são atribuídas sedes fixas na escola, o que, segundo a diretora, colabora para a redução da rotatividade dos docentes. Em seu depoimento destacou positivamente este formato, uma vez que permite ao professor conhecer e se integrar à realidade escola. Os contratos de trabalho são regidos pela Consolidação das Leis Trabalhistas - CLT e os aprovados passam por um período probatório de 03 (três) anos.

\section{- Estrutura para Alunos com Deficiência}

A escola possui acessibilidade para pessoas com dificuldade de mobilidade em todas as suas instalações. Os recursos tecnológicos e, principalmente, de capacitação para o atendimento de alunos PNE é provido pela SME por meio do setor de AEE. Também são disponibilizados, para cada estudante, um plano de trabalho individualizado, que é acompanhado, quando necessário, por um professor auxiliar ou estagiário.

\section{- Captação de Recursos Externos}

A escola não realiza nenhum tipo de captação de recursos externa, além daquela recebida pela APM. Porém, a Diretora informou contar com a parceria de prestadores de serviços e comerciantes locais que realizam a venda de artigos para a escola a preço de custo e com condições de pagamento diferenciadas. Citou a recente troca das cortinas das salas de aula, cujos tecidos foram adquiridos em loja local, a preço de custo e com opção de pagamento 'de acordo com a disponibilidade de caixa da APM da escola'. Segundo 
verificado, a captação de recursos via APM é realizada mensalmente por meio de um envelope (Figura 55) levado para casa pelos alunos.

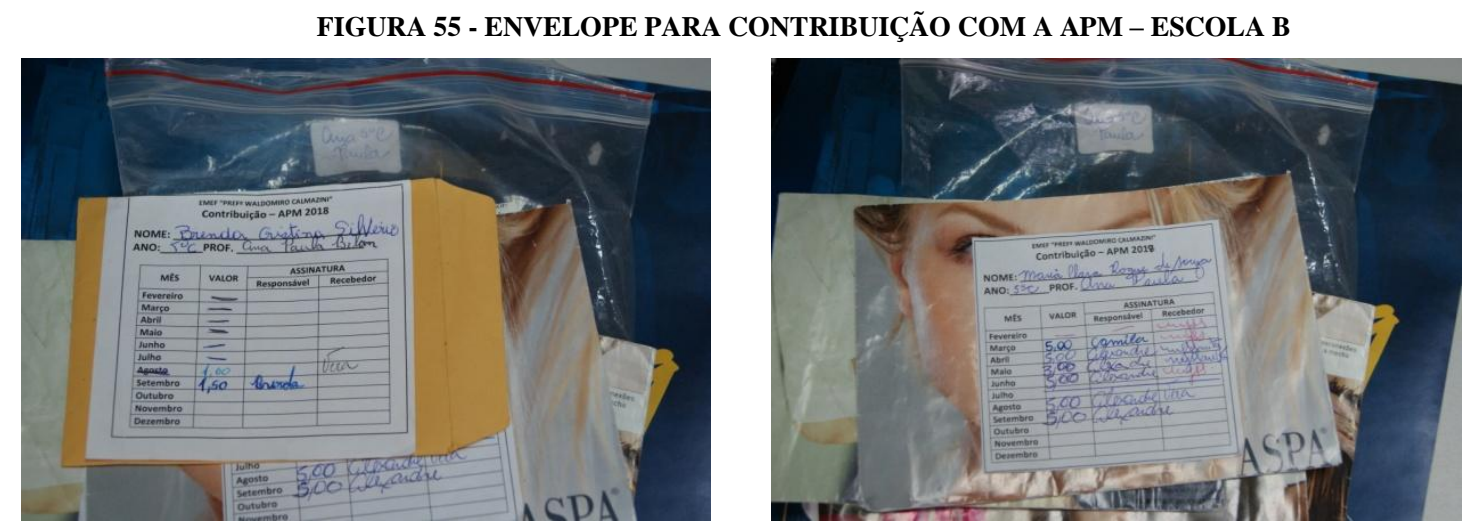

Fonte: arquivo pessoal do autor.

\section{- Investimentos e Manutenção da Escola}

O acompanhamento das necessidades de manutenção da escola é de responsabilidade do Diretor que, ao identificar a necessidade, deve comunicar o setor de manutenção da SME para que providencie as obras necessárias.

A Diretora relatou que, eventualmente, utiliza-se de recursos particulares para pequenos reparos e serviços de jardinagem, que são solicitados, prioritariamente a pais de alunos ou membros da comunidade local. Citou como exemplo o grafismo realizado na fachada da escola e a tela pintada na sala dos professores, que foi realizada de forma voluntária por ex-aluna da instituição, e o plantio de flores próximo ao pátio pelos estudantes durante aula de língua estrangeira (Figura 56).

FIGURA 56 - REFORMAS REALIZADAS POR EX-ALUNOS - ESCOLA B
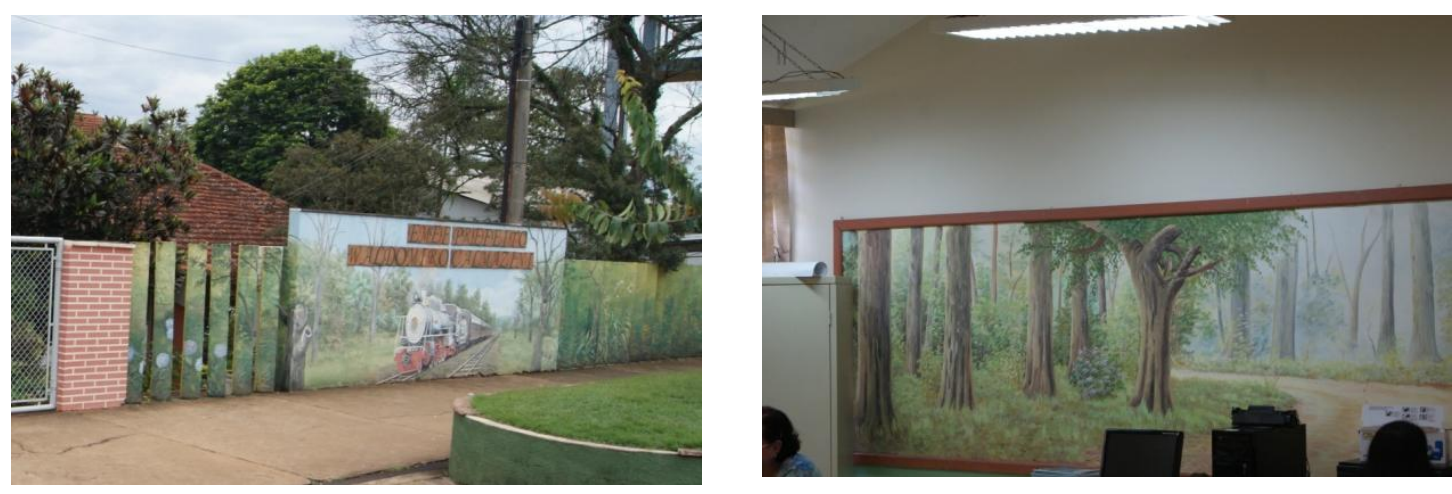

continua 


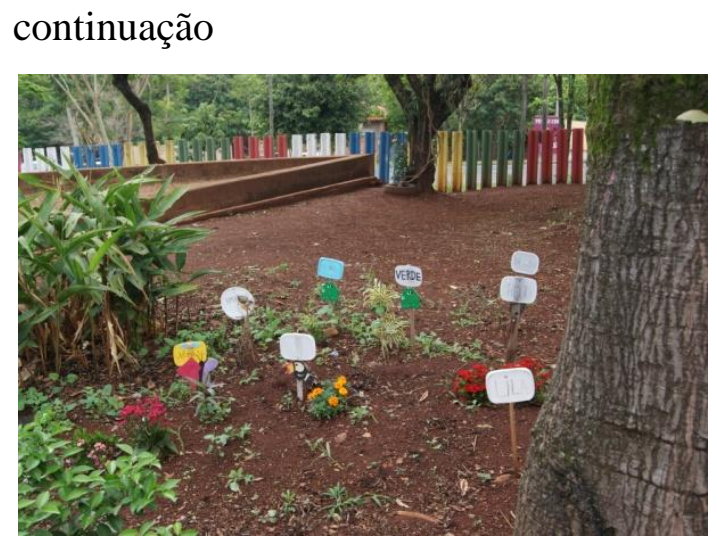

Fonte: arquivo pessoal do autor.

\subsection{Práticas pedagógicas}

\section{- Oferta de Reforço no Contraturno}

Segundo o Supervisor, o município dispõe de 50 (cinquenta) professores, sendo parte deles do CEAPE, que atuam de segunda a quinta-feira neste processo, dedicando a sexta-feira para os programas de capacitação docente, e parte de docentes da própria rede, que realizam o reforço escolar. O reforço é oferecido no contraturno, com transporte e refeição garantidos aos alunos. Exceto nos casos de alunos residentes em zona rural, cujo transporte demanda maior tempo, procura-se oferecer o reforço dentro do período regular das aulas, tirando-o da sala durante as aulas da disciplina em que está em dificuldade, de forma a garantir seu nivelamento para que possa acompanhar a turma.

- Acompanhar a Aprendizagem dos Alunos e Promover Ações de Combate à

\section{Reprovação}

Segundo o Supervisor entrevistado, a SME acredita que os prejuízos com a reprovação são maiores do que os eventuais benefícios, uma vez que afeta diretamente a autoestima do aluno e estimula o abandono escolar. Por esta razão, o município adota o regime de Progressão Continuada por ciclos. Neste sistema os alunos somente podem ser reprovados ao final de cada ciclo, mediante reunião e aprovação da SME. São adotados os seguintes ciclos:

- Primeiro ciclo - Alfabetização: $1^{\circ}$ ao $3^{\circ}$ ano

- Segundo ciclo - Intermediário: do $4^{\circ}$ ao $6^{\circ}$ ano

- Terceiro ciclo - Final: do $7^{\circ}$ ao $9^{\circ}$ ano

Em razão do sistema adotado, verificou-se nos depoimentos e na análise dos documentos, que o município se preocupa com o acompanhamento frequente do desempenho 
dos estudantes. Assim, a cada final de bimestre e de semestre, são realizados os fechamentos das notas para o acompanhamento do aproveitamento dos estudantes, dando origem a um documento que apresenta o quadro de alunos em risco de cada turma (Figura 57).

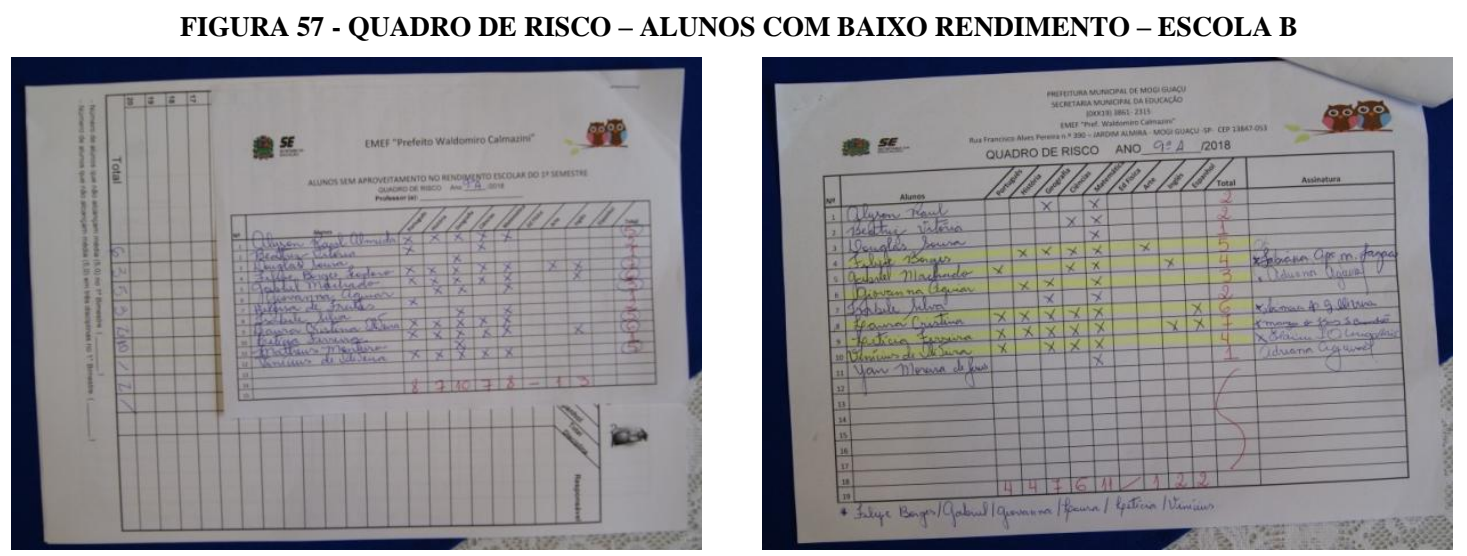

Fonte: arquivo pessoal do autor.

Este documento é complementando pelo "Relatório de Avaliação de Alunos com Defasagem" (Figura 58), que é preenchido pelos professores para cada aluno, individualmente. $\mathrm{O}$ documento foi desenvolvido pela Coordenadora Pedagógica da escola, e replicada para toda a rede, permite o acompanhamento da evolução dos aspectos comportamentais e de aprendizagem do estudante. O preenchimento do instrumento é bimestral, e é apresentado aos pais, que devem assiná-lo, a cada reunião.

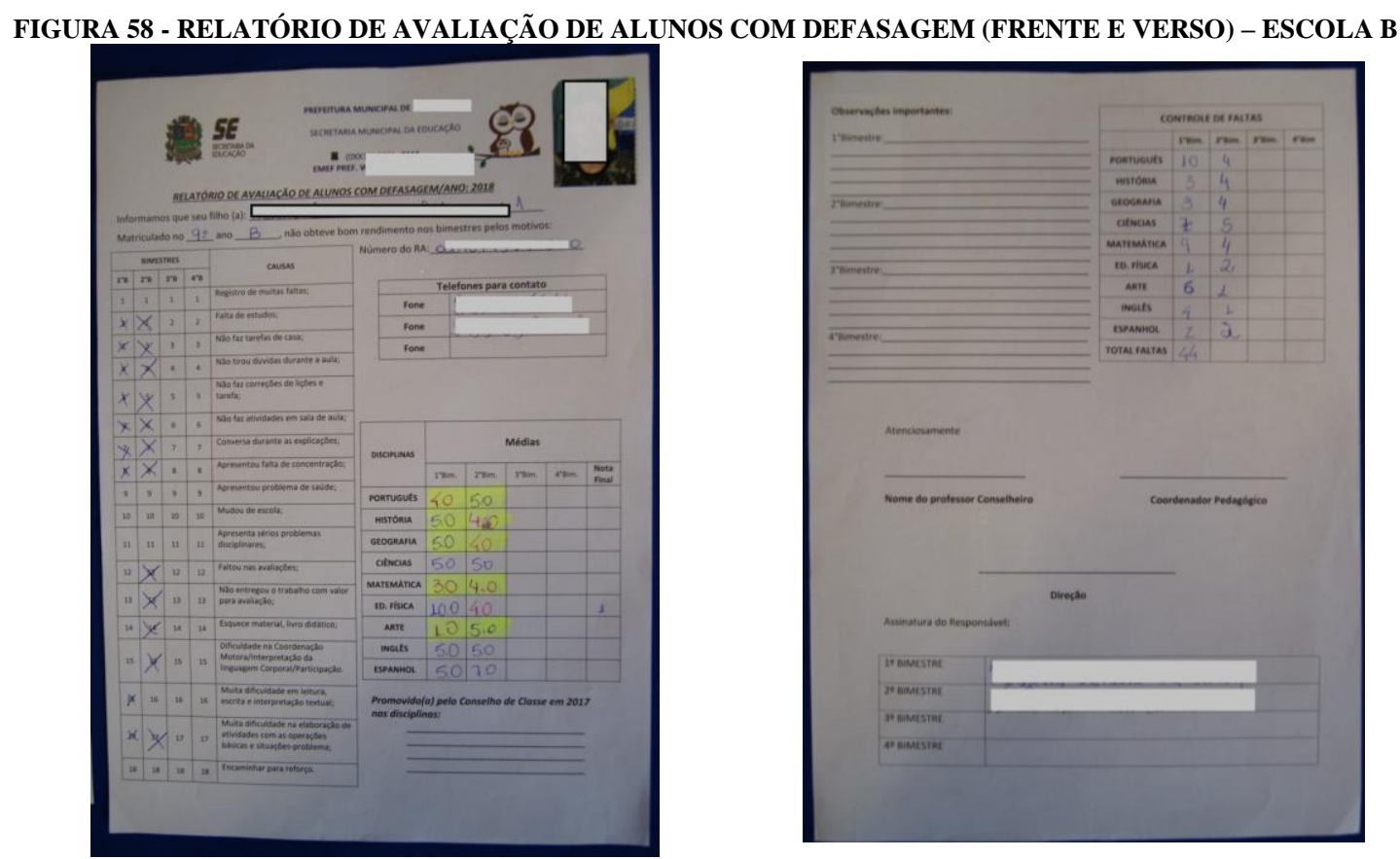

Fonte: arquivo pessoal do autor. 
Segundo informado pelos entrevistados e verificado na visita, estes relatórios dão subsídio para a formulação das estratégias de recuperação dos estudantes em risco. Para cada aluno é traçado um plano de ações e estratégias em conjunto com a Coordenação Pedagógica (Figura 59). Estes documentos também são utilizados para que os professores das diferentes séries e segmentos tenham conhecimento prévio do perfil de alunos que irá receber.

FIGURA 59- PLANO DE ESTRATÉGIAS INDIVIDUAL PARA RECUPERAÇÃO DE ALUNOS EM RISCO - ESCOLA B

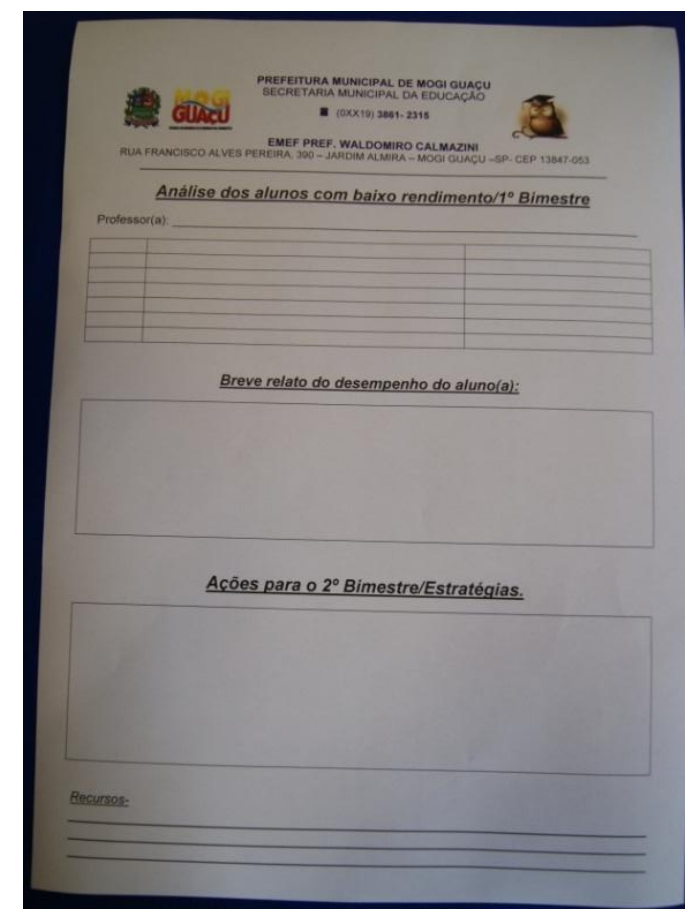

Fonte: arquivo pessoal do autor.

\section{- Acompanhamento dos Resultados do SAEB}

A SME, segundo relato do Supervisor, utiliza-se dos indicadores do IDEB para a avaliação e planejamento das eventuais ações de melhoria. A Diretora informou que logo após a divulgação dos resultados do SAEB e do IDEB, a SME encaminha a cada escola um relatório com os 'pontos a melhorar'. Estes resultados são apresentados aos professores e dão subsídio para a confecção de um Plano de Ações para melhoria. Segundo a professora de língua portuguesa, a última preparação específica para a Prova Brasil foi realizada pelo município em 2012, na forma de simulado. Desde então, não é realizado qualquer tipo de preparação.

Na visita, verificou-se que o resultado do último IDEB fica à mostra aos alunos, professores, funcionários e visitantes, por meio de um quadro instalado no principal corredor de salas de aula (Figura 60). 
FIGURA 60 - PLACA COM RESULTADO DO IDEB - ESCOLA B

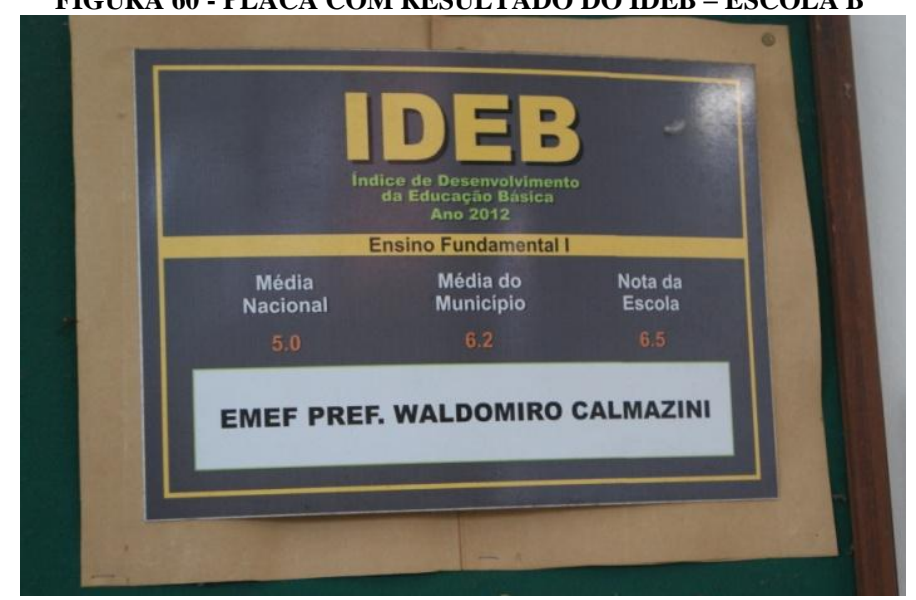

Fonte: arquivo pessoal do autor.

Além do SAEB e do IDEB, foi informado que a prefeitura se utiliza de uma prova diagnóstica própria, denominada Avaliação de Aprendizagem e Processo (AAP), que avalia o aluno em Língua Portuguesa e Matemática. Trata-se de uma prova padronizada aplicada à todas as escolas do município a cada bimestre. Os resultados desta avaliação também dão origem a um relatório com os dados mais recentes sobre o desempenho dos estudantes (Figura 61). Este relatório apresenta um comparativo de todas as turmas de uma determinada série/ano, bem como a frequência de respostas dada pelos alunos em cada uma das questões. Os dados são utilizados para a atualização e redirecionamento do Plano de Ação, quando necessário.

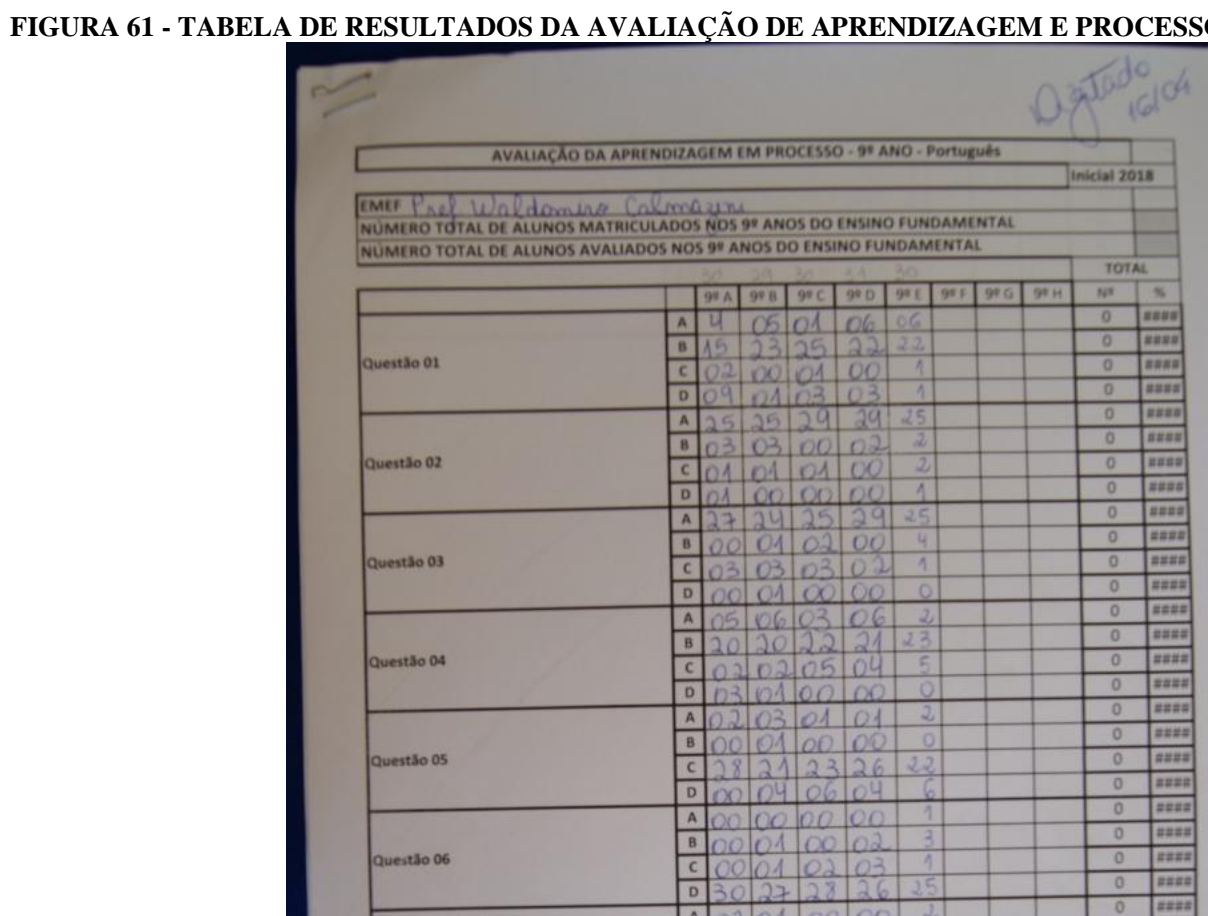

Fonte: arquivo pessoal do autor. 


\section{- Formação de Turmas}

Segundo depoimento da Diretora, a formação de turmas é realizada de forma heterogênea em relação ao rendimento e desempenho dos estudantes. Um rodízio é realizado a cada ano entre as turmas, procurando equilibrá-las com alunos de alto e baixo desempenho. De acordo com a Diretora, esta forma de divisão permite ao estudante de melhor desempenho auxiliar aquele com desempenho fraco, além de auxiliar o professor na condução da turma e na disciplina. Por orientação do CME, as turmas de $1^{\circ}$ ano devem ter até 23 alunos; as de segundo a quinto anos, até 28 , e de sento ao novo, 60 alunos por sala.

\section{- Projetos Temáticos}

Alguns projetos são realizados no âmbito municipal com foco na educação. São eles:

- Sementeira - projeto voltado à educação musical e realizado em parceria com a Secretaria Estadual de Cultura, com apoio de duas grandes empresas locais (Figura 62);

- Comunidade de Aprendizagem - por meio de parceria com a Ufscar e Natura, ajudam alunos e a comunidade a "ensinagem"dos alunos;

- Concurso Municipal de Poesia.

FIGURA 62 - CARTAZ DO PROJETO SEMENTEIRA - SME - MUNICÍPIO B

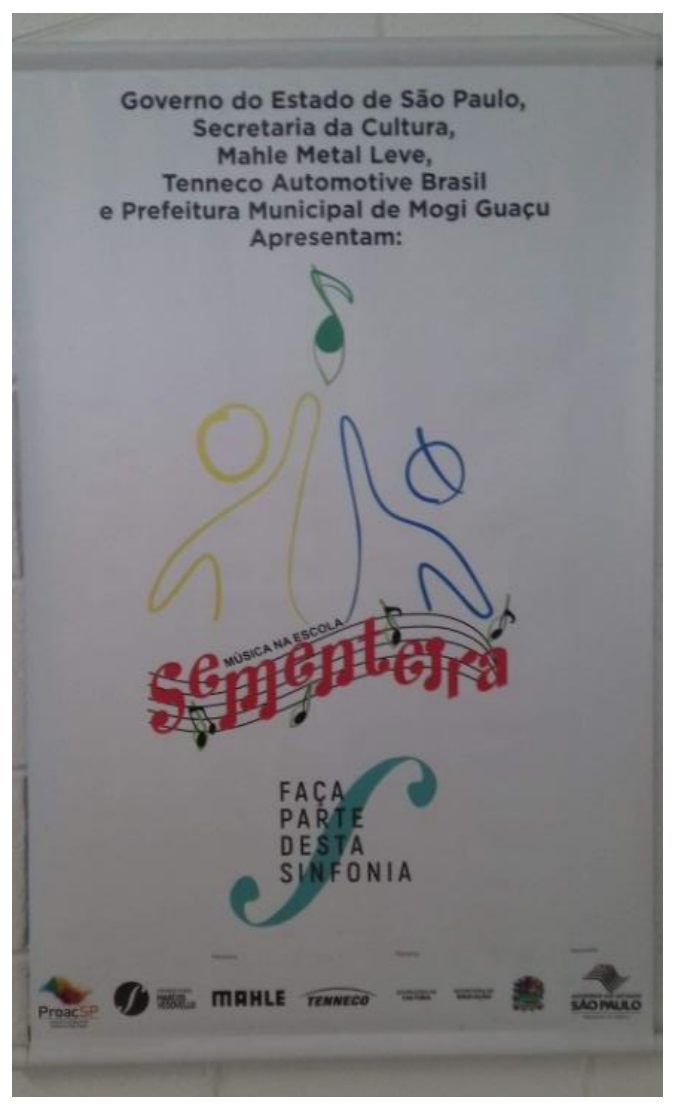

Fonte: arquivo pessoal do autor. 
Também são realizados projetos temáticos promovidos pela escola:

- Poezini - concurso de poesias realizado na escola. Os melhores classificados recebem uma premiação e são indicados para o Concurso Municipal de Poesia, promovido pela Biblioteca Municipal;

- Projeto Patrono das Turmas: cada turma elege um personagem histórico como seu "Patrono". Professores específicos são destacados para cada série, de forma a coordenar as atividades da classe (Figura 63). O personagem, suas obras efeitos são, então, estudados ao longo do ano. No final do ano, cada turma realiza uma apresentação sobre o patrono de sua turma aos seus pais;

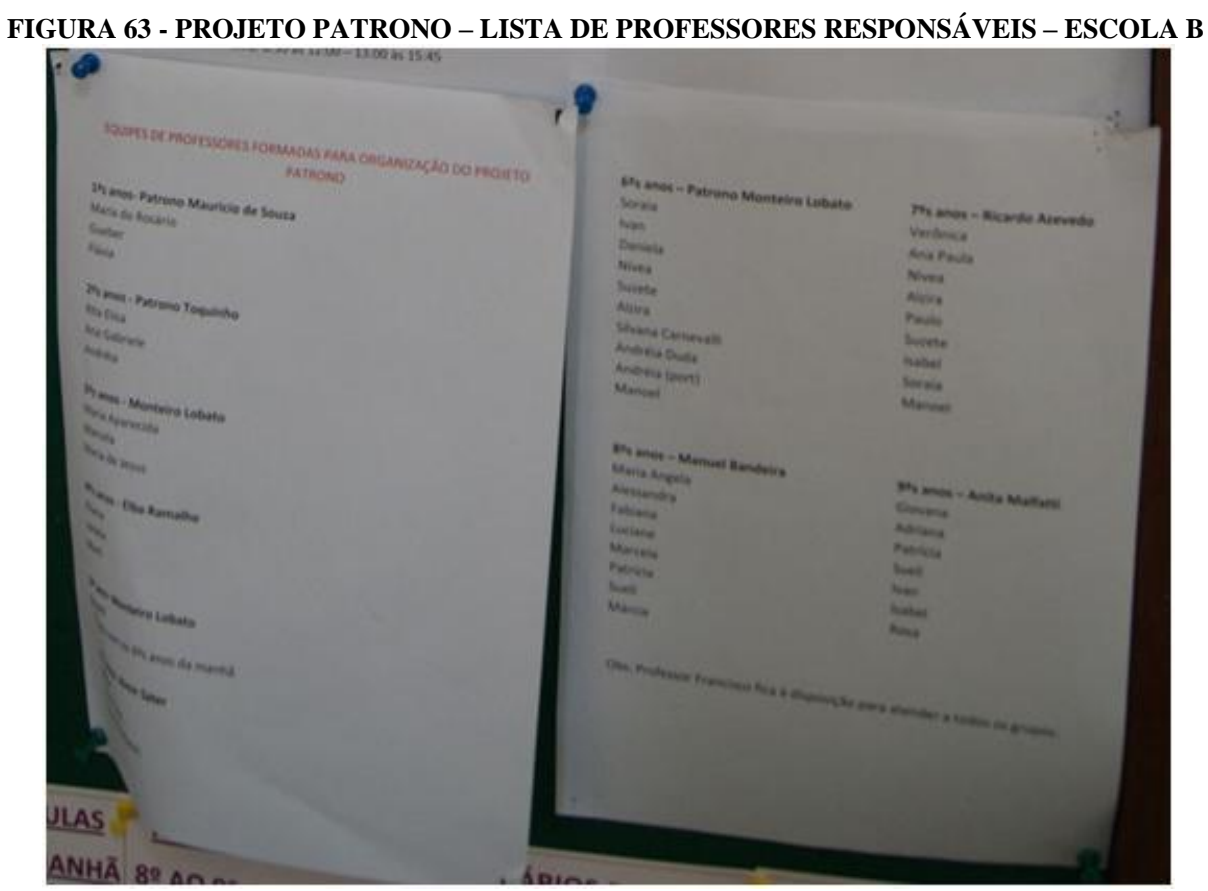

Fonte: arquivo pessoal do autor.

\section{2.2.3.4 Atuação com a família e a comunidade}

Os relatos do Supervisor, da Coordenadora e Professora entrevistados, convergem para a importância da Diretora neste sentido. Segundo os entrevistados, a Diretora, que atua na escola há 12 anos, é uma referência na comunidade local. Mora próximo à escola e tem entre seus alunos, seus próprios netos.

O regime de matrículas adotado pela rede municipal é por zoneamento, para garantir a proximidade da comunidade com a escola e reduzir os custos municipais com transporte. Porém, a escola visita é vista no município como referência, fazendo com que pais de toda a 
cidade tentem matricular seus filhos. Assim, nesta escola a matrícula se dá por ordem de pedido, criando uma espécie de concorrência informal entre os estudantes. A Figura 64, retirada do sistema de cadastro e controle do transporte escolar apresenta a distribuição geográfica de matrículas da escola avaliada. Nela é possível verificar a existência de alunos de todos os bairros do município, mesmo daqueles que possuem outras opções mais próximas da residência dos estudantes, representadas pelos pontos azuis e vermelhos.

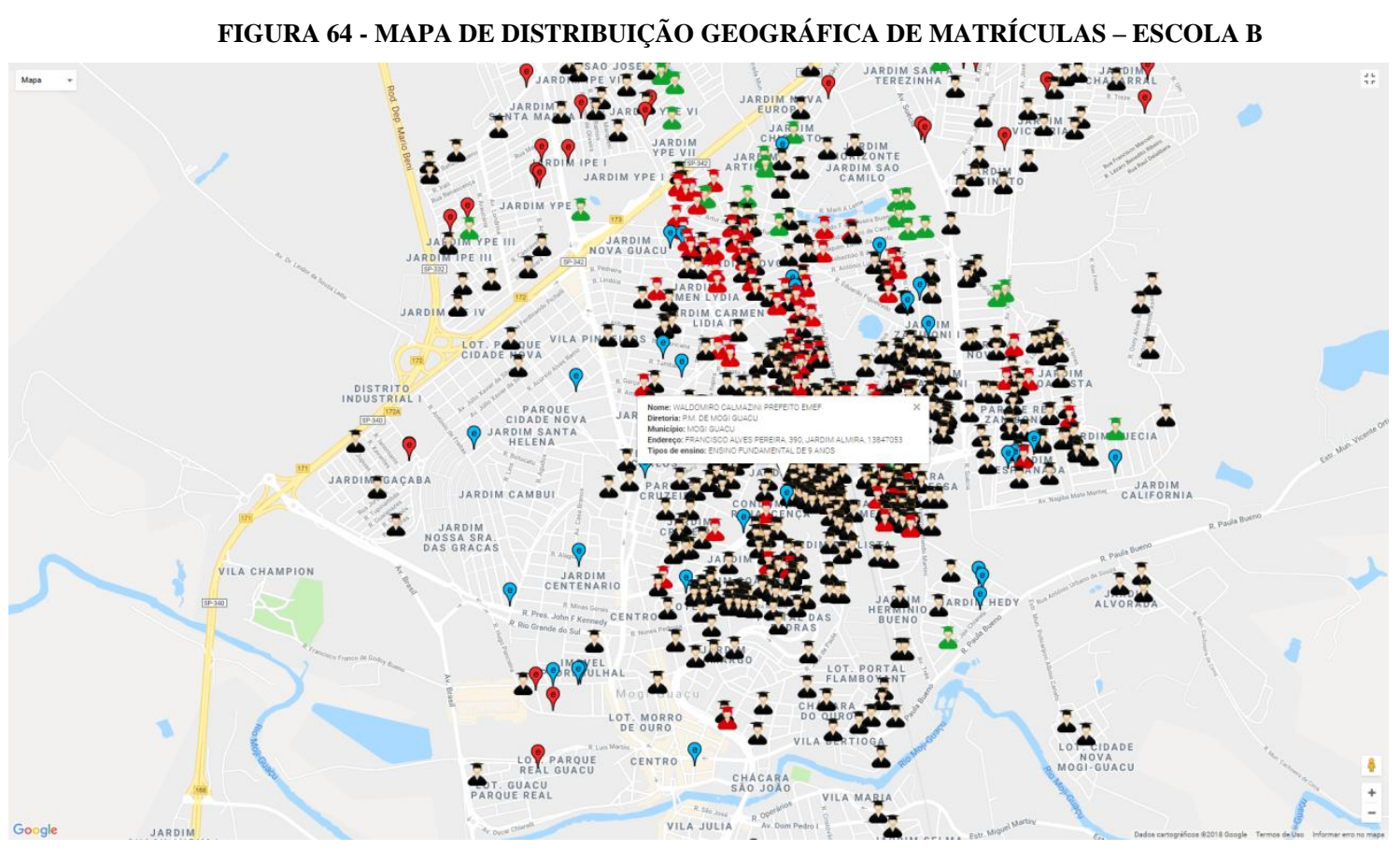

Fonte: arquivo pessoal do autor.

A prática adotada de recepcionar os alunos diariamente na porta da escola também foi apontado como um fator relevante para a aproximação com as famílias. Segundo a Diretora, a melhor forma de integrar a família à escola é 'promover o bom atendimento'. Também foi apontado pela equipe de Coordenação, Supervisor e Professora, a importância da continuidade da gestão na escola.

Os horários de trabalho e atendimento da equipe diretiva e dos demais funcionários da escola ficam disponíveis para consulta no mural da escola (Figura 65), para permitir o fácil acesso pelos pais e comunidade, quando necessário. 
FIGURA 65 - QUADRO DE HORÁRIOS DE TRABALHO DOS FUNCIONÁRIOS - ESCOLA B

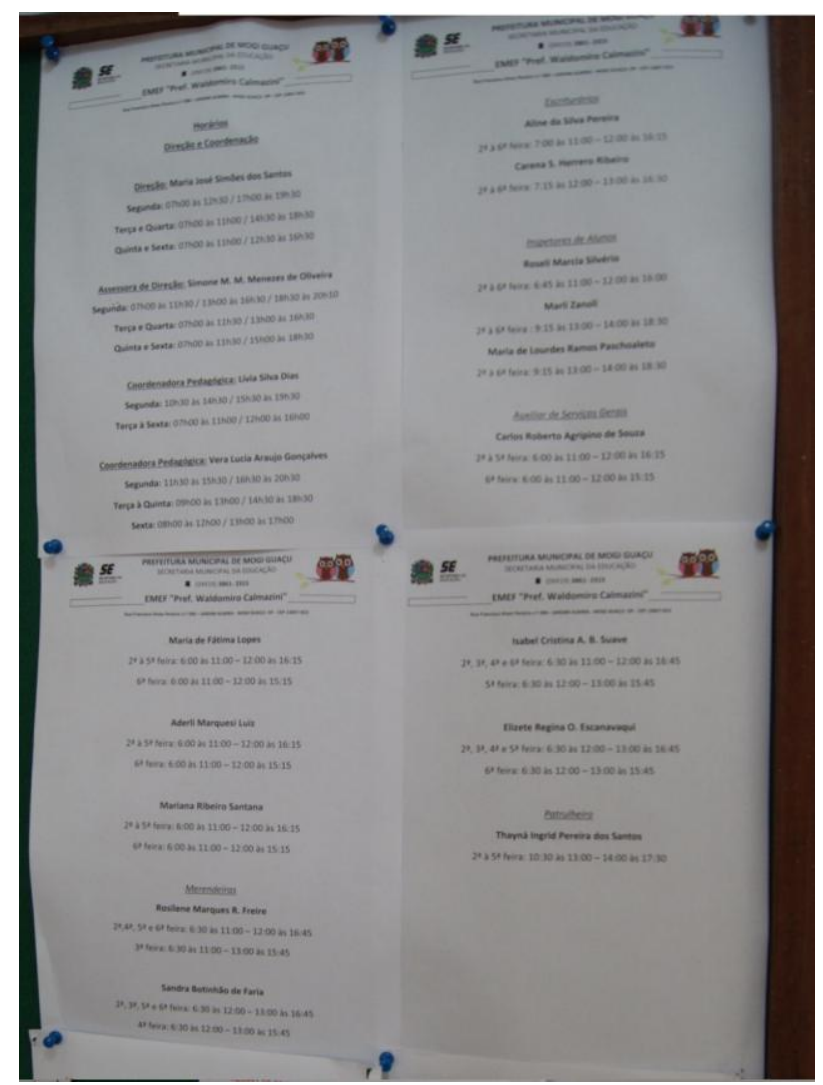

Fonte: arquivo pessoal do autor.

Aos finais de semana, a escola é disponibilizada pela direção para a realização de eventos promovidos pela igreja local, como bingos e festividades.

\section{- Horta Comunitária}

A escola cede parte do terreno não utilizado para moradores locais cultivarem uma horta (Figura 66). Com isto, a manutenção do espaço se torna compartilhada pela comunidade, que auxilia na sua conservação e proteção. Parte da pequena produção é destinada à escola, que a utiliza na merenda escolar, aumentando a integração com os estudantes. 


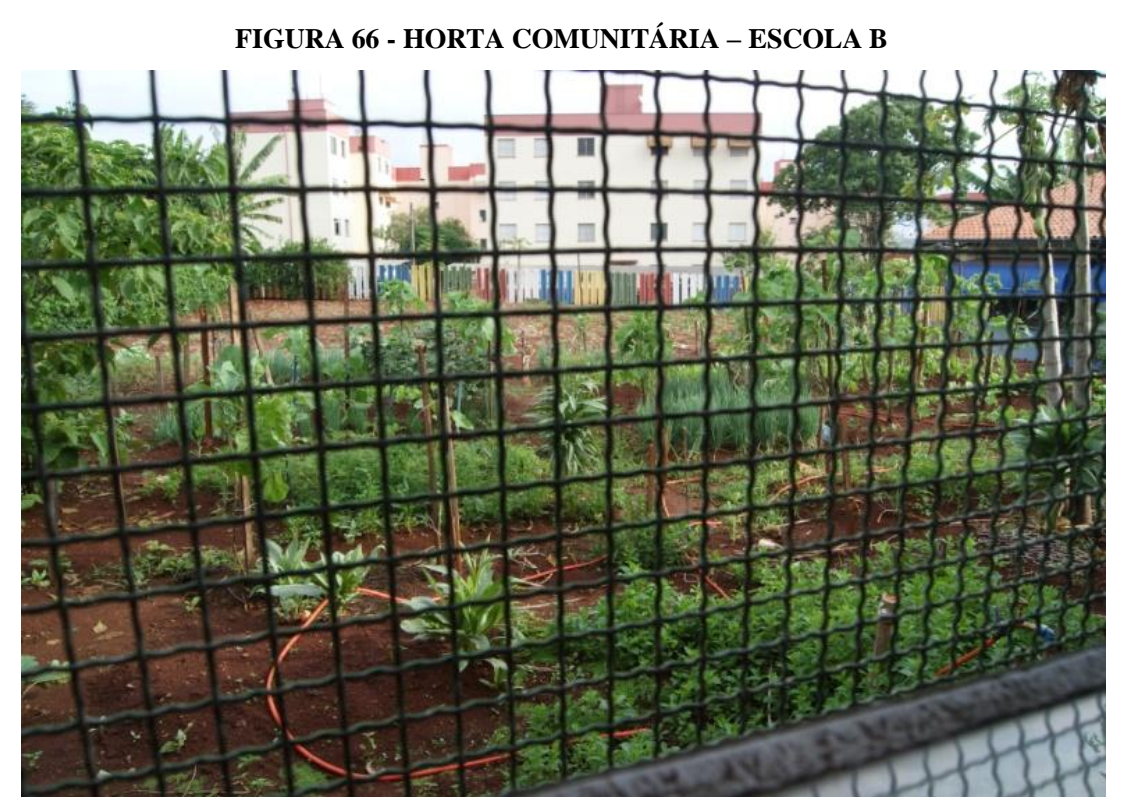

Fonte: arquivo pessoal do autor.

\section{- Projeto Amigos da Merenda}

Os pais e a comunidade também participam ativamente do processo de avaliação da merenda escolar. Por este projeto, qualquer pessoa da comunidade, independentemente de ter filhos matriculados na escola, pode se servir da merenda escolar, sem necessidade de aviso prévio e, ao final, preencher uma ficha de avaliação, com suas impressões sobre a qualidade da alimentação servida.

Além de permitir a integração com a comunidade, este projeto ainda auxilia na propagação da informação sobre o bom atendimento prestado pela escola aos estudantes, gerando ainda mais valorização de suas ações.

\section{- Reuniões dos Conselhos de Classe e Conselho Escolar}

As reuniões dos Conselhos são realizadas quatro vezes ao ano, de forma ordinária, e constam do Calendário Escolar, que é disponibilizado aos pais no início do ano letivo. $\mathrm{O}$ cronograma das reuniões fica disponível para consulta pública no mural de comunicados da escola (Figura 67). 


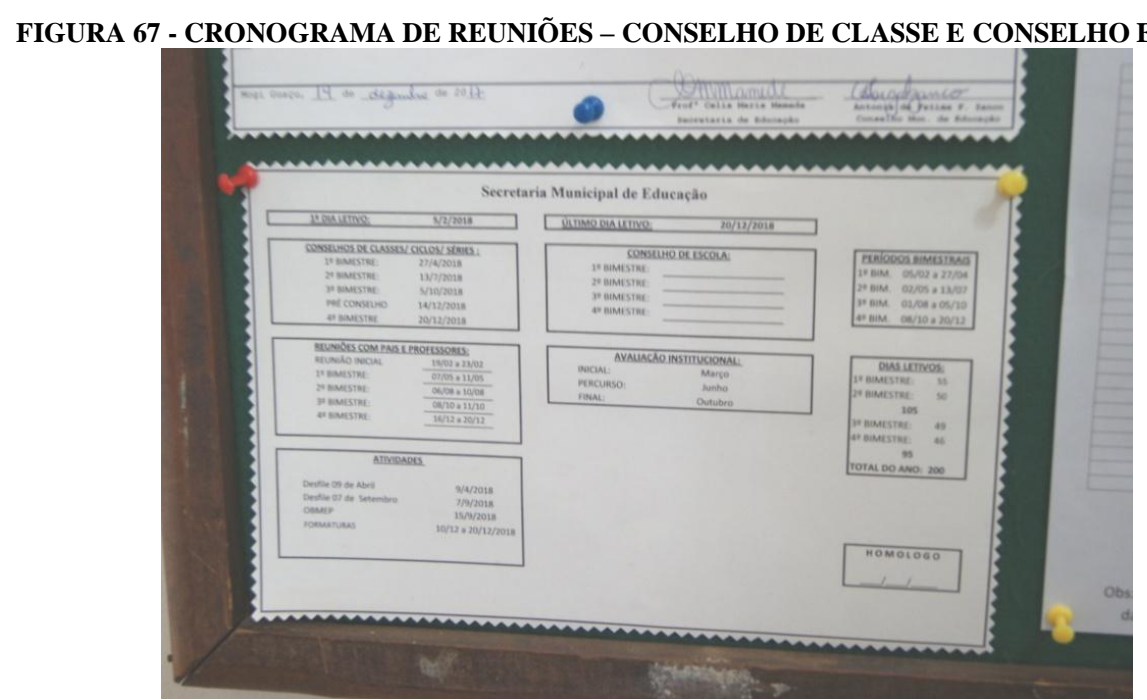

Fonte: arquivo pessoal do autor.

\section{- Reuniões de Pais}

Foi relatado que é realizada uma reunião de pais no início do ano letivo, para integração com os professores e a escola. Para as turmas do ensino fundamental I, as reuniões são individuais, por turma. Para o ensino fundamental II, a reunião e coletiva. Ao longo do ano são realizadas reuniões bimestrais, onde são apresentados aos pais o Relatório de Avaliação de Alunos com Defasagem, que contém o resumo de notas e faltas, bem como o Plano de Estratégias Individual para Recuperação de Alunos em Risco, quando for o caso.

A Diretora procura agendar estas reuniões para às $18 \mathrm{~h} 45$, de forma a permitir a participação dos pais que trabalham durante o dia. Segundo as entrevistadas, a taxa média de comparecimento para o ensino fundamental II é de $50 \%$ (cinquenta por cento), porém, ao longo dos dias seguintes à reunião, os demais pais comparecem para receber atendimento individual, como se pode observar na Lista de Comparecimento, Figura 68.

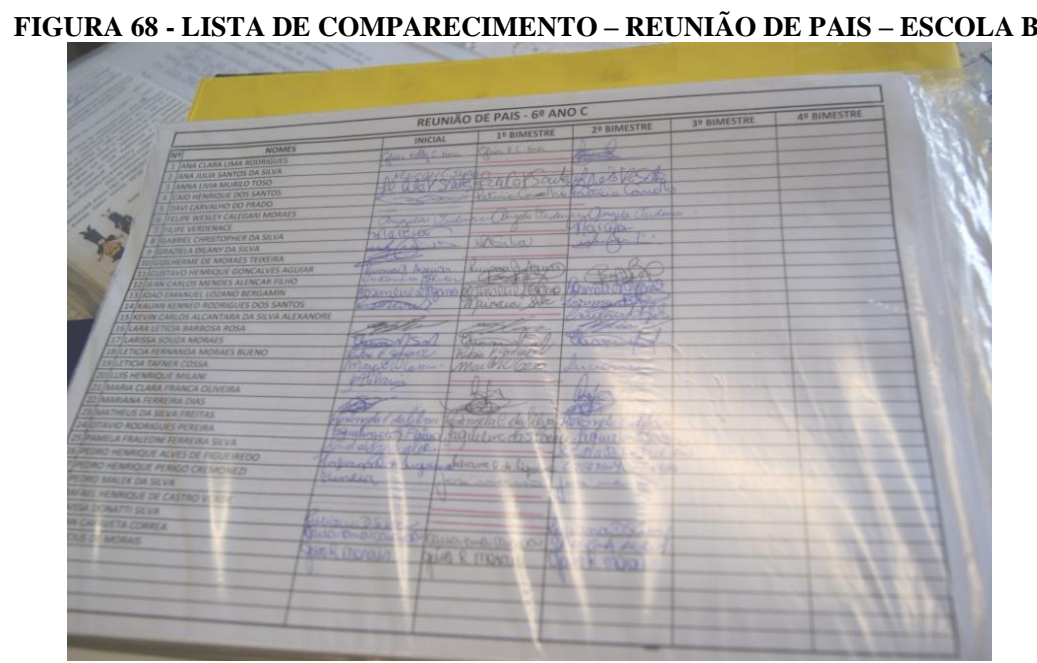

Fonte: arquivo pessoal do autor. 


\subsubsection{Professor}

\subsection{Perfil}

A professora entrevistada possuía, à época da entrevista, 20 (vinte) anos de experiência como docente, profissão que adotou por desejo e disponibilidade na região. Possui licenciatura em Letras e em Pedagogia, bem como especializações em Educação Inclusiva e em Letramento, todas realizadas em instituições de ensino superior privadas da região.

Segundo a professora, o curso de Pedagogia a auxiliou por fornecer a compreensão dos processos de aprendizagem e fazes da alfabetização, contribuição importante uma vez que, segundo ela, o curso de Letras foca o ensino das teorias e regras da língua, sem oferecer, no entanto, informações importantes sobre o "como ensinar".

\subsection{Regime de trabalho}

\section{- Contratação via CLT ou Contrato Temporário}

A contratação no município se dá mediante a aprovação em concurso público, sendo que, segundo dados da SME, 100\% dos docentes é contratado sob o regime da Consolidação das Leis do Trabalho (CLT), que prevê um período probatório de 03 (três) anos. O professor é lotado em uma escola, onde mantém sua sede, não sendo permitida a troca para outra unidade escolar.

\section{- Dedicação Exclusiva à Escola}

A professora informou que também atua em uma escola da rede estadual, cumprindo carga horária semanal de 62 (sessenta e duas) horas, o que lhe proporciona desgaste físico e emocional. A decisão de atuar nas duas redes (municipal e estadual) se deve ao interesse de obter duas aposentadorias. A remuneração dos docentes no município é mais atrativa do que a dos Diretores, segundo a SME. Também colabora para isso o Plano de Carreira do município, que não engloba o cargo de Diretor. A cada dois anos, o professor recebe um acréscimo de 5\% (biênio) e de mais 5\% a cada cinco anos (quinquênio). A cada quatro anos o professor pode solicitar a evolução na carreira, que lhe rende mais 3\% de acréscimo, mediante avaliação anual realizada pelo Diretor, que considera sua frequência, assiduidade e pro atividade. 
Cursos de Pós-graduação (lato e stricto sensu), também geram ganho de 5\% sobre o salário, podendo ser solicitado a cada período de 4 anos.

\section{2.2.4.3 Atuação com a direção}

\section{- Participação na Elaboração do Projeto Pedagógico}

Os entrevistados informaram que o Plano Municipal de Educação conta com a participação de todos os professores da rede, de forma consultiva. Os livros didáticos são escolhidos pela escola, mediante consulta aos professores. Desde 2013 tem sido adotado o Livro Didático do Governo Estadual.

Segundo a professora, os docentes têm autonomia para elaborar o Plano de Ensino da disciplina para o bimestre (Figura 69), onde são informados os conteúdos a serem dados. Ao final de cada bimestre, o professor deve informar se conseguiu cumprir integralmente o programa. Caso não, a justificativa deve ser inserida no documento para ser discutido junto à Coordenação Pedagógica. Apesar da autonomia para o planejamento, a professora informou que lhes são cobrados os registros formais destes documentos.

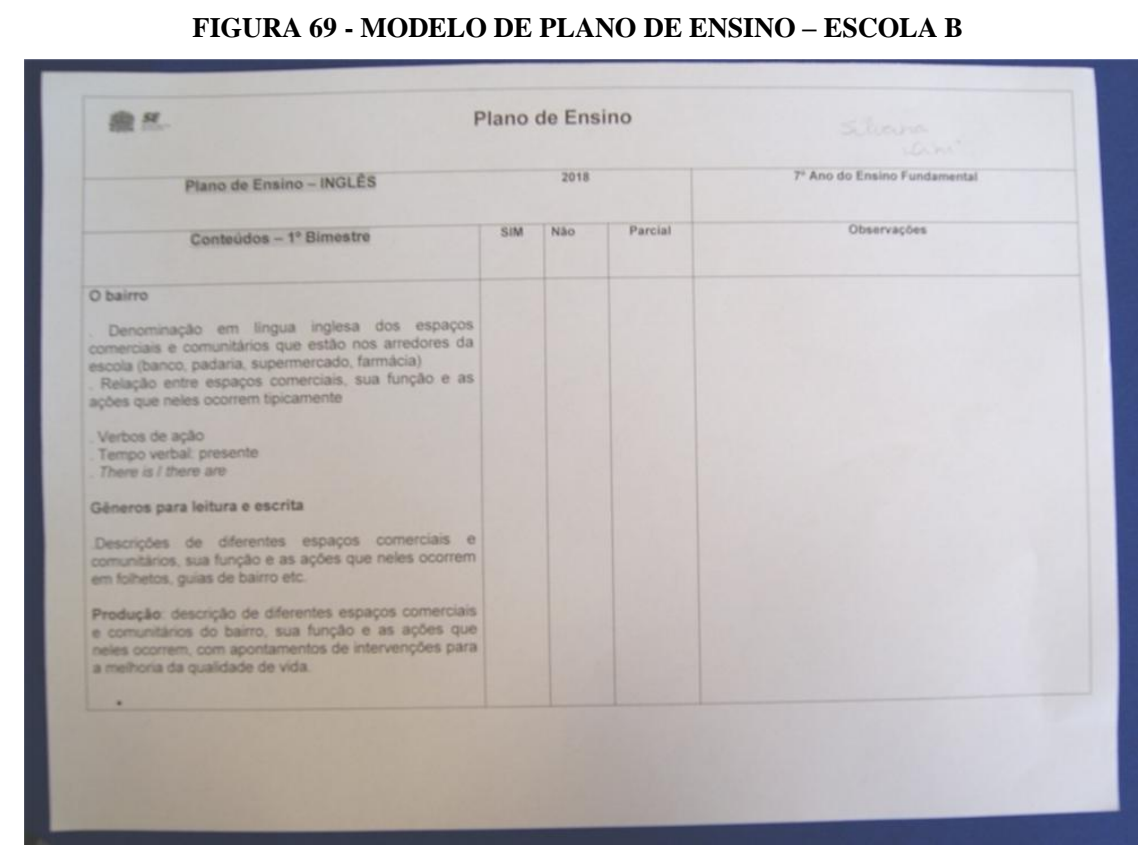

Fonte: arquivo pessoal do autor.

\section{- Discussão Semanal das Metas}

A cada semana os conteúdos são avaliados pela Coordenação Pedagógica, para a garantia do cumprimento do conteúdo proposto. 


\subsection{Atividade docente}

\section{- Reuniões Semanais com Outros Professores}

Semanalmente são realizadas as reuniões de HTPC, onde são discutidas as eventuais dificuldades dos estudantes entre os professores. O Plano de Ações também é discutido em grupo, quando necessário.

\section{- Dedicar mais Tempo às Aulas}

A professora informou que, de forma geral, dedica-se quase que exclusivamente às aulas, com pouca participação em questões administrativas da escola.

\section{- Garantir o Cumprimento de Todo o Conteúdo}

A professora informou conseguir cumprir cerca de $95 \%$ dos conteúdos da disciplina a cada semestre, o que é acompanhado pela Coordenação por meio do "Plano de Ensino".

\section{- Oferta e Correção do Dever de Casa}

O professor tem autonomia para definir a oferta do dever de casa. A professora relatou que envia tarefas semanais aos alunos que, em geral, são na forma de trabalhos ou pesquisas, evitando-se o uso de exercícios de repetição.

A correção é política da escola, segundo depoimento da Diretora, Coordenadora e Professora. Todos os professores devem 'vistar' as tarefas oferecidas e, obrigatoriamente, corrigi-las em sala. Segundo relato da professora, o material utilizado - "São Paulo Faz Escola" -, exige o constante envio das tarefas, que é utilizado para o monitoramento do desempenho do estudante. Ao efetuar a correção em sala, a professora verifica e analisa os erros com os alunos, para auxiliá-lo a compreender.

Os professores enviam à Direção a relação dos estudantes que não realizaram a tarefa de casa, o que pôde ser comprovado no momento da visita, quando a professora de Geografia entregou sua lista (Figura 70). 
FIGURA 70 - RELAÇÃO DE ALUNOS QUE NÃO REALIZARAM O DEVER DE CASA - ESCOLA B

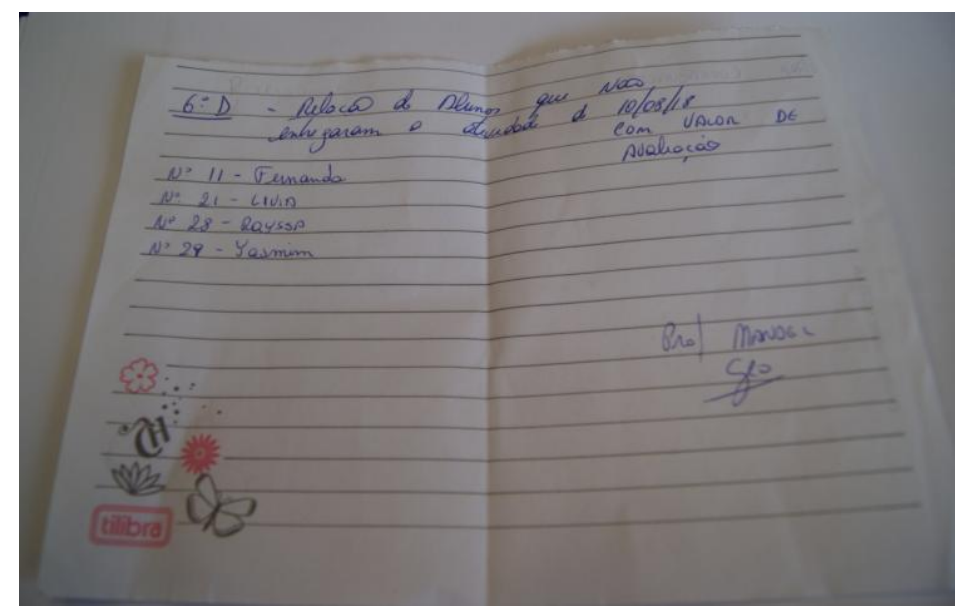

Fonte: arquivo pessoal do autor.

Os pais dos alunos que não cumpriram com a entrega são comunicados pela Direção, via recado escrito ou abordagem na entrada da escola.

\section{- Uso de Recursos Didáticos e Incentivo à Participação dos Alunos}

A professora destacou a realização de atividades voltadas à leitura e interpretação de textos, que geram no aluno estímulo e o levantamento de dúvidas. Nestes momentos, a professora busca realizar atividades pré-leitura, por meio da contextualização da época e dos fatos que envolviam a elaboração do texto, e pós-leitura, por meio de rodas de conversa e discussão em sala. Em alguns casos são solicitadas a realização de trabalhos, que são expostos aos demais alunos.

Entre as estratégias utilizadas está a produção de textos. Os alunos escrevem poesias para o Poezini, concurso de poesias promovido pela escola. Os textos melhor classificados pela opinião dos professores e alunos são encaminhados para representar a escola no Concurso Municipal de Poesias. Segundo a professora, a possibilidade de participar das competições estimula os alunos, uma vez que na edição municipal do evento, a família participa da cerimônia de premiação.

Também são produzidos Cordéis, que, depois de prontos, são disponibilizados em varais nos corredores da escola para leitura pelos demais alunos.

Uma vez que a escola não dispõe de biblioteca, a professora leva para a sala de aula, semanalmente, uma caixa de leitura, conforme apresentado anteriormente. Segundo a professora, os estudantes não têm o hábito da leitura por conta própria, assim, são 
incentivados a ler um livro por semana, em geral da literatura clássica brasileira, para as atividades da disciplina.

O Projeto Patrono também incentiva à leitura. A turma deve ler a história de seu patrono, por meio de livros ou pesquisas na internet, para elaborar seus trabalhos.

\subsubsection{Aluno e família}

Uma vez que os estudantes não foram entrevistados diretamente, os apontamentos a seguir são realizados com base nos depoimentos colhidos da Professora, Diretora e Coordenadora Pedagógica.

\subsection{Comportamento}

\section{- Manter a Disciplina e Frequência às Aulas}

Segundo os entrevistados, a escola não enfrenta problemas de indisciplina, que ocorrem em níveis baixos quando comparados a outras escolas da rede. Também foi relatado haver baixo índice de faltas entre os estudantes, dado o volume de alunos matriculados.

\section{- Realizar o Dever de Casa}

A professora relatou que, em geral, os alunos têm o hábito de realizar o dever de casa e a escola conta com o apoio dos pais na cobrança, uma vez que são notificados quando o estudante não realiza a entrega.

\section{- Leitura Frequente de Livros}

Em seu depoimento, a professora informou que são poucos os estudantes que têm o hábito da leitura fora do ambiente escolar. Somente a realizam quando a leitura faz parte de alguma atividade a ser avaliada ou utilizada em aula.

\subsection{Ambiente familiar e social}


A equipe da Direção reportou contar com o apoio da maioria dos pais, tanto na cobrança pela assiduidade, participação nas atividades da escola e disciplina.

\section{- Possuir Computador em Casa}

Os entrevistados não souberam informar o percentual de estudantes que dispõe de computadores em casa. Porém, quando questionada sobre a eventual existência de diferença de desempenho entre os estudantes que possuem e os que não possuem o equipamento, informou não ser possível constatar tal afirmação.

\subsubsection{Análise do município C - baixo desempenho}

O Município C possuía, em 2010, 29 mil habitantes, com PIB per capita de R\$ 31.168,75 (IBGE, 2015), e está localizado no interior do estado de São Paulo, a 16 quilômetros da cidade de Piracicaba (Figura 71), para onde converge grande parte da força de trabalho local. A cidade conta com escolas municipais, estaduais e privadas para a oferta de educação básica.

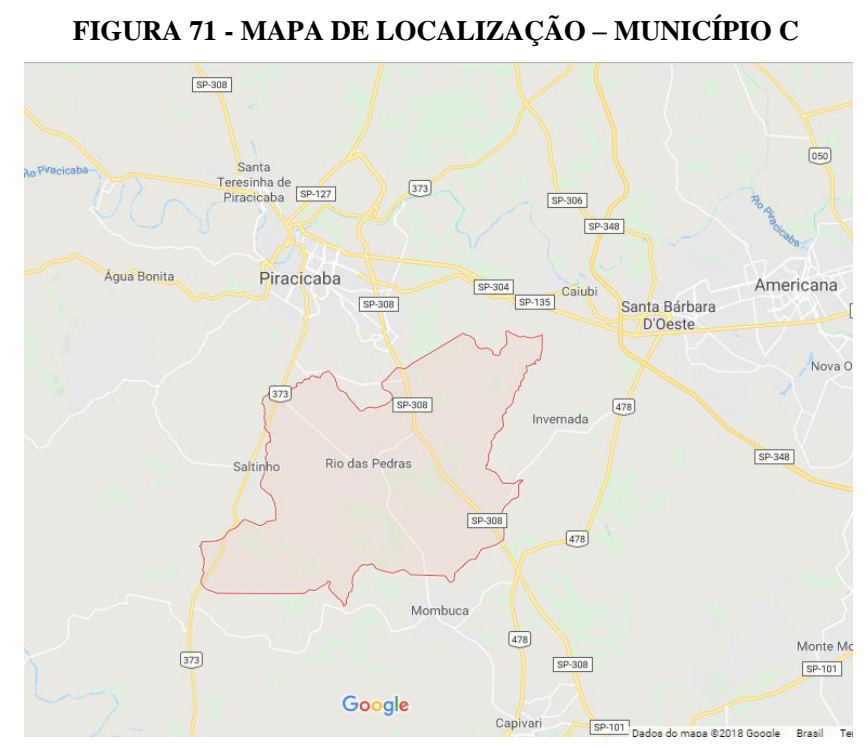

Fonte: Google Maps.

No setor educacional, o município apresenta taxa de escolarização da população de 06 a 14 anos de idade de 98,4\% (IBGE, 2010). O município dispunha no período da visita de 389 professores concursados, via regime CLT, além de 74 temporários, contratados via empresa terceirizada. A Tabela 12 apresenta a síntese dos dados do município. 
TABELA 12 - DADOS DEMOGRÁFICOS MUNICÍPIO C

\begin{tabular}{|l|l|l|l|l|l|}
\hline População $(*)$ & $\begin{array}{l}\text { IDH } \\
(*)\end{array}$ & $\begin{array}{l}\text { Renda Per Capita } \\
\text { Anual }(* *)\end{array}$ & $\begin{array}{l}\text { Número de } \\
\text { Escolas }(* * *)\end{array}$ & $\begin{array}{l}\text { Número } \\
\text { Alunos EF }\end{array}$ & $\begin{array}{l}\text { Investimento Anual Médio } \\
\text { por Aluno }(* * * *)\end{array}$ \\
\hline 29.501 & 0,759 & $\mathrm{R} \$ 31.168,75$ & 17 & 3.924 & $* * * 8$ \\
\hline
\end{tabular}

Fonte: Elaborado pelo autor.

Base: (*) IBGE 2010; (**) IBGE 2015; (***) Censo Escolar 2015 (****); FINBRA Investimento médio entre 2012, 2013 e 2014.

O Gráfico 23 apresenta a distribuição dos gastos em educação do município. Verificase que a maior despesa se refere justamente às etapas do ensino fundamental, que recebe $73,11 \%$ da verba total.

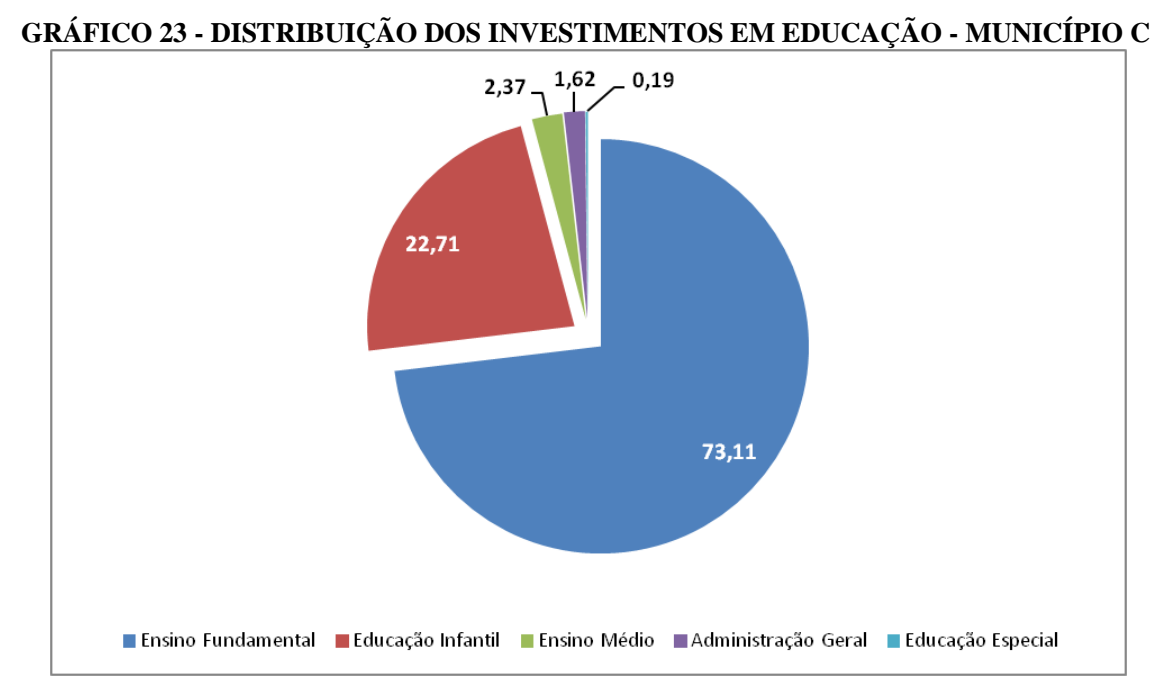

Fonte: Elaborado pelo autor. Base: Lei Orçamentária Anual 2015 do município.

A visita ao município foi realizada no dia 09 de outubro de 2018 , mediante prévio agendamento com a Secretaria Municipal de Educação. A seguir são apresentados os resultados das entrevistas realizadas com os Supervisores de Educação do Município, Diretora, Vice-Diretora e professora de Língua Portuguesa da escola selecionada.

\subsubsection{Análise da Secretaria Municipal de Educação}

O atual Secretário foi recentemente empossado, não tendo dados relevantes do período desejado para a pesquisa. Assim, a entrevista foi realizada com dois Supervisores de Ensino

\footnotetext{
${ }^{8}$ Não calculado em razão da ausência de dados de investimento do município para o ano de 2013.
} 
do Município, sendo que um deles atuou como Secretário no período da realização da Prova Brasil, objeto deste estudo.

\section{- Estrutura da Secretaria Municipal de Educação}

Verificou-se que a SME não dispõe de uma estrutura clara, nem tampouco de organograma com definição das funções, sendo que apenas no mandato do atual prefeito foram realizadas três trocas de Secretários.

O Secretário é assessorado por três Supervisores, sendo cada um responsável por um segmento: 1) Administração; 2) Ensino Fundamental I; 3) Ensino Fundamental II.

\section{- Plano de Metas e Objetivos}

Segundo relato dos Supervisores, a SME possui um Plano Municipal de Educação (PME), com vinte metas. Além do acompanhamento pelo próprio município, os resultados do plano são acompanhados pela União dos Dirigentes Municipais de Educação (UNDIME). Porém, ao ser questionada sobre a existência de um planejamento com estabelecimento de metas educacionais, a Diretora demonstrou desconhecimento do PME, informando que o município não possui um plano, apontando para uma possível falha de comunicação das estratégias pela SME.

\section{- Captação de Recursos Financeiros}

Não há no município, segundo os relatos, projetos ou setores responsáveis pela busca e captação de recursos financeiros com órgãos externos ou empresas. Todos os recursos são, exclusivamente, públicos. Segundo os Supervisores, $98 \%$ do gasto é direcionado ao pagamento de salários.

\section{- Transporte Escolar}

Foi informado que a SME oferece transporte gratuito para todos os estudantes, sendo que nos casos de estudantes moram em área rural, são enviados carros da prefeitura, diariamente.

\section{- Manutenção das Escolas}

Segundo os Supervisores, os Diretores são os responsáveis pelo acompanhamento e identificação das necessidades de manutenção das escolas. A SME realiza o gerenciamento 
dos pedidos, porém, a liberação e gestão dos recursos cabem ao setor de Administração da prefeitura que, quando necessário, realiza os processos licitatórios cabíveis.

\section{- Cobrança de Resultados dos Diretores}

Segundo os Supervisores, os cargos de Diretor e Coordenador não são atrativos em razão da remuneração. Os diretores são professores do município, indicados pelo prefeito e aprovados pelo SME. O contrato é feito com base na hora relógio (60 minutos), diferentemente do contrato docente, que é baseado na hora-aula (50 minutos) e perde-se o direito ao Descanso Semanal Remunerado (DSR). Desta forma, a composição salarial do Diretor lhe rende, em média, um salário de $\mathrm{R} \$ 3.400,00$, frente a uma remuneração média de $\mathrm{R} \$ 2.500,00$ do professor. Mesmo com esta diferença, torna-se mais atrativo no município o exercício da docência, uma vez que o professor consegue realizar salário similar ao do Diretor com a aplicação de aulas de substituição pelo período de uma semana. Por isto, segundo os entrevistados, a cobrança por resultados é feita com certa restrição junto aos diretores, uma vez que é muito comum que solicitem deixar o cargo para voltar à sala de aula. Na opinião da Diretora, o salário não é atrativo nem condizente com as responsabilidades do cargo - dar aulas lhe renderia maior rendimento. O município também não dispõe de um sistema de gratificação ou premiação dos diretores por alcance de metas.

São pré-requisitos para a assunção do cargo, ser professor concursado, que tenha vencido o estágio probatório, com 5 anos de experiência em sala de aula, além de graduação em Pedagogia ou pós-graduação em Gestão Escolar.

A indicação dos diretores como cargo de confiança, segundo os Supervisores, tem como vantagem a possibilidade de permitir a substituição daqueles que não estão correspondendo às expectativas, situação que não seria possível na hipótese de efetivação no cargo. A cada mudança na gestão municipal, muitos diretores são substituídos.

\section{- Trabalho com a SME e Autonomia do Diretor}

Verificou-se uma contradição entre os depoimentos prestados pela equipe da SME e a Direção da escola. Segundo a SME, o grau de autonomia dos Diretores é alta. Podem elaborar o Projeto Político Pedagógico (PPP) da escola; realizar a escolha do material didático, mediante consulta aos professores; elaboração de controles internos; bem como tomar medidas adequadas à realidade local. Têm como rotina padrão estabelecida pela SME as reuniões do Conselho Escolar e a prestação de contas sobre as verbas utilizadas e sobre o 
Programa Dinheiro Direto na Escola (PDDE). Porém, segundo a diretora, sua autonomia é restrita e questões políticas afetam suas decisões.

São realizadas reuniões quinzenais com os diretores escolas, prática averiguada no momento da visita, momento em que os Diretores trocam informações entre si.

\section{- Programas de Capacitação de Diretores e Professores}

No período de 2011 a 2015, período em que o município utilizava o sistema de ensino Anglo, eram realizadas capacitações semestrais por ele promovidas. $\mathrm{O}$ foco dos treinamentos estava em: "Práticas de Alfabetização", "Práticas de Inclusão (Jornada do Autismo) e "Gestão em Educação Municipal (GEM)".

Segundo relato da Diretora e Vice-Diretora, não são ofertadas capacitações pelo município, cabendo ao próprio funcionário identificar e custear, às suas expensas, eventuais treinamentos que julgue necessário. A professora informou ter participado da capacitação de "Práticas de Inclusão", a qual classificou como 'muito teórica e pouco prática', tendo sido de pouca valia para o desempenho de suas funções.

\section{- Estrutura para Atendimento Educacional Especializado (AEE)}

Os Supervisores informaram que o município dispõe de um Núcleo para o AEE, com Orientadora e Psicóloga, ambas especialistas em Educação Especial e AEE, os quais acompanham os professores no atendimento aos alunos nestas condições. Informaram, ainda, que as escolas possuem Salas de Recursos, que funciona no contraturno. O município possui 50 estudantes com necessidade de AEE, os quais são acompanhados individualmente em sala por estagiários - alunos de pedagogia contratados via CIEE. O município possui 50 estagiários.

\subsubsection{Análise da escola "C"}

A escola está localizada em bairro periférico do município (Figura 72), a cerca de um quilômetro do Centro. 
FIGURA 72 - MAPA DE LOCALIZAÇÃO DA ESCOLA C

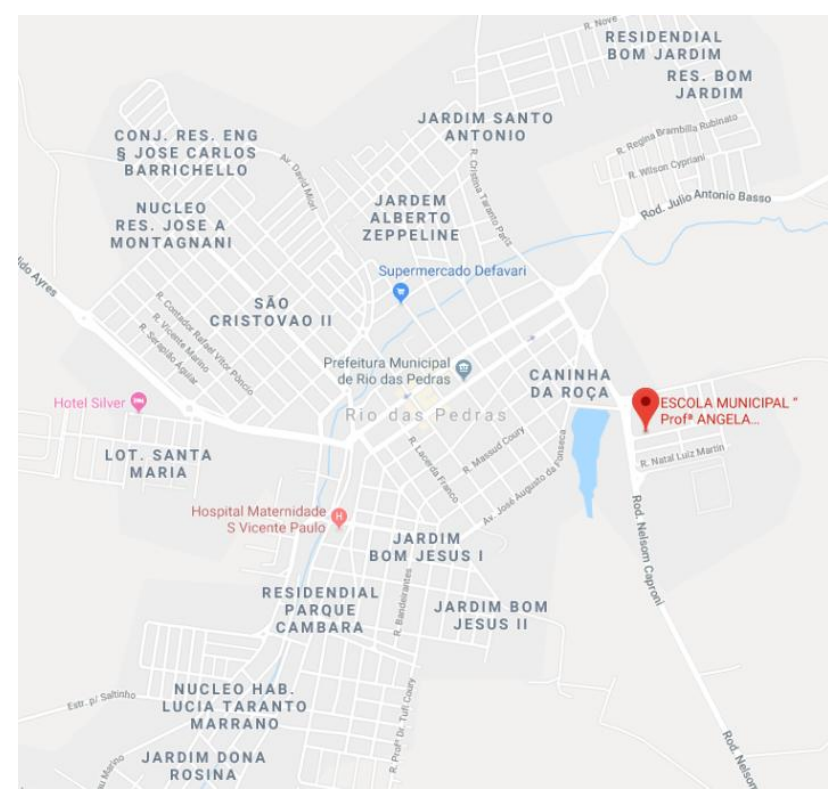

Fonte: Google Maps.

Segundo dados do Censo, a escola contava, em 2015, ano de realização da Prova Brasil, com 42 funcionários, responsáveis pelo atendimento de 158 estudantes do ensino fundamental I e 154 do ensino fundamental II..

A fachada da escola não possui boa aparência, com muros pichados e identificação precária. No momento da visita encontrava-se com os portões de acesso (externo e interno) abertos e sem controle de entrada. Um amplo estacionamento é disponível a professores e funcionários (Figura 73).

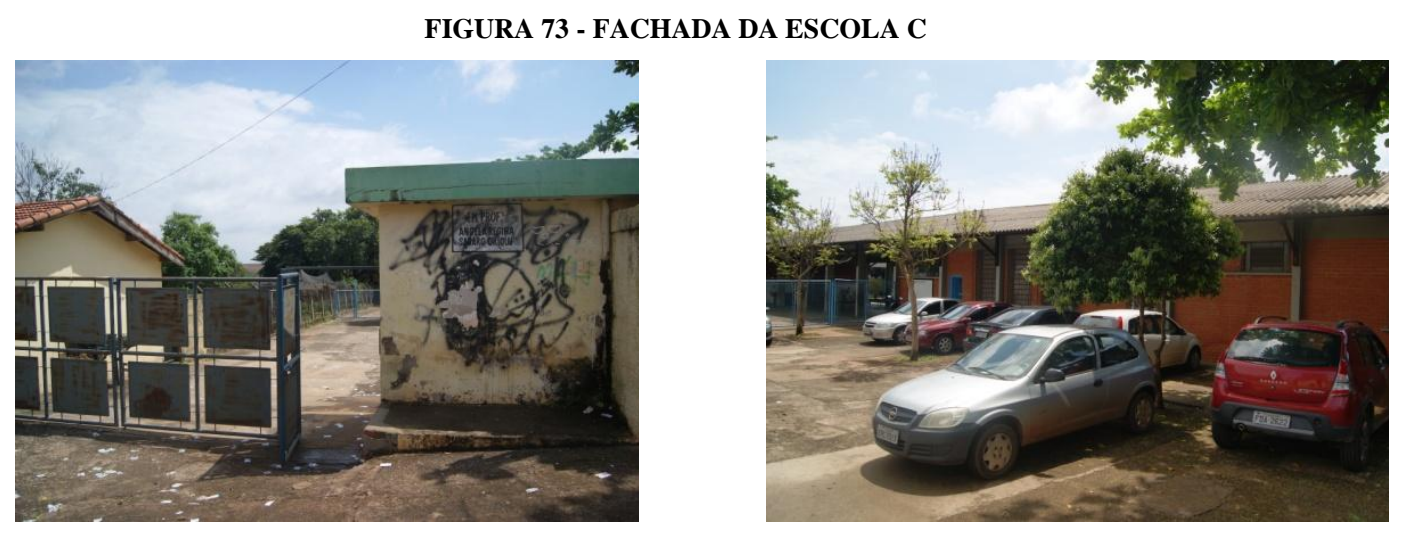

Fonte: arquivo pessoal do autor.

Os banheiros da escola são pequenos e individuais (Figura 74), e, apesar de estarem em piso nivelado, não possuem barras de acessibilidade. 


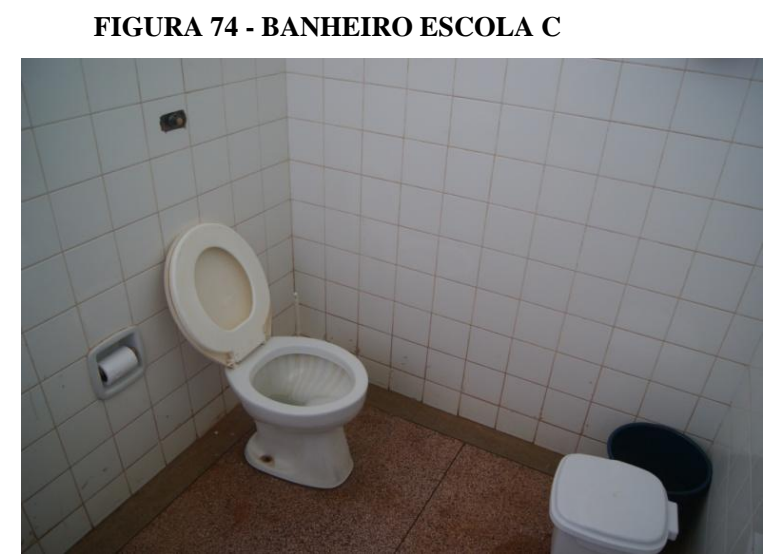

Fonte: arquivo pessoal do autor.

As instalações administrativas (salas da direção e secretaria), bem como as áreas externas (jardinagem e pátio) se apresentam conservadas (Figura 75).
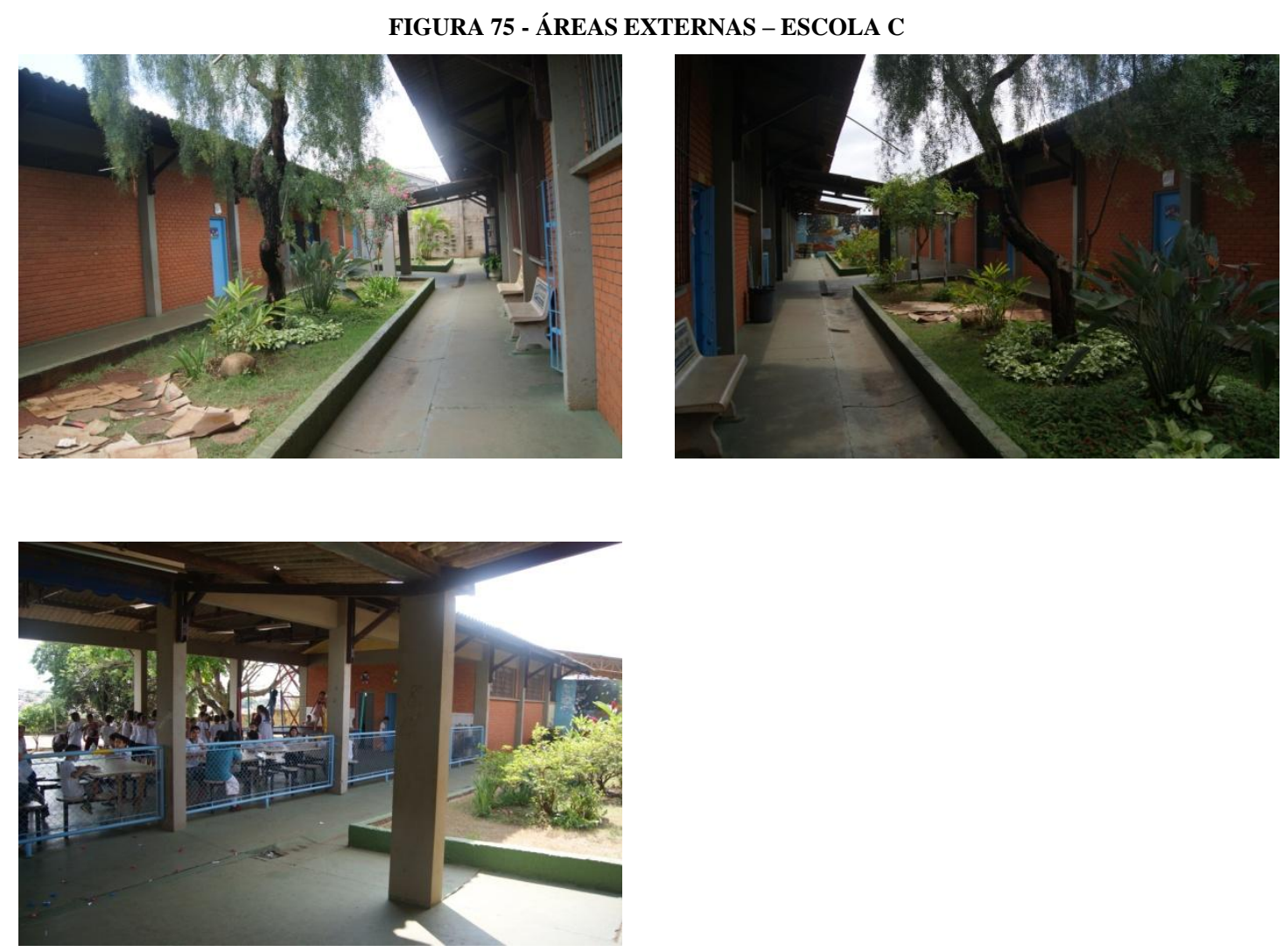

Fonte: arquivo pessoal do autor.

As salas de aula apresentam boa estrutura e mobiliário, com janelas amplas e ventiladores, garantindo, assim, boa luminosidade e ventilação, além de lousas brancas, sem 
uso de giz, e lousa digital em todas as salas (Figura 76). No momento da visita as salas de aula passavam por pintura.

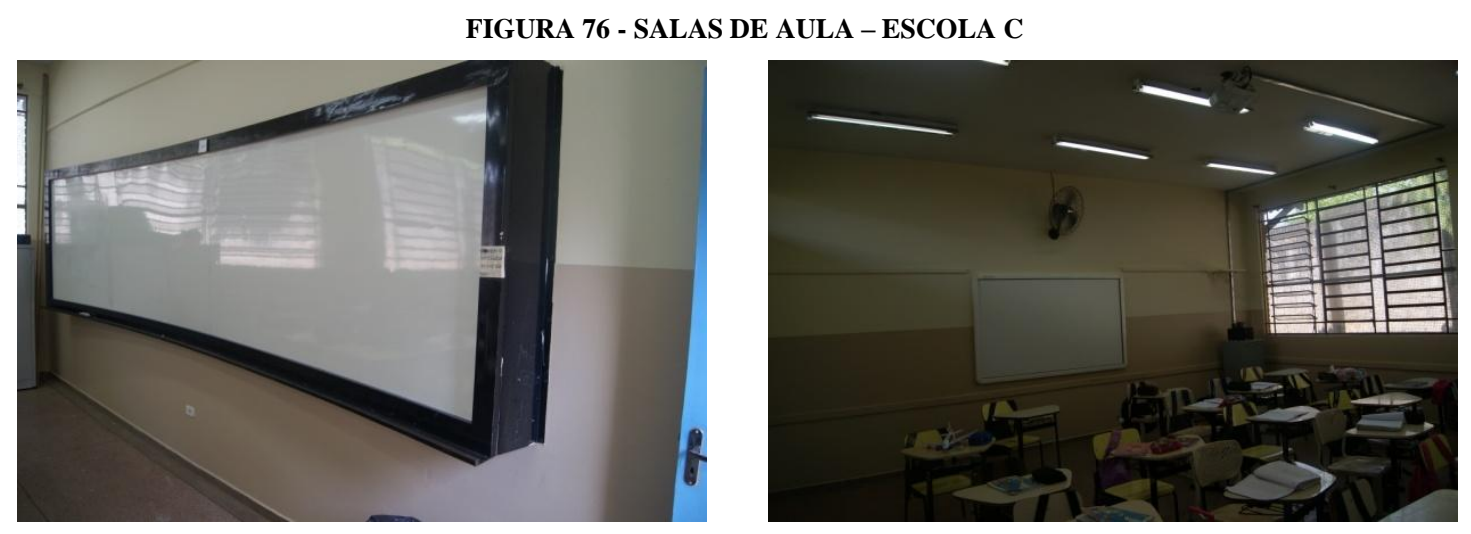

Fonte: arquivo pessoal do autor.

Uma vez que todas as salas dispõem de lousa digital, a escola não possui uma sala específica com recursos multimídia. A escola oferece a disciplina de Língua Inglesa como língua estrangeira.

\section{- Recursos de Informática}

Todas as salas da escola possuem lousa digital e wifi. A escola dispõe, ainda, de um pequeno laboratório de informática com 07 computadores (sendo que 3 já se encontravam quebrados há muito tempo), o que, segundo a Diretora e a Professora entrevistadas, não é suficiente para o número de alunos. Segundo a professora, a internet para de funcionar com frequência.

Os entrevistados informaram que, no ano de 2009, quando foram implantadas as lousas digitais, todos os docentes receberam um notebook da SME, para que pudessem realizar pesquisas e trabalhos para enriquecimento das aulas. Porém, segundo a professora, pouco ou nenhum resultado foi observado em razão da falta de treinamento para seu uso. Segundo ela, a maioria dos professores (inclusive ela), não soube como utilizar o recurso adequadamente. Também houve problema de compatibilidade do equipamento com os softwares educacionais da lousa digital, impossibilitando seu uso.

Estes equipamentos ainda permanecem em poder dos docentes, porém, em grande parte, obsoletos em razão do tempo de uso e da falta de manutenção. A escola possui computadores para uso da Direção e da secretaria. 


\section{- Acessibilidade}

Observou-se que a escola é pequena, toda em nível térreo, com acessibilidade para todas as instalações acadêmicas e administrativas, à exceção dos banheiros, que não dispõe de estrutura específica para alunos com dificuldades de mobilidade.

\section{- Merenda Escolar}

Os Supervisores informaram que a SME conta com uma nutricionista e uma Economista Doméstica que centralizam a confecção do cardápio para o município. Os itens são adquiridos pela SME e distribuídos para as escolas, onde a preparação é realizada por equipe própria. O Conselho de Alimentação Escolar (CAE), composto por pais, alunos, professores e funcionários, exercem a fiscalização da merenda. Segundo a Diretora, a merenda é ofertada em quantidade e qualidade adequadas. Todos os alunos recebem um lanche às $8 \mathrm{~h} 35$ e aqueles que moram em área rural, cujo horário de chegada em suas casas após as aulas ocorre por volta das $15 \mathrm{~h} 30$, recebem, adicionalmente, um almoço 'reforçado' às 12:20. A estrutura para a preparação da merenda foi avaliada como adequada pela equipe da Direção (Figura 77).

Segundo a SME, a verba da Secretaria para este item é insuficiente, e o município complementa com outras fontes próprias.
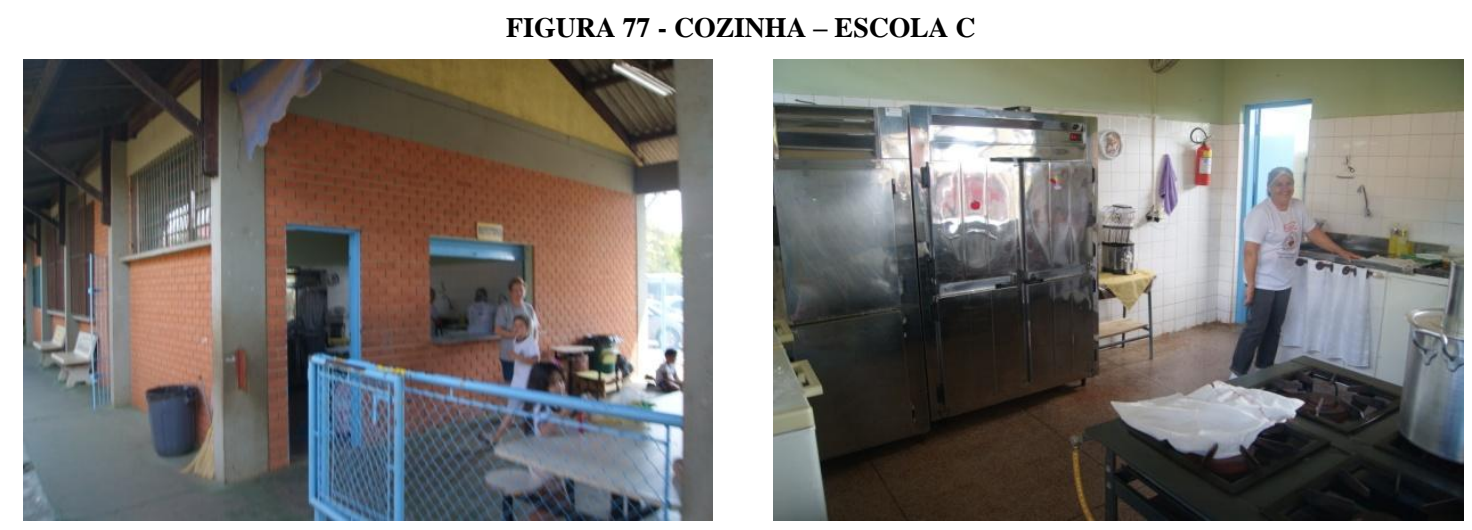

Fonte: arquivo pessoal do autor.

\section{- Biblioteca}

A escola possui uma pequena biblioteca, que compartilha o espaço com o laboratório de informática (Figura 78). Ela não dispõe de funcionário próprio, ficando as chaves com uma professora que, quando solicitada, abre as instalações. Os alunos podem retirar livros e levar 
para casa, mas ela não é aberta à comunidade. No momento da visita estava sendo utilizada como sala de aula em razão de serviço de pintura nas salas regulares.
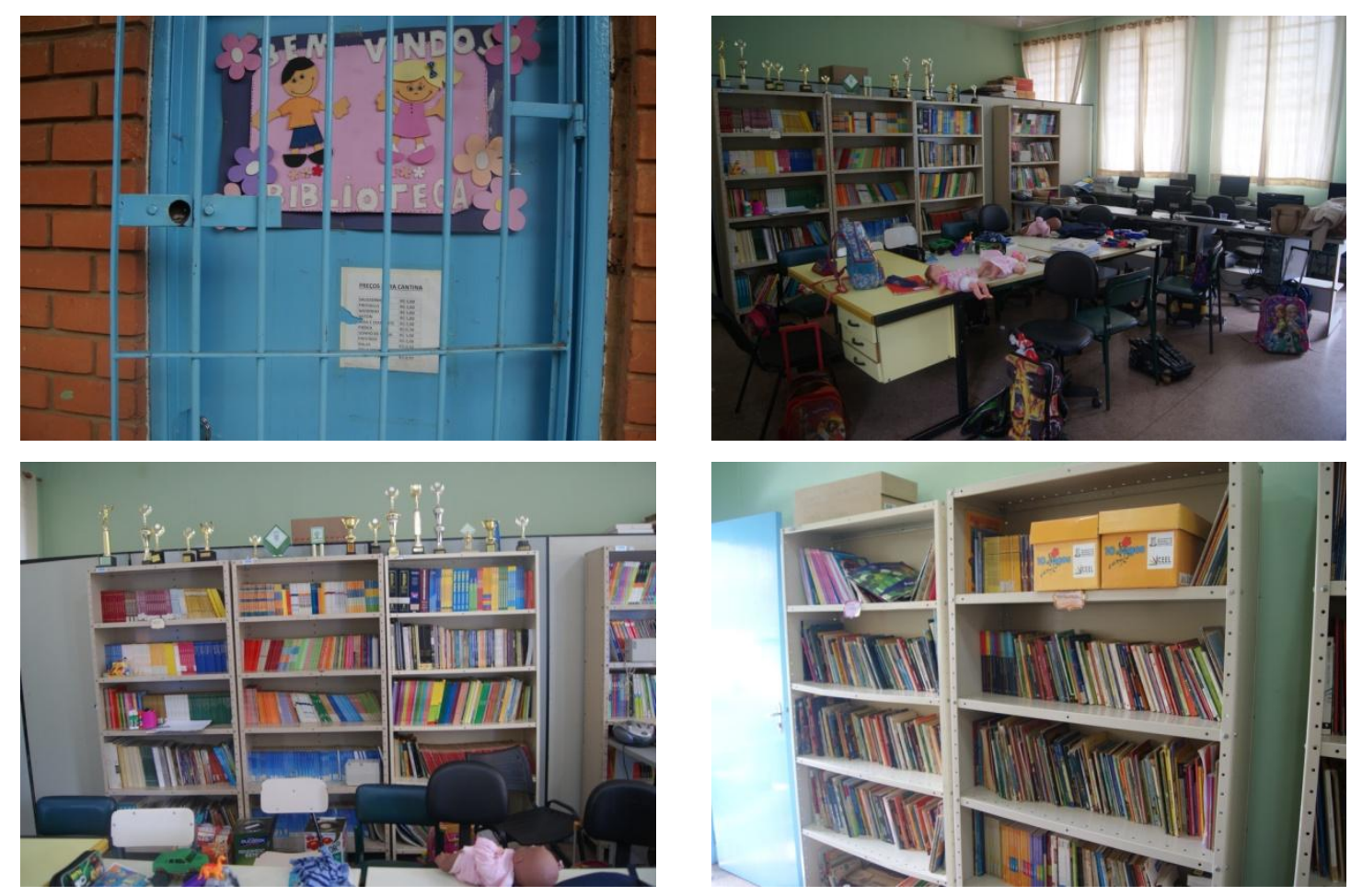

Fonte: arquivo pessoal do autor.

Pôde-se verificar que a maior parte dos volumes dispostos nas prateleiras são livros didáticos, com poucas obras literárias. Segundo a Diretora, a escola recebeu verbas do PDDE para aquisição de livros, mas o volume foi insuficiente. A variedade do acervo é pequena e não estimula o aluno à continuidade da leitura e a Coordenadora leva para a escola livros de sua coleção particular para complementar.

Ciente da deficiência, a SME criou o programa Baú da Leitura, que consiste na distribuição de livros em regime de rodízio entre as escolas, por meio de baús temáticos com livros diversificados para cada nível escolar e tema proposto. Estes baús ficam 15 dias em cada escola, sendo substituídos por um novo a cada período. A Figura 79 apresenta como exemplo um Baú da Leitura para alunos do ensino infantil. 
FIGURA 79 - PROJETO BAÚ DA LEITURA - SME C
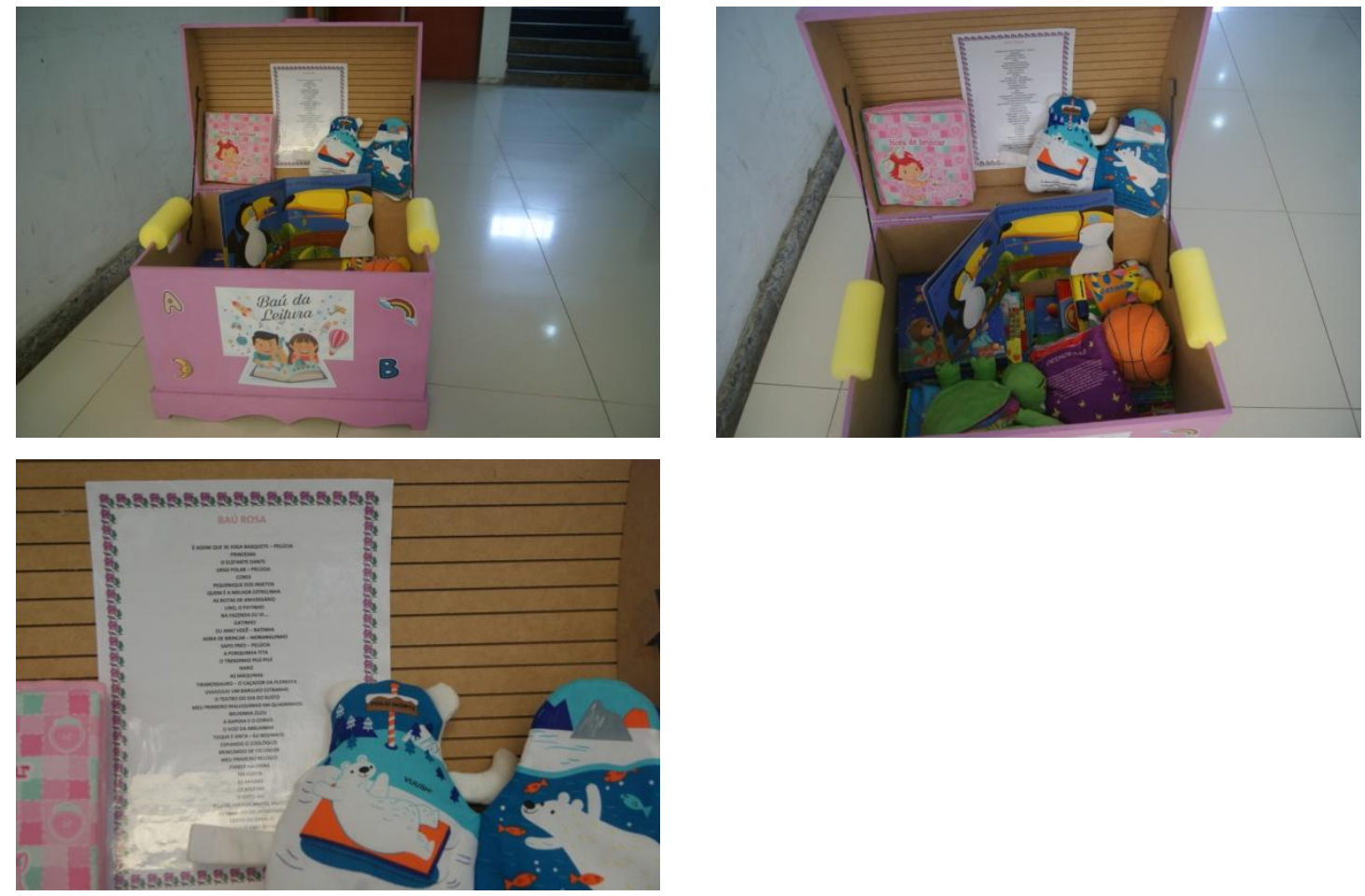

Fonte: arquivo pessoal do autor.

\section{- Recursos para os Professores}

Os professores têm uma sala própria, anexa à Diretoria. Além de um computador com internet para uso na preparação das aulas, a sala oferece, ainda, uma pequena copa, onde os docentes podem armazenar e aquecer suas refeições, bem como preparar cafés e lanches (Figura 80).
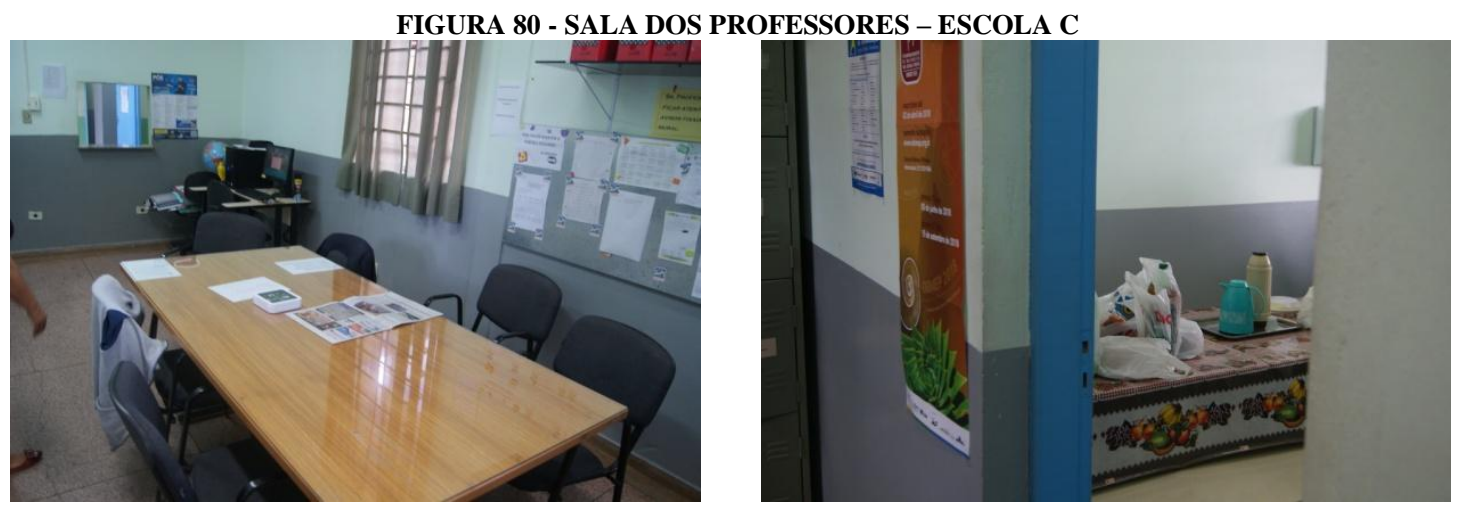

Fonte: arquivo pessoal do autor.

\section{- Disciplina discente e Regime Disciplinar}

$\mathrm{O}$ relato da professora aponta para um bom índice de disciplina discente. Também relatou que não há problemas ligados ao tráfico e consumo de entorpecentes no interior da 
escola e que possuem a parceria com a Polícia Militar por meio do PROERD. Porém, informou identificar falta de interesse pela matéria e falta de responsabilidade com a execução das atividades extraclasse.

A Diretora relatou que os pais têm conhecimento das regras disciplinares da escola, as quais, apesar de não formalizadas, são informadas no início de cada ano em reunião de pais. Segundo ela, em geral, recebem apoio da família em relação às eventuais decisões disciplinares e, por vezes, cobram dos professores e da direção uma postura enérgica, como forma de auxiliá-los na educação dos filhos.

Sempre que algum ato de indisciplina grave é cometido, os pais são comunicados via telefone imediatamente, juntamente com o professor e o aluno, prática que tem tido boa adesão da comunidade.

\subsubsection{Diretor}

\subsection{Regime de trabalho, formação e experiência profissional}

O acesso ao cargo de Diretor se dá por meio de indicação do prefeito, mediante posterior anuência da SME.

A Diretora informou ter 25 anos de experiência como professora e 06 anos no cargo de direção. Em sua avaliação, a experiência prévia na docência é essencial para a atuação como Diretora, pois permite conhecer o funcionamento da sala de aula, o trato com o aluno e a família, bem como permite ganhar experiência na solução de conflitos. Sua formação é em Licenciatura em Letras, com especialização em Gestão Escolar e em Produção de Texto, além de ter feito o magistério em nível médio.

Além das 40 horas no cargo, a Direto informou dar aulas de Língua Portuguesa no estado, como forma de complementação da renda e garantia de aposentadoria adicional.

\subsection{Práticas de gestão}

\section{- Ações de Combate ao Abandono e à Evasão Escolar}

Segundo os supervisores, o acompanhamento das faltas e da evasão escolar é de responsabilidade das escolas e o município não dispõe de sistema integrado de controle de ausência. 
Em sua entrevista, Diretora e Vice-Diretora informaram que os índices de ausência são baixos. Após três faltas consecutivas, os pais são contatos via telefone pelo Diretor ou algum funcionário da Secretaria. Não havendo solução, o fato é notificado ao Conselho Tutelar para as medidas cabíveis.

Entre os principais problemas apontados para a evasão da escola está a falta de incentivo e participação das famílias. Em seu relato, mencionou casos em que encaminhou e acompanhou pais de alunos a atendimentos psicológicos, ação que se mostrou efetiva nos casos aplicados. Segundo ela, a evasão é um "sintoma de uma família desestruturada".

O depoimento da professora corrobora com a afirmação da Diretora. Ela ainda pontuou que diversos estudantes preferem abandonar o ensino regular para, mais tarde, obter a certificação por meio do Ensino de Jovens e Adultos (EJA), em menor tempo e com menor cobrança.

Nos casos em que os alunos apresentem grandes períodos de faltas ou afastamentos, a professora informou que são solicitados trabalhos de compensação de ausência para realização individual, em casa.

\section{- Quadro Funcional da Escola}

Segundo a Diretora, o quadro funcional da escola está incompleto em razão do afastamento da Secretária. Também enfrenta problema com a falta de professores de algumas disciplinas, sendo frequente a necessidade de uso de substitutos que, por vezes, são formados em áreas diversas daquelas que ministram. A escola conta com 25 professores concursados e 12 terceirizados pelo Centro de Integração Empresa Escola (CIEE).

Segundo a SME, a turma de alunos do $9^{\circ}$ ano de 2015, participantes da Prova Brasil daquele ano, enfrentaram problema atípico com a troca de 6 professores de Língua Portuguesa ao longo do ano letivo, o que, segundo a SME, causou à turma prejuízo pedagógico claro, resultando no baixo desempenho dos estudantes na avaliação.

\section{- Atribuição de Aulas}

A atribuição de aulas e escolha da escola onde irá lecionar se dá por meio do sistema de pontos, em que o docente com maior pontuação - adquirida pelo tempo de trabalho, número de aulas ministradas e cursos realizados - tem preferência na escolha da escola onde irá atuar. Para a SME, o ponto forte deste sistema está na possibilidade de serem montados times de trabalho por afinidade, uma vez que, em geral, o docente acompanha o diretor em quem confia no trabalho - o diretor muda de escola, o professor vai junto. Porém, como 
desvantagem foi citado eventual prejuízo para a alfabetização dos alunos, uma vez que a troca constante de professores causa, também, a perda do histórico de desenvolvimento dos estudantes da escola, no período do primeiro ao quinto ano.

Este problema também foi apontado pela diretora, que informou haver alta rotatividade docente, com mudanças praticamente todos os anos, fazendo com que a cada ano seja necessário um novo período para adaptação do docente à escola e aos alunos, perdendose o histórico de trabalhos realizados anteriormente.

\section{- Estrutura para Alunos com Deficiência}

Verificou-se na escola a existência da Sala de Recursos (Figura 81), que, no momento da visita, contava com uma professora pedagoga preparando os conteúdos para uso no período da tarde. A professora entrevistada informou que a especialista comparece em horários específicos (contraturno) para o atendimento a cada aluno.

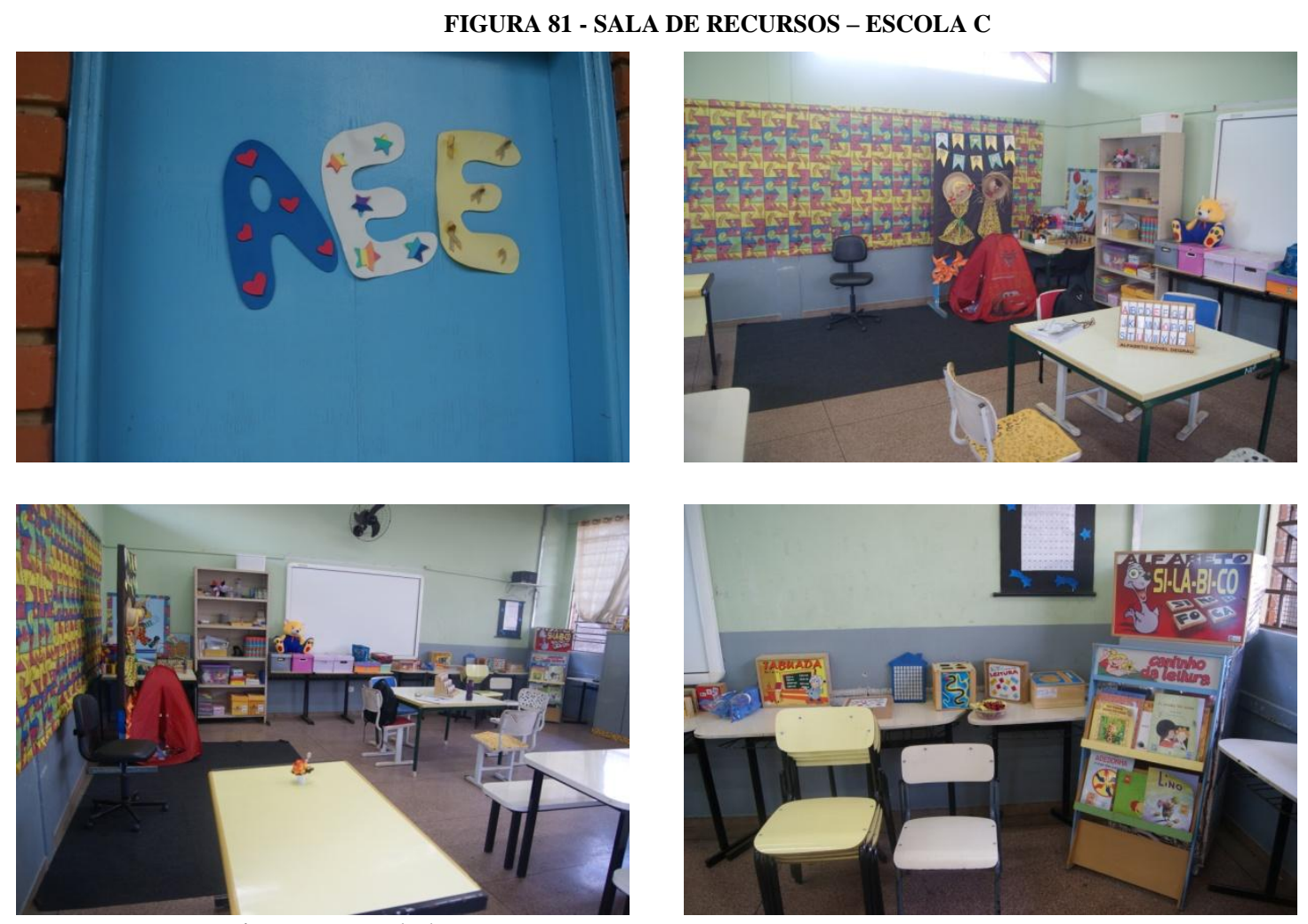

Fonte: arquivo pessoal do autor.

Segundo ela, apesar de receber orientações da equipe responsável pelo AEE, elas superficiais e não fornecem ferramental para o trabalho cotidiano. Informou ter havido interrupção do serviço de estagiários ao longo do ano letivo. Em sua opinião, a maior 
dificuldade está relacionada em saber lidar com o comportamento dos alunos e não como transmitir os conteúdos.

\section{- Captação de Recursos Externos}

A SME informou que não um setor ou profissional responsável pela captação de recursos financeiros junto a entidades e organizações, sendo a única fonte de recursos o financiamento público.

Segundo a Diretora, uma das principais dificuldades para o exercício de sua função é a falta de materiais para uso em aula. Relatou o caso de uma professora que, recém concursada e atuante na rede privada de ensino, precisou de auxílio e orientação para se adaptar à rotina da escola pública para o exercício da docência. Era prática desta professora a solicitação de materiais para a realização das atividades, os quais a escola não dispunha. A Diretora esclareceu que são realizados eventos festivos ao longo do ano, como Festa Juninha e Festa da Primavera, onde há a captação de recursos por meio da venda de produtos, os quais são doados por empresas locais, mediante solicitação de pais de alunos da escola, ou doados pelos próprios pais. A arrecadação da APM foi classificada pela Direção como baixa, variando de $\mathrm{R} \$ 50,00$ a $\mathrm{R} \$ 100,00$ por ano.

\section{- Investimentos e Manutenção da Escola}

A responsabilidade pelo acompanhamento e identificação das necessidades de manutenção da escola é do diretor. Os pedidos são encaminhados à SME que gerencia dos pedidos da rede, providenciando o envio dos materiais e equipe solicitados. Os recursos provenientes de programas como o PDDE e as verbas da prefeitura, são destinados para aquilo que haviam sido originalmente pleiteadas, cumprindo-se o prazo para sua liberação e uso. Os recursos captados nas arrecadações e festividades podem ser utilizados pela equipe Diretiva da escola com maio autonomia e liberdade.

\subsection{Práticas pedagógicas}

\section{- Oferta de Reforço no Contraturno}

A oferta do reforço no município é destinada apenas a alunos com defasagem em Língua Portuguesa e ocorre no contraturno. Os alunos são divididos de acordo com a série. Uma vez que o reforço não se inicia imediatamente após o horário de almoço, alunos 
provenientes da zona rural costumam ficar nas casas de parentes que residem próximos à escola à espera do horário do reforço. Para estes não é ofertada refeição entre os horários.

- Acompanhar a Aprendizagem dos Alunos e Promover Ações de Combate à

\section{Reprovação}

Segundo a SME, o município somente adota a progressão continuada até o $2^{\circ}$ ano. A partir do $3^{\circ}$ ano o aluno pode ser reprovado, sendo que o professor tem autonomia para isso. Porém, todas as reprovações passam, obrigatoriamente, pelo Conselho de Classe. Segundo os depoimentos dos Supervisores, várias reprovações ocorrem anualmente e não há, por parte da SME, qualquer tipo de orientação a respeito, uma vez que, segundo eles, "o importante é o aprendizado do aluno e não somente o resultado do IDEB”, ficando sob a responsabilidade do professor e da escola a análise, caso a caso.

A Diretora informou que o acompanhamento do desempenho dos estudantes é realizado por meio dos resultados das avaliações dos estudantes, que são enviados via e-mail para a Coordenadora Pedagógica, e das discussões semanais no HTPC. Informou, ainda, que até o $5^{\circ}$ ano ela assiste a algumas aulas com as turmas para avaliação do desempenho da turma e do docente.

\section{- Acompanhamento dos Resultados do SAEB}

O IDEB é acompanhado. Em reuniões junto aos Diretores o problema sobre o fluxo escolar é discutido. Foram realizadas aplicações de provas anteriores da ANA junto aos estudantes, para avaliação diagnóstica dos estudantes que irão participar da avaliação. As habilidades com pior desempenho são trabalhadas junto aos estudantes.

Adicionalmente, é aplicada uma prova diagnóstica a nível municipal para alunos até o $5^{\circ}$ ano, de todas as disciplinas.

\section{- Formação de Turmas}

A escola possui apenas uma turma para cada série, mas, nos casos em que o número de alunos matriculados numa série exija a divisão, a Diretora informou que procura realizá-la de forma heterogênea em relação ao desempenho dos estudantes. 


\section{- Projetos Temáticos}

Os projetos do município são focados, em especial, para a leitura, uma vez que foi identificado que o desempenho dos estudantes na Avaliação Nacional da Alfabetização (ANA) em leitura é mais baixo do que o desempenho em escrita. Além do Pacto Nacional pela Alfabetização na Idade Certa (PNAIC) e do Ler e Escrever, outros dois são organizados pela SME. São eles:

- Projeto Leitura: os alunos levam uma 'sacola' para casa, contendo livros que devem ser lidos com a família. Não há avaliação do aluno neste projeto;

- Projeto "A Leitura como Elo nas Relações Escola-Família": o projeto, realizado a pedido do Ministério do Trabalho, tinha início proposto para outubro, porém ainda não havia sido iniciado na data da visita em razão da falta de liberação da verba necessária pelo Ministério.

\subsection{Atuação com a família e a comunidade}

As matrículas no município são realizadas de acordo com a escolha dos pais, sem existência de critério de zoneamento para isso, segundo a SME e a Direção da escola. Em depoimento, os Supervisores informaram serem comuns as solicitações de vagas pelos pais diretamente à SME, tanto para matrícula quanto para transferência, nos casos em que são negadas pela equipe da escola, que segue o critério de ordem de pedido.

A SME informou incentivar a realização de eventos para a comunidade. Informou que as Festas Juninas das escolas são integralmente custeadas pela SME. Outras atividades relatadas foram o projeto Escola da Família e a Festa da Primavera, para os quais cabe à escola a articulação para arrecadação de fundos. A Diretora informou ser frequente e relevante a participação dos pais nestas atividades.

A quadra da escola permanece aberta à comunidade " 24 horas" e os espaços da escola são cedidos para eventos da igreja local aos sábados, quando solicitado.

\section{- Horta Comunitária}

A escola realizou um projeto para a implantação de uma horta (Figura 82), que era, inicialmente, cuidada pelos alunos, sob a supervisão de um professor. Com o afastamento do docente, a horta foi oferecida à comunidade, sendo adotara por um morador local, que se responsabiliza pelo plantio e cuidados, que distribui parte do que é colhido entre os alunos mais necessitados. 


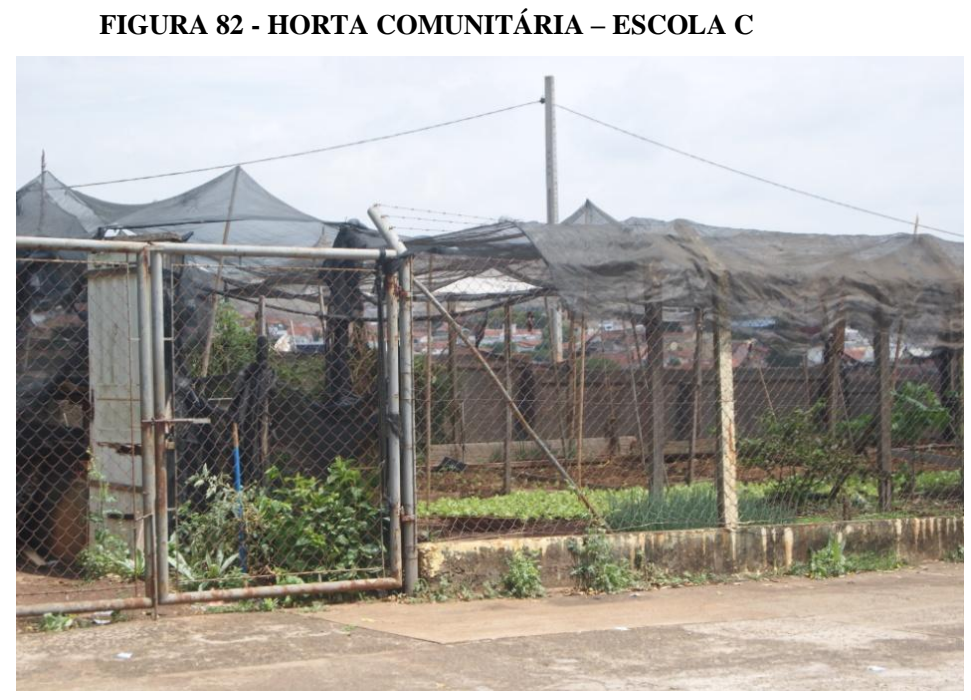

Fonte: arquivo pessoal do autor.

\section{- Reuniões dos Conselhos de Classe e Conselho Escolar}

As reuniões do Conselho de Classe são bimestrais, segundo a Diretora e a Professora, e o Conselho Escolar somente é convocado quando necessário.

\section{- Reuniões de Pais}

A Diretora informou ter baixa adesão dos pais nas reuniões, em razão das dificuldades de horário, uma vez que boa parte trabalha durante o dia. A professora informou que os pais dos alunos do ensino fundamental I comparecem em maio volume, sendo que os dos alunos do fundamental II não têm o mesmo acompanhamento. Os pais comparecem ao longo do período para a retirada e assinatura dos boletins de notas, quando são abordados pelos professores para rápidas reuniões.

\subsubsection{Professor}

\subsection{Perfil}

A professora entrevistada possui formação no Magistério em nível médio, Licenciatura em Letras e especialização em Gestão Escolar. Avaliou que sua formação em licenciatura foi deficitária nas questões didáticas, sendo o maior foco nos aspectos técnicos da Língua Portuguesa, sem, no entanto, lhe fornecer a preparação necessária para a transmissão 
do conteúdo e para a compreensão do processo de aprendizagem pelo aluno. Realizou sua graduação em faculdade privada. Atua há 17 anos como docente, profissão que escolheu por conta da disponibilidade de vagas no mercado de trabalho e do curso em sua região.

\subsection{Regime de trabalho}

\section{- Contratação via CLT ou Contrato Temporário}

Os docentes são contratados via concurso público, sob a égide da CLT. Segundo depoimento dos Supervisores, o plano de carreira docente do município é 'um dos melhores da região', atraindo professores de outros municípios por duas razões:

1) Valor pago por hora-aula atrativo: $\mathrm{R} \$ 14,00$ a $\mathrm{R} \$ 17,00$;

2) Pagamento do adicional de 1/3 (um terço): neste quesito, segundo os entrevistados, é que está o maior atrativo, uma vez que, por razão que os entrevistados desconhecem, é calculado de forma diversa dos demais municípios. Por exemplo: um professor que tem 25 (vinte e cinco) aulas semanais, com o adicional de 1/3 receberá por 37 (trinta e sete) horas-aula. Assim, um professor que dê efetivamente 25 aulas semanais terá uma remuneração mensal de $\mathrm{R} \$ 2.516,00$, salário significativo para a região.

O plano de carreira docente permite a progressão salarial por meio da apresentação de certificados de pós-graduação (lato e stricto sensu). Estes certificados também somam pontos para a escolha da escola no início do ano letivo.

\section{- Dedicação Exclusiva à Escola}

A professora entrevistada tem carga-horária semanal de 25 aulas, com mais 05 destinadas ao HTPC na escola avaliada. Mencionou que atua em outras duas escolas além daquela, sendo mais uma municipal e uma estadual, o que gera cansaço e desgaste, e restringe seu tempo para preparação das aulas. 


\subsection{Atuação com a direção}

\section{- Participação na Elaboração do Projeto Pedagógico}

No período de 2009 a 2015, o município contava com o sistema Anglo de ensino, que apresentava um projeto pré-elaborado para implantação nas escolas. Segundo a SME, após o encerramento do contrato, cada escola realiza seu Projeto Político Pedagógico (PPP), para o qual os professores devem ser consultados.

\section{- Discussão Semanal das Metas}

A professora relatou não haver reunião periódica com a equipe diretiva e coordenação para acompanhamento de metas educacionais.

\subsection{Atividade docente}

\section{- Reuniões Semanais com Outros Professores}

A professora informou que, uma vez que existe apenas uma turma de cada série, não realizam reuniões específicas para a discussão de problemas e melhorias no ensino da disciplina. Informalmente, os professores do ensino fundamental I e fundamental II conversam sobre o desempenho dos estudantes na sala dos professores, prática não estabelecida formalmente na escola.

\section{- Dedicar mais Tempo às Aulas}

A Diretora informou que somente é solicitado aos docentes o apoio na organização de eventos escolares festivos, sem atuação em assuntos ou órgãos administrativos.

\section{- Garantir o Cumprimento de Todo o Conteúdo}

À época do uso do sistema de ensino, havia um cronograma de aulas com todo o planejamento para o ano letivo, que visava à garantia de sua execução. Atualmente, o plano da disciplina é realizado integralmente pelo professor, sem haver, segundo a Diretora, um planejamento por parte da Coordenação para acompanhamento e garantia do cumprimento. Segundo a professora entrevistada, ela consegue cumprir com $80 \%$ do conteúdo proposto, nas 6 aulas semanais que tem com cada turma. Informou que o correto seria a 'redução do 
conteúdo'. Também classifica como boa sua autonomia para a elaboração das avaliações, que são realizadas por provas bimestrais com questões dissertativas e objetivas, além da avaliação da ficha de leitura.

Não há por parte da SME, segundo os Supervisores, um acompanhamento em relação ao cumprimento do conteúdo curricular, ficando a cargo da Direção esta responsabilidade.

\section{- Oferta e Correção do Dever de Casa}

A professora informou que no período em que se adotava o sistema Anglo na rede (2009 a 2015), a oferta de deveres de casa era diária. Após o encerramento do contrato, passou a ser semanal. Os alunos entregam a atividade pronta para correção e a professora lhes devolve corrigida e com nota, sem, no entanto, realizar a correção junto à turma. A professora informou que a cobrança dos pais neste quesito é baixa para os alunos do ensino fundamental II. Atribuiu a isso a falta de estudos e de conhecimento dos pais sobre os conteúdos vistos nesta etapa.

\section{- Uso de Recursos Didáticos e Incentivo à Participação dos Alunos}

A professora informou que se utiliza, basicamente, da aula expositiva, com cópias de textos e leitura do livro didático. O livro didático é lido pelo método da leitura compartilhada em sala. A caba bimestre apresenta aos estudantes um gênero textual, que são buscados da internet. Complementarmente é solicitada a leitura e o preenchimento de uma ficha de leitura a cada bimestre e, semanalmente ou quinzenalmente os estudantes são levados à biblioteca, onde os alunos têm liberdade para a escolha dos livros. Com os alunos do $9^{\circ}$ ano realiza leitura externa à sala de aula. Para o desenvolvimento da oratória, solicita a apresentação de seminários e realiza atividades de discussão pós-leitura.

A professora informou, ainda, que, uma vez que a maioria dos alunos não possui computador em casa, não são solicitadas tarefas ou trabalhos para casa que exijam o uso do equipamento. Estes pedidos somente são realizados durante o período das aulas, quando os alunos podem se utilizar dos computadores da escola. Nestas ocasiões são solicitadas a realização de pesquisas de exemplos de texto dos gêneros textuais estudados no período.

\subsubsection{Aluno e a família}

Uma vez que os estudantes não foram entrevistados diretamente, os apontamentos a seguir são realizados com base nos depoimentos colhidos da Professora, Diretora e Coordenadora Pedagógica. 


\subsection{Comportamento}

\section{- Manter a Disciplina e Frequência às Aulas}

Segundo os depoimentos, a escola enfrenta poucos casos de indisciplina e ausência às aulas.

\section{- Realizar o Dever de Casa}

Os deveres de casa, segundo a professora, são realizados com regularidade pelos estudantes, porém, sem acompanhamento dos pais, fato que atribui à falta de conhecimento destes sobre os assuntos estudantes, em razão da baixa escolaridade.

\section{- Leitura Frequente de Livros}

Segundo a professora, os alunos leem, em média, um livro por bimestre por exigência da disciplina. Entre as literaturas preferidas estão os livros da "Coleção Vagalume", a coleção "Diário de um Banana" e "De uma Garota Popular", não estando entre os mais procurados os clássicos da literatura brasileira. Também classificou como comum a apresentação de fichamentos de revistas em quadrinhos.

\subsection{Ambiente familiar e social}

Os relatos da professora e equipe diretiva convergem em relação à situação familiar dos estudantes. Segundo elas, é comum a existência de estudantes com pais ausentes, com problemas psicológicos e oriundos de casamentos desfeitos. Segundo elas, este fator tem grande impacto sobre o exercício da profissão, uma vez que exige dos professores e equipe diretiva habilidades "humanas" - como saber ouvir, paciência e empatia - mais apuradas do que as capacidades técnicas para a docência.

\section{- Possuir Computador em Casa}

Segundo a professora, a maior parte dos estudantes não dispõe de computadores particulares, reduzindo, assim, as possibilidades de atividades solicitadas para casa. 
4.2.4 Análise do município D - baixo desempenho

O Município D possuía, em 2010, 51 mil habitantes (IBGE, 2010), com PIB per capita de R\$ 30.453,74 (IBGE, 2015), e está localizado no interior do estado de São Paulo, distante de grandes centros como Ribeirão Preto, 130 km e Campinas 160 km (Figura 83). O poder público é o maior empregador do município, sendo também o responsável pela maior parte da economia local, seguido da indústria e agricultura, respectivamente. O município possui uma rede de escolas privadas de ensino básico.

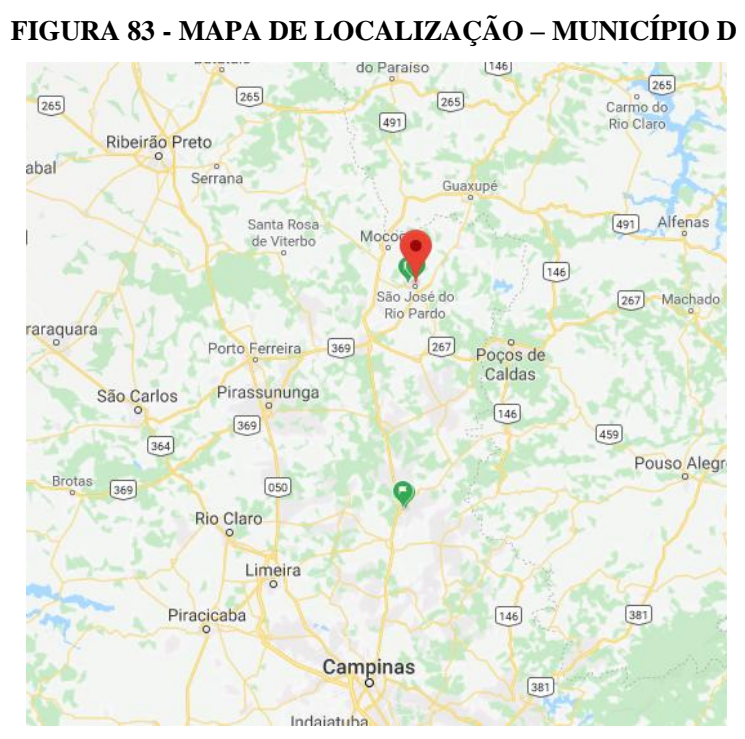

Fonte: Google Maps.

No setor educacional, o município apresenta taxa de escolarização da população de 06 a 14 anos de idade de 97,6\% (IBGE, 2010). A Tabela 13 apresenta a síntese dos dados do município.

TABELA 13 - DADOS DEMOGRÁFICOS - MUNICÍPIO D

\begin{tabular}{|l|l|l|l|l|l|}
\hline População $(*)$ & $\begin{array}{l}\text { IDH } \\
(*)\end{array}$ & $\begin{array}{l}\text { Renda Per Capita } \\
\text { Anual }(* *)\end{array}$ & $\begin{array}{l}\text { Número de } \\
\text { Escolas }(* * *)\end{array}$ & $\begin{array}{l}\text { Número } \\
\text { Alunos EF }\end{array}$ & $\begin{array}{l}\text { Investimento Anual Médio } \\
\text { por Aluno }(* * * *)\end{array}$ \\
\hline 51.900 & 0,774 & $\mathrm{R} \$ 30.453,74$ & 26 & 5.858 & $\mathrm{R} \$ 6.822,04$ \\
\hline
\end{tabular}

Fonte: Elaborado pelo autor.

Base: (*) IBGE 2010; (**) IBGE 2015; (***) Censo Escolar 2015 (****); FINBRA Investimento médio entre 2012, 2013 e 2014.

A análise da Lei Orçamentária Anual do município para o exercício de 2015 permitiu verificar um equilíbrio entre os gastos públicos com a educação infantil e a educação fundamental, os quais representam, respectivamente, $35,27 \%$ e $35,93 \%$ das despesas. Chama 
a atenção o investimento em educação especial, de 7,72\%, maior valor empenhado dentre os quatro municípios visitados. O Gráfico 24 resume a distribuição dos investimentos em educação.

GRÁFICO 24 - DISTRIBUIÇÃO DOS INVESTIMENTOS EM EDUCAÇÃo - MUNICÍPIO D

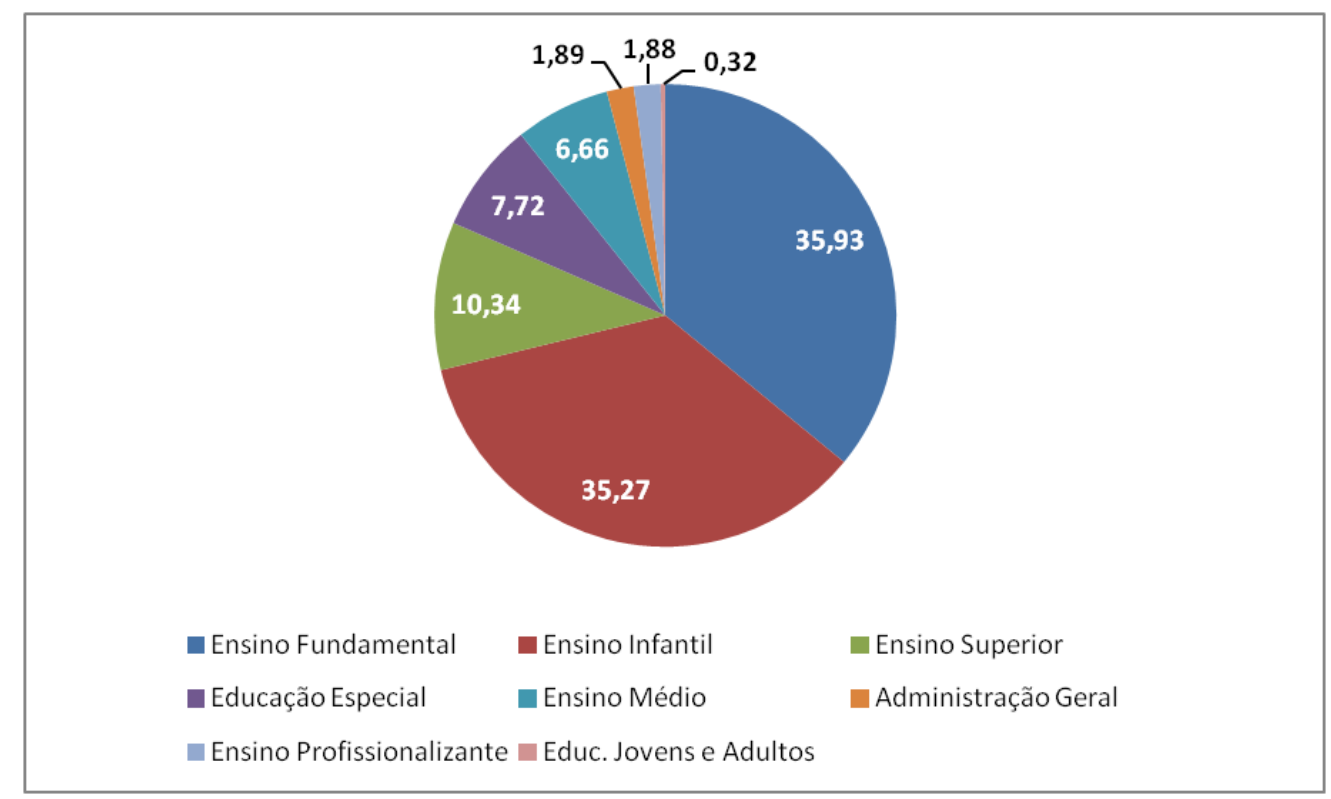

Fonte: Elaborado pelo autor. Base: Lei Orçamentária Anual 2015 do município

A visita ao município foi realizada no dia 25 de outubro de 2018 , mediante prévio agendamento com a Secretaria Municipal de Educação. A seguir são apresentados os resultados das entrevistas realizadas com o Supervisor de Educação do Município, Diretora, Vice-Diretora e professora de Língua Portuguesa da escola selecionada.

\subsubsection{Análise da Secretaria Municipal de Educação}

Segundo os entrevistados (Secretária Municipal de Educação, Diretora, Vice-Diretora e Professora), é prática no município a troca do Secretário de Educação pelos prefeitos ao longo do mandato, como resultado de decisões políticas e não necessariamente técnicas. Apenas no último ano a pasta passou por três alterações. Ainda, segundo eles, estas alterações recorrentes causaram prejuízos à política educacional do município, que não consegue estabelecer um programa próprio nem manter as práticas implantadas pelo período necessário à consecução dos objetivos esperados.

A atual Secretária possui Licenciatura em Educação Física e em Pedagogia, com especialização em Psicopedagogia e Treinamento Esportivo, além de Mestrado em Ciências 
Humanas. Atuou como professora por 10 anos e como Diretora por $2 \frac{1}{2}$ anos, antes de ser indicada ao cargo. Ocupava o cargo há um mês, tendo sido Diretora de escola que compartilha o mesmo prédio da SME nos últimos dois anos e meio. Em razão disto, solicitou-se que, ao responder às questões, fornecesse informações acerca das atividades realizadas pelo órgão no período anterior ao seu mandato, uma vez que dispunha de acesso diário à pasta e aos Secretários anteriores.

\section{- Estrutura da Secretaria Municipal de Educação}

A Secretaria Municipal de Educação (SME) dispõe de estrutura enxuta, com 10 (dez) funcionários administrativos, além da equipe de Diretores e Coordenadores escolares, conforme organograma a seguir (Figura 84).

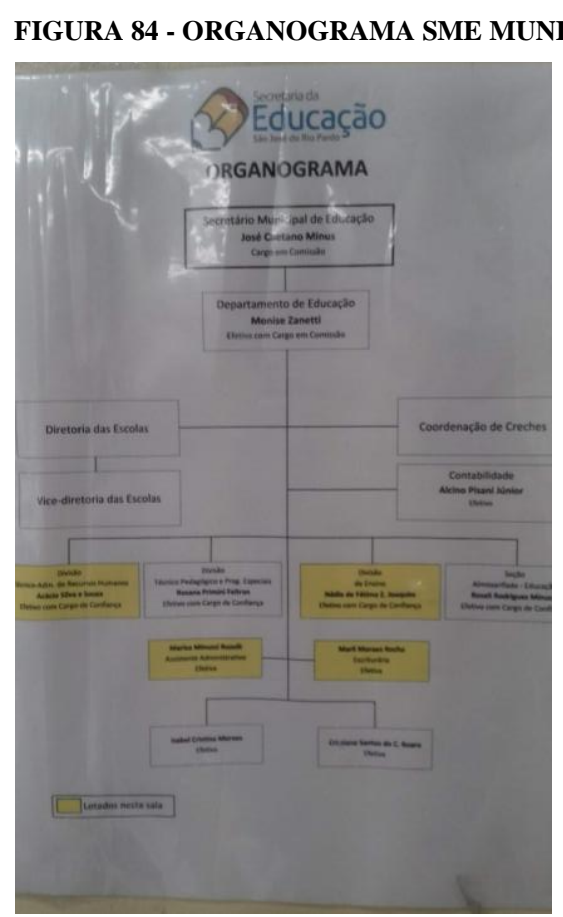

Fonte: arquivo pessoal do autor.

Verificou-se que a estrutura não se apresenta clara em relação às responsabilidades de alguns dos funcionários, bem como uma possível intersecção de atuação de dois departamentos (Divisão Técnico Pedagógico e Programas Especiais x Divisão de Ensino). Também se verificou que setores importantes, como Merenda, Transporte e Compras, são lotados em outras pastas, limitando a atuação do Secretário nos processos decisórios destas áreas, cujos responsáveis são indicados pelo Prefeito. 


\section{- Plano de Metas e Objetivos}

O município não dispõe de um plano de metas nem de um planejamento operacional para direcionamento das ações, sendo a atuação da Secretária de Educação voltada, quase que exclusivamente, à administração das contingências que lhe são apresentadas pelos setores internos, diretores e pais de alunos. Não há a definição de indicadores internos para o acompanhamento da educação municipal, nem tampouco uma política de incentivo ou responsabilização dos professores e diretores pelo alcance dos resultados.

\section{- Captação de Recursos Financeiros}

A SME utiliza-se, exclusivamente, das subvenções recebidas pela Prefeitura Municipal, sem dispor de um serviço para a captação de recursos adicionais junto às demais esferas do poder público ou de instituições privadas por meio de parcerias.

\section{- Transporte Escolar}

Foi reportado pela Diretora e pela SME que o município oferece transporte a todos os alunos, não tendo ocorrido episódios de paralisação do serviço. O transporte é gerido por órgão externo à SME, e não é disponibilizado aos pais em dias de reunião escolar.

\section{- Manutenção das Escolas}

O acompanhamento das necessidades de manutenção da escola é de responsabilidade da Diretora que encaminha os pedidos à SME. Segundo a Diretora, a SME encaminha pessoal e equipe para a realização dos reparos, porém, não disponibiliza as verbas necessárias. $\mathrm{O}$ custeio do reparo deve ser feito a partir das arrecadações promovidas pela escola nos eventos próprios, bem como pelos recursos advindos do PDDE, fato confirmado pela SME, que destacou a carência de recursos do município. Foi relatado que há cerca de 10 anos a Direção pleiteia a pintura da escola, ação não realizada. A pintura interna foi realizada com a utilização de recursos advindos da APM e dos eventos realizados ao longo do ano.

\section{- Trabalho com a SME e Autonomia do Diretor}

A Diretora informou ter boa autonomia, porém, têm pouco contato com a Secretária de Educação, em razão das frequentes mudanças no município. Quinzenalmente são realizadas reuniões entre os diretores escolares, cuja organização fica a cargo de um Diretor que atua como Coordenador do grupo, sendo que a Secretária somente participa nas ocasiões em que 
são necessárias decisões ou esclarecimentos de âmbito geral. A SME informou ser frequente a demanda de pais diretamente ao setor, para a resolução de conflitos, em especial ligados à medidas disciplinas e à oferta de vagas nas unidades escolares. Nestes casos, a SME se reúne com o Diretor, o aluno e os pais, atuando como mediadores.

\section{- Programas de Capacitação de Diretores e Professores}

Os relatos da Secretária e da Diretora dão conta de que o município realiza anualmente (ao final do mês) de julho, a "Semana da Educação", que consiste de palestras sobre temas levantados pelos diretores junto aos seus professores durante as reuniões nas horas atividade.

Porém, em palavras da professora entrevistada, "a prefeitura está negligenciado totalmente este assunto". Informou que as únicas capacitações de que havia participado, eram promovidas por parceiros, para atuação direta sobre os projetos em desenvolvimento, como, por exemplo, capacitação promovida pelo Sicredi recentemente.

\section{- Estrutura para Atendimento Educacional Especializado (AEE)}

Segundo a SME,o município dispõe de 10 professoras para a realização do AEE. Estas profissionais são responsáveis pelo acompanhamento das 23 escolas que compõe a rede. A abertura de uma sala para AEE nas escolas é condicionada à matrícula de aluno com a apresentação de laudo médico com a respectiva CID (Classificação Internacional de Doença).

\subsubsection{Análise da escola " $D$ "}

A escola está localizada em bairro periférico (Figura 85).

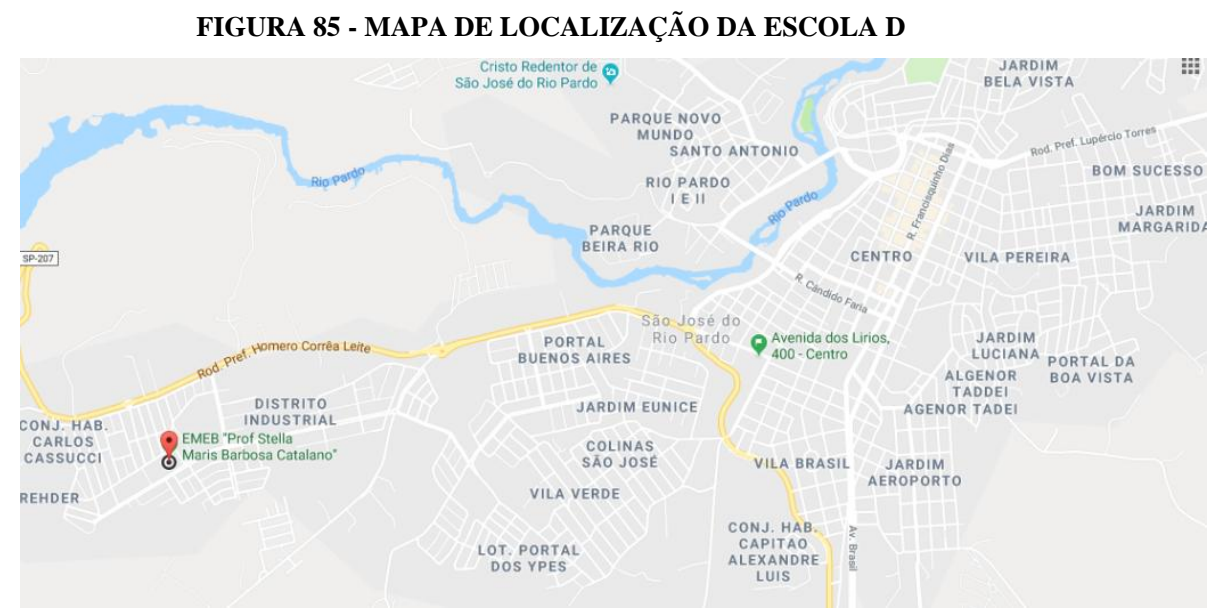

Fonte: Google Maps. 
Segundo dados do Censo, a escola contava, em 2015, ano de realização da Prova Brasil, com 67 funcionários, responsáveis pelo atendimento de 754 estudantes, os quais são matriculados por zoneamento.

As instalações foram pertenciam a um Centro de Atenção Integral à Criança (CAIC) (Figura 86).

FIGURA 86 - FACHADA DA ESCOLA D
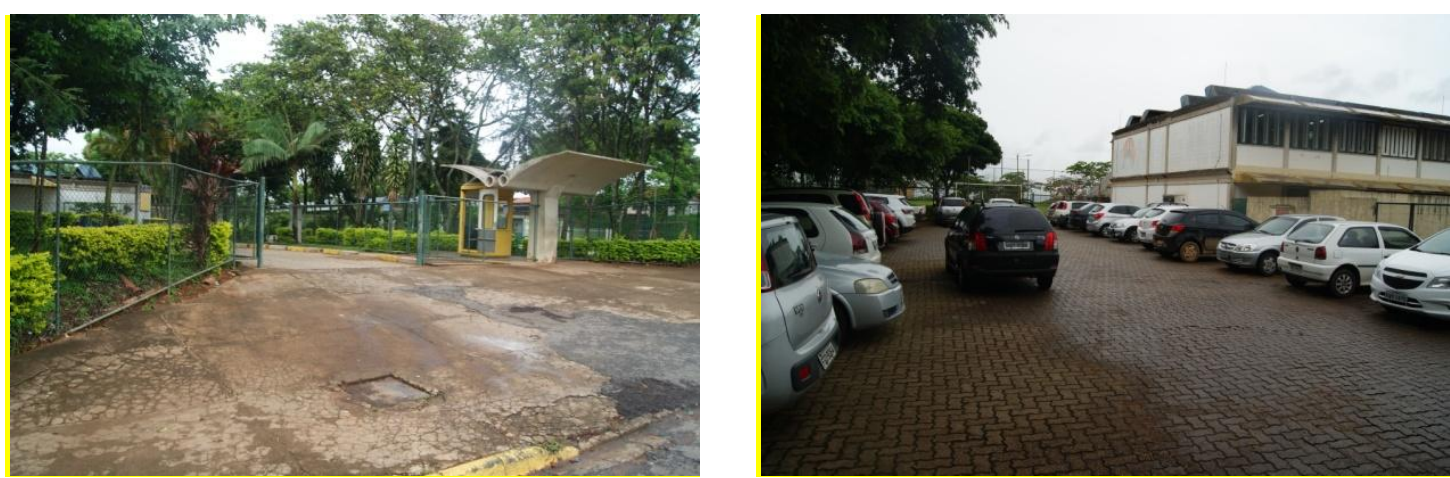

Fonte: arquivo pessoal do autor.

A estrutura da escola apresenta excelente estado de conservação (paredes, corredores, telhados, piso, portas, janelas) conforme Figura 87, sendo que recebeu serviços de pintura, cujo dinheiro para a compra de materiais advém de sobras do PDDE e das arrecadações promovidas em eventos comunitários. Não foram relatados problemas pelos entrevistados em relação às instalações elétricas e hidráulicas.

FIGURA 87 - INFRAESTRUTURA - ESCOLA D
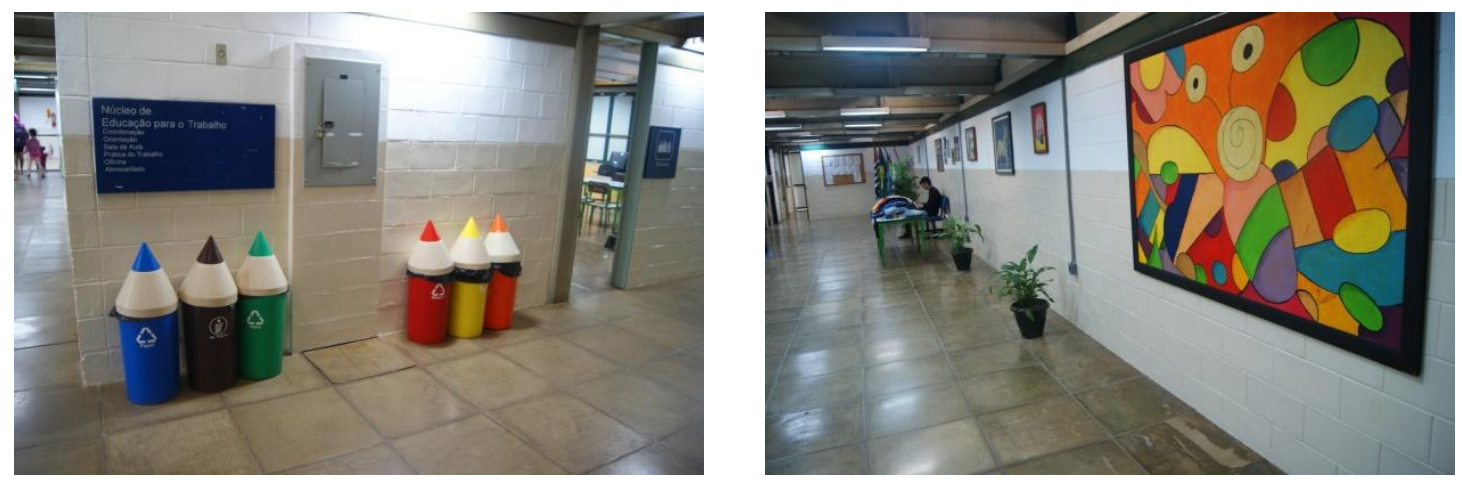

continua 
continuação
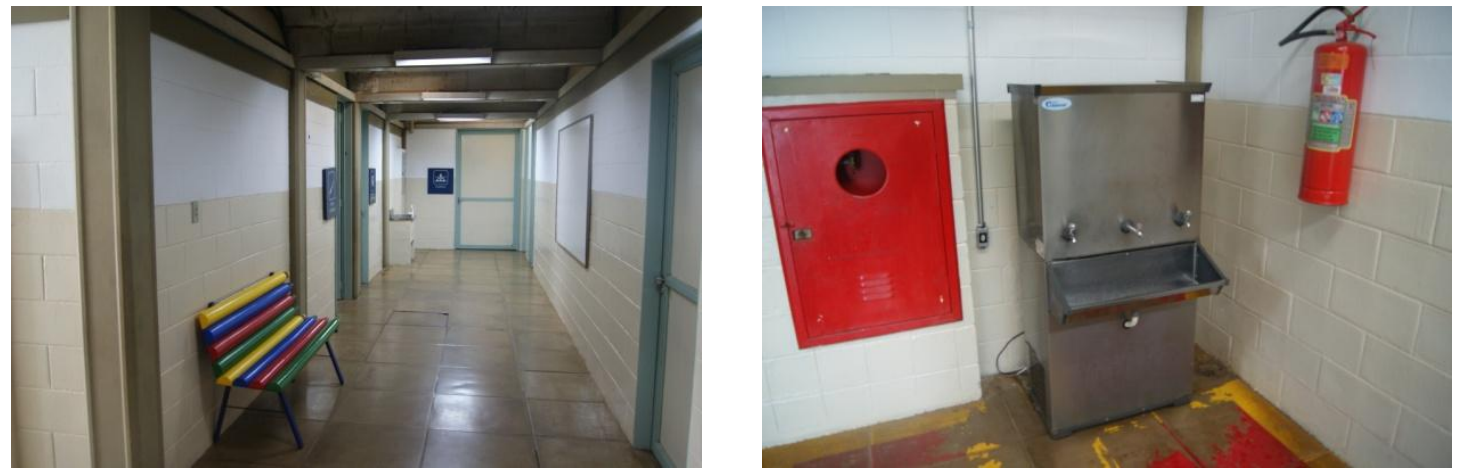

Fonte: arquivo pessoal do autor.

O pátio e as áreas externas são bem conservados e limpos (Figura 88).

FIGURA 88 - PÁTIO E ÁREAS EXTERNAS - ESCOLA D
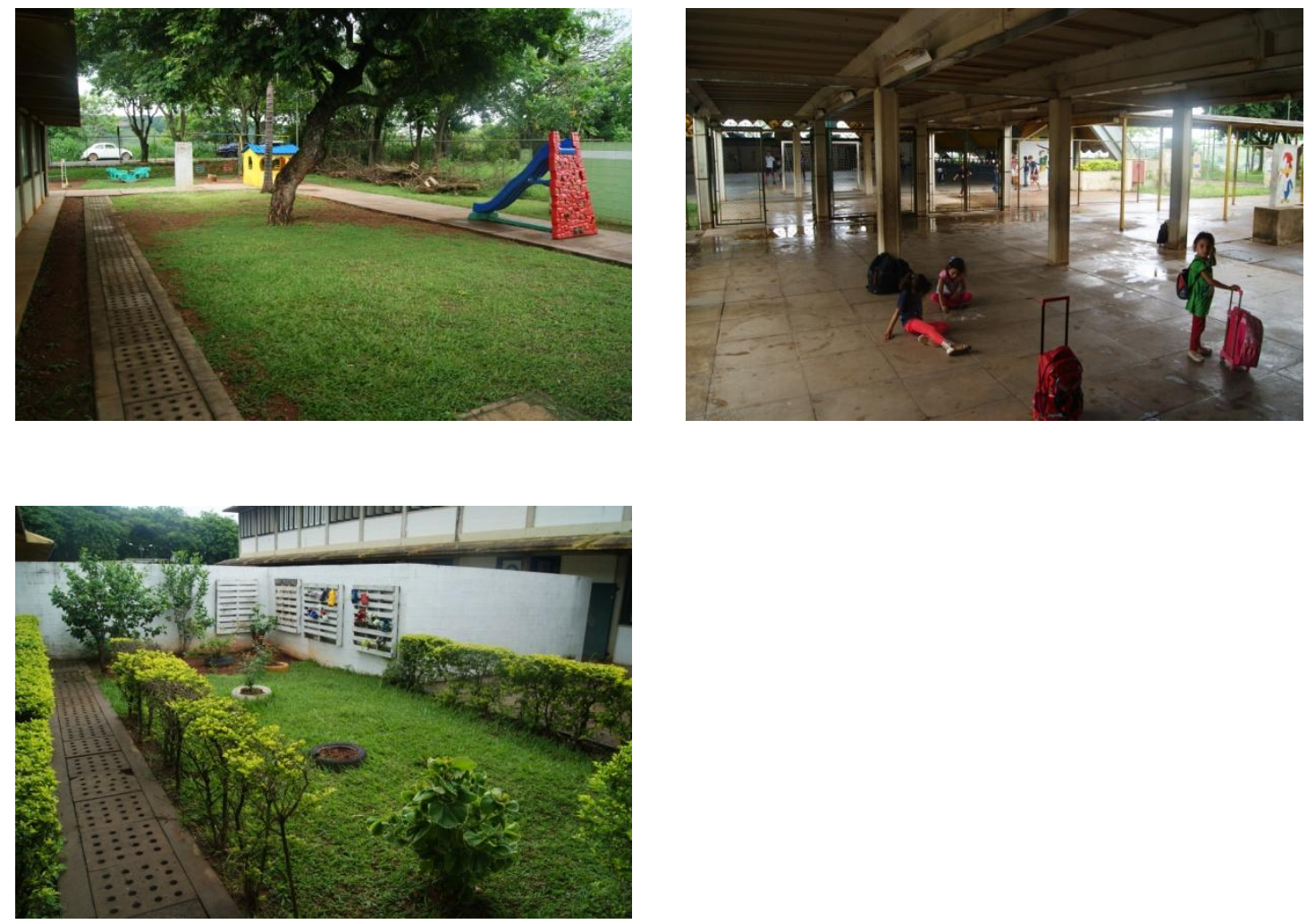

Fonte: arquivo pessoal do autor.

Os banheiros haviam sido pintados recentemente, assim como todo o interior da escola, e se apresentavam limpos e funcionando, conforme Figura 89. 
FIGURA 89 - BANHEIROS ESCOLA D
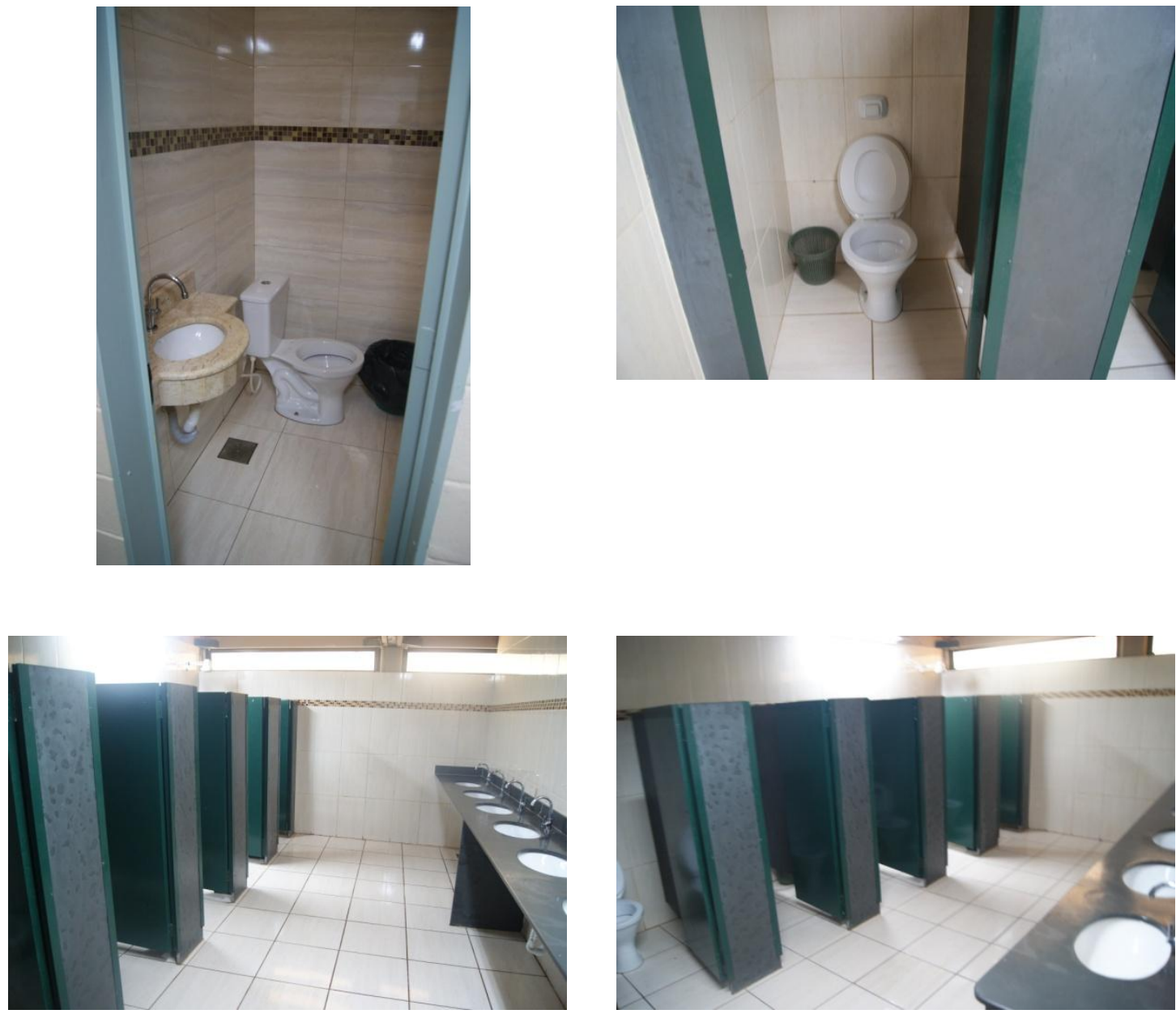

Fonte: arquivo pessoal do autor.

As instalações administrativas (salas de coordenação e direção) são conservadas e organizadas, com mobiliário novo e corredores decorados, proporcionando um ambiente agradável aos funcionários e estudantes (Figura 90).
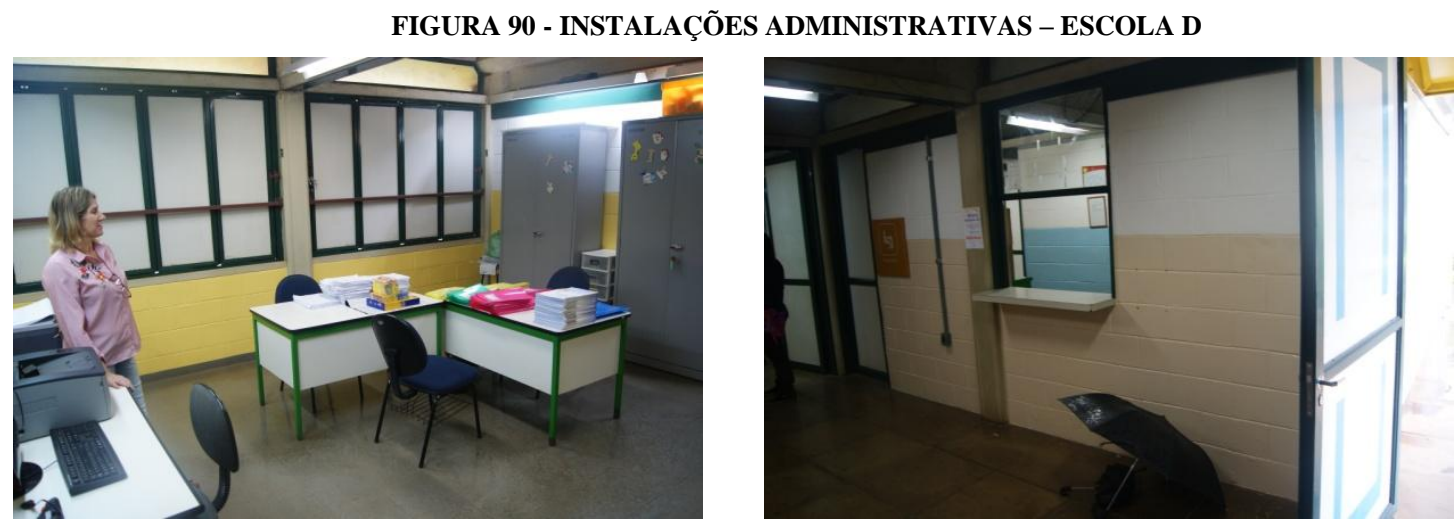

continua 
continuação

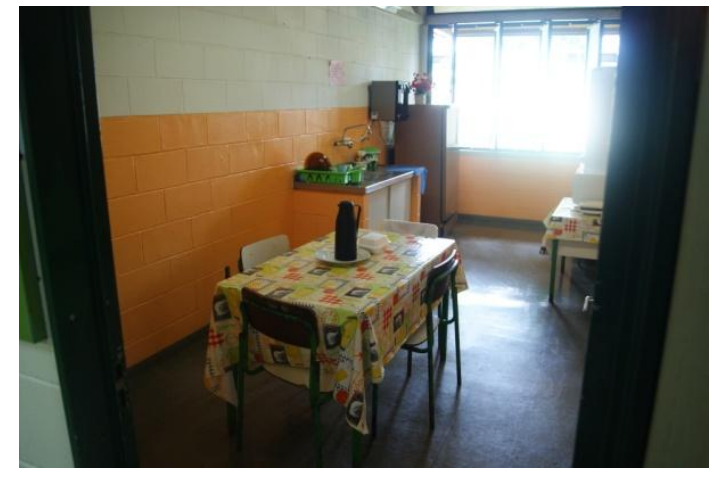

Fonte: arquivo pessoal do autor.

A escola também dispõe de um almoxarifado, onde se pôde verificar uma grande quantidade e variedade de materiais escolares para uso dos alunos, além de roupas, fantasias e alegorias utilizados em festividades, além dos livros didáticos recebidos a cada ano (Figura 91).

FIGURA 91 - ALMOXARIFADO - ESCOLA D
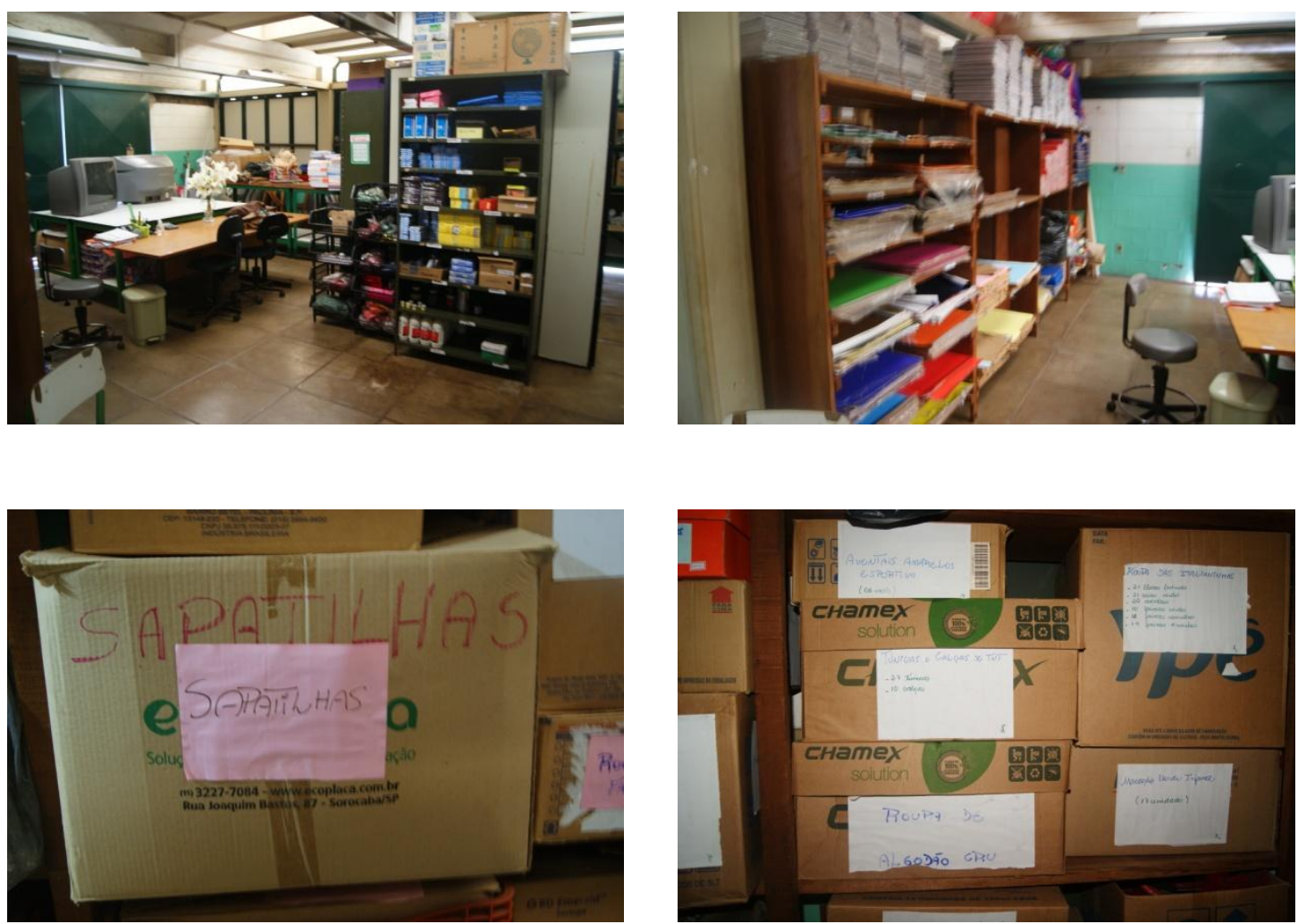

Fonte: arquivo pessoal do autor.

As salas de aula para os alunos do ensino fundamental I apresentam boa estrutura e mobiliário, com janelas amplas e ventiladores, garantindo, assim, boa luminosidade e 
ventilação, com janelas amplas. São limpas e em bom estado de conservação, como se pode observar na Figura 92.

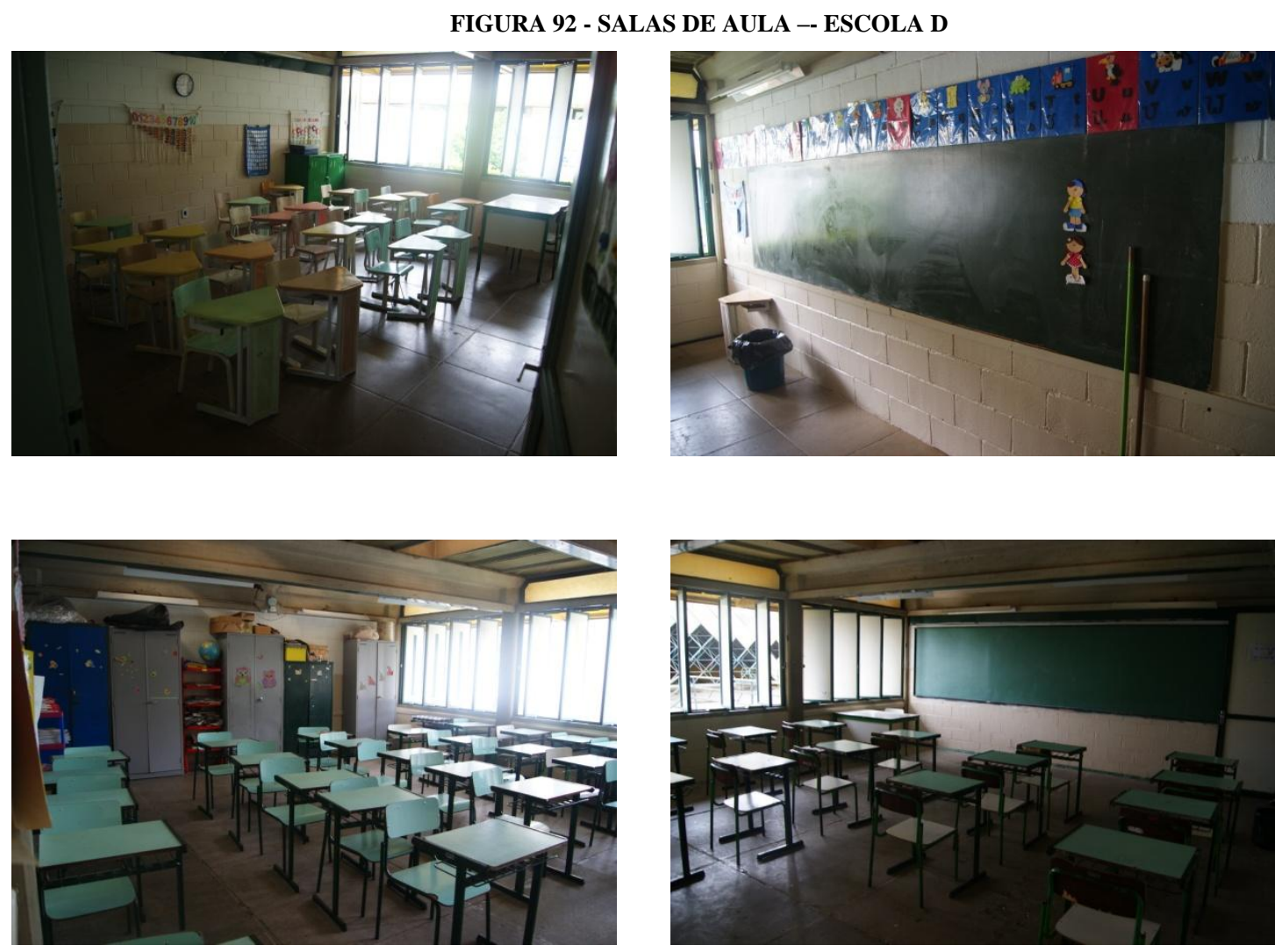

Fonte: arquivo pessoal do autor.

Apesar de estarem localizadas no mesmo corredor, as salas de aula dos alunos do ensino fundamental I e fundamental II são separadas por uma grade, conforme Figura 93. Esta divisão, segundo a Diretora, se deve à tentativa de evitar o contato entre os alunos mais velhos e mais jovens, como forma de proteção destes últimos em relação aos primeiros que, segundo o relato, apresentam comportamento mais indisciplinado. 
FIGURA 93 - CORREDOR ESCOLA D

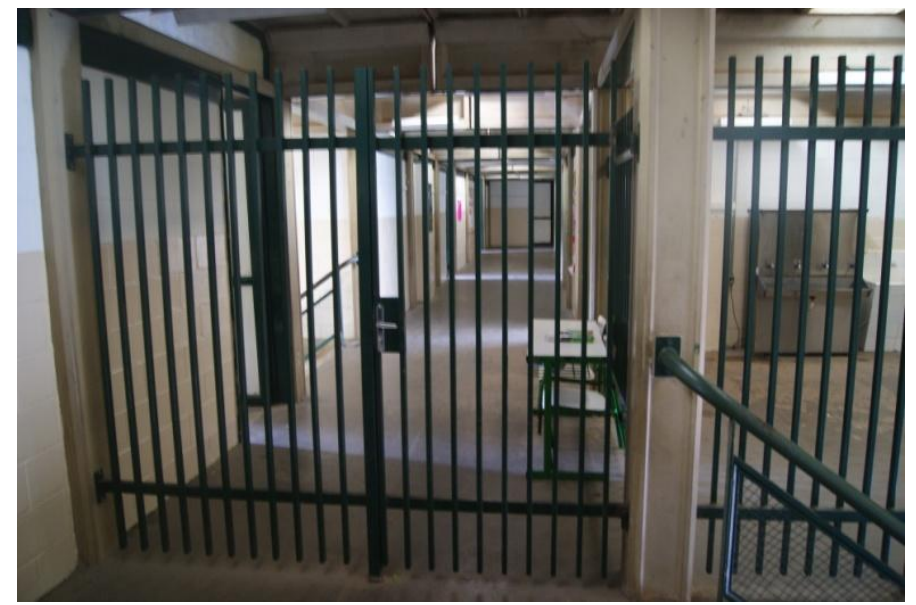

Fonte: arquivo pessoal do autor.

A escola possui um anfiteatro com capacidade para 100 alunos, com projetor multimídia (Figura 94). Esta estrutura fica disponível para uso dos docentes mediante agendamento do recurso.

FIGURA 94 - ANFITEATRO - ESCOLA D
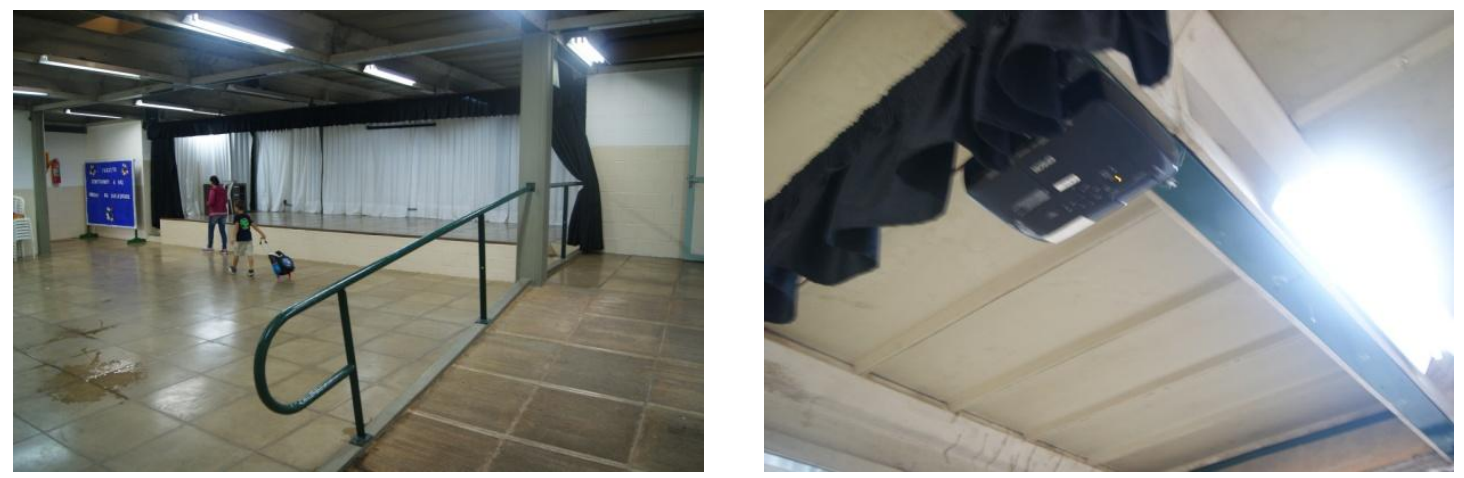

Fonte: arquivo pessoal do autor.

\section{- Oferta de Língua Estrangeira}

Segundo a Diretora, a oferta da disciplina de Língua Estrangeira (Inglês), ocorre a partir do $6^{\circ}$.

\section{- Recursos de Informática}

A escola possui um laboratório com 14 computadores para uso dos alunos, adquiridos por meio do Proinfo. Porém, os equipamentos não funcionam razão da falta de manutenção, não havendo, também, serviço de internet disponível. 
- Acessibilidade

Verifica-se que o projeto da escola foi realizado visando à acessibilidade dos alunos com dificuldade de mobilidade. As portas e corredores são amplos, rampas estão disponíveis nas instalações que apresentam desnível no piso térreo, como o anfiteatro, por exemplo, e um banheiro adaptado está disponível no piso térreo (Figura 95).
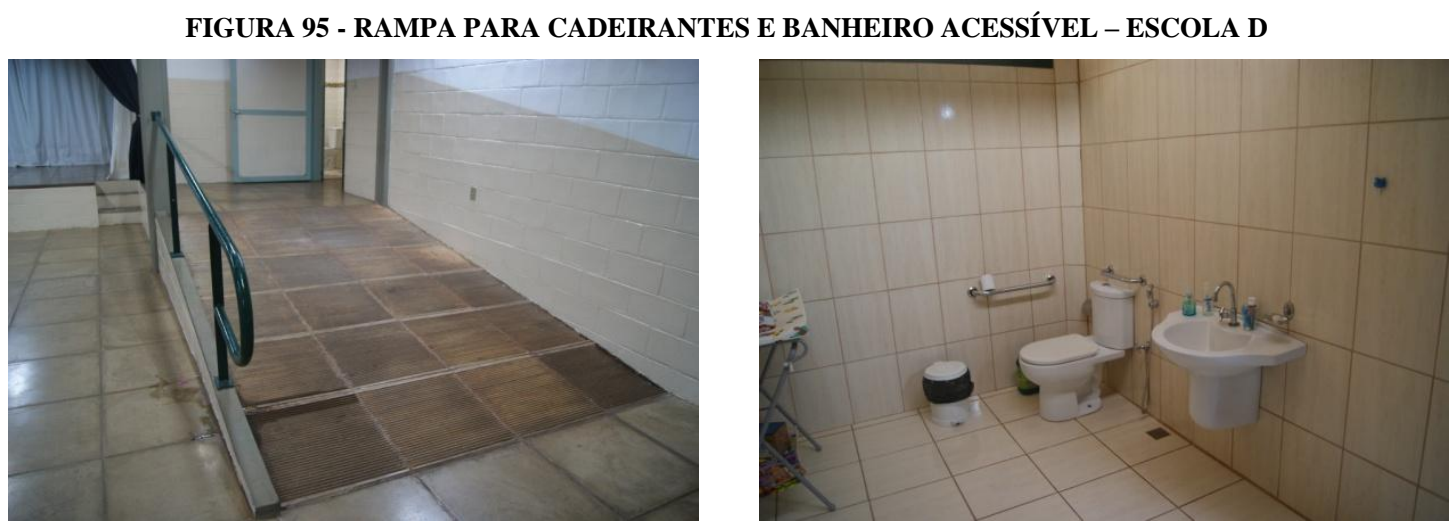

Fonte: arquivo pessoal do autor.

Porém, o acesso às salas de aula do piso superior é realizado exclusivamente por escadas, uma vez que o elevador para cadeirantes (Figura 96), segundo a Diretora, apesar de instalado, nunca chegou a funcionar.

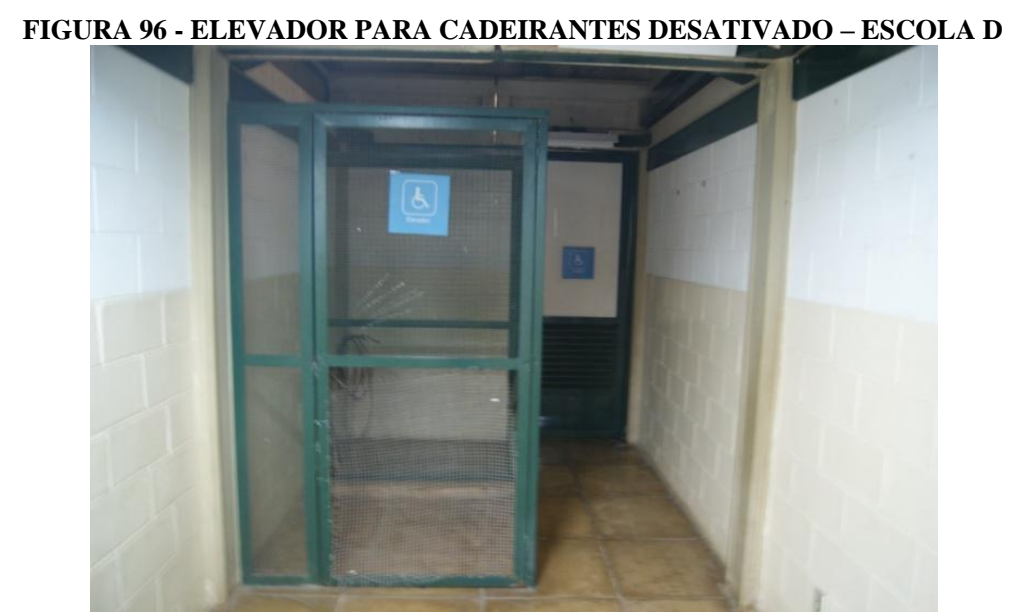

Fonte: arquivo pessoal do autor.

\section{- Merenda Escolar}

Segundo a SME, a coordenação da merenda escolar é realizada por equipe externa à Secretaria de Educação, composta por uma gestora e duas nutricionistas que elaboram o cardápio semanal (Figura 97). Os itens são adquiridos pela prefeitura e encaminhados às 
escolas, que se responsabilizam pelo preparo. Os depoimentos da SME e da Diretora convergem para a qualidade da merenda ofertada. Segundo elas, não há falta de recursos para a aquisição de alimentos, que são oferecidos em quantidade e qualidade adequadas.

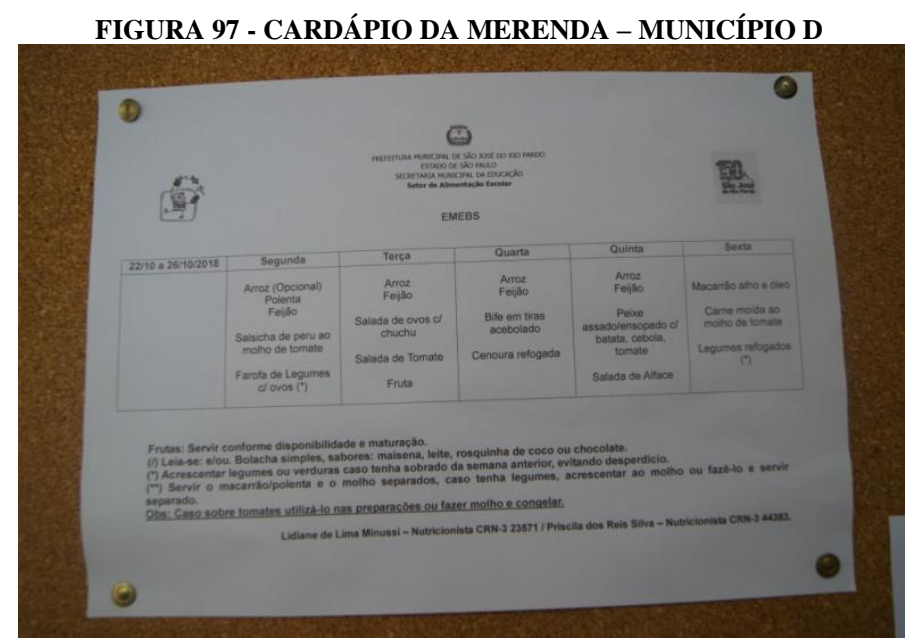

Fonte: arquivo pessoal do autor.

Os estudantes recebem duas refeições: os do período da manhã, um lanche e o almoço, e os do período da tarde recebem o almoço e um lanche (pré-jantar). Segundo a Diretora, a escola serve cerca de 760 refeições por dia, servida em regime de self-service. A Figura 98 apresenta a infraestrutura da escola para o preparo e consumo da merenda.
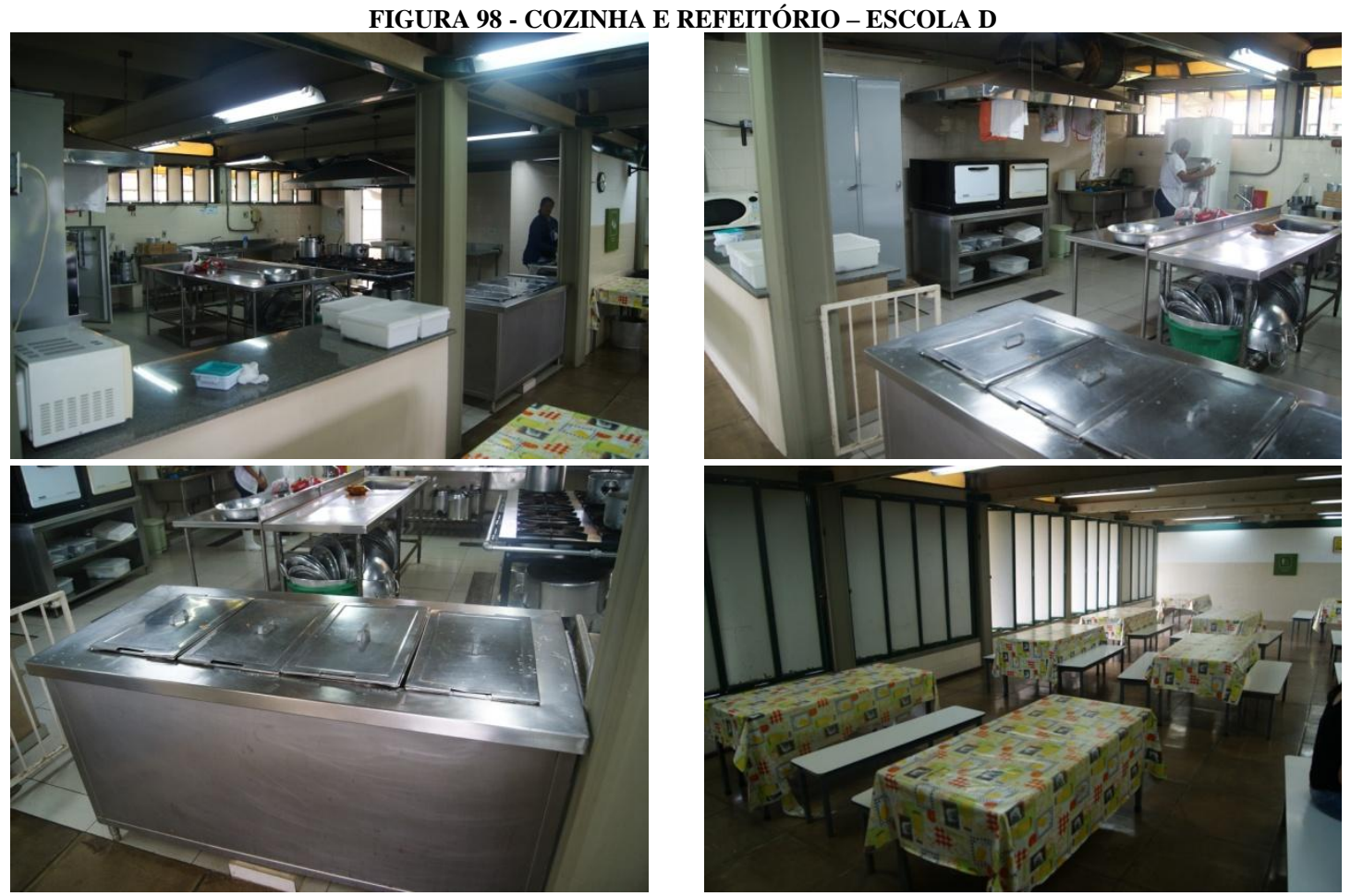

Fonte: arquivo pessoal do autor. 
- Biblioteca

A biblioteca da escola, que é de uso exclusivo dos alunos e professores, não sendo aberta à comunidade, apresenta boa infraestrutura e permanece abertura durante todo o horário de funcionamento da escola, com funcionária responsável pela sua organização e atendimento. A estrutura ainda conta mesas de leitura e equipamentos de áudio e vídeo para a apresentação de documentários e filmes (Figura 99).

A SME não destina recursos específicos para a composição do seu acervo. Segundo a Diretora, os livros são adquiridos mediante verbas do PDDE e da Feira do Livro, organizado anualmente em parceria com uma editora, que reverte cerca de $10 \%$ do valor das vendas em livros para a biblioteca, o que, segundo a entrevistada, equivale a uma doação de cerca de 05 livros por edição.
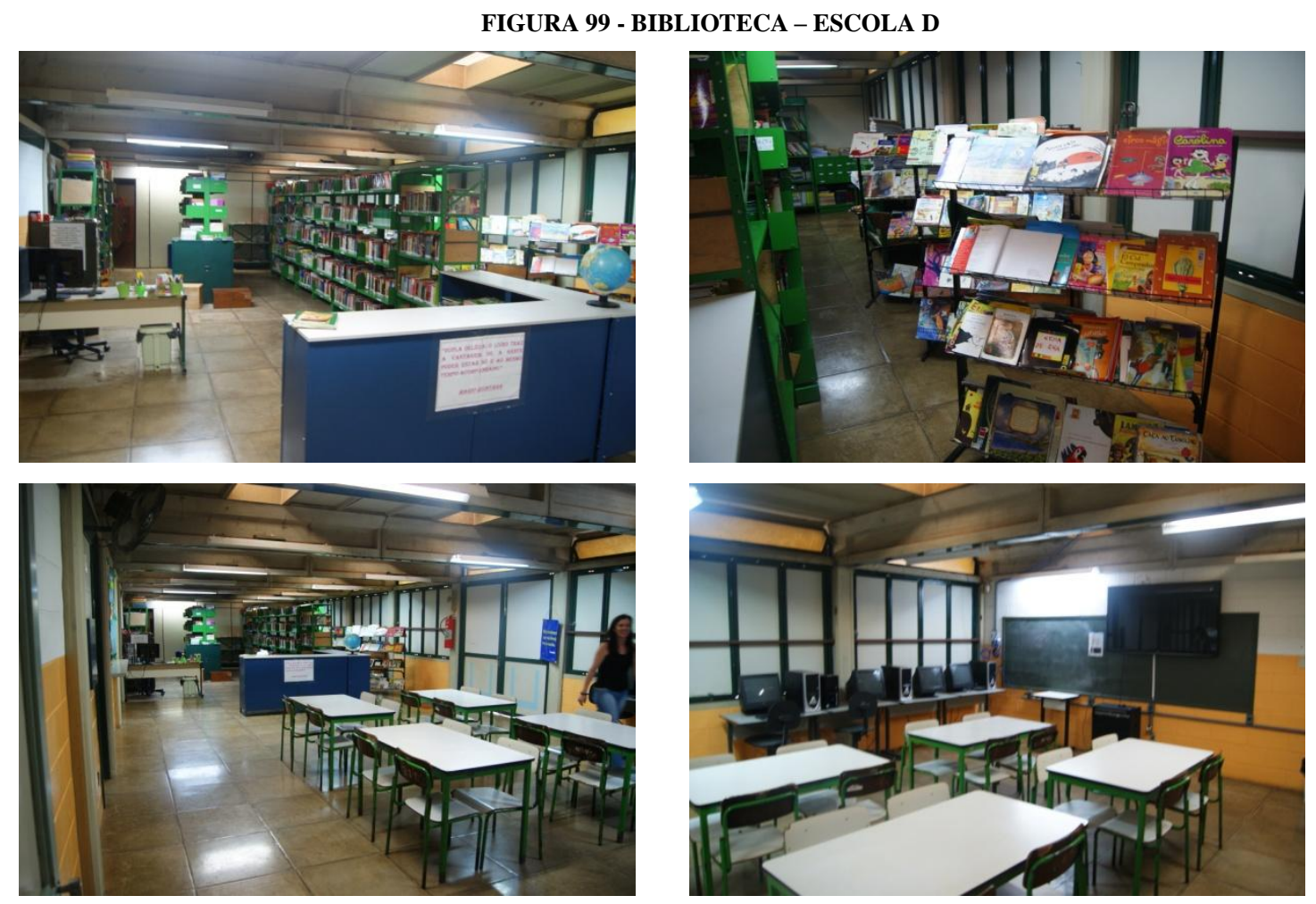

Fonte: arquivo pessoal do autor.

A professora informou incentivar a retirada bimestral de livros pelos alunos, que escolhem os títulos livremente. Relatou ainda, que apesar da boa infraestrutura e variedade de títulos, a quantidade de volumes de cada título é insuficiente para a realização de um trabalho conjunto com a turma. 


\section{- Recursos para os Professores}

A professora destacou negativamente a falta de recursos físicos e materiais para uso nas aulas. Segundo ela, a escola não oferece computadores nem internet para uso docente na preparação das aulas e pesquisa de materiais. Informou que também não dispõe de impressora ou equipamento de fotocópia, sendo que os materiais que entrega ao aluno traz impresso de sua casa. A escola disponibiliza o papel, porém a professora arca com os custos do toner.

A escola possui uma sala de professores com copa para uso dos docentes (Figura 100).

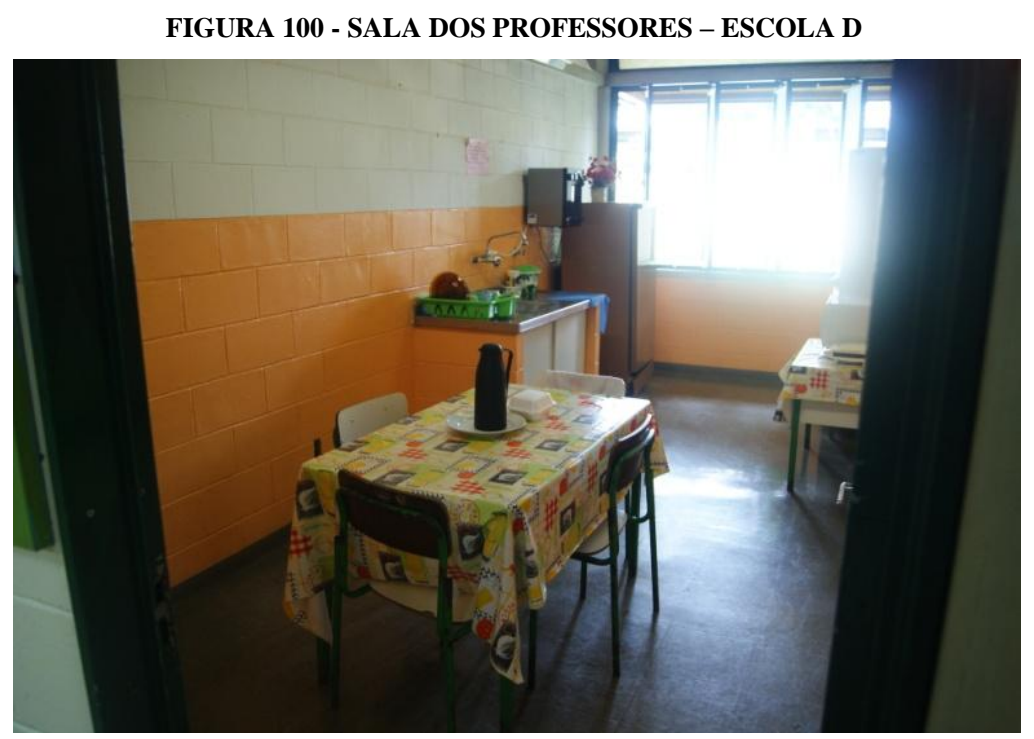

Fonte: arquivo pessoal do autor.

\section{- Disciplina discente e Regime Disciplinar}

Nas entrevistas, Diretora, Vice-Diretora e Professora relataram que a escola possui baixo número de alunos por sala - 18 em média - o que colabora para o controle da disciplina. Porém, relataram a existência de casos graves, envolvendo agressões físicas e depredação das instalações da escola. Os alunos nestas condições são encaminhados para a psicóloga do município, que tem sede de atuação na própria escola, e ao Departamento de Saúde, quando é o caso. Estes casos, segundo os relatos, são mais comuns entre os alunos do ensino fundamental II, em especial entre aqueles que estão na $6^{\mathrm{a}}$ série e que passam por período de adaptação com o novo sistema de ensino.

Em razão disto, algumas medidas foram tomadas pela Direção, como a instalação de grade de separação entre as salas do ensino fundamental I e fundamental II, e a divisão dos horários de intervalo. A escola possui 7 diferentes horários de intervalo, sendo um para cada série, isoladamente, com o objetivo de garantir o controle dos estudantes durante este período. 
A Diretora informou que uma circular impressa, contendo o resumo do Regimento da escola, é entregue aos pais na primeira reunião do ano. Estas regras eram comuns a todas as escolas da rede até ano de 2017 o que, segundo a entrevistada, apresentava como desvantagem a impossibilidade de adequação das regras à realidade de cada escola. A partir de 2018 as escolas foram autorizadas a alterar o conjunto de regras, criando diretrizes próprias.

\subsubsection{Diretor}

\subsection{Regime de trabalho, formação e experiência profissional}

Os diretores são indicados pela Secretária de Educação do Município, constituindo-se cargo de confiança. Como pré-requisito exige-se um tempo mínimo de 8 anos como docente, além de possuir graduação em Pedagogia ou pós-graduação em Gestão Escolar.

Segundo a SME e a Diretora entrevistada, o município enfrenta dificuldades para a contratação de Diretores em razão da remuneração oferecida, que não é atrativa. O salário base para o Diretor no município é de $\mathrm{R} \$ 2.700,00$, para carga horária semanal de 40 horas, valor equivalente ao salário de um professor com carga horária semanal de 24 horas.

A Diretora entrevistada possuía licenciatura em Ciências Biológicas, com pósgraduação em Gestão Escolar e em Práticas Pedagógicas. Atuou 18 anos como docente, experiência que classificou como a mais relevante para o exercício do cargo diretivo. Foi, ainda, por 4 anos Coordenadora em outra unidade escolar do município e por 5 anos como Vice-Diretora da escola onde hoje exerce a direção.

Além de atuar como Diretora na escola visitada, ainda leciona no estado para complemento de sua renda, atividade que avaliou como 'cansativa' e de influência negativa para o desempenho de ambas as funções.

\section{- Transporte Escolar}

Foi relatado que o transporte escolar é oferecido a todos os alunos, sem ter ocorrido episódios de interrupção. 
4.2.4.3.2 Práticas de gestão

\section{- Ações de Combate ao Abandono e à Evasão Escolar}

O acompanhamento das faltas é de responsabilidade da Direção que, quando comunicados pelos professores a ocorrência e 3 faltas consecutivas, realiza uma ligação para os responsáveis do estudante. Após estas tentativas, não havendo sucesso, um representante da escola realiza visita à residência do aluno. Nos casos em que estas instâncias não se mostram eficazes, é feito o encaminhamento da informação ao Conselho Tutelar.

Segundo a professora, há pouca preocupação dos pais em relação às faltas dos filhos, sendo comum que somente tomem ação neste aspecto nos casos em que o estudante esteja em risco de reprovação ou de abandono permanente, situação que pode ocasionar a perda do benefício do programa Bolsa Família.

\section{- Quadro Funcional da Escola}

Foi relatado pela Direção que a escola carece de diversos profissionais em seu quadro, como faxineiros, merendeiras e inspetores de alunos. Também foi informado ser frequente os casos de faltas de professores, sem aviso prévio, causando transtornos internos para o remanejamento das aulas e reposição dos conteúdos.

Foi informado que o município previa em seu plano de carreira, um bônus equivalente a $10 \%$ do salário do professor nos meses em que não registrasse falta. Após a retirada deste benefício o índice de absenteísmo docente cresceu na escola, com grande recorrência entre os docentes concursados.

\section{- Atribuição de Aulas}

A atribuição de aulas para o ensino fundamental II é feita pela pontuação do professor, que considera o tempo de serviço e os cursos realizados.

\section{- Estrutura para Alunos com Deficiência}

A escola dispõe de uma sala para o AEE (Figura 101), e de uma profissional responsável pelo atendimento, no contraturno, aos estudantes identificados e triados mediante a apresentação de laudo médico com CID. A sala conta com jogos pedagógicos, mesas para trabalho coletivo, computadores para uso de aplicativos pedagógicos e um banheiro acessível. 
Em seu depoimento, a professora informou não ter recebido capacitação para a atuação com alunos em AEE, e que seu aprendizado se dá com a prática.
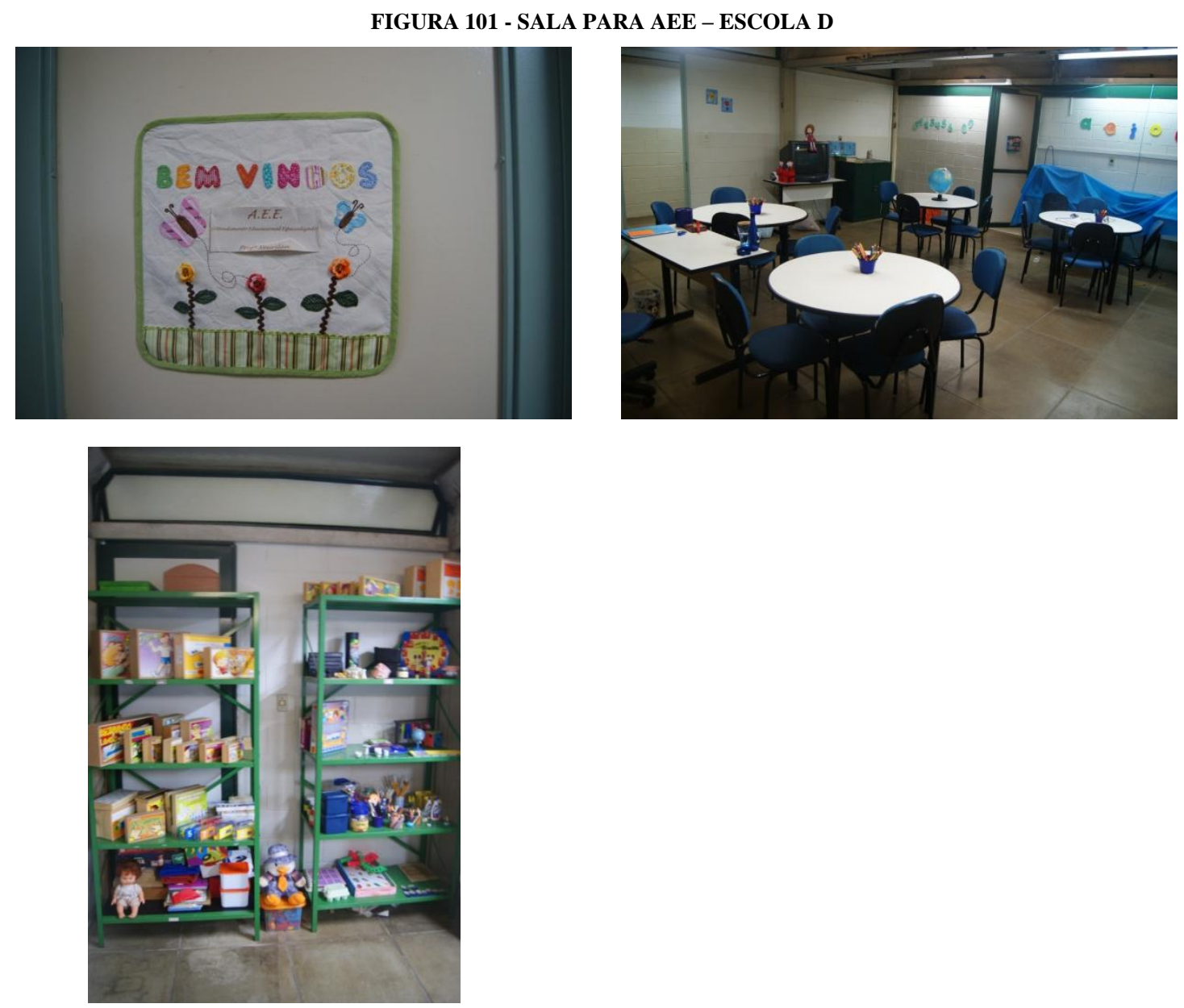

Fonte: arquivo pessoal do autor.

\section{- Captação de Recursos Externos}

A escola realiza diversos eventos visando à arrecadação de fundos para sua manutenção. A APM arrecada, em média, R\$ 300,00 por mês, por meio de envelopes individuais entregues aos alunos. Na Festa Junina, que conta com forte participação da comunidade, são comercializadas 'caixas surpresa', que angariam boa parte dos recursos do evento. Também são promovidas a 'Ação Entre Amigos', com sorteio de tablets, a Festa da Primavera e a Festa do Sorvete. Os itens são adquiridos com recursos do caixa da escola e, então, revendidos aos alunos e à comunidade. A escola também pleiteia com regularidade verbas do PDDE. 


\section{- Investimentos e Manutenção da Escola}

Como já relatado, apesar de o município não disponibilizar recursos financeiros para as escolas, em razão de indisponibilidade orçamentária, a estrutura se apresentou bem conservada e limpa. A Diretora, quando identifica a necessidade de reparo, solicita o apoio da SME, que oferece a mão de obra para os serviços, sendo de sua responsabilidade a compra dos materiais necessários, por meio de recursos captados em eventos ou pelo PDDE. O Diretor tem autonomia total para a destinação dos recursos arrecadados nos eventos promovidos pela escola. Entre as melhorias, destacaram a pintura interna da escola, recém realizada.

\subsection{Práticas pedagógicas}

\section{- Oferta de Reforço no Contraturno}

A Diretora informou que, em razão de indisponibilidade orçamentária, não é ofertado o reforço no contraturno.

- Acompanhar a Aprendizagem dos Alunos e Promover Ações de Combate à Reprovação

O município não adota a progressão continuada e os professores têm autonomia para reprovar em todas as séries, sem necessidade de consulta à Direção ou aos Conselhos (de Classe e Escolar), exceto nos casos de alunos em AEE, cuja análise é feita pelo Conselho. O acompanhamento pela Direção se dá pela Avaliação em Processo, aplicada em toda a rede, que é realizada apenas para os alunos do ensino fundamental I, que ocorre nos meses de março e novembro e, segundo a professora, pelas reuniões de HTPC promovidas semanalmente (2 horas/semana). De acordo com as entrevistadas, a principal causa de reprovação é a falta de interesse por parte dos alunos, em especial nas séries finais $\left(6^{\circ}\right.$ ao $9^{\circ}$ ano). Nos relatos, informaram ser comum a associação dos estudantes deste ciclo ao tráfico de drogas local, como forma de obter renda. Os alunos não associam os estudos à possibilidade de uma vida melhor e não sentem motivação para se dedicarem. Adicionalmente, foi informado que a escola não oferece o reforço no contraturno. Segundo a professora, o processo de 'recuperação' do estudante é realizado ao longo do ano letivo, mediante a aplicação de provas substitutas valendo metade da nota, oportunidade em que o estudante pode tentar recuperar a pontuação necessária à sua aprovação. 
Informaram que até 2013 havia na escola o serviço de Apoio Pedagógico, com atividades no contraturno, serviço que foi interrompido, gerando, segundo a Diretora, perda pedagógica importante para os alunos. Ofereceram o Programa Mais Educação do Governo do Estado, o qual também avaliaram como inadequado, uma vez que os conteúdos ministrados para Língua Portuguesa e Matemática não estava conectados aos ofertados em sala pelos professores, uma vez que o Programa trabalhava com 'projetos' específicos. Também foi implantado o Programa Mais Alfabetização, que consiste em um monitor em sala de aula, auxiliando os estudantes de $1^{\circ}$ e $2^{\circ}$ anos no processo de alfabetização. A Diretora e a Vice-Diretora avaliaram como ineficaz o projeto pela forma como foram selecionados os monitores: um processo seletivo composto por prova e apresentação de projeto, sem levar em conta a experiência docente anterior. Com isso, a escola recebeu uma estagiária sem experiência docente que, segundo elas, não conseguiu apresentar resultados satisfatórios.

A Diretora informou não haver programa específico da escola para a redução desta taxa, sendo a única ação o comunicado aos pais na última reunião de pais do ano. Informou, ainda, que, quando os professores e a Direção identificam casos de alunos que consideram ‘irrecuperáveis' em razão de seu comportamento e desinteresse pelos estudos, optam pela 'aprovação automática' pois avaliam que não há mais alternativa para recuperação deste estudante.

\section{- Acompanhamento dos Resultados do SAEB}

Segundo a Secretária, não há no município uma prática instituída para o acompanhamento dos resultados do SAEB e para a implementação de ações visando à melhoria dos índices. Estas ações são designadas às escolas, individualmente.

Em seu depoimento, a Diretora informou apresentar os resultados da Prova Brasil e do IDEB são apresentados aos professores na reunião de planejamento e que são realizados simulados com os alunos a partir da matriz de referência da Prova Brasil, informação confirmada pela professora, posteriormente.

A professora informou que os resultados das avaliações externas não são utilizados para a organização de seu currículo e de suas aulas. Seu foco é na preparação dos estudantes para o vestibulinho realizado pela ETEC do município, sendo que, para isso, se utiliza de provas anteriores desta escola como simulado aos estudantes. 


\section{- Formação de Turmas}

A Diretora informou que os alunos são divididos em turmas com rendimento heterogêneo.

\section{- Projetos Temáticos}

A SME informou que não existem projetos temáticos de âmbito municipal, sendo de responsabilidade de cada escola a proposição e execução.

Na escola estão desenvolvidos diversos projetos temáticos:

- Jovem Empreendedor;

- A União Traz a Vida;

- Aulas de Balé, com sala de aula montada pela empresa AES Tietê;

- Construindo a Paz: A Unidade na Diversidade;

- Semana Euclidiana

\subsection{Atuação com a família e a comunidade}

Os relatos de todas as entrevistadas convergem para o problema relacionado ao tráfico e consumo de drogas nas imediações da escola. Segundo elas, é comum que, nos finais de semana, os alambrados da escola sejam pulados ou cortados por usuários e traficantes que utilizam o lugar como refúgio para o consumo e guarda de entorpecentes.

Assim, diversos eventos são realizados junto à comunidade visando a sua integração ao ambiente escolar, como a Festa Junina, Festa da Primavera, Feira do Livro e a Festa do Sorvete.

Também são promovidas reuniões bimestrais com os pais, para maior integração, além do projeto "Escola de Pais", composto por palestras e oficinas.

Os pais também têm acesso direto à equipe gestora, que disponibiliza em quadro de aviso seus horários de atendimento (Figura 102). 


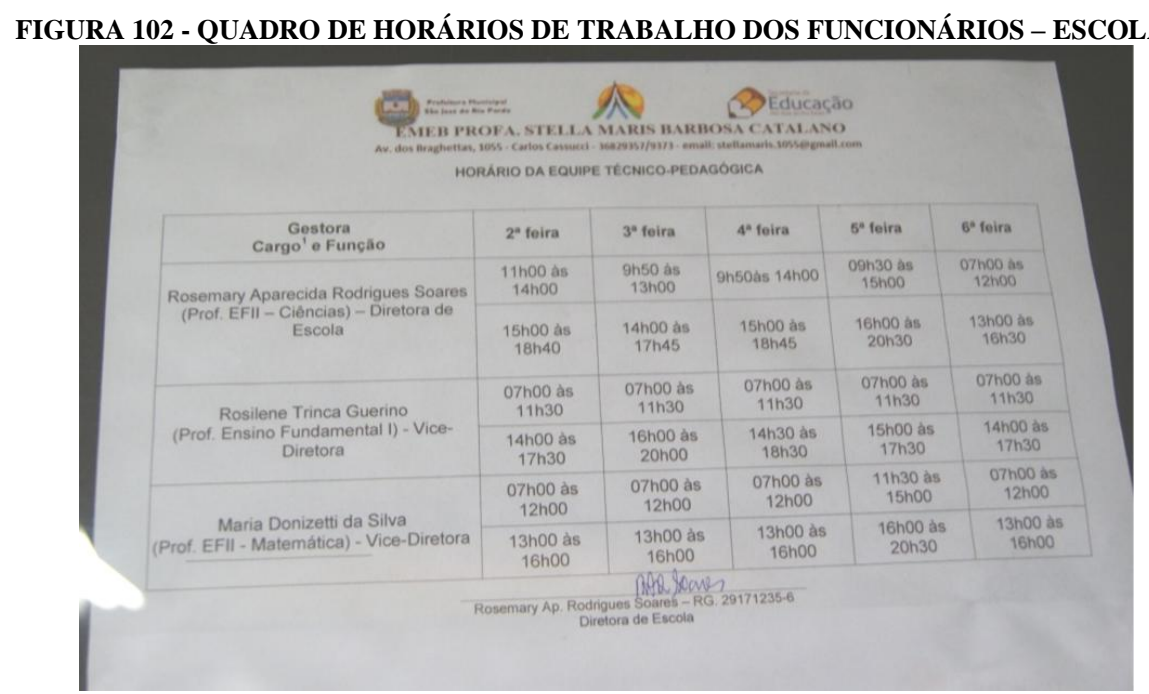

Fonte: arquivo pessoal do autor.

\section{- Reuniões dos Conselhos de Classe e Conselho Escolar}

As reuniões dos Conselhos de Classe são realizadas bimestralmente e do Conselho Escolar cinco vezes ao ano. O cronograma das reuniões, definido no início do ano letivo, fica disponível para consulta pública no mural de comunicados da escola (Figura 103). Segundo a professora, cada docente coordena uma sala, sendo o responsável pela elaboração prévia da pauta junto aos demais colegas.

FIGURA 103 - CRONOGRAMA DE REUNIÕES - CONSELHO ESCOLAR

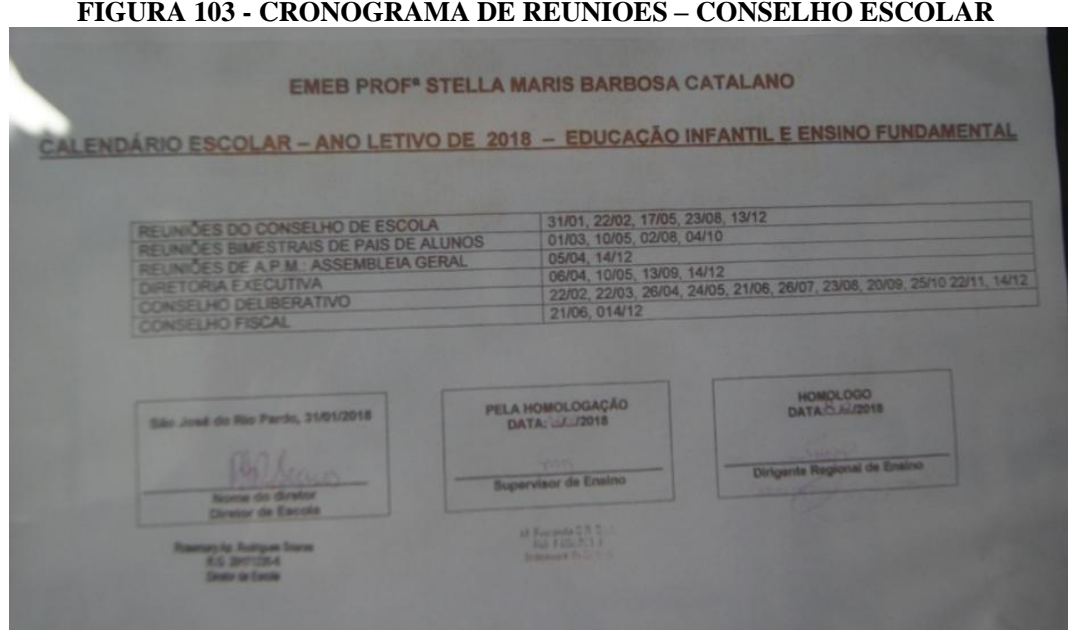

Fonte: arquivo pessoal do autor.

\section{- Reuniões de Pais}

As reuniões de pais são realizadas quatro vezes ao ano, conforme calendário definido no início do ano letivo e divulgado nos murais (Figura 103).

Segundo a Diretora, a participação dos pais nestas reuniões diminui à medida que os estudantes avançam nas séries. Os pais dos estudantes do ensino fundamental I comparecem 
com mais frequência do que os pais dos alunos do fundamental II. A participação dos pais na última reunião do ano é obrigatória aos alunos em risco (por faltas ou nota), sendo que o não comparecimento gera ao estudante a reprova. Segundo ela, esta medida tem auxiliado no comparecimento dos pais.

A professora informou que a média de comparecimento é de menos de $30 \%$ dos pais, conforme evidenciado pela lista de presença de pais do $8^{\circ}$ ano (Figura 104), contabilizando-se aqueles que estão presentes na data agendada e aqueles que procuram os professores em data posterior.

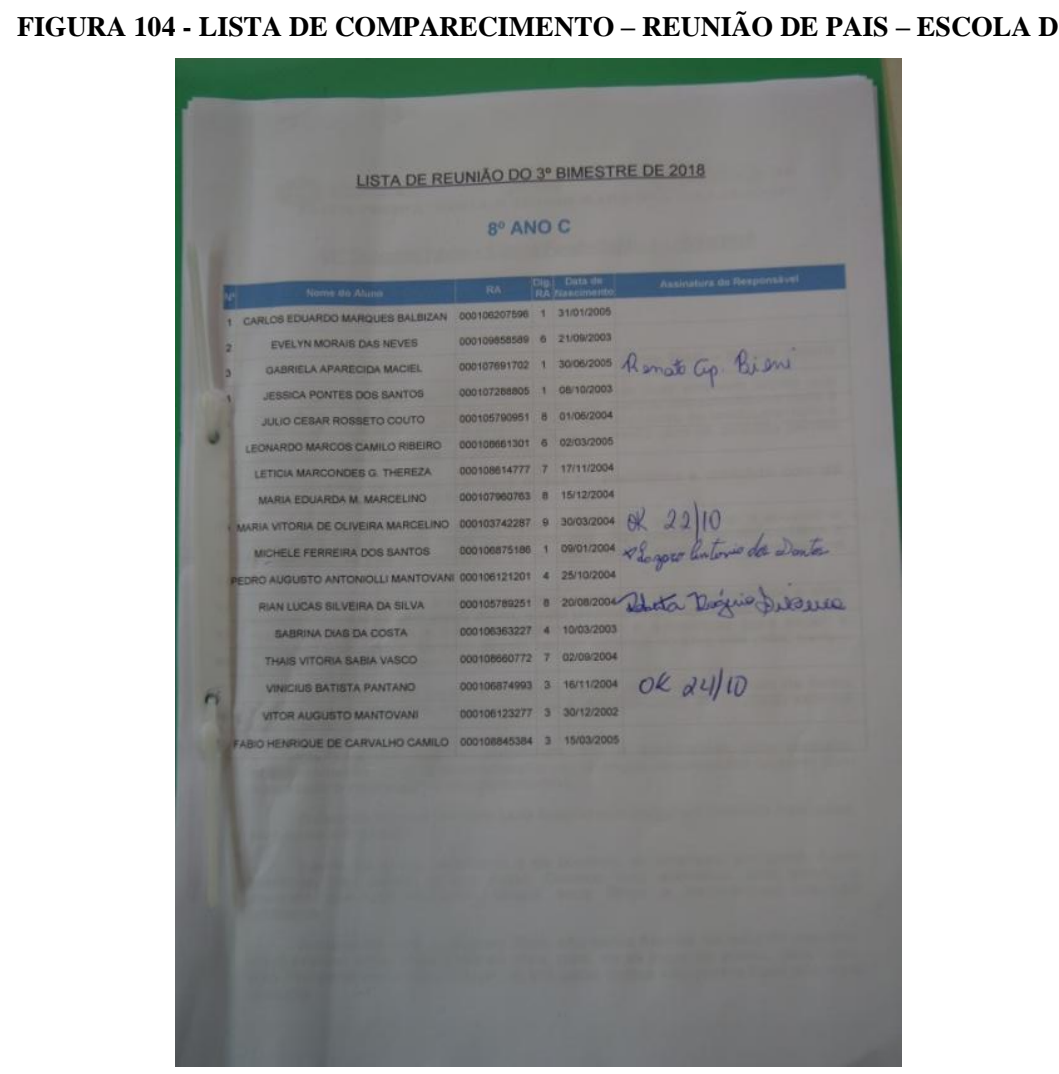

Fonte: arquivo pessoal do autor.

\subsubsection{Professor}

\subsection{Perfil}

A professora possuía 5 anos de experiência docente, sendo Licenciada em Letras e em Pedagogia, com especialização em Alfabetização e Letramento. Procurou realizar o curso de Pedagogia para complementar sua formação em Letras, que julgou deficitária em relação aos 
aspectos da didática. A especialização na área escolhida se deu em razão de receber muitos alunos no $6^{\circ}$ ano, ainda sem saber ler ou escrever.

Leciona as disciplinas de Língua Portuguesa e Práticas de Leitura.

\subsection{Regime de trabalho}

\section{- Contratação via CLT ou Contrato Temporário}

A contratação dos docentes é realizada via concurso público, sendo todos sob o regime estatutário.

\section{- Dedicação Exclusiva à Escola}

A professora informou que cumpre carga horária semanal de 28 horas na escola e que o município não cumpre a lei do 1/3 (lei que garante ao professor $1 / 3$ de sua carga horária em atividades extraclasse, como a preparação das aulas e avaliações e a correção das atividades). Para complementar a renda, de $\mathrm{R} \$ 2.000,00$, a professora dá aulas de inglês em escola particular do município, o que, segundo ela, somado ao não cumprimento da lei do $1 / 3$, causa dificuldade na preparação prévia dos conteúdos das aulas aos estudantes.

A SME afirmou que o Plano de Carreiras do município estava em revisão, uma vez que o salário pago aos docentes estava abaixo da média da região. A cada período de 3 anos, o professor pode ter progressão salarial por tempo de serviço - 5\% (cinco por cento) de acréscimo. Com o mesmo intervalo de tempo, pode pleitear progressão mediante a apresentação de certificado de cursos de especialização (+ $5 \%)$ e de mestrado $(+5 \%)$.

\subsection{Atuação com a direção}

\section{- Participação na Elaboração do Projeto Pedagógico}

O Projeto Pedagógico é elaborado pela escola e submetido à Diretoria de Ensino Regional para aprovação final, segundo a Diretora. Cada professor elabora, individualmente, o plano de sua disciplina e submete à aprovação da Direção.

\section{- Discussão Semanal das Metas}

Segundo os relatos, as metas acompanhadas pela Direção estão relacionadas ao cumprimento dos conteúdos propostos no planejamento. Este acompanhamento é realizado 
pela leitura dos diários de classe e nas reuniões semanais do HTPC. Não há metas claras advindas da Direção ou da SME para a aferição do desempenho dos alunos e dos docentes, informação ratificada pela Diretora. O município aplica anualmente uma Avaliação Docente pelo Diretor, cujo resultado pode influenciar na evolução da carreira. Porém, segundo a Diretora, não há clareza nos aspectos a serem considerados, sendo a avaliação feita de forma subjetiva.

\subsection{Atividade docente}

\section{- Reuniões Semanais com Outros Professores}

A Diretora informou que não há, na escola, a prática de alinhamento de conteúdos entre os professores das diversas séries ou entre os docentes que atuam como as mesmas turmas. A professora citou como exemplo as disciplinas de Língua Portuguesa e Práticas de Leitura que deveriam ser complementares entre si, mas que, quando lecionadas por professores diferentes, seguem caminhos independentes, sem objetivo comum ou complementar. Segundo a professora, apenas nos HTPCs é que os docentes discutem o desempenho dos estudantes limitando-se, no entanto, às questões comportamentais.

\section{- Dedicar mais Tempo às Aulas}

A professora informou que consegue dedicar seu tempo na escola exclusivamente para as aulas, sem grandes interrupções por problemas de comportamento ao longo do período letivo.

\section{- Garantir o Cumprimento de Todo o Conteúdo}

A professora informou que a divisão da carga horária destinada à disciplina de Língua Portuguesa com a disciplina Práticas de Leitura prejudicou o cumprimento do conteúdo proposto para a primeira. A escola oferece 4 horas semanais de Língua Portuguesa, sendo que o ideal seriam 6 horas semanais. Com isso a professora somente consegue cumprir cerca de $60 \%$ do conteúdo proposto.

A cada semestre, a SME realiza um Replanejamento, para a adequação dos conteúdos. Nestas ocasiões, invariavelmente são eliminados conteúdos que não serão passíveis de cumprimento no período seguinte. 


\section{- Oferta e Correção do Dever de Casa}

A definição da periodicidade de oferta e forma de correção dos deveres de casa são de responsabilidade dos professores das disciplinas.

A professora informou que para a disciplina de Práticas de Leitura, encaminha deveres de casa semanais e vista os cadernos nas semanas seguintes. Não prática realizar a correção dos deveres em sala nem individualmente. Para a disciplina de Língua Portuguesa informou não ofertar, pois não há adesão por parte dos alunos. Segundo ela, a maioria dos pais não acompanha a execução das tarefas pelos alunos. Em sua opinião, parte dos pais age desta forma por também não possuir formação escolar e, muitas vezes, desconhecer o conteúdo estudado pelos filhos, não sabendo auxiliar na sua execução.

\section{- Uso de Recursos Didáticos e Incentivo à Participação dos Alunos}

Uma vez que a escola não oferece laboratório de informática e internet, a professora não consegue utilizar aplicativos pedagógicos ou mesmo realizar pesquisas junto aos alunos. Assim, informou que prioriza o uso de outras estratégias de ensino para estímulo dos estudantes, como músicas para auxiliar na compreensão das figuras de linguagem, e a leitura de crônicas e contos curtos e engraçados, uma vez que os estudantes não gostam de copiar conteúdos da lousa, de utilizar o livro didático ou mesmo de ler livros e textos longos.

Foca seu trabalho nos gêneros textuais, na interpretação e escrita de textos. Entre os projetos que realiza juntamente com os alunos estão um Sarau de Poesias, charges e tirinhas, que são expostos na escola. Também frisou que procura ensinar as regras gramaticais por meio de textos contextualizados, ao invés de utilizar os exemplos do livro didático.

\subsubsection{Aluno}

Os apontamentos a seguir são realizados com base nos depoimentos colhidos da Professora, Diretora e Coordenadora Pedagógica.

\subsection{Comportamento}

\section{- Manter a Disciplina e Frequência às Aulas}

A maioria dos alunos mantém boa disciplina, porém existem casos de problemas graves de comportamento entre os estudantes. Também foram relatados problemas em relação 
à depredação da escola por parte dos estudantes. O índice de faltas é considerado 'mediano' pela professora, que ressaltou a prática dos estudantes faltarem propositadamente nos dias das avaliações. Segundo a professora, os pais têm baixo nível de preocupação com o índice de absenteísmo dos filhos.

\section{- Realizar o Dever de Casa}

Segundo a professora, nem todos os estudantes realizam os deveres de casa, em especial da disciplina de Língua Portuguesa, para a qual já não é mais cobrada.

\section{- Leitura Frequente de Livros}

Em seu depoimento, a professora informou que não são propensos à leitura, ficando limitados aos livros utilizados na disciplina de Práticas de Leitura, cuja demanda é de 1 título por bimestre. Também informou que, sendo a escolha dos livros para a disciplina, livre pelos alunos, estes tendem a buscar os títulos menores. Em suas palavras, elegem "o menor livro disponível".

\subsection{Ambiente familiar e social}

Os depoimentos dos entrevistados convergem para o grave problema social do entorno da escola. Foram relatados diversos casos de estudantes presos por tráfico, sendo comum seu ingresso no crime a partir do $6^{\circ}$ ano em razão da situação de vulnerabilidade das famílias. Segundo a Diretora, os pais somente procuram a escola para tratar de problemas ligados ao comportamento dos alunos ou para questionar eventuais punições impostas aos estudantes pelos professores e escola.

\section{- Possuir Computador em Casa}

A professora não soube precisar o percentual de estudantes que possuem computador em casa, porém, informou que consegue verificar diferença de desempenho ao analisar os resultados dos deveres de casa solicitados para a disciplina de Prática de Leitura, em que os alunos que dispõe do equipamento em casa conseguem, de maneira geral, produzir melhores conteúdos a partir de suas pesquisas. Porém, em sua opinião, a maior colaboração para diferença de desempenho está ligada às diferenças de condição social entre os estudantes e não propriamente ao uso do equipamento. 


\subsection{Análise quali-quantitativa e discussão dos resultados}

A variáveis identificadas na etapa quantitativa foram agrupadas, consolidando-se num quadro de proposta de práticas (QUADRO 16). No total, foram encontradas 51 práticas relativas à atuação dos diversos atores do processo educacional: professores, diretores, dos alunos e sua família. Os estudos de caso permitiram a compreensão aprofundada de como estas práticas se realizam no dia a dia das escolas, o que, juntamente com a literatura disponível contribui para a discussão dos resultados, a qual é apresentada neste capítulo. 
QUADRO 16 - PRÁTICAS IDENTIFICADAS NA ETAPA QUANTITATIVA

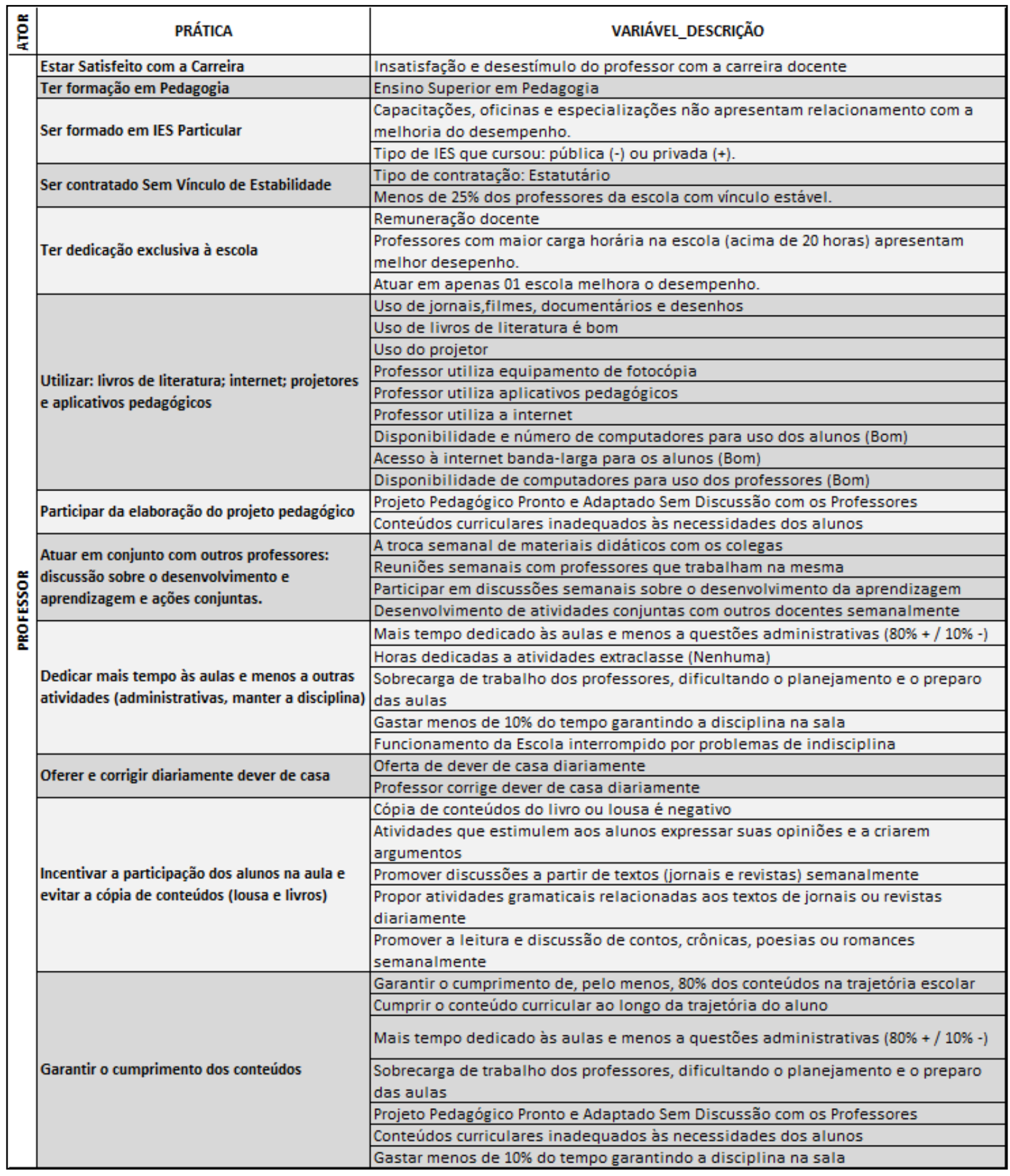


Continuação

\begin{tabular}{|c|c|c|c|}
\hline 兽 & GRUPO & PRÁTICA & VARIÁVEL_DESCRIÇÃO \\
\hline & \multirow{6}{*}{$\begin{array}{l}\text { Regime de Trabalho, } \\
\text { Formação e Experiência }\end{array}$} & \multirow{2}{*}{ Ter dedicação exclusiva à escola } & Dedicação Exclusiva à Escola \\
\hline & & & Possui 40 horas semanais OU + de carga horária na escola \\
\hline & & $\begin{array}{l}\text { Contratação via Concurso Público ou Indicação } \\
\text { Direta }\end{array}$ & Ingresso no cargo via Concurso Público ou Indicação Direta \\
\hline & & Cursar Especialização & Possuir Pós-graduação (Especialização, no mínimo) \\
\hline & & \multirow{2}{*}{$\begin{array}{l}\text { Atuar na mesma escola pelo período de } 06 \text { a } 10 \\
\text { anos }\end{array}$} & Experiência anterior como professor (+ de 20 anos) \\
\hline & & & Diretor na mesma escola pelo período de 06 a 10 anos \\
\hline & \multirow{9}{*}{$\begin{array}{l}\text { Atuação com a Família e a } \\
\text { Comunidade }\end{array}$} & \multirow{2}{*}{$\begin{array}{l}\text { Manter contato com os pais e informar sobre o } \\
\text { desempenho do aluno }\end{array}$} & $\begin{array}{l}\text { Frequência com que o Diretor comunica os pais sobre problemas relacionados aos } \\
\text { aluno (Sempre ou Quase Sempre) }\end{array}$ \\
\hline & & & Participação dos pais em reuniões escolares \\
\hline & & Promover projetos temáticos & $\begin{array}{l}\text { Diretor promover projetos temáticos (como bullying, desigualdades e impactos } \\
\text { socioambientais) (Frequentemente) }\end{array}$ \\
\hline & & Promover eventos para a comunidade & Diretor promover eventos para a comunidade (Frequentemente) \\
\hline & & Ceder a escola para eventos comunitários & Diretor ceder o espaço escolar para eventos realizados pela comunidade (Nunca) \\
\hline & & 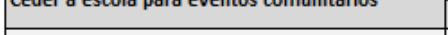 & Biblioteca permite acesso do acervo à comunidade. \\
\hline & & & Receber apoio da Comunidade. \\
\hline & & Promover projetos de voluntariado & $\begin{array}{l}\text { Diretor promover a participação da comunidade realizando trabalhos voluntários } \\
\text { para a escola. }\end{array}$ \\
\hline & & $\begin{array}{l}\text { Admitir alunos considerando o local de } \\
\text { residência }\end{array}$ & $\begin{array}{l}\text { Adotar política de admissão de alunos pelo local de residência (vizinhança da } \\
\text { escola) }\end{array}$ \\
\hline \multirow{35}{*}{ 产 } & \multirow{32}{*}{ Práticas de Gestão } & $\begin{array}{l}\text { Atribuir aulas por pontuação dos professores } \\
\text { (tempo de serviço e formação) }\end{array}$ & $\begin{array}{l}\text { Atribuição de aulas considerando a escolha dos professores, de acordo com a } \\
\text { pontuação por tempo de serviço e formação. }\end{array}$ \\
\hline & & \multirow{2}{*}{$\begin{array}{l}\text { Realizar reuniões de conselhos (de Classe e } \\
\text { Escolar) pelo menos } 3 \text { vezes ao ano }\end{array}$} & $\begin{array}{l}\text { Diretor realiza e participa de reuniões de Conselho Escolar por três vezes ou mais } \\
\text { no ano. }\end{array}$ \\
\hline & & & $\begin{array}{l}\text { Diretor promover reuniões de conselho classe (órgão formado por todos os } \\
\text { professores que lecionam em cada série) por três vezes ou mais no ano. }\end{array}$ \\
\hline & & $\begin{array}{l}\text { Incentivar os docentes para a formação } \\
\text { continuada }\end{array}$ & $\begin{array}{l}\text { O Diretor informa com frequência sobre possibilidades de aperfeiçoamento aos } \\
\text { professores }\end{array}$ \\
\hline & & Atuar em conjunto com as instâncias superiores & Receber apoio das instâncias superiores. \\
\hline & & \multirow{4}{*}{$\begin{array}{l}\text { Prover merenda em quantidade e qualidade } \\
\text { adequadas }\end{array}$} & Merenda escolar: Disponibilidade de recursos financeiros (Bom ou acima) \\
\hline & & & Merenda escolar: Quantidade de Alimentos (Ótimo) \\
\hline & & & Merenda escolar: Qualidade dos Alimentos (Ótimo) \\
\hline & & & Merenda escolar: Espaço Físico para Cozinhar (Ótimo) \\
\hline & & \multirow{4}{*}{$\begin{array}{l}\text { Garantir o quadro funcional (administrativo e } \\
\text { pedagógico) completo }\end{array}$} & Garantir que o quadro de pessoal de apoio pedagógico esteja completo \\
\hline & & & Garantir que o quadro docente esteja completo. \\
\hline & & & $\begin{array}{l}\text { Garantir que o quadro de funcionários administrativos seja adequado à estrutura } \\
\text { da escola. }\end{array}$ \\
\hline & & & $\begin{array}{l}\text { Garantir que o quadro de apoio pedagógico (coordenador, supervisor, orientador) } \\
\text { esteja completo. }\end{array}$ \\
\hline & & \multirow{2}{*}{\begin{tabular}{|l|} 
Garantir a manutenção da infraestrutura \\
(completa em boas condiçōes de conservação e \\
funcionamento)
\end{tabular}} & Apresentar infraestrutura em boas condições de conservação e em funcionamento. \\
\hline & & & Todas as salas são bem iluminadas. \\
\hline & & \multirow{2}{*}{$\begin{array}{l}\text { Garantir policiamento e combate ao tráfico } \\
\text { dentro e nas imediações da escola e controle de } \\
\text { entrada. }\end{array}$} & Controle de entrada de pessoas estranhas (Bom) \\
\hline & & & $\begin{array}{l}\text { Sistema policiamento para inibição ao tráfico de drogas dentro da escola e nas } \\
\text { imediações (Bom) }\end{array}$ \\
\hline & & \multirow{6}{*}{$\begin{array}{l}\text { Garantir computadores, impressora e internet } \\
\text { adequados (para alunos, professores e } \\
\text { funcionários) }\end{array}$} & Disponibilidade e número de computadores para uso dos alunos (Bom) \\
\hline & & & Acesso à internet banda-larga para os alunos (Bom) \\
\hline & & & Disponibilidade de computadores para uso dos professores (Bom) \\
\hline & & & Acesso à internet banda-larga para os professores (Bom) \\
\hline & & & Disponibilidade de computadores para uso dos funcionários administrativos \\
\hline & & & Escola possui impressora \\
\hline & & \multirow{2}{*}{$\begin{array}{l}\text { Atuar sobre as normas administrativas e } \\
\text { manutenção da escola. }\end{array}$} & O Diretor se envolve com frequência com as normas administrativas \\
\hline & & & O Diretor se envolve com frequência na manutenção da escola \\
\hline & & \multirow{2}{*}{ Captar recursos financeiros externos } & Buscar apoio financeiro de empresas particulares. \\
\hline & & & Não haver interrupção das atividades escolares por falta de recursos financeiros. \\
\hline & & Garantir estrutura para AEE & $\begin{array}{l}\text { Diretor garantir uma infraestrutura adequada para atendimento às pessoas com } \\
\text { deficiência ou necessidades especiais. }\end{array}$ \\
\hline & & \multirow{4}{*}{$\begin{array}{l}\text { Manter Biblioteca com estrutura e acervo } \\
\text { adequados }\end{array}$} & Existência de sala de leitura para os alunos. \\
\hline & & & Existência de pessoa responsável pelo atendimento na biblioteca \\
\hline & & & Biblioteca permite acesso do acervo à comunidade. \\
\hline & & & Existência de Biblioteca em boas condições de uso. \\
\hline & \multirow{3}{*}{ Práticas Pedagógicas } & \multirow{3}{*}{ Acompanhar a Aprendizagem dos Alunos } & $\begin{array}{l}\text { O professor e o diretor compreenderem que a qualidade é uma responsabilidade } \\
\text { coletiva auxilia na melhora do desempenho }\end{array}$ \\
\hline & & & $\begin{array}{l}\text { Diretor discute com os professores medidas com o objetivo de melhorar o ensino e } \\
\text { a aprendizagem dos alunos (Sempre ou Quase Sempre) }\end{array}$ \\
\hline & & & $\begin{array}{l}\text { Discussão frequente com a Direção sobre as metas educacionais melhora o } \\
\text { desempenho }\end{array}$ \\
\hline
\end{tabular}




\section{Continuação}

\begin{tabular}{|c|c|c|c|}
\hline 常 & GRUPO & PRÁTICA & VARIÁVEL_DESCRIÇÃO \\
\hline \multirow{11}{*}{ 营 } & \multirow{11}{*}{ Práticas Pedagógicas } & \multirow{2}{*}{ Garantir os livros didáticos para todos os alunos } & Escola receber os livros didáticos escolhidos no início das aulas \\
\hline & & & Todos os alunos terem o livro didático \\
\hline & & \begin{tabular}{|l|} 
Oferecer disciplina de Lingua Estrangeira \\
\end{tabular} & Oferta da disciplina Língua Estrangeira está associada ao bom desempenho. \\
\hline & & \multirow{3}{*}{ Acompanhar resultados do SAEB } & Diretor acompanhar os resultados do SAEB da escola \\
\hline & & & Diretor acompanhar os resultados do SAEB do município \\
\hline & & & Diretor acompanhar os resultados do SAEB do estado \\
\hline & & $\begin{array}{l}\text { Formar turmas heterogêneas em relação ao } \\
\text { rendimento }\end{array}$ & Adotar critério de formação de turmas heterogêneas em relação ao rendimento. \\
\hline & & \multirow{2}{*}{ Realizar ações de combate à evasão } & Diretor realizar ações para redução das taxas de abandono. \\
\hline & & & Cobrança dos pais para a frequência às aulas \\
\hline & & \multirow{2}{*}{ Oferecer reforço no contraturno } & Adoção de ações para a redução da reprovação \\
\hline & & & Oferta de reforço no contraturno \\
\hline \multirow{34}{*}{ 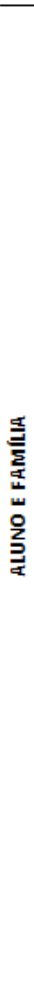 } & \multirow{31}{*}{ Participação da Família } & Participar das reuniões escolares & Participação dos pais em reuniões escolares \\
\hline & & Cobrar a realização do dever de casa & Cobrança dos pais sobre os deveres de casa \\
\hline & & \multirow{7}{*}{ Incrementar a própria escolaridade } & Mãe com ensino primário incompleto \\
\hline & & & Mãe com curso superior completo \\
\hline & & & Pai com curso superior completo \\
\hline & & & Pai sabe ler e escrever \\
\hline & & & Mãe sabe ler e escrever \\
\hline & & & Influência do meio social do aluno \\
\hline & & & \begin{tabular}{|l|} 
Nivel cultural dos pais \\
\end{tabular} \\
\hline & & \multirow{2}{*}{ Manter o hábito da leitura } & Vê a mãe lendo \\
\hline & & & Vê o pai lendo \\
\hline & & Possuir computador em casa & Possui computador em casa tem efeito positivo \\
\hline & & \multirow{6}{*}{ Cobrar a disciplina e frequência às aulas } & Desinteresse e falta de esforço dos alunos \\
\hline & & & Baixa Autoestima do Aluno \\
\hline & & & \begin{tabular}{|l|l|} 
Indisciplina dos alunos \\
\end{tabular} \\
\hline & & & Alto índice de faltas do aluno $(++)$ \\
\hline & & & Cobrança dos pais para a frequência às aulas \\
\hline & & & Funcionamento da Escola interrompido por problemas de indisciplina \\
\hline & & Pais incentivarem o uso da biblioteca escolar & Utilizar a biblioteca e sala de leitura da escola (Sempre) \\
\hline & & \multirow{3}{*}{ Controlar o tempo com atividades recreativas } & Frequência com que vai cinema (Sempre) \\
\hline & & & Frequência com que vai a espetáculos e exposições (Sempre) \\
\hline & & & Tempo gasto com tv, internet e jogos (uma a duas horas/dia) \\
\hline & & \multirow{9}{*}{$\begin{array}{l}\text { Incentivar a leitura (especialmente de livros de } \\
\text { literatura) }\end{array}$} & Incentivo dos pais à leitura \\
\hline & & & Frequência de leitura de livros de interesse geral (Sempre) \\
\hline & & & Frequência de leitura de jornais (Sempre) \\
\hline & & & Frequência de leitura de gibis (Algumas vezes) \\
\hline & & & Frequência de leitura de livros de Literatura (Sempre) \\
\hline & & & Frequência de leitura de revistas de comportamento (Sempre) \\
\hline & & & Frequência de leitura de revistas em geral (Sempre) \\
\hline & & & Frequência de leitura de notícias na Internet (Sempre) \\
\hline & & & Frequência de visitas à Biblioteca (Sempre) \\
\hline & \multirow{3}{*}{ Comportamento } & Gostar da Disciplina de Língua Portuguesa & Gosta da Disciplina de Língua Portuguesa \\
\hline & & \multirow{2}{*}{ Realizar o dever de casa } & Frequência com que faz o dever de casa de Língua Portuguesa (Sempre) \\
\hline & & & Cobrança dos pais sobre os deveres de casa \\
\hline
\end{tabular}

Fonte: Elaborado pelo autor.

\subsubsection{Resultados para o professor}

Dentre as variáveis restantes, 43 estão relacionadas ao professor, podendo ser agregados em 04 Grupos e 11 práticas, conforme Figura 105. 


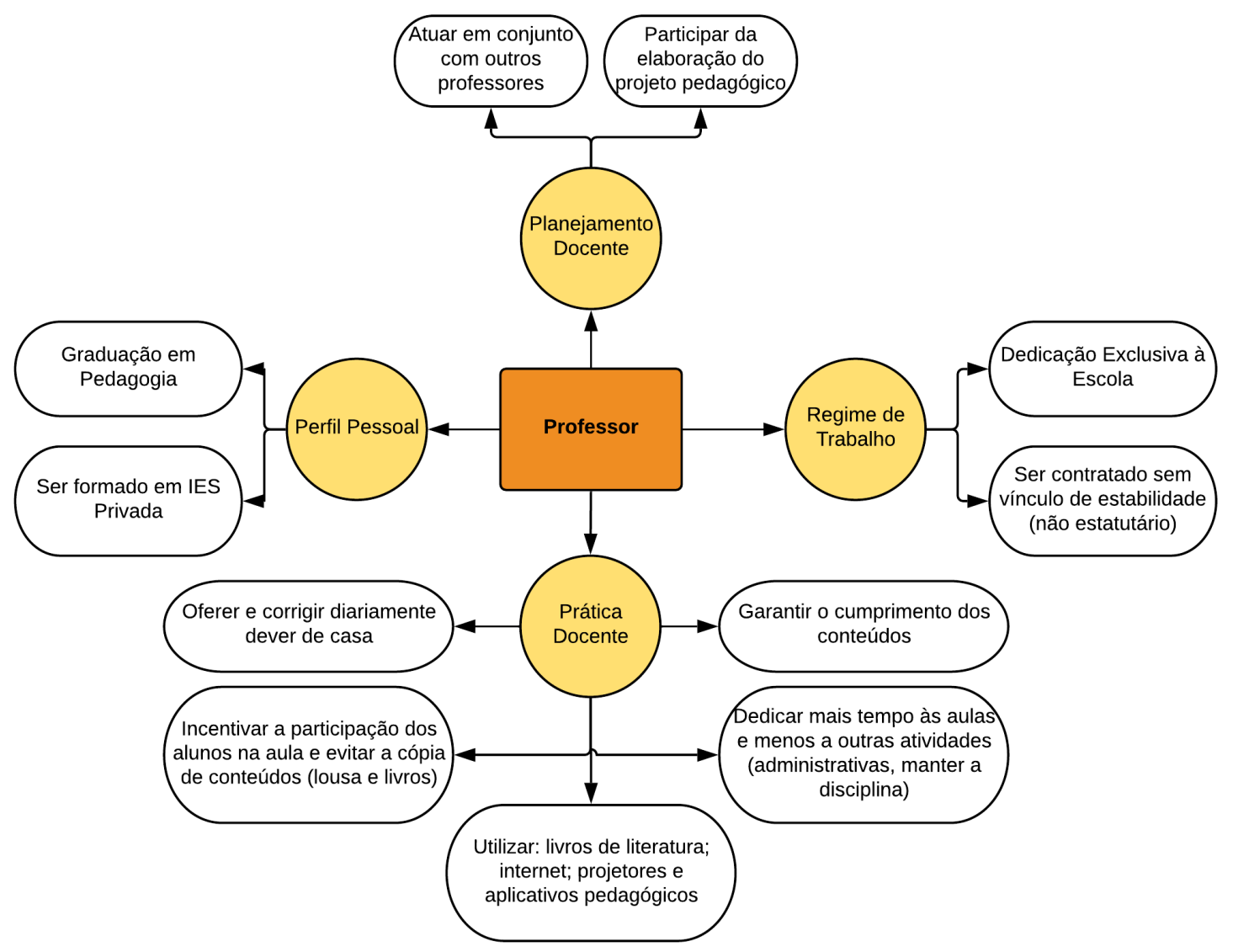

Fonte: Elaborado pelo autor.

\section{- Perfil Pessoal}

Em relação ao perfil, análise apontou que as professoras apresentam melhores resultados do que os professores, estando mais relacionadas às escolas de alto desempenho, e a satisfação com a carreira também influencia no desempenho.

A análise mostra que os professores que também possuem formação em pedagogia, estão mais associados ao melhor desempenho dos estudantes, sendo que não foi encontrada diferença significativa entre aqueles que possuem licenciatura em letras, o que era esperado, uma vez que esta é pré-requisito para lecionar na disciplina de Língua Portuguesa. A formação docente por meio de "Complementação Pedagógica", ao invés de curso de licenciatura está associada ao baixo desempenho.

Possuir graduação em pedagogia também se mostrou benéfico para os resultados educacionais. Nas entrevistas, todos os professores informaram ter cursado pedagogia, como forma de complementação de sua licenciatura. Segundo seus depoimentos, o curso de licenciatura em letras teve mais foco nos aspectos formais da língua portuguesa, com pouca 
ou nenhuma abordagem sobre o processo de ensino-aprendizagem e sobre metodologias de ensino, fato encontrado durante a pesquisa bibliográfica e apresentado no capítulo "O ensino da Língua Portuguesa" do referencial teórico. Levantamento realizado por Gatti e Nunes (2009) apontou que apenas 10,5\% do currículo dos cursos de Licenciatura em Letras do país é direcionado à prática docente.

Foi encontrada diferença significativa, também, entre os professores graduados em faculdades públicas e privadas, com maior associação entre aqueles oriundos das faculdades privadas e o melhor desempenho. Este fato é possivelmente explicado pela composição dos currículos. Segundo Gatti e Nunes (2009), enquanto a média nacional da carga horária dos cursos de Licenciatura em Letras direcionado aos "Conhecimentos Específicos da Área" é de $51,6 \%$, nas instituições estaduais este percentual sobe para 69,4\%, em detrimento de disciplinas voltadas à prática pedagógica, desequilíbrio que pode "conduzir a formações pouco sólidas" (GATTI; NUNES, 2009) do ponto de vista técnico.

Fato que merece destaque é a aparente relação entre a graduação do docente por meio de cursos na modalidade a distância e os resultados positivos sobre os alunos.

Em relação à formação continuada dos docentes, não foram encontradas diferenças significativas entre as escolas de alto e baixo desempenho. Segundo os entrevistados, o incentivo à educação continuada se dá pelo Plano de Carreira Docente dos municípios, que atrela seu critério de pontos à comprovação, via certificado, da realização de cursos de educação continuada (aperfeiçoamento, especialização e extensão). Porém, de forma geral, não há um direcionamento das SMEs para os temas dos cursos aceitos. As entrevistas permitiram verificar que as SMEs não se utilizam de ferramentas diagnósticas para avaliar as deficiências e/ou carências de formação dos docentes para direcionamento dos treinamentos. Em sua maioria, os treinamentos são realizados pelos professores em instituições de ensino superior, sobre temas de seu interesse particular, sendo os certificados apresentados e convalidados pelas SMEs para a atribuição dos pontos.

Sobre este ponto, o estudo de Mello e Souza (2005), realizado em três municípios do Rio de Janeiro, traz contribuição relevante, reforçando nossos achados: segundo a investigação dos autores, os cursos de 'reciclagem' realizados pelos docentes somente apresentam resultado positivo em relação ao desempenho dos estudantes quando são ofertados pelas SMEs. Na contramão, cursos realizados em por instituições externas apresentam resultados negativos. Contrariando os resultados de Mello e Souza (2005), que encontraram relação positiva entre a realização de cursos de especialização pelos docentes e melhores resultados dos estudantes, nossa análise verificou que cerca de $60 \%$ dos docentes de todas as 
escolas completaram uma pós-graduação, mas não foram encontrados indícios de diferença no desempenho por esta razão. A participação em oficinas sobre metodologias de ensino, embora importantes para a formação do professor, também não apresentou influência no desempenho dos alunos, exceto nos casos em que a área de aperfeiçoamento seja de "Alfabetização e Letramento" ou voltado especificamente para "anos iniciais" ou "anos finais". Treinamentos em outras áreas como meio ambiente, diversidade sexual, direitos humanos, direitos do adolescente e Afro, também não apresentaram ganhos de desempenho.

\section{- $\quad$ Regime de Trabalho}

O tipo de contrato de trabalho aparentemente tem forte influência sobre o resultado. Professores contratados sob a égide da CLT, ou como temporários, apresentaram melhor desempenho do que aqueles contratados sob o regime estatutário. Neste aspecto, o trabalho de Gatti e Nunes (2009) também traz à luz contribuição interessante: ao avaliar os conteúdos cobrados pelos concursos públicos do país para a contratação de docentes para a disciplina de Língua Portuguesa, verificaram que as provas objetivas utilizadas nos certames praticamente não avaliavam os conhecimentos dos candidatos em relação à prática docente. Na Tabela 14 é possível verificar que apenas $1,6 \%$ dos conteúdos das provas são direcionados às Didáticas Específicas, Metodologia e Práticas Pedagógicas. Os itens com maior peso nas avaliações diziam respeito à Língua Portuguesa (27,5\%) e Fundamentos Gerais da Educação (23,9\%), seguidos de Currículo, planejamento e avaliação (19,4\%).

TABELA 14 - CONCURSOS PARA DOCENTES DE LÍNGUA PORTUGUESA - CONTEÚDOS AVALIADOS

\begin{tabular}{|c|c|c|c|c|c|c|c|c|c|c|}
\hline & \multicolumn{2}{|c|}{ Norte } & \multicolumn{2}{|c|}{ Nordeste } & \multicolumn{2}{|c|}{ Sudeste } & \multicolumn{2}{|c|}{ Sul } & \multicolumn{2}{|c|}{ Total geral } \\
\hline & No & $\%$ & $\mathbf{N}^{\circ}$ & $\%$ & $\mathbf{N}^{\circ}$ & $\%$ & $\mathrm{~N}^{\circ}$ & $\%$ & $\mathbf{N}^{\circ}$ & $\%$ \\
\hline $\begin{array}{l}\text { Fundamentos gerais da } \\
\text { Educação }\end{array}$ & 23 & $21,5 \%$ & 2 & $10,5 \%$ & 38 & $27,2 \%$ & 27 & $24,6 \%$ & 90 & $23,9 \%$ \\
\hline $\begin{array}{l}\text { Fundamentos específicos } \\
\text { das disciplinas }\end{array}$ & 6 & $5,6 \%$ & 1 & $5,3 \%$ & 8 & $5,7 \%$ & 14 & $12,7 \%$ & 29 & $7,7 \%$ \\
\hline Legislação & 10 & $9,3 \%$ & 1 & $5,3 \%$ & 14 & $10,0 \%$ & 9 & $8,2 \%$ & 34 & $9,0 \%$ \\
\hline $\begin{array}{l}\text { Currículo, planejamento e } \\
\text { avaliação }\end{array}$ & 25 & $23,5 \%$ & 5 & $26,3 \%$ & 28 & $20,0 \%$ & 15 & $13,6 \%$ & 73 & $19,4 \%$ \\
\hline $\begin{array}{l}\text { Didáticas específicas, } \\
\text { Metodologia e Práticas } \\
\text { Pedagógicas }\end{array}$ & 0 & $0,0 \%$ & 0 & $0,0 \%$ & 4 & $2,9 \%$ & 2 & $1,8 \%$ & 6 & $1,6 \%$ \\
\hline Língua Portuguesa & 38 & $35,5 \%$ & 8 & $42,0 \%$ & 22 & $15,7 \%$ & 35 & $31,8 \%$ & 103 & $27,5 \%$ \\
\hline Alfabetização & 1 & $0,9 \%$ & 1 & $5,3 \%$ & 0 & $0,0 \%$ & 0 & $0,0 \%$ & 2 & $0,5 \%$ \\
\hline Matemática & 0 & $0,0 \%$ & & $0,0 \%$ & 8 & $5,7 \%$ & 0 & $0,0 \%$ & 8 & $2,1 \%$ \\
\hline EJA & 0 & $0,0 \%$ & 1 & $5,3 \%$ & 3 & $2,1 \%$ & 1 & $0,9 \%$ & 5 & $1,3 \%$ \\
\hline Educação Especial & 1 & $0,9 \%$ & 0 & $0,0 \%$ & 3 & $2,1 \%$ & 1 & $0,9 \%$ & 5 & $1,3 \%$ \\
\hline Outros Saberes & 3 & $2,8 \%$ & 0 & $0,0 \%$ & 12 & $8,6 \%$ & 6 & $5,5 \%$ & 21 & $5,6 \%$ \\
\hline Total geral & 107 & $100,0 \%$ & 19 & $100,0 \%$ & 140 & $100,0 \%$ & 110 & $100,0 \%$ & 376 & $100,0 \%$ \\
\hline
\end{tabular}

Fonte: Gatti e Nunes (2009, p. 87) 
A soma destes fatores (não avaliação dos conhecimentos didáticos do professor e a estabilidade do regime estatutário) contribui para a perpetuação dos problemas relacionados à prática docente. Contrariamente, nos municípios com maior percentual de docentes contratados sob o regime da CLT ou com contratos temporários, apresentam resultados mais promissores. Nestes locais, os docentes podem ser constantemente avaliados e substituídos nos casos que não venha a atingir os resultados esperados.

A dedicação do professor à atividade docente e à escola em que está locado influencia significativamente os resultados de desempenho dos estudantes. Os professores que possuem carga horária semanal de 40 horas e que atuam em apenas uma escola apresentaram desempenho melhor do que aqueles com dedicação parcial de tempo (20 horas semanais) e/ou que atuam em diversas escolas.

Também tem influência neste quesito o tempo de carreira. Professores com até 16 anos de docência estão associados ao melhor desempenho, sendo que apresentam melhores resultados durante o primeiro ano.

O salário, embora seja fator determinante para a dedicação do professor à atividade, e foco de muitas discussões nesta área, como em praticamente todo o segmento de serviços, não apresentou diferença significativa entre as escolas de alto e baixo desempenho.

\section{- Prática Docente}

A entrega dos livros didáticos aos alunos desde o começo do período letivo está relacionada ao desempenho adequado dos alunos, resultado que corrobora com o trabalho de Mello e Souza (2005). Já o seu processo de escolha - com ou sem a participação do docente não parece fazer diferença.

Entre os recursos didáticos, a utilização de filmes, livros, jornais e revistas não se mostraram eficientes para incremento do desempenho. Já a utilização de retroprojetores ${ }^{9}$, de aplicativos pedagógicos e da internet, parece ter efeito positivo. A disponibilidade de equipamento de fotocópia ao corpo docente também apresenta relação positiva.

A frequência de oferta de dever de casa é importante para o desempenho, sendo que deve ser feita, pelo menos semanalmente. Segundo Dolz (2016), os exercícios escolares

\footnotetext{
${ }^{9} \mathrm{O}$ termo "Retroprojetor" também é comumente utilizado para identificar os equipamentos de datashow, hoje
} mais comuns nas instalações escolares. 
voltados à área da linguagem não devem ser idealizados para avaliar as capacidades dos alunos, mas sim para ajudá-los a identificar suas dificuldades e superar estes obstáculos. Neste sentido, também se mostrou relevante a prática da correção destas atividades em sala, juntamente com os alunos. Cerqueira (2010) destaca que o papel do professor nesta prática dever ser no sentido de incentivar a reflexão pelo aluno,

Ao invés de servir como "corretor" do texto do aluno, apontando sempre aquilo que está em desacordo com as regras prescritivas da Gramática Normativa, o professor irá atuar como orientador na reescrita do aluno. $\mathrm{O}$ seu trabalho consistirá em apontar estratégias de refacção do texto em todos os níveis de análise que julgar necessário, trabalhando, assim, como uma espécie de "catalisador" das dificuldades dos alunos (CERQUEIRA, 2010).

Nas escolas de melhor desempenho, verificou-se que aulas com metodologias que garantam a participação do aluno no processo de ensino-aprendizagem, como discussões em sala apresentam-se mais efetivas. A adoção destas metodologias fomenta a autoaprendizagem e auxiliam os alunos na internalização dos suportes pedagógicos externos (DOLZ, 2016). Segundo Dolz (2016), “o projeto (didático) inovador precisa deixar um espaço para as interações entre os alunos e as intervenções locais do professor que ajudam a compreender a atividade realizada". Contrariamente, nas escolas de baixo desempenho verificou-se maior frequência de aulas em que o professor despende a maior parte do tempo fazendo com que os alunos copiem conteúdos da lousa. Este efeito negativo também foi verificado por Mello e Souza (2005). Os autores também verificaram que o professor que baseia suas aulas apenas falando e utilizando lousa e giz, prejudica a aprendizagem de seus estudantes. Neste sentido, Parisotto e Rinaldi (2016), destacam a influência da formação do professor, que apresenta deficiência no fornecimento de ferramental prático para uso em sala de aula. Segundo os autores,

O que se observa, de um modo geral, é que o professor dos anos iniciais do Ensino Fundamental encontra-se sem um respaldo teórico-metodológico que norteie a sua prática. Nesse sentido, torna-se reprodutor de conteúdos programáticos desajustados da realidade do aluno, priorizando o estudo da metalinguagem, ou seja, o estudo da nomenclatura gramatical, deixando de propiciar aos seus alunos momentos de uso efetivo da língua materna. A formação inicial deficiente que não os preparou para a reflexão sobre oralidade, variação linguística, ensino de leitura e de produção textual (PARISOTTO; RINALDI, 2016).

A adoção de metodologias mais atrativas, além de auxiliar na assimilação do conhecimento pelos estudantes, tem o importante papel de despertar seu interesse e gosto pela disciplina. E este aspecto - interesse do aluno - é fator preponderante para seu resultado na 
disciplina, como se verá adiante no item 4.3.4, cabendo ao professor exercer o papel de estimulador e entusiasta para seus alunos.

O tempo do professor dedicado à transmissão dos conteúdos da disciplina também apresentou associação direta ao bom desempenho. Nas escolas de melhor desempenho o docente diz gastar $80 \%$ do seu tempo, ou mais, lecionando e, consequentemente, conseguem desenvolver melhor o programa pedagógico. Nestas escolas eles também informaram nos questionários conseguirem cumprir com todo o conteúdo proposto. Neste quesito nossos achados se alinham aos de Mello e Souza (2005). Os autores também verificaram que a garantia do cumprimento do conteúdo planejado influencia positivamente os resultados dos estudantes. As entrevistas permitiram compreender alguns dos fatores apontados pelos docentes para o não cumprimento do conteúdo: 1) carga horária da disciplina não condizente com conteúdo proposto; 2) presença de alunos com dificuldades de aprendizagem nas turmas e; 3) constantes interrupções por problemas disciplinares dos estudantes. Não se verifica nestes casos a sobrecarga do professor e nem desestímulo para o desempenho de sua função.

Nas escolas de baixo desempenho os docentes informam gastar mais tempo em atividades administrativas ou tentando manter a disciplina da turma durante as aulas.

\section{- Planejamento Docente}

Nas escolas de melhor desempenho os docentes conhecem o projeto pedagógico e participam ativamente na sua elaboração. Nestas escolas, também são verificadas outras rotinas importante para a troca de informações entre a direção, coordenação e entre os professores semanalmente sobre a aprendizagem dos alunos e o desenvolvimento de ações conjuntas entre estes.

\subsubsection{Resultados para o diretor}

Para Dhuey e Smith (2014), embora a maioria dos estudos sobre o tema foque na influência dos fatores sociais e da qualidade dos professores no desempenho escolar, o papel do diretor no desempenho dos estudantes não pode ser desconsiderado, e os economistas têm voltado sua atenção à sua importância no processo educacional. Em seu trabalho, os autores verificaram que o diretor pode influir positivamente nos resultados de leitura e de matemática dos estudantes. 
No nível do diretor, foram encontradas 25 práticas entre as 61 variáveis correspondentes, com diferença significativa entre os quintis superior e inferior, indicando, assim, a importância desta figura para o desempenho escolar. Os fatores ligados ao gestor identificado entre as escolas de melhor desempenho podem ser agrupados em 04 categorias: Regime de Trabalho, Formação e Experiência; Práticas de Gestão; Práticas Pedagógicas e Atuação com a Família e a Comunidade. A Figura 106 sintetiza os achados.

FIGURA 106 - PRÁTICAS PARA MELHORIA DO DESEMPENHO ESCOLAR ASSOCIADOS AO DIRETOR

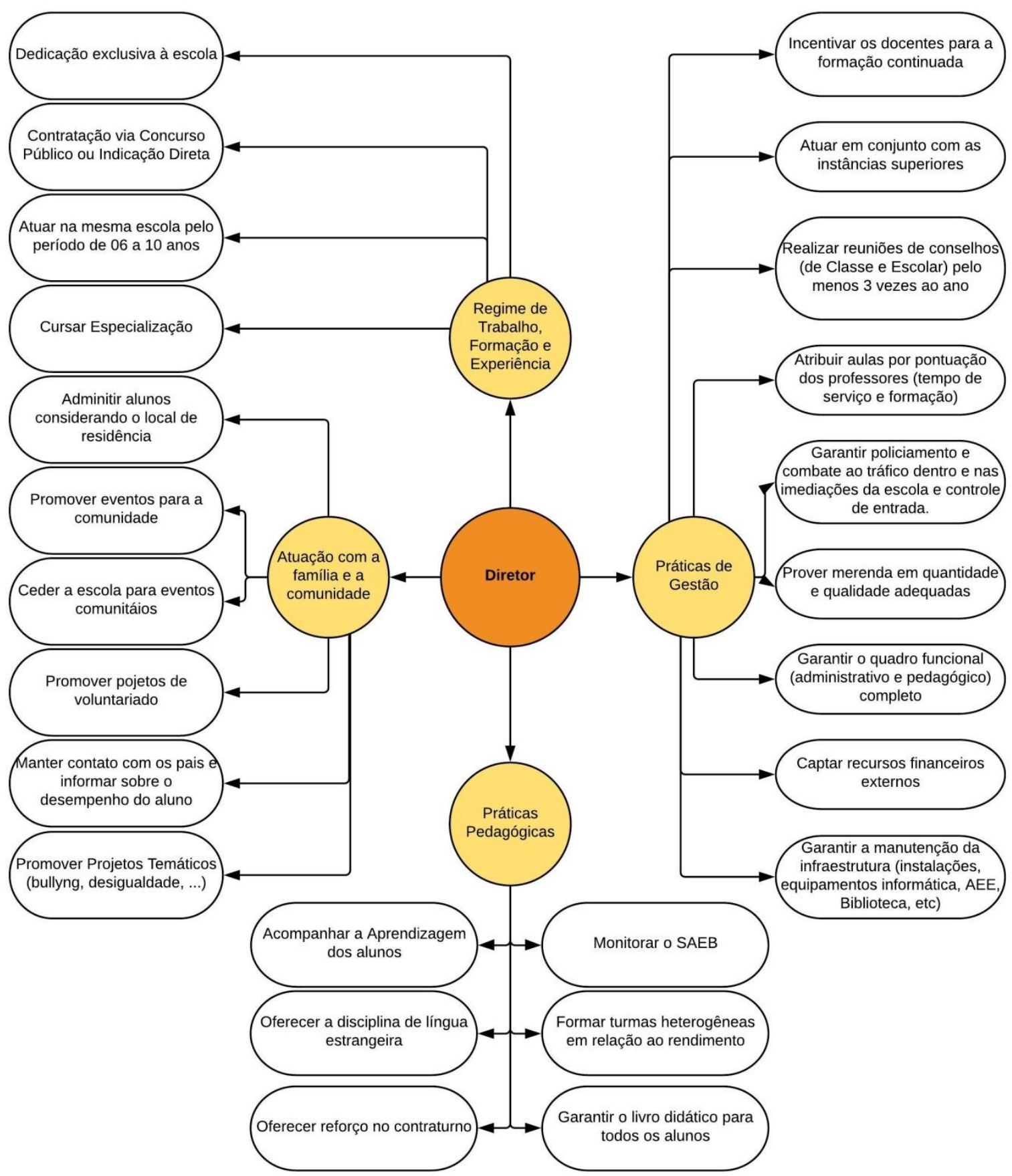

Fonte: Elaborado pelo autor. 


\section{- Regime de Trabalho, Formação e Experiência}

Em relação à formação, o gestor ter feito, no mínimo uma especialização, colabora para a melhoria do desempenho da escola, em especial se esta formação estiver ligada à área de alfabetização e/ou letramento.

Quanto à experiência profissional, os dados mostram que o exercício anterior do magistério aparentemente não se relaciona à melhoria do desempenho, embora este fator tenha sido considerado como relevante por todos os diretores entrevistados nos estudos de caso. Segundo eles, esta experiência lhes permite conhecer as dificuldades do professor para o exercício de suas funções, permite compreender o processo de aprendizagem dos estudantes, além de fornecer experiência na mediação de conflitos. Esta experiência também é apontada como relevante por Dhuey e Smith (2014). Possivelmente, a inexistência de diferença significativa nesta variável entre as escolas de alto e baixo desempenho esteja no fato de que, na maioria dos municípios brasileiros, o exercício prévio do magistério é exigência para a ascensão ao cargo de diretor.

A permanência no cargo por mais de 20 anos parece ter efeito negativo sobre o desempenho, observação que se alinha aos achados de Dhuey e Smith (2014). Adicionalmente, constatou-se que o período de melhor desempenho do gestor está entre 6 a 10 anos de exercício da função. Estes dados corroboram com os achados de Branch et al. (2012). Segundo os autores, diretores com mais tempo de experiência e com cerca de 6 anos de atuação na mesma escola estão associados ao melhor desempenho dos estudantes. Esta descoberta pode estar relacionada à necessidade de um período de adaptação e conhecimento das características da escola e do corpo de docentes e discentes, bem como ao tempo necessário para que as ações propostas possam ser efetivamente implantadas pelo diretor e seus efeitos observados.

A forma de ingresso na carreira também parece ter ligação com o desempenho. Diretores empossados mediante eleição estão mais ligados às escolas de baixo desempenho. Este resultado também foi verificado por Mello e Souza (2005), que atribuem a esta observação a influência de eventuais influências políticas no ambiente escolar - uma vez que o diretor procura por votos para a manutenção de seu cargo - o que pode significar a eventual adoção de medidas 'populares' ao invés de medidas disciplinares. Uma vez que nas escolas visitadas não foi encontrado este quadro, o presente trabalho não se dispõe de informações mais aprofundadas para a discussão deste efeito. Contrariamente, aqueles diretores que 
ingressam via processo seletivo/concurso e/ou indicação, estão mais presentes nas escolas de alto desempenho. A análise ainda permitiu verificar que nestas escolas, o gestor conta com o apoio das instâncias superiores do município para o desempenho de suas funções e maior independência para suas tomadas de decisão. Mello e Souza (2005) verificaram que a ampliação dos poderes da escola, representada pela figura do diretor, colabora para a melhoria do processo de ensino-aprendizagem, afetando positivamente os resultados dos estudantes. Neste quesito os autores ressaltam a autonomia em relação a três aspectos: autonomia administrativa; autonomia pedagógica e autonomia para a gestão de pessoal, fatores igualmente observados nos resultados deste trabalho.

O tempo dentro da escola também tem influência no resultado, sendo que gestores com pelo menos 40 horas semanais de dedicação à mesma unidade escolar demonstram melhores resultados. A carga-horária identificada indica a dedicação exclusiva do diretor à escola, análise que está em linha com Mello e Souza (2005), que relacionaram o exercício de atividade de trabalho do diretor fora da escola a reflexos negativos no desempenho dos estudantes. Quanto à remuneração do diretor, não foi possível estabelecer relação direta com os resultados. Porém, apesar de não haver uma aparente relação direta entre o valor do salário do diretor e o desempenho dos estudantes, os estudos de caso permitiram compreender melhor os efeitos desta variável.

Nos dois municípios de alto desempenho visitados, os diretores recebiam remunerações maiores do que os professores, tornando a função atrativa, enquanto que naqueles de baixo desempenho, os vencimentos eram similares aos dos docentes, porém com o acréscimo da carga horária de trabalho o que, na prática, reduz o valor-hora das remunerações. Esta observação será melhor adiante no item 4.3.5. Estes dois resultados dedicação exclusiva e remuneração - também são compartilhados por Mello e Souza (2005). Os autores também não encontraram relação direta entre o valor dos salários dos diretores dos municípios estudados e os resultados. Porém, sua pesquisa não se aprofundou na análise da atratividade da função de dirigente pela investigação das diferenças de salário entre professores e diretores. Em relação à dedicação exclusiva, seu estudo também corrobora com nossos resultados.

\section{- Práticas de Gestão Práticas Pedagógicas}

O diretor pode influir indiretamente nos resultados escolares por meio da gestão dos recursos materiais e humanos, e pela adoção de políticas administrativas e pedagógicas 
(DHUEY; SMITH, 2014). Este efeito pôde ser observado nos dados. A análise permitiu verificar que entre as escolas de melhor desempenho os diretores compreendem que a qualidade é de responsabilidade coletiva, além de acompanhar os dados de desempenho do SAEB, envolvendo-se diretamente nos aspectos relacionados à aprendizagem dos estudantes.

Para Mello e Souza (2005), o envolvimento do diretor nos aspectos pedagógicos, em especial naqueles relacionados ao processo ensino-aprendizagem, é das práticas a ele atribuídas a que apresenta maior poder de melhoria no desempenho dos estudantes. Verificouse nos estudos de casos que o envolvimento e cobrança do diretor neste aspecto gera nos professores um senso de responsabilidade maior, uma vez que há uma cobrança direta de instância superior.

Nas escolas de alto desempenho o diretor promove ações de combate à evasão escolar e à reprovação. A oferta de reforço no contraturno apareceu como uma ação de destaque, tanto na etapa quantitativa quanto na qualitativa. Segundo Vandecandelaere et al. (2016), outras pesquisas também identificaram os benefícios desta prática, por meio da oferta de aulas durante o período de férias escolares aos estudantes em risco de reprova.

Quanto à atribuição das aulas, nas escolas de alto desempenho os diretores adotam o critério de pontuação, formação e experiência, permitindo ao professor escolher as turmas.

A gestão participativa também foi identificada como eficaz, por permitir a promoção das políticas e o compartilhamento das responsabilidades. Identificou-se que nas escolas de maior desempenho, os diretores costumam reunir-se semanalmente com seu corpo docente para discutir as metas educacionais. A atuação conjunta e frequente com os órgãos colegiados, como o Conselho de Classe e o Conselho Escolas também é verificada como prática nestas escolas, com a realização de, no mínimo, 03 reuniões anuais com estes conselhos. Mello e Souza (2005) reforçam a importância desta atuação conjunta, ressaltando que, em especial nos aspectos ligados ao currículo escolar, esta prática apresenta alto poder de agregação de resultados.

A organização de turmas heterogêneas em relação ao desempenho dos estudantes também mostrou relação com a melhoria do desempenho.

A análise também permitiu verificar que o envolvimento do diretor com as normas administrativas e a preocupação com a manutenção da escola, incluindo neste último a busca de apoio financeiro de empresas particulares para a sua melhoria, têm efeito positivo sobre o desempenho. Nas escolas do quintil superior, verificou-se que não houve falta de recursos financeiros, de equipamentos de informática para docentes, discentes e corpo administrativo, 
bem como de professores e profissionais de apoio pedagógico, como coordenadores, por exemplo.

A entrega dos livros didáticos no início do período letivo e sua disponibilidade a todos os estudantes também está associada ao melhor desempenho dos estudantes.

Ainda, verificou-se que a garantia de merenda em quantidade e qualidade adequadas colaboram para o desempenho, bem como a manutenção de uma política de combate ao tráfico de drogas na escola e seu entorno.

\section{- Atuação com a Família e a Comunidade}

Verificou-se adicionalmente que variáveis ligadas à capacidade de liderança do gestor para o envolvimento da família e da comunidade com os assuntos da escola têm relação com a melhoria no desempenho. Para Dhuey e Smith (2014), o estilo de liderança do diretor pode ser influenciado pelo histórico familiar dos alunos e pelas características dos professores e da comunidade local. Assim, a capacidade de se adaptar ao meio e garantira integração escolafamília se mostra uma característica fundamental para o exercício da função diretiva.

Entre as ações identificas, a comunicação frequentemente aos pais sobre problemas relacionados aos alunos e a realização de reuniões individuais na escola e até a visita na residência do aluno são mais observados nas escolas de alto desempenho. Porém, esta prática não pode ser a única para a manutenção do vínculo. Parisotto e Rinaldi (2016), asseveram:

As relações entre família e escola têm-se perpetuado, ao longo dos anos, a partir de algum tipo de problema. Tal fato não contribui para que essas instituições possam formar uma parceria profícua, orientada por fatores que propiciem um avanço nas discussões e reflexões sobre os aspectos positivos e negativos presentes no cotidiano escolar. Dessa forma, por haver uma tensão entre família e escola, as colocações atinentes a essa relação são sempre carregadas de discursos defensivos e acusativos, sem que isso contribua para a reflexão sobre os reais e cotidianos problemas enfrentados pelas escolas (PARISOTTO; RINALDI, 2016).

Assim, verificou-se que, além dos contatos para o reporte dos problemas pedagógicos comportamentais aos pais, as escolas de alto desempenho buscam a aproximação e a criação de um vínculo com a família não apenas nestes momentos. Por meio da adoção do critério de admissão pelo endereço do aluno (vizinhança da escola), pela promoção de ações de voluntariado, de eventos junto à comunidade e pela cessão dos espaços para uso coletivo, os diretores das escolas de melhor desempenho garantem a criação de um elo profícuo entre a escola, a família e a comunidade, estabelecendo uma relação de parceria. 
Alguns exemplos de ações neste sentido são:

- Projeto Amigos da Merenda

- Horta Comunitária

- Projeto de Monitoria com Ex-alunos da escola

\subsubsection{Infraestrutura da escola}

A análise dos dados quantitativos indica uma relação entre a estrutura da escola e o desempenho dos estudantes. Nas escolas de melhor desempenho, verificou-se que a infraestrutura básica (conservação de salas, banheiros e demais dependências, bem como a iluminação, instalações elétricas e hidráulicas) é adequada e encontra-se em bom estado de conservação, permitindo sua adequada utilização. Possuir cozinha adequada para o preparo da merenda também apresenta diferença significativa entre os quintis inferior e superior, contribuindo positivamente com as de melhor resultado.

A quantidade e disponibilidade de equipamentos de televisão, DVD, retroprojetores e equipamentos de som é maior nas escolas de alto desempenho, permitindo ao professor sua utilização no dia a dia.

Quanto à estrutura de informática, verifica-se que a maior disponibilidade de computadores e internet, tanto aos alunos, quanto aos funcionários administrativos, colabora para o desempenho. A liberação da biblioteca para acesso direto pelos alunos também é fator positivo. As escolas de melhor desempenho, ainda apresentam estrutura adequada para atender alunos com deficiência. A oferta da disciplina de Língua Inglesa aparentemente também colabora para o bom resultado.

Também foi possível verificar que a presença de policiamento, dentro e nas redondezas da escola para o combate às drogas, bem como o controle de entrada e saída nas escolas auxiliam na melhoria do desempenho.

Em razão das melhores condições, verifica-se que nas escolas de melhor desempenho a procura por vagas é maior do que o número ofertado, gerando uma espécie de 'processo seletivo' para o ingresso do estudante. Também se verifica índices mais baixos de evasão quando comparadas às escolas menos eficientes. 
A análise da infraestrutura da escola remete, em parte, à análise da capacidade de gestão do diretor. Cabe aos dirigentes das unidades escolares o acompanhamento e garantia da adequada manutenção e funcionamento da escola e de seus recursos materiais.

Porém, os estudos de caso não permitiram confirmar estes achados. Entre as escolas visitadas não foi possível identificar diferenças significativas entre a infraestrutura e a disponibilidade de recursos, que permitissem atribuir excessivo peso ao quesito para as diferenças de desempenho. Cabe ressaltar que, neste quesito, a escola que apresentou melhor infraestrutura, disponibilidade de recursos e melhor estado de conservação apresentava baixo desempenho. Nesta última, porém, relatou-se o problema local com o tráfico de drogas, que, inclusive, se utiliza das instalações escolares aos finais de semana para uso e guarda dos entorpecentes.

A Figura 107 apresenta um resumo dos fatores da escola associados ao melhor desempenho.

FIGURA 107 - FATORES PARA A MELHORIA DO DESEMPENHO ESCOLAR ASSOCIADO À ESCOLA

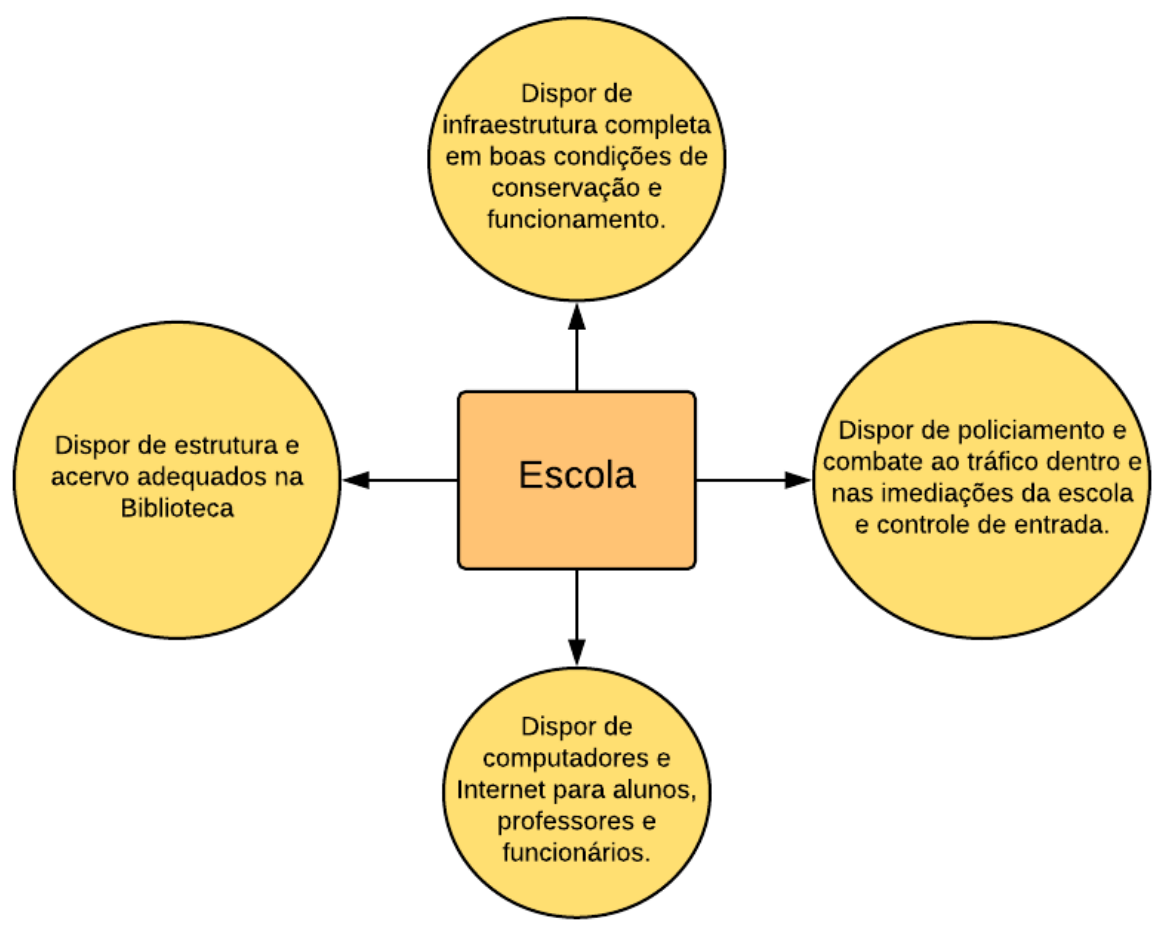

Fonte: Elaborado pelo autor. 
4.3.4 Resultados para o aluno e a família

Muitos trabalhos atribuem a fatores externos à escola, em especial àqueles ligados ao próprio aluno, como seu NSE, por exemplo, parte relevante da responsabilidade pelo seu desempenho acadêmico.

A análise de quintil permitiu identificar vários destes fatores, por meio dos questionários preenchidos pelos próprios estudantes e pelos professores na Prova Brasil. Ao final das análises dos questionários e agrupamentos de itens semelhantes entre os questionários, restaram 33 variáveis relativas ao aluno e à sua família, as quais foram sintetizadas em 11 práticas, conforme Figura 108.

FIGURA 108 - PRÁTICAS ASSOCIADAS AO ALUNO E À FAMÍLIA

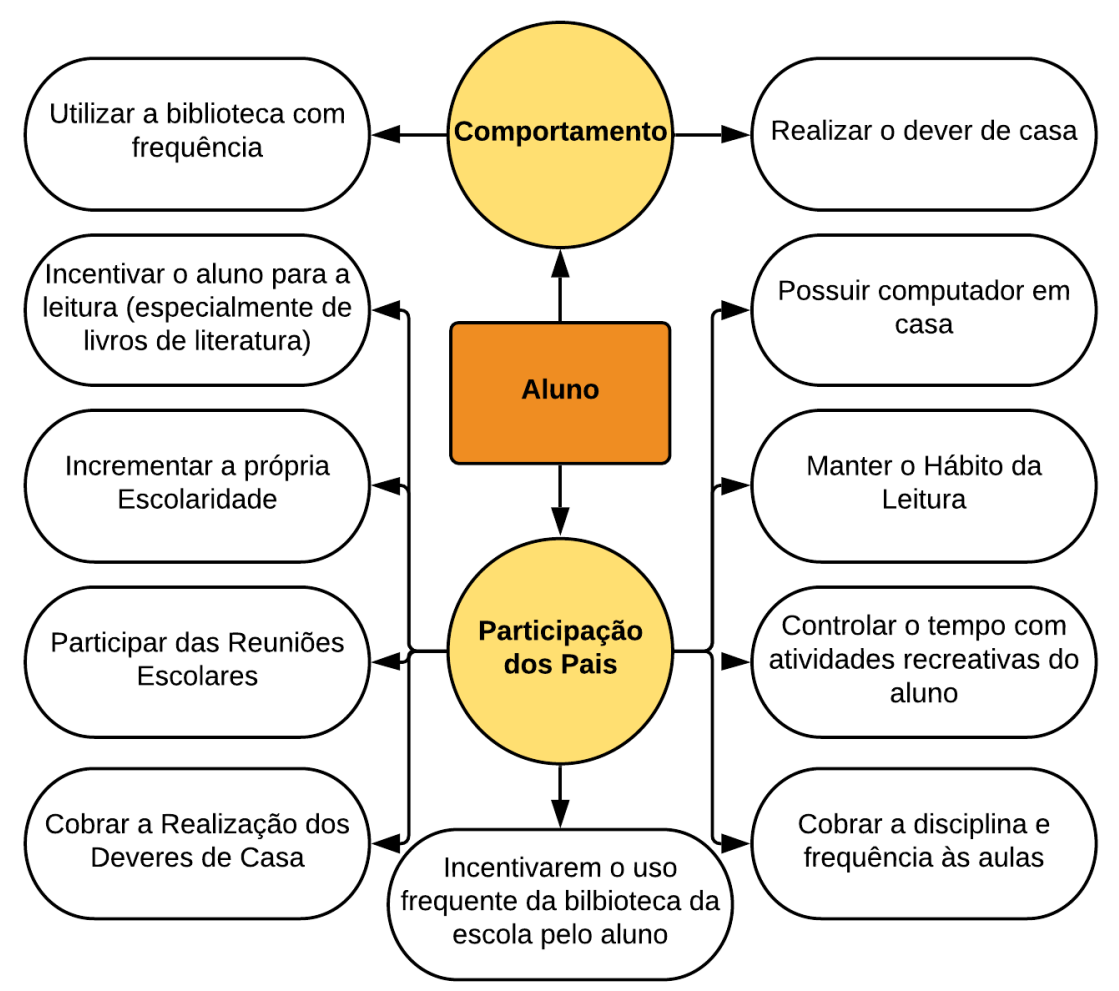

Fonte: Elaborado pelo autor.

Inicialmente merece destaque a verificação de que os alunos que declararam gostar da disciplina de língua portuguesa estão mais presentes nas escolas de melhor desempenho, fator também identificado por Parisotto e Rinaldi (2016) e por Chen et al. (2018). O gosto pela disciplina pode ser resultado de hábitos culturais familiares, como aqueles ligados à leitura, por exemplo, e que serão apresentados a seguir, ou à capacidade dos professores de tornarem 
os conteúdos agradáveis e interessantes aos estudantes, por meio da utilização de didáticas inclusivas e estimulantes, como já apresentado. O desenvolvimento do gosto do aluno pela disciplina é, certamente, uma das formas mais eficazes para a promoção da melhoria de seu desempenho, uma vez que passa a ser de seu interesse o aprendizado e a busca pelo conhecimento.

Foi possível verificar que os alunos que possuem computador em casa estão mais associados ao bom desempenho. A quantidade de computadores também influenciou: quanto mais computadores, melhor. Este talvez seja mais um indicativo de seu NSE, uma vez que demonstra sua capacidade financeira para a aquisição destes bens.

Quanto aos seus hábitos, mostrou-se positivo para o resultado o aluno frequentar a biblioteca regularmente, bem como realizar os deveres de casa com frequência. Os hábitos de leitura também estão diretamente ligados ao desempenho. Além da frequência (quanto mais, melhor), o tipo de leitura escolhido também tem impacto. A leitura de livros de literatura e de assuntos gerais contribui fortemente para o melhor desempenho. Contrariamente, jornais, revistas de generalidades, revistas de comportamento, gibis e notícias na internet estão associados ao baixo desempenho. Assistir a espetáculos não demonstrou diferença significativa entre os quintis superior e inferior e a alta frequência a cinemas mostrou-se prejudicial ao desempenho.

Quanto aos pais dos alunos, foi possível observar que têm forte influência sobre os resultados. A alfabetização e o nível de escolaridade (do pai e da mãe) afetam diretamente o desempenho. Quanto maior o nível de escolaridade de ambos, melhor o desempenho do aluno. A participação na vida escolar do aluno é outro fator identificado. Os pais de alunos de escolas de melhor desempenho incentivam os filhos a realizar as tarefas de casa e a frequentar as aulas. Também participam com mais frequência de reuniões escolares.

Corroboram com esta observação Gremaud, Felício e Biondi (2007), que afirmam que “alunos com mães mais instruídas (com pelo menos ensino médio completo) e a preocupação ativa dos pais com relação à educação de seus filhos (pais incentivam a estudar) contribuem significativamente para o melhor desempenho". Mello e Souza (2005) também verificaram a influência desta variável em sua pesquisa. Para eles, "ativa dos pais tem consequências apreciáveis para o sucesso escolar dos filhos”.

Os dados também revelaram que os hábitos de leitura dos pais podem contribuir positivamente para o desempenho dos estudantes. Os alunos das escolas de melhor desempenho informaram que costumam ver os pais lendo e são incentivados por eles para a leitura, resultado similar ao encontrado por Alves et al. (2013) em sua análise sobre os fatores 
familiares sobre o desempenho escolar. É importante notar que, como afirmam Andrade e Soares (2008), as habilidades de leitura do estudante sofrem mais influência dos fatores familiares, do que aqueles ligados a disciplinas como a matemática, por exemplo. Parisotto e Rinaldi (2016) reforçam este achado ao afirmar que é necessário compreender a importância dos fatores extraescolares no processo de letramento.

Também se mostrou significativamente relevante a diferença de desempenho de alunos que trabalham fora de casa: os dados mostram que estudantes nestas condições apresentaram pior desempenho, o que corrobora com os achados de Gremaud, Felício e Biondi (2007).

Outro fator relevante e com poder de influência negativa sobre os resultados a baixa autoestima e, em especial, a indisciplina dos alunos em sala. Em sua pesquisa, Parisotto e Rinaldi (2016) verificaram que este aspecto - indisciplina discente - é o terceiro item mais apontado pelos docentes como razão para o fraco desempenho acadêmico. Ainda, segundo Horoi e Ost (2015), alunos com problemas comportamentais, além de apresentarem baixo desempenho, são capazes de reduzir substancialmente o desempenho dos seus pares em sala, fato que deve ser considerado de extrema relevância, visto que sua influência pode incidir sobre todo o grupo de estudantes.

\subsubsection{Evidências exclusivamente qualitativas oriundas dos estudos de caso}

Além das contribuições para o aprofundamento da compreensão das práticas identificadas na etapa quantitativa, a etapa qualitativa, que envolveu a realização dos múltiplos estudos de caso, contribui para a identificação de 4 práticas adicionais. É importante destacar que estas práticas foram verificadas pela comparação entre 4 escolas (duas de alto e duas de baixo desempenho), em 4 municípios paulistas, não sendo, portanto, amostra representativa para permitir generalizações de resultados, mas merecem atenção em razão da profundidade das análises que se pôde realizar. São elas:

- Permanência do(a) Secretário(a) Municipal de Educação: pôde-se verificar que, nos dois municípios de baixo desempenho, o(a) Secretário(a) Municipal de Educação foi alterado diversas vezes ao longo do mandato do prefeito, sendo que em um deles, foram realizadas três alterações no período de um ano. Segundo os entrevistados, estas alterações foram 
prejudiciais uma vez que não permitiram a implantação de um plano de objetivos e metas no município e causaram a descontinuidade dos projetos implantados, além de gerar insegurança e falta de apoio desta instância às ações realizadas pelos diretores nas unidades escolares.

Este fator também é avaliado como preponderante para os resultados educacionais ligados à atuação dos diretores escolares por Dhuey e Smith (2014), para quem as lideranças e políticas municipais são particularmente importantes, uma vez que afetam diretamente sua atuação, supervisão e cobrança sobre os resultados e melhorias.

- Plano Municipal de Educação: decorrência da condição mencionada anteriormente, se verificou nos depoimentos que os municípios de alto desempenho possuem políticas educacionais são claras, as quais emanam do principal órgão do município (a Secretaria Municipal de Educação - SME). Nestes, a SME atua direta e ativamente sobre a cobrança dos resultados educacionais. Em contrapartida, nos municípios de baixo desempenho, ao serem questionados sobre as políticas para acompanhamento da aprendizagem, sobre a adoção de práticas para a melhoria do desempenho dos estudantes ou sobre o acompanhamento da frequência, as SMEs informaram delegar exclusivamente às escolas a autonomia para a implementação/ou não, de práticas para estes fins.

- Política de Remuneração adequada para Diretores: apesar de não terem sido verificadas diferenças significativas entre o valor da remuneração dos diretores e os resultados educacionais, as entrevistas revelaram a importância deste item para a cobrança dos resultados pela gestão municipal. Nos municípios de baixo desempenho, verificou-se que a remuneração dos diretores escolares não apresentava diferença entre os valores pagos aos docentes. $\mathrm{Na}$ prática, em ambos os municípios de baixo desempenho, ao se tornar diretor os profissionais apresentam uma redução proporcional dos vencimentos, uma vez que o valor nominal permanecia o mesmo, porém, com aumento das atribuições e da carga horária. Assim, os relatos dos diretores convergiram para o desestímulo para o exercício da função. E os relatos dos Secretários(as) convergiram para a dificuldade de nomeação de profissionais para o cargo e para a cobrança dos resultados, uma vez que o aumento da pressão pelas SMEs acaba gerando a desistência da função. Assim, conclui-se que o incentivo para o exercício do cargo depende da existência de um diferencial salarial no município em relação à carreira docente.

- Adoção de regime de progressão continuada por ciclo: a adoção/ou não, do regime de progressão continuada tem sido amplamente debatida na literatura, com fortes argumentos conflitantes pró e contra esta prática. Os autores pró-repetência, argumentam que dar mais tempo aos estudantes em dificuldade para o desenvolvimento de competências que serão essenciais na vida adulta e que, as crianças promovidas automaticamente estão mais 
propensas a novos fracassos futuros. De outro lado, os autores a favor da progressão continuada argumentam que a repetência precoce afeta a autoestima dos estudantes, gerando problemas de comportamento e até a disposição para o abandono escolar (VANDECANDELAERE et al., 2016).

Em trabalho que investigou os efeitos da repetência entre estudantes universitários, Tafreschi e Thiemann (2016), verificou que, apesar de auxiliar no incremento das notas, a repetência dos estudantes trazia como consequência o desestímulo para a continuidade dos estudos e o aumento nas taxas de abandono. Suas descobertas mostram que a possibilidade de desistência após a reprova, aumenta à medida que diminui a idade dos alunos avaliados.

Hill (2014), também encontrou uma associação danosa dos efeitos da repetição ao avaliar estudantes americanos do ensino médio. Em seu estudo, verificou que a existência de alunos repentes na proporção de 5\% a $10 \%$ da turma, afeta negativamente os resultados dos demais estudantes da classe, em especial daqueles que já apresentavam risco de fracasso escolar.

Sob este aspecto, os estudos de caso mostraram que os dois municípios onde estão localizadas as escolas de alto desempenho adotam o um 'regime de progressão continuada por ciclo', enquanto que nos dois municípios de baixo desempenho este modelo não é adotado, sendo permitida ao professor a retenção do estudante na série mediante análise de seu desempenho acadêmico. Neste modelo (progressão continuada por ciclo), os estudantes somente podem ser reprovados nos ciclos e não séries (por exemplo: $1^{\circ}$ ciclo corresponde aos alunos da $1^{\mathrm{a}}$ à $3^{\mathrm{a}}$ séries). Como consequência, as eventuais carências identificadas na $1^{\mathrm{a}}$ série, por exemplo, podem ser trabalhadas nas duas seguintes. Os SME e diretores das escolas de alto desempenho entrevistados posicionaram favoráveis ao modelo. Em seus depoimentos, informaram que os eventuais benefícios da repetência, a saber, a revisão dos conteúdos e o estímulo para o esforço do aluno, não justificam os altos custos para o estudante como a piora de sua autoestima, da família e possível incremento do desinteresse pelos estudos.

Entretanto, outra análise está implícita nesta prática. Verificou-se nos discursos dos entrevistados que a adoção deste sistema pelos municípios de alto desempenho foi acompanhada de uma política e uma cultura educacional que compreende que os resultados na melhoria da qualidade do ensino são uma responsabilidade compartilhada entre os gestores e professores, não responsabilizando exclusivamente os alunos e a família. Nestes municípios são realizadas, a cada ciclo, Conselhos de Classe para que sejam traçadas estratégias de recuperação e nivelamento do aprendizado dos estudantes em dificuldade. Esta ação institucional se mostrou uma preocupação por parte dos gestores, que acompanham os 
resultados dos estudantes nas avaliações padronizadas do SAEB. Por outro lado, nos municípios de baixo desempenho não se observou uma política clara ou ações para recuperação dos estudantes em estado de fracasso escolar e a adoção do regime de reprovação se apresentou como ferramenta de coerção e responsabilização quase que exclusiva dos estudantes pelos seus resultados, o que se verificou nos depoimentos de professores e dirigentes, que de forma geral, atribuíam aos fatores familiares e extraescolares o fracasso escolar.

Esta observação vai ao encontro dos resultados de Vandecandelaere et al. (2016) que, ao estudar os efeitos da repetência nos resultados de matemática em alunos da primeira infância e do ensino primário, verificaram que a prática é prejudicial aos estudantes, em especial àqueles no ensino primário, causando um efeito espiral negativo. Para os autores, o ideal é que sejam promovidas políticas e ações para o fornecimento de apoio adicional aos estudantes em risco de falha, ao invés de simplesmente reprová-los.

A Figura 109 sintetiza as práticas identificadas nos estudos de caso.

\section{FIGURA 109 - PRÁTICAS ASSOCIADAS À SECRETARIA MUNICIPAL DE EDUCAÇÃO}

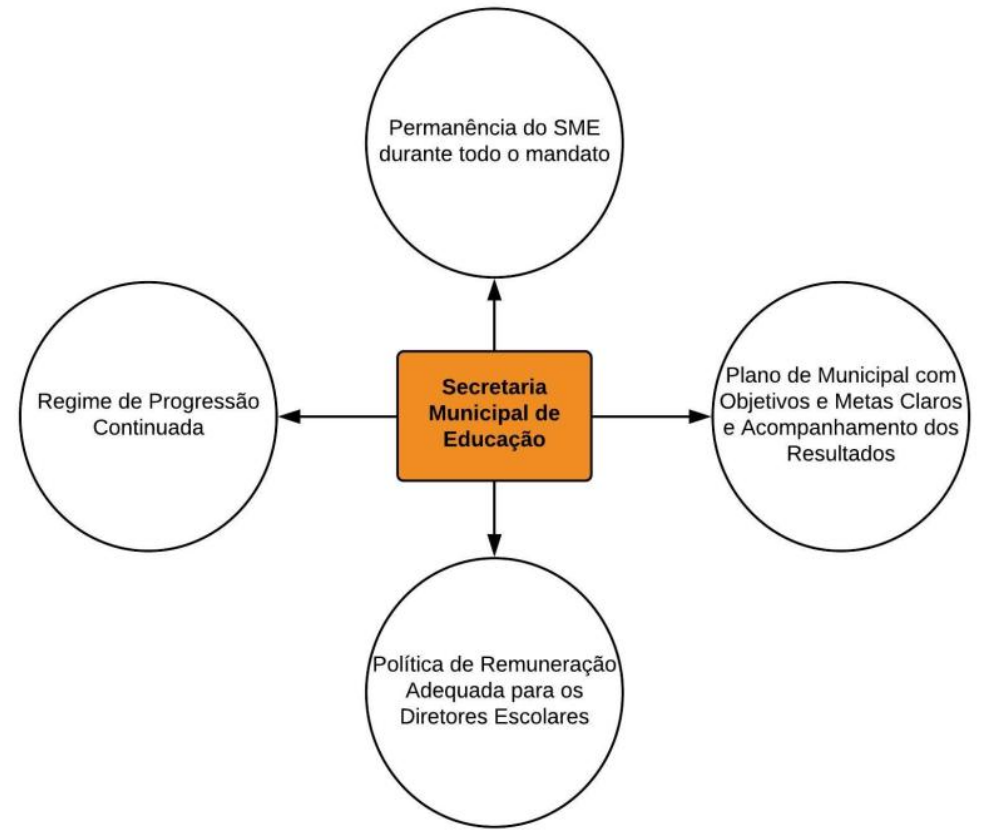

Fonte: Elaborado pelo autor. 


\section{CONCLUSÃO}

Apesar dos crescentes investimentos realizados pelo Brasil na área da educação, os resultados em termos qualitativos têm se mostrado insatisfatórios. As avaliações em larga escala de leitura e escrita expõe, a cada nova edição, as deficiências dos estudantes nestas habilidades fundamentais. Para além da influência dos fatores socioeconômicos, os fatores intraescolares capazes de influir nos resultados educacionais devem ser investigados e compreendidos. Porém, poucos estudos apresentam propostas de práticas claras para o direcionamento dos dirigentes educacionais e formuladores de políticas públicas. Assim, o presente estudo teve como objetivo o preenchimento desta lacuna por meio da identificação e proposição de práticas administrativas e pedagógicas que possam colaborar para a melhoria do desempenho dos alunos de escolas de ensino fundamental II em avaliações padronizadas de língua portuguesa. Para isso foram analisados os resultados do SAEB e os dados do Censo Escolar e dos Questionários Contextuais da Prova Brasil de 3330 escolas municipais de ensino fundamental II de NSE 5 e 6, por meio do método quanti-qualitativo proposto por Salgado Junior e Novi (2014), com o uso da técnica DEA em dois estágios. As análises permitiram concluir que as práticas administrativas e pedagógicas adotadas pelas escolas influem diretamente sobre os resultados educacionais de seus estudantes. O trabalho propõe 55 boas práticas que podem auxiliar na melhoria do desempenho do aluno em leitura e escrita. Estas práticas são direcionadas ao Secretário(a) Municipal de Educação, à escola, ao Diretor escolar, ao professor e ao aluno e sua família. Verificou-se que o Diretor é figura fundamental no processo educacional, sendo a ele atribuída a maior quantidade das práticas - 25 no total. Sua atuação, embora influa de forma indireta nos resultados dos estudantes, é essencial no fornecimento de condições adequadas aos professores e alunos pela garantia de uma a estrutura adequada ao funcionamento da escola, pela implantação de políticas de acompanhamento do desempenho dos estudantes e de acompanhamento à frequência e ao combate à evasão, e pela manutenção de um regime administrativo e disciplinar adequado. Destaca-se, aqui, a constatação da importância do papel de liderança do Diretor na promoção da integração entre a escola, a família e a comunidade, fator considerando preponderante para o sucesso escolar em diversos estudos, assim como neste. Em relação ao professor, foram encontradas 11 práticas, que podem ser dividias em quatro grupos: regime de trabalho; planejamento docente; prática docente e perfil pessoal. Em relação aos docentes, cabe citar que os dados não apontaram para diferenças significativas de desempenho em razão da remuneração recebida. O estudo também revelou a importância da atuação familiar no 
processo educacional. No total, 11 práticas foram atribuídas aos pais dos estudantes. Basicamente, além do background educacional-cultural, representado pelo nível escolar dos pais e pelos seus hábitos de leitura, a atuação familiar se concentra no acompanhamento frequente da vida acadêmica do aluno e na cobrança pelos estudos. Em relação à escola, a disponibilização de infraestrutura adequada e a existência de policiamento e ações de combate às drogas são os fatores observados. Porém, neste quesito também se destaca a importância do Diretor, uma vez que a adoção destas medidas é de sua responsabilidade. Os estudos de caso permitiram identificar a importância da existência e manutenção de um Plano Estratégico Municipal, com objetivos e metas claros, bem como a prática de monitoramento e acompanhamento. Nos municípios de alto desempenho, além da existência desta prática, verificou-se a manutenção do Secretário(a) Municipal de Educação por todo o período da gestão, contrariamente ao observado naqueles com baixo desempenho. Embora os dados quantitativos não tenham apresentado diferença de resultado em razão do valor da remuneração dos diretores, verificou-se que existência de uma política de remuneração diferenciada para estes em relação aos professores dos municípios visitados é necessária para o incentivo ao exercício da função e para a adoção de uma política de cobrança por resultados. Por fim, a comparação entre os resultados do IDEB e o investimento médio por aluno dos municípios avaliados, mostrou não haver correlação entre o aumento dos gastos públicos em educação e a melhoria dos resultados educacionais, constatação que reforça nossos achados acerca da existência de práticas administrativas e pedagógicas mais adequadas ao serviço educacional. Assim, as práticas aqui propostas podem ser aplicadas nos municípios brasileiros para a melhoria da educação básica no país.

\subsection{Limitação e sugestão para trabalhos futuros}

Apesar da ampla base de dados utilizada para a consecução deste trabalho, é importante observar que o estudo foi realizado exclusivamente com escolas públicas municipais de NSE 5 e 6, não sendo possível extrapolar os seus resultados para as escolas municipais dos demais NSE, nem para escolas da rede privada, uma vez que ambas estão inseridas e contextos sociais diversos. Também se deve atentar ao reduzido número de estudos de caso realizados - quatro - que não possui representatividade suficiente da amostra para permitir a generalização dos resultados qualitativos observados. 
Estudos futuros poderiam avaliar a aplicação das práticas identificadas em escolas com características semelhantes às da amostra, para sua validação. A atuação familiar poderia ser melhor investigada por meio da realização de entrevista junto aos estudantes e seus pais e/ou responsáveis, enriquecendo ainda mais as práticas relativas a estes atores do processo educacional. A metodologia também pode ser replicada para outras disciplinas, além da Língua Portuguesa; para outras redes de ensino - privada, estadual e federal - e para outros estados. Ainda em relação à metodologia, trabalhos futuros poderiam focar os estudos de caso apenas em escolas de alto desempenho, enriquecendo, assim, os resultados qualitativos. Para isto, poderiam ser aplicadas às escolas visitadas apenas as questões dos roteiros de entrevista relativas às variáveis para as quais a escola tenha atingido a meta, focando, assim, apenas nos pontos em que as escolas sejam benchmarking. 


\section{REFERÊNCIAS BIBLIOGRÁFICAS}

ALMEIDA, M. S. DE S. Elaboração de projeto, TCC, dissertação e tese: uma abordagem simples, prática e objetiva. 1. ed. São Paulo: Atlas, 2011.

ALVES, M. T. G. et al. Fatores Familiares e Desempenho Escolar: Uma Abordagem Multidimensional. DADOS - Revista de Ciências Sociais, v. 56, n. 3, p. 571-603, 2013.

ALVES, M. T. G.; SOARES, J. F. Efeito-escola e estratificação escolar: o impacto da composição de turmas por nível de habilidade dos alunos. Educação em Revista, v. 45, p. 25-59, 2007a.

ALVES, M. T. G.; SOARES, J. F. As pesquisas sobre o efeito das escolas: contribuições metodológicas para a sociologia da educação. Sociedade e Estado, v. 22, n. 2, p. 435-473, $2007 \mathrm{~b}$.

ALVES, M. T. G.; SOARES, J. F. Medidas de nível socioeconômico em pesquisas sociais: uma aplicação aos dados de uma pesquisa educacional. Opinião Pública, v. 15, n. 1, p. 1-30, 2009.

ALVES, M. T. G.; SOARES, J. F. Contexto escolar e indicadores educacionais: condições desiguais para a efetivação de uma política de avaliação educacional. Educação e Pesquisa, v. 39, n. 1, p. 177-194, 2013.

ALVES, M. T. G.; SOARES, J. F.; XAVIER, F. P. Índice Socioeconômico das Escolas de Educação Básica Brasileiras. Ensaio: Avaliação e Políticas Públicas em Educação, v. 22, n. 84, p. 671-703, 2014.

ALVES, T.; SILVA, R. M. DA. Estratificação das oportunidades educacionais no Brasil: contextos e desafios para a oferta de ensino em condições de qualidade para todos. Educação \& Sociedade, v. 34, n. 124, p. 851-879, 2013.

AMâNCIO-VIEIRA, S. F. et al. A relação entre custo direto e desempenho escolar: uma análise multivariada nas escolas de ensino fundamental de Londrina/PR. Educação em Revista, v. 31, n. 1, p. 169-194, 2015.

ANDRADE, R. DE. Teoria do capital humano e a qualidade da educação nos estados brasileiros. Porto Alegre: Universidade Federal do Rio Grande do Sul, 2010.

ANDRADE, R. J.; SOARES, J. F. O efeito da escola básica brasileira. Estudos em Avaliação Educacional, v. 19, n. 41, p. 378-406, 2008.

ANGElO, C. M. P.; MENEGASSI, R. J. A Leitura Compartilhada em Sala de Apoio. Educação em Revista, v. 32, n. 3, p. 267-292, 2016. 
APARICIO, R. J. et al. Using non-radial DEA to assess school efficiency in a cross-country perspective: An empirical analysis of OECD countries. Omega, v. 000, p. 1-12, 26 jul. 2017.

ARDOIN, S. P. et al. Repeated versus wide reading: A randomized control design study examining the impact of fluency interventions on underlying reading behavior. Journal of School Psychology, v. 59, p. 13-38, 2016.

AZIZIFAR, A. et al. The Effect of Pre-reading Activities on the Reading Comprehension Performance of Ilami High School Students. Procedia - Social and Behavioral Sciences, v. 192, p. 188-194, 2015.

BANKER, R. D.; CHARNES, A.; COOPER, W. W. Some Models for Estimating Technical and Scale Inefficiencies in Data Envelopment Analysis. Management Science, v. 30, n. 9, p. 1078-1092, 1984.

BARBOSA, M. E. F.; FERNANDES, C. A escola brasileira faz diferença? Uma investigação dos efeitos da escola na proficiência em matemática dos alunos da $4^{\mathrm{a}}$ série. In: FRANCO, C. (ORG) (Ed.). . Promoção, ciclos e avaliação Educacional. Curitiba: ArtMed, 2001.

BARRA, C.; ZOTTI, R. Measuring Efficiency in Higher Education: An Empirical Study Using a Bootstrapped Data Envelopment Analysis. International Atlantic Economic Society, v. 22, p. 11-33, 2016.

BAUER, A.; ALAVARSE, O. M.; OLIVEIRA, R. P. DE. Avaliações em larga escala: uma sistematização do debate. Educação e Pesquisa, v. 41, n. n. especial, p. 1367-1382, 2015.

BLIACHERIENE, A. N. A. C. Teoria do Desenvolvimento e as perspectivas para um controle popular das contas públicas. Revista da Informação Legislativa, v. 52, n. 205, p. 107-126, 2015.

BLOOM, N. et al. Does Management Matter in schools? Economic Journal, v. 125, n. 584, p. 647-674, 2015.

BRANCH, G. F. et al. Estimating the Effect of Leaders on Public Sector Productivity: The Case of School Principals. Cambridge: [s.n.]. Disponível em: <http://www.nber.org/papers/w17803>. Acesso em: 3 mar. 2019.

BRASIL. Constituição da República Federativa do Brasil - 1988Brasília, DF, 1988. Disponível em: <https://proap.ufabc.edu.br/images/PDF/Constituicao_Federal_de_1988Capitulo_III_artigo_208.pdf>.Acesso em: 6 jan. 2018

BRASIL. Saiba como é a divisão do sistema de educação brasileiro. Disponível em: $<$ http://www.brasil.gov.br/educacao/2014/05/saiba-como-e-a-divisao-do-sistema-deeducacao-brasileiro/view>.

BRASIL. Base Nacional Comum Curricular, 2017. Disponível em: <http://basenacionalcomum.mec.gov.br/images/BNCC_20dez_site.pdf>. Acesso em: 7 jan. 2018 
BRAY, M.; ADAMSON, B.; MASON, M. Comparative Education Research Approaches and Methods. 2. ed. Hong Kong: Springer, 2014.

BROOKE, N.; SOARES, J. F. Pesquisa em Eficácia Escolar: Origem e Trajetórias. 1. ed. Belo Horizonte: Editora UFMG, 2008.

BROOKE, N.; SOARES, J. F. Pesquisa em eficácia escolar: origem e trajetória. Estudos em Avaliação Educacional, v. 22, n. 50, p. 593-597, 2011.

CARDOSO GOMES, M. H. S.; BRESCIANI, L. P.; AMORIM, W. A. Políticas sociais, educação e desenvolvimento econômico: busca por evidências correlacionais a partir das avaliações do Ideb de três municípios paulistas. Gestão \& Regionalidade, v. 32, n. 94, 2016.

CARVALHO, L. D. B. DE; SOUSA, M. DA C. S. DE. Eficiência das Escolas Públicas Urbanas das Regiões Nordeste e Sudeste do Brasil: Uma Abordagem em três Estágios. Estudos Econômicos, v. 44, n. 4, p. 649-684, 2014.

CAVAliERE, A. M. Tempo de escola e qualidade na educação pública. Educação \& Sociedade, v. 28, n. 100, p. 1015-1035, 2007.

CERQUEIRA, M. S. DE. Atividade versus exercício: concepções teóricas e a prática da produção textual no ensino de língua portuguesa. Trabalhos em Linguística Aplicada, v. 49, n. 1, p. 129-143, 2010.

CHARNES, A.; COOPER, W.; RHODES, E. Measuring the efficiency of decision making unitsCompany European Journal of Operational Research. [s.l: s.n.]. Disponível em: $<$ https://ac.els-cdn.com/0377221778901388/1-s2.0-0377221778901388main.pdf?_tid=5d681270-c8ea-45b8-882e-

94217470dd65\&acdnat $=1551544067 \_7 b a d 7 b 9 d 28654 f e f 866 c 5 c 9 a 1 c 833 c 2 f>$. Acesso em: 2 mar. 2019.

CHEN, J. A. et al. Technology-rich activities: One type does not motivate all. Contemporary Educational Psychology, v. 54, p. 153-170, jul. 2018.

COLEMAN, J. S. et al. Equality of educational opportunity. Washington, DC: [s.n.]. Disponível em: <http://files.eric.ed.gov/fulltext/ED012275.pdf>. Acesso em: 1 out. 2017.

CORRAR, L. J.; PAULO, E.; DIAS FILHO, J. M. Análise Multivariada: para os cursos de Administração, Ciências Contábeis e Economia. São Paulo: Editora Atlas, 2009.

COTTA, T. C. Avaliação educacional e políticas públicas: a experiência do Sistema Nacional de Avaliação da Educação Básica (Saeb). Revista do Serviço Público, v. 52, n. 4, p. 89-111, 2001.

DE WITTE, K.; LÓPEZ-TORRES, L. Efficiency in education: A review of literature and a way forward. Journal of the Operational Research Society, v. 68, n. 4, p. 339-363, 2015. 
DELGADO, V. M. S.; MACHADO, A. F. Eficiência das Escolas Públicas Estaduais de Minas Gerais. Pesquisa e Planejamento Econômico, v. 37, n. 3, p. 427-464, 2007.

DEUTSCH, J.; DUMAS, A.; SILBER, J. Estimating an educational production function for five countries of Latin America on the basis of the PISA data. Economics of Education Review, v. 36, p. 245-262, 2013.

DHUEY, E.; SMITH, J. How important are school principals in the production of student achievement? Canadian Journal of Economics, v. 47, n. 2, p. 634-663, 2014.

DI LIBERTO, A.; SCHIVARDI, F.; SULIS, G. Managerial Practices and Students' Performance. Economic Policy. Anais...Roma: 2014Disponível em: <http://www.economicpolicy.org/wp-content/uploads/2014/10/Di-Liberto-Schivardi-Sulis.pdf >. Acesso em: 3 mar. 2019

DOLZ, J. As atividades e os exercícios de língua: uma reflexão sobre a engenharia didática. DELTA, v. 32, n. 1, p. 237-260, 2016.

DUARTE, N. DE S. O impacto da pobreza no Ideb: um estudo multinível. Revista Brasileira de Estudos Pedagógicos RBEP-INEP, v. 94, n. 237, p. 343-363, 2013.

DUMCIUVIENE, D. The Impact of Education Policy to Country Economic Development. Procedia - Social and Behavioral Sciences, v. 191, p. 2427-2436, 2015.

EISENHARDT, K. M. Building Theories from Case Study Researh. The Academy of Management Review, v. 14, n. 4, p. 532-550, 1989.

ENSSLIN, L.; VIANNA, W. B. O design na pesquisa quali-quantitativa em Engenharia de Produção - questões epistemológicas. Revista Produção Online, v. 8, n. 1, 2008.

FARIA, F. P.; JANNUZZ, P. D. M.; SILVA, S. J. DA. Eficiência dos gastos municipais em saúde e educação: uma investigação através da análise envoltória no estado do Rio de Janeiro. Revista de Administração Pública, v. 42, n. 1, p. 155-177, 2008.

FARRELL, M. J. The measurement of productive efficiency. Journal of the Royal Statistical Society Series A, v. 120, p. 253-281, 1957.

FELÍCIO, F. DE; FERNANDES, R. O efeito da qualidade da escola sobre o desempenho escolar: uma avaliação do ensino fundamental no estado de São Paulo. Anais ANPEC. Anais...Belo Horizonte: ANPEC, 2005Disponível em: <http://www.anpec.org.br/encontro2005/artigos/A05A157.pdf>. Acesso em: 13 jul. 2018

FERNANDES, R. et al. Políticas públicas educacionais e desempenho escolar dos alunos da rede pública de ensino. 1. ed. Ribeirão Preto: FUNPEC - Editora, 2014. 
FERNANDES, R.; GREMAUD, A. P. Qualidade da educação: avaliação, indicadores e metas. In: VELOSO, F. ET AL (ORGS) (Ed.). . Educação Básica no Brasil: construindo o país do futuro v.1. Rio de Janeiro: Elsevier, 2009. p. 213-238.

FERREIRA, J. Boas práticas administrativo-pedagógicas que colaboram para o desempenho dos alunos de escolas municipais do ensino fundamental do estado de São Paulo no IDEB. Ribeirão Preto: Universidade de São Paulo - USP, 2015.

FLACH, L. et al. Efficiency of expenditure on education and learning by Brazilian states : A study with Data Envelopment Analysis. Contabilidad y Negocios, v. 12, n. 23, p. 111-128, 2017.

FNDE. Fundo de Manutenção e Desenvolvimento da Educação Básica e de Valorização dos Profissionais da Educação. Disponível em: <http://www.fnde.gov.br/financiamento/fundeb/sobre-o-plano-ou-programa/funcionamento>. Acesso em: 7 jan. 2017.

GATTI, B. A.; NUNES, M. M. R. Formação de professores para o Ensino Fundamental: estudo de currículos das licenciaturas em Pedadogia, Língua Portuguesa, Matemática e Ciências Biológicas. São Paulo: [s.n.]. v. 29

GERALDI, J. W. et al. O Texto na Sala de Aula. 5. ed. São Paulo: Ática, 2013.

GIL, A. C. Métodos e Técnicas de Pesquisa Social. $6^{\text {a }}$ ed. São Paulo: Atlas, 1999.

GLEWWE, P.; ZHENG, H. The Contribution of Education to Economic Growth: A Review of the Evidence, with Special Attention and an Application to Sub-Saharan Africa. World Development, v. 59, p. 379-393, 2014.

GOLDENBERG, P.; MARSIGLIA, R. M. G.; GOMES, M. H. DE A. O Clássico e o Novo tendências, objetos e abordagens em ciências sociais e saúde. Rio de Janeiro: Editora Fiocruz, 2003.

GOMES, C. S. Eficiência dos sistemas municipais de educação no Estado de São Paulo. Ribeirão Preto: FEARP - USP, 2010.

GONÇALVES, F. DE O.; FRANÇA, M. T. A. Eficiência na Provisão de Educação Pública Municipal: Uma Análise em três Estágios dos Municípios Brasileiros. Estudos em Economia, v. 43, n. 2, p. 271-299, 2013.

GOUVEIA, A. B.; SOUZA, Â. R. DE. Efetividade da política para o ensino fundamental em municípios brasileiros. Cadernos de Pesquisa, v. 43, n. 150, p. 836-855, 2013.

GREMAUD, A. P.; FELÍCIO, F. DE; BIONDI, R. L. Indicador de Efeito Escola: Uma Metodologia para a identificação dos sucessos escolares a partir dos dados da Prova Brasil. Brasília: Instituto Nacional de Estudos e Pesquisas Educacionais Anísio Teixeira, 2007. 
GRIFFITH, A. L.; RASK, K. N. Peer effects in higher education: A look at heterogeneous impacts. Economics of Education Review, v. 39, p. 65-77, 2014.

HAELERMANS, C.; RUGGIERO, J. Estimating technical and allocative efficiency in the public sector: A nonparametric analysis of Dutch schools. European Journal of Operational Research, v. 227, n. 1, p. 174-181, 16 maio 2013.

HAIR JR, J. F. et al. Fundamentos de Métodos de Pesquisa em Administraçao. Porto Alegre: Bookman, 2005.

HILL, A. J. The costs of failure: Negative externalities in high school course repetition. Economics of Education Review, v. 43, p. 91-105, 2014.

HOCHFELD, T. et al. Does school breakfast make a difference? An evaluation of an inschool breakfast programme in South Africa. Internationa Journal of Educational Development, v. 51, p. 1-9, 2016.

HOROI, I.; OST, B. Disruptive peers and the estimation of teacher value added. Economics of Education Review, v. 49, p. 180-192, 2015.

HOUAISS, A. Dicionário Houaiss da Língua Portuguesa. Rio de Janeiro: Ed. Objetiva, 2001.

IBGE. Censo Demográfico 2010. Disponível em: <https://cidades.ibge.gov.br>. Acesso em: 20 out. 2018.

IBGE. Censo Demográfico 2015. Disponível em: <https://cidades.ibge.gov.br>. Acesso em: 20 out. 2018.

INEP. SAEB. Disponível em: <http://portal.inep.gov.br/educacao-basica/saeb>. Acesso em: 10 dez. 2017.

INEP. Nota Técnica $n^{0}$ 040/2014- Indicador para mensurar a complexidade da gestão nas escolas a partir dos dados do Censo Escolar da Educação Básica1BrasíliaMinistério da Educação, , 2014. Disponível $<$ http://download.inep.gov.br/informacoes_estatisticas/indicadores_educacionais/2014/escola _complexidade_gestao/nota_tecnica_indicador_escola_complexidade_gestao.pdf $>$. Acesso em: 3 mar. 2019

INEP. SAEB 2015: Resumo dos resultados. Brasília: [s.n.]. Disponível em: $<$ http://portal.inep.gov.br/artigo/-/asset_publisher/B4AQV9zFY7Bv/content/inep-apresentaresultados-do-saeb-prova-brasil-2015/21206>.

INEP. Censo Escolar da Educação Básica 2016 - Notas Estatísticas. Brasília: [s.n.]. Disponível em: <http://download.inep.gov.br/educacao_basica/censo_escolar/notas_estatisticas/2017/notas_e statisticas_censo_escolar_da_educacao_basica_2016.pdf>. Acesso em: 6 jan. 2018a. 
INEP. Cartilha SAEB 2017Brasília, 2017b. Disponível em: <http://download.inep.gov.br/educacao_basica/saeb/2017/documentos/Cartilha_Saeb_2017.p df>. Acesso em: 5 fev. 2018

INEP. Sinopse Estatística da Educação Básica 2018. Brasília, DF: [s.n.]. Disponível em: <http://inep.gov.br/web/guest/sinopses-estatisticas-da-educacao-basica〉.

JABBOUR, C. J. C. et al. Eco-innovations in more sustainable supply chains for a low-carbon economy: A multiple case study of human critical success factors in Brazilian leading companies. International Journal of Production Economics, v. 164, p. 245-257, 2015.

JOHNES, J.; PORTELA, M.; THANASSOULIS, E. Efficiency in education. Journal of the Operational Research Society, v. 68, n. 4, p. 331-338, 2017.

JOHNSON, A. L.; RUGGIERO, J. Nonparametric measurement of productivity and efficiency in education. Ann Oper Res, v. 221, p. 197-210, 2014.

JOHNSON, E. M. Balancing comprehension and conversation: How elementary teachers manage multiple purposes for text discussions. Teaching and Teacher Education, v. 66, p. 325-337, 2017.

KHALILIAQDAM, S. ZPD, Scaffolding and Basic Speech Development in EFL Context. Procedia - Social and Behavioral Sciences, v. 98, p. 891-897, 2014.

KRUSS, G. et al. Higher education and economic development: The importance of building technologial capabilities. International Journal of Educational Development, v. 43, p. 22 $31,2015$.

LIMA, R. P. O ensino da língua portuguesa: aspectos metodológicos e linguísticos. Educar, v. 4, n. 1, p. 4-19, 1985.

LITRON, F. F. Recursos e Materiais Didáticos para o Ensino de Leitura e Escrita. in Centro Universitário Hermínio Ometto, Curso de Prática de Leitura e Escrita IArarasCentro Universitário Hermínio Ometto, , 2014. Disponível em: <ava.uniararas.br/2018/course/view.php?id=20>. Acesso em: 10 fev. 2018

LÚCIO, P. S.; PINHEIRO, Â. M. V.; NASCIMENTO, E. DO. A Influência de Fatores Sociais, Individuais e Lingüísticos no Desempenho de Crianças na Leitura em Voz Alta de Palavras Isoladas. Psicologia: Reflexão e Crítica, v. 23, n. 3, p. 496-505, 2010.

MARIANO, E. B. Conceitos Básicos de Análise de Eficiência produtiva. XIV SIMPEP. Anais...Bauru: 2007Disponível em: $<$ https://s3.amazonaws.com/academia.edu.documents/43698135/Conceitos_Bsicos_de_Anlise _de_Eficincia_20160313-14288-

18ha6jv.pdf?AWSAccessKeyId=AKIAIWOWYYGZ2Y53UL3A\&Expires $=1531392058 \&$ Si gnature $=$ odsfsDihguvd9I7qa3VBI0S 1xEE\%3D\&response-content-disposition=inline $>$.

Acesso em: 12 jul. 2018 
MARQUES, R. C.; SILVA, D. Statistical Inference of Efficiency Estimators obtained with the DEA Nonparametric Frontier Technique. A Bootstrap Methodology. Investigação Operacional, v. 26, p. 89-110, 2006.

MASCI, C.; DE WITTE, K.; AGASISTI, T. The influence of school size, principal characteristics and school management practices on educational performance: An efficiency analysis of Italian students attending middle schools. Socio-Economic Planning Sciences, v. 61, p. 52-69, 2018.

MATOS, D. A. S. et al. Impactos das práticas familiares sobre a proficiência em Língua Portuguesa e Matemática no Ensino Fundamental. pro.posições, v. 28, n. 82, p. 33-54, 2017.

MELHUISH, E. Efeitos de longo prazo da Educação Infantil: evidências e política. Cadernos de Pesquisa, v. 43, n. 148, p. 124-149, 2013.

MELLO, A. DE; SOUZA, A M. E. Determinantes da aprendizagem em escolas municipais. Ensaio: Avaliação e Políticas Públicas em Educação, v. 13, n. 49, p. 413-434, 2005.

MERCAN, M.; SEZER, S. The Effect of Education Expenditure on Economic Growth: The Case of Turkey. Procedia - Social and Behavioral Sciences, v. 109, p. 925-930, 2014.

MEZA, L. A. et al. Curso de Análise de Envoltória de Dados. XXXVII Simpósio Brasileiro de Pesquisa Operacional. Anais...Gramado, RS: 2005Disponível em: <http://www.din.uem.br/ ademir/sbpo/sbpo2005/pdf/arq0289.pdf>. Acesso em: 26 jan. 2018

MITAL, P.; MOORE, R.; LLEWELLYN, D. Analyzing K-12 education as a complex system. Procedia Computer Science, v. 28, n. Cser, p. 370-379, 2014.

MONTEIRO, J. Gasto Público em Educação e Desempenho Escolar. Revista Brasileira de Economia, v. 69, n. 4, p. 467-488, 2 dez. 2015.

NEAMTU, D. M. Education, the economic development pillar. Procedia - Social and Behavioral Sciences, v. 180, p. 413-420, 2015.

OCDE. Education at a Glance 2017: OECD Indicators. Paris: [s.n.]. Disponível em: $<$ http://download.inep.gov.br/acoes_internacionais/eag/documentos/2017/relatorio_education _at_a_glance_2017.pdf>. Acesso em: 16 mar. 2018.

OECD. PISA 2015: Results in Focus. [s.l: s.n.]. Disponível em: <http://www.oecd.org/pisa/pisa-2015-results-in-focus.pdf>. Acesso em: 2 fev. 2018.

OLIVEIRA, A. C. P. DE; WALDHELM, A. P. S. Liderança do diretor, clima escolar e desempenho dos alunos: qual a relação? Ensaio: aval. pol. públ. Educ, v. 24, n. 93, p. 824$844,2016$. 
OLIVEIRA, K. L. DE; BORUCHOVITCH, E.; SANTOS, A. A. A. DOS. Leitura e desempenho escolar em português e matemática no ensino fundamental. Paidéia (Ribeirão Preto), v. 18, n. 41, p. 531-540, 2008.

OSHIRO, C. H.; SCORZAFAVE, L. G.; DORIGAN, T. A. Impacto sobre o desempenho escolar do pagamento de bônus aos docentes do ensino fundamental do estado de São Paulo. Revista Brasileira de Economia, v. 69, n. 2, p. 213-249, 2015.

PANA, M.-C.; MOSORA, C. From quantity to quality in addressing the relationship between education and economic development. Procedia - Social and Behavioral Sciences, v. 93, p. 911-915, 2013.

PARISOTTO, A. L. V.; RINALDI, R. P. Ensino de língua materna: dificuldades e necessidades formativas apontadas por professores na Educação Fundamental. Educar em Revista, v. 60, p. 261-276, 2016.

PENA, R. A. S. DA S. P. Bourdieu, sociologia e teoria da reprodução. As contribuições à discussão curricular. VI Colóquio Internacional "Educação e Contemporaneidade". Anais...São Cristóvão-SE: 2012Disponível em: <http://educonse.com.br/2012/eixo_17/PDF/45.pdf>. Acesso em: 17 jul. 2018

POKER JUNIOR, J. H.; NUNES, R. DA C.; NUNES, S. P. P. Uma avaliação de efetividade e eficiência do gasto em educação em municípios brasileiros. Caderno de Finanças Públicas, v. 13, p. 263-287, 2013.

RAMZI, S.; AFONSO, A.; AYADI, M. Assessment of efficiency in basic and secondary education in Tunisia: A regional analysis. International Journal of Educational Development, v. 51, p. 62-76, 1 nov. 2016.

REGALO, E. H. et al. Melhores Práticas que Podem Contribuir para o Desempenho dos Alunos Brasileiros do Ensino Fundamental. Meta: Avaliação, v. 8, n. 22, p. 1-28, 2016.

RODLI, M. Applaying PQ4R strategy for teaching reading. Indonesia EFL Journal, v. 1, n. 1, p. 31-41, 2015.

RUDIO, F. V. Introdução ao projeto de pesquisa científica. 34. ed. Petrópolis: Vozes, 2007.

SALEM, A. A. M. S. Scaffolding Reading Comprehension Skills. English Language Teaching, v. 10, n. 1, p. 97, 2016.

SALGADO JUNIOR, A. P.; NOVI, J. C. Proposta metodológica: avaliação externa e desempenho dos alunos. Revista Brasileira de Política e Administração da Educação, v. 30, n. 3, p. 583-618, 2014. 
SALGADO JUNIOR, A. P.; NOVI, J. C. Proposta de práticas administrativo-pedagógicas que possam contribuir para o desempenho dos alunos de escolas municipais do ensino fundamental na Prova Brasil. Ensaio: Avaliação e Políticas Públicas em Educação, v. 23, p. 631-662, 2015.

SALGADO JUNIOR, A. P.; NOVI, J. C.; FERREIRA, J. Práticas escolares e desempenho dos alunos: uso das abordagens quantitativa e qualitativa. Educação e Sociedade, v. 37, n. 134, p. 217-243, 2016.

SAMUELSSON, K.; LINDBLAD, S. School management, cultures of teaching and student outcomes: Comparing the cases of Finland and Sweden. Teaching and Teacher Education, v. 49, p. 168-177, 2015.

SARDINHA, M. DA G.; AZEVEDO, F. J.; RATO, R. Promoção da leitura na escola portuguesa: metodologias e crenças dos professores do Ensino Básico. Investigaciones Sobre Lectura, v. 4, p. 25-50, 2015.

SOARES, J. F.; ALVES, M. T. G. Efeitos de escolas e municípios na qualidade do ensino fundamental. Cadernos de Pesquisa, v. 43, n. 149, 2013.

SOARES, T. M. et al. Modelos de valor agregado para medir a eficácia das escolas Geres. Ensaio: Avaliação e Políticas Públicas em Educação, v. 25, n. 94, p. 59-89, 2017.

SORIANO, F. F. Proposta de práticas administrativo-pedagógicas que colaborem para o desempenho das escolas municipais do ensino fundamental, de baixo nível socioeconômico, no IDEB: um estudo multicaso no estado do Ceará (CE). [s.l.] Universidade de São Paulo - USP, 2017.

SOUZA, D. B. DE; FARIA, L. C. M. DE. Reforma del Estado, descentralización y municipalización de la enseñanza en Brasil: la gestión política de los sistemas públicos de la enseñanza pos LDB 9.394/96. Ensaio: Avaliação e Políticas Públicas em Educação (Brasil), v. 12, n. 45, p. 925-944, 2004.

TAFRESCHI, D.; THIEMANN, P. Doing it twice, getting it right? The effects of grade retention and course repetition in higher education. Economics of Education Review, v. 55, p. 198-219, 2016.

TAVARES, P. A. The impact of school management practices on educational performance: Evidence from public schools in São Paulo. Economics of Education Review, v. 48, p. 1-15, 2015.

THANASSOUliS, E.; PORTELA, M. DA C. A. S. School Outcomes: Sharing the Responsibility Between Pupil and School1. Education Economics, v. 10, n. 2, p. 183-207, 2010.

VANDECANDELAERE, M. et al. The effects of early grade retention: Effect modification by prior achievement and age. Journal of School Psychology, v. 54, p. 77-93, 2016. 
WU, Q.; LIU, C.; ZHANG, H. X. Urban education differentiation and its socio-economic consequences: An internet-survey-based structural equation modeling analysis of new white collar workers in Nanjing, China. Research in Social Stratification and Mobility, v. 48, p. $1-9,2017$.

YIN, R. K. Estudo de caso: planejamento e métodos. 2. ed. Porto Alegre: Bookman, 2001.

YIN, R. K. Estudo de caso: planejamento e métodos. 4. ed. São Paulo: Bookman, 2010.

ZOGHBI, A. C. P. et al. Mensurando o Desempenho e a Eficiência dos Gastos Estaduais em Educação Fundamental e Média. Estudos Econômicos, v. 39, n. 4, p. 785-809, 2009.

ZOGHBI, A. C.; ROCHA, F.; MATTOS, E. Education production efficiency: Evidence from Brazilian universities. Economic Modelling, v. 31, n. 1, p. 94-103, 2013. 


\section{APÊNDICE A - Instrumento de Pesquisa}

\begin{tabular}{|c|c|c|c|c|c|c|c|c|c|c|c|c|}
\hline \multirow{3}{*}{\multicolumn{2}{|c|}{$\overrightarrow{\underline{z}}$}} & & \multirow{3}{*}{ PRÁTICA } & \multirow{3}{*}{ 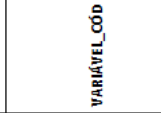 } & \multirow{3}{*}{ VARIÁvEL } & \multirow{3}{*}{ 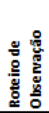 } & \multicolumn{6}{|c|}{ QUESTÕES DO INSTRUMENTO (REFERENTE À PRÁTICA) } \\
\hline & & & & & & & \multicolumn{2}{|r|}{ SME } & \multicolumn{2}{|c|}{ DIRETOR } & \multicolumn{2}{|c|}{ PROFESSOR } \\
\hline & & & & & & & Questão & Autor & Questão & Autor & Questão & Autor \\
\hline $\mathrm{p}$ & $\mathrm{P}$ & $\mathrm{CE}$ & - & C_PROF_CONS_V03 & Percentual de professores do sexo feminino & - & - & - & - & - & - & - \\
\hline$P$ & $\mathrm{p}$ & CE & - & PB_PROF_V142 & Frequência com que vai ao cinema & - & - & - & - & - & $\cdot$ & - \\
\hline P & $\mathrm{p}$ & $\mathrm{PB}$ & - & PB_PROF_V270 & $\begin{array}{l}\text { Insatisfação e desestimulo do professor com a } \\
\text { carreira docente }\end{array}$ & - & 007 & Lima et al. (2014) & B16 & Lima et al. (2014) & $\begin{array}{l}\text { A31; A46; } \\
\text { A54; A55; } \\
\text { A56 }\end{array}$ & Lima et al. (2014) \\
\hline $\mathrm{p}$ & $\mathrm{p}$ & $\mathrm{PB}$ & $\begin{array}{l}\text { Ter formação em } \\
\text { Pedagogia }\end{array}$ & PB_PROF_V10 & Ensino Superior em Pedagogia & - & - & - & - & - & A41 & $\begin{array}{l}\text { Salgado Junior e } \\
\text { Novi (2015); } \\
\text { Soriano (2017) } \\
\end{array}$ \\
\hline $\mathrm{p}$ & $\mathrm{p}$ & $\mathrm{PB}$ & $\begin{array}{l}\text { Ser formado em IES } \\
\text { Particular }\end{array}$ & PB_PROF_V91 & $\begin{array}{l}\text { Capacitações, oficinas e especializações não } \\
\text { apresentam relacionamento com a melhoria do } \\
\text { desempenho. }\end{array}$ & - & $\mathrm{Cos} ; 009$ & $\begin{array}{l}\text { Salgado Junior e } \\
\text { Novi (2015); } \\
\text { Soriano (2017) }\end{array}$ & $\begin{array}{l}\text { B17; B18; } \\
\text { B67 }\end{array}$ & \begin{tabular}{|l} 
Ferrarotto e \\
Malavasi (2015); \\
Chirin e Brand \\
(2015) Tavarez \\
(2015) Lima (2013) \\
Silva (2014); Silva, \\
Bonamino e \\
Ribeiro (2012); \\
Fagnani (2014); \\
Nardi, Schneider \\
e Rios (2014); \\
Miranda e \\
Rodrigues (2010); \\
Miranda (2008); \\
Garcia (2011)
\end{tabular} & $\begin{array}{l}\text { A16; A17; } \\
\text { A41 }\end{array}$ & $\begin{array}{l}\text { Salgado Junior e } \\
\text { Novi (2015); } \\
\text { Soriano (2017) }\end{array}$ \\
\hline $\mathrm{p}$ & $\mathrm{p}$ & $\mathrm{PB}$ & & PB_PROF_V17 & Tipo de IES que cursou: pública (-) ou privada (+). & - & - & - & - & - & A42; A43 & $\begin{array}{l}\text { Salgado Junior e } \\
\text { Novi (2015); } \\
\text { Soriano (2017) }\end{array}$ \\
\hline $\mathrm{p}$ & $\mathrm{P}$ & $\mathrm{PB}$ & $\begin{array}{l}\text { Ser contratado Sem } \\
\text { Vinculo de }\end{array}$ & PB_PROF_V71 & Tipo de contratação: Estatutário & - & $\mathrm{C} 43 ; \mathrm{C} 45$ & \begin{tabular}{|l} 
Salgado Junior e \\
Novi (2015); \\
Soriano (2017) \\
\end{tabular} & - & - & A57 & $\begin{array}{l}\text { Salgado Junior e } \\
\text { Novi (2015); } \\
\text { Soriano (2017) } \\
\end{array}$ \\
\hline $\mathrm{p}$ & $\mathrm{P}$ & $\mathrm{PB}$ & Estabilidade & PB_DIR_V151 & $\begin{array}{l}\text { Menos de } 25 \% \text { dos professores da escola com vínculo } \\
\text { estável. }\end{array}$ & - & c60 & \begin{tabular}{|l} 
Salgado Junior e \\
Novi (2015); \\
Soriano (2017)
\end{tabular} & 882 & \begin{tabular}{|l} 
Salgado Junior e \\
Novi (2015); \\
Soriano (2017)
\end{tabular} & - & 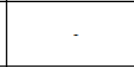 \\
\hline $\mathrm{p}$ & $\mathrm{P}$ & PB & & PB_PROFESSOR_V37 & Remuneração docente & - & C58; 559 & \begin{tabular}{|l|} 
Salgado Junior e \\
Novi (2015); \\
Soriano (2017)
\end{tabular} & B81; 882 & \begin{tabular}{|l} 
Salgado Junior e \\
Novi (2015); \\
Soriano (2017)
\end{tabular} & A56 & $\begin{array}{l}\text { Salgado Junior e } \\
\text { Novi (2015); } \\
\text { Soriano (2017) }\end{array}$ \\
\hline P & D & $\mathrm{PB}$ & $\begin{array}{l}\text { Ter dedicacẫo } \\
\text { exclusiva à escola }\end{array}$ & PB_PROF_V78 & $\begin{array}{l}\text { Professores com maior carga horária na escola (acima } \\
\text { de } 20 \text { horas) apresentam melhor desepenho. }\end{array}$ & - & - & t & - & tom & A58 & $\begin{array}{l}\text { Salgado Junior e } \\
\text { Novi (2015); } \\
\text { Soriano (2017) }\end{array}$ \\
\hline $\mathrm{p}$ & $\mathrm{p}$ & PB & & PB_PROF_V80 & Atuar em apenas 01 escola melhora o desempenho. & - & - & - & B80; 881 & $\begin{array}{l}\text { Cadraval (2010); } \\
\text { Garcia (2011); } \\
\text { Miranda (2008); }\end{array}$ & $\begin{array}{l}\text { A30; A54; } \\
\text { A55; A59 }\end{array}$ & $\begin{array}{l}\text { Cadraval (2010); } \\
\text { Garcia (2011); } \\
\text { Miranda (2008); }\end{array}$ \\
\hline $\mathrm{p}$ & $\mathrm{p}$ & $\mathrm{PB}$ & & PB_PROF_V158 & $\begin{array}{l}\text { Uso de jornais,filmes, documentários e desenhos não } \\
\text { causa impacto }\end{array}$ & - & - & - & - & 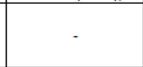 & $\begin{array}{l}\mathrm{A} 60 ; \mathrm{A} 61 ; \\
\mathrm{A} 62 ; \mathrm{A} 63\end{array}$ & $\begin{array}{l}\text { Salgado Junior e } \\
\text { Novi (2015); } \\
\text { Soriano (2017) }\end{array}$ \\
\hline $\mathrm{p}$ & $\mathrm{p}$ & $\mathrm{PB}$ & & PB_PROF_V153 & Uso de livros de literatura é bom & - & - & - & - & - & $\begin{array}{l}\mathrm{A} 60 ; \mathrm{A} 61 ; \\
\mathrm{A} 62 ; \mathrm{A} 63\end{array}$ & $\begin{array}{l}\text { Salgado Junior e } \\
\text { Novi (2015); } \\
\text { Soriano (2017) }\end{array}$ \\
\hline $\mathrm{p}$ & $\mathrm{p}$ & $\mathrm{PB}$ & & PB_PROF_V157 & Uso do projetor & - & - & - & - & - & $\begin{array}{l}\mathrm{A} 60 ; \mathrm{A} 61 ; \\
\mathrm{A} 62 ; \mathrm{A} 63\end{array}$ & $\begin{array}{l}\text { Salgado Junior e } \\
\text { Novi (2015); } \\
\text { Soriano (2017) }\end{array}$ \\
\hline $\mathrm{p}$ & $\mathrm{p}$ & $\mathrm{PB}$ & & PB_PROF_V165 & Professor utiliza equipamento de fotocópia & $\mathrm{x}$ & - & - & - & - & $\begin{array}{l}\mathrm{A} 60 ; \mathrm{A} 61 ; \\
\mathrm{A} 62 ; \mathrm{A} 63\end{array}$ & $\begin{array}{l}\text { Salgado Junior e } \\
\text { Novi (2015); } \\
\text { Soriano (2017) } \\
\end{array}$ \\
\hline $\mathrm{p}$ & $\mathrm{p}$ & $\mathrm{PB}$ & & PB_PROF_V169 & Professor utiliza aplicativos pedagógicos & - & c54 & $\begin{array}{l}\text { Nardi, Schneider } \\
\text { e Rios (2014); } \\
\text { Carvalho, } \\
\text { Bonamine e } \\
\text { Kappel (2011) }\end{array}$ & - & - & A40 & \begin{tabular}{|l|} 
Silva (2014); \\
Miranda e \\
Rodrigues (2010); \\
Carvalho, \\
Bonamino e \\
Kappel (2011)
\end{tabular} \\
\hline $\mathrm{p}$ & $\mathrm{p}$ & $P B$ & Utilizar: livros de & PB_PROF_V173 & Professor utiliza a internet & $\mathrm{x}$ & - & - & - & - & A40 & \begin{tabular}{|l|} 
Silva (2014); \\
Miranda e \\
Rodrigues (2010); \\
Carvalho, \\
Bonamino e \\
Kappel (2011)
\end{tabular} \\
\hline ESC & APL & $P B$ & $\begin{array}{l}\text { projetores e } \\
\text { aplicativos } \\
\text { pedagógicos }\end{array}$ & PB_ESC_V91 & $\begin{array}{l}\text { Disponibilidade e número de computadores para uso } \\
\text { dos alunos (Bom) }\end{array}$ & $\mathrm{x}$ & C54 & \begin{tabular}{|l} 
Silva (2014); \\
Nardi, SChneider \\
e Rios (2014); \\
Miranda e \\
Rodrigues (2010); \\
Gouveia (2009); \\
Gomes (2010); \\
Carvalho, \\
Bonamino e \\
Kappel (2011) \\
\end{tabular} & 870 & \begin{tabular}{|l} 
Silva (2014); \\
Nardi, Schneider \\
e Rios (2014); \\
Miranda e \\
Rodrigues (2010); \\
Gouveia (2009); \\
Gomes (2010); \\
Carvalho, \\
Bonamino e \\
Kappel (2011) \\
\end{tabular} & $\mathrm{A} 40$ & \begin{tabular}{|l} 
Silva (2014); \\
Nardi, Schneider \\
e Rios (2014); \\
Miranda e \\
Rodrigues (2010); \\
Gouveia (2019); \\
Gomes (2010); \\
Carvalho, \\
Bonamino e \\
Kappel (2011) \\
\end{tabular} \\
\hline ESC & APL & & & PB_ESC_V97 & Acesso à internet banda-larga para os alunos (Bom) & $\mathrm{x}$ & - & 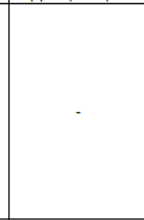 & 870 & $\begin{array}{l}\text { Salgado Junior e } \\
\text { Novi (2015); } \\
\text { Soriano (2017) }\end{array}$ & $\mathrm{A} 40$ & $\begin{array}{l}\text { Silva (2014); } \\
\text { Nardi, Schneider } \\
\text { e Rios (2014); } \\
\text { Miranda e } \\
\text { Rodrigues (2010); } \\
\text { Gouveia (2009); } \\
\text { Gomes (2010); } \\
\text { Carvalho, } \\
\text { Bonamino e } \\
\text { Kappel (2011) }\end{array}$ \\
\hline ESC & APL & PB & & PB_ESC_V103 & $\begin{array}{l}\text { Disponibilidade de computadores para uso dos } \\
\text { professores (Bom) }\end{array}$ & $x$ & - & - & - & - & A40 & \begin{tabular}{|l|} 
Silva (2014); \\
Miranda e \\
Rodrigues (2010); \\
Carvalho, \\
Bonamino e \\
Kappel (2011)
\end{tabular} \\
\hline
\end{tabular}

\section{continua}




\begin{tabular}{|c|c|c|c|c|c|c|c|c|c|c|c|c|}
\hline \multirow{3}{*}{$\frac{\vec{z}}{z}$} & \multirow{3}{*}{\multicolumn{2}{|c|}{ 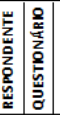 }} & \multirow{3}{*}{ PRÁTICA } & \multirow{3}{*}{ 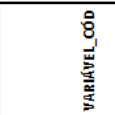 } & \multirow{3}{*}{ VARIÁVEL } & \multirow{3}{*}{ 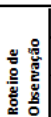 } & \multicolumn{6}{|c|}{ QUESTÕES DO INSTRUMENTO (REFERENTE À PRÁTICA) } \\
\hline & & & & & & & \multicolumn{2}{|r|}{ SME } & \multicolumn{2}{|c|}{ DIRETOR } & \multicolumn{2}{|c|}{ PROFESSOR } \\
\hline & & & & & & & Questão & Autor & Questão & Autor & Questão & Autor \\
\hline $\mathrm{p}$ & \begin{tabular}{l|l}
$\mathrm{P}$ & $\mathrm{PB}$
\end{tabular} & & \multirow[t]{2}{*}{$\begin{array}{l}\text { Participar da } \\
\text { elaboração do projeto } \\
\text { pedagógico }\end{array}$} & PB_PROF_V178 & $\begin{array}{l}\text { Projeto Pedagógico Pronto e Adaptado Sem Discussão } \\
\text { com os Professores }\end{array}$ & - & $\mathrm{C} 57 ; \mathrm{C} 61$ & \begin{tabular}{|l|} 
Lima et al. (2014); \\
Gouveia (2009); \\
Miranda (2008); \\
Carvalho, \\
Bonamino e \\
Kappel (2011) \\
\end{tabular} & $B 74 ; 877$ & \begin{tabular}{|l|} 
Lima et al. (2014); \\
Gouveia (2009); \\
Miranda (2008); \\
Carvalho, \\
Bonamino e \\
Kappel (2011) \\
\end{tabular} & $\begin{array}{l}\text { A47; A48; } \\
\text { A49; A64 }\end{array}$ & $\begin{array}{l}\text { Lima et al. (2014); } \\
\text { Gouveia (2009); } \\
\text { Miranda (2008); } \\
\text { Carvalho, } \\
\text { Bonamino e } \\
\text { Kappel (2011) } \\
\end{array}$ \\
\hline $\mathrm{p}$ & \begin{tabular}{l|l}
$\mathrm{P}$ & $\mathrm{PB}$
\end{tabular} & PB & & PB_PROF_V264 & $\begin{array}{l}\text { Conteúdos curriculares inadequados às necessidades } \\
\text { dos alunos }\end{array}$ & - & - & 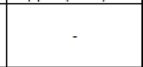 & 874 & \begin{tabular}{|l|} 
Salgado Junior e \\
Novi (2015); \\
Soriano (2017) \\
\end{tabular} & A47; A48 & \begin{tabular}{|l|} 
Salgado Junior e \\
Novi (2015); \\
Soriano (2017)
\end{tabular} \\
\hline $\mathrm{p}$ & \begin{tabular}{l|l}
$\mathrm{P}$ & $\mathrm{PB}$
\end{tabular} & \multirow{4}{*}{\multicolumn{2}{|c|}{$\begin{array}{l}\text { Atuar em conjunto } \\
\text { com outros } \\
\text { professores: discussão } \\
\text { sobre o } \\
\text { desenvolvimento e } \\
\text { aprendizagem e açōes } \\
\text { conjuntas. }\end{array}$}} & PB_PROF_V196 & $\begin{array}{l}\text { A troca semanal de materiais didáticos com os } \\
\text { colegas }\end{array}$ & - & - & - & - & 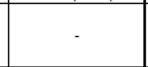 & A52; A53 & \begin{tabular}{|l|} 
Salgado Junior e \\
Novi (2015); \\
Soriano (2017)
\end{tabular} \\
\hline $\mathrm{p}$ & \begin{tabular}{l|l}
$\mathrm{P}$ & $\mathrm{PB}$
\end{tabular} & & & PB_PROF_V201 & $\begin{array}{l}\text { Reuniôes semanais com professores que trabalham } \\
\text { na mesma }\end{array}$ & - & - & - & - & - & A52; A53 & $\begin{array}{l}\text { Salgado Junior e } \\
\text { Novi (2015); } \\
\text { Soriano (2017) }\end{array}$ \\
\hline p & \begin{tabular}{l|l}
$\mathrm{P}$ & $\mathrm{PB}$
\end{tabular} & & & PB_PROF_V206 & $\begin{array}{l}\text { Participar em discussões semanais sobre o } \\
\text { desenvolvimento da aprendizagem }\end{array}$ & - & - & - & 875 & \begin{tabular}{|l|} 
Salgado Junior e \\
Novi (2015); \\
Soriano (2017)
\end{tabular} & A52; A53 & $\begin{array}{l}\text { Salgado Junior e } \\
\text { Novi (2015); } \\
\text { Soriano (2017) }\end{array}$ \\
\hline $\mathrm{p}$ & \begin{tabular}{l|l}
$\mathrm{P}$ & $\mathrm{PB}$
\end{tabular} & & & PB_PROF_V211 & $\begin{array}{l}\text { Desenvolvimento de atividades conjuntas com outros } \\
\text { docentes semanalmente }\end{array}$ & $\cdot$ & - & - & - & 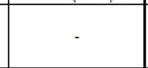 & A52; A53 & \begin{tabular}{|l|} 
Salgado Junior e \\
Novi (2015); \\
Soriano (2017)
\end{tabular} \\
\hline $\mathrm{p}$ & \begin{tabular}{l|l}
$P$ & $P B$
\end{tabular} & & \multirow{5}{*}{$\begin{array}{l}\text { Dedicar mais tempo } \\
\text { às aulas e menos a } \\
\text { outras atividades } \\
\text { (administrativas, } \\
\text { manter a disciplina) }\end{array}$} & PB_PROF_V321 & $\begin{array}{l}\text { Mais tempo dedicado às aulas e menos a questões } \\
\text { administrativas }(80 \%+/ 10 \%-)\end{array}$ & - & - & - & 875 & \begin{tabular}{|l|} 
Salgado Junior e \\
Novi (2015); \\
Soriano (2017)
\end{tabular} & - & (1) \\
\hline p & 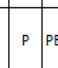 & & & PB_PROF_V84 & Horas dedicadas a atividades extraclasse (Nenhuma) & - & - & - & 875 & $\begin{array}{l}\text { Salgado Junior e } \\
\text { Novi (2015); } \\
\text { Soriano (2017) }\end{array}$ & . & - \\
\hline p & $\mathrm{P} P \mathrm{PE}$ & & & PB_PROF_V268 & $\begin{array}{l}\text { Sobrecarga de trabalho dos professores, dificultando } \\
\text { o planejamento e o preparo das aulas }\end{array}$ & $\cdot$ & - & - & 875 & $\begin{array}{l}\text { Salgado Junior e } \\
\text { Novi (2015); } \\
\text { Soriano (2017) } \\
\end{array}$ & - & - \\
\hline p & \begin{tabular}{l|l}
$\mathrm{P}$ & $\mathrm{PE}$ \\
\end{tabular} & & & PB_PROF_V310 & $\begin{array}{l}\text { Gastar menos de } 10 \% \text { do tempo garantindo a } \\
\text { disciplina na sala }\end{array}$ & - & . & - & B03 & $\begin{array}{l}\text { Salgado Junior e } \\
\text { Novi (2015); } \\
\text { Soriano (2017) }\end{array}$ & A02 & \begin{tabular}{|l|} 
Salgado Junior e \\
Novi (2015); \\
Soriano (2017)
\end{tabular} \\
\hline $\mathrm{p}$ & \begin{tabular}{l|l}
$\mathrm{P}$ & $\mathrm{PE}$ \\
$\mathrm{P}$ &
\end{tabular} & $\mathrm{PB}$ & & PB_DIR_V457 & $\begin{array}{l}\text { Funcionamento da Escola interrompido por } \\
\text { problemas de indisciplina }\end{array}$ & - & - & - & B03; 804 & \begin{tabular}{|l|} 
Silva, Bonamino e \\
Ribeiro (2012); \\
Miranda (2008)
\end{tabular} & $\begin{array}{l}\text { A02; } \mathrm{A03} ; \\
\mathrm{A} 13\end{array}$ & $\begin{array}{l}\text { Silva, Bonamino e } \\
\text { Ribeiro (2012); } \\
\text { Miranda (2008) }\end{array}$ \\
\hline p & \begin{tabular}{l|l}
$\mathrm{P}$ & $\mathrm{PE}$
\end{tabular} & \multirow{2}{*}{\multicolumn{2}{|c|}{$\begin{array}{l}\text { Oferer e corrigir } \\
\text { diariamente dever de } \\
\text { casa }\end{array}$}} & PB_PROF_V336 & Oferta de dever de casa diariamente & - & - & - & Bo9 & \begin{tabular}{|l|} 
Salgado Junior e \\
Novi (2015); \\
Soriano (2017) \\
\end{tabular} & A06 & \begin{tabular}{|l} 
Salgado Junior e \\
Novi (2015); \\
Soriano (2017) \\
\end{tabular} \\
\hline p & A $\mathrm{PE}$ & & & \begin{tabular}{|l} 
PB_PROF_V342 \\
\end{tabular} & Professor corrige dever de casa diariamente & - & - & - & - & ton & A07 & \begin{tabular}{|l} 
Salgado Junior e \\
Novi (2015); \\
Soriano (2017) \\
\end{tabular} \\
\hline p & \begin{tabular}{l|l}
$\mathrm{P}$ & $\mathrm{PE}$ \\
$\mathrm{P}$
\end{tabular} & PB & \multirow{5}{*}{$\begin{array}{l}\text { Incentivar a } \\
\text { participação dos } \\
\text { alunos na aula e } \\
\text { evitar a cópia de } \\
\text { conteúdos (lousa e } \\
\text { livros) }\end{array}$} & PB_PROF_V360 & Cópia de conteúdos do livro ou lousa é negativo & - & . & - & - & . & $\begin{array}{l}\text { A60; A61; } \\
\text { A62; A63 }\end{array}$ & \begin{tabular}{|l|} 
Salgado Junior e \\
Novi (2015); \\
Soriano (2017)
\end{tabular} \\
\hline p & $\mathrm{P} P \mathrm{PE}$ & & & PB_PROF_V366 & $\begin{array}{l}\text { Atividades que estimulem aos alunos expressar suas } \\
\text { opiniôes e a criarem argumentos }\end{array}$ & - & - & - & - & - & $\begin{array}{l}\mathrm{A} 60 ; \mathrm{A} 61 ; \\
\mathrm{A} 62 ; \mathrm{A} 63\end{array}$ & $\begin{array}{l}\text { Salgado Junior e } \\
\text { Novi (2015); } \\
\text { Soriano (2017) }\end{array}$ \\
\hline $\mathrm{p}$ & $\mathrm{P} P \mathrm{PE}$ & & & PB_PROF_V377 & $\begin{array}{l}\text { Promover discussões a partir de textos (jornais e } \\
\text { revistas) semanalmente }\end{array}$ & - & . & - & . & - & $\begin{array}{l}\mathrm{A} 60 ; \mathrm{A} 61 ; \\
\mathrm{A} 62 ; \mathrm{A} 63\end{array}$ & \begin{tabular}{|l|} 
Salgado Junior e \\
Novi (2015); \\
Soriano (2017) \\
\end{tabular} \\
\hline p & $\mathrm{P} P \mathrm{PE}$ & PB & & PB_PROF_V402 & $\begin{array}{l}\text { Propor atividades gramaticais relacionadas aos } \\
\text { textos de jornais ou revistas diariamente }\end{array}$ & - & . & - & - & . & $\begin{array}{l}\mathrm{A} 60 ; \mathrm{A} 61 ; \\
\mathrm{A} 62 ; \mathrm{A} 63\end{array}$ & \begin{tabular}{|l|} 
Salgado Junior e \\
Novi (2015); \\
Soriano (2017)
\end{tabular} \\
\hline $\mathrm{p}$ & 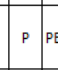 & PB & & PB_PROF_V389 & $\begin{array}{l}\text { Promover a leitura e discussão de contos, crônicas, } \\
\text { poesias ou romances semanalmente }\end{array}$ & - & - & . & - & - & $\begin{array}{l}\mathrm{A} 60 ; \mathrm{A} 61 ; \\
\mathrm{A} 62 ; \mathrm{A} 63\end{array}$ & $\begin{array}{l}\text { Salgado Junior e } \\
\text { Novi (2015); } \\
\text { Soriano (2017) }\end{array}$ \\
\hline $\mathrm{p}$ & 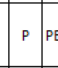 & PB & \multirow{7}{*}{$\begin{array}{l}\text { Garantir o } \\
\text { cumprimento dos } \\
\text { conteúdos }\end{array}$} & PB_PROF_V330 & $\begin{array}{l}\text { Garantir o cumprimento de, pelo menos, } 80 \% \text { dos } \\
\text { conteúdos na trajetória escolar }\end{array}$ & - & $\mathrm{C55} ; \mathrm{C56}$ & \begin{tabular}{|l|} 
Salgado Junior e \\
Novi (2015); \\
Soriano (2017)
\end{tabular} & $B 72 ; 873$ & \begin{tabular}{|l|} 
Salgado Junior e \\
Novi (2015); \\
Soriano (2017)
\end{tabular} & A47; A48 & \begin{tabular}{|l|} 
Salgado Junior e \\
Novi (2015); \\
Soriano (2017)
\end{tabular} \\
\hline $\mathrm{P}$ & \begin{tabular}{l|l}
$\mathrm{P}$ & $\mathrm{PE}$
\end{tabular} & PB & & PB_PROF_V267 & $\begin{array}{l}\text { Cumprir o conteúdo curricular ao longo da trajetória } \\
\text { do aluno }\end{array}$ & - & $\mathrm{C} 55 ; \mathrm{C} 56$ & $\begin{array}{l}\text { Salgado Junior e } \\
\text { Novi (2015); } \\
\text { Soriano (2017) }\end{array}$ & B72; 873 & \begin{tabular}{|l|} 
Salgado Junior e \\
Novi (2015); \\
Soriano (2017)
\end{tabular} & $\mathrm{A} 47 ; \mathrm{A} 48$ & \begin{tabular}{|l|} 
Salgado Junior e \\
Novi (2015); \\
Soriano (2017)
\end{tabular} \\
\hline $\mathrm{p}$ & \begin{tabular}{l|l}
$P$ & $P E$ \\
$P E$
\end{tabular} & PB & & PB_PROF_V321 & $\begin{array}{l}\text { Mais tempo dedicado às aulas e menos a questões } \\
\text { administrativas }(80 \%+/ 10 \%-)\end{array}$ & - & . & 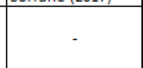 & 875 & \begin{tabular}{|l|} 
Salgado Junior e \\
Novi (2015); \\
Soriano (2017)
\end{tabular} & . & 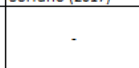 \\
\hline P & 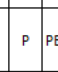 & & & PB_PROF_V268 & $\begin{array}{l}\text { Sobrecarga de trabalho dos professores, dificultando } \\
\text { o planejamento e o preparo das aulas }\end{array}$ & - & . & . & 875 & $\begin{array}{l}\text { Salgado Junior e } \\
\text { Novi (2015); } \\
\text { Soriano (2017) }\end{array}$ & - & . \\
\hline $\mathrm{p}$ & 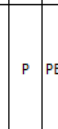 & PB & & PB_PROF_V178 & $\begin{array}{l}\text { Projeto Pedagógico Pronto e Adaptado Sem Discussão } \\
\text { com os Professores }\end{array}$ & - & $\mathrm{C57} ; 061$ & $\begin{array}{l}\text { Lima et al. (2014); } \\
\text { Gouveia (2009); } \\
\text { Miranda (2008); } \\
\text { Carvalho, } \\
\text { Bonamino e } \\
\text { Kappel (2011) }\end{array}$ & $B 74 ; 877$ & $\begin{array}{l}\text { Lima et al. (2014); } \\
\text { Gouveia (2009); } \\
\text { Miranda (2008); } \\
\text { Carvalho, } \\
\text { Bonamino e } \\
\text { Kappel (2011) }\end{array}$ & $\begin{array}{l}\text { A47; A48; } \\
\text { A49; A64 }\end{array}$ & \begin{tabular}{|l} 
Lima et al. (2014); \\
Gouveia (2009); \\
Miranda (2008); \\
Carvalho, \\
Bonamino e \\
Kappel (2011)
\end{tabular} \\
\hline $\mathrm{p}$ & $\mathrm{P} P \mathrm{PE}$ & $\mathrm{PB}$ & & PB_PROF_V264 & $\begin{array}{l}\text { Conteúdos curriculares inadequados às necessidades } \\
\text { dos alunos }\end{array}$ & - & $\mathrm{c57}$ & \begin{tabular}{|l|} 
Salgado Junior e \\
Novi (2015); \\
Soriano (2017) \\
\end{tabular} & B74 & \begin{tabular}{|l|} 
Salgado Junior e \\
Novi (2015); \\
Soriano (2017) \\
\end{tabular} & A47; A48 & \begin{tabular}{|l|} 
Salgado Junior e \\
Novi (2015); \\
Soriano (2017) \\
\end{tabular} \\
\hline p & $\mathrm{p} P \mathrm{Pt}$ & $\mathrm{PB}$ & & PB_PROF_V310 & $\begin{array}{l}\text { Gastar menos de } 10 \% \text { do tempo garantindo a } \\
\text { disciplina na sala }\end{array}$ & - & - & fortom & Bо3 & $\begin{array}{l}\text { Salgado Junior e } \\
\text { Novi (2015); } \\
\text { Soriano (2017) } \\
\end{array}$ & A02 & \begin{tabular}{|l} 
Salgado Junior e \\
Novi (2015); \\
Soriano (2017) \\
\end{tabular} \\
\hline $\mathrm{D}$ & $\mathrm{D} P \mathrm{PE}$ & PB & \multirow{2}{*}{$\begin{array}{l}\text { Ter dedicacãa } \\
\text { exclusiva à escola }\end{array}$} & PB_DIR_V37 & Dedicação Exclusiva à Escola & - & - & - & $\begin{array}{l}\text { B55; B56; } \\
\text { B57;879 }\end{array}$ & Miranda (2008) & - & 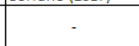 \\
\hline D & $\mathrm{D} P \mathrm{PE}$ & $\mathrm{PB}$ & & PB_DIR_V54 & $\begin{array}{l}\text { Possui } 40 \text { horas semanais oU + de carga horária na } \\
\text { escola }\end{array}$ & . & . & . & 855 & \begin{tabular}{|l|} 
Salgado Junior e \\
Novi (2015); \\
Soriano (2017) \\
\end{tabular} & - & . \\
\hline D & $\mathrm{D} P \mathrm{PE}$ & $\mathrm{PB}$ & $\begin{array}{l}\text { Contratação via } \\
\text { Concurso Público ou } \\
\text { Indicação Direta }\end{array}$ & PB_DIR_V61 & $\begin{array}{l}\text { Ingresso no cargo via Concurso Público ou Indicação } \\
\text { Direta }\end{array}$ & - & $\mathrm{C42} ; \mathrm{C44}$ & $\begin{array}{l}\text { Salgado Junior e } \\
\text { Novi (2015); } \\
\text { Soriano (2017) }\end{array}$ & $\begin{array}{l}\mathrm{B} 8 \mathrm{~B} ; \mathrm{B5} ; \\
\mathrm{B} 60\end{array}$ & \begin{tabular}{|l|} 
Carvalho, \\
Bonamino e \\
Kappel (2011); \\
Tavares (2015) \\
\end{tabular} & - & - \\
\hline D & $\mathrm{D} P \mathrm{PH}$ & $\mathrm{PB}$ & Cursar Especialização & PB_DIR_V30 & Possuir Pós-graduação (Especialização, no mínimo) & - & $\mathrm{C40} ; \mathrm{C41}$ & $\begin{array}{l}\text { Carvalho, } \\
\text { Bonamino e } \\
\text { Kappel (2011) }\end{array}$ & $853 ; 854$ & \begin{tabular}{|l|} 
Tavares (2015); \\
Nardi, Schneider \\
e Rios (2014); \\
Mello e Luz \\
(2015); Carvalho, \\
Bonamino e \\
Kappel (2011) \\
\end{tabular} & . & - \\
\hline D & $\mathrm{D} P \mathrm{Pt}$ & $\mathrm{PB}$ & \multirow{2}{*}{$\begin{array}{l}\text { Atuar na mesma } \\
\text { escola pelo periodo de } \\
06 \text { a } 10 \text { anos }\end{array}$} & PB_DIR_V75 & Experiência anterior como professor (+ de 20 anos) & - & $\begin{array}{l}\text { C37; C38; } \\
\quad \text { C39 }\end{array}$ & $\begin{array}{l}\text { Salgado Junior e } \\
\text { Novi (2015); } \\
\text { Soriano (2017) }\end{array}$ & $\begin{array}{l}\mathrm{B} 50 ; \mathrm{B} 51 ; \\
\mathrm{B2} ; \mathrm{B} 58\end{array}$ & \begin{tabular}{|l|} 
Tavares (2015); \\
Nardi, Schneider \\
e Rios (2014); \\
Mello e Luz (2015)
\end{tabular} & - & - \\
\hline D & $\mathrm{D} P \mathrm{PE}$ & & & PB_DIR_V90 & $\begin{array}{l}\text { Diretor na mesma escola pelo período de } 06 \text { a } 10 \\
\text { anos }\end{array}$ & - & - & - & - & - & - & - \\
\hline
\end{tabular}




\begin{tabular}{|c|c|c|c|c|c|c|c|c|c|c|c|c|}
\hline \multirow{3}{*}{$\frac{\overrightarrow{\underline{u}}}{\mathrm{u}}$} & \multirow{3}{*}{\multicolumn{2}{|c|}{ 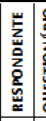 }} & \multirow{3}{*}{ PRÁtICA } & \multirow{3}{*}{ 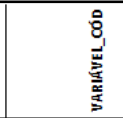 } & \multirow{3}{*}{ VARIÁVEL } & \multirow{3}{*}{ 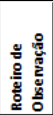 } & \multicolumn{6}{|c|}{ QUESTÕES DO INSTRUMENTO (REFERENTE À PRÁTICA) } \\
\hline & & & & & & & \multicolumn{2}{|r|}{ SME } & \multicolumn{2}{|c|}{ DIRETOR } & \multicolumn{2}{|c|}{ PROFESSOR } \\
\hline & & 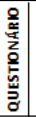 & & & & & Questão & Autor & Questão & Autor & Questão & Autor \\
\hline D & D & PB & & PB_DIR_V276 & $\begin{array}{l}\text { Frequência com que o Diretor comunica os pais sobre } \\
\text { problemas relacionados aos aluno (Sempre ou Quase } \\
\text { Sempre) }\end{array}$ & - & - & - & 846 & $\begin{array}{l}\text { Salgado Junior e } \\
\text { Novi (2015); } \\
\text { Soriano (2017) } \\
\end{array}$ & A33 & $\begin{array}{l}\text { Salgado Junior e } \\
\text { Novi (2015); } \\
\text { Soriano (2017) } \\
\end{array}$ \\
\hline A & A & PB & \begin{tabular}{|l|} 
Manter contato com \\
os pais e informar \\
sobre o desempenho \\
do aluno
\end{tabular} & PB_ALUN_V29 & Participação dos pais em reuniões escolares & - & - & - & 813 & $\begin{array}{l}\text { Lima et al. (2014); } \\
\text { Barbosa e Mello } \\
\text { (2015); Barbosa e } \\
\text { Wilhelm (2009); } \\
\text { Miranda (2008); } \\
\text { Garcia (2011); } \\
\text { Silva (2009) }\end{array}$ & A13; A33 & $\begin{array}{l}\text { Lima et al. (2014); } \\
\text { Barbosa e Mello } \\
\text { (2015); Barbosa e } \\
\text { Wilhelm (2009); } \\
\text { Miranda (2008); } \\
\text { Garcia (2011); } \\
\text { Silva (2009) }\end{array}$ \\
\hline D & D & PB & $\begin{array}{l}\text { Promover projetos } \\
\text { temáticos }\end{array}$ & PB_DIR_V311 & $\begin{array}{l}\text { Diretor promover projetos temáticos (como bullying, } \\
\text { desigualdades e impactos socioambientais) } \\
\text { (Frequentemente) }\end{array}$ & - & c34 & $\begin{array}{l}\text { Salgado Junior e } \\
\text { Novi (2015); } \\
\text { Soriano (2017) }\end{array}$ & B47;848 & $\begin{array}{l}\text { Salgado Junior e } \\
\text { Novi (2015); } \\
\text { Soriano (2017) } \\
\end{array}$ & A34 & $\begin{array}{l}\text { Salgado Junior e } \\
\text { Novi (2015); } \\
\text { Soriano (2017) } \\
\end{array}$ \\
\hline D & D & PB & $\begin{array}{l}\text { Promover eventos } \\
\text { para a comunidade }\end{array}$ & PB_DIR_V317 & $\begin{array}{l}\text { Diretor promover eventos para a comunidade } \\
\text { (Frequentemente) }\end{array}$ & - & c36 & $\begin{array}{l}\text { Salgado Junior e } \\
\text { Novi (2015); } \\
\text { Soriano (2017) }\end{array}$ & $845 ; 849$ & \begin{tabular}{|l} 
Salgado Junior e \\
Novi (2015); \\
Soriano (2017)
\end{tabular} & A35 & $\begin{array}{l}\text { Salgado Junior e } \\
\text { Novi (2015); } \\
\text { Soriano (2017) }\end{array}$ \\
\hline D & D & PB & Ceder a escola para & PB_DIR_V321 & $\begin{array}{l}\text { Diretor ceder o espaço escolar para eventos } \\
\text { realizados pela comunidade (Nunca) }\end{array}$ & - & c36 & $\begin{array}{l}\text { Salgado Junior e } \\
\text { Novi (2015); } \\
\text { Soriano (2017) } \\
\end{array}$ & 849 & $\begin{array}{l}\text { Salgado Junior e } \\
\text { Novi (2015); } \\
\text { Soriano (2017) } \\
\end{array}$ & A35 & $\begin{array}{l}\text { Salgado Junior e } \\
\text { Novi (2015); } \\
\text { Soriano (2017) } \\
\end{array}$ \\
\hline ESC & APL & PB & eventos comunitários & PB_ESC_V172 & Biblioteca permite acesso do acervo à comunidade. & - & - & - & 808 & \begin{tabular}{|l} 
Salgado Junior e \\
Novi (2015); \\
Soriano (2017) \\
\end{tabular} & - & - \\
\hline D & D & PB & Promover projetos de & PB_DIR_V472 & Receber apoio da Comunidade. & - & - & - & B13 & $\begin{array}{l}\text { Salgado Junior e } \\
\text { Novi (2015); } \\
\text { Soriano (2017) }\end{array}$ & - & - \\
\hline $\mathrm{D}$ & D & $\mathrm{PB}$ & voluntariado & PB_DIR_V327 & $\begin{array}{l}\text { Diretor promover a participação da comunidade } \\
\text { real lizando trabal hos voluntários para a escola. }\end{array}$ & - & c36 & $\begin{array}{l}\text { Salgado Junior e } \\
\text { Novi (2015); } \\
\text { Soriano (2017) }\end{array}$ & 849 & $\begin{array}{l}\text { Salgado Junior e } \\
\text { Novi (2015); } \\
\text { Soriano (2017) } \\
\end{array}$ & A35 & $\begin{array}{l}\text { Salgado Junior e } \\
\text { Novi (2015); } \\
\text { Soriano (2017) }\end{array}$ \\
\hline D & D & PB & $\begin{array}{l}\text { Admitir alunos pelo } \\
\text { local de residência }\end{array}$ & PB_DIR_V212 & $\begin{array}{l}\text { Adotar política de admissão de alunos pelo local de } \\
\text { residência (vizinhança da escola) }\end{array}$ & - & C19 & $\begin{array}{l}\text { Salgado Junior e } \\
\text { Novi (2015); } \\
\text { Soriano (2017) } \\
\end{array}$ & 828 & $\begin{array}{l}\text { Salgado Junior e } \\
\text { Novi (2015); } \\
\text { Soriano (2017) } \\
\end{array}$ & - & 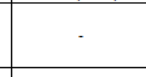 \\
\hline D & D & PB & \begin{tabular}{|l|} 
Atribuir aulas por \\
pontuação dos \\
professores (tempo de \\
serviço e formaçãa)
\end{tabular} & PB_DIR_V232 & $\begin{array}{l}\text { Atribuição de aulas considerando a escolha dos } \\
\text { professores, de acordo com a pontuação por tempo } \\
\text { de serviço e formação. }\end{array}$ & - & c29 & $\begin{array}{l}\text { Salgado Junior e } \\
\text { Novi (2015); } \\
\text { Soriano (2017) }\end{array}$ & 839 & $\begin{array}{l}\text { Salgado Junior e } \\
\text { Novi (2015); } \\
\text { Soriano (2017) }\end{array}$ & A31 & $\begin{array}{l}\text { Salgado Junior e } \\
\text { Novi (2015); } \\
\text { Soriano (2017) }\end{array}$ \\
\hline D & D & PB & $\begin{array}{l}\text { Realizar reuniōes de } \\
\text { conselhos (de Classe e }\end{array}$ & PB_DIR_V161 & $\begin{array}{l}\text { Diretor realiza e participa de reuniões de Conselho } \\
\text { Escolar por três vezes ou mais no ano. }\end{array}$ & - & C14 & $\begin{array}{l}\text { Lima et al. (2014); } \\
\text { Nardi, Schneider } \\
\text { e Rios (2014); } \\
\text { Miranda e } \\
\text { Rodrigues (2010); } \\
\text { Gouveia (2009); } \\
\text { Miranda (2008); } \\
\text { Komatsu (2013); } \\
\text { Martins e Silva } \\
\text { (2011) }\end{array}$ & 824 & $\begin{array}{l}\text { Lima et al. (2014); } \\
\text { Nardi, Schneider } \\
\text { e Rios (2014); } \\
\text { Miranda e } \\
\text { Rodrigues (2010); } \\
\text { Gouveia (2009); } \\
\text { Miranda (2008); } \\
\text { Komatsu (2013); } \\
\text { Martins e Silva } \\
\text { (2011) }\end{array}$ & A19 & $\begin{array}{l}\text { Lima et al. (2014); } \\
\text { Nardi, Schneider } \\
\text { e Rios (2014); } \\
\text { Miranda e } \\
\text { Rodrigues (2010); } \\
\text { Gouveia (2009); } \\
\text { Miranda (2008); } \\
\text { Komatsu (2013); } \\
\text { Martins e Silva } \\
\text { (2011) }\end{array}$ \\
\hline D & PF & PB & $\begin{array}{l}\text { Escolar) pelo menos } 3 \\
\text { vezes ao ano }\end{array}$ & PB_PROF_V186 & $\begin{array}{l}\text { Diretor promover reuniões de conselho classe (órgão } \\
\text { formado por todos os professores que lecionam em } \\
\text { cada série) por três vezes ou mais no ano. }\end{array}$ & - & C14 & $\begin{array}{l}\text { Lima et al. (2014); } \\
\text { Nardi, Schneider } \\
\text { e Rios (2014); } \\
\text { Miranda e } \\
\text { Rodrigues (2010); } \\
\text { Gouveia (2009); } \\
\text { Miranda (2008); } \\
\text { Komatsu (2013); } \\
\text { Martins e Silva } \\
\text { (2011) } \\
\end{array}$ & 824 & $\begin{array}{l}\text { Lima et al. (2014); } \\
\text { Nardi, Schneider } \\
\text { e Rios (2014); } \\
\text { Miranda e } \\
\text { Rodrigues (2010); } \\
\text { Gouveia (2009); } \\
\text { Miranda (2008); } \\
\text { Komatsu (2013); } \\
\text { Martins e Silva } \\
\text { (2011) } \\
\end{array}$ & A19 & $\begin{array}{l}\text { Lima et al. (2014); } \\
\text { Nardi, Schneider } \\
\text { e Rios (2014); } \\
\text { Miranda e } \\
\text { Rodrigues (2010); } \\
\text { Gouveia (2009); } \\
\text { Miranda (2008); } \\
\text { Komatsu (2013); } \\
\text { Martins e Silva } \\
\text { (2011) }\end{array}$ \\
\hline D & PF & PB & $\begin{array}{l}\text { Incentivar os docentes } \\
\text { para a formação } \\
\text { continuada }\end{array}$ & PB_PROF_V222 & $\begin{array}{l}\text { O Diretor informa com frequência sobre } \\
\text { possibilidades de aperfeiçoamento aos professores }\end{array}$ & - & C08; 009 & $\begin{array}{l}\text { Ferrarotto e } \\
\text { Malavasi (2015); } \\
\text { Chirin e Brand } \\
\text { (2015) Tavarez } \\
\text { (2015) Lima (2013) } \\
\text { Silva (2014); Silva, } \\
\text { Bonamino e } \\
\text { Ribeiro (2012); } \\
\text { Fagnani (2014); } \\
\text { Nardi, Schneider } \\
\text { e Rios (2014); } \\
\text { Miranda e } \\
\text { Rodrigues (2010); } \\
\text { Miranda (2018); } \\
\text { Garcia (2011) }\end{array}$ & B17; B18 & $\begin{array}{l}\text { Ferrarotto e } \\
\text { Malavasi (2015); } \\
\text { Chirin e Brand } \\
\text { (2015) Tavarez } \\
\text { (2015) Lima (2013) } \\
\text { Silva (2014); Silva, } \\
\text { Bonamino e } \\
\text { Ribeiro (2012); } \\
\text { Fagnani (2014); } \\
\text { Nardi, Schneider } \\
\text { e Rios (2014); } \\
\text { Miranda e } \\
\text { Rodrigues (2010); } \\
\text { Miranda (2008); } \\
\text { Garcia (2011) }\end{array}$ & - & - \\
\hline D & D & PB & $\begin{array}{l}\text { Atuar em conjunto } \\
\text { com as instâncias } \\
\text { superiores }\end{array}$ & PB_DIR_V464 & Receber apoio das instâncias superiores. & - & $\begin{array}{c}\mathrm{C} 2 \mathrm{C}^{2} \mathrm{C} 1 \text {; } \\
\mathrm{C} 33\end{array}$ & $\begin{array}{l}\text { Mesquita (2012); } \\
\text { Miranda (2008); } \\
\text { Carvalho, } \\
\text { Bonamino e } \\
\text { Kappel (2011); } \\
\text { Garcia (2011); } \\
\text { Oliveira (2014) }\end{array}$ & $\begin{array}{l}\mathrm{B} 21 ; \mathrm{B} 42 ; \\
\mathrm{B} 43\end{array}$ & $\begin{array}{l}\text { Mesquita (2012); } \\
\text { Miranda (2008); } \\
\text { Carvalho, } \\
\text { Bonamino e } \\
\text { Kappel (2011); } \\
\text { Garcia (2011); } \\
\text { Oliveira (2014) } \\
\end{array}$ & - & - \\
\hline D & D & $\mathrm{PB}$ & & PB_DIR_V368 & $\begin{array}{l}\text { Merenda escolar: Disponibilidade de recursos } \\
\text { financeiros (Bom ou acima) }\end{array}$ & - & $\begin{array}{c}\mathrm{C} 49 ; \mathrm{C} 50 ; \mathrm{C} \\
51\end{array}$ & $\begin{array}{l}\text { Salgado Junior e } \\
\text { Novi (2015); } \\
\text { Soriano (2017) }\end{array}$ & B 65; B 66 & $\begin{array}{l}\text { Salgado Junior e } \\
\text { Novi (2015); } \\
\text { Soriano (2017) }\end{array}$ & - & - \\
\hline D & D & PB & Prover merenda em & PB_DIR_V376 & Merenda escolar: Quantidade de Alimentos (Ótimo) & - & $\begin{array}{c}\mathrm{C} 49 ; \mathrm{C} 50 ; \mathrm{C} \\
51\end{array}$ & $\begin{array}{l}\text { c Salgado Junior e } \\
\text { Novi (2015); } \\
\text { Soriano (2017) }\end{array}$ & 866 & \begin{tabular}{|l} 
Salgado Junior e \\
Novi (2015); \\
Soriano (2017) \\
\end{tabular} & - & - \\
\hline $\mathrm{D}$ & D & PB & qualidade adequadas & PB_DIR_V383 & Merenda escolar: Qualidade dos Alimentos (Ótimo) & - & $\begin{array}{c}\mathrm{C} 49 ; \mathrm{C} 50 ; \mathrm{C} \\
51\end{array}$ & $\begin{array}{l}\text { c Salgado Junior e } \\
\text { Novi (2015); } \\
\text { Soriano (2017) }\end{array}$ & 866 & $\begin{array}{l}\text { Salagado Junior e } \\
\text { Novi (2015); } \\
\text { Soriano (2017) }\end{array}$ & - & - \\
\hline D & D & & & PB_DIR_V390 & Merenda escolar: Espaço Físico para Cozinhar (Ótimo) & $\mathrm{x}$ & $\begin{array}{c}\mathrm{C} 49 ; \mathrm{C} 50 ; \mathrm{C} \\
51\end{array}$ & $\begin{array}{l}\text { Salgado Junior e } \\
\text { Novi (2015); } \\
\text { Soriano (2017) }\end{array}$ & 865 & \begin{tabular}{|l} 
Salgado Junior e \\
Novi (2015); \\
Soriano (2017)
\end{tabular} & - & - \\
\hline
\end{tabular}

\section{continua}




\begin{tabular}{|c|c|c|c|c|c|c|c|c|c|c|c|c|}
\hline \multirow{3}{*}{\begin{tabular}{|l|}
$\underline{\underline{\underline{u}}}$ \\
\end{tabular}} & \multirow{3}{*}{\multicolumn{2}{|c|}{ 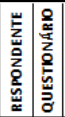 }} & \multirow{3}{*}{ PRÁTICA } & \multirow{3}{*}{ 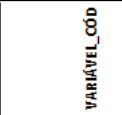 } & \multirow{3}{*}{ VARIÁvel } & \multirow{3}{*}{ 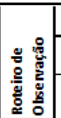 } & \multicolumn{6}{|c|}{ QUESTÕES DO INSTRUMENTO (REFERENTE À PRÁTICA) } \\
\hline & & & & & & & \multicolumn{2}{|r|}{ SME } & \multicolumn{2}{|c|}{ DIRETOR } & \multicolumn{2}{|c|}{ PROFESSOR } \\
\hline & & & & & & & Questão & Autor & Questão & Autor & Questão & Autor \\
\hline D & D & $\mathrm{PB}$ & \multirow{4}{*}{\begin{tabular}{|l} 
Garantir o quadro \\
funcional \\
(administrativo e \\
pedagógico) completo
\end{tabular}} & PB_PROF_V263 & $\begin{array}{l}\text { Garantir que o quadro de pessoal de apoio } \\
\text { pedagógico esteja completo }\end{array}$ & - & $\mathrm{C43} ; \mathrm{C45}$ & $\begin{array}{l}\text { Salgado Junior e } \\
\text { Novi (2015); } \\
\text { Soriano (2017) }\end{array}$ & $861 ; 862$ & $\begin{array}{l}\text { Salgado Junior e } \\
\text { Novi (2015); } \\
\text { Soriano (2017) } \\
\end{array}$ & - & - \\
\hline D & D F & PB & & PB_DIR_V406 & Garantir que o quadro docente esteja completo. & - & $\mathrm{C} 43 ; \mathrm{C45}$ & \begin{tabular}{|l|} 
Salgado Junior e \\
Novi (2015); \\
Soriano (2017)
\end{tabular} & $861 ; 862$ & \begin{tabular}{|l|} 
Salgado Junior e \\
Novi (2015); \\
Soriano (2017)
\end{tabular} & - & - \\
\hline $\mathrm{D}$ & D P & $\mathrm{PB}$ & & PB_DIR_V412 & $\begin{array}{l}\text { Garantir que o quadro de funcionários } \\
\text { administrativos seja adequado à estrutura da escola. }\end{array}$ & . & $\mathrm{C} 43 ; \mathrm{C45}$ & $\begin{array}{l}\text { Salgado Junior e } \\
\text { Novi (2015); } \\
\text { Soriano (2017) }\end{array}$ & $861 ; 862$ & $\begin{array}{l}\text { Salgado Junior e } \\
\text { Novi (2015); } \\
\text { Soriano (2017) }\end{array}$ & - & - \\
\hline $\mathrm{D}$ & $\mathrm{D}$ & $\mathrm{PB}$ & & PB_DIR_V418 & $\begin{array}{l}\text { Garantir que o quadro de apoio pedagógico } \\
\text { (coordenador, supervisor, orientador) esteja } \\
\text { completo. }\end{array}$ & - & C43; C45 & $\begin{array}{l}\text { Salgado Junior e } \\
\text { Novi (2015); } \\
\text { Soriano (2017) }\end{array}$ & $861 ; 862$ & $\begin{array}{l}\text { Salgado Junior e } \\
\text { Novi (2015); } \\
\text { Soriano (2017) }\end{array}$ & - & - \\
\hline ESC & APL & $\mathrm{PB}$ & \begin{tabular}{|l|} 
Garantir a \\
manutenção da \\
infraestrutura \\
(completa em boas \\
condiçőes de
\end{tabular} & PB_ESC_V14 & $\begin{array}{l}\text { Apresentar infraestrutura em boas condições de } \\
\text { conservação e em funcionamento. }\end{array}$ & $\mathrm{x}$ & $\mathrm{C} 12 ; \mathrm{C} 13$ & $\begin{array}{l}\text { Nardi, Schneider } \\
\text { e Rios (2014); } \\
\text { Carvalho, } \\
\text { Bonamino e } \\
\text { Kappel (2011) } \\
\end{array}$ & B 22; B 23 & $\begin{array}{l}\text { Nardi, Schneider } \\
\text { e Rios (2014); } \\
\text { Carvalho, } \\
\text { Bonamino e } \\
\text { Kappel (2011) } \\
\end{array}$ & - & - \\
\hline ESC & APL & PB & conservação e & PB_ESC_V43 & Todas as salas são bem iluminadas. & $\mathrm{x}$ & - & - & - & -2 & - & - \\
\hline ESC & APL & $\mathrm{PB}$ & Garantir policiamento & PB_ESC_V61 & Controle de entrada de pessoas estranhas (Bom) & $x$ & - & $\cdot$ & - & $\cdot$ & - & $\cdot$ \\
\hline ESC & APL & $\mathrm{PB}$ & $\begin{array}{l}\text { e combate ao tráfico } \\
\text { dentro e nas } \\
\text { imediaçôes da escola }\end{array}$ & PB_ESC_V79 & $\begin{array}{l}\text { Sistema policiamento para inibição ao tráfico de } \\
\text { drogas dentro da escola e nas imediaçôes (Bom) }\end{array}$ & - & c53 & $\begin{array}{l}\text { Salgado Junior e } \\
\text { Novi (2015); } \\
\text { Soriano (2017) }\end{array}$ & 869 & $\begin{array}{l}\text { Salgado Junior e } \\
\text { Novi (2015); } \\
\text { Soriano (2017) }\end{array}$ & A39 & $\begin{array}{l}\text { Salgado Junior e } \\
\text { Novi (2015); } \\
\text { Soriano (2017) }\end{array}$ \\
\hline ESC & APL & PB & & PB_ESC_V91 & $\begin{array}{l}\text { Disponibilidade e número de computadores para uso } \\
\text { dos alunos (Bom) }\end{array}$ & $\mathrm{x}$ & c54 & $\begin{array}{l}\text { Silva (2014); } \\
\text { Nardi, Schneider } \\
\text { e Rios (2014); } \\
\text { Miranda e } \\
\text { Rodrigues (2010); } \\
\text { Gouveia (2009); } \\
\text { Gomes (2010); } \\
\text { Carvalho, } \\
\text { Bonamino e } \\
\text { Kappel (2011) } \\
\end{array}$ & 870 & \begin{tabular}{|l|} 
Silva (2014); \\
Nardi, Schneider \\
e Rios (2014); \\
Miranda e \\
Rodrigues (2010); \\
Gouveia (2009); \\
Gomes (2010); \\
Carvalho, \\
Bonamino e \\
Kappel (2011) \\
\end{tabular} & A40 & \begin{tabular}{|l} 
Silva (2014); \\
Nardi, Schneider \\
e Rios (2014); \\
Miranda e \\
Rodrigues (2010); \\
Gouveia (2009); \\
Gomes (2010); \\
Carvaliho, \\
Bonamino e \\
Kappel (2011) \\
\end{tabular} \\
\hline ESC & APL & PB & & PB_ESC_V97 & Acesso à internet banda-larga para os alunos (Bom) & $\mathrm{x}$ & $\mathrm{c54}$ & $\begin{array}{l}\text { Salgado Junior e } \\
\text { Novi (2015); } \\
\text { Soriano (2017) }\end{array}$ & 870 & $\begin{array}{l}\text { Salgado Junior e } \\
\text { Novi (2015); } \\
\text { Soriano (2017) }\end{array}$ & A40 & $\begin{array}{l}\text { Silva (2014); } \\
\text { Nardi, Schneider } \\
\text { e Rios (2014); } \\
\text { Miranda e } \\
\text { Rodrigues (2010); } \\
\text { Gouveia (2009); } \\
\text { Gomes (2010); } \\
\text { Carvalho, } \\
\text { Bonamino e } \\
\text { Kappel (2011) } \\
\end{array}$ \\
\hline ESC & APL & $\mathrm{PB}$ & \begin{tabular}{|l|} 
Garantir \\
computadores, \\
impressora e internet \\
adequados (para \\
alunos, professores e \\
funcionários)
\end{tabular} & PB_ESC_V103 & $\begin{array}{l}\text { Disponibilidade de computadores para uso dos } \\
\text { professores (Bom) }\end{array}$ & $\mathrm{x}$ & c54 & $\begin{array}{l}\text { Salgado Junior e } \\
\text { Novi (2015); } \\
\text { Soriano (2017) }\end{array}$ & $B 71$ & \begin{tabular}{|l} 
Salgado Junior e \\
Novi (2015); \\
Soriano (2017)
\end{tabular} & A40 & \begin{tabular}{|l} 
Silva (2014); \\
Nardi, Schneider \\
e Rios (2014); \\
Miranda e \\
Rodrigues (2010); \\
Gouveia (2009); \\
Gomes (2010); \\
Carvalho, \\
Bonamino e \\
Kappel (2011) \\
\end{tabular} \\
\hline ESC & APL & $\mathrm{PB}$ & & PB_ESC_V109 & $\begin{array}{l}\text { Acesso à internet banda-larga para os professores } \\
(B \circ))\end{array}$ & $\mathrm{x}$ & $\mathrm{c54}$ & $\begin{array}{l}\text { Salgado Junior e } \\
\text { Novi (2015); } \\
\text { Soriano (2017) }\end{array}$ & 871 & \begin{tabular}{|l} 
Salgado Junior e \\
Novi (2015); \\
Soriano (2017)
\end{tabular} & A40 & \begin{tabular}{|l} 
Silva (2014); \\
Nardi, Schneider \\
e Rios (2014); \\
Miranda e \\
Rodrigues (2010); \\
Gouveia (2009); \\
Gomes (2010); \\
Carvalho, \\
Bonamino e \\
Kappel (2011) \\
\end{tabular} \\
\hline ESC & APL & $\mathrm{PB}$ & & C_ESC_V14 & $\begin{array}{l}\text { Disponibilidade de computadores para uso dos } \\
\text { funcionários administrativos }\end{array}$ & $\mathrm{x}$ & c54 & \begin{tabular}{|l|} 
Salgado Junior e \\
Novi (2015); \\
Soriano (2017)
\end{tabular} & 871 & \begin{tabular}{|l|} 
Salgado Junior e \\
Novi (2015); \\
Soriano (2017)
\end{tabular} & - & Rоррет (2011) \\
\hline EsC & APL & CE & & C_ESC_vo9 & Escola possui impressora & $\mathrm{x}$ & c54 & $\begin{array}{l}\text { Salgado Junior e } \\
\text { Novi (2015); } \\
\text { Soriano (2017) }\end{array}$ & 871 & \begin{tabular}{|l} 
Salgado Junior e \\
Novi (2015); \\
Soriano (2017)
\end{tabular} & A40 & \begin{tabular}{|l} 
Silva (2014); \\
Nardi, Schneider \\
e Rios (2014); \\
Miranda e \\
Rodrigues (2010); \\
Gouveia (2009); \\
Gomes (2010); \\
Carvalho, \\
Bonamino e \\
Kappel (2011) \\
\end{tabular} \\
\hline D & p & $\mathrm{PB}$ & \begin{tabular}{|l|} 
Atuar sobre as normas \\
administrativas e
\end{tabular} & PB_PROF_V231 & $\begin{array}{l}\text { O Diretor se envolve com frequência com as normas } \\
\text { administrativas }\end{array}$ & . & c11 & \begin{tabular}{|l|} 
Salgado Junior e \\
Novi (2015); \\
Soriano (2017) \\
\end{tabular} & B21 & \begin{tabular}{|l|} 
Salgado Junior e \\
Novi (2015); \\
Soriano (2017) \\
\end{tabular} & . & 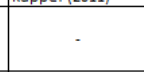 \\
\hline D & $p$ & $\mathrm{~PB}$ & $\begin{array}{l}\text { manutenção da } \\
\text { escola. }\end{array}$ & PB_PROF_V235 & $\begin{array}{l}\text { O Diretor se envolve com frequência na manutenção } \\
\text { da escola }\end{array}$ & . & $\mathrm{C} 12 ; \mathrm{C} 13$ & $\begin{array}{l}\text { Salgado Junior e } \\
\text { Novi (2015); } \\
\text { Soriano (2017) }\end{array}$ & $B 22 ; B 23$ & $\begin{array}{l}\text { Salgado Junior e } \\
\text { Novi (2015); } \\
\text { Soriano (2017) }\end{array}$ & . & . \\
\hline D & D & PB & $\begin{array}{l}\text { Captar recursos } \\
\text { financeiros externos }\end{array}$ & PB_DIR_V488 & Buscar apoio financeiro de empresas particulares. & . & с30 & $\begin{array}{l}\text { Nardi, Schneider } \\
\text { e Rios (2014); } \\
\text { Carvalho, } \\
\text { Bonamino e } \\
\text { Kappel (2011); } \\
\text { Silva (2009) }\end{array}$ & $\begin{array}{c}840 ; 841 ; \\
B 42\end{array}$ & $\begin{array}{l}\text { Nardi, Schneider } \\
\text { e Rios (2014); } \\
\text { Carvalho, } \\
\text { Bonamino e } \\
\text { Kappel (2011); } \\
\text { Silva (2009) }\end{array}$ & . & - \\
\hline $\mathrm{D}$ & $\mathrm{D}$ & $\mathrm{PB}$ & & PB_DIR_V400 & $\begin{array}{l}\text { Não haver interrupção das atividades escolares por } \\
\text { falta de recursos financeiros. }\end{array}$ & . & $\begin{array}{l}\text { C30; } 331 ; \\
\quad \text { C34 }\end{array}$ & $\begin{array}{l}\text { Salgado Junior e } \\
\text { Novi (2015); } \\
\text { Soriano (2017) }\end{array}$ & 844 & \begin{tabular}{|l|} 
Salgado Junior e \\
Novi (2015); \\
Soriano (2017)
\end{tabular} & A32 & \begin{tabular}{|l} 
Salgado Junior e \\
Novi (2015); \\
Soriano (2017)
\end{tabular} \\
\hline D & D & $\mathrm{PB}$ & $\begin{array}{l}\text { Garantir estrutura } \\
\text { para AEE }\end{array}$ & PB_DIR_V342 & $\begin{array}{l}\text { Diretor garantir uma infraestrutura adequada para } \\
\text { atendimento as pessoas com deficiência ou } \\
\text { necessidades especiais. }\end{array}$ & . & $\begin{array}{c}\text { C46; } \\
\text { C47;C48 }\end{array}$ & $\begin{array}{l}\text { Salgado Junior e } \\
\text { Novi (2015); } \\
\text { Soriano (2017) }\end{array}$ & $863 ; 864$ & $\begin{array}{l}\text { Salgado Junior e } \\
\text { Novi (2015); } \\
\text { Soriano (2017) }\end{array}$ & A36; A37 & $\begin{array}{l}\text { Salgado Junior e } \\
\text { Novi (2015); } \\
\text { Soriano (2017) }\end{array}$ \\
\hline
\end{tabular}

\section{continua}




\begin{tabular}{|c|c|c|c|c|c|c|c|c|c|c|c|c|}
\hline \multirow{3}{*}{$\frac{\overrightarrow{\underline{z}}}{2}$} & \multirow{3}{*}{\multicolumn{2}{|c|}{ 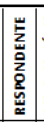 }} & \multirow{3}{*}{ PRÁtICA } & \multirow{3}{*}{ 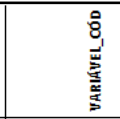 } & \multirow{3}{*}{ VARIÁVEL } & \multirow{3}{*}{ 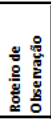 } & \multicolumn{6}{|c|}{ QUESTÕES DO INSTRUMENTO (REFERENTE À PRÁTICA) } \\
\hline & & & & & & & \multicolumn{2}{|r|}{ SME } & \multicolumn{2}{|c|}{ DIRETOR } & \multicolumn{2}{|c|}{ PROFESSOR } \\
\hline & & 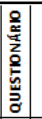 & & & & & Questão & Autor & Questão & Autor & Questão & Autor \\
\hline ESC & APL & PB & \multirow[b]{4}{*}{$\begin{array}{l}\text { Manter Biblioteca } \\
\text { com estrutura e } \\
\text { acervo adequados }\end{array}$} & PB_ESC_V133 & Existência de sala de leitura para os alunos. & $\mathrm{x}$ & - & - & - & - & A05 & $\begin{array}{l}\text { Diaz (2012); } \\
\text { Miranda (2008) }\end{array}$ \\
\hline EsC & APL & PL PB & & PB_ESC_V181 & $\begin{array}{l}\text { Existência de pessoa responsável pelo atendimento } \\
\text { na biblioteca }\end{array}$ & $\mathrm{x}$ & - & - & - & - & - & . \\
\hline ESC & c APL & PL $\mathrm{PB}$ & & PB_ESC_V172 & Biblioteca permite acesso do acervo à comunidade. & - & - & - & B06 & $\begin{array}{l}\text { Salgado Junior e } \\
\text { Novi (2015); } \\
\text { Soriano (2017) }\end{array}$ & - & - \\
\hline ESC & c APL & PL PB & & PB_ESC_V127 & Existência de Biblioteca em boas condições de uso. & $\mathrm{x}$ & c52 & \begin{tabular}{|l|} 
Nardi, Schneider \\
e Rios (2014); \\
Miranda e \\
Rodrigues (2010); \\
Diaz (2012); \\
Gouveia (2009); \\
Gomes (2010); \\
Carvalho, \\
Bonamino e \\
Kappel (2011); \\
Oliveira (2014)
\end{tabular} & B05; 868 & $\begin{array}{l}\text { Nardi, Schneider } \\
\text { e Rios (2014); } \\
\text { Miranda e } \\
\text { Rodrigues (2010); } \\
\text { Diaz (2012); } \\
\text { Gouveia (2009); } \\
\text { Gomes (2010); } \\
\text { Carvalho, } \\
\text { Bonamino e } \\
\text { Kappel (2011); } \\
\text { Oliveira (2014) }\end{array}$ & A38 & $\begin{array}{l}\text { Nardi, Schneider } \\
\text { e Rios (2014); } \\
\text { Miranda e } \\
\text { Rodrigues (2010); } \\
\text { Diaz (2012); } \\
\text { Gouveia (2009); } \\
\text { Gomes (2010); } \\
\text { Carvalho, } \\
\text { Bonamino e } \\
\text { Kappel (2011); } \\
\text { Oliveira (2014) }\end{array}$ \\
\hline $\mathrm{D}$ & $P$ & PB & \multirow{3}{*}{$\begin{array}{l}\text { Acompanhar a } \\
\text { Aprendizagem dos } \\
\text { Alunos }\end{array}$} & PB_PROF_V219 & $\begin{array}{l}\text { O professor e o diretor compreenderem que a } \\
\text { qualidade é uma responsabilidade coletiva auxilia } \\
\text { na melhora do desempenho }\end{array}$ & - & - & 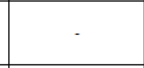 & $B 14 ; 815$ & \begin{tabular}{|l}
$\begin{array}{l}\text { Salgado Junior e } \\
\text { Novi (2015); } \\
\text { Soriano (2017) }\end{array}$ \\
\end{tabular} & A14; A15 & $\begin{array}{l}\text { Salgado Junior e } \\
\text { Novi (2015); } \\
\text { Soriano (2017) } \\
\end{array}$ \\
\hline D & $P$ & PB & & PB_DIR_V264 & $\begin{array}{l}\text { Diretor discute com os professores medidas com o } \\
\text { objetivo de melhorar o ensino e a aprendizagem dos } \\
\text { alunos (Sempre ou Quase Sempre) }\end{array}$ & - & $\mathrm{c} 10$ & Miranda (2008) & $\begin{array}{l}\text { B17; B18; } \\
\text { B34; B36 }\end{array}$ & Miranda (2008) & \begin{tabular}{|c} 
A;18; $A 25 ;$ \\
A27
\end{tabular} & Miranda (2008) \\
\hline $\mathrm{p}$ & $\mathrm{P}$ & PB & & PB_PROF_V215 & $\begin{array}{l}\text { Discussão frequente com a Direção sobre as metas } \\
\text { educacionais melhora o desempenho }\end{array}$ & - & c07 & \begin{tabular}{|l|} 
Silva, Bonamino e \\
Ribeiro (2012), \\
Miranda (2008) \\
\end{tabular} & $\begin{array}{l}\text { B15; B;16; } \\
\text { B19; B76 }\end{array}$ & \begin{tabular}{|l|} 
Silva, Bonamino e \\
Ribeiro (2012), \\
Miranda (2008)
\end{tabular} & A18; A50; & $\begin{array}{l}\text { Silva, Bonamino e } \\
\text { Ribeiro (2012), } \\
\text { Miranda (2008) }\end{array}$ \\
\hline $\mathrm{D}$ & $\mathrm{P}$ & PB & \multirow{2}{*}{$\begin{array}{l}\text { Garantir os livros } \\
\text { didáticos para todos } \\
\text { os alunos }\end{array}$} & PB_DIR_V503 & Escola receber os livros didáticos escolhidos & - & $\mathrm{C} 64 ; \mathrm{C} 30$ & $\begin{array}{l}\text { Nardi, Schneider } \\
\text { e Rios (2014); } \\
\text { Carvalho, } \\
\text { Bonamino e } \\
\text { Kappel (2011) } \\
\end{array}$ & - & For & - & (2) \\
\hline D & $\mathrm{P}$ & $\mathrm{PB}$ & & PB_DIR_V509 & Todos os alunos terem o livro didático & - & $\mathrm{C} 64 ; \mathrm{C3O}$ & $\begin{array}{l}\text { Nardi, Schneider } \\
\text { e Rios (2014); } \\
\text { Carvalho, } \\
\text { Bonamino e } \\
\text { Kappel (2011) } \\
\end{array}$ & - & - & - & - \\
\hline$\top$ & APL & PLCE & $\begin{array}{l}\begin{array}{l}\text { Oferecer disciplina de } \\
\text { Lingua Inglesa }\end{array} \\
\end{array}$ & C_TURM_V08 & $\begin{array}{l}\text { Oferta da disciplina Língua Estrangeira está } \\
\text { associada ao bom desempenho. }\end{array}$ & - & - & 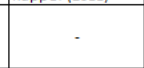 & 883 & $\begin{array}{l}\text { Salgado Junior e } \\
\text { Novi (2015); } \\
\text { Soriano (2017) }\end{array}$ & - & - \\
\hline $\mathrm{D}$ & D & PB & \multirow{3}{*}{$\begin{array}{l}\text { Acompanhar } \\
\text { resultados do SAEB }\end{array}$} & PB_DIR_V196 & Diretor acompanhar os resultados do SAEB da escola & - & $\begin{array}{c}\mathrm{C} 15 ; \\
\mathrm{C} 16 ; \mathrm{C} 17\end{array}$ & \begin{tabular}{|l|} 
Salgado Junior e \\
Novi (2015); \\
Soriano (2017); \\
Barbosa e Mello \\
(2015) Lima \\
(2013); Machado \\
e Alavarse (2014); \\
Nardi, Schneider \\
e Rios (2014); \\
Carvalho, \\
Bonamine e \\
Kappel (2011) \\
\end{tabular} & $\begin{array}{c}\text { B25; } 826 ; \\
\text { B27 } \\
\end{array}$ & $\begin{array}{l}\text { Salgado Junior e } \\
\text { Novi (2015); } \\
\text { Soriano (2017); } \\
\text { Barbosa e Mello } \\
\text { (2015) Lima } \\
\text { (2013); Machado } \\
\text { e Alavarse (2014); } \\
\text { Nardi, Schneider } \\
\text { e Rios (2014); } \\
\text { Carvalho, } \\
\text { Bonamino e } \\
\text { Kappel (2011) } \\
\end{array}$ & $\begin{array}{l}\text { A20; A21; } \\
\text { A22; A23 }\end{array}$ & $\begin{array}{l}\text { Salgado Junior e } \\
\text { Novi (2015); } \\
\text { Soriano (2017); } \\
\text { Barbosa e Mello } \\
\text { (2015) Lima } \\
\text { (2013); Machado } \\
\text { e Alavarse (2014); } \\
\text { Nardi, Schneider } \\
\text { e Rios (2014); } \\
\text { Carvalho, } \\
\text { Bonamino e } \\
\text { Kappel (2011) } \\
\end{array}$ \\
\hline D & D & PB & & PB_DIR_V201 & $\begin{array}{l}\text { Diretor acompanhar os resultados do SAEB do } \\
\text { municipio }\end{array}$ & - & $\begin{array}{l}\mathrm{C} 15 ; \\
\mathrm{C} 16 ; \mathrm{C} 17\end{array}$ & $\begin{array}{l}\text { Salgado Junior e } \\
\text { Novi (2015); } \\
\text { Soriano (2017); } \\
\text { Barbosa e Mello } \\
\text { (2015) Lima } \\
\text { (2013); Machado } \\
\text { e Alavarse (2014); } \\
\text { Nardi, Schneider } \\
\text { e Rios (2014); } \\
\text { Carvalho, } \\
\text { Bonamino e } \\
\text { Kappel (2011) } \\
\end{array}$ & $\begin{array}{c}\text { B25; B26; } \\
\text { B27 } \\
\end{array}$ & $\begin{array}{l}\text { Salgado Junior e } \\
\text { Novi (2015); } \\
\text { Soriano (2017); } \\
\text { Barbosa e Mello } \\
\text { (2015) Lima } \\
\text { (2013); Machado } \\
\text { e Alavarse (2014); } \\
\text { Nardi, Schneider } \\
\text { e Rios (2014); } \\
\text { Carvalho, } \\
\text { Bonamino e } \\
\text { Kappel (2011) }\end{array}$ & $\begin{array}{l}\text { A20; } \mathrm{A} 21 ; \\
\text { A22; } \mathrm{A} 23\end{array}$ & $\begin{array}{l}\text { Salgado Junior e } \\
\text { Novi (2015); } \\
\text { Soriano (2017); } \\
\text { Barbosa e Mello } \\
\text { (2015) Lima } \\
\text { (2013); Machado } \\
\text { e Alavarse (2014); } \\
\text { Nardi, Schneider } \\
\text { e Rios (2014); } \\
\text { Carvallo, } \\
\text { Bonamino e } \\
\text { Kappel (2011) }\end{array}$ \\
\hline $\mathrm{D}$ & D & PB & & PB_DIR_V206 & Diretor acompanhar os resultados do SAEB do estado & - & $\begin{array}{c}\mathrm{C} 15 ; \\
\mathrm{C} 16 ; \mathrm{C} 17\end{array}$ & \begin{tabular}{|l|} 
Salgado Junior e \\
Novi (2015); \\
Soriano (2017); \\
Barbosa e Mello \\
(2015) Lima \\
(2013); Machado \\
e Alavarse (2014); \\
Nardi, Schneider \\
e Rios (2014); \\
Carvalho, \\
Bonamino e \\
Kappel (2011) \\
\end{tabular} & $\begin{array}{c}\text { B25; } 826 ; \\
\text { B27 } \\
\end{array}$ & \begin{tabular}{|l} 
Salgado Junior e \\
Novi (2015); \\
Soriano (2017); \\
Barbosa e Mello \\
(2015) Lima \\
(2013); Machado \\
e Alavarse (2014); \\
Nardi, Schneider \\
e Rios (2014); \\
Carvalho, \\
Bonamino e \\
Kappel (2011) \\
\end{tabular} & $\begin{array}{l}\text { A20; } \mathrm{A} 21 ; \\
\text { A22; } \mathrm{A} 23\end{array}$ & $\begin{array}{l}\text { Salgado Junior e } \\
\text { Novi (2015); } \\
\text { Soriano (2017); } \\
\text { Barbosa e Mello } \\
\text { (2015) Lima } \\
\text { (2013); Machado } \\
\text { e Alavarse (2014); } \\
\text { Nardi, Schneider } \\
\text { e Rios (2014); } \\
\text { Carvalho, } \\
\text { Bonamino e } \\
\text { Kappel (2011) } \\
\end{array}$ \\
\hline $\mathrm{D}$ & D & PB & $\begin{array}{l}\text { Formar turmas } \\
\text { heterogêneas em } \\
\text { relação ao rendimento }\end{array}$ & PB_DIR_V226 & $\begin{array}{l}\text { Adotar critério de formação de turmas heterogêneas } \\
\text { em relação ao rendimento. }\end{array}$ & - & $\mathrm{c} 20$ & $\begin{array}{l}\text { Salgado Junior e } \\
\text { Novi (2015); } \\
\text { Soriano (2017) }\end{array}$ & 829 & $\begin{array}{l}\text { Salgado Junior e } \\
\text { Novi (2015); } \\
\text { Soriano (2017) }\end{array}$ & A24 & $\begin{array}{l}\text { Salgado Junior e } \\
\text { Novi (2015); } \\
\text { Soriano (2017) }\end{array}$ \\
\hline $\mathrm{D}$ & D & PB & \multirow{2}{*}{$\begin{array}{l}\text { Realizar açōes de } \\
\text { combate à evasão }\end{array}$} & PB_DIR_V246 & $\begin{array}{l}\text { Diretor realizar ações para redução das taxas de } \\
\text { abandono. }\end{array}$ & - & $\begin{array}{l}\mathrm{C} 21 ; \mathrm{C} 22 ; \\
\mathrm{C} 23\end{array}$ & $\begin{array}{l}\text { Nardi, Schneider } \\
\text { e Rios (2014); } \\
\text { Barbosa e } \\
\text { Wilhelm (2009); } \\
\text { Miranda (2008) }\end{array}$ & $\begin{array}{c}\text { B05; B30; } \\
\text { B31; в32; } \\
\text { B33 }\end{array}$ & $\begin{array}{l}\text { Nardi, Schneider } \\
\text { e Rios (2014); } \\
\text { Barbosa e } \\
\text { Wilhelm (2009); } \\
\text { Miranda (2008) }\end{array}$ & - & - \\
\hline A & A & AB & & PB_ALUN_V38 & Cobrança dos pais para a frequência às aulas & - & - & $\overline{4}$ & $B 05 ; 813$ & $\begin{array}{l}\text { Salgado Junior e } \\
\text { Novi (2015); } \\
\text { Soriano (2017) }\end{array}$ & A13 & \begin{tabular}{|l} 
Salgado Junior e \\
Novi (2015); \\
Soriano (2017)
\end{tabular} \\
\hline $\mathrm{D}$ & $\mathrm{D}$ & PB & \multirow[b]{2}{*}{$\begin{array}{l}\text { Oferecer reforço no } \\
\text { contraturno }\end{array}$} & PB_DIR_V253 & Adoção de ações para a redução da reprovação & - & $\begin{array}{l}\mathrm{C} 24 ; \mathrm{C} 25 ; \\
\mathrm{C} 26 ; \mathrm{C} 27\end{array}$ & \begin{tabular}{|l|} 
Nardi, Schneider \\
e Rios (2014); \\
Barbosa e \\
Wilhelm (2009); \\
Miranda (2008); \\
Gomes (2010) \\
\end{tabular} & $\begin{array}{c}\text { B34; B35; } \\
\text { B36; B37; } \\
\text { B38 }\end{array}$ & \begin{tabular}{|l|} 
Nardi, Schneider \\
e Rios (2014); \\
Barbosa e \\
Wilhelm (2009); \\
Miranda (2018); \\
Gomes (2010) \\
\end{tabular} & $\begin{array}{l}\text { A26; A27; } \\
\text { A29; A30 }\end{array}$ & $\begin{array}{l}\text { Nardi, Schneider } \\
\text { e Rios (2014); } \\
\text { Barbosa e } \\
\text { Wilhelm (2009); } \\
\text { Miranda (2008); } \\
\text { Gomes (2010) }\end{array}$ \\
\hline $\mathrm{D}$ & D & PB & & PB_DIR_V258 & Oferta de reforço no contraturno & - & $\mathrm{c} 28$ & \begin{tabular}{|l|} 
Ferrarotto e \\
Malavasi (2015) \\
Lima et al. (2014); \\
Silva, Bonamino e \\
Ribeiro (2012); \\
Brandão e \\
Carvalho (2015); \\
Nardi, Schneider \\
e Rios (2014)
\end{tabular} & B37 & \begin{tabular}{|l|} 
Ferrarotto e \\
Malavasi (2015) \\
Lima et al. (2014); \\
Silva, Bonamino e \\
Ribeiro (2012); \\
Brandão e \\
Carvalho (2015); \\
Nardi, Schneider \\
e Rios (2014)
\end{tabular} & A28 & \begin{tabular}{|l} 
Ferrarotto e \\
Malavasi (2015) \\
Lima et al. (2014); \\
Silva, Bonamino e \\
Ribeiro (2012); \\
Brandão e \\
Carvalho (2015); \\
Nardi, Schneider \\
e Rios (2014)
\end{tabular} \\
\hline
\end{tabular}




\begin{tabular}{|c|c|c|c|c|c|c|c|c|c|c|c|c|}
\hline \multirow{3}{*}{$\overrightarrow{\underline{\underline{z}}}$} & \multirow{3}{*}{\multicolumn{2}{|c|}{ 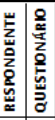 }} & \multirow{3}{*}{ PRÁtICA } & \multirow{3}{*}{ 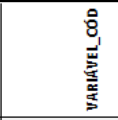 } & \multirow{3}{*}{ VARIÁVEL } & \multirow{3}{*}{ 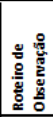 } & \multicolumn{6}{|c|}{ QUESTÕES DO INSTRUMENTO (REFERENTE À PRÁTICA) } \\
\hline & & & & & & & \multicolumn{2}{|r|}{ SME } & \multicolumn{2}{|c|}{ DIRETOR } & \multicolumn{2}{|c|}{ PROFESSOR } \\
\hline & & & & & & & Questão & Autor & Questão & Autor & Questão & Autor \\
\hline A & A & $\mathrm{PB}$ & $\begin{array}{l}\text { Participar das } \\
\text { reuniôes escolares }\end{array}$ & PB_ALUN_V29 & Participação dos pais em reuniões escolares & - & - & - & B13 & \begin{tabular}{|l|} 
Lima et al. (2014); \\
Barbosa e Mello \\
(2015); Barbosa e \\
Wilhelm (2009); \\
Miranda (2008); \\
Garcia (2011); \\
Silva (2009)
\end{tabular} & A13; A33 & $\begin{array}{l}\text { Lima et al. (2014); } \\
\text { Barbosa e Mello } \\
\text { (2015); Barbosa e } \\
\text { Wilhelm (2009); } \\
\text { Miranda (2008); } \\
\text { Garcia (2011); } \\
\text { Silva (2009) }\end{array}$ \\
\hline A & A & $\mathrm{PB}$ & $\begin{array}{l}\text { Cobrar a realização do } \\
\text { dever de casa }\end{array}$ & PB_ALUN_V34 & Cobrança dos pais sobre os deveres de casa & - & - & - & B13 & \begin{tabular}{|l|} 
Lima et al. (2014); \\
Barbosa e \\
Willelm (2009); \\
Miranda (2008); \\
Garcia (2011); \\
Silva (2009)
\end{tabular} & A13 & $\begin{array}{l}\text { Lima et al. (2014); } \\
\text { Barbosa e } \\
\text { Wilhelm (2009); } \\
\text { Miranda (2008); } \\
\text { Garcia (2011); } \\
\text { Silva (2009) }\end{array}$ \\
\hline A & A & $\mathrm{PB}$ & \multirow{7}{*}{$\begin{array}{l}\text { Incrementar a própria } \\
\text { escolaridade }\end{array}$} & PB_ALUN_V07 & Mãe com ensino primário incompleto & - & - & - & - & $\cdot$ & - & - \\
\hline A & A & $\mathrm{PB}$ & & PB_ALUN_V11 & Mãe com curso superior completo & - & - & - & - & - & - & - \\
\hline A & $A$ A & & & PB_ALUN_V22 & Pai com curso superior completo & - & - & - & - & - & - & - \\
\hline A & A & $\mathrm{PB}$ & & PB_ALUN_V24 & Pai sabe ler e escrever & - & - & - & - & - & - & - \\
\hline A & $A$ & $\mathrm{~PB}$ & & PB_ALUN_V44 & Mãe sabe ler e escrever & - & - & $\cdot$ & $\cdot$ & 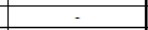 & - & 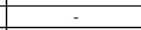 \\
\hline A & $\mathrm{p}$ & $\mathrm{PB}$ & & PB_PROF_V272 & Influência do meio social do aluno & - & $\mathrm{CO1} ; 005$ & $\begin{array}{l}\text { Colleman et al } \\
\text { (1966) }\end{array}$ & B12 & \begin{tabular}{|l|}
$\begin{array}{l}\text { Colleman et al } \\
(1966)\end{array}$ \\
\end{tabular} & A12 & $\begin{array}{l}\text { Colleman et al } \\
(1966)\end{array}$ \\
\hline A & $\mathrm{p}$ & $\mathrm{PB}$ & & PB_PROF_V274 & Nivel cultural dos pais & - & $\cos$ & $\begin{array}{l}\text { Colleman et al } \\
\text { (1966) }\end{array}$ & B03 & $\begin{array}{l}\text { Colleman et al } \\
\text { (1966) }\end{array}$ & A12 & $\begin{array}{l}\text { Colleman et al } \\
\text { (1966) }\end{array}$ \\
\hline A & $A$ & $\mathrm{~PB}$ & Manter o hábito da & PB_ALUN_V47 & Vê a mãe lendo & - & - & -2 & - & +2 & - & 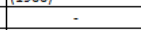 \\
\hline A & A & PB & leitura & PB_ALUN_V27 & Vê o pai lendo & - & - & - & - & - & - & 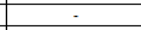 \\
\hline A & A & $\mathrm{PB}$ & $\begin{array}{l}\text { Possuir computador } \\
\text { em casa }\end{array}$ & PB_ALUN_V02 & Possui computador em casa tem efeito positivo & - & - & - & - & - & $\mathrm{A} 10 ; \mathrm{A} 11$ & $\begin{array}{l}\text { Salgado Junior e } \\
\text { Novi (2015); } \\
\text { Soriano (2017) }\end{array}$ \\
\hline A & $\mathrm{P}$ & PB & \multirow{6}{*}{$\begin{array}{l}\text { Cobrar a disciplina e } \\
\text { frequência às aulas }\end{array}$} & PB_PROF_V280 & Desinteresse e falta de esforço dos alunos & - & - & - & B01 & $\begin{array}{l}\text { Salgado Junior e } \\
\text { Novi (2015); } \\
\text { Soriano (2017) } \\
\end{array}$ & A01 & \begin{tabular}{|l} 
Salgado Junior e \\
Novi (2015); \\
Soriano (2017)
\end{tabular} \\
\hline A & $p$ p & $P B$ & & PB_PROF_V278 & Baixa Autoestima do Aluno & - & - & - & - & -2 & - & - \\
\hline A & $\mathrm{P}$ & PB & & PB_PROF_V282 & Indisciplina dos alunos & - & - & - & B03; B04 & \begin{tabular}{|l|} 
Silva, Bonamino e \\
Ribeiro (2012); \\
Miranda (2008) \\
\end{tabular} & $\begin{array}{c}\mathrm{A} 02 ; \mathrm{AO} ; \\
\mathrm{A} 13\end{array}$ & \begin{tabular}{|l} 
Silva, Bonamino e \\
Ribeiro (2012); \\
Miranda (2008)
\end{tabular} \\
\hline A & $\mathrm{P}$ & $\mathrm{PB}$ & & PB_PROF_V284 & Alto índice de faltas do aluno $(++)$ & - & $\mathrm{CO2} ; \mathrm{CO3}$ & $\begin{array}{l}\text { Salgado Junior e } \\
\text { Novi (2015); } \\
\text { Soriano (2017) }\end{array}$ & 805 & \begin{tabular}{|l|} 
Salgado Junior e \\
Novi (2015); \\
Soriano (2017)
\end{tabular} & A04 & $\begin{array}{l}\text { Salgado Junior e } \\
\text { Novi (2015); } \\
\text { Soriano (2017) }\end{array}$ \\
\hline A & A & PB & & PB_ALUN_V38 & Cobrança dos pais para a frequência às aulas & - & - & $x_{1}$ & B05; B13 & \begin{tabular}{|l|} 
Salgado Junior e \\
Novi (2015); \\
Soriano (2017)
\end{tabular} & A13 & $\begin{array}{l}\text { Salgado Junior e } \\
\text { Novi (2015); } \\
\text { Soriano (2017) }\end{array}$ \\
\hline A & $\mathrm{P}$ & PB & & PB_DIR_V457 & $\begin{array}{l}\text { Funcionamento da Escola interrompido por } \\
\text { problemas de indisciplina }\end{array}$ & - & - & - & B03; B04 & \begin{tabular}{|l|} 
Silva, Bonamino e \\
Ribeiro (2012); \\
Miranda (2008) \\
\end{tabular} & $\begin{array}{c}\mathrm{A} 02 ; \mathrm{A} 03 ; \\
\mathrm{A} 13\end{array}$ & $\begin{array}{l}\text { Silva, Bonamino e } \\
\text { Ribeiro (2012); } \\
\text { Miranda (2008) }\end{array}$ \\
\hline A & A & $\mathrm{PB}$ & $\begin{array}{l}\text { Pais incentivarem o } \\
\text { uso da biblioteca } \\
\text { escolar }\end{array}$ & PB_ALUN_V107 & $\begin{array}{l}\text { Utilizar a biblioteca e sala de leitura da escola } \\
\text { (Sempre) }\end{array}$ & - & - & - & - & - & A05 & \begin{tabular}{|l} 
Salgado Junior e \\
Novi (2015); \\
Soriano (2017)
\end{tabular} \\
\hline A & A & PB & \multirow{3}{*}{$\begin{array}{l}\text { Controlar o tempo } \\
\text { com atividades } \\
\text { recreativas }\end{array}$} & PB_ALUN_V66 & Frequência com que vai cinema (Sempre) & - & - & - & - & - & - & $-\quad$ \\
\hline A & A & $\mathrm{PB}$ & & PB_ALUN_V69 & $\begin{array}{l}\begin{array}{l}\text { Frequência com que vai a espetáculos e exposições } \\
\text { (Sempre) }\end{array} \\
\end{array}$ & - & - & - & - & - & - & . \\
\hline A & A & $\mathrm{PB}$ & & PB_ALUN_V74 & $\begin{array}{l}\text { Tempo gasto com tv, internet e jogos (uma a duas } \\
\text { horas/dia) }\end{array}$ & - & - & - & - & $\cdot$ & - & - \\
\hline A & A & PB & \multirow{9}{*}{$\begin{array}{l}\text { Incentivar a leitura } \\
\text { (especialmente de } \\
\text { livros de literatura) }\end{array}$} & PB_ALUN_V36 & Incentivo dos pais à leitura & - & - & - & B02 & $\begin{array}{l}\text { Salgado Junior e } \\
\text { Novi (2015); } \\
\text { Soriano (2017) }\end{array}$ & - & - \\
\hline A & A & $\mathrm{PB}$ & & PB_ALUN_V45 & \begin{tabular}{|l|}
$\begin{array}{l}\text { Frequência de leitura de livros de interesse geral } \\
\text { (Sempre) }\end{array}$ \\
\end{tabular} & - & - & - & B10; B11 & Miranda (2008) & A08 & Miranda (2008) \\
\hline A & A & PB & & PB_ALUN_V42 & Frequência de leitura de jornais (Sempre) & - & - & - & B10; $B 11$ & $\begin{array}{l}\text { Salgado Junior e } \\
\text { Novi (2015); } \\
\text { Soriano (2017) }\end{array}$ & A09 & \begin{tabular}{|l|} 
Salgado Junior e \\
Novi (2015); \\
Soriano (2017)
\end{tabular} \\
\hline A & A & PB & & PB_ALUN_V55 & Frequência de leitura de gibis (Algumas vezes) & - & - & - & B10; B11 & $\begin{array}{l}\text { Salgado Junior e } \\
\text { Novi (2015); } \\
\text { Soriano (2017) }\end{array}$ & A09 & \begin{tabular}{|l} 
Salgado Junior e \\
Novi (2015); \\
Soriano (2017) \\
\end{tabular} \\
\hline A & A & PB & & PB_ALUN_V48 & Frequência de leitura de livros de Literatura (Sempre) & - & - & - & B10; 811 & $\begin{array}{l}\text { Salgado Junior e } \\
\text { Novi (2015); } \\
\text { Soriano (2017) } \\
\end{array}$ & A09 & \begin{tabular}{|l} 
Salgado Junior e \\
Novi (2015); \\
Soriano (2017) \\
\end{tabular} \\
\hline A & A & $\mathrm{PB}$ & & PB_ALUN_V57 & $\begin{array}{l}\text { Frequência de leitura de revistas de comportamento } \\
\text { (Sempre) }\end{array}$ & - & - & - & B10; B11 & $\begin{array}{l}\text { Salgado Junior e } \\
\text { Novi (2015); } \\
\text { Soriano (2017) }\end{array}$ & A09 & \begin{tabular}{|l} 
Salgado Junior e \\
Novi (2015); \\
Soriano (2017) \\
\end{tabular} \\
\hline A & A & PB & & PB_ALUN_V51 & Frequência de leitura de revistas em geral (Sempre) & - & - & - & B10; B11 & $\begin{array}{l}\text { Salgado Junior e } \\
\text { Novi (2015); } \\
\text { Soriano (2017) }\end{array}$ & A09 & \begin{tabular}{|l} 
Salagado Junior e \\
Novi (2015); \\
Soriano (2017)
\end{tabular} \\
\hline A & A & $\mathrm{PB}$ & & PB_ALUN_V60 & $\begin{array}{l}\text { Frequência de leitura de notícias na Internet } \\
\text { (Sempre) }\end{array}$ & - & - & - & B10; B11 & $\begin{array}{l}\text { Salgado Junior e } \\
\text { Novi (2015); } \\
\text { Soriano (2017) }\end{array}$ & A09 & $\begin{array}{l}\text { Salgado Junior e } \\
\text { Novi (2015); } \\
\text { Soriano (2017) }\end{array}$ \\
\hline A & A & PB & & PB_ALUN_V63 & Frequência de visitas à Biblioteca (Sempre) & - & - & - & - & tom & A05 & \begin{tabular}{|l} 
Salgado Junior e \\
Novi (2015); \\
Soriano (2017) \\
\end{tabular} \\
\hline A & A & PB & \begin{tabular}{|l|} 
Gostar da Disciplina \\
de Lingua Portuguesa
\end{tabular} & PB_ALUN_V87 & Gosta da Disciplina de Língua Portuguesa & - & - & - & $B 01$ & \begin{tabular}{|l} 
Salgado Junior e \\
Novi (2015); \\
Soriano (2017)
\end{tabular} & A01 & $\begin{array}{l}\text { Salgado Junior e } \\
\text { Novi (2015); } \\
\text { Soriano (2017) } \\
\end{array}$ \\
\hline A & A & $\mathrm{PB}$ & \multirow{2}{*}{$\begin{array}{l}\text { Realizar o dever de } \\
\text { casa }\end{array}$} & PB_ALUN_V89 & $\begin{array}{l}\text { Frequência com que faz o dever de casa de Língua } \\
\text { Portuguesa (Sempre) }\end{array}$ & - & - & - & - & tom & A06 & \begin{tabular}{|l} 
Salgado Junior e \\
Novi (2015); \\
Soriano (2017) \\
\end{tabular} \\
\hline A & A & $\mathrm{PB}$ & & PB_ALUN_V34 & Cobrança dos pais sobre os deveres de casa & - & - & - & B13 & $\begin{array}{l}\text { Salgado Junior e } \\
\text { Novi (2015); } \\
\text { Soriano (2017) }\end{array}$ & A13 & $\begin{array}{l}\text { Salgado Junior e } \\
\text { Novi (2015); } \\
\text { Soriano (2017) }\end{array}$ \\
\hline
\end{tabular}

Fonte: Adaptado de Soriano (2017) 


\section{APÊNDICE B - Roteiro de Entrevista - Professor (A)}

\begin{tabular}{|c|c|}
\hline GRUPO & PROFESSOR(A) \\
\hline & $\begin{array}{l}\text { 1. Como você avalia o interesse dos alunos pela sua disciplina? } \\
\text { 2. Como você classifica a disciplina dos alunos? } \\
\text { 3. As regras disciplinares são claras e de conhecimento geral? Quais as medidas } \\
\text { disciplinares adotadas pela escola? Você acha que são adequadas? } \\
\text { 4. Existem atividades de reposição de conteúdo para os alunos após as } \\
\text { eventuais faltas? } \\
5 \text { Com que frequência você utiliza e incentiva a utilização da biblioteca e a sala } \\
\text { de leitura? } \\
6 \text { Com que frequência você oferece dever de casa? Com que frequência os } \\
\text { alunos realizam os deveres de casa? } \\
\text { 7. Como é feita a correção do dever de casa? } \\
\text { 8. Como você avalia a frequência de leitura dos alunos? Qual é a média de } \\
\text { livros lidos por aluno semestralmente? } \\
\text { 9. Que tipo de publicação os alunos costumam ler? }\end{array}$ \\
\hline NSE & $\begin{array}{l}\text { 10. São solicitadas atividades para casa que exigem uso de computador? } \\
\text { 11. Você vê alguma diferença de desempenho entre os estudantes que têm e os } \\
\text { que não têm computador em casa? } \\
\text { 12. Como você avalia a influência do meio social e da família no interesse e } \\
\text { desempenho dos alunos? }\end{array}$ \\
\hline $\begin{array}{l}\text { Participação } \\
\text { da Família }\end{array}$ & $\begin{array}{l}\text { 13. Sobre a participação dos pais: } \\
\text { a. Comparecem e participam das reuniões? Quais as razões para o não } \\
\text { comparecimento? } \\
\text { b. Procuram os professores e a escola para saber sobre o desempenho dos } \\
\text { filhos? } \\
\text { c. Participam dos eventos que acontecem nas escolas? } \\
\text { d. } \quad \text { Participam da APM? } \\
\text { e. } \quad \text { Conhecem e apoiam as regras/ações da escola? } \\
\text { f. Acompanham os deveres escolares? } \\
\text { g. Se preocupam com a frequência dos alunos? }\end{array}$ \\
\hline
\end{tabular}




\begin{tabular}{|c|c|}
\hline Gestão & 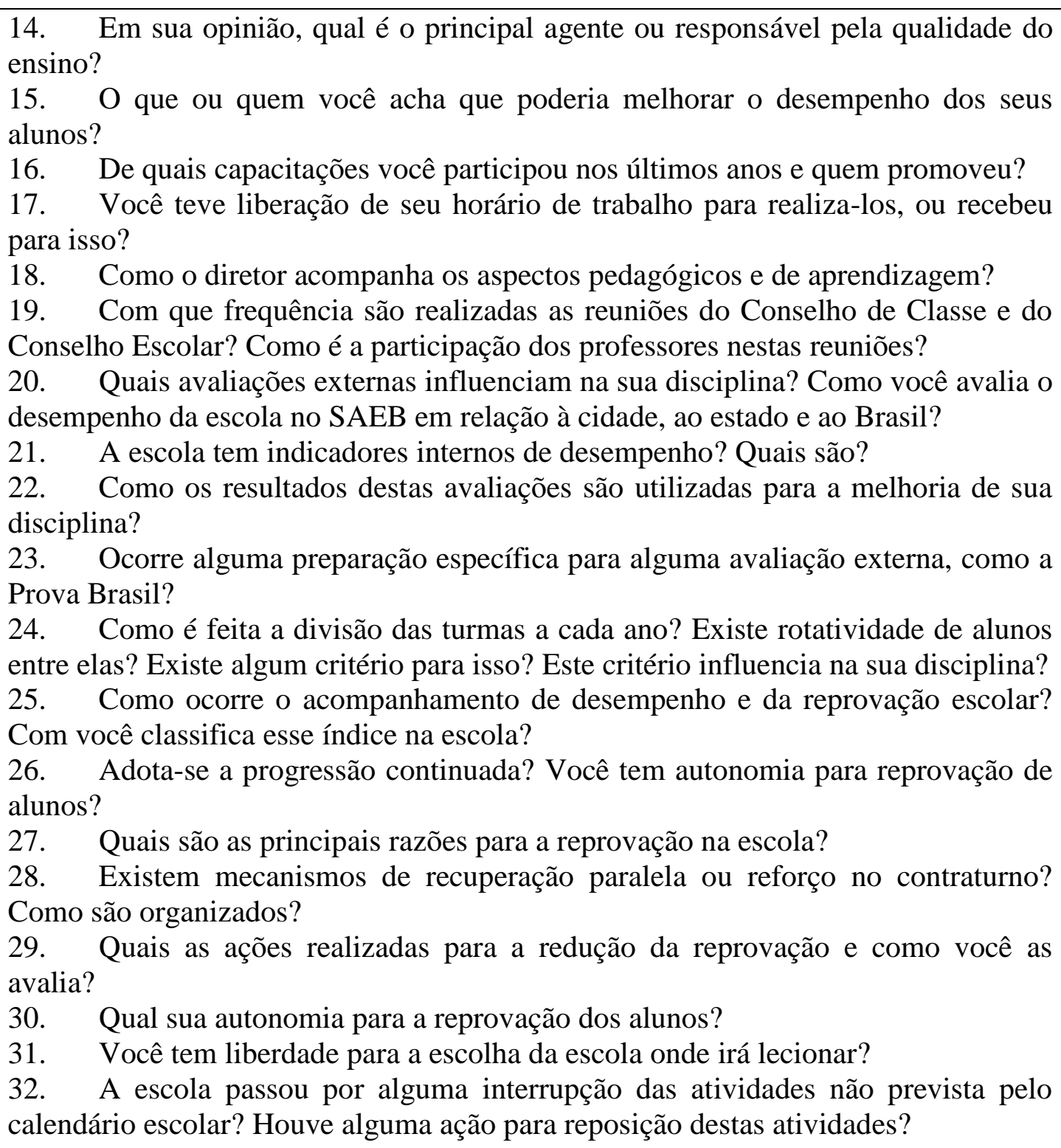 \\
\hline $\begin{array}{l}\text { Integração } \\
\text { com } \\
\text { comunidade }\end{array}$ & $\begin{array}{l}\text { 33. A escola promove eventos que permitam a interação entre pais e professores? } \\
\text { 34. Existem projetos temáticos promovidos pela escola? Quais os impactos } \\
\text { destes projetos junto aos alunos? } \\
\text { 35. Quais eventos são promovidos para integrar a comunidade à escola? Qual a } \\
\text { adesão? }\end{array}$ \\
\hline Recursos PNE & $\begin{array}{l}\text { 36. Você possui alunos PNE? Está habilitado a trabalhar com eles? Recebeu } \\
\text { algum treinamento para isso? } \\
\text { 37. De que estrutura a escola dispõe? Ela é condizente com as necessidades dos } \\
\text { alunos? }\end{array}$ \\
\hline Biblioteca & $\begin{array}{l}\text { 38. Em relação à biblioteca, como você classifica o volume e variedade do } \\
\text { acervo? }\end{array}$ \\
\hline $\begin{array}{l}\text { Recursos e } \\
\text { Infraestrutura }\end{array}$ & $\begin{array}{l}\text { 39. A escola tem problema relacionado ao uso ou comércio de drogas dentro das } \\
\text { instalações ou nas imediações? }\end{array}$ \\
\hline
\end{tabular}




\begin{tabular}{|c|c|}
\hline & $\begin{array}{l}\text { 40. Sobre os recursos de informática: } \\
\text { a. O número de computadores disponíveis no laboratório de informática é } \\
\text { suficiente para os alunos? Qual a condição de uso? Há restrições para uso? } \\
\text { b. A internet é de boa qualidade? } \\
\text { c. Que atividades são realizadas? Como e com qual frequência? } \\
\text { d. Você dispõe de computadores para preparação das aulas e pesquisa prévia de } \\
\text { atividades? } \\
\text { e. Você utiliza aplicativos pedagógicos? Quais? Com que resultado? }\end{array}$ \\
\hline Perfil Pessoal & $\begin{array}{l}\text { 41. Qual é o seu nível de escolaridade? } \\
\text { a. ( ) Ensino Superior Completo } \\
\text { b. } \\
\text { c. Qual área? } \\
\text { d. ( ) Licenciatura em Pedagogia } \\
\text { e. } \quad \text { Qual área? } \\
\text { f. ( ) Outras. } \\
\text { g. Qual área? } \\
\text { 42. Onde você fez sua graduação? Escola pública ou privada? } \\
\text { 43. Como você avalia sua formação - contribuiu para a atividade docente? O } \\
\text { curso forneceu instrumental prático para as aulas? Acha que faltou algo? } \\
\text { 44. Há quanto tempo você atua como professor? } \\
\text { 45. Ministra quais disciplinas? } \\
\text { 46. } \quad \text { Por que você se tornou professor? Esta era sua primeira opção de carreira? }\end{array}$ \\
\hline $\begin{array}{l}\text { Planejamento } \\
\text { Docente }\end{array}$ & $\begin{array}{l}\text { 47. Qual seu grau de autonomia para planejar sua disciplina? } \\
48 \text {. Você acredita que a carga horária de sua disciplina é suficiente para o } \\
\text { conteúdo proposto? } \\
\text { 49. Como você classifica a sua autonomia no ensino da disciplina quanto à } \\
\text { forma de avaliação? } \\
50 \text {. Como são realizadas as discussões com a Direção sobre as metas } \\
\text { educacionais e melhoria do desempenho dos alunos? } \\
51 \text { A escola possui um planejamento? Os objetivos são claros? Como é feito e } \\
\text { qual a sua participação? } \\
52 \text {. Qual a frequência de reuniões envolvendo professores do ensino fundamental } \\
\text { I e II para alinhamento de conteúdo? } \\
53 \text { Como os professores interagem para a melhoria do desempenho dos alunos } \\
\text { na disciplina? }\end{array}$ \\
\hline $\begin{array}{l}\text { Regime } \\
\text { Trabalho }\end{array}$ & $\begin{array}{l}\text { 54. Como é o plano de carreira para os docentes? O salário é atrativo? Você } \\
\text { precisa complementar sua renda com outras atividades? } \\
\text { 55. Quais são os critérios para os professores serem promovidos? } \\
\text { Qualificação Profissional. } \\
\text { Tempo de Serviço. } \\
\text { Quantidade de treinamentos realizados. } \\
\text { Combinação das alternativas (b) + (c). } \\
\text { Outro critério. Especifique: } \\
\text { 56. Existe algum incentivo em relação ao desempenho apresentado pelo } \\
\text { docente? } \\
57 . \quad \text { Qual seu tipo de contrato - CLT ou estatutário? } \\
\text { 58. Qual sua carga horária nesta escola? } \\
\text { 59. Em quantas escolas você trabalha? Você acha que isso ajuda ou atrapalha em } \\
\text { sua atividade? Por quê? }\end{array}$ \\
\hline
\end{tabular}




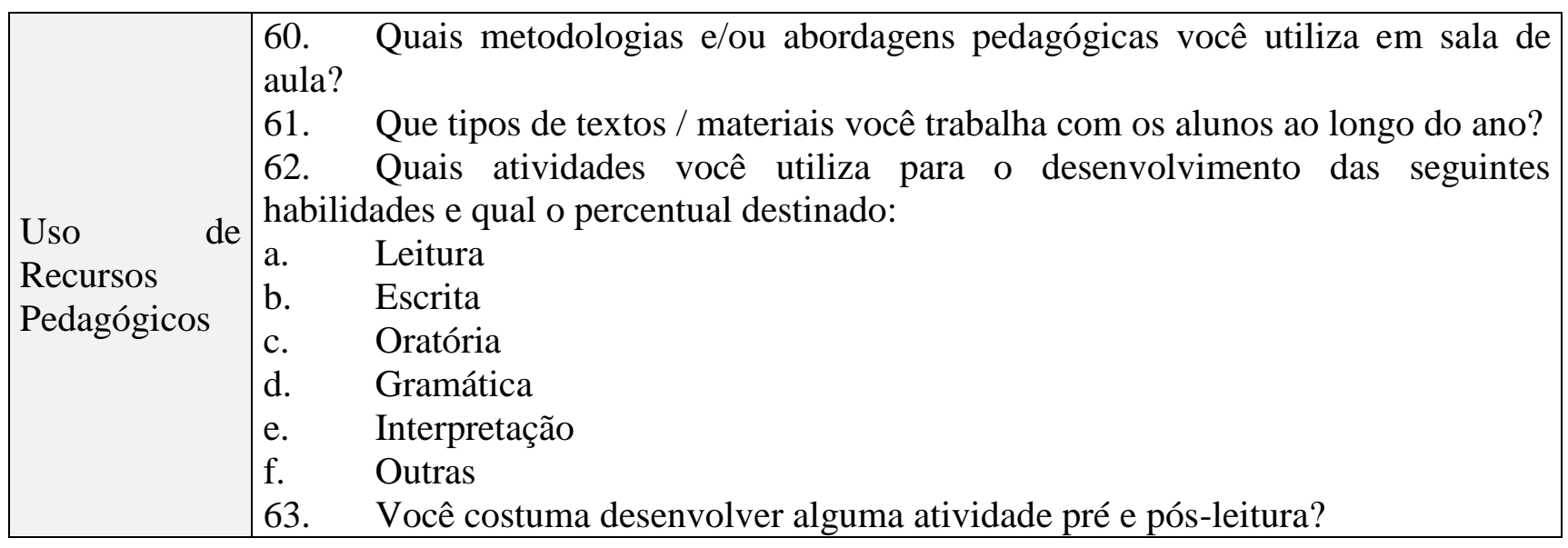

Fonte: Adaptado de Soriano (2017) 


\section{APÊNDICE C - Roteiro de Entrevista - Diretor (B)}

\begin{tabular}{|c|c|}
\hline GRUPO & QUESTÕES \\
\hline $\begin{array}{l}\text { Hábitos } \\
\text { Aluno }\end{array}$ & 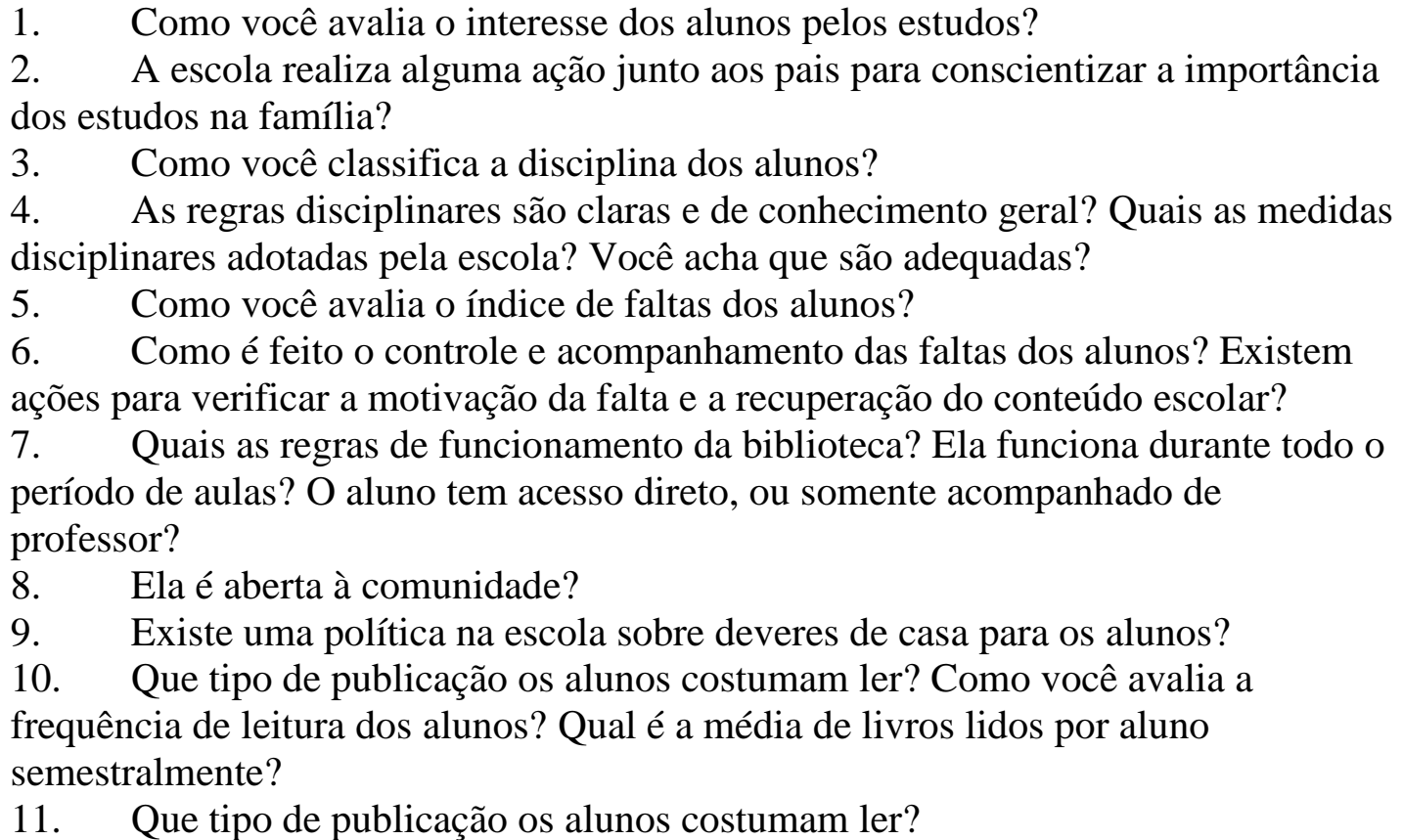 \\
\hline NSE & $\begin{array}{l}\text { 12. Como você avalia a influência do meio social e da família no interesse e } \\
\text { desempenho dos alunos? }\end{array}$ \\
\hline $\begin{array}{l}\text { Participação } \\
\text { da Família }\end{array}$ & $\begin{array}{l}\text { 13. Sobre a participação dos pais: } \\
\text { a. Comparecem e participam das reuniões? Quais as razões para o não } \\
\text { comparecimento? } \\
\text { b. } \quad \text { Procuram os professores e a escola para saber sobre o desempenho dos } \\
\text { filhos? } \\
\text { c. Participam dos eventos que acontecem nas escolas? } \\
\text { d. } \quad \text { Participam da APM? } \\
\text { e. } \quad \text { Conhecem e apoiam as regras/ações da escola? } \\
\text { f. Acompanham os deveres escolares? } \\
\text { a. } \quad \text { Se preocupam com a frequência dos alunos? }\end{array}$ \\
\hline Gestão & $\begin{array}{l}\text { 14. Em sua opinião, qual é o principal agente ou responsável pela qualidade do } \\
\text { ensino? } \\
\text { 15. O que ou quem você acha que poderia melhorar o desempenho dos seus } \\
\text { alunos? } \\
\text { 16. Existe uma política de incentivo ou de responsabilização de professores em } \\
\text { relação aos resultados educacionais? Quais? } \\
\text { 17. Como você identifica as necessidades de capacitação dos professores? } \\
18 \text {. Existe política de formação continuada para professores e diretores? Como } \\
\text { funciona? } \\
19 . \quad \text { Como você acompanha o desempenho / aprendizado dos alunos? } \\
20 . \quad \text { Como este acompanhamento é utilizado para a promoção de melhorias junto } \\
\text { aos professores? Quanto do seu tempo é destinado a estes assuntos? } \\
21 . \quad \text { Qual sua autonomia para definição das normas administrativas da escola? } \\
\text { Quais os requisitos para sua alteração? } \\
22 . \quad \text { Como é feito o acompanhamento da manutenção da escola? } \\
23 . \quad \text { Qual sua autonomia para destinação dos recursos? }\end{array}$ \\
\hline
\end{tabular}




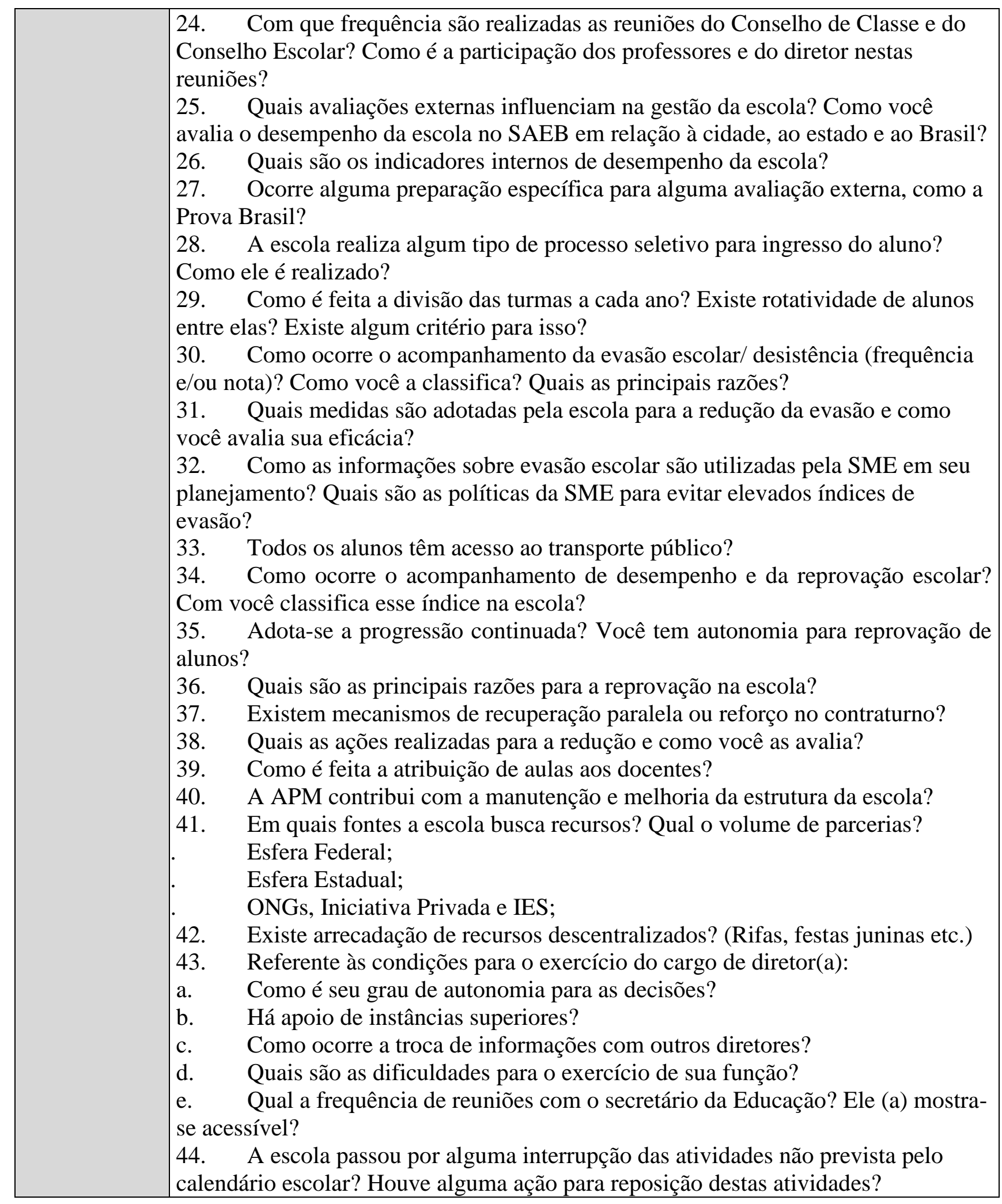




\begin{tabular}{|c|c|}
\hline $\begin{array}{l}\text { Integração } \\
\text { com a } \\
\text { comunidade }\end{array}$ & $\begin{array}{l}\text { 45. A escola promove eventos que permitam a interação entre pais e professores? } \\
\text { 46. Como os pais são comunicados sobre eventuais problemas relacionados aos } \\
\text { alunos? } \\
\text { 47. Quais projetos da gestão escolar anterior permanecem em andamento? } \\
\text { 48. Projetos pedagógicos: } \\
\text { a. Quais são os projetos implantados pela SME? } \\
\text { b. Quais são os resultados dos projetos implantados? } \\
\text { c. Quais são os projetos que dão atenção especial aos alunos com dificuldades } \\
\text { de aprendizagem? } \\
\text { d. Quais projetos da gestão anterior permanecem em andamento na SME? } \\
49 \text { Quais eventos são promovidos para integrar a comunidade à escola? Qual a } \\
\text { adesão? }\end{array}$ \\
\hline Perfil Pessoal & 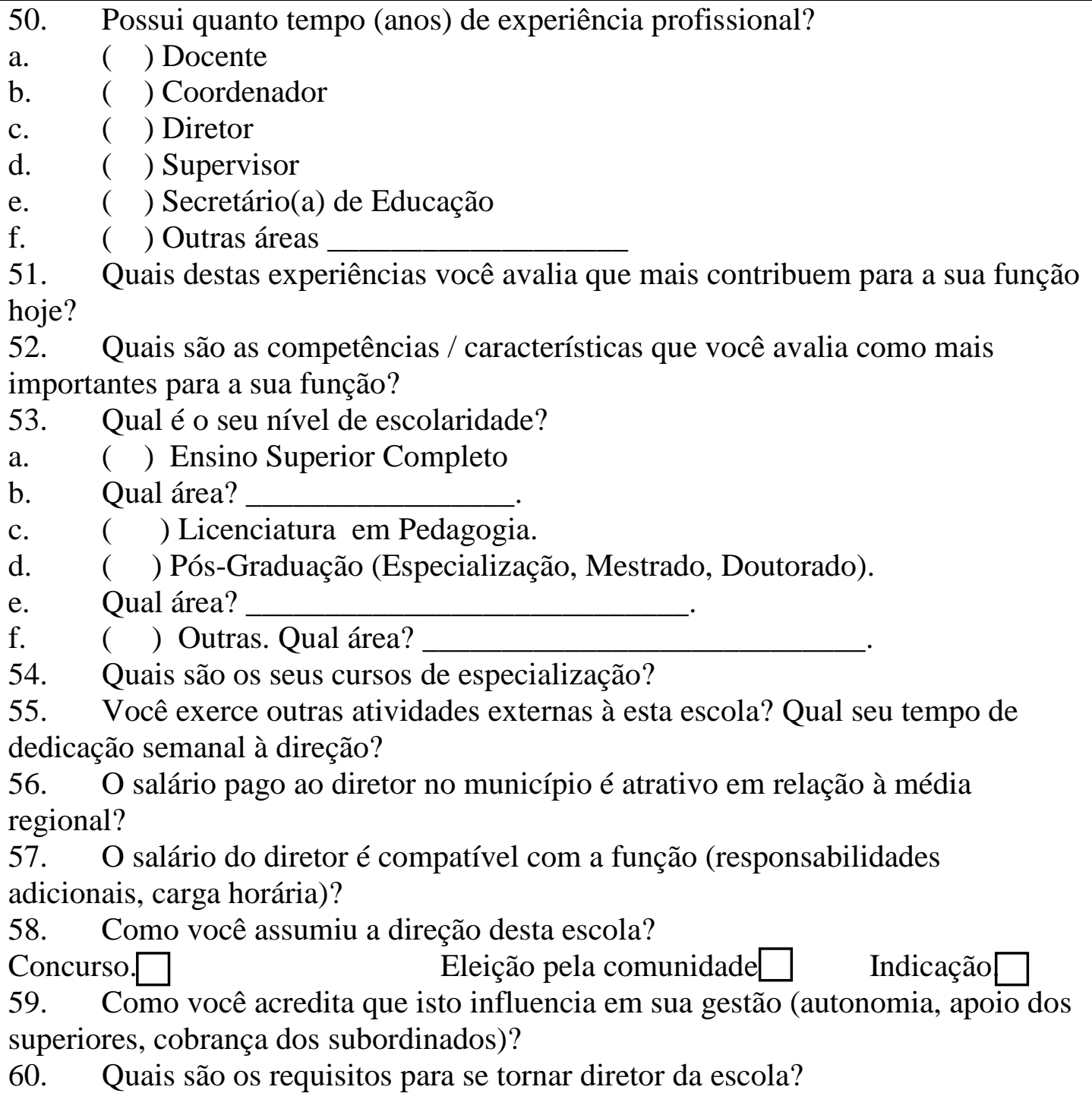 \\
\hline
\end{tabular}




\begin{tabular}{|c|c|}
\hline $\begin{array}{l}\text { Recursos e } \\
\text { Infraestrutura }\end{array}$ & $\begin{array}{l}\text { 61. A escola tem carência de algum tipo de profissional (administrativo, } \\
\text { pedagógico ou de professores)? } \\
\text { 62. O diretor tem autonomia para a contratação de pessoal administrativo? } \\
\text { 63. Quais recursos a escola possui para alunos PNE? Elas condizem com as } \\
\text { necessidades dos alunos? } \\
\text { 64. Os professores foram capacitados para o uso? } \\
\text { 65. Como é a organização da merenda escolar na sua escola? } \\
\text { 66. A merenda é adequada em relação à: } \\
\text { a. Quantidade } \\
\text { b. } \quad \text { Variedade } \\
\text { c. Qualidade } \\
\text { 67. Os professores da disciplina de Língua Portuguesa têm formação específica } \\
\text { na área das disciplinas que lecionam? }\end{array}$ \\
\hline Biblioteca & $\begin{array}{l}\text { 68. A escola recebe recursos para a biblioteca? Quais investimentos foram } \\
\text { feitos? }\end{array}$ \\
\hline $\begin{array}{l}\text { Recursos e } \\
\text { Infraestrutura }\end{array}$ & $\begin{array}{l}\text { 69. A escola possui problema com segurança nas escolas? Existem ações e } \\
\text { policiamento para coibir o tráfico de drogas nas imediações das escolas? } \\
70 . \quad \text { O número de computadores disponíveis no laboratório de informática é } \\
\text { suficiente para os alunos? } \\
71 \text { Q Qual a condição dos equipamentos de informática (computadores e internet) } \\
\text { para uso administrativo? }\end{array}$ \\
\hline $\begin{array}{l}\text { Planejamento } \\
\text { Docente }\end{array}$ & $\begin{array}{l}\text { 72. Existe um planejamento para garantir o cumprimento do conteúdo } \\
\text { pedagógico anual? Como funciona? } \\
\text { 73. Qual é a carga horária da disciplina de Português (absoluta e percentual)? } \\
\text { 74. Qual o grau de autonomia do docente em relação ao conteúdo ministrado? } \\
\text { 75. A escola delega funções administrativas aos professores? Quais? Com que } \\
\text { frequência? } \\
\text { 76. Como são realizadas as discussões com os professores sobre as metas } \\
\text { educacionais e melhoria do desempenho dos alunos? } \\
\text { 77. Qual o grau autonomia para a elaboração do projeto pedagógico da escola? } \\
\text { Como é realizado? } \\
\text { 78. Como é feito alinhamento do conteúdo das disciplinas entre as turmas e entre } \\
\text { os ensinos fundamentais I e II? }\end{array}$ \\
\hline $\begin{array}{l}\text { Regime } \\
\text { Trabalho }\end{array}$ & $\begin{array}{l}\text { 79. Quais ações são tomadas pela SME objetivando a atração e retenção dos } \\
\text { diretores? } \\
\text { 80. Quais ações são tomadas pela SME objetivando a atração e retenção dos } \\
\text { docentes? } \\
\text { 81. Existe plano de carreira estruturado e diferenciado para professores e } \\
\text { diretores? } \\
\text { 82. Qual o percentual ou número de docentes: } \\
\text { a. Concursados: } \\
\text { b. Temporários: } \\
\text { c. CLT: }\end{array}$ \\
\hline Disciplinas & 83. A escola oferece alguma disciplina de língua estrangeira? Quais? \\
\hline
\end{tabular}

Fonte: Adaptado de Soriano (2017) 


\section{APÊNDICE D - Roteiro de Entrevista - Secretário Municipal De Educação (C)}

\begin{tabular}{|c|c|}
\hline GRUPO & SECRETÁRIO(A) MUNICIPAL DE EDUCAÇÃO \\
\hline $\begin{array}{l}\text { Hábitos } \\
\text { Aluno }\end{array}$ & $\begin{array}{l}\text { 1. A SME realiza alguma ação junto aos pais para conscientizar a importância } \\
\text { dos estudos na família? } \\
\text { 2. } \quad \text { Como você avalia o índice de faltas dos alunos? } \\
\text { 3. } \quad \text { Como é feito o controle e acompanhamento das faltas dos alunos? Existem } \\
\text { ações para verificar a motivação da falta e a recuperação do conteúdo escolar? } \\
\text { 4. } \quad \text { Existe algum projeto da SME para de incentivo à leitura e aos estudos? }\end{array}$ \\
\hline NSE & $\begin{array}{l}\text { 5. Como você avalia a influência do meio social e da família no interesse e } \\
\text { desempenho dos alunos? }\end{array}$ \\
\hline $\begin{array}{l}\text { Participação } \\
\text { da Família }\end{array}$ & $\begin{array}{l}\text { 6. Como é a relação e o acesso dos pais à SME? Existem ações positivas para } \\
\text { incluí-los no processo educacional municipal? }\end{array}$ \\
\hline Gestão & 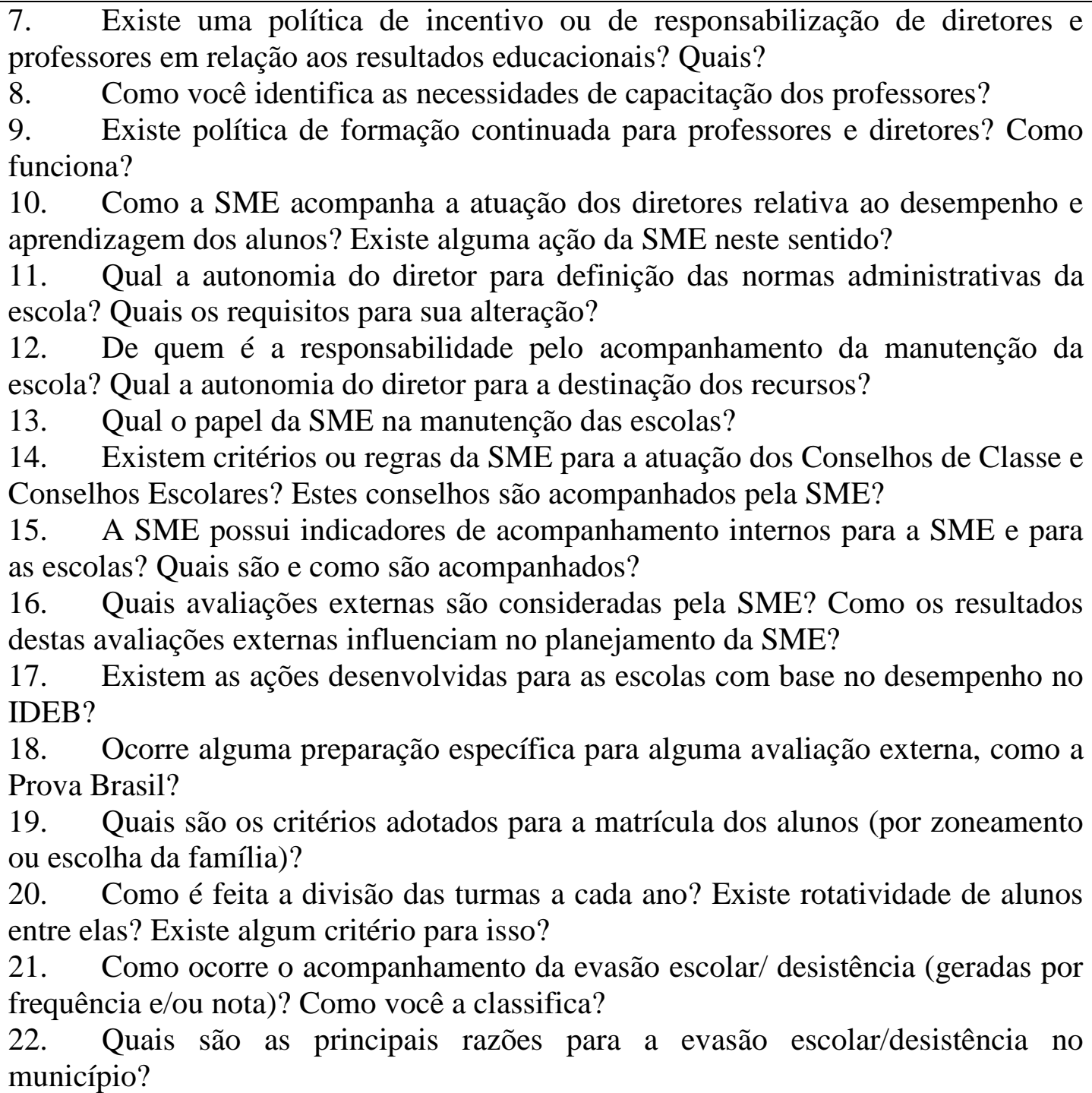 \\
\hline
\end{tabular}




\begin{tabular}{|c|c|}
\hline Gestão & $\begin{array}{l}\text { 23. O município oferta transporte público para todos os alunos? Há casos de } \\
\text { interrupção? } \\
\text { 24. Quais são os critérios da rede municipal em relação à reprovação dos alunos? } \\
\text { Os docentes têm autonomia quanto a esta questão ou existem políticas pré-definidas } \\
\text { pela SME? } \\
\text { 25. Adota-se a progressão continuada? O professor tem autonomia para } \\
\text { reprovação de alunos? } \\
26 \text {. Como ocorre o acompanhamento da reprovação escolar? Como você } \\
\text { classifica esse índice no município? } \\
27 \text { Quais são as principais razões para a reprovação no município? } \\
28 \text {. Existem mecanismos de recuperação paralela ou reforço no contraturno? } \\
29 \text {. Como é feita a atribuição de aulas aos docentes? } \\
30 \text {. Como é a participação das APM quanto à captação de recursos financeiros? } \\
\text { Estes são repassados à SME ou às escolas? } \\
31 \text { Q Quais projetos de captação de recursos a SME realiza? Quais os resultados? } \\
\text { 32. São realizadas reuniões com os diretores das escolas? Com que frequência? } \\
\text { Qual a frequência de reuniões entre a equipe da SME e os diretores das escolas? } \\
\text { 33. Qual o grau de autonomia administrativa e pedagógica é concedida aos } \\
\text { diretores? } \\
\text { 34. As escolas ou a SME passaram por alguma interrupção das atividades não } \\
\text { prevista? Houve alguma ação para reposição destas atividades? }\end{array}$ \\
\hline $\begin{array}{l}\text { Integração } \\
\text { com } \\
\text { comunidade }\end{array}$ & $\begin{array}{l}\text { 35. Existem projetos temáticos promovidos pela SME? Quais os impactos destes } \\
\text { projetos junto aos alunos e às escolas? } \\
\text { 36. A SME incentiva a promoção de eventos de integração das escolas com a } \\
\text { comunidade? }\end{array}$ \\
\hline Perfil Pessoal & 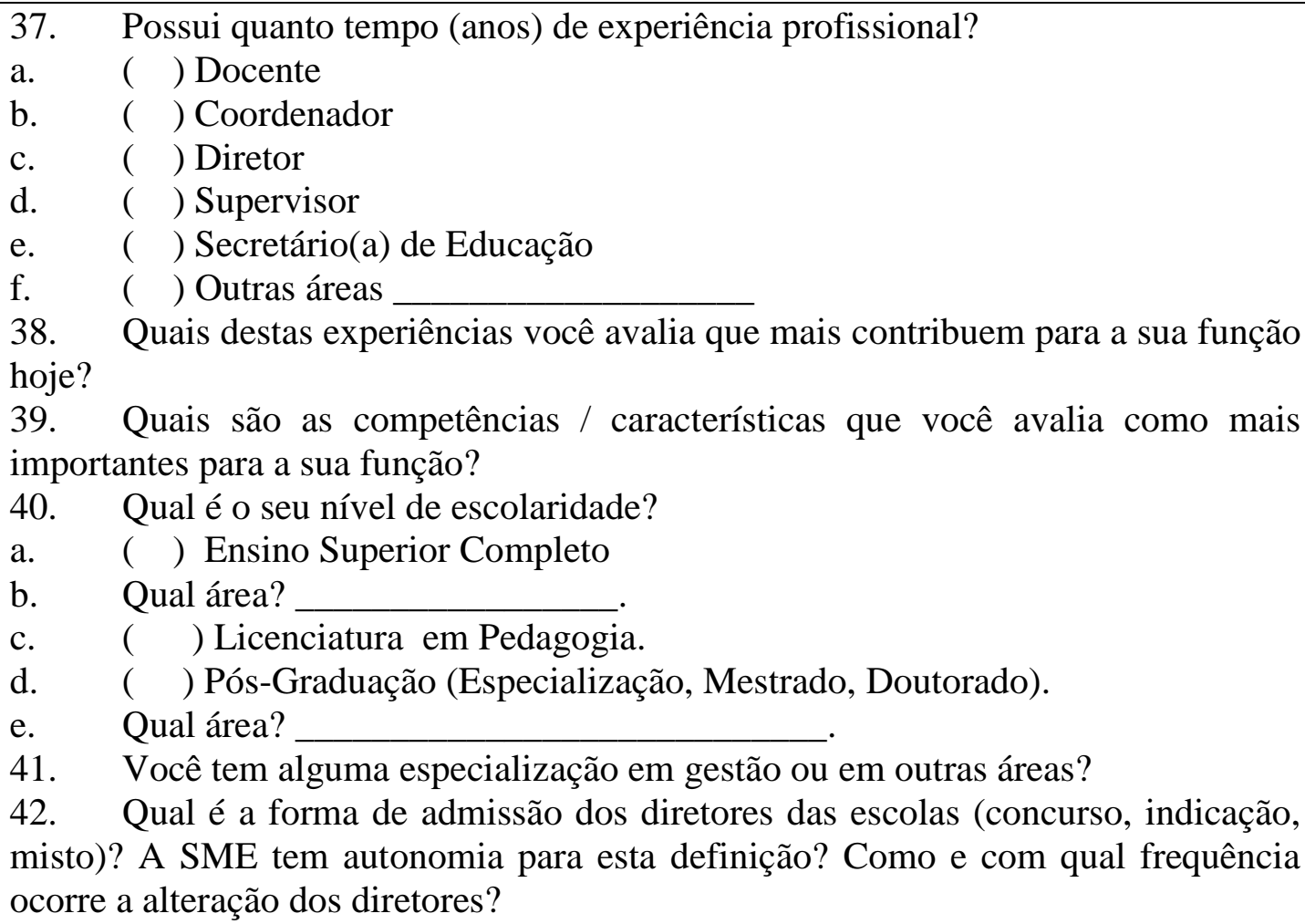 \\
\hline
\end{tabular}




\begin{tabular}{|c|c|}
\hline Perfil Pessoal & $\begin{array}{l}\text { 43. Qual é a forma de admissão dos funcionários da SME (concurso, indicação, } \\
\text { misto)? Como e com qual frequência ocorre a alteração do quadro de funcionários? } \\
\text { 44. Como é feita a escolha do SME? }\end{array}$ \\
\hline $\begin{array}{l}\text { Recursos e } \\
\text { Infraestrutura }\end{array}$ & $\begin{array}{l}\text { 45. As escolas têm autonomia para a contratação de pessoal administrativo? } \\
\text { 46. } \\
\text { PNE? } \\
\text { 47. } \\
\text { 48. As escolas possuem infraestrutura adequada a este público? } \\
\text { 49. } \quad \text { Como é organitica de capacitação dos professores a este respeito? } \\
\text { 50. } \quad \text { Os recursos disponíveis são suficientes? } \\
\text { 51. } \quad \text { Qual o grau de autonomia das escolas para a merenda escolar? }\end{array}$ \\
\hline Biblioteca & $\begin{array}{l}\text { 52. A SME destina recursos especificamente para o acervo das bibliotecas das } \\
\text { escolas? }\end{array}$ \\
\hline $\begin{array}{l}\text { Recursos e } \\
\text { Infraestrutura }\end{array}$ & $\begin{array}{l}\text { 53. A cidade possui problema com segurança nas escolas? Existem ações e } \\
\text { policiamento para coibir o tráfico de drogas nas imediações das escolas? } \\
\text { 54. A SME destina recursos especificamente para a aquisição e manutenção de } \\
\text { equipamentos e recursos de informática nas escolas? } \\
\text { 55. Existe um planejamento para garantir o cumprimento do conteúdo } \\
\text { pedagógico anual? Como funciona? } \\
\text { 56. Qual é a carga horária da disciplina de Português (absoluta e percentual)? } \\
\text { 57. Qual o grau de autonomia do docente em relação ao conteúdo ministrado? }\end{array}$ \\
\hline $\begin{array}{l}\text { Regime } \\
\text { Trabalho }\end{array}$ & $\begin{array}{l}\text { 58. Qual a média salarial dos docentes no município? O valor é atrativo em } \\
\text { relação à remuneração oferecida na região? } \\
\text { 59. Qual a política de benefícios e plano de carreira para os docentes? } \\
\text { 60. Qual o percentual de professores nas seguintes condições: } \\
\text { a. } \\
\text { b. } \\
\text { concursados/Efetivos: } \\
\text { c. } \\
\text { Temporários: }\end{array}$ \\
\hline
\end{tabular}

Fonte: Adaptado de Soriano (2017) 


\section{ANEXO A - Questionário da Escola - Prova Brasil}

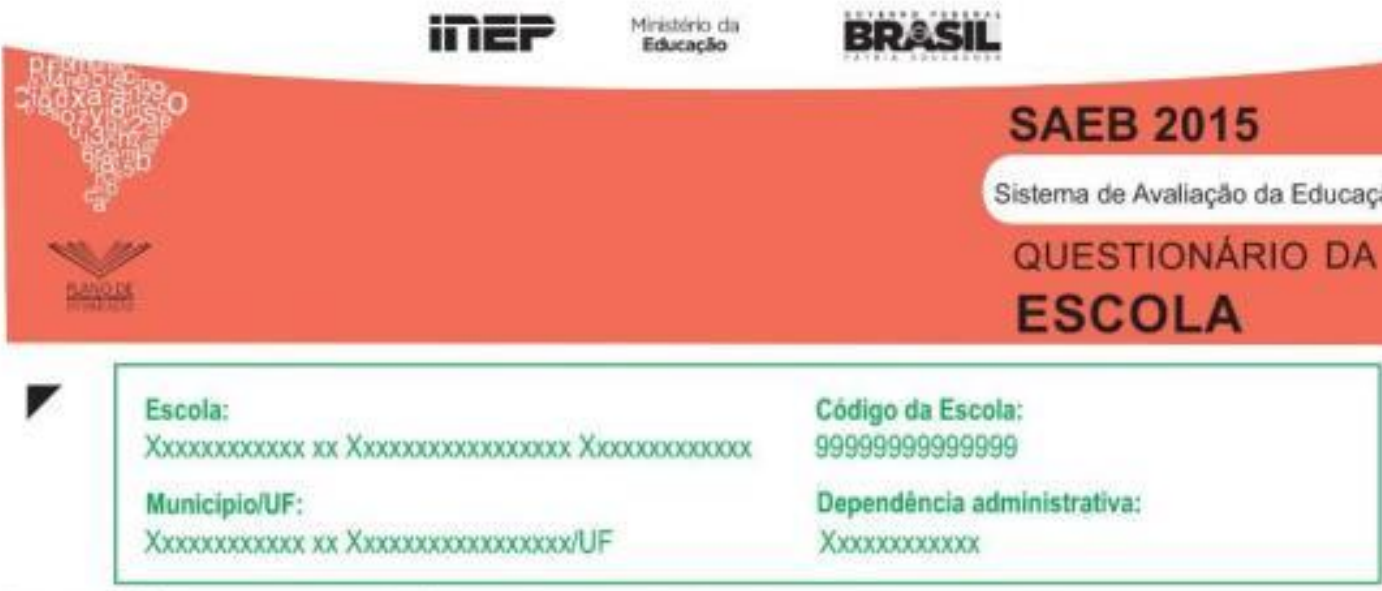

CASO VOCE NÄO TEAHA REALZZADO A APLICAÇ, D̆O DO SAEB NESTA ESCOLA, NOIOUE O MOTIVO:
(9) Escola inexistente.
(4) Escela inativa poc ostra causa,
(2) Escola recusa-se a participar
(5) Escola extinta.
(3) Escola inativa por reforma
(6) Outro-Qual?

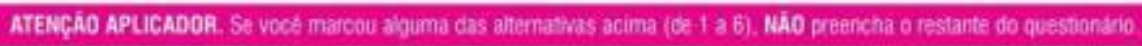

AVALIE O ESTADO DE CONSEAVAÇAO DOS ITENS E EOUIPAMENTOS DO PRÉDO:

\begin{tabular}{|c|c|c|c|c|c|c|c|c|c|}
\hline & 8om & Aazalat & Puim. & haibente. & & Ban. & Reguar. & Aum. & movition. \\
\hline 7. Teltaso. & (A): & (B) & (C) & (2) & 14. Portas & (A) & (a) & (C) & (D) \\
\hline a. Parodes. & (A) & (B) & (C) & (C) & 15. Janelas. & (A) & (b) & (C) & (D) \\
\hline 9. Pros. & (A) & (i) & (c) & (C) & 16. Aanheiros. & (A) & (1) & (c) & (D) \\
\hline 10. Entrade do Pitide. & (A) & (B) & (C) & (C) & 17. Carinha. & (A) & (i) & (C) & (D) \\
\hline 11. Patio. & (a) & (B) & (c) & (C) & 18. Instubecbes sidesuicas. & (A) & (i) & (C) & (D) \\
\hline 12. Cunndores. & (4) & (B) & (C) & (2) & 19. instevaçbes sietricas & (A) & (A) & (C) & (D) \\
\hline 13. Salas da Mala. & (A) & (B) & (C) & (D) & & & & & \\
\hline
\end{tabular}

\begin{tabular}{|c|c|c|c|c|}
\hline & Totas. & $\begin{array}{l}\text { Yais a a } \\
\text { matade }\end{array}$ & $\begin{array}{l}\text { Menos da } \\
\text { metade }\end{array}$ & Nentima \\
\hline 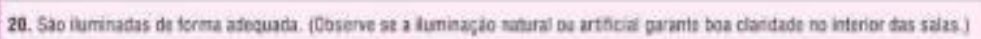 & (A) & (B) & (C) & (D) \\
\hline 21. Sin arejadas de forru adacuadr. & (4) & (B) & (c) & (D) \\
\hline
\end{tabular}

\begin{tabular}{|c|c|c|c|c|}
\hline & Bon. & Resular. & Aum. & haisterte \\
\hline 22. Cortrols te ertada e suifa de atimos. & (4) & (1) & (C) & (D) \\
\hline 23. Contud se errasa ge pessous esturhas te escele. & (4) & (1) & (C) & (D) \\
\hline 24. Viginosa pars o seriece dina. & (a) & (8) & (C) & (D) \\
\hline 25. Viglincia pane seriedo fourum. & (4). & (19) & (c) & (D) \\
\hline 26. Wgatincis pera cs frass de semuna e heiados. & (4) & (B) & (C) & (D) \\
\hline 27. Esquema de poiciamento para inbiçate de lurtos, topbos e outras formas de viatincia & (4) & (14) & (C) & (D) \\
\hline 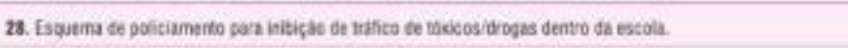 & (A) & (i) & (c) & (D) \\
\hline 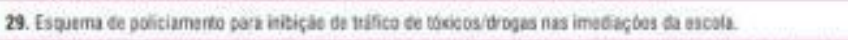 & (4) & (B) & (C) & (D) \\
\hline 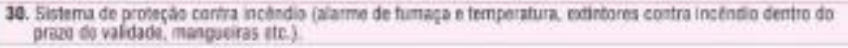 & (4) & (b) & (C) & (D) \\
\hline 31. fuminaças to lato de son da esoda. & (4) & (B) & (C) & (D) \\
\hline
\end{tabular}




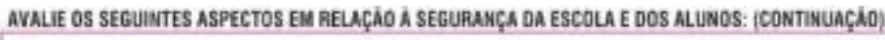

\begin{tabular}{|c|c|c|c|c|}
\hline & & & $\sin$. & Nas. \\
\hline 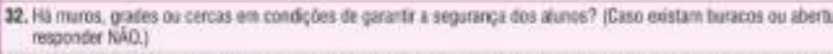 & mitrm e acosso de ef & shos, & (6) & (1) \\
\hline 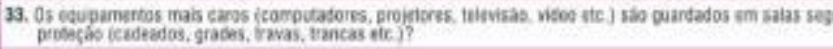 & ssuam mecanismes & & (4) & (i) \\
\hline 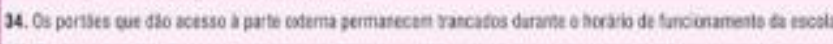 & & & (A) & (6) \\
\hline 35, A escela adoca alguma madida te sagurasça pan proboset os aluros nas suas imedeçses? & & & (Q) & (9) \\
\hline 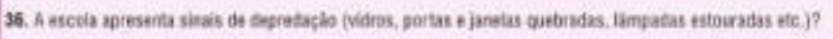 & (4) Sim, muitos. & (b) $s$ & & Nik. \\
\hline
\end{tabular}

INDIOUE SE NESTA ESCOLA EXISTEM OU NÃO OS RECURSOS APONTADOS E QUAIS SAOO SUAS CONDIÇOES DE USO.

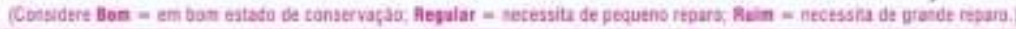

\begin{tabular}{|c|c|c|c|c|c|c|c|c|c|}
\hline & Bam. & Rasuir: & Fuim. & treestent & & Bam. & Pegular. & Rain: & inecesets \\
\hline M. Comprtatover para use cos sunce. & (4) & (7) & (C) & (c) & 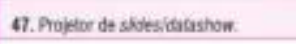 & (4) & (6) & (C) & (D) \\
\hline 58. Acasso \& hisecret para uso dos funcs. & (A) & (8) & (C) & (D) & 4. Wtencasern ou aqueth de DVD. & (A) & (2) & (C) & (D) \\
\hline 31. Comoutadans para uso des prolessores. & (A) & (Đ) & (C) & (0) & 49. Ninisio. & (4) & (9) & (C) & (D) \\
\hline 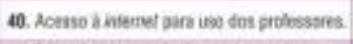 & (A) & (b). & (C) & (D) & 50. Manetgats. & (4) & (8) & (C) & (D) \\
\hline 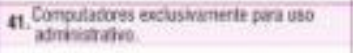 & (4) & (Đ) & (C) & (D) & 51. Cresera totogratica: & (4) & (2) & (C) & (D) \\
\hline 42. Flas or wobo ou ono leavertinas; & (4) & (B) & (C) & (D) & 52. Nilsua pastica. & (a) & (ㄹ) & (C) & (D) \\
\hline 43. Fitas on vibos ou CWD (azan? & (A) & (i) & (C) & (D) & 53. benent con tonesio Bsota Laga. & (A) & (C) & (C) & (D) \\
\hline 44. Winini copiatora. & (4) & (1) & (c) & (D) & 54. Lna trielosica. & (4) & (C) & (C) & (D) \\
\hline 45. intretesson. & (A) & (1) & (c) & (D) & 53. Novereco of fax & (4) & (6) & (c) & (D) \\
\hline 46. Perraspopto. & (A) & (B) & (C) & (D) & St. Roarele o de sam. & (4) & (C) & (c) & () \\
\hline
\end{tabular}

INDIQUE A EXISTENCIA E AS CONDIÇOES DE USO DOS SEGUINTES ESPAÇOS DA ESCOLA:

(Coesidere Boet - am bour eatato de conservaçac, Regular - setessita de pequena reforma, Raim - necessita de pante reforma.)

\begin{tabular}{|c|c|c|c|c|}
\hline & Bam. & Regular: & Bain & inecesecte \\
\hline 57. Belditea. & (4) & (a) & (C) & (D) \\
\hline 5a, Sala of istira & (4) & (C) & (c) & (D) \\
\hline 59. Oazoda de asportes. & (4) & (B) & (C) & (D) \\
\hline 60. Latonatsrio de ifformatca: & (4) & (8) & (C) & (D) \\
\hline 61. Latonation de Citirias. & (A) & (C) & (C) & (D) \\
\hline 62. Auteborio. & (4) & (2) & (C) & (D) \\
\hline 6. Sala para abidates de mitica. & (4) & (8) & (C) & (D) \\
\hline 64. Sah pera abeitases de artes plasteas. & (4) & (B) & (C) & (D) \\
\hline
\end{tabular}

\begin{tabular}{|c|c|c|c|}
\hline \multicolumn{4}{|l|}{ EM BELAC,AD A BIBLLOTECA OU SALA DE LEITURA: } \\
\hline & $\sin$ & Nan. & 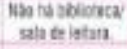 \\
\hline 65. Possui acuvo diversitcato que dosperso o inturesse cos aunos. & (a) & (C) & (C) \\
\hline 66. Possul bunquedsteca & (4) & (9) & (C) \\
\hline 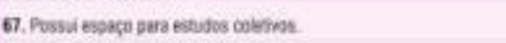 & (4) & (e) & (C) \\
\hline 68. 05 anos votim ser inanusados a entrestados. & (4) & (6) & (c) \\
\hline 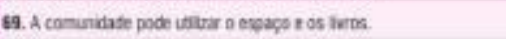 & (a) & (2) & (C) \\
\hline 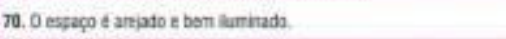 & (A) & (9) & (C) \\
\hline 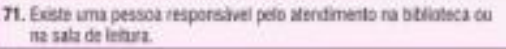 & (4) & () & (c) \\
\hline
\end{tabular}

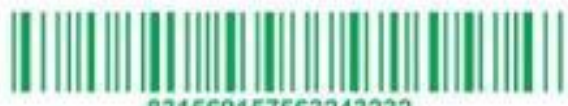

OS SEGUINTES USUÁRIOS DA BIBLIOTECA (OU SALA DE LEITURA) LEVAM LVROS PARA CASA:

\begin{tabular}{|c|c|}
\hline n. Os sunes: & 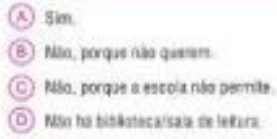 \\
\hline T3. As znotosseros: & 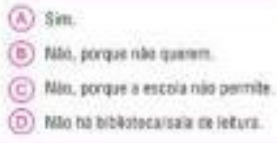 \\
\hline $\begin{array}{l}\text { 74. Os nentras ea } \\
\text { conorivide: }\end{array}$ & 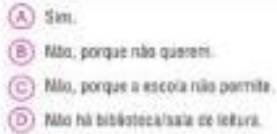 \\
\hline
\end{tabular}


ANEXO B - Questionário do Diretor - Prova Brasil

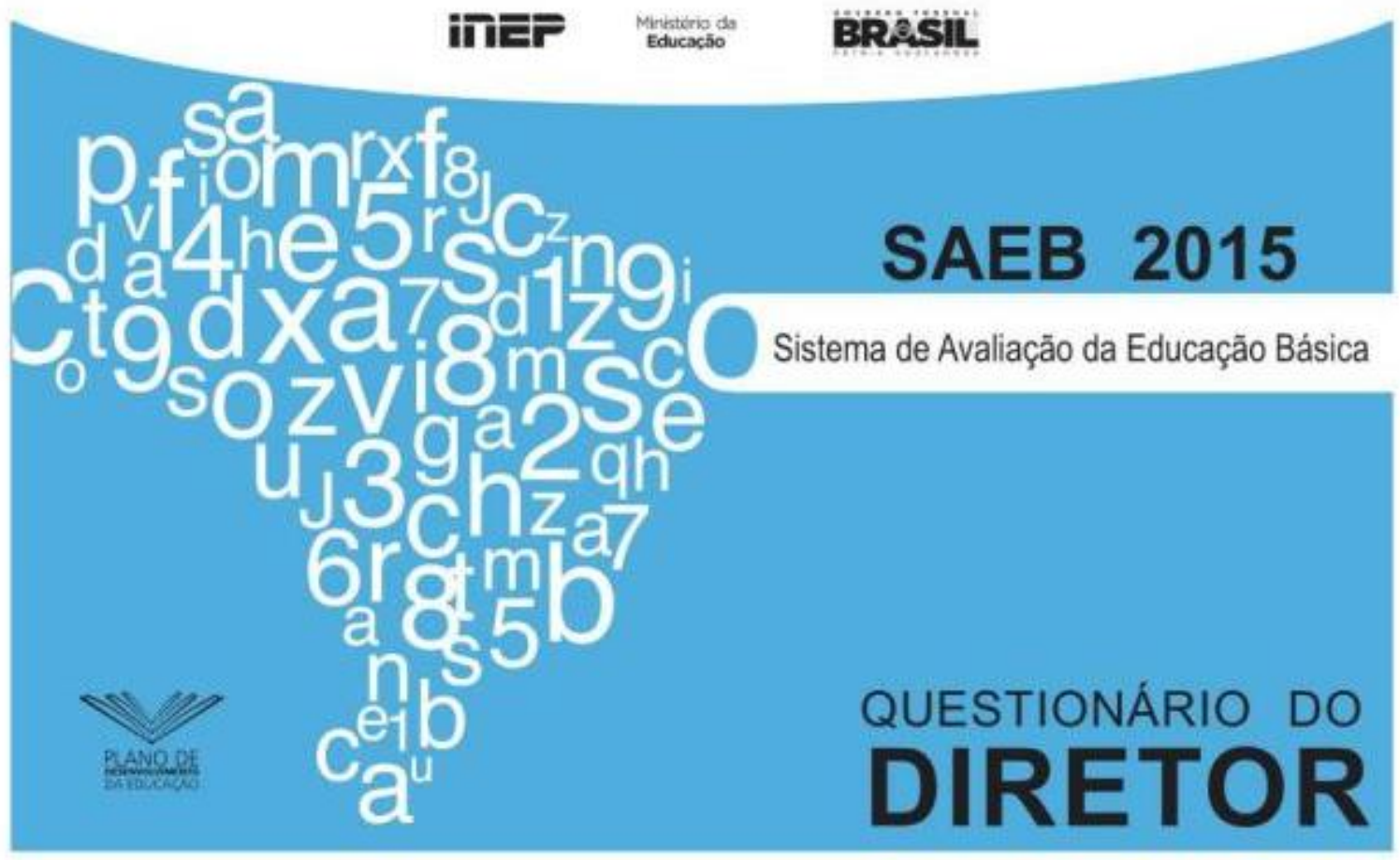

Senhor(a) Diretor(a),

O Sistema de Avaliação da Educação Básica, SAEB, é composto por dois tipos de instrumentos de avaliação: as provas aplicadas aos estudantes e os questionários socioeconômicos, que devem ser respondidos pelos estudantes, professores e diretores das escolas avaliadas.

O presente questionário tem como objetivo coletar dados acerca da formação profissional, práticas gerenciais e do perfil socioeconômico e cultural dos diretores das escolas em que a avaliação está sendo aplicada. Para responder a cada questão deste questionário, preencha, no CARTÃO-RESPOSTA, o campo correspondente à alternativa de sua escolha. Utilize caneta esferográfica de tinta azul ou preta.

A sua colaboração ao preencher este questionário será de grande valia para o êxito da avaliação e para o aprimoramento da educação brasileira. 
INFORMAGÖES BASICAS - Estas quest0es são sobre sua tormaçäa, experitencia profissiocal e caractaristicas funcionais

\section{OUAL E o SEU SERo? \\ 4. Masculing \\ 1 Ferinine.}

\section{A. Ale 24 anos. \\ I) De 25 a 29 anos. \\ c. De 30 a 39 asos \\ if De 40 a 49 anos \\ E. De 50 a 54 anos. \\ if. 55 ancos ou mass}

2. WOCÉ POOERIA NDS OIZER A SUA FAIXA ETÁAIA?

\begin{tabular}{|c|c|}
\hline & OMO VOCE SE CONSIDERA? \\
\hline A & Branco(a). \\
\hline B & Pardo(a). \\
\hline c & Preta(a). \\
\hline b & Amarelo(a) \\
\hline E & indgena. \\
\hline $\mathrm{f}$ & Neso cuero decharar. \\
\hline if & Noose. \\
\hline
\end{tabular}

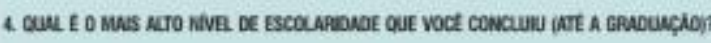

A. Mernos que o Ensino Media (antigo $2^{\circ}$ grau)

1 Ensino Midia - Magisterio (arsgo $2^{\circ}$ grau)

c. Ensino Madio - Outros (antipo $2^{\circ}$ graus.

B. Ensino Superior - Pedacogia.

1. Ensino Superior - Curso Normal Superion

F Ensino Superior - Licenciatura em Matemalica.

6. Ensino Superior - Lioencialura em Letras

In Ensino Superior - Outras Licenciaturas.

1 Ensino Superior - Outras areas.

5. HA QUANTOS ANOS VOCE OBTEVE O NIVEL DE ESCOLARIDADE ASSIMALADO ANTERIOHMENTE (ATEA A GADUACCAO)?
4. Hámenos de 2 anos.
I. De 2 a 7 anos.
C. De 8 a 14 anos.
D. De 15 a 20 anos.
i. Ha mais de 20 anos.

\section{INDIQUE EM OUE TIPO DE IKSTITUICh̆O VOCE OATEVE SEU DIPLOM DE ENSINO} SUPEAIOA.

4. Nin conshai o Ensino Suseriot:

1. Pivati.

c. Piolica Fedard.

D. Pibica Esadial.

E. Pibita Murikied.

\section{OE OUE FOALA VOCE REAUZOU OCURSO OE ENSINO SUPLAIOR? \\ A. Nan conclus o Ensino Superiox. \\ 1. Presencial \\ c. Sempresencial. \\ D. A distántia.}

\author{
8. INDIQUE O CLASO DE POS-GRUDUAÇÃO DE MAIS ALTA TITULAÇÃO QUE VOCE POSSUI. \\ A. Nio fre ou nalo cumpletei corso de pes-pradiacto.

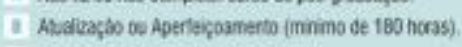 \\ C. Especiabrac 20 inirim de 350 horas) \\ 10 Mestado. \\ E. Dostondo

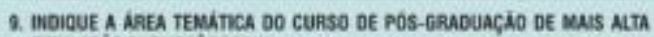 \\ TITULAÇOQ QUE VOCE POSSUI \\ A Nao fiz ou nato completele curso de pos-praduaçato. \\ 1 Educaça, entatizanto atabetzaçio

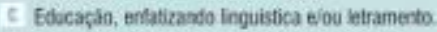 \\ IV Edicaça, entatizando educaçan matematica. \\ t. Educacáa - odras èntases. \\ f. Outres treas que nilo a Educaçio \\ 10. COMO DIRETOG QUAL E, APROXIMADAMENTE, O SEU SALARIO BRUTO? ICOM \\ ADICIONAS, SE ROUVER). \\ A A Atie Rs 788,00. \\ 1 De RS 788,0 t ate RS $1,182,00$ \\ C DeRS 1.182,01 att RS $1.576,00$ \\ IV De RS 1.576,01 ate RS 1970,00 \\ E De RS 1.970,01 ate AS 2354,00 \\ f. De R5 2.364.01 ats R5 $2.758,00$ \\ (6) De Rs $2.758,01$ ate RS 3.152 .00 \\ II De RS 3.152.01 ate RS 3940,00 \\ 1 De R5 3.940,01 ate RS $5.516,00$ \\ f) De Rs 5.516 .01 ate RS 7.600 .00 \\ C. PS $7.880,01$ ou mais
}

11. ALEU DA DIAEÇÃO OESTA ESCOLA VOCE EXERCE OUTRA ATIVIDADE QUE CONTRISUI PARA SUA RENDA PESSOAL?

A. Sim, na area ce educaçalo.

1 Sim, fora da area da edxacąa.

c. Nao.

12. CONSIDERANDO TOAAS AS ATIVIDADES QUE VOCE EXERCE (DENTAO E FOAA DA AGEA DE EDUCACAOO), QUAL E, APROXIMEDAMENTE, 0 SEU SALARIO BRUTO? (COM ADICIONAIS, SE HOUVEA)

A. Ate RS 785,00 .

18 De RS 788.01 at RS $1.182,00$

C. De RS $1.182,01$ atie RS $1.576,00$

D. De RS $1.576,01$ ath Rs 1.970 .00

E. De RS 1.970,01 ant R3 2.38400

F De RS 2.364.01 ate R5 2.758 .00 .

5. De RS 2.758.01 ath RS 3.152 .00

if De RS 3.152,01 ate R3 3.940 .00

(1) De R5 3.940 .01 atd R5 5.516 Co

2. De RS 5.516.01 ath RS 7.880.00.

K. AS 7.890 .01 ou mais

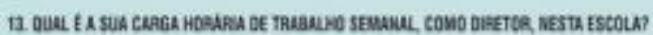

4. Mais de 40 thoras.

If 40 horas.

c. De 20 a 39 horas.

D. Menes de 20 horas. 


\section{VOCE ASSUMUU A DIREÇAO DESTA ESCOLA POA MEIO DE \\ 1. Concurso piblico apenas \\ 1) Elekça asenas. \\ c. Indicaço apenas. \\ 1) Processo saintive apenas \\ E. Processo saintino e Beiçâo. \\ F Processo selativo e holcaçio. \\ i) Outra forma}

\section{POH QUANTO TEMPO VOCE TRABALHOU COMO PAOFESSORLAI ANTES DE SE} TOREAR DIRETOR(A)?

A. Flunca.

1. Menos de un ano.

c. $1-2$ anos

if $3-5$ ances

I. 6-10 anos.

F. 11.15 anos

Ii $16-20$ anos

11. Mais de 20 anos

\section{Ha QUuNOS ANOS WOCE EXERCE FUMÇOES DE DIREÇAOAO?}

4. Menos de um ano.

I. $1-2$ anos.

c. 3.5 anos

D. $6-10$ anos

1. 11.15 anos

F. 16-20 anos

(5) Mais de 20 anos.

\section{Hh CUANTOS ANOS VOCEE OIRETORIA) DESTA ESCOLA?}

A. Menos de um ano.

I. 1.2 anss.

c. 3.5 anes.

i) $6-10$ anes.

f. $11-15$ anos

F $16-20$ anos

(4) Mais de 20 anos
18. HA OLCANTOS ANOS WOCE TRABALHA NU AREA DE EDUCACĂOO?

A Menos de um ano

1. 1.2 anos

C. 3.5 anos

D. 6-10 anos.

f. $11-15$ anos

f. $16-20$ anos

If. Mais de 20 anos.

19. DURANTE OS UUTIMOS DOIS ANOS, VOCE PAGIICPOU DE ALGUMA ATIVIDADE DE DESEWOLYMENTO PROFISIONULL?

A Na

E Sim

\section{SE VDCL RARTICIPOU DE MLEUMU ATIVIDUDE DE DESENOLIVIMENTO PRCFISSIONGL}

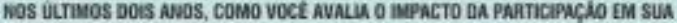
ATIVIDAOE COMO DIRETOH(A)?

(A) Nas participe:

5. Sim e nto hoive ingacto.

c. Sim e howe un poqueno irroacto.

5. Sim e have un impacto moderado.

E. Sim, o howe un grande impacto

21. N0S ÚLTIMOS DOIS ANOS, VOCÉ COSTARIA DE TER PRHTICIPADO DE MAIS ATIVIDADES DE DESEWVLLVIMENTO PHOFISSIONGL DO QUE VOCE PURTICIPOU?

A. Nă

1 sim

\section{Comando das}

SE VOCE GOSTARIA DE TER PARTICIPADO DE MAIS ATIVIDADES DE DESENVOLVIMENTO PROFISSIONAL, OS SEGUINTES MOTIVOS MPEDIFAM SUA PARTICIPACAO'

\begin{tabular}{|c|c|c|c|}
\hline & $\begin{array}{l}\text { Was gostina ofo } \\
\text { ter particpado. }\end{array}$ & Mbs. & Sim \\
\hline 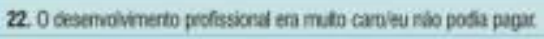 & A & II & c \\
\hline 22. Howe corfts can o meu hordito de rabaho. & A & II & c \\
\hline 24. Máo trcha dispontildada de tampo. & A & i & c \\
\hline 25. Mata touve olerta en minha area da interesse. & A & 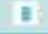 & E \\
\hline
\end{tabular}

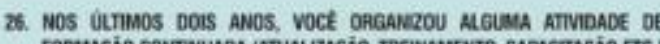

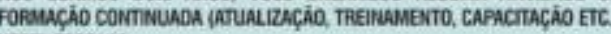
NESTA ESCOLA?

A. NaO.

II. Sim.
27. QUAL FOI A QUANTDADE DE DOCEMTES DESTA ESCOLA OUE PARTICIPOU DAS ATMDAOES DE FORMACín CONTIUUADA QUE VOCE ORGAMIZOU NOS ÚLTMOS DOIS AnOS?

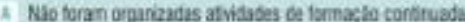

I. Poices protessoes.

c. Um pouco moros da metade das prolassoves.

1. Un pouco mais da metade des prolessates.

f. Quase totos ou tofos os protessores. 
CARACTERISTICAS DA EQUIPE ESCOLAR - Gestariamos de lhe parguntar sobre as atividades e composiça da equipe escotar

28. oun t O percentual oe
A Menor ou igual a $25 \%$
I. De $26 \%$ a $50 \%$.
C De $51 \%$ a $75 \%$.
D De 765 a $90 \%$.
I De $91 \%$ a $100 \%$

29. D CONSELHO ESCOLAR E UM COLEgLado geralmente CONSTIUIDO POR REPAESENTAUTES DA ESCOLA E DA COMUNIDADE QUE TEM COANO OAETWO ACOMPRNHAR AS ATVIDADES ESCOLARES, NESTE ANO, QUANTAS VEZES SE REUNIU O CONSEUHO ESCOLAR?

A. Map existe Censelho Escolar

1 Nenturna vor.

c. Una ver.

Q Duas vexes.

T.és vezes ou màs.

\section{ALEM DE VOCE, QUEM PARTICIPA DO CONSELHO ESCOLAR?}

\footnotetext{
A. Năo existe Conseho Escolat

1. Protessores, funcionarios, alunos e paisiesponsabes.

c. Protessores, tuncionàios e paisinesoensaveis.

D. Prolessores, alunos $=$ pais/resporsàtis.

F. Protessores, funcienarios e alunos.

F. Protessores e pais/responstveis.

5 Outros.
}

\author{
31. O CONSEUHO DE CUASSE E UM OAGLO FORAADO POA TODOS OS PADFESORES \\ QUE LECIONAM EM CADA TUAMMASÉRIE. NESTE ANO E NESTA ESCOLA, QUANTAS \\ VEIES SE REUNIU O CONSELHO DE CLASSE? \\ A. Nao existe Conselho de Casse. \\ A. Nentruma vez. \\ c. Uiravez \\ D. Deas veess. \\ F. Tís veares ou mas.
}

32. NESTE ANO E KESTA ESCOLA, COMO SE DEU A ELABORACÁO DO PROJETO PEDAGOGICO?

(A) Nobo sei coms foi dasetvolido

I Nio esiste Frojsa Pedagsaco

c. Uilizande-se um modolo prorto, sem dscrssto com a equipe escolar.

D. Utilendo-se um mosto prorta, nas com discussio com a ecuipe escolar

I. Utilizando-se um modelo pronto. porem con adaptaçoes, sem discussato con a touipe escols:

I. Utiizasdo-se um modein pronta, poriem con adaptaçóes e con dscussáo com a cocuipe escolat.

a Elaborou-se um modelo proprio, mas náo houve dscussaio com a equipe escolar

if Elaborce-se um moddo probrio e houve discussán com a equipe escolat

POLITICAS, AÇOES E PROCRAMAS ESCOLARES - Gostariamos de the perguntar sobre as politicas utilizadlas para admissato e

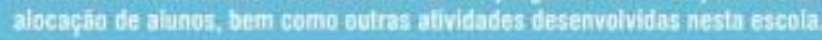

\section{ESTAESCOLA PAATCFOU DA ERTVA BRASIL DE 2013?}

(a) Sim.
it Nào.
ic Não sel

Cemanto das

Questies 34 a 36

VOCE CONHECE OS RESULTADOS DO SAEB (PROVA BAASIL E/OU ANEB) DE 2013?

\begin{tabular}{|c|c|c|}
\hline 34. DESTA ESCOLA? & 35. DO SEU MUNICIRA? & 36. DO SEU ESTADO? \\
\hline A $\mathrm{Sim}$. & A $\sin$ & A $8 \mathrm{~m}$ \\
\hline I Nas. & 3 Nas. & if NaO. \\
\hline c. Minha escola nata participou. & c. Meu musicipia nfo participou. & \\
\hline
\end{tabular}

37. MESTE ANQ QUAL FOI O CAITERIO PARA A ADNISSATO DE ALUNOS NESTA ESCOLA?
A Prova de seteçalo
B Sortalo.
c. Leca de marada.
D. Piocibade por ordent de chegaca.
E. Outro criteris

\section{MESTE AMQ COMO FOI A SITUACAO DA OFERTA DE VAGAS NESTA ESCOLAT}

A. Ages a processo de matricula. a escola ainda tinha ragas dispaniveis.

If A procura por vaga na sscola preencheu todas as vagas oferecidas

C. A procun por vaga na escola toi um pouco maiar que as vagas alerocidas.

D. A procura per vaga na escola superou em muilo o nümere de vagas oferecides: 


\footnotetext{
39. NESTE ANO. QUAL FOI O PRUNCIPAL CRITERBO UTILIZADO PARA A FORMACAOO DAS TUAMUS MESTA ESCOLA?

A. Hornogeneidade quanto a idaba (alunos com a masma idada)

1. Homogensidade quanto ao rendimento escolar falunos com rendimento similar).

c. Hateropenedode quarto a idade (atunos com idades oferentes)

D. Heterogeneddade quarto an rendiments escolar (alunos com rendimentos difterentes)

f. Qutro crtèrio.

f. Maso have crtário
}

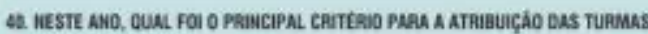
AOS PROFESSOAES?

\section{Pretertncia des protessores.}

1. Escolha dos professones, de acordo com a partaçalo por sempo de sieviço e

6. Protessores experientes com turmas de aprendizapim mais rapida.

D. Professoras experientes com turmas de aprendzagem mais lenta.

I. Manuterçăo do srolessor com a mesera turma

f. Fevezamento dos professores entre as(0s) séries/anos.

9. Sorlicio das turmas entre os professores.

it Atrbuiçào pela dreçio da escola

1 Outro critorio

I. Maso howe crtaria

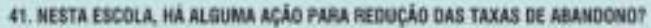

A. Nało ha açâa embera exista o prutiema.

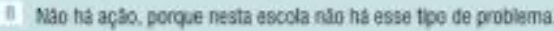

c. Sin, mas com resultasos anda insatistatorios.

(1) Sim, com resutados satistancios.

E. Sim, mes anda no avaĩamos o resustacia.

\section{VESTA ESCOLA, HA MLGUMA ACAAD PARA REDUCi, OAS TAXAS DE REPROVACLiO?}

A. Nio Ha acào, enbora exista oproblema

1 Noba acáo, porque nesta escola nbo la esse lipo de problema.

5. Sim, mas com nesutados ainda insabstaboics.

D. Sim, com resaltados satistatorios.

1. Sin. mas ainta nás avaliamos o resutado.

\section{NESTA ESCOLA, HA ALGUMA AÇÁ PARA O REFOHÇO ESCOLAR A APAENDIZAGEM} DOS ALUNOS ONOKETORLA, AULA DE REFORÇO, RECUPERAC,IO ETC.I?

A. Năo.

i) Sim.

44. NESTA ESCOLA, NMDieUE CON QUE FREDUENCLA VOCE DISCUTE COM OS PROFESSORES MEDIOAS COH O OBJeTIVO DE MELHORAR O EMSINO E A APRENDRZAEEM DOS ALUNOS.

A. Nunca.

at Algumas veres:

5. Frecuertameme.

D. Sempre ou quase serpore.

\begin{tabular}{|c|c|c|c|}
\hline Nanca. & $\begin{array}{l}\text { Ngumas } \\
\text { venes. }\end{array}$ & Frequentemente. & $\begin{array}{l}\text { Stmprs ov } \\
\text { quase sempre }\end{array}$ \\
\hline A. & I & c & 0 \\
\hline A & I & C & 0 \\
\hline A & B & c & u \\
\hline A & D & c & 0 \\
\hline A & E & c & 0 \\
\hline
\end{tabular}

INDIQUE COM QUAL FREQUENCIA VOCE DESENVOLVEU AS SEGUINTES ATIVIDADES NESTE AMO E NESTA ESCOLA.

\begin{tabular}{|c|c|c|c|c|}
\hline & vanca. & $\begin{array}{l}\text { Agamas } \\
\text { veans }\end{array}$ & Ficquerbernerte. & $\begin{array}{l}\text { Sempre ow } \\
\text { quase sempre. }\end{array}$ \\
\hline se. Desenvolweu abvidades etracumicuares en esporte. & A & 1 & c. & D. \\
\hline 51. Desenvobu atvidades itracuricuares en artes. & A & B & c & a \\
\hline 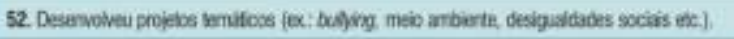 & A & 1 & c. & a \\
\hline 53. Naste ano, a escola promoveu evertos para a conunidads. & A & i. & c & 0 \\
\hline 54. 0s espoços desta escola slo uficados para evertos promovidos pela comuritade. & A & B & c & a \\
\hline 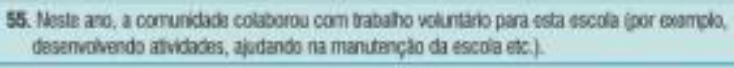 & A & 1 & c & dI \\
\hline
\end{tabular}


56. QUANTOS ESTUDANTES COM DEFCEENCIA OU NECESSIDADES ESPECUIS ESTUDAM NESTA ESCOLA NESTE ANO?
A Nenhum.
1). Entre 1 e 5 alunos.
C. Entre 6 a 10 alunos.
D. Entre 11 e 20 alunos.
E. Mais de 20 alunos.

Comanto das

57. A IFFAAESTRUTURA DA ESCOLA EADEOLADA AS PESSOAS COM
DEFICIENCIA OO NECESSIDADES ESPECLAIS?
A Nio.
it Sim, mas pouco adequada.
5. Sim, sificienternente adosuada.

58. A ESCOLA POSSU SALA DE RECURSOS MULTIFUNCIOMAIS PARA ATENDIMENTO EDUCACIOMAL ESPECIALIZDO (AEE)?
A. Nas posssi sala de recussos
I. Sim mas com poucos rtcursos.
c. Sim, cam recurses sefcientes.

60. OS PROFESSORES OESTA ESCOLA POSSUEM FOAMACÃD ESPECIFICA PARA TRABALHAR COM ESTUDANTES COM DEFCIENCIA OU NECESSIDADES ESPECIAIS?
A. Măอ.
1. Sin, mas em nemero insuficente.
c. Sim, em numero sificiante

\section{OS OEMUS FUNCIONÄROS DESTA ESCOLA POSSUEM FORMAChO PARA TRABALRAR} COA ESTUOANTES COM DEFICIENCIA OU NECESSIDADES ESPECIAIS?
A Náo.
18. Sim. mas em numare insuficients
c. Sim, en némero súfiente.

\section{VoCE POSSUI FOPMACIO ESPECIFICA PARA TRABAL HA CON ESTUDANTES COM DEFICIENCLA OU RECESSIDADES ESPECIAIS? \\ A Niso. \\ II Sim, mas apenas em uma areardefichencia. \\ c. Sim, am mais do uma areavdeficióncia.}

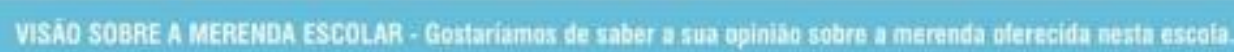

62. Ficursos financeins

63. Quantidade de arnertos.

64. Qualdade dos alimentos.

65. Espaca fisico para covinhar

66. Dsponiahdade de funcionatios.

\begin{tabular}{|c|c|c|c|c|}
\hline Insestente. & Aaim. & Ranodvel. & Bom. & Otine. \\
\hline A & 1 & c & D & I \\
\hline A & i & c & D & E \\
\hline a & E & c & D & E \\
\hline A & 1 & c & D & E \\
\hline A & 8 & c & $\theta$ & $E$ \\
\hline
\end{tabular}

VSARO SOERE OS PROBLEMAS DA ESCOLA E DIFCULDADE DE GESTR̆o - Cosiariamas de gaber a sua opinifio sobre os principais problemas desta escola e as dificuldades que voce encontre na gestâs ascolar.

Comando das

Questoes 67 a 76

O FUNCIONAMENTO DA ESCOLA FOI DIFICULTADO POR ALGUM DOS SEGUUNTES PROBLEMAS?

\begin{tabular}{|c|c|c|c|c|}
\hline & Na. & Sm, pouco. & $\begin{array}{l}\text { Sim } \\
\text { modradamente. }\end{array}$ & Sin, mals \\
\hline 67. ksafcianoi de recursos financeros. & A & s & c & b \\
\hline 68. Feistinca de prodessores para algumas doccplinas ou stries. & A & B & c & b \\
\hline 49. Crincia de pesscal actinibratvo. & A & If & c & n \\
\hline 70. Cartncia de pessoal de acob pedagogico isupervisoc coordenador, orientador educacionali). & A & B & c & D \\
\hline 71. Fata de recursos pedagogos. & A & B & c & D \\
\hline 72. Ktemupcalo das andades escodiras. & A & B & c & $\mathrm{n}$ \\
\hline 73. Abo hdoe de tatas por parte dos probessores. & A & B & c & D \\
\hline 74. Abo indoe de tatas por parte dos alunas. & A & B & c & D \\
\hline 75. Ala rotalividade do cono docate. & A & B & c & D \\
\hline 76. hifsecplina per parte dos alunos. & a & $B$ & c & 0 \\
\hline
\end{tabular}


77. Ha intartatricia de abres eternas em sua gasthe?

78. Ha apoo de instancias superiores?

79. Ha troca de intomaches com limeres de outras excolas?

80. Ha apoio da comuricade a sua gesta??

\begin{tabular}{|c|c|}
\hline Sin & Keo \\
\hline A & B \\
\hline A & B \\
\hline A & B \\
\hline A & B \\
\hline
\end{tabular}

RECURSOS FIMANCEIROS ELINROS DiDATICOS - Gostariamos de saber as tontes de recursos que contribuem para o funcienamento desta escola e sohre os ivros diditices.

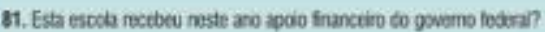

62. Exar escoda resebeu neste ano spoio fnanceivo of govemo astadiar?

83. Esta escola recebeu reste ano apoio fruanceivo co governo muricica?

24. Esta escola recebeu mate ano apoio fnanceiro de emoresas ou doadores individas?

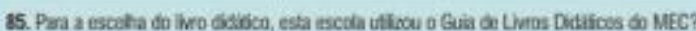

\begin{tabular}{|c|c|}
\hline Sin & N2o \\
\hline A & B \\
\hline A & B \\
\hline A & B \\
\hline A & B \\
\hline A & B \\
\hline
\end{tabular}

\section{CONE SE DEU A ESCOLHA DO LIVRO DIDATICO NESTE ANO?}
A Nasse:
if Fol escolhido de forma participanva pelos professores
c. Foi escolido por somante algans mentbros da nesipe escolar.
D. Foi escolido por árgáas extemos a escola
f. Foi escothido de outra maneira.

\section{NESTE ANO, NESTA ESCOLA, OCORRERAM AS SEQUINTES SITUAÇOEE:}

87. Os thros chaparan en benpo hadil para o ricio das aulas

88. Fataram ivos para cs aunes

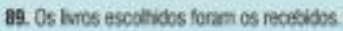

\begin{tabular}{|c|c|c|}
\hline Sh & Nas & Nas sai \\
\hline A & B & C \\
\hline A & 3 & C \\
\hline A & B & C \\
\hline
\end{tabular}

VIOLĖYCLA NA ESCOLA - Gustariamos de saber sobre a ocorrencia de falos que afetam a sepurança nesta escola.

Cemando das

SOBRE OS FATOS LISTADOS ABAIX0, DIGA SE ELES ACONTECERAM OU MAO ESTE ANO, NESTA ESCOLA:

\begin{tabular}{|c|c|c|}
\hline & $\sin$ & $\mathrm{N} 3 \mathrm{O}$. \\
\hline se. Agressa vetai ou fisica ce aunos a professors ou fircioniros da escola. & A & B \\
\hline 91. Agressas vertai ou hisica de alunos a outros atunos da escola. & A & B \\
\hline 92. Vocé foi vitme de dostaco a vida & A & B \\
\hline 92. Voct foi ameacado por alyum auno. & A & $B$ \\
\hline 94. Voct foi vilms of furto (sem uso de vioitencis). & A & B \\
\hline 95. Voce foi vifma de rouso (com uso de viciencla). & A & B \\
\hline 96. Alanos tequertaram a escosa sob atalo de bebida dicoolia & A & B \\
\hline 97. Alsnos tequertacam a escola sob efteho de drogas locitas. & A & $B$ \\
\hline 98. Alinos tequertaram a escola portando arma branca (tacas, canivetes fec). & a & B \\
\hline 9. Alunog tequectaram a escola portando arma de togo. & A & s \\
\hline
\end{tabular}


Questbes 100 a 10

NESTA ESCOLA, HA PRONETOS MAS SEGUINTES TEMATICAS:

\begin{tabular}{|c|c|c|}
\hline & $\sin$ & Nto \\
\hline 100. Voitrca. & A & $B$ \\
\hline 101. Ds mabricias do uso de dogas. & A & B \\
\hline 102. Raciano & A & B \\
\hline 103. Machismo e homodobia & A & s \\
\hline 164. Bulying & A & 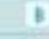 \\
\hline 105. Seusulade e gravidez na abolesctrcia & A & B \\
\hline 106. Desigualades socias. & A & B \\
\hline 107. Dersidade ralgosa. & A & 5 \\
\hline 108. Mab anberte. & A & s \\
\hline
\end{tabular}

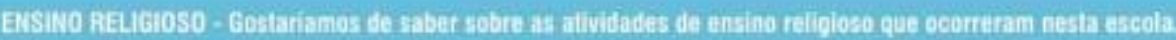

Comando das

Questies 109 a 111

NESTA ESCOLA, 0 ERSINO RELIGIOSO

\begin{tabular}{|c|c|c|c|}
\hline & $\begin{array}{l}\text { Naio hid auta de } \\
\text { exsina relogioso. }\end{array}$ & $\sin$ & Neo. \\
\hline 169. Ede presenca obrigascria. & A & B & c \\
\hline 110. Segun uma migio rspoctica. & A & is & c \\
\hline 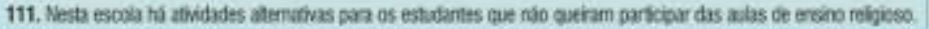 & A & B & c \\
\hline
\end{tabular}




\section{ANEXO C - Questionário do Professor - Prova Brasil}

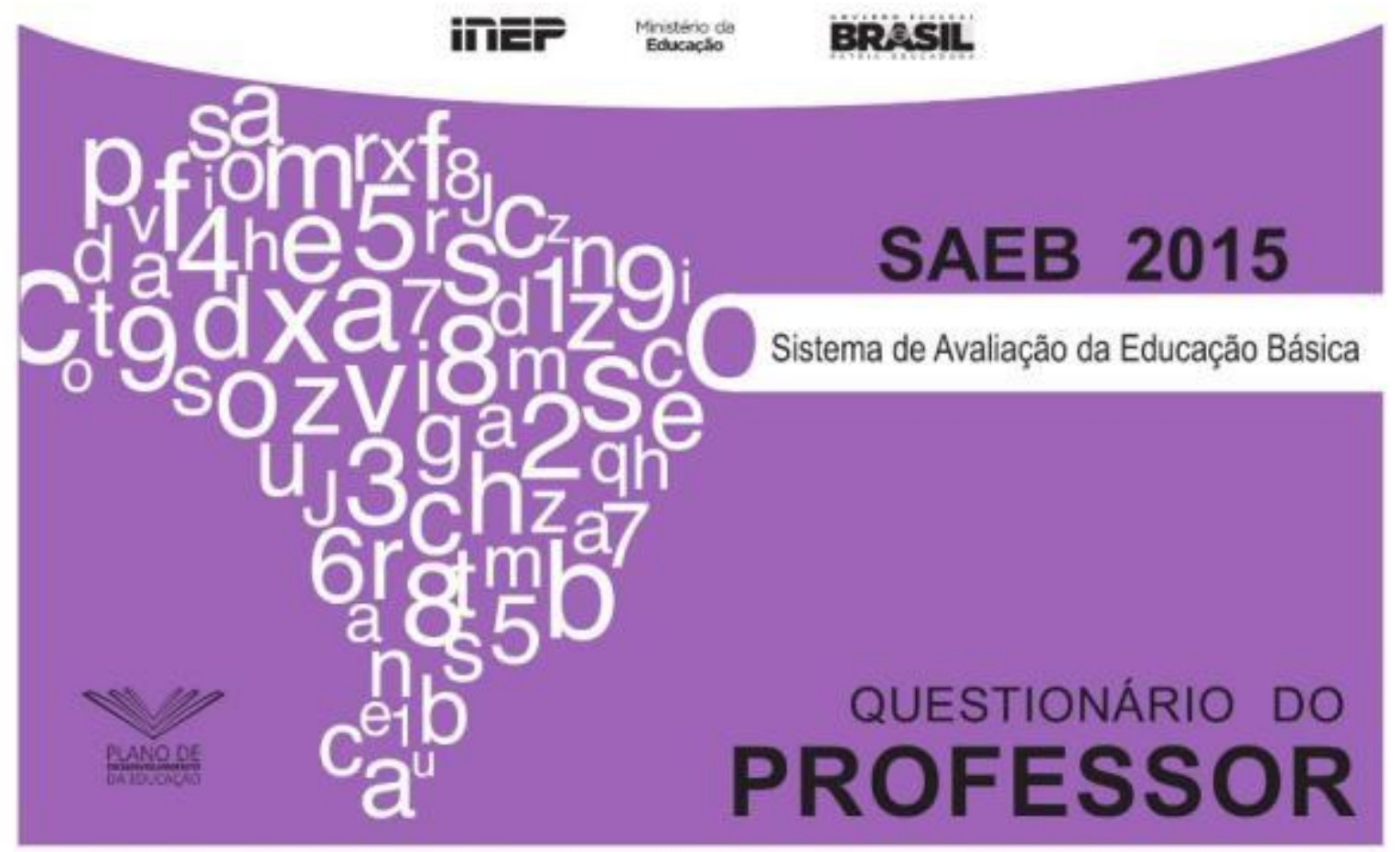

\section{Senhor(a) Professor(a),}

O Sistema de Avaliação da Educação Básica, SAEB, é composto por dois tipos de instrumentos de avaliação: as provas aplicadas aos estudantes e os questionários socioeconômicos, que devem ser respondidos pelos estudantes, professores e diretores das escolas avaliadas.

O presente questionário tem como objetivo coletar dados acerca da formação profissional, das práticas pedagógicas e do perfil socioeconômico e cultural dos professores das turmas em que a avaliação está sendo aplicada. Para responder a cada questão deste questionário, preencha, no CARTÃO-RESPOSTA, o campo correspondente à alternativa de sua escolha. Utilize caneta esferográfica de tinta azul ou preta .

Atenção: Antes de preencher ao questionário, verifique no cabeçalho do Cartão-Resposta a turma, ano/série e disciplina que você deverá utilizar como referência. Caso você tenha recebido mais de um Cartão-Resposta, atente-se que os dados do cabeçalho são diferentes e por isso você deverá preenche-los por completo.

A sua colaboração ao preencher este questionário será de grande valia para o êxito da avaliação e para o aprimoramento da educação brasileira. 


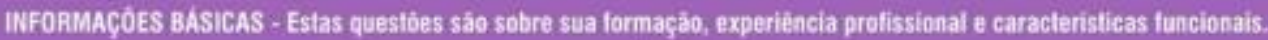

1. Dual E o SEu sewo?
A. Masculno.
I Faminina.

\section{VOCE PODERIA NOS DIRER A SUA FAIXA ETARIA?}
A. Ate 24 anos.
I. De 25 a 29 aros
C. De 30 a 39 aros
D. De 40 a 49 anos.
E. De 50 a 54 inos.
F. 55 anos ou mais.

\begin{tabular}{|c|c|}
\hline \multicolumn{2}{|c|}{ I. COWO VOCE SE CONSIDERA? } \\
\hline A & Besten(a). \\
\hline I & Pardo(a) \\
\hline c & Preto(a). \\
\hline D & Amaralo(a). \\
\hline t & Indgena. \\
\hline F & Niso quevo declaras: \\
\hline e & Niose. \\
\hline
\end{tabular}

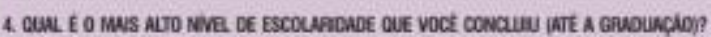

A. Menos que o Ensino Medio (antigo 2.' grau)

I. Essino veedo-Magisterio (antico $2^{\circ}$ graul.

c. Easino Medio-Outres (antigs $2^{\circ} \mathrm{grau}$ ).

D. Essino Stoerior-Padegogia.

E. Essino Suparior - Cursa Normal Saperiac

1. Essino Superior - Licenciatura tm Matematica

6. Ensino Sisparior - Lictnciatura em Letras.

if. Ensing Suparior - Outras Licinciaturas.

(1. Essing Sugeriur-Outras areas

\section{HA QUANTOS ANOS VOCE OBTEVE O MIVEL DE ESCOLAHIDADE ASSIMALADO} AMTEAIORMENTE (ATE A GAADUACCAO)?
A. Ha menos de 2 anos
I. De 2 a 7 anos.
c. De 8 a 14 anos:
D. Do 15 a 20 anos.
I. Ha mas de 20 anos

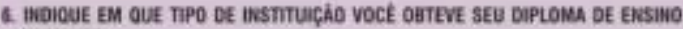
SUPERIOR.
A. Na concluic Ensing Suseriot
B Pivada.
c. Pubica Federal
i. Piblica Estadial.
E. Piblica Municipal.

\section{DE QUE FOAMA VOCE RERLIZOU O CURSO DE ENSINO SUPERIOA?}

A. Niso contuio fensino Superior

8. Prestncial.

c Semitresercial.

D A estincia

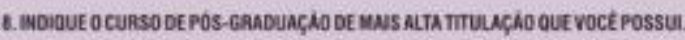

A. Kias fiz ou nto completei curso de pos-gratuaça

B Atualzaça ou Acerfeicoamento inichto of 380 tonast.

c. Especialosedo iminimo $6 \mathrm{se} 362$ heras)

D Mastrado.

E Doutorado

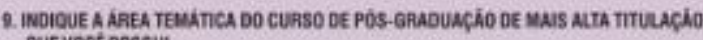
QUEV VOCE POSSUI.

A. Náo fiz ou nado complotel curso do pos-graduaça

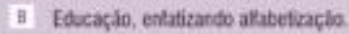

C. Edscaça, entatizas do finguistica elou bitramerto.

D. Educaça, entatizando educaçà matenatica.

E Edocacio - ourns étases.

F. Outras zreas que nio a Educaça

10. COMO PRDFESSOB, OUAL E, APROXIMADAMENTE, O SEU SALARIO SRUTO? (COMADICIONAIS, SEHOUVER).

A. Ane RS 788,00

i. DeRS 788.01 atét AS $1.182,00$.

C De RS 1.18201 ate RS $1.575,00$.

D. De R\$ 1.576.01 ate R\$ $1.970,00$

I DeRS 1.970 .01 ate HS 2354,00 ,

I. De RS 2.384.01 ate A5 2.758.00

(C) DERS 2.758.01 atte R 3.152 .00 ,

H DER 3.152,01 ate RS $3.990,00$.

1 De RS 3.940 .01 att RS 5516,00

I De R\$ 5.516 .01 ate $R S 7.880,00$.

K. R5 7.880.01 ou mas.

11. ALEK DA ATIVEADE CONO DOCENTE NESTA ESCOLA. VDCE EXEACE OUTRA ATWIDADE QUE CONTRIBUI PARA SUA RENDA PESSOAL?

A. Sim, na àrea de eoducaçằ

1i. Sim, fora da aras de edacaçào.

C. Nàa

12. CONSIDERANDO TODAS AS ATWIBADES QUE VOCE EXEACE IDENTHO E FOA DA AREA DE EDUCACLO), QUAL E, APROXIMADANENTE, O SEU SALAFIO BRUTO? (COM ADICIONALS, SE HOUVER?.

A. Ae R5 788,00

II De RS 7B8.01 atte RS $1.182,00$.

C. De RS 1.18201 ate RS 1.576,00.

D. DeRS 1.576.91 ate R5 1.970 .00

E DERS 1.970 .01 até RS 2364.00 .

F De RS 2.364.01 ate RS 2.758,00.

f5 De RS 275801 ate Rs 3152.00

II De AS 3.152.01 até RS 3940,00

1 De RS 3940,01 ate RS $5.516,00$

1 De R5 5.516.01 ate RS 7.880.00

K. R57.880.01 nu mas.

\section{HA QUANTOS ANOS VOCE TRABALHA COMO PROFESSORIA]?}

A Meu primero ano

B) 1.2 anos

C. 3.5 anos

1. 6-10 anas:

E. 11-15 anos.

F. $16 \cdot 20$ anos.

6. Mals de 20 anas. 


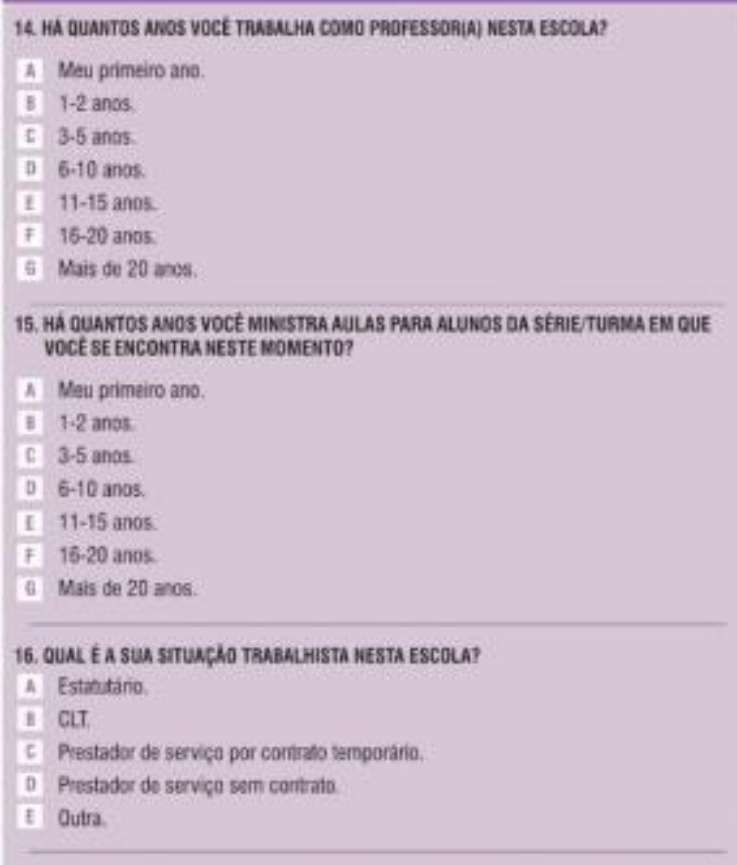

17. MESTA ESCOLA, OULL E A SUA CARLA HORARLA SEMANAL? ICONSIDERE A CARGA HORARIA CONTRATUAL: HORAS-AULA MAIS HORAS PARA ATVIDAOES, SE HOUVER. KAO CONSIDERE AULAS PARTICULARES)

17. Mais de 40 haras

I. 40 hons.

c. De 20 a 39 toras.

D. Menos de 20 horas.

\author{
18. EM QUANTAS ESCOLAS vOCE TRABALHA? \\ A. Apenas nesta escola \\ i. Em 2 escolas. \\ C. Em 3 escotas. \\ II Em 4 ou meis esodas.
}

19. COHSIDERANDO-SE TODAS AS ESCOLAS EM QUE VOCE THABALLA ATUALUENTE COMO PRDFESSOAIAI OUUL, EA SUA CARGA HORLARIA SEMUMAL?

(COHSIDERE A CARGA HOAMRIA CONTHATUAL-HOAAS-AULA MAIS HORAS PARA ATIVIDADES, SE HOUUER. KG̈O CONSIDEAE AULAS PARTICULAREST)
A. Mais of 40 hatas
ii 40 horas.
c. De 20 a 39 horas
D. Menos of 20 haras.

20. CONSIDERANDO-SE TODAS AS ESCOUS EM DUE VOCE TRUALLA ATURLMEITE COMO

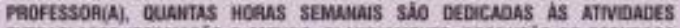

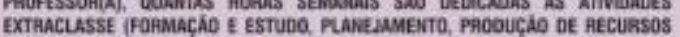
oiohncoserci?
A Nentuma.
if Menos de 1/3 da carga horairiz
C $1 / 3$ da carpatoriris.
D. Mais de 1/3 da carga horkia.

\section{DESENVOLVIMENTO PROFISSIONAL - Nesta parte, Desenvolvimento Protissional" é definido como atividades que tem por objetive} desenvolver habilidades, conhecimento, experitencia e outras caracteristicas do protessor.

Comando das Ouesties 21 a 24 DURANTE OS ULTIMOS DOIS ANOS, VOCE PARTCIPOU DE QUALQUER UM DOS SEGUIMTES TIPOS DE ATIVDDAES DE DESENYOLYIMEMTO PROFISSIOMAL EQUAL FOI OIRPACTO DESSA ATIVIDADE EM SUA PRATICA CONO PAOFESSORCAI?

\section{A Nåso participes. \\ 1. Sim e noso houve impacto \\ 5 Sin. a houve um paquero impacto. \\ D. Sin. e houve um incacto moderado. \\ E Sin, $e$ huure um garde inpacto.}

21. CURSOS/OFICINAS SOBRE METODOLOGIAS DE ENSIKO KA SUA LAEE DE MTUACLIO

\section{CURSOS.OFACINAS SOBAE OUTROS TOPICOS EM EDUCACiO \\ A Nas participel. \\ I. Sim. enau houve impasth. \\ I5 Sim, a houre um pequeno impacto. \\ 1. Sim, e howe un impacto moderado \\ E. Sim e howe um grande impacto}

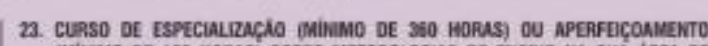
(MINMMO oE tEs HORAS) SOBRE METODOLOGUS DE ENSHO HA SUA AREA OE aruecía.
A Náo participel
I. Sin t náo houve impactn
c. Sim, shouve um pequese impact.
D. Sm. thouve um imcacto moderado.
E. Sin, thouve um panse ingacto.

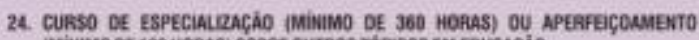 (Mivimo oE 180 HORAS) SOBRE OUTHOS TOPICOS EM EDUCACiO
A Nà participe:
If Sim t nảo houve impacto.
C. Sim. a houre um pequeno impactn.
D. Sim. o houve um imcacto modarado.
E. Sir o houve um grando irvacta

25. DAS ATMIDADES DE OESENVOLVIMENTO PROFISIONAL. DE OUE VOCE PARTICIPOU NOS GUTIMOS DOIS ANOS, QUANTAS VOCE, PESSOMLMENTE, TEVE OUE PAGAR PARA PARTCIPAR?

A. Nenhuma.

B Algumas.

C Tosas: 


\begin{tabular}{|c|c|c|c|c|}
\hline & $\begin{array}{c}\text { Nio ha } \\
\text { tectssidade. }\end{array}$ & $\begin{array}{c}\text { Babo navel } \\
\text { de necessidade. }\end{array}$ & $\begin{array}{l}\text { Novel moderndo } \\
\text { de recessidade. }\end{array}$ & $\begin{array}{c}\text { Ato nine } \\
\text { de necessidade. }\end{array}$ \\
\hline 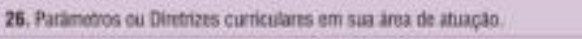 & A & a & c & D \\
\hline 27. Cortejdes espechites da minha decipina pincipal de auseto. & A & a & c & D \\
\hline 28. Prabcas de Ensino ma minha disopira princpa de atuaca. & A & i & c & D \\
\hline 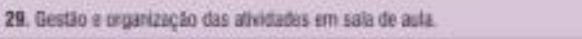 & 1 & I & c & D \\
\hline 30, Metsdoiogas se maliacto dos alinos. & A & II & c & D \\
\hline 31. Uso padagogico das Teenobgias de informaçao o Cominicaçäo. & $A$ & 要 & c & (1) \\
\hline 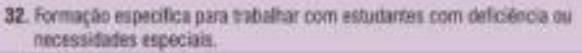 & A & B & c & D \\
\hline
\end{tabular}

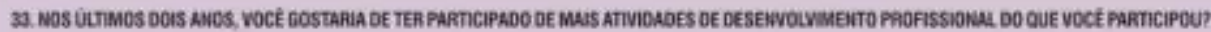

A Nan.

I) $\sin$.

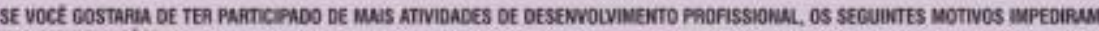
SEA PARICIPAÇAOQ?

\begin{tabular}{|c|c|c|c|}
\hline & $\begin{array}{l}\text { Nao gostaria } \\
\text { de ter particieado. }\end{array}$ & Was. & sim \\
\hline 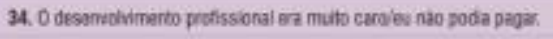 & A. & B & c \\
\hline 35. Howe contids cen o meu horario de trabatha. & A & B & c \\
\hline 36. Mas ticha dasaribidade de tempo. & A & B & c \\
\hline 37. Niso have oferta em nivha frea de itustsse. & A & in & c \\
\hline
\end{tabular}

HABITOS DE LEITURA CULTURAIS - Gestariamos de saber quais sta as atividadas que voct costuma realizar em seu tempo livre.

\begin{tabular}{|c|c|c|c|}
\hline & $\begin{array}{l}\text { Nunca ou } \\
\text { quase aurce. }\end{array}$ & De ver em guanda & $\begin{array}{l}\text { Sempore ou } \\
\text { Quase serppre. }\end{array}$ \\
\hline 38. Ler jomis o ronstas en gral. & A & 8 & c \\
\hline 39. Ler hmos. & A & ] & c \\
\hline 40. Ler sites na ixtemet. & A & I & t \\
\hline 41. frequentar bibiotecrs. & a & B & c \\
\hline 42. rav chema. & A & B & c \\
\hline 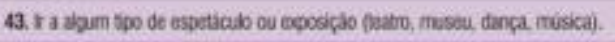 & A & 8 & c \\
\hline
\end{tabular}

UTILIZAÇÃO DE RECURSOS AUDIOVISUAIS E DIDÁniCOS - Nesta seçẩo, objeliva-se averiguar o uso de recursos para FiNS PEDAGOGICOS pelo protessoc.

Comando das Questites 44 a 50

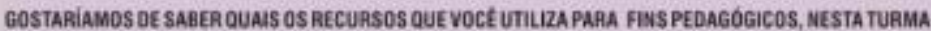

\begin{tabular}{|c|c|c|c|c|}
\hline & $\begin{array}{l}\text { Nibo unizo perque a } \\
\text { escola nasom }\end{array}$ & Munca. & De ver en quando. & $\begin{array}{c}\text { Sempre os } \\
\text { quase sempre }\end{array}$ \\
\hline 44. Jomais e revestas intornabvas. & A & B & c & D \\
\hline 45. Uvins de heranun em gral & A & B & c & D \\
\hline 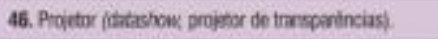 & A & is & c & D \\
\hline 47. Fines, desarhos aninados ou documentinos. & A & B & c & D \\
\hline 48. Miquina copiadora (oartax). & A & i & c & D \\
\hline 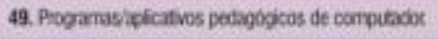 & A & B & c & D \\
\hline so. hitumet. & A & E & c & D \\
\hline
\end{tabular}




\section{INTEGRAÇĀOO DA EOUIPE ESCOLAR - Costariamos de the perguntar sobre a inteqraçăo da equipe escolar NESTA ESCOLA.}

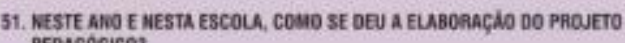
PEDAGOGico?

A. Na sei como foi deservaledo.

II Ne suste Proimo Fedagoica

C. Utilands-se um modilo prom, sem oscussto cam a eqaite escolar.

D. utizanda-se um motilo prorto, mas com discussio con a equipe escolv

I. Utilizando-se um modeb prenta, porem con adaphaçoes, sem ăscussjo com a equipe escolat

F. Uthizando-se um nodelo prento, parém com adaptaç0es e con dscussdo com a equjpe escolar

5. Flaborou-se im modeio pitpria mas nito towe dscussio com a equice escolat

H. Flabarou-se im modala prtpris e houve discussin can a eape escotr.
52. O CONSELHO DE CLASSE E UM ORCÄO FOAMADO POR TODOS OS PROFESSORES QUE LECIONAM EM CADA TURMA SERIE. NESTE ANQ E MESTA ESCOLA OUANTAS VEZZS SE REUNIU O COKSEH HODE CLASSE?

A. Nio euistn Conselho de Carsa nesta escola.

B. Nenthama vez

C. Una vez.

0 Das vazes

F. Tres vezes ou mas

\begin{tabular}{|c|c|c|c|c|c|}
\hline & Nunca. & $\begin{array}{l}\text { Uima vez } \\
\text { Bor ans. }\end{array}$ & $\begin{array}{l}\text { De } 3 \text { a } 4 \\
\text { vedes } 30 \text { ano. }\end{array}$ & Mersaimenth. & Sesasament. \\
\hline 53. Paricipou do pianejamerto do curiculo escolar cu parto dele. & A & E & c & D & E \\
\hline 54. Trocou muntas sethcos com seas colegas. & A & B & c. & b. & E \\
\hline $\begin{array}{l}\text { 55. Paracipou on reuribes com cokgas que trahaham con a mesma séle (anol) } \\
\text { para alo) qual lociora. }\end{array}$ & A & B & c. & D & E \\
\hline $\begin{array}{l}\text { 56. Paricipou em dscussóes sobre a desencolinerto da aprendieagen de } \\
\text { deterninabs aunos. }\end{array}$ & A & B & c & D. & E \\
\hline 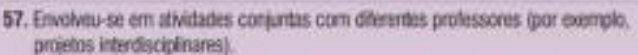 & A & B & c & D) & E \\
\hline
\end{tabular}

\begin{tabular}{|c|c|c|c|c|}
\hline & Nunce. & finumas veras. & Firequartemeste. & $\begin{array}{l}\text { Senpes ou } \\
\text { quase sempre }\end{array}$ \\
\hline 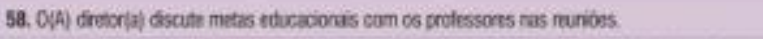 & A & B & c & D \\
\hline 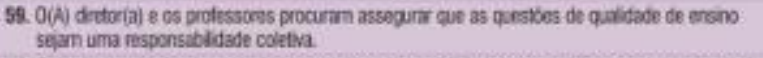 & A & 甲 & c & D \\
\hline 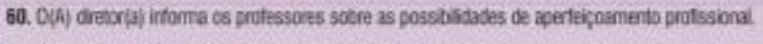 & A & I & c. & 0 \\
\hline 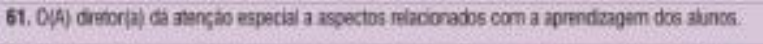 & A & B. & c & D. \\
\hline 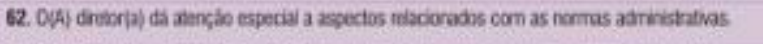 & A & B. & c & D. \\
\hline 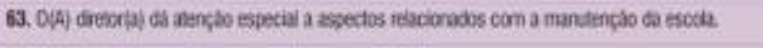 & A & B & c & D \\
\hline 64. OAf) dietoria) me arima eme motiva para o trataho. & A & B & c & D. \\
\hline 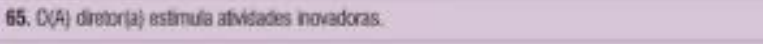 & A & B & c & D \\
\hline 66. Sintome respetado polo(2) dintorta). & A & i & c & a \\
\hline 67. Kerto conlisnça toca) dretor(a) como profissioral. & A & I & c & D \\
\hline 68. Parscipo das decistes relicionadas con meu trabaho. & A & B & c & a \\
\hline 69. A equpe de podessores leve am corsidoraça mithas iseiss. & a & 田 & c & D \\
\hline
\end{tabular}




\begin{tabular}{|c|c|c|c|}
\hline \multicolumn{4}{|c|}{$\begin{array}{l}\text { PAOBLEMAS DE APRENDIZAGEM - Gostariamos de conhecer sua percepçäo sobre as causas dos possiveis } \\
\text { problemas de aprendizagem nas turmas em que voce leciona NESTA ESCOLA. }\end{array}$} \\
\hline \multirow[t]{2}{*}{ Comando das Questies 70 a 82} & \multicolumn{3}{|c|}{ 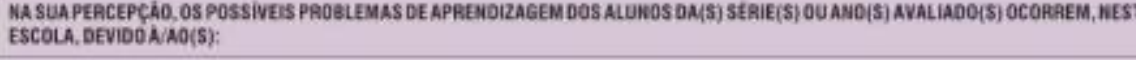 } \\
\hline & & Sim. & Nan. \\
\hline \multicolumn{2}{|c|}{ 70. Carbicia de intrestrutura isica. } & A & E \\
\hline \multicolumn{2}{|c|}{ 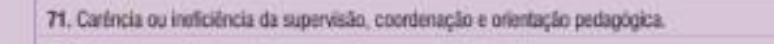 } & A & E \\
\hline \multicolumn{2}{|c|}{ 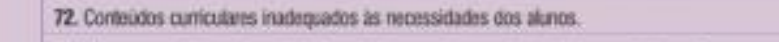 } & A & B \\
\hline \multicolumn{2}{|c|}{ 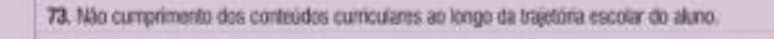 } & A & 而 \\
\hline \multicolumn{2}{|c|}{ 74. Sobrecarga de tabaho dos professures, dinculando oplanejamento e e preparo das alias. } & A) & B \\
\hline \multicolumn{2}{|c|}{ 75. rsafsfacto e deses3mibo do professar com a carrera docenthe. } & A & 旦 \\
\hline \multicolumn{2}{|c|}{ 76. Meio spcial en qoe o aturo vive. } & A & E \\
\hline \multicolumn{2}{|c|}{ n. Ahit cutural dos pais dos adunos. } & A & E \\
\hline \multicolumn{2}{|c|}{ 72. Filta da assistencia e acomcorhanento dos pais na vida escodar do auno. } & A & 且 \\
\hline \multicolumn{2}{|c|}{ 79. Bawa a toestina dos atunos. } & A & E \\
\hline \multicolumn{2}{|c|}{ 20. Desintresse e filta de esturço fo atuna. } & A & E \\
\hline \multicolumn{2}{|c|}{ 81. hodscpira cos aims on sala do ada. } & A & B \\
\hline \multicolumn{2}{|c|}{ 82. Abo indoe de fatas por parte dos alunos. } & A & B \\
\hline
\end{tabular}

VIOLENCIA NA ESCOLA - Gostariamos de lhe perguntar sobre ocorrelnclas de violęncia nesta escola.

Comando das Questbes 83 a 92 SOBRE 0S FaTOS USTAdOS aBaix0, DIGA SE ELES ACONTECERAM OURÄO NESTE ANO, NESTA ESCOLA:

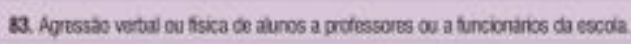

84. Agresiab vetal ou fisica de aums a outros átnos da escola.

85. Voct foi vifma de abrbobo i with

65. Vocei foi anaçado por alyum aluno.

87. Voce fai vitma de furto (sem uso de violendial).

83. Vocé foi vitrma de routo (con uso de violéncia).

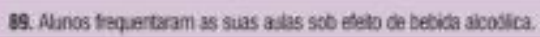

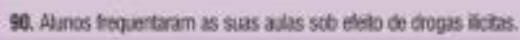

91. Alanos frquitaran as suas ajas portundo arme branca facas. cavictes etc).

92. Alanos trquertaram as suas alias portando ama de fogo.

\begin{tabular}{|l|l|}
\hline Sim. & Nab \\
\hline A & II \\
A & I \\
A & E \\
\hline A & B \\
\hline A & E \\
\hline A & I \\
\hline A & D \\
\hline A & B \\
\hline A & I \\
\hline A & B \\
\hline
\end{tabular}

EXPECTATIVAS - Nesta seçio gostariamos de saber sua expectativa quanto à trajetoria educacional futura de seus alunos.

\begin{tabular}{|c|c|c|c|c|}
\hline & $\begin{array}{l}\text { Poutos } \\
\text { atunos: }\end{array}$ & $\begin{array}{l}\text { Um posco menos } \\
\text { da matade } \\
\text { dos dinos. }\end{array}$ & $\begin{array}{l}\text { Umpouco mats } \\
\text { da nesade } \\
\text { des diunss. }\end{array}$ & $\begin{array}{l}\text { Quase todos } \\
\text { os aurnos: }\end{array}$ \\
\hline 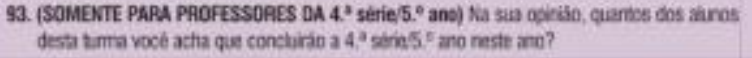 & A & I & c & D \\
\hline 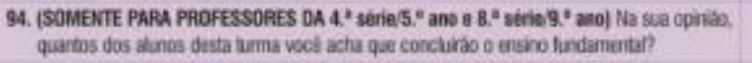 & A & 5 & C & D \\
\hline 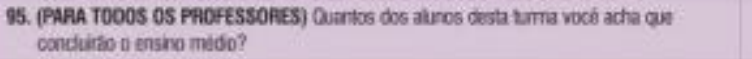 & A & 9 & c & 8 \\
\hline 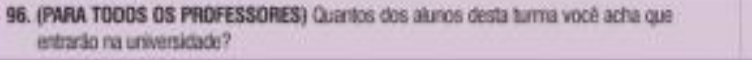 & A & $\mathrm{E}$ & c & D \\
\hline
\end{tabular}




\begin{tabular}{|c|c|}
\hline 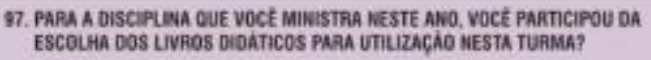 & 100. OS ALUNOS DESTA TURMA RECEAERAM O UVRQ DIDATCO NO INECIO DO ANO LETVO? \\
\hline $\sin$ & A $\mathrm{Sim}$ \\
\hline 1) Nลa. & I Nao. \\
\hline & C Näo sei. \\
\hline $\begin{array}{l}\text { 98. } 0 \text { LUNO DIOATICO ESCOLHIDO FOI } 0 \text { RECEBIOO? } \\
\text { A SID. }\end{array}$ & \multirow{6}{*}{ 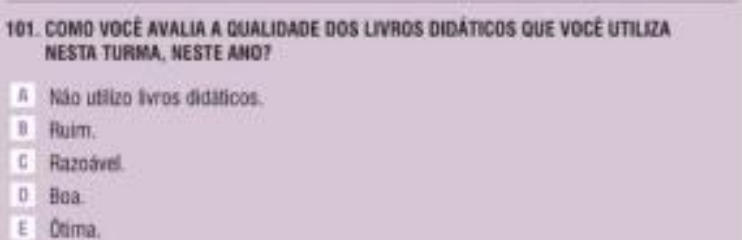 } \\
\hline is Má. & \\
\hline c. Măo sel & \\
\hline & \\
\hline & \\
\hline & \\
\hline 92. OS ALUROS DESTA TURMA TEM UVROS DIDÁtiCOS? & \\
\hline A Nas, esta brma ná receheu o linro Gdarca. & \\
\hline it Sim, manos da metade ca turma tem. & \\
\hline c. Sin, metase da turma sem. & \\
\hline D. Sin a macraten. & \\
\hline E $\operatorname{Sin}$ asdos tem. & \\
\hline
\end{tabular}

\section{Comanto en Questies} 102 a 104
PARA ESTA TURMA, DUAL O PERCENTUAL DO TEMPO DE AULA OUE VOCE USUALGENTE GASTOU AEALZAKDO CADA UMA DAS SEGUNTS ATVIDADES:
102. AEALZANDO TaAEFAs ADMINISTHATNAS ( $x$ - FAZINDO A CHAMADA, PREENCHENDO FORMULARIOS ETC.).

A. Menes de $10 \%$

1) De $10 \mathrm{~s}$ a manos $20 \mathrm{~s}$.

C. De $20 \%$ a menos de $40 \%$.

II De $40 \%$ a menos de $60 \%$.

E. De 60s a menos de 80\%.

I. Bos, ou rais.

\section{MAKTENOD A ORDTM DISCEPLYA KA SALA DE AULA.}

A. Menos de tor.

1. De $10 \%$ a manos $20 \%$.

C. De $20 \%$ a menos ds $40 \%$.

D. De $40 \%$ a manos de $60 \%$.

E. De $60 \%$ a menos de $80 \%$.

I. $80 \%$ ca mais.

\section{REALZANDO ATVIDADES DE ENSINOE} APRENDIZAGEM.

A Menos de $10 \%$.

i. De tor a manos $20 \%$.

C. De $20 \%$ a manos $6040 \%$.

D. De $40 \mathrm{~s}$ a menos of $60 \%$.

E. De $60 \%$ a menos do $00 \%$.

I. 805 cumais

\section{PRATICAS PEDAGOGICAS - Nesta seça gostariamos de the perguntar sobre as estraléglas pedagogicas que voct} utiliza com os alunos DESTA TURMA.

105. NESTA TURMA, OUAL DESCIPLIMA VOCE LECIONA:
A Lingus Pertugues:
II Matematica
c. Mais de uma dscipina

\section{QUANTO DO CONTEUDO PREVISTO VOCE CONSEGUIU DESENWOLVER COM OS ALUNOS DESTA TURMA NESTE AMO?}
A. Menos de $20 \%$.
is De $20 \%$ a menos de $40 \%$
C. De $40 \%$ a menos $\$ 8$ 60\%.
D. Dn bOW a menos din $80 \%$.
E. 805 su mais 
BLOCO GERAL - Práticas pedagónicas dos Protessores.

Comando Eas Questles 107 a 113

\begin{tabular}{|c|c|c|c|c|c|c|}
\hline & Nunca. & $\begin{array}{l}\text { Uma vet } \\
\text { parano. }\end{array}$ & $\begin{array}{l}\text { De } 3 \text { a } 4 \\
\text { veces as ano. }\end{array}$ & Mensyimertice. & Semanshesth & Diariamente. \\
\hline 107. Proper dever de casa. & a & E & E & D & E & F \\
\hline 10e. Conigir con es aunas o drre de casa & A & 3 & c & B & E & F \\
\hline 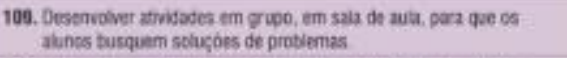 & A & 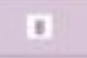 & c & e & E & f \\
\hline 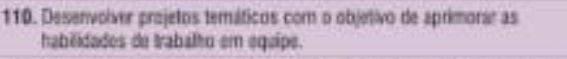 & A & $\mathrm{s}$ & c & D & E & F \\
\hline $\begin{array}{l}\text { 111. Solicaar que as aunos copiem lenos t athifates do livo didatico } \\
\text { ou do qadro nepo fousal). }\end{array}$ & a & 3 & t & D & E. & f \\
\hline 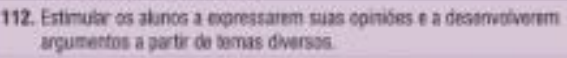 & A & 3 & c & D. & E & F \\
\hline $\begin{array}{l}\text { 113. Prapor stuaples de apinadzagem que sejam fanliars eu se } \\
\text { hiteresse dos auns. }\end{array}$ & A & 8 & c. & D & E & $F$ \\
\hline
\end{tabular}

SE VOCE E EROFESSOR DE LINGUA PORTUGUESA NESTA TURMA, RESPONDA SOMENTE AS QUESTÓES DE 114 A 119. SE VOCÉ E PROFESSOR DE MATEMÁTICA NESTA TURMA, RESPONDA SOMENTE AS QUESTÓES DE 120 A 125.

BLOCO ESPECIFICO - PRATICAS PEDAGOGICAS DOS PROFESSORES DE LIMGUA POATUGUESA.

\section{Comando cas Questies}

114 a 119

\section{INDIOUE A FREQUEUCU COM QUE VOCÉ DESENVOLVE AS SEGUINTES PAÁTICAS PEDAGOGICAS NESTA TUAMA}

\begin{tabular}{|c|c|c|c|c|c|c|}
\hline & Nunca & $\begin{array}{l}\text { Jimavex } \\
\text { psrano. }\end{array}$ & $\begin{array}{l}\text { De } 3 a 4 \\
\text { veces ao ano. }\end{array}$ & Mensamerte: & Sumanabeth. & Diarianente. \\
\hline 114. Fhomover discussbes a partr do sodos on jomais ou revistas. & A & e & c & D & E & F \\
\hline 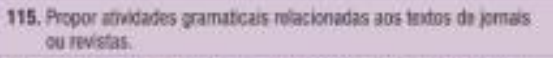 & a & $\mathbf{B}$ & c & b & E & F \\
\hline 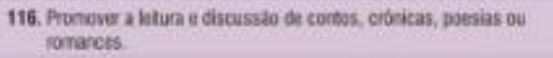 & a & B & c & D & E & f \\
\hline $\begin{array}{l}\text { 117. Usilear contos. cubnicas, poesias ou romantes para eserctar } \\
\text { aspectos da gramitica. }\end{array}$ & A & 9 & c & D. & E & f \\
\hline 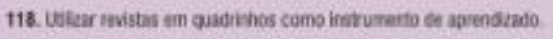 & a & a & c & E & E & F \\
\hline 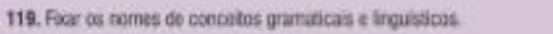 & A & B & c & D & E & $F$ \\
\hline
\end{tabular}

\section{BLOCO ESPECIFICO - PRATICAS PEDAGOGICAS DOS PROFESSORES DE MATERAATICA.}

\section{Comando cas Questles} 120 a 125

\section{INDIOUE A FREQUEMCIA COM QUE VOCÉ DESENVOLVE AS SEGUINTES PRÁTICAS PEDAGOGICAS NESTA TUAMA:-}

\begin{tabular}{|c|c|c|c|c|c|c|}
\hline & Ninka: & $\begin{array}{l}\text { Umu vis } \\
\text { psrano. }\end{array}$ & $\begin{array}{l}\text { De } 3=4 \\
\text { veves as ane. }\end{array}$ & Mansalmarte. & Semanamecte. & Ciarianents. \\
\hline 120. Fazer beercicios para fas procedmentos e regras & a & 8 & E & b & E & $f$ \\
\hline 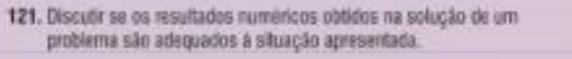 & A & $\mathbf{t}$ & c & D & E & $F$ \\
\hline 122. Discutir diferertes mados para resalvet prodiemes e calculos. & A & $\mathbf{E}$ & c & D. & ( & f \\
\hline 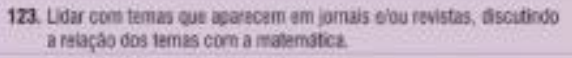 & a & I & c & D & E & F \\
\hline 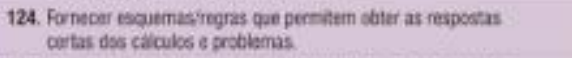 & a & $\mathbf{1}$ & c & e & E & f \\
\hline 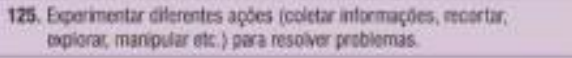 & A & 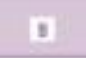 & c & D & E & F \\
\hline
\end{tabular}




\section{ANEXO D - Questionário do Aluno - Prova Brasil}

\section{BRASIL.}

एक ince

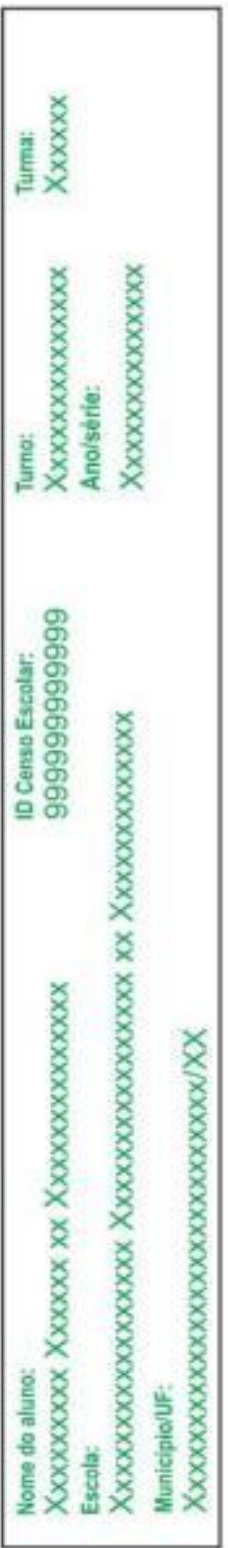

Sistema de Avaliação da Educação Básica

QUESTIONARIO DO ALUNO $-9^{\circ}$ ANO ( $8^{a}$ SÉRIE) DO ENSINO FUNDAMENTAL
1. Qual to o seu serv? (A) Masculina (b) Feming 2. Como vock se considera?
(4) Brancotal:
(0) Amareio(a)
(C) Pardolas
(E) indigena.
(C) Presto(a)
(F) Nas Sol.

3. Voci poderta ness diace qual 6 o mats de seu aniversirio?
(4) Janeiro
(9) Juha
(C) Fonereira
(4) Agosso
(C) Marco
(1) Setembro
(C) Nat
(C) Ounoro
(c) Mato
(k) Novambirs
(c) Junto.
(1) Dezambra

4 Em que ano voct nasceur?
(A) 2003 os seppois
(c) 1999
(B) 2002
(c) 1998
(C) 2001
(C) 1997
(D) 2000
(A) 1006 ou antent

5. Na sua casa tem teievisto eme cores?
(4) NBo $\lim$.
(c) $\operatorname{sim}$, dua
(E) Sim, quatro
(B) $\operatorname{sim}$ una. (D) Sim, ires
ou mass.

6. Na sua casa tem ritato?

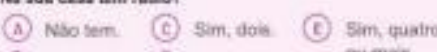

(ii) sim, un (D) sim, tries.

7. Na sua cass tem videocassess siou OVD?

(4) Nbo sem. (C) Sim, dobs. (E) $\operatorname{sim}$ quatre

(B) $\operatorname{sim}$, un (b) sim, thes

Q. Na sua cass tem peiadera?

(4) Nbolem. (C) Sim, dums. (C) Sim, quatro

(i) sim, ima (D) $\operatorname{sim}, 1$ irs

(1) oumas.

2. Na sua casa tem froezar (parte da gelastira duplex)?
(4) Neo tom
(c) $\mathrm{sm}, \mathrm{doc}$
(C) sim, quat

(b) $\operatorname{sim}, u n$ (C) $\operatorname{sim}$, trits

10. Na sua casa tem trevarar separado da geladeira?
(4) NSo in
(c) $s$ im, does.
(C) sim, quats
(D) $\operatorname{sim}$, trís
ou mas.

(B) $\operatorname{sim}, \mathrm{um}$

11. Na sua cass tem maquina de lavar roupa (0 tanquinhe Näo deve ser considerabol?
(a) $\mathrm{Nso} \mathrm{mm}$
(C) $\sin$, duan
(1) sim, quati
ou mas.

(1) $\operatorname{sim}$ ume (D) Sim, tres

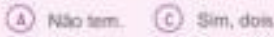
(B) $\operatorname{sim}$ im.
(C) $\sin$, don
(C) $\operatorname{sim}$ quatin ou ${ }^{2}$ m.

13. Na sus casa tem coeputator?

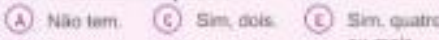

(C) $\sin$, um (D) $\mathrm{sin}$, tres

14. Na sua casa tem banheire?

(A) Naotem (C) Sim oois (E) sim quatro

(b) $5 \mathrm{~mm}$ um. (D) Sim tres. ou mais.

15. Na sua casa tem quartos para dormin?

(A) Nào tam (C) $\sin$, dois (C) $\sin$, quatro

(C) $\sin$, um. (D) $\sin$ ints

ou male

16. Incluindo voce, quantas pesseas vivem atuaimente em sua casa?

(4) Unva, pois maro suzintro(a)

(B) Duas.

(C) Tiso.

(D) Ouatro

(E) Cinco

(E) Sesis perseas ou mais

17. En sua casa tabalha emprogado(a) dombstico(a) pelo manes Cince das por semana?
(a) $\mathrm{Nas}$

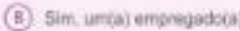
(C) Sim, doivituan) empropudos(as)
(D) $\operatorname{sim}$ bés empregodos(as)
(C) Sim puatro bu mis entipegastos(as)

18. Voce moea com sua mbe?

$\begin{array}{ll}\text { (a) } \sin & \text { (C) Nab, mas mono cons sutra }\end{array}$

(B) Nao muher responsaved por mit

19. Atb que serie sua mie, ou a mulher responsivel por vocb.

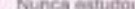

(b) Nas pompletou a 4 4 "seriel5" ano do Ensins

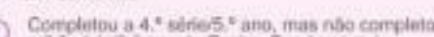

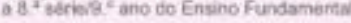

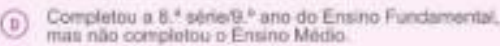

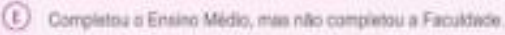

(C) Condeleu a Faculode

(C) Nào seb

26. Sua mab, ou a multar respensàvel por voch, sabe ler : escrever?
(a) $\sin$
(b) Nâs

21. Vocit vê sus mäb, ow a mulher responsabel por voch, lends?
(a) Sim
(e) Nầ. 
QUESTIONARIO DO ALUNO - $9^{\circ}$ ANO ( $8^{a}$ SERIE) DO ENSINO FUNDAMENTAL

22. Vocé mona com seu pai?

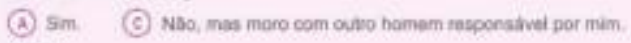

(e) Náa

23. Ate que sirie seu pal, ow o homem responstivel por vock, estudou?

(A) Nuncas estudou

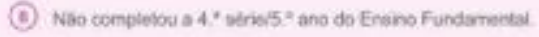

(C) Complebou a 4," sorie/5." ano, mas nas compielou a \& " serie/g," ano do Essino Fundarmental.

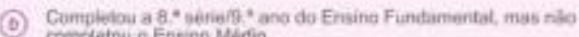

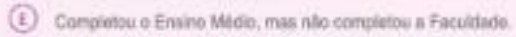

(1) Conpintou a Faculdade.

(C) Nas sei.

24. Sou pai, ou o homen respensatres por vect, sabe leir (A) Sim. (B) NBo

25. Voce ve o seu pai, os a homem responstreil por roct, (A) Sim. (3) Nas lendo?

26. Com qual troguéncia seus pais, ou responsiveis por voch, vảo a r rouniajo de pais?

(a) Sompre ou quase servere. (c) Nunca ou quase nunca.

(B) De vez em quando.

27. Seus pais ou responsivels incentivan roce a estudar? (4) $\sin$ (1) Nas

28. Seus pais ou responsiveis incantivas vock a tazer

o devor do casa wou os trabolhos da escola?

29. Seus pais ou responsabeis incestivam voct a len?

30. Seus pais ou responsatveis incentivam voct a ir a

escola eiou nio faltar as aulas?

31. Seus pais ou responsiveis conversam een voci sobre o qua acentece na escola?

Com qual frequedecia voct it:

(a) $\sin$ (b) $\mathrm{Nas}$

(A) $\sin (B) \operatorname{Nan}$

(A) $\sin$ (B) $\mathrm{NSO}$

(d) $\sin$ (B) Nas

32. Jusas. (A) (D) (C)

32.4 ins em goral. (A) (B) (C)

34. Unow de ingahra: (a) (3) (C)

35. Pevistas em perat (a) (B) (C)

36. Revistas em nanerinhos (gotis)

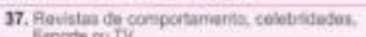

(A) (9) (C)

3. Noticas na intemes (ex: blog, noticia)

39. Com qual frequéncia voct costuma ir a biblioteca?

$\begin{array}{ll}\text { (4) Sempre ou quase sempre. (C) Nunca osi quase nunica. } & \text { (C) }\end{array}$

(b) De vnz em quanda.

40. Com qual frequencia voce costuma ir ac cinema?

(A) Sempre ou quase sempre. (C) Nunce os quase nunca

(B) De ver em quando.

41. Com qual frequencia voct costuma ir a aigum tipo de espeticulo ou exposiçio fteatro, museu, dançs, música)?

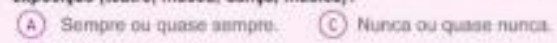

(B) De vez ens quando.

42. Com qual freguincis voct participa de festas na sua vizinhaspa ou comulidade?

(d) Sempre ou quase sempre. (C) Nunca ou nuase nunch.

(C) Dever am quento.

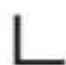

43. Em dias de aula, quanto tempo voeè gasta assistinde a TV, navegando na

$\begin{array}{ll}\text { (A) Menoa de } 1 \text { hora. } & \text { (D) Mais de } 3 \text { horas. }\end{array}$

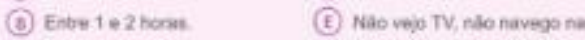

(c) Mass de 2 horas, ate 3 haras.

habernet e náo jogo jogas eleirónicon

4. En dias de aula gaanto tempo vect gasta fazondo trabainos domésticos

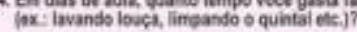
(a) Menes de 1 hork
(D) Mais de 3 horss.

(C) Enire 1.22 horas

(C) Nao taje trisbahos comésticos:

(C) Mais de 2 horas, atb 3 hocas.

45. Absalmento voce tratbalha fora de casa

(recebendo ou nia salario|?

46. Quando vocé entrou na escola?

(A) Na crecte 10 s 3 ancos? (C) Ny praveira sète ou priteiro uno

(3) Na pre-escola (4 a 5 anob).

(a) $\operatorname{sim}$ (1) Nao

97. A partir da quinta sterie ou sexto ano, em que tipo de escola voce estudou?

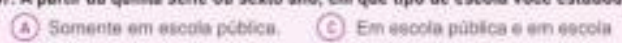

(D) Somente om osconls parfoger particulo:

43. Voct $j \mathrm{f}$ toi reprovado?
(4) Niso
(C) Sim, duas vores ou mais.

(B) Sim, uma vaz

4. Vocb ia atandonou a eacola durante o pariedo de aules 6 ficeu fors da escola o resto do ano?
(a) Niko.
(C) Sin duas weres ou mais

(B) Sim uma vez

50. Voel gosta de estudar Lingus Portoguesa? (A) $5 \mathrm{~m}$. (B) Nac

51. Vecb far o dever de casa de Lingua Pertuguesa?

$\begin{array}{ll}\text { (4) Sempre ou quase sempre. } & \text { (C) Nunca ou quase nunca }\end{array}$

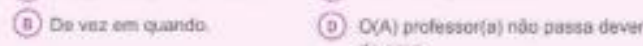

52. O(A) professof(a) comige o dever de casa do Lingua Portuguesa?

(4) Sempre ou quase sempre. (C) Nunca ou quase nunca

(B) De vez em quanda.

(C) O(A) professonta) nán passa dever da casa.

53. vect gosta so estudar Munamatica? (A) $5 \mathrm{im}$ (8) Näo

54. Vocb faz o dever de casa de Natemitica?
(4) Sempre ou gasae sempre.
(C) Nunca ou quase nunca
(6) De vexcem quando
(D) O(A) peofossur(a) nào passa dever

55. O(A) protessor(a) carrige o dever de casa de Nentemitica?
(A) Sempre ou quase serrore.
(C) Nunca ou quase nunca
(8) De vez em quando
(D) O(A) profossur(a) nsa passa dever se cusa.

54. Voct utiliza a biblisteca su sala de hitura da sus escola?
(A) Sempre bu quane sempris.
(C) Nuncas cur eqase munca.
(B) De ver em quando
(C) A rscida niso Bonk

57. Quando voce teminar o 9 ane(d" serie), vect pretende:
(a) Somente contmuar muludanda. (C)

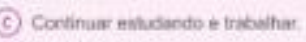
(0) Somente trabalnar
(D) Nonde nto sel 
ANEXO E - Carta de Autorização - Escola A

\section{PREFEITURA DO MUNICÍPIO DE}

SECRETARIA MUNICIPAL DE EDUUCAÇÃO

\section{AUTORIZAÇÃO}

Mediante solicitação do Prof. Dr. Alexandre Pereira Salgado Jr, coordenador do Grupo de Estudos en Eficiência, da Faculdade de Economia, Administração e Contabilidade de Ribeirão Preto da Universidade de Säo Paulo (FEA-RP/USP), autorizamos visita à Secretaria Municipal de Educação de SP e a escola objetivo de realizar entrevistas com a secretaria da educação e supervisores e com diretores, professores e da referida escola.

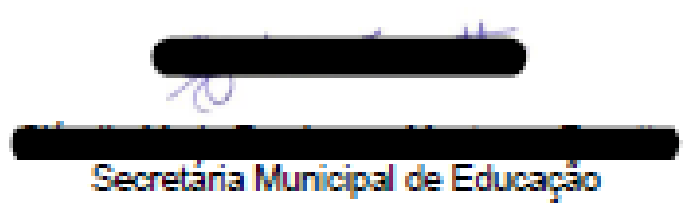


ANEXO F - Carta de Autorização - Escola B
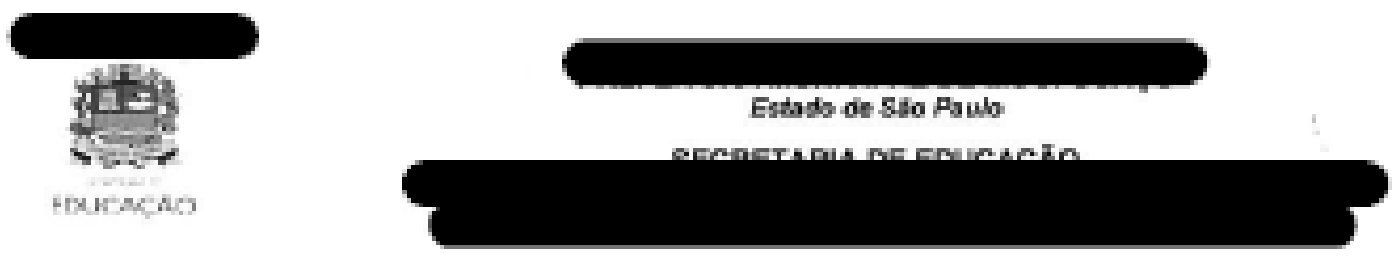

Oficio n $\mathrm{n}^{4} 217 / \mathrm{SE} / 2017$

ande junho de 2017

Mediante solicitaça do Prof. Dr. Alexandre Pereira Balgado Jr, coordenador do Grupo de Estudos em Eficiencia, da Faculdade de Economia, Administraço e Contabilidade de Rbeirao Preto da Universidade de Sá Paulo (FEA-RPUSP), autorizamos visita a Secretaria Municipal de Educaçao de $1 \mathrm{SP}$ e la escola

com objetwo de realizar entrevistas com a secretaria da educaçâo, supervisores; diretores, coordenadores e prolessores da referida escola.

SP, 30 de junho de 2017.

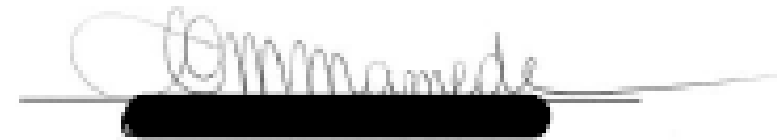

Secretaria Municipal de Educacaio 


\section{ANEXO G - Carta de Autorização - Escola C}

\section{AUTORIZACĀO}

Mediante solicitacalo do Prof. Dr. Alexandre Pereira Salgado Jr, cooedenador do Grupo de Estados em Eficiéncia, da Faculdade de Economia, Administraçâno e Contabilidade de Ribeiräo Preto da Universidade de Säo Paulo (FEA-RP/USP), aubrizamos visita à Secretaria Municipol de Educaçla de Co ì escola nom objetive de realizar enirevistas com a secretdriat Wh educação e supervisoecs e com diretores, coordenadores e professores da referida escolis.

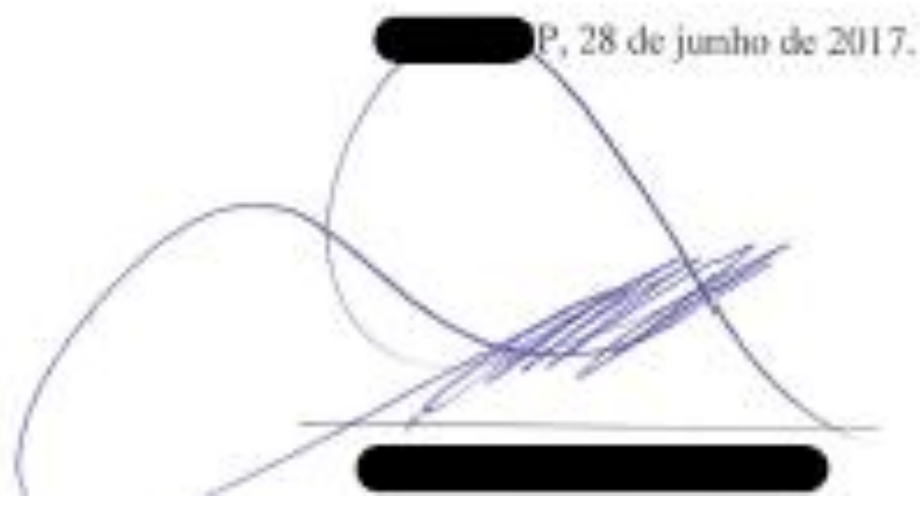


ANEXO H - Carta de Autorização - Escola D

\section{AUTORIZAÇĀO}

Mediante solicitação do Prof. Dr. Alexandre Pereira Salgado Jr, coordenador do Grupo de Estudos em Eficiência, da Faculdade de Economia, Administração e Contabilidade de Ribeirão Preto da Universidade de São Paulo (FEA-RP/USP), autorizamos visita à Secretaria Municipal de Educação dc

SP e a escola

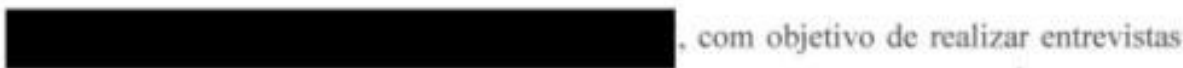
com a secretaria da educaçào e supervisores e com diretores, professores e da referidas escola.

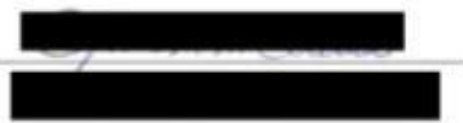

Secretária Municipal de Educação 